\title{
Malaxideae (Orchidaceae) in Madagascar, the Mascarenes, Seychelles and Comoro Islands
}

\author{
Johan Hermans $^{1,2}{ }^{10}$, Simon Verlynde ${ }^{3}$, Phillip Cribb ${ }^{1}$, Brigitte Ramandimbisoa ${ }^{4}$, Jean-Michel Hervouet ${ }^{5}$ \\ \& Patrice Bernet ${ }^{6}$
}

Summary. The tribe Malaxideae (Orchidaceae, subfamily Epidendroideae) (sensu Pridgeon et al. 2005: 453) in Madagascar and adjacent archipelagos is revised. In this region it comprises the four genera: Liparis, Malaxis, Oberonia and Stichorkis. All of the species are described and their typification, history, identification, distribution and habitat are discussed. Conservation assessments and distribution maps are included. A checklist of the genera and species and a key to their identification are provided. Six new species: Liparis bemarahensis, $L$. bosseri, $L$. chantaliae, L. laurentii, L. magnifica and $L$. superclareae are described.

Key Words. Conservation assessments, Liparis, Malaxis, new species, Oberonia, revision, taxonomy, Stichorkis.

\section{Introduction}

This is the first review of the tribe Malaxideae (Orchidaceae, subfamily Epidendroideae) from the Madagascar region since 1936 when Henri Perrier de la Bâthie (henceforth Perrier) published his Les Liparidinées de Madagascar, which was later summarised in his treatment of the Orchidaceae in the Flore de Madagascar (Perrier 1939). His work covered the same genera but only from Madagascar and the Comoros, the present revision also adds the adjoining archipelagos of the Mascarenes (Réunion, Mauritius, Rodriguez) and the Seychelles.

Historically, accounts of the orchids of the area under consideration have been fragmented with revisions being undertaken separately for Madagascar, the Comoros, the Mascarenes and the Seychelles. This sometimes resulted in confusion with the same species being known under different names within its range: thus Liparis scaposa Frapp. ex Cordem. (Frappier in Cordemoy 1895: 183) described from Réunion is identical to Liparis microcharis Schltr. (Schlechter 1924: 144) from Madagascar, as shown below.

This account is also the first since Ridley's monographs (1887 \& 1888) where the species from the region were compared with those from mainland Africa and elsewhere. Increased collecting in some parts of Madagascar and improved communication have meant that today much more material is available for research in herbaria around the world. This is in contrast to the time of Perrier's revision when many of the species were only known from their type collection.

The large genus Liparis has caused problems for earlier authors and disproportionate numbers of plants have been either misidentified or left unidentified in herbaria. This is not surprising as many of the species have few good and consistent characteristics. Plant habit, lip morphology, shape of the column and shape of the anther can all vary to some extent within a species but rarely are any of their individual characteristics unique to a single species. Therefore, one must often rely on a combination of features that are not always obvious. Frustratingly, in herbarium specimens the lip of the flower is often damaged, distorted or has lost some of its defining characters, the anther cap is also frequently missing.

The typification of $18^{\text {th }}$ and early $19^{\text {th }}$ century species can be challenging because specimens were commonly moved or incorporated into other herbaria. Frappier (1880) and Frappier in Cordemoy (1895), working on the orchid flora of Réunion, was vague as to which collection or collections were the basis for his new species. Schlechter and Perrier, in their descriptions, frequently cited several collections, each often comprising several herbarium sheets.

Accepted for publication 24 October 2019. Published online 7 May 2020

1 Herbarium, Royal Botanic Gardens, Kew, Richmond, Surrey, TW9 3AE, UK. e-mail: j.hermans@kew.org

2 Core Facility, Botanical Garden, University of Vienna, Rennweg 14, 1030, Vienna, Austria.

3 Missouri Botanical Garden (MBG), Africa \& Madagascar Department et Institut de Systématique, Évolution et Biodiversité, Muséum National d’Histoire Naturelle, 57 rue Cuvier, 75231, Paris, France.

4 Missouri Botanical Garden, Madagascar Research and Conservation Program, BP 3391-Anjohy, 101, Antananarivo, Madagascar.

561 rue du Lieutenant Ricard, Chatou, France.

6 Bas du Ruisseau, 97414, lle de la Réunion, France. 
Therefore, where necessary, a careful selection has been made in this paper to assign a lectotype or new material was assigned as a neotype to best reflect their descriptions. Some of Perrier's earlier collections followed a different numbering system from that used by Schlechter for the same specimens. In addition it was once thought that the material sent by Perrier to Schlechter in Germany was not returned and was lost during World War II and therefore most of the Paris specimens would have been isotypes. However, the loan and return dates of herbarium sheets are indicated very clearly on various herbarium labels and it is therefore certain that the holotypes and other material was returned to Paris (e.g. Perrier 14358, 16485, 15336 etc. in P). For clarity and following the International Code of Nomenclature (Turland et al. 2018) and also taking into account McNeill (2014: 1112) for species described prior to 1958, holotypes were recognised when one particular specimen was indicated by the author in the protologue as the type and/or used by the author when no type was indicated (article 9.1); for example Perrier and Schlechter generally annotated the Paris (P) herbarium specimens as 'type', thereby clearly indicating the particular original material used by them (article 9.4). In the case of more than one sheet of original material with the same collecting number being available, the identity was checked and the most representative sheet designated as lectotype and the others as isolectotypes or isotypes (article 9.5). If additional collections of original material were mentioned in the protologue and found to be correctly identified and used by the author they were considered syntypes (article 9.6) or lectoparatypes following the instructions for this journal. On a few occasions neotypes had to be selected when original material is missing or destroyed (article 9.8).

\section{Methods}

This revision is based on detailed work during the last 25 years on the orchid flora of Madagascar and neighbouring islands. J. \& C. Hermans (in Du Puy et al. 1999) published a comprehensive bibliography which was revised (Hermans in Hermans et al. 2007) and has been kept up-to-date since then. At the same time, photographs, drawings and data were assembled from herbaria (including BM, BR, BRLU, CGE, DUB, G, HEID, K, M, MO, P, SZU, TAN, TEF, W, WU, M, SZL, ZSS). The authors visited many type and other localities during extensive fieldwork and visits to Madagascar and Réunion.

A new checklist was compiled, based upon examination of herbarium and photographic material in all the major collections. Species were typified or retypified as necessary, a provisional key to the species was also prepared. All the unidentified herbarium specimens and photographic records were then attempted to be identified and named, some being recognised as novelties. A few proved to be impossible to identify because of their poor condition or missing parts. New descriptions, including information on distribution, habitat, elevation etc. were prepared for all the species. The keys were tested on further herbarium and spirit material made available by Patrice Bernet and others from Réunion and on the extensive collections provided by Simon Verlynde and Tariq Stévart from the Ambatovy orchid conservation project in Madagascar. Meanwhile, new botanical drawings were commissioned by the Royal Botanic Gardens Kew to illustrate novelties and other significant species not illustrated before. Simon Verlynde with input from Brigitte Ramandimbisoa provided the detailed preliminary Conservation assessments. JeanMichel Hervouet extracted the locality information and constructed distribution maps for each species.

As mentioned above, it was often necessary to rely on a combination of characters to identify many of the species in this tribe: plant habit, shape and features of the lip, shape of the column wings and anther cap are only reliable characteristics for species when used in combination. The key features for each species are emphasised in the descriptions and especially in comparison with similar species. Many Liparis are very variable in respect of the number and lay-out of the floral veins and these characteristics were therefore not included unless significant or unusual. The shape and size of the lip and the calli on the surface can also be variable. These variations are both within individual plants and between different plants; for example, in Liparis ochracea Ridl. (Ridley 1885: 461) the upper flowers are sometimes incomplete, irregular and misshapen. A species can vary locally but the differences are not enough to recognise them as distinct taxa. In some cases it is possible that they are developing into new species but it is difficult to be certain how these sporadic, isolated variations have evolved.

Only the most relevant illustrations and literature are mentioned in this revision. References to additional literature and illustrations for all the species can be found in the annotated bibliography in Hermans et al. (2007). Photographs and / or drawings or references are provided for all species accepted in this revision. Because of the general confusion and often misidentification of specimens of Malaxideae in herbaria, all specimens that we have examined are listed.

Type specimens are only indicated for those names from the region under review and not for synonyms from elsewhere. Most of the Cordemoy herbarium material has been on long-term loan to $\mathrm{P}$ and later to REU but belongs to the Herbarium at the St. Charles 
University, Marseille (MARS), it has therefore been indicated as such (also see Bosser 2011: 118).

Since there is a lack of detailed genetic research, no distinct sections in the genus Liparis are accepted in this paper. It is evident that some species cannot be assigned easily to the sections designated by previous authors. They overlap with the classical sections Mollifoliae and Coriifoliae used for Liparis in Africa and Asia. For identification purposes (and in the key) three broad, overlapping groups are recognised for Liparis:

1. Species with pseudobulbs often caespitose, the older ones retaining their leaves. Leaf blade more or less flat, rigid or leathery.

2. Species with few (one to two) pseudobulbs, the older ones disintegrating. Only the newest growth bears leaves; leaves plicate and thin.

3. Species with very small, often clustered pseudobulbs. Plants very small to small. With small rounded pseudobulbs and ligulate-lanceolate leaves.

Unlike some descriptions in the literature, overall plant size given does not include the inflorescence. Inflorescences are often disproportionate to the plant and far more variable than the vegetative parts of the plant, it was therefore considered a better characteristic.

Measurements definitions used for plants are as follows: very small $<8 \mathrm{~cm}$; small $>8 \mathrm{~cm}<15 \mathrm{~cm}$; medium $>15 \mathrm{~cm}<20 \mathrm{~cm}$; large $>20 \mathrm{~cm}$. For flowers: very small $<5 \mathrm{~mm}$; small $>5 \mathrm{~mm}<10 \mathrm{~mm}$; medium $>$ $10 \mathrm{~mm}<15 \mathrm{~mm}$; large $>15 \mathrm{~mm}$.

Unless otherwise stated, all cited specimens have been seen by the first author. Herbarium barcodes (if existing) were only indicated if no collection numbers were available or if there was a possibility of confusion.

\section{Conservation status}

Using the IUCN Red List Categories and Criteria (IUCN 2012), we produced preliminary risk of extinction assessments for each species. In order to gather the most comprehensive georeferenced distribution dataset, historical collections were georeferenced post facto when locality information was sufficiently precise and if not, these specimens were not taken into account in the preliminary assessments. We imported georeferenced specimen data into the dedicated $\mathrm{R}$ package, ConR (Dauby et al. 2017) to calculate the Extent of Occurrence (EOO) and Area of Occurrence (AOO). Minimal AOO was calculated using a cell area set to $4 \mathrm{~km}^{2}$ (cell size $=2 \times 2 \mathrm{~km}$ ) as recommended by IUCN (2017). The number of locations (sensu IUCN) were estimated with regard to the size of the main threat, in which a single location may encompass more than one adjacent subpopulation. For these preliminary assessments, only the criterion $\mathrm{B}$, based on three parameters, EOO, AOO and number of locations thresholds, was used. These preliminary assessments should not be considered as IUCN Red List assessments, but as reliable indication of the threat level weighing on these species. (S. V.).

The assessments showed a considerable number (15\%) of Malaxideae species in the area are Critically Endangered (CR), the vast majority (47\%) are Endangered (EN), $18 \%$ are Vulnerable (VU) and only $18 \%$ are of Least Concern (LC). The main threats are habitat loss through slash-and-burn farming, logging, charcoal production and mining.

\section{History}

The earliest collections of Malaxideae in the region were made in the Mascarene Islands. Jean-Baptiste Lamarck described the first two species in 1783, namely, Epidendrum cespitosum Lam. (Lamarck 1783: 187) (now Liparis cespitosa (Lam.) Lindl. (Lindley 1825: sub t. 882) and Epidendrum distichum Lam. (Lamarck 1783: 189) (now Oberonia disticha (Lam.) Schltr. (Schlechter 1924: 132)). They were likely collected, respectively on Réunion and Mauritius, by Philibert Commerson who explored the region from 1768, dying on Mauritius in 1773 (Dorr 1997: 93). His collections were incorporated into various herbaria, including those of Lamarck and Antoine-Laurent de Jussieu in P. In 1807 Christiaan Persoon described Epipactis salassia (Liparis salassia (Pers.) Summerh. (Summerhayes 1953: 133)) collected by Commerson on Réunion and now in the Jussieu herbarium in P.

Louis Marie Aubert-Aubert du Petit-Thouars was the first to collect and describe plants himself from the area which he visited mainly from 1795 to 1798 . In 1809 he described Leptorkis Thouars (1809: 317) and Stichorkis Thouars (1809: 318) as distinct genera but it was not until 1822 in his Histoire Particulière des Plantes Orchidées Recueillies sur les Trois Iles Australes D'Afrique that he described and illustrated new species, namely, Malaxis flavescens Thouars (1822: t.25) (now Liparis flavescens (Thouars) Lindl. (Lindley 1825: sub t.882)) and Malaxis disticha Thouars (1822 t.89) (now Stichorkis disticha (Thouars) Pfitzer (1897: 103)). Du PetitThouars used both his own peculiar formulation of names and those more akin to the Linnaean system; this way he has both Leptorkis purpuroleptis and Malaxis purpurascens (now Liparis salassia), the latter names were adopted by subsequent authors.

The genus Liparis was established in 1817 by LouisClaude Richard based upon two species: L. loeselii (L.) Rich. (Richard 1817: 38) with a Northern temperate distribution and L. liliiflora (L.) Rich. ex Lindl. (Lindley 1825: sub. t.882) from $\mathrm{N}$ America. The former was selected as the type species for the genus. Liparis was conserved over Thouars' Leptorkis / Leptorchis as was Oberonia over Iridorkis / Iridorchis. 
John Lindley (1825) described Liparis foliosa Lindl. (Lindley 1825: t.882), based on a cultivated plant supplied by Robert Barclay and originating from Charles Telfair who collected it on Mauritius. Lindley (1830a), in his Genera and Species of Orchidaceous Plants, also produced the first account of the tribe and included five species from the region.

Heinrich Gustav Reichenbach (1826) proposed to replace Liparis with his new genus Sturmia Rchb. (Reichenbach 1826: 39), claiming invalidly that the name had already been used for a genus of moths. To be valid generic names only have to be unique within Kingdom Plantae and Animalia; it is interesting to note that Liparis Scopoli (1777: 453) is also a genus of fish from the Northern Hemisphere. Reichenbach's son, also Heinrich Gustav (Reichenbach f. 1885), added two species: Liparis polycardia Rchb.f. (Reichenbach f. 1885: 543) and Malaxis cardiophylla, both collected by Léon Humblot in the Comoro Islands.

Henry Ridley was the first to produce monographs of Liparis, Microstylis and Malaxis (Ridley 1886b, 1888). Ridley (1886b) provided a key to Liparis and also described nine new species from Madagascar (Liparis bicornis Ridl. (Ridley 1885: 458), L. connata Ridl. (Ridley 1885: 462), L. longicaulis Ridl. (Ridley 1885: 461), L. lutea Ridl. (Ridley 1885: 458), L. ochracea, L. ornithorrhynchos Ridl. (Ridley 1885: 460), L. puncticulata Ridl. (Ridley 1886b: 119) and L. xanthina Ridl. (Ridley 1886b: 275)). The majority of his types were collected in Madagascar by the missionary William Deans Cowan and the rest by another missionary Richard Baron and the German collector Johann Hildebrandt. Deans Cowan's sketchbook at the London Natural History Museum, London (Cowan 1880) features some of the orchids discovered by him and are sometimes the only record.

At about the same time Charles Frappier was working on the orchids of Réunion. He produced a checklist in 1880 and, after his death in 1885, his work was incorporated in Eugène de Cordemoy's Flore de l'ille de la Réunion of 1895. Twelve species of Malaxideae were included, of which seven were new (Liparis bernieri Frapp. ex Cordem. (Frappier in Cordemoy 1895: 185), L. caulescens Frapp. ex Cordem. (Frappier in Cordemoy 1895: 186), L. flammula Frapp. ex Cordem. (Frappier in Cordemoy 1895: 183), L. nectarina Frapp. ex Cordem. (Frappier in Cordemoy 1895: 184), L. punctilabris Frapp. ex Cordem. (Frappier in Cordemoy 1895: 184), L. scaposa, L. verrucosa Frapp. ex Cordem. (Frappier in Cordemoy 1895)). Plants were mainly collected by Frappier and Cordemoy but some also by Louis Boivin.

There then followed a period with very few new species emerging from the Madagascar region: Johannes Klinge (1898) added Microstylis madagascariensis (Malaxis madagascariensis (Klinge)
Summerh. (Summerhayes 1954: 578)) to the list from a collection by L. Hamelin. Fritz Kraenzlin (1902) described Liparis seychellarum Kraenzl. (Kraenzlin 1902: 60) (now Malaxis seychellarum (Kraenzl.) Summerh. (Summerhayes 1954: 578)), collected by Schimper. Robert Allan Rolfe (1908) described Liparis warpurii Rolfe (1908: 69), named for its collector G. Warpur.

A great resurgence of botanical activity took place during the height of French colonial rule of Madagascar during the first half of the $20^{\text {th }}$ century. Most of the work was done by Perrier who explored the island extensively between 1913 and 1932, initially as a mining prospector and later on behalf of the Paris Museum (P) where his extensive collections are now housed. Initially, the German botanist Rudolf Schlechter described the plants found by Perrier, starting in 1913 and 1916 but culminating in 1924 1925 with his Orchidaceae Perrierianae, where he named fourteen new Liparis from the island, all collected by Perrier. Schlechter added a total of 18 new Malaxideae to the flora of Madagascar (Liparis andringitrana Schltr. (Schlechter 1924: 135), L. bathiei Schltr. (Schlechter 1924: 135), L. cladophylax Schltr. (Schlechter 1916: 321), L. densa Schltr. (Schlechter 1924: 137), L. dryadum Schltr. (Schlechter 1924: 138), L. gracilipes Schltr. (Schlechter 1924: 138), L. henrici Schltr. (Schlechter 1924: 139), L. hildebrandtiana Schltr. (Schlechter 1924: 140), L. imerinensis Schltr. (Schlechter 1924: 141), L. jumelleana Schltr. (Schlechter 1916: 320), L. latilabris Schltr. (Schlechter 1924: 142), L. listeroides Schltr. (Schlechter 1924: 143), L. microcharis, L. perrieri Schltr. (Schlechter 1913: 164), L. rivalis Schltr. (Schlechter 1924: 146), L. sambiranoensis Schltr. (Schlechter 1924: 147), L. stenophylla Schltr. (Schlechter 1924: 148) and Malaxis physuroides (Schltr.) Summerh. (Summerhayes 1954: 578)).

Following Schlechter's death in 1925, Perrier assumed the taxonomic work, describing several new species and in 1936 published Les Liparidinées de Madagascar, a major revision of the Malaxideae of Madagascar including Oberonia, Microstylis and Liparis. He added six new species to the tribe (Liparis anthericoides H.Perrier (1936: 243), L. bulbophylloides H.Perrier (1936: 242), L. cardiophylla H.Perrier (1936: 244), L. danguyana H.Perrier (1936: 248), Malaxis atrorubra (H.Perrier) Summerh. (Summerhayes 1954: 578) and M. francoisii (H.Perrier) Summerh. (Summerhayes 1954: 578)), all except one collected by himself, the other by Raymond Decary. In addition to several other works on the flora he also produced the family account for Henri Humbert's Flore de Madagascar (Perrier 1939).

Little more appeared until 2014 when Liparis vulturiceps Hermans \& P.J.Cribb (2014: 9517: 4) was described. In the present work six new species (Liparis bemarahensis, L. bosseri, L. chantaliae, L. laurentii, L. 
magnifica, L. superclareae) are added and several other adjustments to the Malaxideae of the area are made. A total of 54 species are now recognised in the Tribe: 46 in Liparis, six in Malaxis, and one each in Oberonia and Stichorkis.

\section{Distribution}

In the Madagascar - Africa region Liparis is widespread in Madagascar, Mascarenes, Comoros and Seychelles but the species are largely endemic, only L. cespitosa has a broader distribution. Malaxis is only found on Madagascar and the Comoros with one species also occurring on mainland Africa. Oberonia is found throughout the area except for the Seychelles and is also widespread on mainland Africa. Stichorkis is only known from the Comoros and the Mascarenes.

A number of species from our area have sister species outside the region, namely: Liparis perrieri from Madagascar vs L. nervosa (Thunb.) Lindl. (Lindley 1830a: 26) with a widespread tropical and subtropical distribution, L. flavescens from the Mascarenes vs L. bowkeri Harv. (Harvey 1863: 6) from Southern Africa, L. foliosa almost exclusively from the Mascarenes vs L. reflexa (R.Br.) Lindl. (Lindley 1825: t.882) from Australia and Malaxis atrorubra from Madagascar vs $M$. welwitschii (Rchb.f.) Hermans from SW Africa. Although they may share some characteristics, it is evident that isolated evolution and possible pollination adaptation have meant that these can be recognised as distinct species.

Malaxideae are predominantly plants of the wet and shaded forest at elevations between sea level and $2500 \mathrm{~m}$ but generally between 500 and $1800 \mathrm{~m}$, very few are found in warmer lower elevations and those tend to be widespread species, such as Liparis cespitosa, L. sambiranoensis and Oberonia disticha. Two new discoveries, Liparis bemarahensis and L. superclareae also come from lower elevations. The flowering season is between October and August with the main season during the rainy season between January and May.

Most species are terrestrials or moss-humus dwellers but many can also grow as epiphytes, generally at the base of trees or on lower branches. The only exclusive epiphytes are Liparis bulbophylloides, L. cladophylax, L. dryadum, L. foliosa, L. parva (Kuntze) Ridl. (Ridley 1885: 462) and Oberonia disticha. All true epiphytes, except Oberonia disticha, are only recorded from the lower parts of trees. None are true lithophytes except perhaps Liparis andringitrana which has watery young pseudobulbs as a xerophytic adaptation to its environment. Several species can be found on rocks but are usually rooted in the humus-rich and mossy substrate and not onto the rock itself.

The vast majority are found in the Eastern forests of Madagascar and the higher elevation forests of the Comoros and Réunion. A few species are widespread on Madagascar, including: Liparis chantaliae, L. clareae Hermans (in Hermans et al. 2007: 216), L. longipetala Ridl. (Ridley 1885: 459), L. ochracea, L. salassia and Oberonia disticha. Others are exclusively from the West of Madagascar, including Liparis bemarahensis, or from the South: L. bosseri, L. densa and a few from the North to North-West: L. perrieri, L. sambiranoensis.

A number of species are relatively common (i.e. known from ten or more different collections) but others are quite rare and localised (fewer than ten collections): including Liparis ambohimangana Hermans (Hermans et al. 2007: 214), L. bathiei, L. bemarahensis, L. bosseri, L. cladophylax, L. danguyana, L. densa, L. gracilipes, L. laurentii, L. lutea, L. magnifica, L. parva, L. vulturiceps, L. zaratananae Schltr. (Schlechter 1924: 151) and all Malaxis except M. seychellarum. A few are known from the type specimen only: Liparis trulliformis Schltr. (Schlechter 1924: 149) and Malaxis madagascariensis, they may well be reassigned to other species when more thoroughly studied using better material. The newly described Liparis superclareae is only known from the type collection which comes from a remote area. The overall distribution of the Tribe is shown in Map 4.

\section{Distribution mapping}

Georeferenced maps with WGS 84 projection have been used as a background for the distribution maps. They have been freely downloaded from the following websites: www.fao.org/geonetwork/srv/en (land cover of Madagascar, dated 2009), https://www.data.gouv.fr (Mayotte and Réunion islands), https://gadm.org (country outlines of Comoros, Mauritius and Seychelles). Similar data can be found at www.diva-gis.org. The locality coordinates come from the authors' own observations, made with Garmin etrex 10 GPS using the WGS 84 projection, or from the Tropicos website gazetteer to Malagasy botanical collecting localities: www.tropicos.org. All the positions of specimens have been double-checked with Google Earth: https:// earth.google.com.

A relational database with two tables: localities and observed species, has been built with the database management system 4D version 11 (www.4d.com), storing a total of about 500 observations or collected specimens. A computer program was then written in $4 \mathrm{D}$ programming language to automatically produce one CSV file per species (ASCII files with commaseparated values), every file containing a list of coordinates for a given species. Eventually the open source Geographical Information System QGIS version 2.18.10 (www.qgis.org) was used to compose the final pictures in jpeg format, combining the countries' outlines, Madagascar land cover and the location spots for every species. Distribution is only shown for the area under review in this paper. 
A simple underlying vegetation map was used as a background for each species, a map of the whole area covered and the distribution of all Malaxideae, as well as maps showing the different provinces and regions of Madagascar are included for reference (Maps 1, 2, 3 and 4).

\section{Phylogenetics \& Cytology}

The Malaxideae tribe has always been difficult to place within the Epidendroideae subfamily because the included taxa lack typical appendages on their pollinia (e.g. they are 'naked', although they appear to have small viscidia in most cases). Column morphology, particularly the structure of pollinia and associated appendages, has always been given pre-eminence in traditional orchid classification, so ideas about relationships within this 'nearly naked' tribe have been limited. In all other aspects Malaxideae are more or less typical epidendroid orchids without any clear evidence for any relationship to any other tribe. In

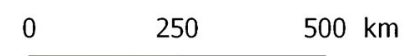

the morphological analysis of Freudenstein \& Rasmussen (1999), two species of Liparis were among a large number of Epidendroideae on a polytomy, whereas in the Cameron et al. (1999) analysis of rbcL data, Liparis and Malaxis were sister to Dendrobieae but without bootstrap support greater than $50 \%$. This placement is noteworthy because both groups have more or less naked pollinia, but Dressler (1993) hypothesised that whereas Dendrobieae appear to be secondarily naked, Malaxideae may be primitively so. As in the case for most clades of Epidendroideae, more data are required before a clearer picture of the relationships of Malaxideae is achieved.

A comprehensive account of Malaxideae has yet to be published although an up-to-date assessment of its phylogeny and classification was provided by Chase \& Cribb in Genera Orchidacearum (Pridgeon et al. 2005). Cameron (2005) examined a selection of species and produced a cladogram which shows that both Liparis s.l. and Malaxis s.l. are polyphyletic. Very few plants from Africa and the
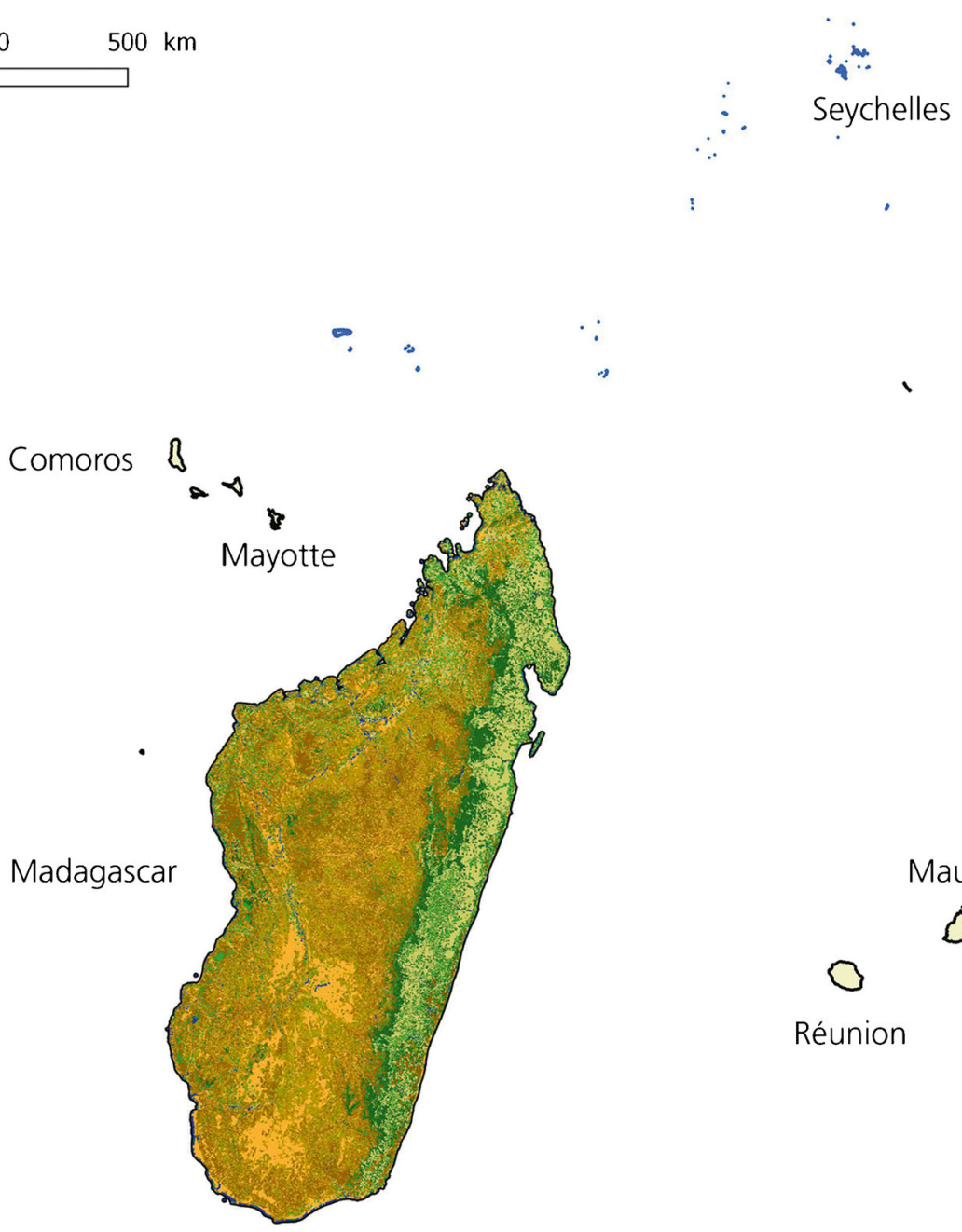

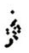

Mauritius

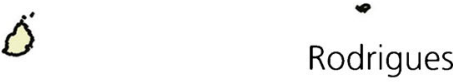

Réunion

Map 1. Madagascar and the surrounding Islands. 


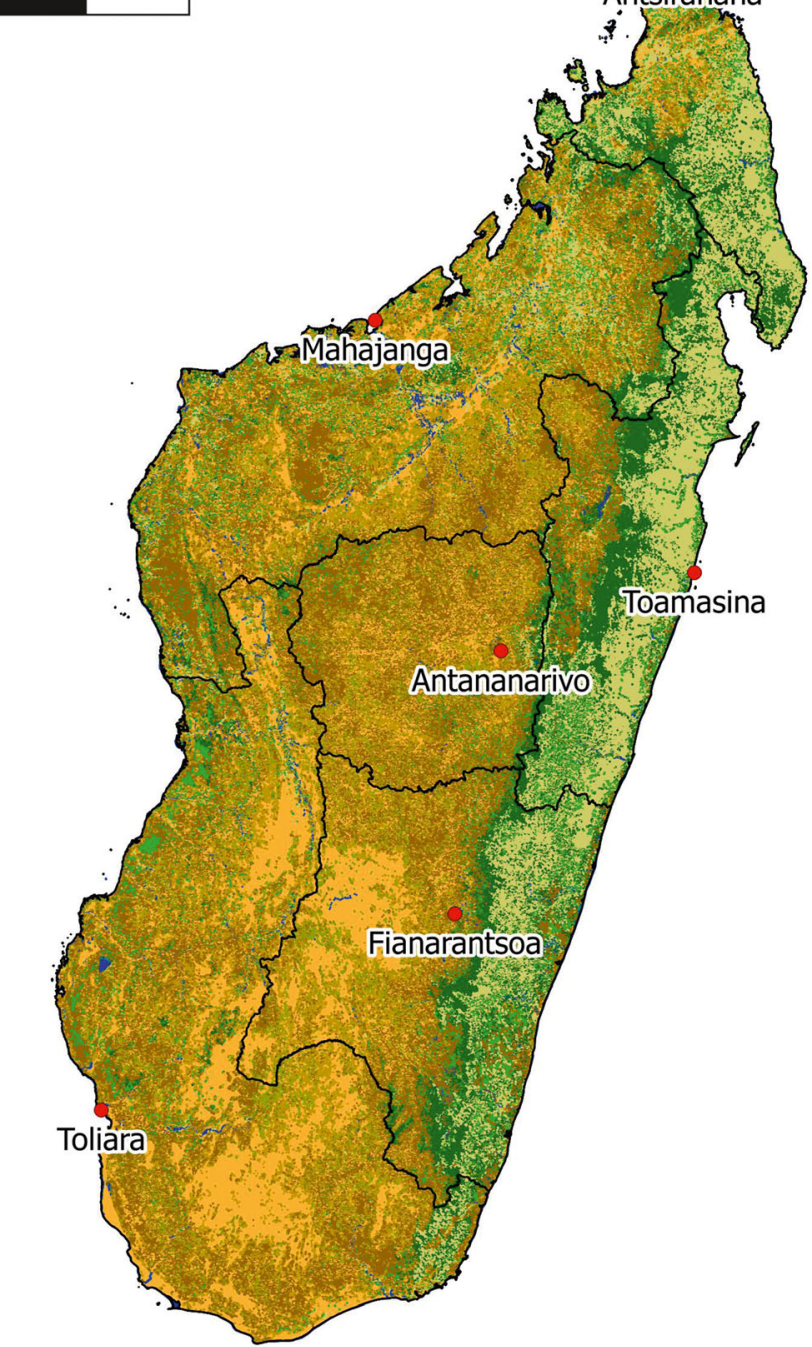

Legend

Post-flooding or irrigated shrub or crops

Rainfed shrub or crops

Mosaic cropland (50-70\%) / vegetation (grassland/shrubland/forest) (20-50\%)

Mosaic vegetation (grassland/shrubland/forest) $(50-70 \%) /$ cropland (20-50\%)

Closed ( $>40 \%$ ) broadleaved deciduous forest $(>5 \mathrm{~m}$ )

Open (15-40\%) broadleaved deciduous forest/woodland $(>5 \mathrm{~m})$

Closed $(>40 \%)$ needleleaved evergreen forest $(>5 \mathrm{~m})$

Open (15-40\%) needleleaved deciduous or evergreen forest $(>5 \mathrm{~m})$

Closed to open $(>15 \%)$ mixed broadleaved and needleleaved forest $(>5 \mathrm{~m})$

Mosaic forest or shrubland $(50-70 \%) /$ grassland $(20-50 \%)$

Mosaic grassland (50-70\%) / forest or shrubland (20-50\%)

Closed to open $(>15 \%)$ (broadleaved or needleleaved, evergreen or deciduous) shrubland $(<5 \mathrm{~m})$

Closed to open (>15\%) herbaceous vegetation (grassland, savannas or lichens/mosses)

Sparse $(<15 \%)$ vegetation

Closed to open (>15\%) broadleaved forest regularly flooded (semi-permanently or temporarily)

Closed ( $>40 \%$ ) broadleaved forest or shrubland permanently flooded - Saline or brackish water

Closed to open $(>15 \%)$ grassland or woody vegetation on regularly flooded or waterlogged soil

Artificial surfaces and associated areas (Urban areas $>50 \%$ )

Water bodies

Mosaic cropland (50-70\%) / grassland or shrubland (20-50\%)

Mosaic vegetation (grassland/shrubland/forest) $(50-70 \%) /$ cropland (20-50\%)

Mosaic forest (50-70\%) / cropland (20-50\%)

Closed or open broadleaved evergreen and/or semi-deciduous forest ( $>5 \mathrm{~m})$

Map 2. Vegetation map and Provinces of Madagascar. 


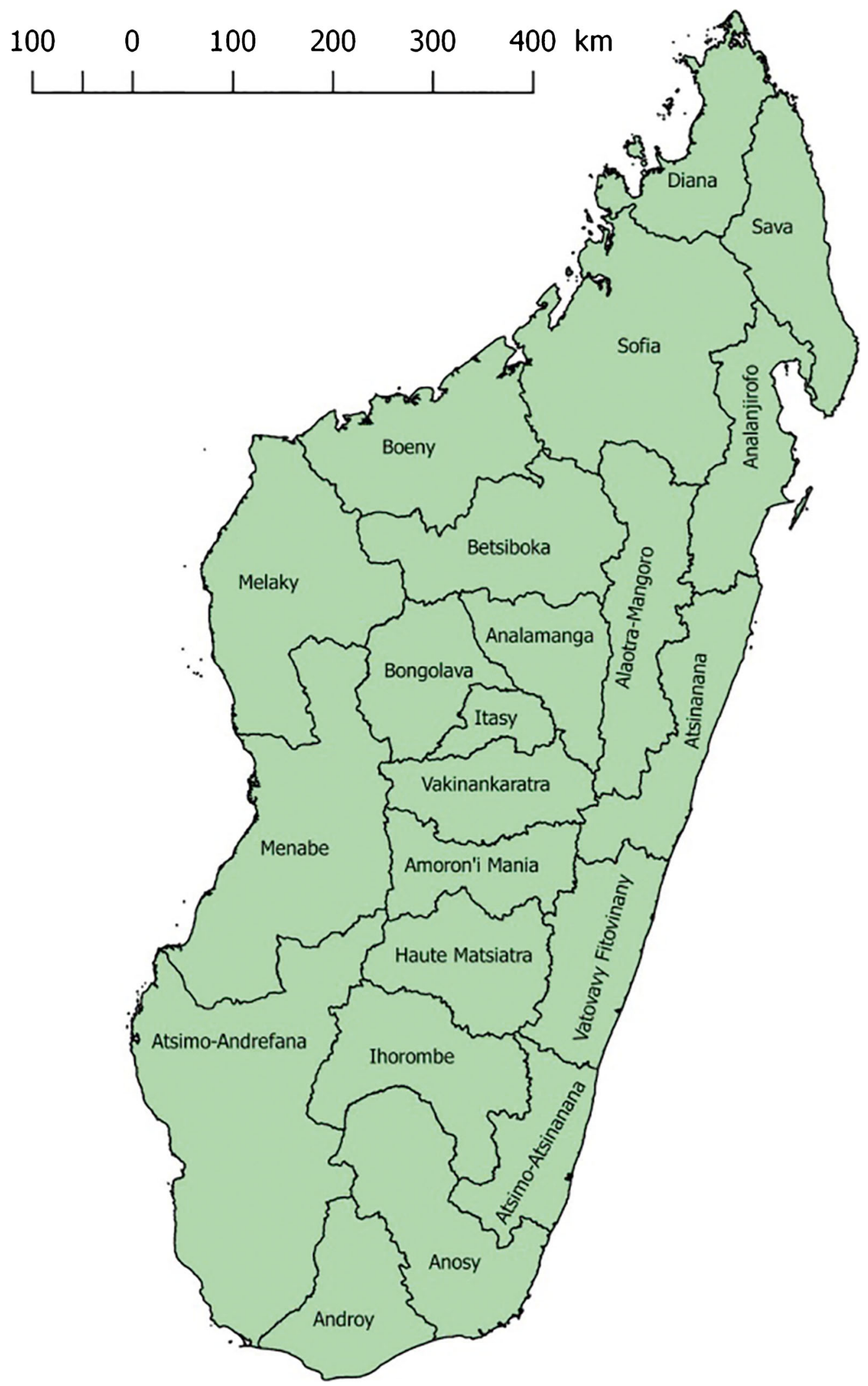

Map 3. Regions of Madagascar. 


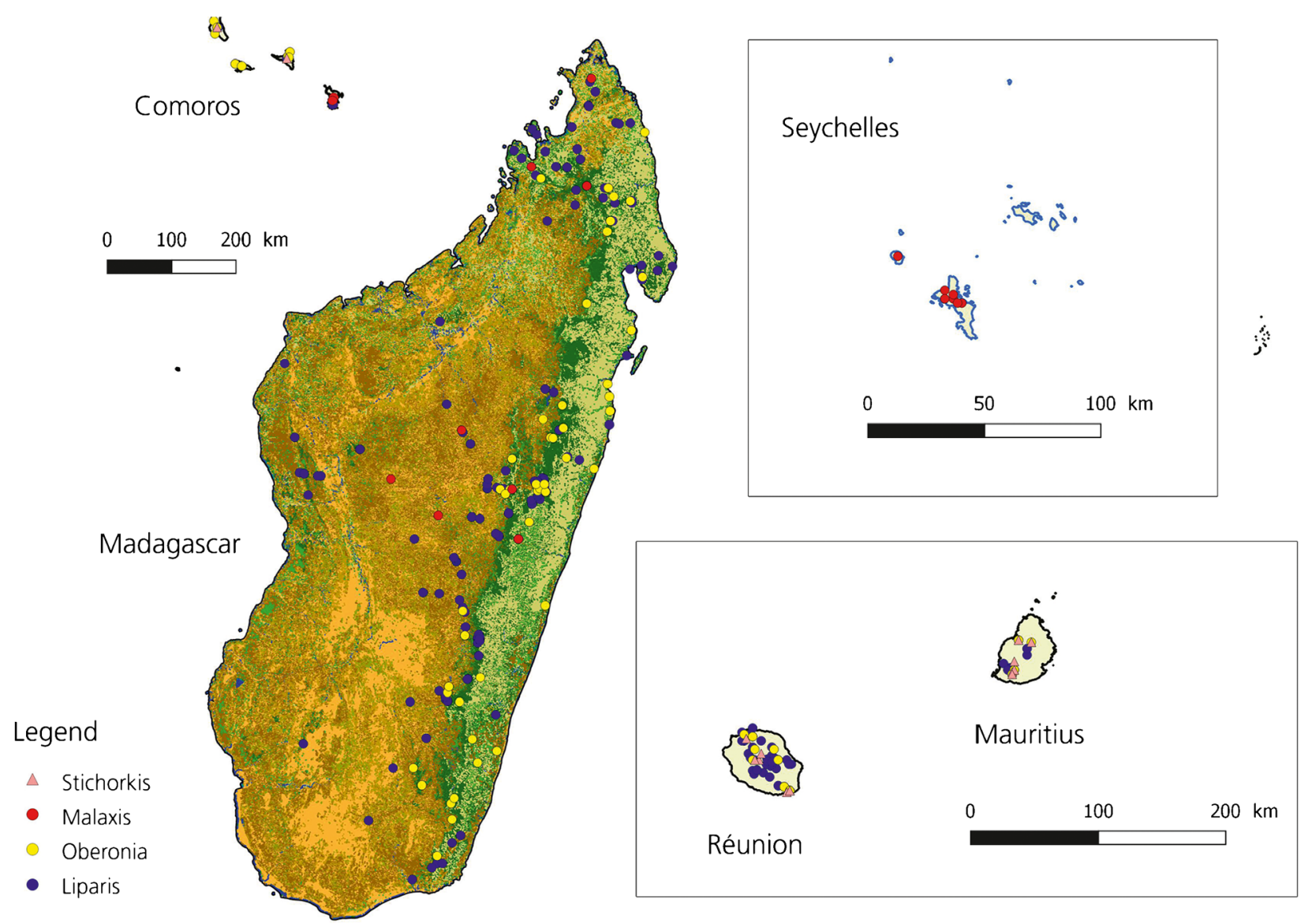

Map 4. Distribution of the genera Malaxideae in Madagascar and the surrounding Islands.

Madagascar region were included in this study and this was recognised by the author: 'Eventually, the tribe will need to be reclassified, but it may be premature to carve Malaxideae into more genera at the present time because fewer than $10 \%$ of the tribe's species have been sampled, and the circumscription of new genera would be somewhat speculative. Substantially more taxa (especially from Africa and the Neotropics) should be sequenced before a thorough revision of this troubled tribe's taxonomy is attempted. Nevertheless, if the current well-supported pattern of species relationships continues to be recovered in larger analysis, it may be that Malaxideae can be reclassified at the genus level based first on habit and vegetative features, with floral characters playing a secondary role. If this is ultimately found to be the case, it will be a remarkable exception within Orchidaceae and angiosperm taxonomy, in general, where the flower above all other organs reigns supreme.'

Szlachetko (1995) recognised 16 genera in subtribe Malaxidinae, seven newly described by him. Szlachetko \& Margonska (2002) accepted 15 genera in the subtribe, two of them new, in their subtribe Oberoniinae. They provided detailed drawings of the gymnostemium structure of representatives of these genera. Senghas (2002: 2710) added new genera to his treatment in the third edition of Schlechter's Die
Orchideen and provided a tabular comparison of some of the segregate genera of Malaxis recognised by Szlachetko \& Margonska. Margonska \& Szlachetko (2004) established another segregate genus, Disticholiparis, for those species previously referred to Liparis sect. Distichae.

We remain to be convinced that all the new segregate genera of Malaxis and Liparis warrant recognition at more than infra-generic rank, as already recommended by Ridley (1888), Smith (1909, 1913), Schlechter (1911a, 1915b) and Seidenfaden (1978). Salazar (personal communication) and Cameron (2005) have suggested on the basis of DNA sequences that the New World taxa of Malaxis and Liparis may be more closely related to each other than to the Old World species in those respective genera. Cameron (2005) identified four major clades in the tribe that are characterised by their habit and leaf type:

1. Epiphytes with a fan of unifacial leaves.

2. Epiphytes with bifacial, linear, conduplicate leaves.

3. Terrestrials with plicate leaves.

4. Terrestrials with one or two, usually rounded, conduplicate leaves.

Results to date support the retention of some segregate genera but not all. Margonska et al. (2012) 
recognise 23 genera within two subtribes in Malaxideae. (Adapted from Cribb \& Chase in Pridgeon et al. 2005: 453)

According to Felix \& Guerra (2010: 245) the Malaxideae tribe has a great diversity in chromosome numbers, with $n=21$ predominating in Liparis and Malaxis and $n=15$ in Oberonia. The most probable basic numbers for the tribe are $x=$ 15 and $x=21, n=21$ being the most frequent haploid number and $n=15$ the second most frequent and the only one that occurs in all three genera. The occurrence of $n=14$ in some species of Liparis and Malaxis, and the high frequency of $n$ $=21$ in these two genera, suggest that these numbers may be related to the polyploid series $x$ $=7,14,21$ that is quite common in orchids. Oberonia has $n=15$ or 30 . The occurrence of $n=$ 15 in Malaxideae further supports the hypothesis that the karyological evolution of the family was principally through dysploidy of approximately one chromosome in the three principal ploidy levels, $n$ $=7,14,21 \pm 1$.

\section{Pollination and Scent}

There are only limited records of pollination or scent analysis of the Malaxideae. Ridley (1887: 250) mentioned Liparis longipes Lindl. (now L. viridiflora (Blume) Lindl.) (Lindley 1830a: 31) from Asia as having an unpleasant scent. Both Liparis longicaulis and L. chantaliae are pleasantly fragrant (Hermans, pers. comm.). Kaiser (1993: 173) mentioned small flies and midges and Feldmann \& Barré (2004: 228) observed fruit flies as pollinators of Liparis.

Kowalkowska \& Margonska (2008) studied the micromorphology of the lip and its connection with pollination in several Liparis species, including L. cespitosa.

Some species, like Liparis nectarina, exude a nectar-like substance on the lip; Margonska et al (2018: 88) analysed the lip secretions of Asian Liparis and its attraction to insects. It has been observed in other genera (Neottia ovata (L.) Bluff \& Fingerh. (Bluff \& Fingerhuth 1838: 435)) that this nectar is harvested / licked by insects including Ichneumon wasps (Claessens \& Kleynen 2017: 130).

Recent observations by one of the authors (J.H.) in the Mantadia reserve in the Eastern forest of Madagascar recorded the interaction of ants with Liparis chantaliae. Large endemic ants, Tetraponera grandidieri Forel (1891: 203), were seen to visit the flowers and eat or harvest a substance from the dark disk of the lip. The anther was partly dislodged by the ant but the pollen stayed in-situ, considering the shape and size of the insect, it could easily have effected pollination (Fig. 15D).
Pollination of orchids by ants is a rare event, they more commonly behave as nectar thieves but in some species they can act as additional pollinators (Claessens \& Seifert 2018: 155).

\section{Taxonomy}

\section{Tribe MALAXIDEAE}

Malaxideae Lindl., Coll. Bot., App. (Lindley 1821: app. 3). Type: Malaxis Sol. ex Sw. (Swartz 1788: 119).

Liparidinae Lindl. ex Miq. (Miquel 1855: 618), as 'Liparidae'.

Microstylidinae Benth. (Bentham 1881: 287), as 'Microstyleae'.

Malaxidinae Benth. \& Hook.f. (Bentham \& Hooker 1883: 463).

Liparideae Pfitzer (1887: 100).

Oberoniinae Aver. (Averyanov 1991: 121).

Terrestrial or epiphytic, autotrophic or rarely holomycotropic herbs, usually with creeping rhizomes. Roots with a velamen. Stem cylindrical to swollen and cormous or pseudobulbous. Leaves one to several, thin-textured to fleshy, plicate or conduplicate, dorsiventrally flattened or iridiform, rarely terete, alternate or distichous, sheathing at base, articulated or not near base, rarely reduced to basal sheaths. Inflorescence terminal, flowers in spirals, whorls or distichously arranged, racemose or sub-umbellate, unbranched; peduncle and rachis cylindrical to markedly winged or angled, glabrous or hairy; floral bracts usually lanceolate, persistent. Flowers thin-textured, resupinate or apparently nonresupinate, often translucent. Sepals free or sometimes lateral sepals more or less fused, entire, usually spreading. Petals free, often smaller than the sepals, linear, often reflexed. Lip entire to lobed, recurved, lacking a spur, usually bearing a callus or ridges or mounds, often auriculate at base. Column often winged at apex, less frequently with lateral or basal wings, lacking a foot; anther terminal or sub dorsal, two-celled, motile, apical or dorsal, pollinia four in two pairs, often of unequal size, rarely two and deeply divided, laterally compressed, lacking a viscidium or with one or two minute viscidia; stigma entire, ventral; rostellum flap-like, often emarginated, seldom elongated. Ovary cylindrical, rarely papillose or winged. Capsule fusiform to suborbicular. (Adapted from Cribb in Pridgeon et al. 2005: 453)

DISTRIBUTION. A tribe of 13 genera widely distributed in the Old and New World tropics and subtropics with a few representatives extending into North Temperate regions. 


\section{Artificial key to the Malaxideae in Madagascar, Mascarenes, Comoros and Seychelles}

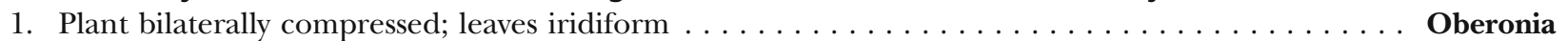

1'. Plant not bilaterally compressed, with a distinguishable stem, pseudobulb or corm; leaves not iridiform. . . 2

2. Rachis bilaterally flattened; floral bracts distichous and imbricate . . . . . . . . . . . . . Stichorkis

2'. Rachis not bilaterally flattened; floral bracts not distinctly distichous and not imbricate . . . . . . . . 3

3. Column very short, less than $1 / 6$ the length of the lip; lip basal auricles erect around sides of column . . . Malaxis

3'. Column slender and often arching, often winged towards apex, more than $1 / 3$ the length of the lip; lip lacking basal auricles, entire to 3-lobed, often with a basal callus, the sides erect on each side of the column . . . . . . . Liparis

Liparis Rich. (Richard 1817: 21) nom. cons. Type species: Liparis loeselii (L.) Rich. (Richard 1817: 38), (basionym: Ophrys loeselii L. (Linné 1753: 947).

Leptorkis Thouars (1809: 317).

Leptorchis Thouars (1822: t.25).

Pseudorchis Gray (1821: 199).

Empusa Lindl.(Lindley 1824 sub t.825).

Anistylis Raf. (Rafinesque 1825: 4).

Sturmia Rchb. (Reichenbach 1826: 39).

Paliris Dumort. (Dumortier 1827: 134).

Empusaria Rchb. (Reichenbach 1828: 69).

Platystylis Lindl. (Lindley 1830a: 18).

Diteilis Raf. Herb. Raf. (Rafinesque 1833).

Mesoptera Raf. (Rafinesque 1838: 73).

Dituilis Raf. (Rafinesque 1838: 49).

Iebine Raf. (Rafinesque 1838: 39).

Alipsa Hoffmanns. (Hoffmannsegg 1842b: 228).

Apation Blume ex Ridl. (Ridley 1886b: 279).

Cestichis Thouars ex Pfitzer (1887: 56).

Platystyliparis Marg. (Margonska 2006: 35).

Ypsilorchis Z.J.Liu, S.C.Chen \& L.J.Chen (2008: 623)

Terrestrial, lithophytic, or epiphytic rhizomatous herbs. Stem pseudobulbous, clustered or not, covered with sterile bracts, especially when young. Leaves one to several, linear to ovate or elliptical, pleated or not, thin-textured to coriaceous. Inflorescence erect or arching, racemose. Flowers yellow, green, orange or purple, often translucent, usually resupinate. Sepals spreading, dorsal sepal free, lateral sepals sometimes fused for part or all of their length. Petals free, often linear and unlike sepals, often reflexed. Lip often reflexed, ovate, oblong or flabellate, entire or lobed, usually with a basal callus or swelling, lacking a spur. Column incurved-arcuate, clavate, winged towards apex and sometimes at base; anther attached by a slender filament, biloculate, pollinia waxy, ovoid, bilaterally flattened, four in two pairs, each with a small viscidium; rostellum thin-textured, blunt. (Adapted from Cribb in Pridgeon et al. 2005: 467).

ETYMOLOGY. From the Greek liparos, shiny or greasy, in allusion to the shiny leaves of the type species Liparis loeselii. TAXONOMIC HISTORY. The genus has a complex history. Du Petit-Thouars (1809) described Leptorkis and Stichorkis as distinct from Malaxis. He remarked that Leptorkis would include species such as Malaxis loeselii (now Liparis loeselii). Du Petit-Thouars (1822) used the alternative spelling 'Leptorchis' (t.25) and also described the first Liparis from Madagascar as Liparis flavileptis and L. purpuroleptis Thouars, named using Du Petit-Thouars' peculiar method of forming plant names (see Friis \& Rasmussen 1975; Rasmussen 1979; Stafleu \& Cowan 1976). The traditional names Malaxis flavescens and $M$. purpurascens were presented as alternatives, and later authors have invariably chosen the traditional epithets.

Stichorkis is here recognised as distinct, but Leptorkis is considered to refer to species currently placed in Liparis. Liparis Rich. (Richard 1817: 21), has been conserved over Leptorkis but not Stichorkis. Leptorkis is available if Liparis is split up following reassessment of the generic limits within Malaxideae. Kuntze (1891) made the combinations of many species in Leptorchis (an unnecessary orthographic variant of Leptorkis). Liparis, as it has been understood historically, is readily characterised by its slender, arcuate, winged column, linear petals, and more or less entire lip, reflexed in the middle and usually bearing a basal bilobed callus. Ridley (1886b) recognised two sections in the genus, Mollifoliae and Coriifoliae, the former with three, the latter with three or four subsections.

Hooker (1888) and Seidenfaden (1978) both recognised three sections: (1) Liparis (Mollifoliae), mostly terrestrial with non-jointed, thin membranous leaves; (2) Coriifoliae, usually epiphytes with jointed, often coriaceous leaves and lax inflorescences lacking imbricating bracts; and (3) Distichae Seidenf. ex Aver. with similar habits and leaves but with distichous, imbricate bracts. Schlechter (1911a) proposed a new system with four subgenera and 12 sections. However, he admitted that circumscriptions of some of his subgenera and sections were poorly defined. Furthermore, by ignoring earlier sectional names his treatment led to confusion.

Ames (1905, 1908) took up Cestichis Thouars ex Pfitzer, based on the Madagascan species, for some Asiatic species, but it was not widely followed.

Garay \& Romero-Gonzales (1999) established three more sections in Liparis: Decumbentes, Aphyllae and Tipuloidea. They also provided a key to the 19 accepted sections of Liparis. Margonska et al. (2012), in an Appendix, includes a listing of the subgeneric divisions of Liparis and their types. 
PHYLOGenetics. Preliminary molecular studies by Cameron (2005) indicate that Liparis in the traditional broad sense is polyphyletic. Some clades are well resolved and can be diagnosed morphologically, others less so, requiring further sampling to produce a more robust classification. Several clades are clearly defined, but as sampling, so far, has largely excluded plants from the African and Madagascan region, results concentrate on Asian species. Fortunately, the species of Liparis sect. Distichae (Stichorkis Thouars (1809)) comprise a wellsupported clade sister to that including both Oberonia and the Asiatic/Pacific clade. Margonska \& Szlachetko (2004) established the superfluous generic name Disticholabris for this group. Liparis cespitosa and its allies: small species with ovoid, one-leaved pseudobulbs and articulate leaves, form a clade that is sister to an Asiatic/ Pacific clade of small-flowered lanceolate-leaved species. Liparis cespitosa was actually included in Stichorkis by Du Petit-Thouars (Thouars 1822) as S. cestichis Thouars (alternative name: Malaxis cespitosa; see Rasmussen
1979). The generic name Cestichis Lindl. ex Pfitzer is based on a misunderstanding of Du Petit-Thouars' way of presenting his new epithets (Friis \& Rasmussen 1975). (Adapted from Cribb \& Rasmussen in Pridgeon et al. 2005: 470)

DISTRIBUTION. Liparis is a large cosmopolitan genus of over 460 (Govaerts WCSP 2017) species, subspecies and varieties with a significant representation in Australasia, subtropical and tropical Americas, Africa and a few species in Europe and North America. 46 species are currently recognised in the Madagascar region of which 36 (c. 80\%) are endemic. Réunion has 10 species, three of them endemic, Mauritius has four species, the Comoros four species and the Seychelles one. Although some have close relatives further afield, Liparis cespitosa is the only species with a much wider distribution in Africa and Australasia.

\section{Taxonomy of Liparis}

\section{Artificial key to Liparis in Madagascar, the Mascarenes, Comoros and Seychelles}

Notes: Key features and measurements are based on mature plants with all segments flattened.

If only one growth is available or in case of uncertainty: use keys starting at both 1 and 23.

1. Pseudobulbs $1-2$; leaves plicate and thin-textured, disintegrating on previous year's growth. . . . . . . 2

1'. Pseudobulbs several, clustered, the older ones retaining their leaves. . . . . . . . . . . . . 23

2. Pseudobulbs bulbous or short, less than four times as long as broad, covered by leaf-like sheaths . . . . . 3

2'. Pseudobulbs elongate, at least four times as long as broad, often much longer, covered by sterile sheaths and

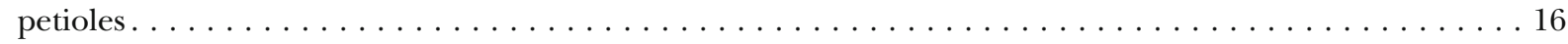

3. Plants compact, less than $8 \mathrm{~cm}$ tall; leaf blade less than $5 \mathrm{~cm}$ long $\ldots \ldots \ldots \ldots$

3'. Plants elongate, more than $8 \mathrm{~cm}$ tall; leaf blade more than $5 \mathrm{~cm}$ long $\ldots \ldots \ldots \ldots$

4. Lip transversely elliptic, distinctly wider than $\operatorname{long} \ldots \ldots \ldots \ldots \ldots \ldots \ldots \ldots$. . . . . . . . . . punctilabris

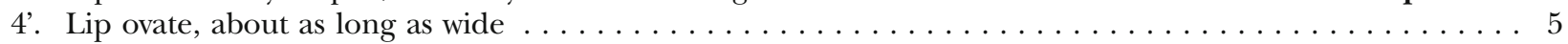

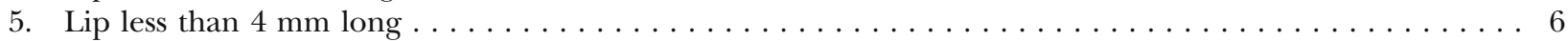

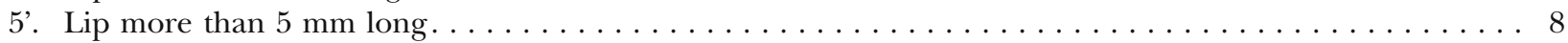

6. Leaf margins undulate; lip with a bilobed basal callus $\ldots \ldots \ldots \ldots \ldots \ldots \ldots \ldots$ dryadum

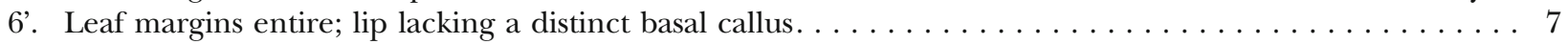

7. Floral bracts large, over $4 \mathrm{~mm}$ long; anther with a distinct spathulate beak; column scarcely winged . . . L. bathiei

7'. Floral bracts small, less than $4 \mathrm{~mm}$ long; anther cordiform; column winged . . . . . . . . . . . . L. lutea

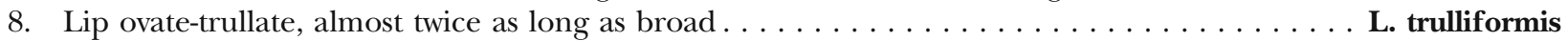

8'. Lip broadly ovate to orbicular when flattened $\ldots \ldots \ldots \ldots \ldots \ldots$

9. Lip lacking a distinct callus; anther with a spathulate beak . . . . . . . . . . . . . . L. bosseri

9'. Lip with a distinctly bilobed basal callus; anther with a $\operatorname{short~} \operatorname{sharp}$ tip $\ldots \ldots \ldots \ldots$

10. Leaves papery in texture; lateral sepals overlapping; lip with an entire margin, lacking viscous droplets on the $\operatorname{lip} \ldots \ldots \ldots \ldots \ldots \ldots \ldots \ldots \ldots \ldots \ldots \ldots \ldots \ldots \ldots \ldots \ldots$. flavescens

10'. Leaves leathery; lateral sepals separate; lip margin emarginate at tip . . . . . . . . . . . . L. nectarina

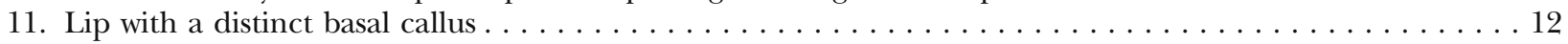

11'. Lip lacking a basal callus, occasionally with a fleshy basal vein . . . . . . . . . . . . L densa

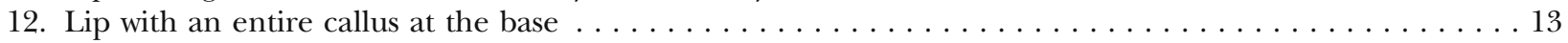

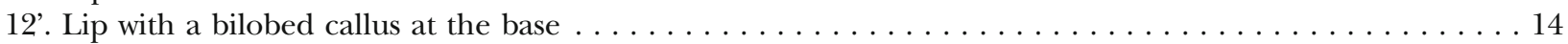

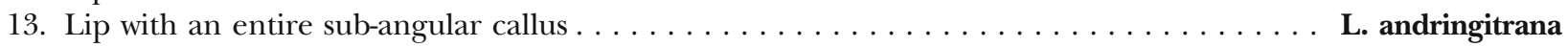

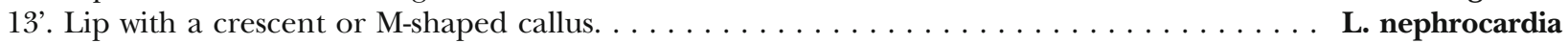

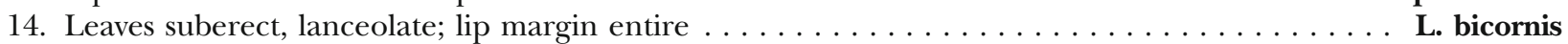

14'. Leaves spreading, elliptic; lip margin denticulate $\ldots \ldots \ldots \ldots \ldots \ldots$

15. Inflorescence laxly flowered; flowers c. $15 \mathrm{~mm}$ across; anther with a sharp beak. . . . . . . L. bemarahensis 
15'. Inflorescence sub-densely flowered; flowers c. $10 \mathrm{~mm}$ across $\ldots \ldots \ldots \ldots \ldots$. . . . . . . . . Lerrieri

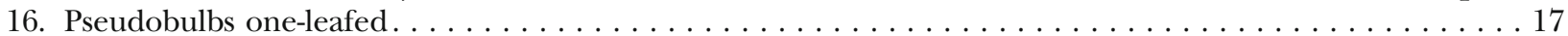

16'. Pseudobulbs two-or more leaved $\ldots \ldots \ldots \ldots \ldots \ldots \ldots \ldots \ldots \ldots$

17. Flowers c. $18 \mathrm{~mm}$ across; lip transversely elliptic, with a 2 -horned basal callus . . . . . . . . . . L. laurentii

17'. Flowers large, $25 \mathrm{~mm}$ across; lip elliptic, lacking a basal callus . . . . . . . . . . . . . . L. superclareae

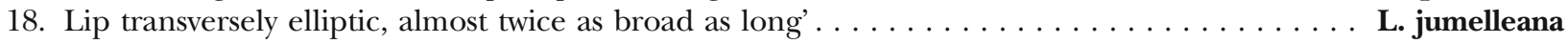

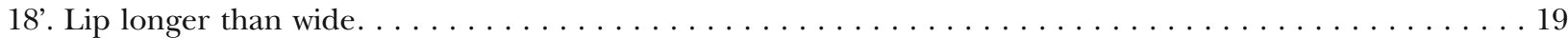

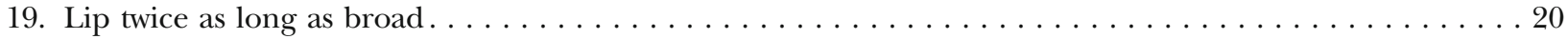

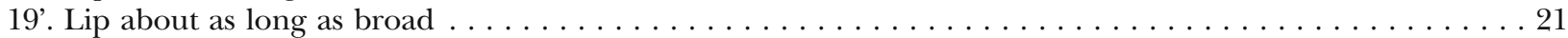

20. Pseudobulbs c. $6 \mathrm{~cm}$ long; lip elliptic; column with long rounded wings . . . . . . . . . . . . L. ochracea

20'. Pseudobulbs $7-18$ cm long; lip with a small distinct basal callus; column with angular wings. . . L. sambiranoensis

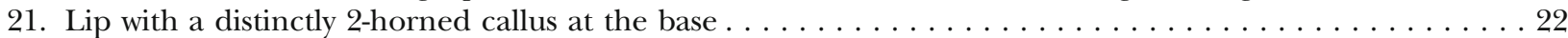

21'. Lip with an indistinct swelling rather than a callus at the base . . . . . . . . . . L. ornithorrhynchos

22'. Anther lacking a beak; column small with triangular wings. . . . . . . . . . . . . . . L. caulescens

22'. Anther beaked; column with elongate wings $\ldots \ldots \ldots \ldots \ldots \ldots \ldots \ldots \ldots \ldots$. . . . . . . L imerinensis

23. Pseudobulbs clustered, with the older ones leafy; leaf blade more or less flat, rigid or leathery . . . . . . . 24

23'. Pseudobulbs very small, globose or ovoid, often clustered; leaves ligulate-lanceolate, thin-textured. . . . . . 41

24. Pseudobulb or stem at least twice as long as the leaf $\ldots \ldots \ldots \ldots \ldots \ldots$

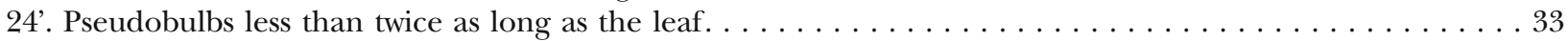

25. Leaves ovate to elliptic-lanceolate, less than 4 times as long as broad . . . . . . . . . . . . . 26

25'. Leaves narrowly lanceolate to ligulate, more than 4 times as long as broad. . . . . . . . . . L. puncticulata

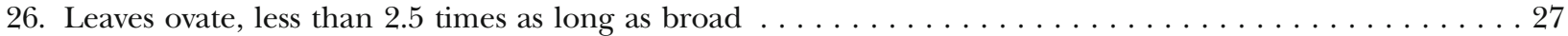

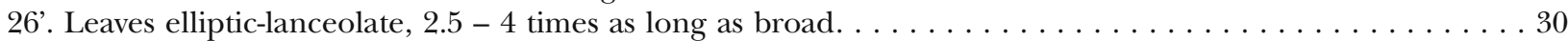

27. Plant $12-40 \mathrm{~cm}$ tall; lip more than $10 \times 5.5 \mathrm{~mm}$, with a dentate margin $\ldots \ldots \ldots$

27'. Plant $8-18 \mathrm{~cm}$ tall; lip less than $8 \times 5 \mathrm{~mm}$, with an entire or slightly sinuate margin . . . . . . . . 29

28. Pseudobulbs round in cross-section; lip triangular at tip, with an indistinct bilobed-rounded callus at the base;

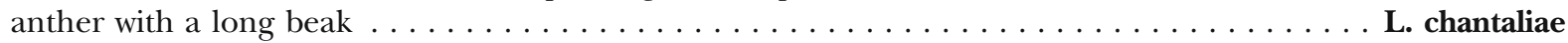

28'. Pseudobulbs angular in cross-section; lip obtuse at tip; callus bilamellar-triangular; anther shortly

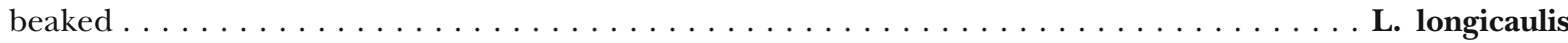

29. Lip with a small cushion-shaped callus at the base; anther rounded with a small angular beak . . L. bernieri

29'. Lip with two distinct rounded calli at the base; anther with a distinctly rounded beak. . . . . . L. danguyana

30. Plant $25-30 \mathrm{~cm}$ tall, with $3-5$ asymmetrical leaves; inflorescence with up to 30 flowers . . . . . L. rivalis

30'. Plant $15-22 \mathrm{~cm}$ tall, with $2-3$ symmetrical leaves; inflorescence up to 15 -flowered . . . . . . . . 31

31. Stem very slender; leaves distinctly petiolate; lip suborbicular with a rounded tridentate basal callus . . L. gracilipes

31'. Stem relatively stout; leaves lacking petioles; lip auriculate at the base, with a tridentate but not rounded callus

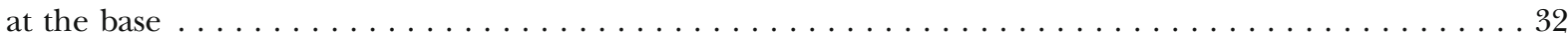

32. Lateral sepals folded beneath the lip; lip orbiculate, with a distinct 2-horned basal callus . . . . L. listeroides

32'. Lateral sepals in a vertical plane with the lip; lip pandurate with an elongated rounded callus and two small ones either side $\ldots \ldots \ldots \ldots \ldots \ldots \ldots \ldots \ldots \ldots \ldots \ldots \ldots \ldots \ldots$. $\ldots \ldots \ldots$.turiceps

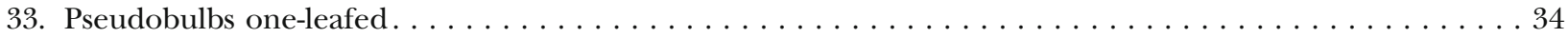

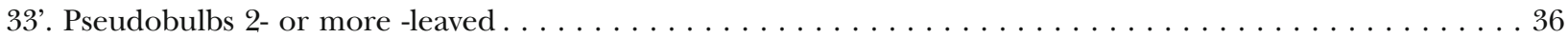

34. Leaf base subcordate; lip with an indistinct basal callus $\ldots \ldots \ldots \ldots \ldots \ldots \ldots \ldots$ clareae

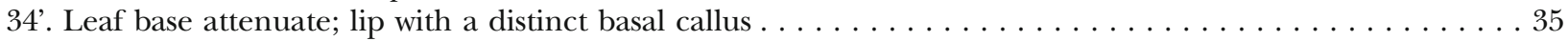

35. Leaf lanceolate with longitudinal silvery bands; peduncle sheaths and floral bracts lanceolate; lip with an

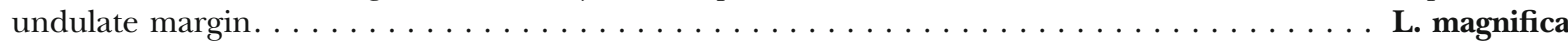

35'. Leaf narrowly ovate, lacking silvery bands; peduncle sheaths and floral bracts cordate; lip with a serrate

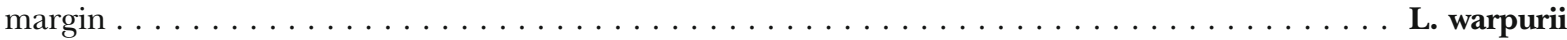

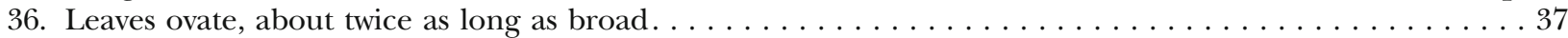

36'. Leaves oblong to ligulate, more than four times as long as wide . . . . . . . . . . . . . . . 38

37. Leaves somewhat fleshy-coriaceous, with undulate margins, purple; lip with a serrate margin; anther sharply

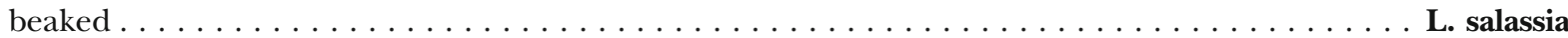

37'. Leaves rather papery, green; lip with subdenticulate margins; anther with a spathulate beak . . . L. zaratananae

38. Pseudobulbs bulbous, less than twice as long as wide $\ldots \ldots \ldots \ldots \ldots \ldots$

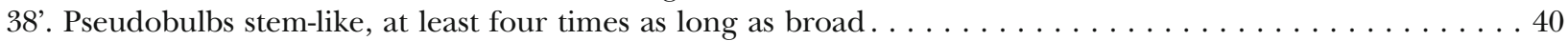

39. Leaves leathery, longly attenuate at the base; lip with callus-like ridges at the base; anther roundly beaked.

L. foliosa 
39'. Leaves papery, shortly conduplicate at the base; lip with a distinctly rounded callus; anther sharply

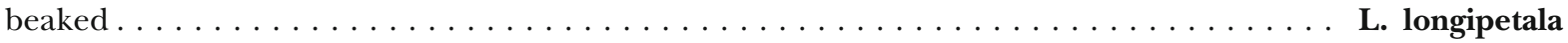

40. Rhizome elongate, ascending; leaves lanceolate, less than 5 times as long as broad; lip obcordate-cuneate, with

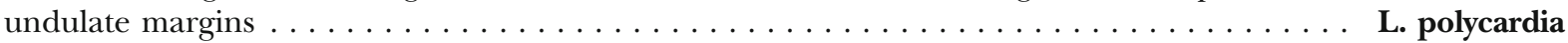

40'. Plant caespitose; leaves narrowly lanceolate, about eight times as long as broad; lip obovate, serrate on the

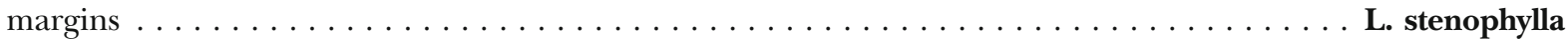

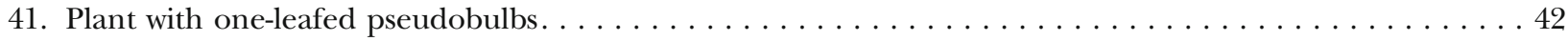

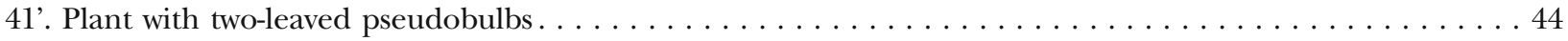

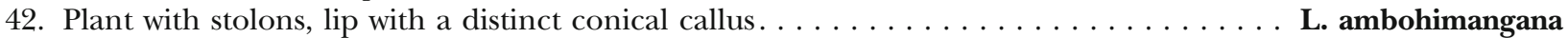

42'. Plant lacking stolons, lip callus not conical $\ldots \ldots \ldots \ldots \ldots$

43. Flowers very small c. $5 \times 4 \mathrm{~mm}$; lip lacking a distinct callus $\ldots \ldots \ldots \ldots \ldots$. . . . . . . . L cespitosa

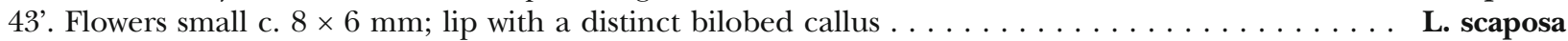

44. Plant with a distinct elongate rhizome; leaves ovate, less than twice as long as wide . . . L. bulbophylloides 44'. Plant with a very short rhizome; leaves oblong-lanceolate, more than twice as long as wide . . . . . . . 45

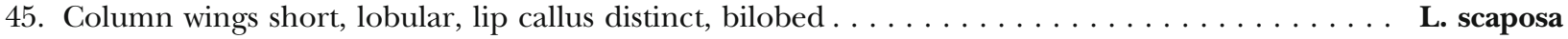

45'. Column wings long, angular, lip callus indistinct $\ldots \ldots \ldots \ldots \ldots \ldots$

46. Pseudobulbs globular, inflorescence laxly flowered, lip callus a slightly raised disk . . . . . . . . . . L. parva 46' Pseudobulbs elongate; inflorescence densely flowered towards the apex, lip callus 'M'-shaped . . . L. cladophylax

Liparis ambohimangana Hermans (in Hermans et al. 2007: 214); Cribb \& Hermans (2009: 153). Type: Madagascar, Ankeramadinika forest, François 4 in herb. Perrier 18548bis (three small plants with stolons selected here, excluding the larger plant without stolon which is L. scaposa, lectotype $\mathrm{P}$ designated here).

Liparis monophylla H.Perrier (1936: 248) non Ames (1920: 294); Perrier (1939: 276). Type as above. The cited syntypes, Decary 6222 and Perrier 18548, are Liparis scaposa.

Dwarf epiphytic or terrestrial plant, $1.5-5 \mathrm{~cm}$ tall at most, with long, slender, pale stolons $0.8-1.4 \mathrm{~mm}$ diam., up to $9 \mathrm{~cm}$ long but often shorter, carrying intermittent scale-like bracteoles, the new pseudobulbs emerging from the extremities. Pseudobulbs conical or globular, single-leaved, $3-12 \times 2.8-7 \mathrm{~mm}$, more or less covered with thin white sheaths. Leaf emerging from the apex of the pseudobulb, lanceolate to narrowly lanceolate, acute, $1.5-4.8 \times 0.5-1.4 \mathrm{~cm}$, with a distinct central vein, petiole narrow, c. $10 \mathrm{~mm}$ long. Inflorescence a little longer than the leaf, up to $7 \mathrm{~cm}$ long, c. $1 \mathrm{~mm}$ diam., carrying an occasional sterile scale, with $1-8$ flowers towards the apex but generally fewer. Peduncle wiry, $3 / 4$ of the inflorescence. Rachis densely racemose. Floral bracts $1 / 3$ the length of the ovary, ovate, acute, $1.4-2.3 \times 0.7-1.2 \mathrm{~mm}$. Flowers small, c. $8 \times 6 \mathrm{~mm}$ pale yellowish-green to pale yellow, the column and lip a little darker, the disk and callus more yellow, anther greenish-white. Pedicel and ovary fusiform, $4.5-6.9 \times 0.3-1.5 \mathrm{~mm}$. Dorsal sepal lanceolate to ligulate, $4-6.9 \times 1-1.8 \mathrm{~mm}$. Lateral sepals oblong-falcate, $3.2-5.1 \times 1.5-2.4 \mathrm{~mm}$. Petals linear, $4.1-6 \times 0.2-0.3 \mathrm{~mm}$. Lip broadly oval to suborbicular, $2.3-3.7 \times 2.2-3.2 \mathrm{~mm}$, broadly winged at the base, more or less sinuate at the margins, with a large $(1.7-2.1 \mathrm{~mm})$ conical callus at the base, callus convex at the anterior margin. Column arched, with characteristic auriculate wings just below the apex, 3.2 $-4 \times 0.2-1.2 \mathrm{~mm}$. Anther very small, $0.4-0.6 \times 0.3-$ $0.6 \mathrm{~mm}$, truncate at the anterior margin. Pollinia two pairs, $0.2-0.4 \times 0.15-0.3 \mathrm{~mm}$. Seed capsule oblong or oblanceolate, $7-10 \times 3.5-4 \mathrm{~mm}$.

RECOGNITION. A very small plant with prominent stolons, a single lanceolate leaf, a peduncle about $3 / 4$ of the few-flowered inflorescence and small flowers with a wide lip with a large conical callus at base, appearing as a single swelling in herbarium material, a column with distinct auriculate wings at the apex, and an anther lacking a distinct beak.

Liparis ambohimangana is similar to L. scaposa (Table 1) with which it has an overlapping distribution but $L$. scaposa does not produce stolons, the plant is larger with a conical pseudobulb, a shorter and narrower leaf (sometimes two), the inflorescence generally longer, slightly larger flowers and smaller and more roundly lobed callus at the base of the lip. It is also similar to L. cespitosa which lacks stolons and has a broadly oval to suborbicular lip (vs oblong-obtuse in L. cespitosa) and lacks a distinct callus.

DISTRIBUTION. Endemic to Madagascar: Antananarivo, Fianarantsoa and Toamasina provinces. Map 5. Records from Réunion (Szelengowicz et al. 2011: 11 and Szelengowicz \& Tamon 2013: 350 - 351) are referable to Liparis scaposa.

SPECIMENS EXAMINED. MADAGASCAR. Ankeramadinika forest, May 1928, François 4 in Herb. Perrier 17548bis (in part, P) lectotype; s. loc., May 1970, Bosser 20317 (P); Fivondronana Moramanga, Ambatovy, $1106 \mathrm{~m}$, June 2008, Antilahimena 6292 (MO, P, TAN); Ambatovy, $1124 \mathrm{~m}$, May 2010, Ramahenina $\mathcal{E}^{\circ}$ Ratodimanana 32 (K, MO, P); Ambatovy, 1080 - 1098 
Table 1. Comparison of Liparis ambohimangana, L. cespitosa, L. parva and L. scaposa.

\begin{tabular}{|c|c|c|c|c|}
\hline & L. ambohimangana & L. cespitosa & L. parva & L. scaposa \\
\hline Plant & up to $5 \mathrm{~cm}$, clear stolon & up to $8 \mathrm{~cm}$, no stolon & $2-3 \mathrm{~cm}$, no stolon & up to $8 \mathrm{~cm}$, no stolon \\
\hline Pseudobulb & globular to conical & ovoid & globular & conical \\
\hline Leaves & 1 , lanceolate & 1 (rarely 2), lanceolate & 2 , lanceolate & 1 or 2, lanceolate \\
\hline Inflorescence & $\begin{array}{l}\text { up to } 7 \mathrm{~cm}, 1-8 \text { flowers, } \\
\text { dense raceme }\end{array}$ & $\begin{array}{l}\text { up to } 8 \mathrm{~cm}, 5-20 \\
\text { flowers, dense raceme }\end{array}$ & $\begin{array}{l}\text { c. } 6 \mathrm{~cm} \text { zig-zag, } 6-12 \\
\text { flowers, loose raceme }\end{array}$ & $\begin{array}{l}\text { up to } 14 \mathrm{~cm}, 3-7 \\
\text { flowers, } \\
\text { dense raceme }\end{array}$ \\
\hline Dorsal sepal (mm) & $4-6.9 \times 1-1.8$ & $1.5-2.5 \times 0.8-1.2$ & c. $6 \times 0.8$ & $5-7 \times 1.2-1.6$ \\
\hline Lateral sepals (mm) & $3.2-5.1 \times 1.5-2.4$ & $1.9-2.5 \times 0.9-1.25$ & c. $5.5 \times 2$ & $3.5-5.1 \times 1.8-2.5$ \\
\hline Petals (mm) & $4.1-6 \times 0.2-0.3$ & $1.5-2.5 \times 0.3-0.5$ & c. $7 \times 0.5$ & $5.5-6.7 \times 0.3-0.4$ \\
\hline Lip $(m m)$ & $2.3-3.7 \times 2.2-3.2$ & $1.9-2.5 \times 1.1-1.75$ & c. $5 \times 3.6$ & $3.9-5.5 \times 4.2-5.5$ \\
\hline Lip callus & large, conical & small swelling & small swelling & medium, rounded lobes \\
\hline Column (mm) & $3.2-4 \times 0.2-1.2$ & $1.1-1.6 \times 0.5$ & $4 \times 1$ & $3-4 \times 0.8-1$ \\
\hline Distribution & $\begin{array}{l}\text { Madagascar: } \\
\text { Antananarivo, } \\
\text { Fianarantsoa and } \\
\text { Toamasina prov. }\end{array}$ & Global & $\begin{array}{l}\text { Madagascar: } \\
\text { Fianarantsoa } \\
\text { \& Toamasina prov. }\end{array}$ & $\begin{array}{l}\text { Madagascar: } \\
\text { Antananarivo, } \\
\text { Toamasina } \\
\text { prov. \& Réunion }\end{array}$ \\
\hline Altitude (m) & $1000-1200$ & $400-1400$ & $1000 ?$ & $1000-1600$ \\
\hline
\end{tabular}

m, May 2012, Ambatovy Shade House 816 (BRLU, K, MO, P, TAN); Ambatovy, May 2012, 1080 - 1098 m, Ambatovy Shade House 1177 (BRLU, K, MO, P, TAN); Ambatovy, 1100 m, Aug. 2012, Stévart et al. 4605
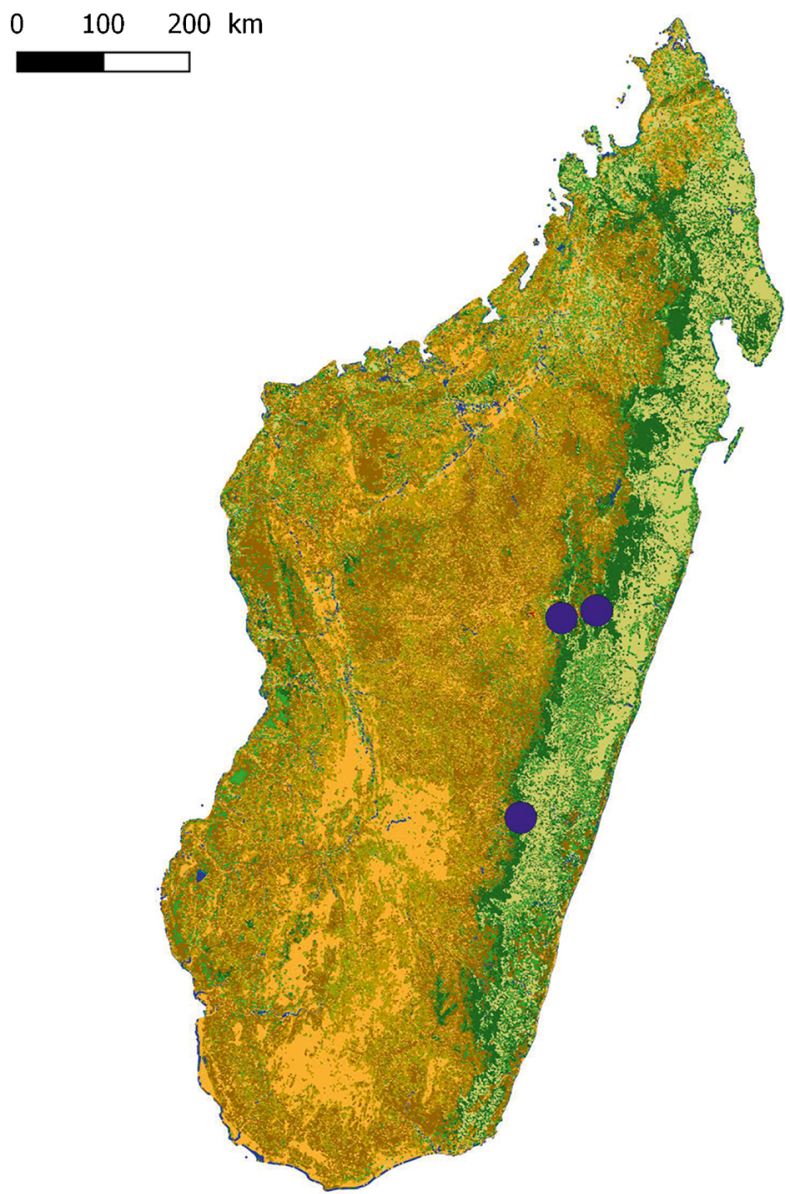

Map 5. Distribution of Liparis ambohimangana.
(BRLU, K, MO, P); Fianarantsoa, Ranomafana area, April 2018, Hermans 8211, 8212, 8216.

HABITAT. Mainly epiphytic on branches and at the base of trees, in moss. On tree ferns (Cyathea), on Harungana madagascariensis Lam. ex Poir. (Lamarck 1804: 314). Terrestrial in humus or moss, mosscovered rocks and on the forest floor. Altitude: 1000 - $1200 \mathrm{~m}$.

CONSERVATION STATUS. Category EN: The extent of occurrence (EOO) of Liparis ambohimangana is estimated to be $5,320 \mathrm{~km}^{2}$ (which exceeds the limits for Endangered status under criterion B1) whereas its minimal area of occupancy (AOO) is estimated to be $12 \mathrm{~km}^{2}$ (which falls within the limits for Endangered status under the criterion B2). With only three known subpopulations representing three locations (sensu IUCN), this rare species has been preliminarily assessed as EN using the green listing method. This species is threatened by mining activities, selective logging, timber harvesting for small-scale subsistence and tavy (slash-and-burn farming), resulting in habitat reduction and habitat quality reduction.

FLOWERING TIME. April to August.

ETYMOLOGY. The species name refers to the Ambohimanga area in the Madagascan Highlands and the origin of Raymond Decary's 1928 collection that was once associated with the type material. Perrier's name Liparis monophylla refers to the single leaf of the plant.

NOTES. This species was described by Perrier in 1936 but the name had already been used in 1920 by Ames for a plant from the Philippines, it was re-named in 2007 (Hermans et al. 2007: 214).

Perrier (1936: 249) listed three collections in his description of Liparis monophylla: Ambohimanga, near Tananarive (Decary 6222, April 1928); Ankeramadinika 
forest (Perrier 18548, May 1928); same locality (François 4). As often the case, he did not designate a type specimen let alone a holotype. A number of sheets are annotated as 'types' by him in the Paris herbarium:

1. Two sheets of Decary 6222 (P00095463 and P00095464), they contain several flowering plants and dissections of Decary '6422' (in error for 6222, Decary 6422 is a plant of the Fabaceae family) and of Perrier 18548, the label is annotated in Perrier's hand as 'Type'.

2. One sheet of François 4 (numbered 18548bis in Perrier's herbarium P00095466), this also is annotated as 'Type'.

3. One sheet of Perrier 18548 (P00095465), this is not indicated as 'Type' but as 'sp. n'.

During field observations two of the authors (J.H. and J-M.H.) realised that there were two distinct species within the dwarf Madagascan Liparis with a single leaf and a distinct callus at the base of the lip. One is generally terrestrial with a relatively short leaf, an inflorescence invariably much longer than the leaf, without stolon and with a roundly lobed callus at the base of the lip. A second is generally epiphytic, with an inflorescence hardly longer than the leaf, with a distinct stolon and with a much larger conical callus at the base of the lip.

Perrier's descriptions (1936: 248 - 249) and (1939: 276) could apply to both these species but he was very clear that his Liparis monophylla had pale filiform stolons and he also used this characteristic to compare it with L. cespitosa, in addition he mentioned a prominent callus. His illustration (1939: 283) also shows long thin stolons. Although not obvious in the type material, the only other Liparis in the region reported (Perrier 1939: 283) to have a stolon is L. parva which has two leaves, flowers a third larger and a differently shaped anther and column (see Table 1).

Detailed analysis of the material indicated as types by Perrier clearly shows that they contain a mixture of two different species and this has been the cause of much confusion: all the plants on Decary 6222 and on Perrier 18548 have no stolons and habit and flowers that correspond clearly with Liparis scaposa which, during Perrier's time, was only recognised from Réunion. The sheet of François 4 (= Perrier 18548bis) has one flowering plant of $L$. scaposa but three plants with flower fragments and buds only but with clear stolons that correspond well with Perrier's description of L. monophylla. It is likely that Perrier assembled all plants with a single leaf that were not $L$. cespitosa as his new species, they may even have become mixed up, especially in specimen Perrier 18548bis.

The stoloniferous plants in François 4 (= Perrier 18548bis) are here designated as the lectotype of Liparis ambohimangana and the other collections
(Decary 6222, Perrier 18548 and the large plant without stolon in Perrier 18548bis) are classified as L. scaposa. Perrier's description combined with the newly selected lectotype allow precise identification and should avoid any future ambiguity.

ILlUStrations. Figs 1, 2; Perrier (1939: 283); the illustrations in Cribb \& Hermans (2009: 157) from Madagascar and Szelengowicz et al. (2011: 11); Szelengowicz \& Tamon (2013, 350 - 1) from Réunion are Liparis scaposa.

Liparis andringitrana Schltr. (Schlechter 1924: 135); Perrier (1939: 287); Hermans et al. (2007: 215); Cribb \& Hermans (2009: 153); Hervouet (2018: 404). Types: Madagascar, Andringitra massif, c. 1800 m, Feb. 1922, Perrier 14396 (P00094939) Lectotype P designated here; Perrier 14396 (P00094940) isolectotype.

Liparis henrici Schltr. (Schlechter 1924: 139) synon. nov.; Perrier (1936: 255); Perrier (1939: 292); Hermans et al. (2007: 219); Cribb \& Hermans (2009: 154). Types: Madagascar, Andringitra massif, Feb. 1922, c. 1800 m, Perrier 14395 (P00094983) lectotype $\mathrm{P}$, designated here; Perrier 14395 (P00094982) isolectotype.

Liparis latilabris Schltr. (Schlechter 1924: 142) non Rolfe (1903: 6) synon. nov. Type: Madagascar, Andringitra massif, Feb. 1922, c. 1800 m, Perrier 14394 (holotype P).

Liparis verecunda Schltr. (Schlechter 1924: 150) synon. nov. Types: Madagascar, Feb. 1919, Ambatofinandrahana, Perrier 12420 (P00094985) lectotype $\mathrm{P}$, designated here; Perrier 12420 (P00094986) isolectotype.

Liparis rectangularis H.Perrier (1936: 254) synon. nov.; Perrier (1936: 254); Hermans et al. (2007: 222); Cribb \& Hermans (2009: 154). Type: Madagascar, Mt Maromizaha, near Analamazoatra, Perrier 16043 (holotype P).

Small to medium size, erect terrestrial or lithophytic plant, $6-16 \mathrm{~cm}$ tall on a short rhizome, the older pseudobulbs not retaining their leaves, roots filiform, flexuose, minutely pilose. Pseudobulbs cylindrical to oblong, more or less compressed-angular, sometimes watery in substance when young, enveloped by $2-3$ sheaths plus often carrying one to two leaf-like sheaths, $2-7.5 \mathrm{~cm}$ long, c. $1-1.5 \mathrm{~cm}$ diam., the flowering growth carrying 2 - 3 erectly-spreading leaves, the older ones erect or oblique, covered by papery sheaths. Leaves oval to elliptic, apiculate or shortly acuminate, thin, sometimes margins sub-crenulate, more or less narrowed into a short petiole (1.3$3 \mathrm{~cm}$ ), blade $4.5-15 \times 2-5 \mathrm{~cm}$, with prominent veins. Inflorescence the same length as or exceeding the leaves, up to $12 \mathrm{~cm}$ long carrying 3 - 12 flowers. Peduncle with $1-2$ lanceolate sheaths, acuminate. 


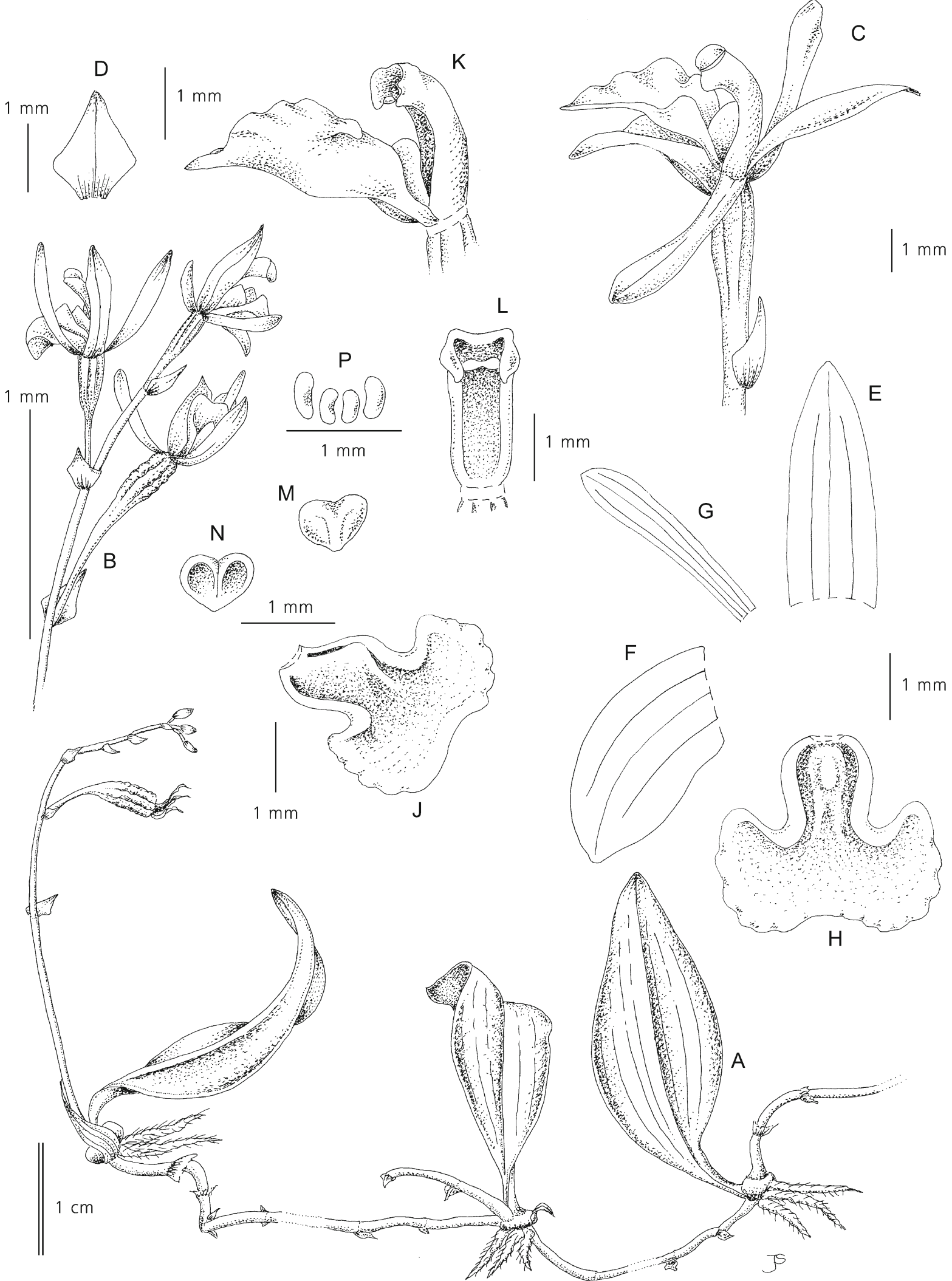

Fig. 1. Liparis ambohimangana. A habit; B inflorescence; C flower; D floral bract; E dorsal sepal; F lateral sepal; G petal; H lip from above; J lip, oblique view; K column and lip, side view; L column, front view, anther cap removed; M anther cap, dorsal view; $\mathbf{N}$ anther cap, ventral view; P pollinia. From Hermans 8211 (K). DRAWN BY JUDI STONE. 

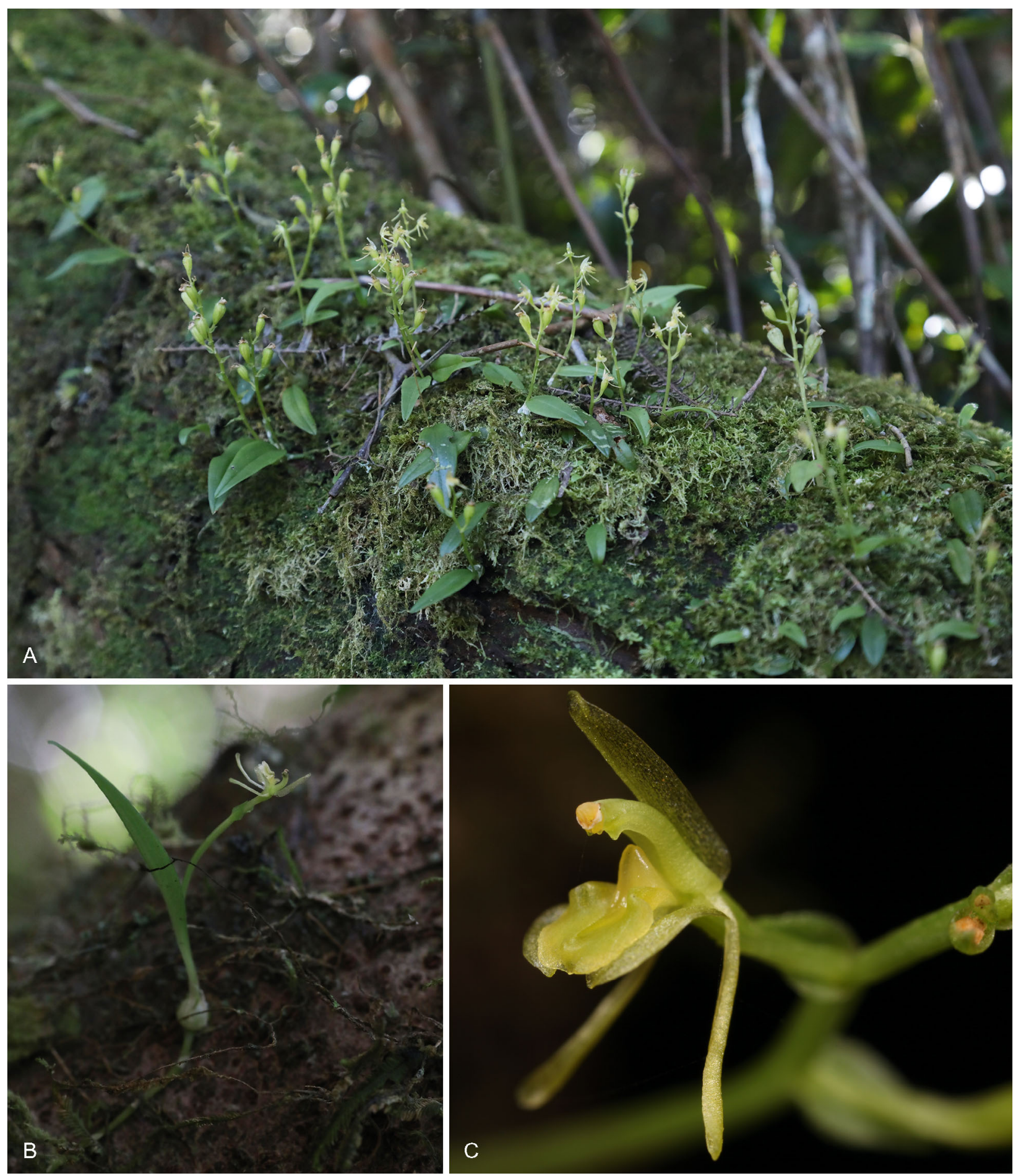

Fig. 2. Liparis ambohimangana. A habit; B habit showing stolon; C flower. PHOTOS: A, B JOHAN HERMANS; C JEAN-MICHEL HERVOUET.

Rachis sub-densely racemose, up to $7 \mathrm{~cm}$ long. Floral bracts erectly spreading, lanceolate, acute, the lower ones as long as the ovary, the higher ones shorter, 4.5 - $7.1 \times 1.9-2.1 \mathrm{~mm}$. Flowers small to medium size, erectly spreading to suberect, av. $10 \times 8 \mathrm{~mm}$, yellowish or pale yellow-brown, greenish yellow, becoming more orange, column yellow towards the apex, anther white.
Pedicel and ovary $6-9 \times 1.2-4 \mathrm{~mm}$, glabrous, strongly winged to slightly ridged, new flowers opening whilst seed pods develop below. Dorsal sepal erect to arching, narrowly lanceolate, somewhat obtuse, base cordateauriculate, $5.6-9.5 \times 0.9-2.1 \mathrm{~mm}$. Lateral sepals semioval to oblong, folded beneath the lip, $4.5-7 \times 2.1-$ $3.2 \mathrm{~mm}$. Petals linear, slightly broader at the base, $5.9-$ 
$8 \times 0.3-0.9 \mathrm{~mm}$. Lip somewhat curved, broadly oval to flabellate, the blade suborbiculate to obovate but occasionally broader than long, widest towards the middle, base slightly narrowed with the basal auricles fairly long (c. $1 \mathrm{~mm}$ ) and obtuse, the front margin rounded and more or less subcrenulate, basal callus sub-angular to transversally oblong, truncate, at the base partly extending into 2 keels and merging with the outer veins, often quite obsolete in dried specimens, $4.1-6.8 \times 3.5-6.2 \mathrm{~mm}$. Column slightly incurved, $2.6-3.9 \times 0.7-1.2 \mathrm{~mm}$, with small rounded wings protruding by the stigma. Anther with a short triangular beak c. $0.6 \times 1 \mathrm{~mm}$. Pollinia in two pairs, oval, av. $0.4 \times 0.6 \mathrm{~mm}$. Seed capsule somewhat ridged, av. $15 \times 5 \mathrm{~mm}$.

RECOGNITION. Liparis andrigitrana is characterised by the 2 - 3-leaved plant on a somewhat elongate, more or less flattened, pseudobulb, with thin strongly veined leaves on a $1.5-3 \mathrm{~cm}$ petiole. Medium sized flowers with the lip rounded and generally subcrenulate at the front, distinct wings at the base and an angular callus at the base. Anther slightly beaked. The seed capsules are often semi-erect and persistent.

It is similar to Liparis nephrocardia Schltr. (Schlechter 1924: 145) both in habit, inflorescence and flower but L. andringitrana is generally larger and taller, the lip shape is slightly different (broadly oval vs obcordate) and the callus is much less obvious and not 'V'-shaped, the anther beak is angular vs obtuse. Similar to L. flavescens but differs by the more elongate pseudobulb and leaf petiole, slightly larger flowers and lip callus (Table 2).

It resembles Liparis bosseri, described below, but that species is much shorter and smaller, with a shorter inflorescence and has flowers with the anther with a spathulate beak (vs short and rounded). It differs from the mainland African L. bowkeri by the smaller plant and flowers with a different lip and column (Table 3). DISTRIBUTION. Probably endemic to Madagascar in Antananarivo, Fianarantsoa, Toamasina and Toliara provinces (Map 6). Szelengowicz \& Tamon (2013: 358) cite and illustrate a plant assigned to this species from Réunion but because of the lack of vouchered material and the quality of the photographs it is impossible to ascertain if this identification is correct. One of the labels on the type material (P00094939) has 'Manongarivo' massif crossed out by Perrier and changed to 'Andringitra' massif. Manongarivo is in Northern Madagascar in the Tsaratanana mountain range. The Andringitra location fits with Perrier's collection numbers in that area and is therefore correct.

SPECIMENS EXAMINED. MADAGASCAR. Andringitra massif, c. 1800 m, Feb. 1922, Perrier 14396 (P00094939) lectotype P; Perrier 14396 (P00094940); Andringitra massif, Feb. 1922, c. 1800 m, Perrier 14395 (P00094983) (lectotype P); Perrier 14395 (P00094982) (isolectotype P); Andringitra massif, Feb. 1922, c. 1800 m, Perrier 14394 (holotype $\mathrm{P}$ in part); Ambatofinandrahana, Feb. 1919, Perrier 12420 (P00094985) (lectotype P); Perrier 12420 (P00094985) (isolectotype $\mathrm{P}$ ); Mt Maromizaha near Analamazoatra, c. 1000 m, Feb. 1924, Perrier 16043 (holotype P); Central, Mt Ibity, c. 800 m, Feb. 1914, Perrier 7039 ter (P); Ambohimanga forest, June 1915, Alleizette s.n. (P); Anjavidilana, Andringitra, Jan. 1950, Guillaumet 3720 (P, TAN); Andringitra, Jan. 1971, Guillaumet 3815 (TAN); High valley of the Menarakaka, E of Ihosy, 100 - 800 m, Jan. 1955, Humbert 28550 (P); Fianarantsoa, $39 \mathrm{~km} \mathrm{~N}$ of Ambositra, 1250 - $1350 \mathrm{~m}$, Jan. 1974, Croat 29475 (K, MO); Toliara, road from Ifarantsa to Enaniliha, $630 \mathrm{~m}$, Feb. 1995, D. DuPuy et al. M869 (K); Kitsamby forest, near Soavinandriana, 1997, Hermans 3553 (K); Antananarivo, near Angavokely forestry station, Dec. 1997, Hermans 2107 (K); along RN4 to Mahajunga, Dec. 1997, Hermans 3941 (K); Fianarantsoa, Andringitra foothills, near Soavihiny, May 2001, 1095 m, Hermans 2860; Toamasina, Moramanga, Andasibe, Menalamba, April 2005, $960 \mathrm{~m}$, Rakotovao $\mathcal{E}$ Edmond 1868 (TAN); Andringitra, Ambarafaranditra, 1770 m, Jan. 2005, Fischer $\mathcal{E}^{\circ}$ Andriantiana 2095 (WU); Toamasina, fokontany Ampitabe, Ambatovy, 1193 m, May 2008, Rakotondrafara 741 (MO, P, TAN); Toamasina, Alaotra Mangoro, Sahavaharina forest, 1012 m, April 2009, Antilahimena 7053 (MO, P, TAN); Toamasina, Andasibe, Eulophiella Lodge forest, May 2018, Hermans 8215 (K).

HABITAT. Montane forest remnants. Amongst rock, in shade beneath shrubby undergrowth, in leaf litter, moss forest. Altitude: $600-1800 \mathrm{~m}$.

CONSERVATION STATUS. Category VU: The extent of occurrence (EOO) of Liparis andringitrana is estimated to be $38,418 \mathrm{~km}^{2}$ (which exceeds the limits for Vulnerable status under criterion B1) whereas its minimal area of occupancy (AOO) is estimated to be $32 \mathrm{~km}^{2}$ (which falls within the limits for Endangered status under the criterion B2). Liparis andringitrana is known from six subpopulations representing eight locations (sensu IUCN), and has this rare species has thus been preliminarily assessed as VU using the green listing method. This species is threatened by mining activities, selective logging, timber harvesting for smallscale subsistence and tavy (slash-and-burn farming), resulting in habitat reduction and habitat quality reduction. Annual fires in the Ambatofinandrahana and Ibity areas have affected several colonies of the species. Its habitat is also affected by harvesting of wood for charcoal production in the Maromizaha reserve.

FLOWERING TIME. December to May.

ETYMOLOGY. Refers to the type locality of the Andringitra mountain range in SE Madagascar, now 
Table 2. Comparison of the type specimens of: Liparis andringitrana, L. flavescens, L. henrici, L. nephrocardia and L. rectangularis, based on average measurements.

\begin{tabular}{|c|c|c|c|c|c|}
\hline & L. andringitrana & L. flavescens & L. henrici & L. nephrocardia & L. rectangularis \\
\hline Specimen & Perrier $14396(\mathrm{P})$ & $\begin{array}{l}\text { Thouars Eै Bory } \\
\text { s.n. (P) }\end{array}$ & Perrier 14395 (P) & Perrier 15746 (P) & Perrier 16043 (P) \\
\hline Plant height $(\mathrm{cm})$ & 12 & 9 & 11 & 8 & 12 \\
\hline Pseudobulb $(\mathrm{cm})$ & $2.5 \times 1.5$ & $2.5 \times 1.3$ & $4 \times 1$ & $2 \times 0.8$ & $3 \times 0.7$ \\
\hline Leaves & $12 \times 4.5 \mathrm{~cm}$ & $8 \times 3 \mathrm{~mm}$ & $9 \times 4 \mathrm{~cm}$ & $7 \times 2.5 \mathrm{~cm}$ & $10.5 \times 3.2 \mathrm{~cm}$ \\
\hline Inflorescence $(\mathrm{cm})$ & 13 & 15 & 15 & 5.5 & 13 \\
\hline No of flowers & c. 12 & c. 10 & c. 14 & c. 8 & c. 12 \\
\hline Dorsal sepal (mm) & $8.5 \times 1.1$ & $7 \times 0.7$ & $8.5 \times 1.8$ & $6.5 \times 1.1$ & $7.3 \times 0.8$ \\
\hline Lateral sepals (mm) & $6 \times 2.2$ & $6.5 \times 2.7$ & $7 \times 3.2$ & $6.5 \times 2.3$ & $6 \times 2.4$ \\
\hline Petal (mm) & $7 \times 1$ & $7 \times 0.3$ & $7.5 \times 0.8$ & $5 \times 0.3$ & $5.5 \times 0.3$ \\
\hline $\operatorname{Lip}(\mathrm{mm})$ & $4.2 \times 3.5$ & $5.3 \times 5$ & $5.5 \times 4.5$ & $4 \times 3.5$ & $5 \times 4$ \\
\hline Lip callus & $\begin{array}{l}\text { indistinct } \\
\text { transversal }\end{array}$ & bi-lobed ridge & obscure, bi-lobed & bi-lobed & indistinct ridges \\
\hline Column & $\begin{array}{l}2.5 \times 0.8 \mathrm{~mm}, \text { small } \\
\text { round wings }\end{array}$ & $\begin{array}{l}4 \times 0.8 \mathrm{~mm} \text {, roundly } \\
\text { winged }\end{array}$ & $\begin{array}{l}3.5 \times 1.3 \mathrm{~mm}, \\
\text { roundly winged }\end{array}$ & $\begin{array}{l}2 \times 0.6 \mathrm{~mm}, \\
\text { triangular wings }\end{array}$ & $\begin{array}{l}2.5 \times 0.6 \mathrm{~mm}, \\
\text { roundly winged }\end{array}$ \\
\hline Anther & sharply beaked & sharply beaked & short sharply beaked & sharply beaked & $\begin{array}{l}\text { sharply or roundly } \\
\text { beaked? }\end{array}$ \\
\hline Distribution & $\begin{array}{r}\text { Madagascar, } \\
\text { E-Central }\end{array}$ & $\begin{array}{l}\text { Mascarenes, } \\
\text { Seychelles } \\
\text { (Madagascar?) }\end{array}$ & $\begin{array}{l}\text { Madagascar: } \\
\text { Fianarantsoa } \\
\text { prov., } \\
\text { Andringitra }\end{array}$ & $\begin{array}{l}\text { Madagascar: } \\
\text { Antsiranana, } \\
\text { Toamasina prov }\end{array}$ & $\begin{array}{l}\text { Madagascar: } \\
\text { Toamasina prov. }\end{array}$ \\
\hline Altitude (m) & c. 1800 & $400-1500$ & c. 1800 & $600-1800$ & c. 1000 \\
\hline Flowering & Jan. - Feb. & March - June & Feb. & Dec. - March & Feb. \\
\hline
\end{tabular}

a National Park. Liparis henrici was named by Rudolf Schlechter for Henri Perrier de la Bâthie (1873 1958), L. latilabris refers to the broad lip, $L$. rectangularis presumably refers to the angles of the lip and $L$. verecunda probably refers to the diminutive nature of plant and flower.

NOTES. Schlechter's descriptions of Liparis andringitrana, L. henrici, L. latilabris and $L$. verecunda are just a few pages apart and could easily apply to all four species; strangely he does not compare them with each other but does so with other species. In the descriptions there are differences in the shape of the lip callus and curvature of the column which are never very clear in dried material. Liparis andringitrana, $L$. henrici and L. latilabris were collected by Perrier in the Andringitra mountains, presumably from almost the same spot with only one number difference in collecting code. Schlechter also illustrated all four species in 1932. Perrier in his revision of Liparis from Madagascar (1936: 242) made L. latilabris and $L$. verecunda synonyms of $L$. henrici, he did not explain the reasons. He first mentioned them under 'species not satisfactorily known' and then listed them as synonyms of $L$. henrici further in the text. In addition Schlechter was unaware that the name L. latilabris had previously been used by Rolfe (1903: 6) for an Indochina/Vietnam species.

On examination of herbarium material of Liparis andringitrana, L. henrici, L. latilabris, L. verecunda and L. rectangularis (Table 2 ) it becomes obvious that they consist of one, variable species. They all share the same plant habit, leaf-shape, lip, lip callus, column and

Table 3. Comparison of Liparis andringitrana, L. bowkeri and L. flavescens.

\begin{tabular}{llll}
\hline \hline & L. andringitrana & L. bowkeri (mainland Africa) & L. flavescens \\
\hline Plant height $(\mathrm{cm})$ & up to 16 & up to 30 & up to 11 \\
Pseudobulb $(\mathrm{cm})$ & $2-7.5$ & $7 \times 5$ & 5 \\
Leaf shape & oval to elliptic & lanceolate to ovate & lanceolate or ovate \\
Leaf size $(\mathrm{cm})$ & $4.5-15 \times 2-5$ & $5-14 \times 2-7.5$ & $5.6-6.5 \times 1.2-3.9$ \\
Inflorescence $(\mathrm{cm})$ & up to 12 & up to 20 & up to 22 (generally much shorter) \\
Floral bract $(\mathrm{mm})$ & up to $4.5-7.1 \times 1.9-2.1$ & $10-15$ & $2.5-5 \times 1.2-1.8$ \\
Dorsal sepal $(\mathrm{mm})$ & $5.6-9.5 \times 0.9-2.1$ & $8-11 \times 1-2.5$ & $4.7-8 \times 0.9-1.4$ \\
Lateral sepals $(\mathrm{mm})$ & $4.5-7 \times 2.1-3.2$ & $6-9 \times 2.5-4$ & $4.8-7.1 \times 2.7-3$ \\
Petal (mm) & $5.9-8 \times 0.3-0.9$ & $5-12 \times \mathrm{c} .0 .5$ & $5.8-7.6 \times 0.3-0.5$ \\
Lip (mm) & $4.1-6.8 \times 3.5-6.2$ & $5-7 \times 6-8$ & $5-6.3 \times 4.9-5.5$ \\
Column $(\mathrm{mm})$ & $3-3.5 \times 1.2-2$ & $3-4$ & $1.8-3.9 \times 0.8-1.2$ \\
Distribution & Madagascar, E-Central & Mainland Africa, Ethiopia to S Africa & Mascarenes, Seychelles (Madagascar?) \\
\hline
\end{tabular}


$0 \quad 100 \quad 200 \mathrm{~km}$

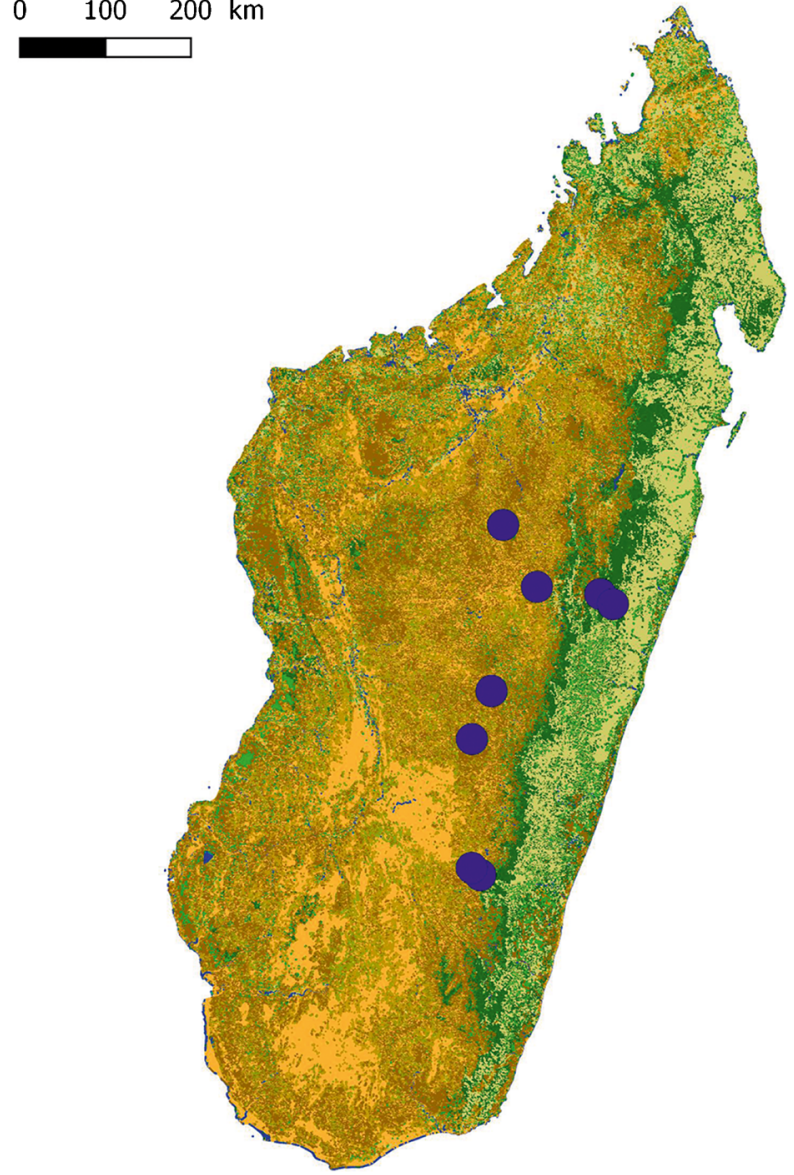

Map 6. Distribution of Liparis andringitrana.

anther. There is a great variance in pseudobulb, leaf size and lip shape but there are a number of intermediate forms.

In plant and flower habit Liparis latilabris corresponds well with the typical form of $L$. andringitrana but the shape of the lip is puzzling: in his description Schlechter describes it as reniform and wider than long, this is reflected in his drawing and also in the type material but Perrier's drawing of the lip kept with the type shows a more typical oval form. On examining the type sheet of L. latilabris (Perrier 14394) the left hand plant has a lip that is broader than long whilst the other plants have a more typical oval lip of L. andringitrana. Liparis latilabris is therefore kept as a synonym.

Liparis verecunda is identical in plant habit, lip shape, column and anther to L. andringitrana and is also kept as a synonym.

Liparis rectangularis is known only from the holotype and consists of two plants collected in the Maromizaha forest in the east of Madagascar. The type is accompanied by a drawing by Perrier of the lip and anther. On dissecting the flowers it is obvious that his drawing somewhat exaggerates the size of the basal wings and the rectangular angles of the blade. This exaggeration is repeated in the original description and in his key (Perrier 1939: 284). It is a local variant of L. andringitrana with which it shares the same habit, flower size, lip and column, it is therefore considered a synonym (Table 2).

The lectotype material of Liparis henrici consists of generally bigger plants and a longer stem than those of the type of L. andringitrana (Table 2). The flowers however, are of a similar size and shape, the lip, lip callus, column and anther shape are identical to those of L. andringitrana. In his description and key Perrier (1939: 288) follows Schlechter's flawed description and singles out the flattened watery bulbs and obtuse rounded anther to differentiate $L$. andringitrana from the other species. The flattened bulbs are not uncommon in plants labelled as L. henrici, the pseudobulb shape is generally somewhat indistinct in dried material and their soft watery nature is likely to be environmental and has been observed in young pseudobulbs of other species, including $L$. densa. Perrier is adamant that the anther of L. andringitrana is rounded at the front (tout à fait arrondie en avant) but on dissecting the type material it is clear that the anther is shortly beaked as in the type of L. henrici. Lip and callus shape are also used as distinguishing characters between the different species but herbarium material has confirmed a great variety of lip shapes, even within a single collection. When dried, the shape of the callus remains as somewhat indistinct raised ridges only.

Extensive field observations by two of the authors (J.H. \& J-M.H.) confirmed the great variability within the species: mature flowering plants within different colonies varied from six $\mathrm{cm}$ to more than $15 \mathrm{~cm}$, some with distinct pseudobulbs and large leaves, others were more diminutive. Length of inflorescence was also found to be variable but the size and shape of the flowers was consistent. The callus of the lip was always prominent as was the anther beak. It was generally impossible to key-out or differentiate between the different populations in Andringitra and the Eastern forest around Andasibe.

Based on these observations it was decided to treat Liparis andringitrana, L. henrici, L. latilabris, L. verecunda and $L$. rectangularis as one, variable species. Liparis andringitrana, based on Perrier 14396 (P00094939), was chosen as the most representative and complete. The type material of L. henrici is less representative of the typical form and has a few deformed flowers.

There are two herbarium sheets of the type of Liparis andringitrana (Perrier 14396); sheet P0094939 has the most representative plants and was therefore chosen as the lectotype, sheet P0094940 has a single plant and the label has 'Manongarivo' as the collecting locality on sheet P0094939, this is an error corrected by Perrier, it is chosen as an isolectotype. There are two herbarium sheets of the type of L. henrici (Perrier 
14395); sheet P0094983 has the most representative plants and was therefore chosen as the lectotype, sheet P0094982 is an isolectotype. The same was done with the type material of Liparis verecunda. The type sheet Perrier 14394 of L. latilabris in $\mathrm{P}$ has three plants and there seems to be considerable variability in the flower, some flowers show the typical L. henrici lip but others have a somewhat deformed lip that is wider than long.

ILLUSTRATIONS. Figs 3, 4; Schlechter (1932: T.51, T.534, 56); Hervouet (2018: 404).

Liparis bathiei Schltr. (Schlechter 1924: 135); Perrier (1939: 291); Hermans et al. (2007: 215); Cribb \& Hermans (2009: 152). Types: Madagascar, Ambatolampy (Ankaratra), 1500 m, March 1921, Perrier 13548 (P00094950) (holotype P); Ambatolampy, Feb. 1925, Perrier 13548 (topotypes G (G00354728), K (K000242139) P (P000951-2)).

Very small to small, erect, terrestrial plant, $6-11.5 \mathrm{~cm}$ high; rhizome short, roots, filiform, flexuose, more or less villous. Pseudobulbs short, 7 - $10 \mathrm{~mm}$ high, 5 $9 \mathrm{~mm}$ diam. in the middle, sub-globular. Leaves soft, generally $2-3$, rarely 4 , erect-spreading from the flowering pseudobulbs, oblong or elliptic-acute to somewhat obtuse, $4.2-6.1 \times 2.2-3.2 \mathrm{~cm}$, gradually narrowed into a petiole towards the base. Inflorescence erect, sub-flexuose, about the same length as the leaves, carrying a few basal sheaths, up to $10 \mathrm{~cm}$ long. Raceme densely flowered, elongate, up to $7 \mathrm{~cm}$, carrying 10 - 20 flowers. Floral bracts leaf-like, erectly spreading, lanceolate, acuminate, the lower ones often a little longer than the ovary, $4-7 \times 3.5-4 \mathrm{~mm}$, the higher ones a little shorter, $4 \times 2.5 \mathrm{~mm}$. Flowers very small to small, erectly spreading, overall c. $4 \times 5 \mathrm{~mm}$, yellow green. Pedicel and ovary $4-5 \mathrm{~mm}$, glabrous, roundly ridged. Dorsal sepal erect, narrowly lanceolate, obtuse, $4.5-5.2 \times 0.5-1.8 \mathrm{~mm}$, the base cordateauriculate. Lateral sepals folded beneath the lip, strongly 3-veined, obliquely oval or oblong, $3.8-4.8$ $\times 1.8-2.7 \mathrm{~mm}$. Petals narrowly linear, obtuse, recurved, $4.2-5 \times 0.3-0.4 \mathrm{~mm}$. Lip oval to lozengeshaped, obtuse, base cordate-auriculate, with the blade somewhat angular at the base, anterior margin irregular, the tip more or less apiculate and recurved, a small obsolete callus near the base, with a central gutter with radiating veins along its length, $3.1-4.2 \times$ $3-3.8 \mathrm{~mm}$. Column a little curved, short $1.8-2.4 \mathrm{~mm}$ and thick c. $1 \mathrm{~mm}$, wings barely present. Anther clavate, 1 - $1.2 \mathrm{~mm}$ long, including the narrow rounded upturned beak, $0.6-0.9 \mathrm{~mm}$ wide. Pollinia oval c. $0.3 \mathrm{~mm}$ diam.

RECOGNITION. One of the smallest members of the genus in Madagascar. It has short and subglobose pseudobulbs, a densely flowered rachis with $10-20$ very small to small flowers, relatively large floral bracts, a lip lacking a prominent callus, and a small column, with an anther with a narrow upturned beak.

Liparis bathiei resembles L. trulliformis, having the same habit, but differs in its smaller flowers, the relatively wider, rhombic, ecallose lip and the comparatively stout column. There are similarities in habit with L. lutea but the lip is bigger, the floral bracts larger and the anther cap has an obtuse rather than an acute beak. It also resembles $L$. bosseri, described below, in plant habit and shape of the anther but the rachis in $L$. bosseri is less dense, the flowers are twice the size, and the lip obovate (vs oval / lozengeshaped). It shares several characteristics with L. xanthina which may be the same species but there is not sufficient reliable material to support this.

DISTRIBUTION. Endemic to Madagascar: Antananarivo province in the Ankaratra Massif in and near the town of Ambatolampy, recently also found a little further South in Fianarantsoa province (Map 7). Records from Réunion are misidentifications: photographs in Szelengowicz \& Tamon (2013: 351) labelled as this species show an unrecognisable but different plant, inflorescence habit and flower, the description copies that of Perrier (1939: 291) for the species.

SPECIMENS EXAMINED. MADAGASCAR. Ambatolampy, 1500 m, March 1921, Perrier 13548 (P00094950) (holotype P); Ambatolampy, Feb. 1925, Perrier 13548 (G00354728, P000951-2 \& K000242139 topotypes G, P, K); Ankaratra, path to Mt Tsiafajavona, Feb. 1964, Bosser 17711 (P); Fianarantsoa, RN7, near col Tapia, Jan. 2019, Hermans 8282 (K).

HABITAT. Terrestrial on laterite clay, in the shade of Acacia dealbata Link (1822: 445). Amongst rock. Altitude: 1500 - $1600 \mathrm{~m}$.

CONSERVATION STATUS. Category EN: the extent of occurrence (EOO) of Liparis bathiei cannot be estimated since it is only known from two remaining subpopulations whereas its minimal area of occupancy (AOO) is estimated to be $8 \mathrm{~km}^{2}$ (which falls within the limits for Critically Endangered status under the criterion B2). This species has been preliminarily assessed as EN using the green listing method. This species is threatened by selective logging, timber harvesting for small-scale subsistence and tavy (slashand-burn farming), resulting in habitat reduction and habitat quality reduction.

FLOWERING TIME. January to March. ETYMOLOGY. Named for Henri Perrier de la Bâthie (1873 - 1958) by Rudolf Schlechter.

NOTES. Liparis bathiei was first found by Perrier in March 1921 and was sent to Schlechter the following month who described it three years later. Perrier made another collection in the same locality in February 1925 and gave them the same collecting number. In his description, Schlechter cited Perrier's 


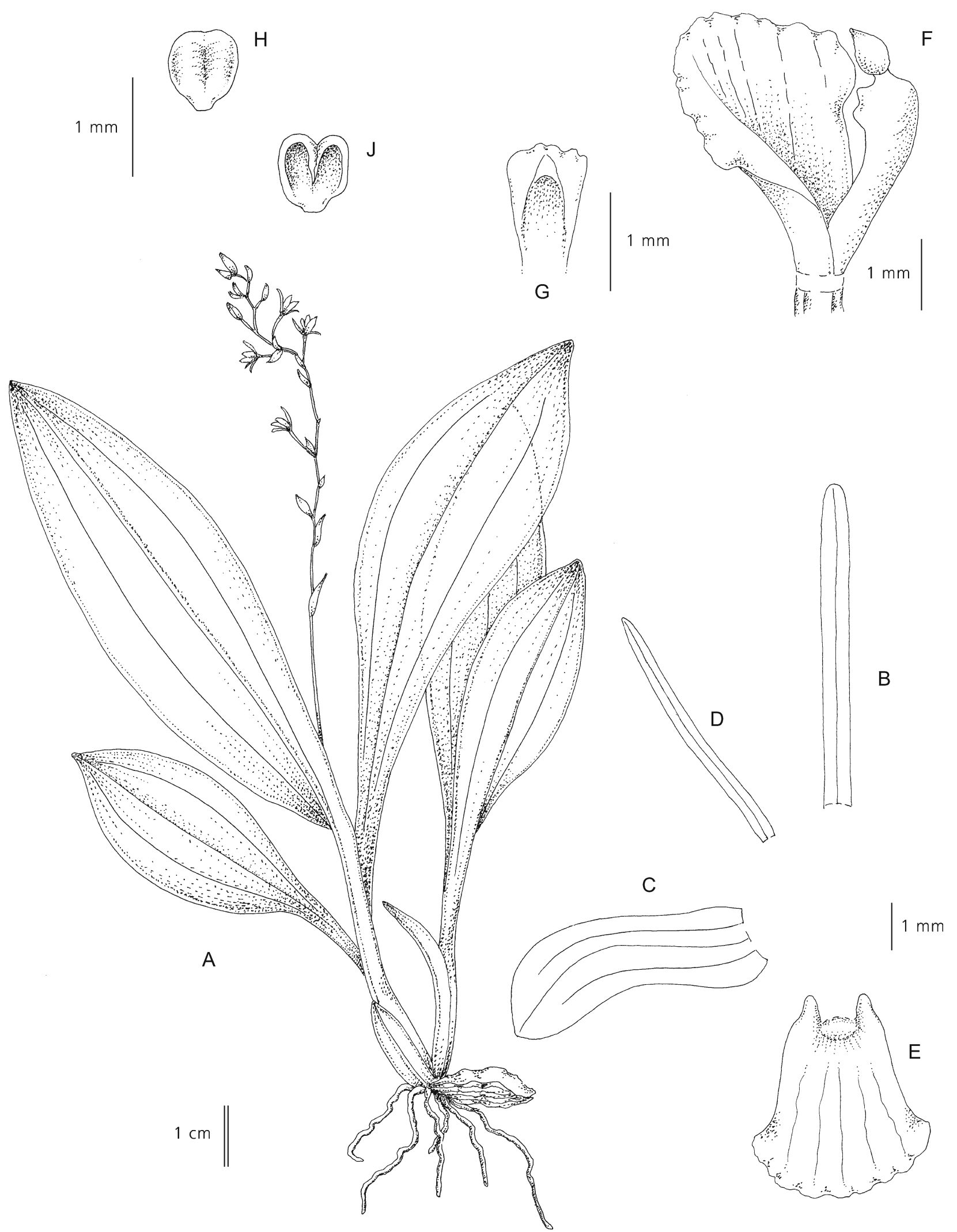

Fig. 3. Liparis andringitrana. A habit; B dorsal sepal; C lateral sepal; D petal; E lip; F column and lip, side view; G top of column, front view; $\mathrm{H}$ anther cap, dorsal view; J anther cap, ventral view. From Perrier 16043 (type of L. rectangularis) (P). DRAWN BY JUDI STONE. 

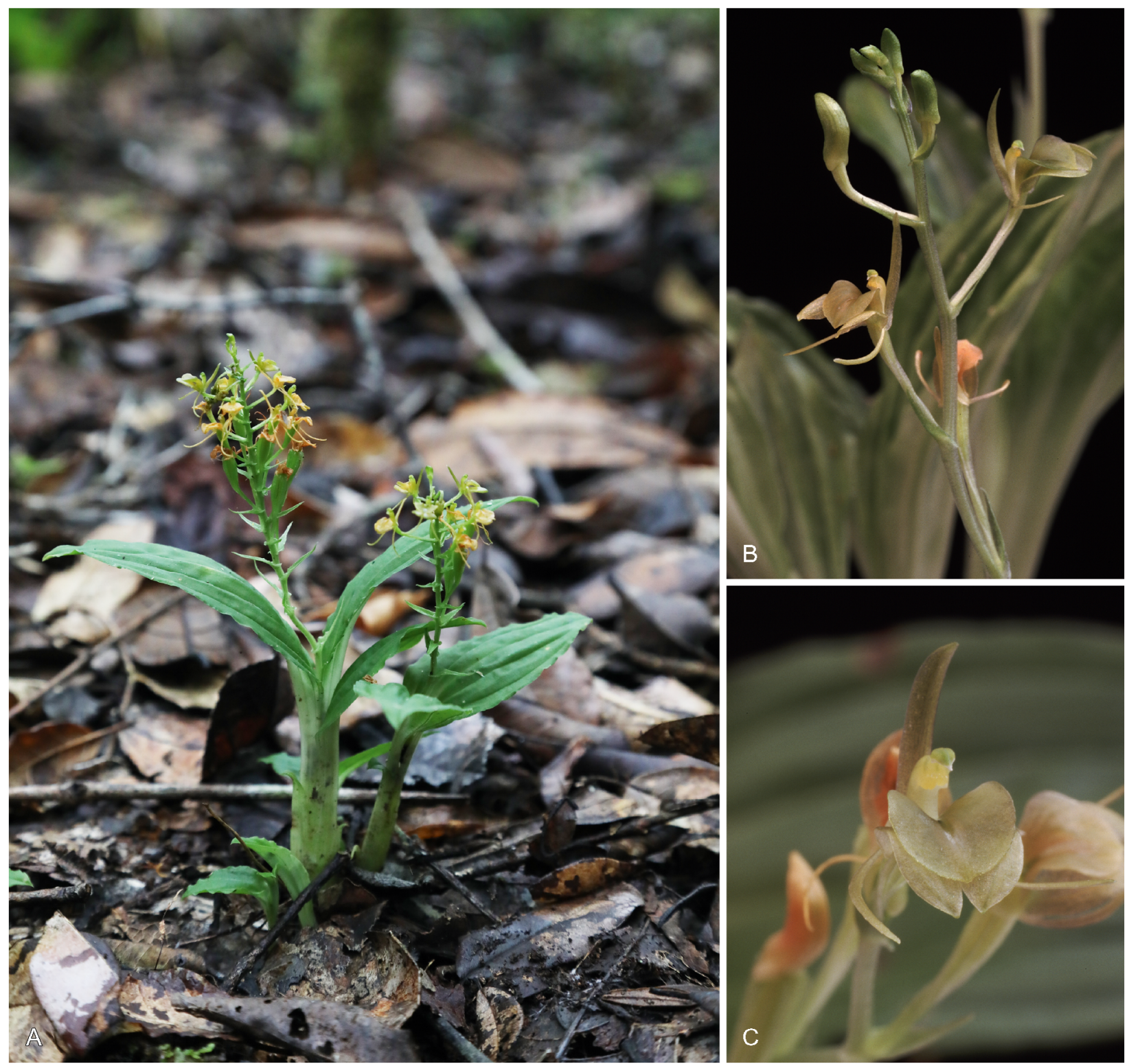

Fig. 4. Liparis andringitrana. A habit; B rachis; C flower. PHOTOS: JOHAN HERMANS.

specimen 13548 as the type with a collecting date of March 1921. Several sheets in G, K and P also have the number of Perrier 13548 but are from the later collection. As they come from the same locality as the holotype but were collected later, they can all be considered as topotypes.

Perrier in an overview of the geographical distribution of Liparis discussed the origin of this species (1936: 259): he first found plants in March 1921 on the immediate outskirts of the then small town of Ambatolampy, a few hundred metres South from the military barracks, at around $1500 \mathrm{~m}$ altitude, in an area that is now very barren, densely populated and cultivated. Further collections were made in Feb. 1925 and duplicates deposited in G and K. According to Perrier the population was still there in 1932. He wrote that the plant grew in good numbers in the shade and in the humus of Acacia dealbata, introduced to Madagascar around 30 years before: “... There is no natural locality for this Liparis, remnants of original forest are more than $60 \mathrm{~km}$ away, and these remnants have been well explored by botanists. Finding this Liparis in these urban conditions under an introduced tree is interesting and not easy to explain except for originating from small seeds transported in the wind. It is also interesting that this species is new and has little resemblance to other Liparisfound in the area (it is related to L. henrici but this species has only been found in Betsileo, i.e. more than $200 \mathrm{~km} \mathrm{~S}$ of Ambatolampy. It has reproduced with vigour in these conditions, very different from those where these species normally grow. Considering these circumstances it appears that this Liparis is a result of recent 


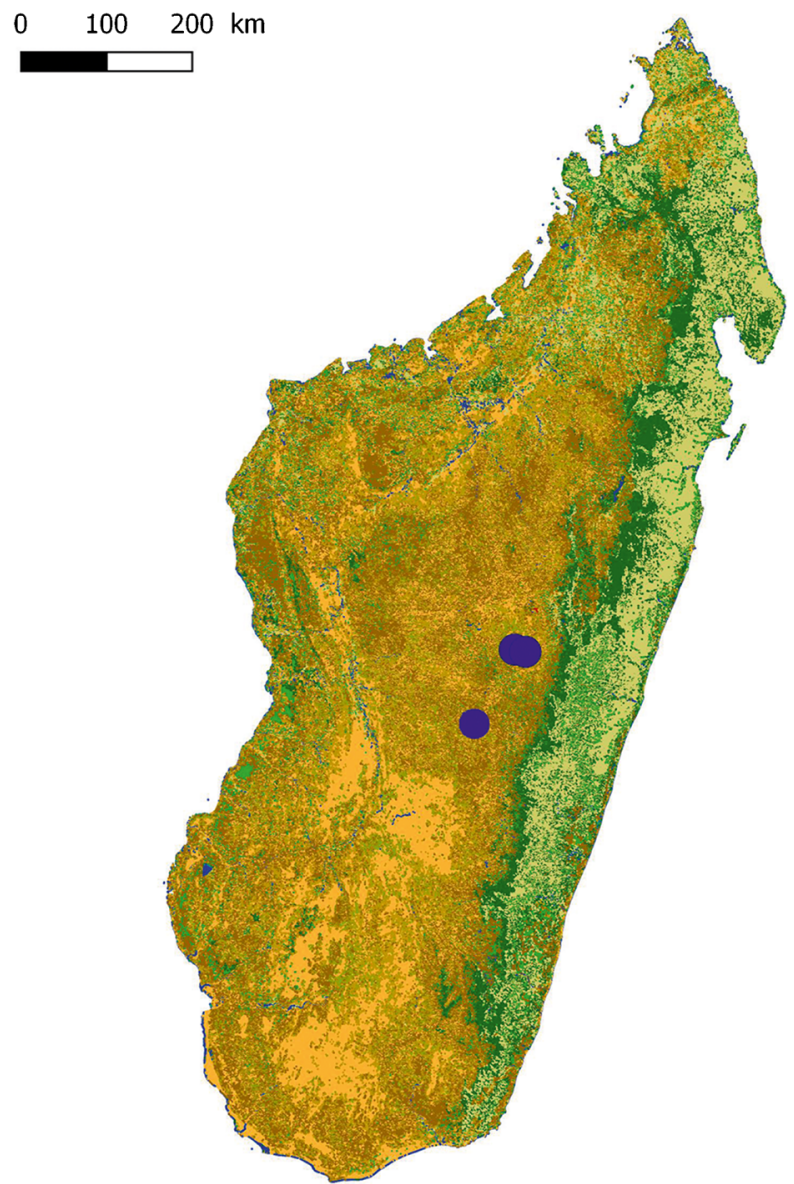

Map 7. Distribution of Liparis bathiei.

evolution, resulting from a seed transported by wind into a very different environment. This example of sudden mutation is especially interesting as it occurred on one of the main link roads of the Island, it is an interesting example of local evolution."

Extensive searches by the first author in and around the town of Ambatolampy, especially near army barracks and underneath Acacia trees did not find plants of this Liparis.

The species has now also been identified from the Mt Tsiafafavona in the Ankaratra Massif (Bosser 17711) which is only around $30 \mathrm{~km}$ from the type locality. A very small and vulnerable colony of plants was recently found c. $150 \mathrm{~km} \mathrm{~S}$ in Fianarantsoa province.

ILLUSTRATION. Fig. 5; Schlechter (1932: T.52).

Liparis bemarahensis Hermans sp. nov. Type: Madagascar, near Ambodiriana, E of Antsalova, 100 - 150 m, Jan. 1960, Léandri E Saboureau 2687 (holotype P (P01778638); isotype P (P01778635)).

http://www.ipni.org/urn:lsid:ipni.org:names:77201709-1
Medium size, erect terrestrial, lithophyte or rarely epiphytic plant $14-18 \mathrm{~cm}$ high, emerging directly from the base of the previous growth, roots filiform, more or less villous, c. $1-2 \mathrm{~mm}$ diam. Pseudobulbs ovoid, narrowly elongate, entirely covered by $3-5$ brown membranous sheaths and by the sheath-like petiole of the lower leaves, with 3 4 leaves, new growth emerging from the previous leafless pseudobulb which is almost completely disintegrated and often divaricate, $3-4 \times 0.5-1$ $\mathrm{cm}$. Leaves erectly spreading, variable in size, blade ovate to broadly elliptic-acuminate, corrugate, with 7 pronounced ridges, narrowed into a short 15 $20 \times 6-8 \mathrm{~mm}$ sheath-like petiole amplexicaul to the pseudobulb, plicate, thin textured, pale green, overall $10-16 \times 5-8.5 \mathrm{~cm}$. Inflorescence erect, up to $30 \mathrm{~cm}$ long, c. $2 \mathrm{~mm}$ diam., on maturity far exceeding the leaves, carrying up to 20 flowers. Peduncle costate, about $1 / 2$ the length of the inflorescence, with a few lanceolate sterile bracts cordate at the base. Rachis laxly racemose, up to $15 \mathrm{~cm}$. Floral bracts shorter than the pedicellate ovary, spreading, ovate-lanceolate, attenuate at the tip, somewhat cordate at the base, green, $3.5-9 \times$ $2.2-4.1 \mathrm{~mm}$, becoming smaller towards the apex. Flowers small to medium in size, erectly spreading, overall up to $15 \times 11 \mathrm{~mm}$, entirely olive green, translucent, fading to ginger-orange. Pedicel and ovary porrect, cylindrical, somewhat winged, 8 - 14 $\times 0.8-1.2 \mathrm{~mm}$. Dorsal sepal erect to incurved, ligulate, margins more or less recurved, $8.1-9.9 \times$ $0.7-1.8 \mathrm{~mm}$. Lateral sepals folded beneath the lip, elliptic, a little narrowed towards the base, $6.3-8.1$ $\times 2.5-3.1 \mathrm{~mm}$. Petals strongly curved backwards, linear, $7-8.5 \times 0.3-0.8 \mathrm{~mm}$. Lip shortly auriculate at the base, then elliptic-rectangular, sinuate and recurved at the anterior margin, with two distinct rounded horn-like calli at the base, 6.1 - $8.2 \times 5.1-6.5 \mathrm{~mm}$. Column curved towards the apex, with distinct rounded wings, $3-5.5 \times 1-2$ $\mathrm{mm}$. Anther ovoid with a short acute beak at the tip, $1.1-1.5 \times 0.9-1.1 \mathrm{~mm}$. Pollinia ovoid c. $0.4 \times$ $0.6 \mathrm{~mm}$.

RECOGNITION. Liparis bemarahensis is characterised by its ovoid pseudobulbs covered by sheaths, the deciduous previous growth, its thin-textured, ovate to elliptic leaves, long inflorescence with up to 20 flowers, the prominent floral bracts, small to medium-sized flowers with an elliptic-rectangular lip with two horn-like calli at the base, and the anther with a short acute beak.

Liparis bemarahensis is similar to several of the softleaved deciduous Liparis species of the region. It is close to L. sambiranoensis but it is a smaller plant with smaller flowers, a shorter stem, and a rectangular lip (vs pandurate), with sinuate anterior margin (vs serrate) region (Table 4). It is vegetatively closest to 

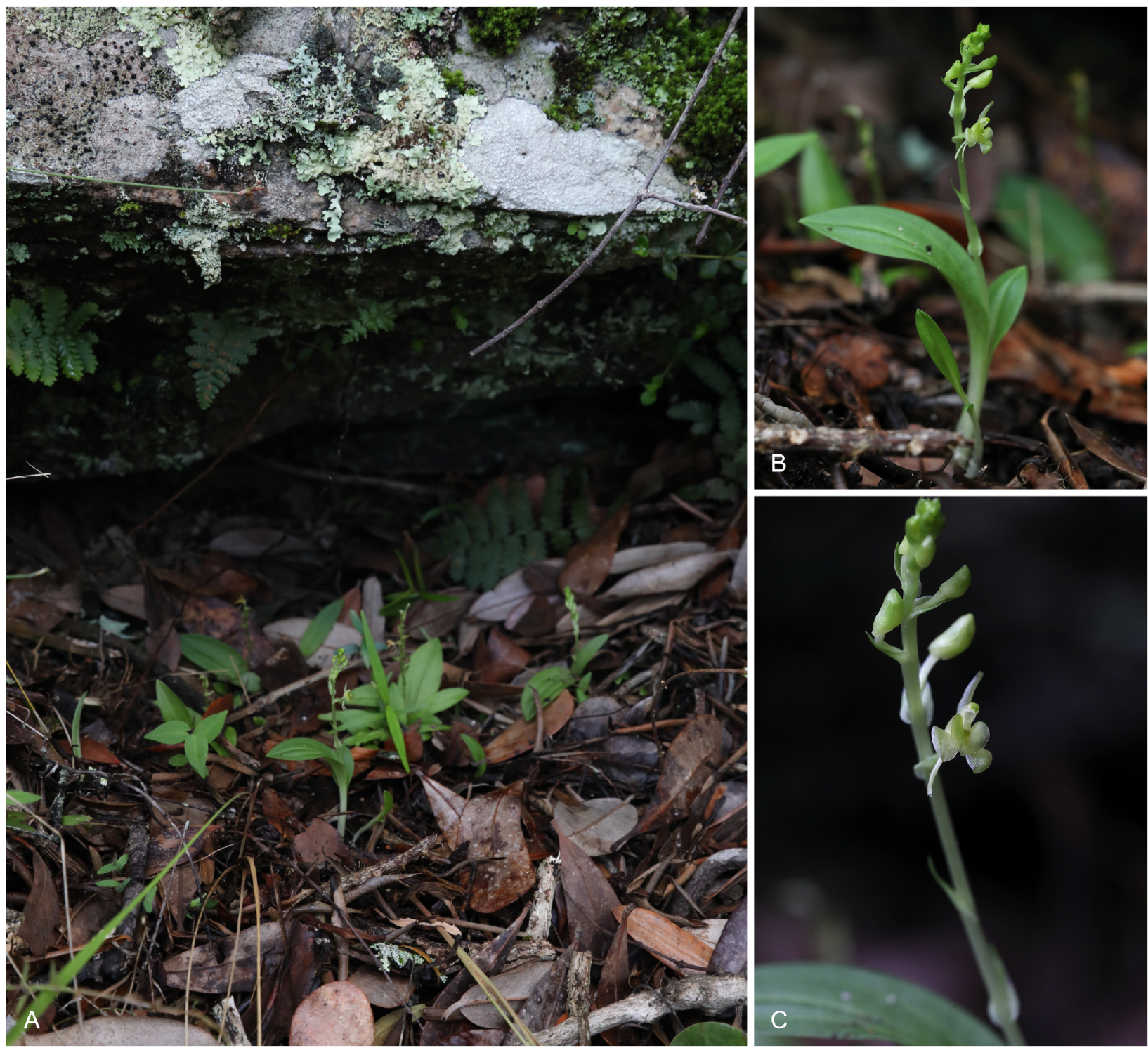

Fig. 5. Liparis bathiei. A plant in habitat; B habit; C rachis. PHOTOS: JOHAN HERMANS.

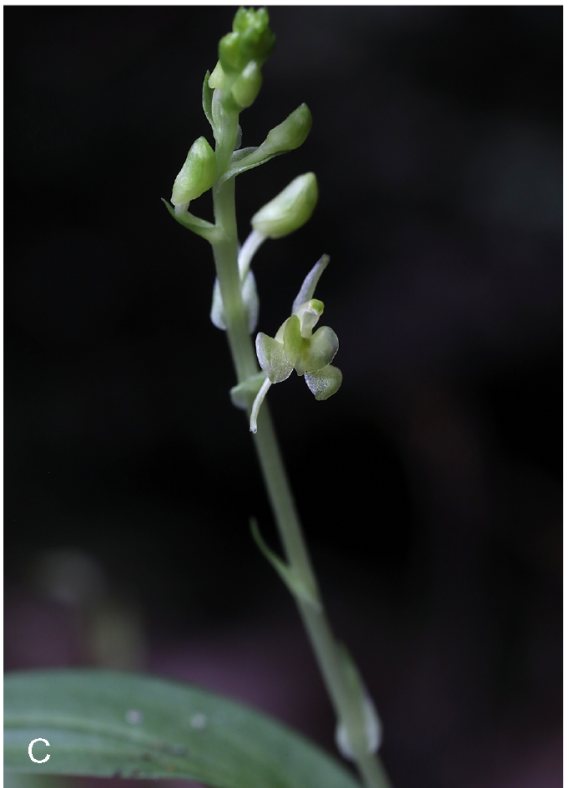

Fig. 5. Liparis bathiei. A plant in habitat, B habit, C rachis. PHOTOS. JOHAN HERMANS.

L. perrieri but the flowers of the new species are larger, the rachis lax (vs sub-dense) and the anther distinctly beaked. There are also some similarities in habit to L. ochracea and L. ornithorrhynchos but the flowers are $1 / 3$ smaller than those of L. ochracea, the lip elliptic-rectangular vs twice as long as broad in L. ochracea and rounded to broadly cordate in L. ornithorrhynchos and the anther with a much shorter beak than L. ornithorrynchos. It is also similar to L. andringitrana but the flowers are larger by $1 / 3$ and more numerous, the lip elliptic-rectangular vs oval-flabellate and the lip with two distinct calli vs sub-angular. The distinct calli and lip-shape are considerably different from all the above. It is has a limited distribution in the Bemaraha area, at lower elevation.
DISTRIBUTION. Madagascar: Mahajanga province only, restricted to the Bemaraha plateau and 'Tsingy' limestone karst (Map 8).

SPECIMENS EXAMINED. MADAGASCAR. Near Ambodiriana, $\mathrm{E}$ of Antsalova, $100-150 \mathrm{~m}$, Jan. 1960, Léandri Ẽ Saboureau 2687 (holotype P (P01778638), isotype $\mathrm{P}$ (P01778635)); towards Ambodiriana, $\mathrm{E}$ of Antsalova, 100 - 150, Dec. 1952, Léandri et al. 2171 (P); Antsingy of Antsalavo, Bemaraha, Jan. 1975, Morat 4867 (P); Majunga, NW of Ambohitsaratelo-Bebao 1985, Barnett et al. 307 (K, MO); Bemaraha area, Tsingy, 700 m, 1999, Hermans 2447 (K); Tsingy of Antsalova, 30 Jan. 1990, Bogner 2070 (M); Antsalova, Tsingy de Bemaraha, c. 10 - 20 m, Feb. 1995, D. DuPuy et al. M883 (K, P, TAN). 
Table 4. Comparison of Liparis bemarahensis and L. sambiranoensis, based on average measurements.

\begin{tabular}{lll}
\hline \hline & L. bemarahensis & L. sambiranoensis \\
\hline Plant height $(\mathrm{cm})$ & $14-18$ & $15-40$ \\
Pseudobulb stem length $(\mathrm{cm})$ & $3-6$ & $7-18$ \\
Leaves (number) & 3 (rarely 4$)$ & $3-4($ rarely 5$)$ \\
Leaf length $(\mathrm{cm})$ & $10-15 \times 5-8$ & $10-18.5-5-7.5$ \\
Inflorescence length $(\mathrm{cm})$ & up to 30 & up to 30 \\
Floral bract $(\mathrm{mm})$ & $3.5-9 \times 2-4$ & $8-12 \times 3.8-4.1$ \\
Number of flowers & up to 20 & up to 25 \\
Dorsal sepal $(\mathrm{mm})$ & $8-9 \times 0.7-1.2$ & $12.5-18 \times 1.2-3.8$ \\
Lateral sepals $(\mathrm{mm})$ & $6.3-8 \times 2.5-3.1$ & $11-16 \times 3.4-5.9$ \\
Petals $(\mathrm{mm})$ & $7-8.3 \times 0.3-0.8$ & $11.4-17 \times 0.5-1.5$ \\
Lip size (mm) & $6-7.1 \times 5.1-7$ & $9.1-14 \times 5.4-8.8$ \\
Lip shape & elliptic-rectangular & broadly oval $/$ suborbiculate \\
Lip callus & two distinct angular horns & bi-gibbose \\
Column size (mm) & $3-5.5 \times 1-2$ & $4.1-6 \times 1.1-1.5$ \\
Column wings shape & short round & wings angular \\
Anther & sharply beaked & acutely beaked \\
Distribution & Madagascar: Mahajanga prov. & Madagascar: Antsiranana, Mahajanga prov. Comoros \\
Altitude $(\mathrm{m})$ & $100-200$ & $200-1000$ \\
\hline
\end{tabular}

HABITAT. Deciduous forest on limestone Tsingy, chalk rock, dense low deciduous forest with a canopy of
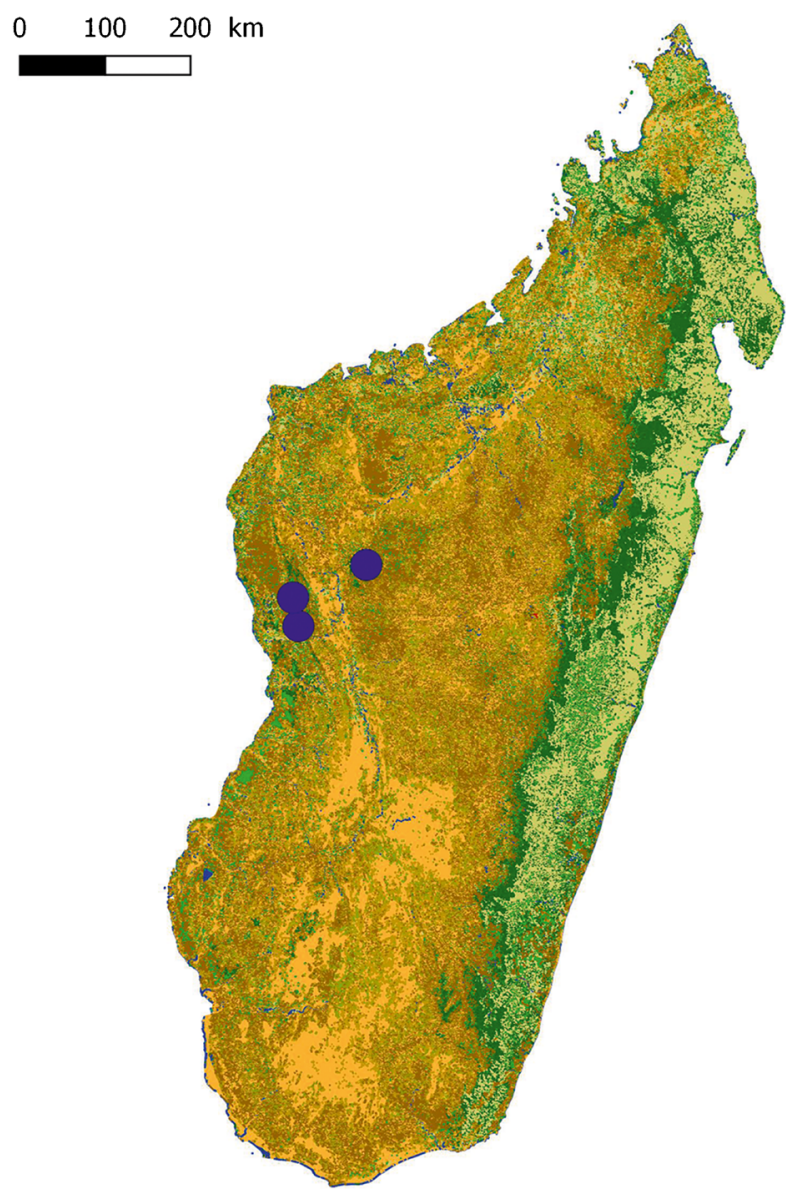

Map 8. Distribution of Liparis bemarahensis. various heights between c. $10-20 \mathrm{~m}$, limestone boulders. Altitude: $100-200 \mathrm{~m}$

CONSERVATION STATUS. Category EN: the extent of occurrence (EOO) of Liparis bemarahensis cannot be estimated since it is only known from two remaining subpopulations whereas its minimal area of occupancy (AOO) is estimated to be $4 \mathrm{~km}^{2}$ (which falls within the limits for Critically Endangered status under the criterion B2). This species is only known from two subpopulations representing two locations (sensu IUCN), and has thus been preliminarily assessed as EN using the green listing method. This species is threatened by selective logging, timber harvesting for small-scale subsistence and tavy (slash-and-burn farming), resulting in habitat reduction and habitat quality reduction.

FLOWERING TIME. December to February.

ETYMOLOGY. Referring to the Bemaraha area, a nature reserve and UNESCO World Heritage site, where this species was first found.

NOTES. Plants were first collected by Léandri, Capuron \& Razafindrakoto in December 1932 during Léandri's second expedition to the West of Madagascar in the then very inaccessible limestone Tsingy area near Ambodiriana, E of Antsalova, now part of the Bemaraha National Park. The collection consisted of several plants in bud. A second collection was made by Léandri \& Saboureau during Léandri's third expedition to the same area in 1960. Since then a number of other collections from the same locality have been mis- or unidentified in herbaria. There are two sheets of the Léandri 1960 collection in $\mathrm{P}$, in both the plants are somewhat damaged but the flowers are intact and therefore make suitable type material.

ILLUSTRATION. Fig. 6. 


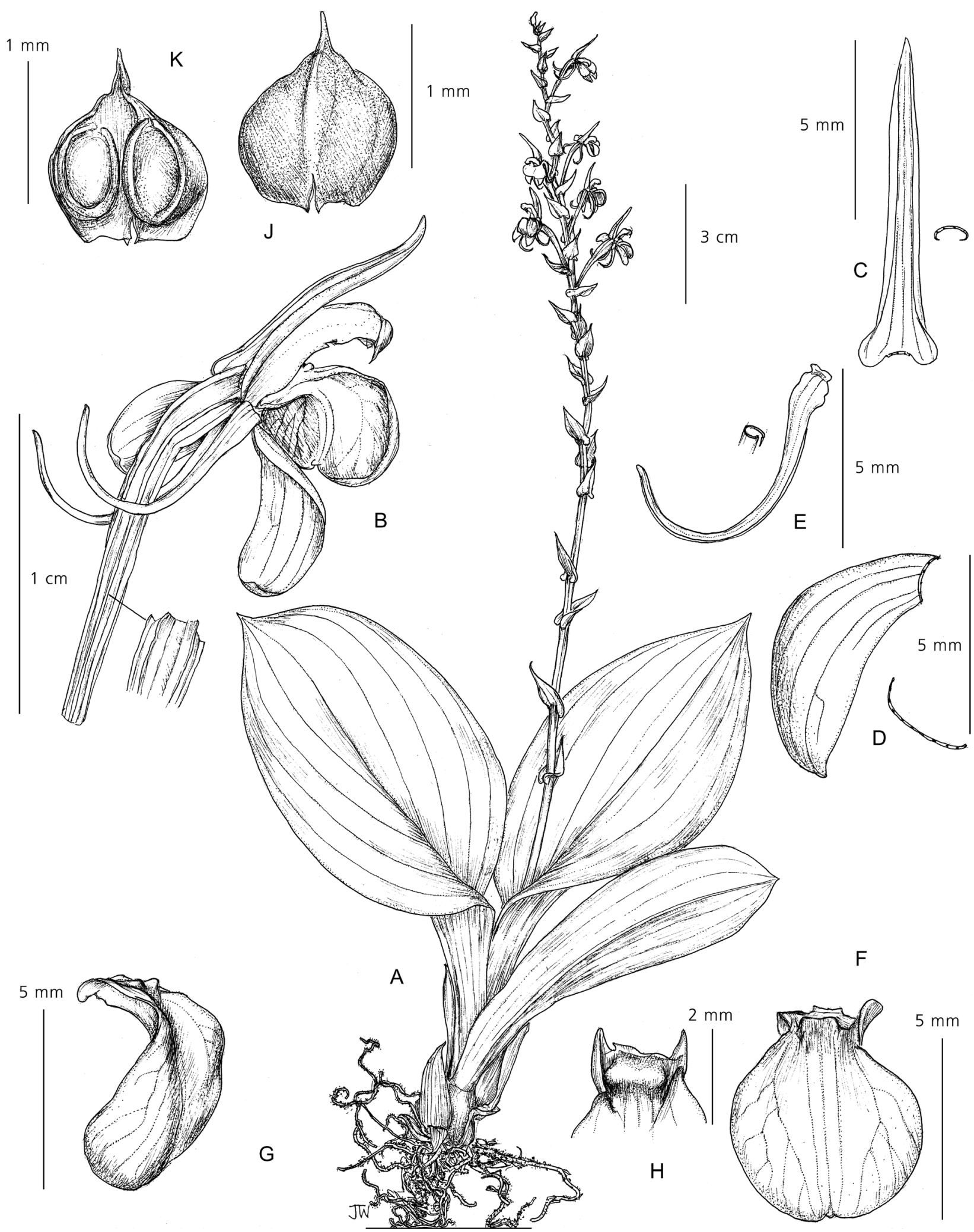

Fig. 6. Liparis bemarahensis. A habit; B flower, side view; flower, C dorsal sepal; D lateral sepal; E petal; F lip, front view; G lip, side view; $\mathrm{H}$ detail of lip calli from above; J anther cap, front view; K anther cap, back view. From Hermans 2447 \& DuPuy et al. M883 (K). DRAWN BY JULIET BEENTJE. 
Liparis bernieri Frapp. ex Cordem. (Frappier in Cordemoy 1895: 185); Bernet (2010a: 84). Type: Réunion, Grand Tampon, 1200 m, July 1853 in Herb Cordemoy 138 (holotype MARS).

Liparis bernieri Frappier (1880: 15) nom. nud.

Liparis plana Frappier in ms. in Herb. Cordemoy (MARS) nom. nud.

Liparis elegans Bernier in ms. in Herb. Cordemoy (MARS) nom. nud.

Liparis boivini Rchb.f in ms. in Herb. Reichenbach $\mathrm{f}$. W (R39775) nom. nud.

Slender, small to medium-sized, erect, epiphytic or terrestrial plant, up to $16 \mathrm{~cm}$ tall, rhizome ascending, very short, roots wiry, more or less villous. Pseudobulbs stem-like, thin, erect, fleshy, enveloped by $3-5$ thin grey striate sheaths, caudate at the apex, slightly overlapping each other, with two, or very rarely three leaves at the apex, the older growths retaining their leaves, up to 13 cm, c. $5 \mathrm{~mm}$ diam. Leaves sub-opposite, erectly spreading to sub-erect, flat, ovate, acute, base rounded to subcordate, sessile or with a $8-12 \mathrm{~mm}$ petiole, somewhat leathery, pale to dark green, glossy, the mid-vein prominent, $2.5-4 \times 1.8-3.2 \mathrm{~cm}$. Inflorescence erect, emerging from within the developing leaves, up to $14 \mathrm{~cm}$ long and almost as long as the pseudobulbs, sub-laxly 3 16-flowered, opening in succession. Peduncle longer than the raceme, slightly ridged, with one to two bract-like lanceolate sheaths, c. $11 \times 3 \mathrm{~mm}$. Rachis loosely racemose, successive flowering, up to $7.5 \mathrm{~cm}$ long. Floral bracts erectly spreading, acuminate, shorter than the pedicellate ovary, $4.1-5.5 \times 1-1.7 \mathrm{~mm}$. Flowers small to medium in size, up to $18 \times 16 \mathrm{~mm}$, greenish-yellow, lip green to greenish-brown with the veins and central groove darker green, column greenish-white, anther green, flowers becoming more yellow-orange with age. Pedicel and ovary fusiform, corrugate, $8-11 \times 1-1.2 \mathrm{~mm}$. Dorsal sepal inclined, oblong to lanceolate, margins slightly reflexed, obtuse, becoming wider towards the base, $7.8-9.1 \times 1.6-2.1 \mathrm{~mm}$. Lateral sepals strongly recurved beneath the lip, ovate, obtuse, $6.6-8.7 \times 2.4-$ $3.5 \mathrm{~mm}$. Petals erectly spreading, linear, falcate, subacute, $5.6-7.7 \times 0.5-1.1 \mathrm{~mm}$. Lip curved, hardly auriculate at the base, expanded into a narrowly ovate to almost pyriform blade, with a central gutter-like depression, the front margin emarginate, slightly sinuate, with a flattened cushion-like thickening at the base, $6.1-7 \times 4.2-$ $5.1 \mathrm{~mm}$. Column curved towards the apex, up to $4.3 \times 1.1$ $\mathrm{mm}$, without distinct wings. Anther ovoid, with a short angular lobule at the anterior margin, exterior somewhat verrucose, c. $1.0 \times 1.1 \mathrm{~mm}$. Pollen ovoid in two attached parts, c. $0.6 \times 0.5 \mathrm{~mm}$.

RECOGNITION. A small to medium size plant, with stemlike, long pseudobulbs bearing two ovate leathery leaves with a distinct central vein. Its inflorescence is almost as long as the plant, with the small to medium- sized flowers borne towards the apex, a relatively wide dorsal sepal, a narrowly ovate to almost pyriform, emarginate, sinuate lip, with a small cushion-shaped callus at base, a scarcely winged column, and a rounded anther with a small beak.

Liparis bernieri is similar to L. danguyana and L. listeroides which are closely allied but distinct morphologically and their distribution is disjunct (Table 5). The leaf of L. danguyana is thinner in texture than those of L. bernieri and L. listeroides which are more leathery with indistinct veins, the leaf shape is ovate, sessile vs more broadly oval, sub-sessile. The flowers of $L$. listeroides are generally smaller than the other two. The lip of L. danguyana has distinct basal lobes, that of $L$. bernieri does not and is almost pyriform, it has two small but distinct calli at the base (in L. bernieri the callus is indistinct and consists of a crescent-like cushion), a front margin that is slightly attenuate at the front margin vs emarginate in L. bernieri. The anther cap of L. bernieri is rounded at the front with a short angular beak, that of L. listeroides is longer and obtusely beaked.

DISTRIBUTION. Endemic to Réunion: in isolated localities in the interior of the Island (Map 9).

SPECIMENS EXAMINED. RÉUNION. Grand Tampon, $1200 \mathrm{~m}$, July 1853 in Herb Cordemoy 138 (holotype MARS); s. loc., Cordemoy s.n. (MARS); s. loc., 1847 - 1852, Boivin s.n. P00738626 (P); s. loc. Boivin s.n. in Herb. Drake (P); s. loc. Boivin 1954 (K); s. loc. Boivin s.n. R39775 (W) (G); s. loc., Commerson s.n. P00112444 (P); s. loc., Delteil s.n. Herb. Drake (P); Ilet de Patience, Feb. 1971, Bosser 20779 (P); Les Masouines, 1350 m, Oct. 1973, Bernardi 14549 (G); Bébour Bélouve, 1400 m, March 2003, Bernet comm., Hermans 8154 (K); Bébour, 1200 m, March 2003, Bernet comm., Hermans 8162 (K). Plaine des Palmistes, July 2007, 1520 m, Ferard $\mathcal{E}^{\circ}$ Pause 1520 (CBNM); Plaine des Palmistes, April 2008, Fontaine 2457 (CBNM); Plaine des Lianes, Nov. 2012, 1120 m, Fontaine E Tamon 5110 (CBNM).

HABITAT. Wet forest, often on humus and mosscovered surfaces, in shade. Altitude: $800-1600 \mathrm{~m}$.

CONSERVATION STATUS. Category EN: the extent of occurrence (EOO) of Liparis bernieri cannot be estimated since it is only known from two remaining subpopulations whereas its minimal area of occupancy (AOO) is estimated to be $4 \mathrm{~km}^{2}$ (which falls within the limits for Critically Endangered status under the criterion B2). With only two known subpopulations representing two locations (sensu IUCN), this species has been preliminarily assessed as EN using the green listing method. This species is threatened by grazing and anthropogenic fires, resulting in habitat reduction and habitat quality reduction.

Previously assessed and published in the IUCN Red data listing as EN (Picot 2013: 17).

FLOWERING TIME. January to March. ETYMOLOGY. Dedicated to Dr Charles Bernier (1802 1858), director of the Jardin Botanique de La Réunion. 
Table 5. Comparison of Liparis bernieri, L. danguyana and L. listeroides, based on average measurements.

\begin{tabular}{llll}
\hline \hline & L. bernieri & L. danguyana & L. listeroides \\
\hline Plant height (cm) & up to 16 & up to 18 & up to 18 \\
Stem $(\mathrm{cm})$ & $6-10$ & $7-12$ & $8-13$ \\
Leaf length $(\mathrm{cm})$ & $3 \times 2.5$ & $3.5 \times 2.5$ & $6.5 \times 1.2$ \\
Leaf texture/veins & leathery, veins indistinct & thin, clearly veined & leathery, veins indistinct \\
Inflorescence length $(\mathrm{cm})$ & up to 14 & up to 7 & up to 15 \\
No. flowers per inflorescence & up to 16 & up to 12 & $6.5 \times 1$ \\
Dorsal sepal $(\mathrm{mm})$ & $9 \times 1.5$ & $8 \times 1.2$ & $5 \times 2.5$ \\
Lateral sepals $(\mathrm{mm})$ & $7 \times 3$ & $5.5 \times 3$ & $6 \times 0.5$ \\
Petals $(\mathrm{mm})$ & $5 \times 0.5$ & $8 \times 1$ & $6 \times 5.5$ \\
Lip size $(\mathrm{mm})$ & $6 \times 4$ & $6 \times 4$ & obcordate, small teeth at \\
Lip shape & ovate-pyriform, emarginate & ovate-orbicular, acuminate at & anterior margin \\
& anterior margin & anterior margin & 2, long \\
Lip callus & small crescent-like cushion & 2, small but distinct & $3.8 \times 1$ \\
Column size $(\mathrm{mm})$ & $4 \times 1.1$ & $3 \times 1$ & wings angular \\
Column wings & no wings & wings thin and small & $1 \times 0.9$ \\
Anther size $(\mathrm{mm})$ & $1 \times 1.1$ & $1 \times 0.8$ & shortly beaked \\
Anther shape & rounded at anterior margin & rounded at anterior margin & Madagascar, widespread \\
Distribution & Réunion & Madagascar: Antananarivo prov. & $1000-1600$ \\
Altitude $(\mathrm{m})$ & $800-1600$ & $1600-1800$ & \\
\hline
\end{tabular}

NOTES. The species was first mentioned as 'Liparis bernieri Frappier' in his listing of the plants of Réunion (Frappier 1880: 15). It was not formally described until
1895 in Cordemoy's Flore, the orchid part being based on Frappier's manuscripts. The description indicated that the author knew the plants in the wild and had

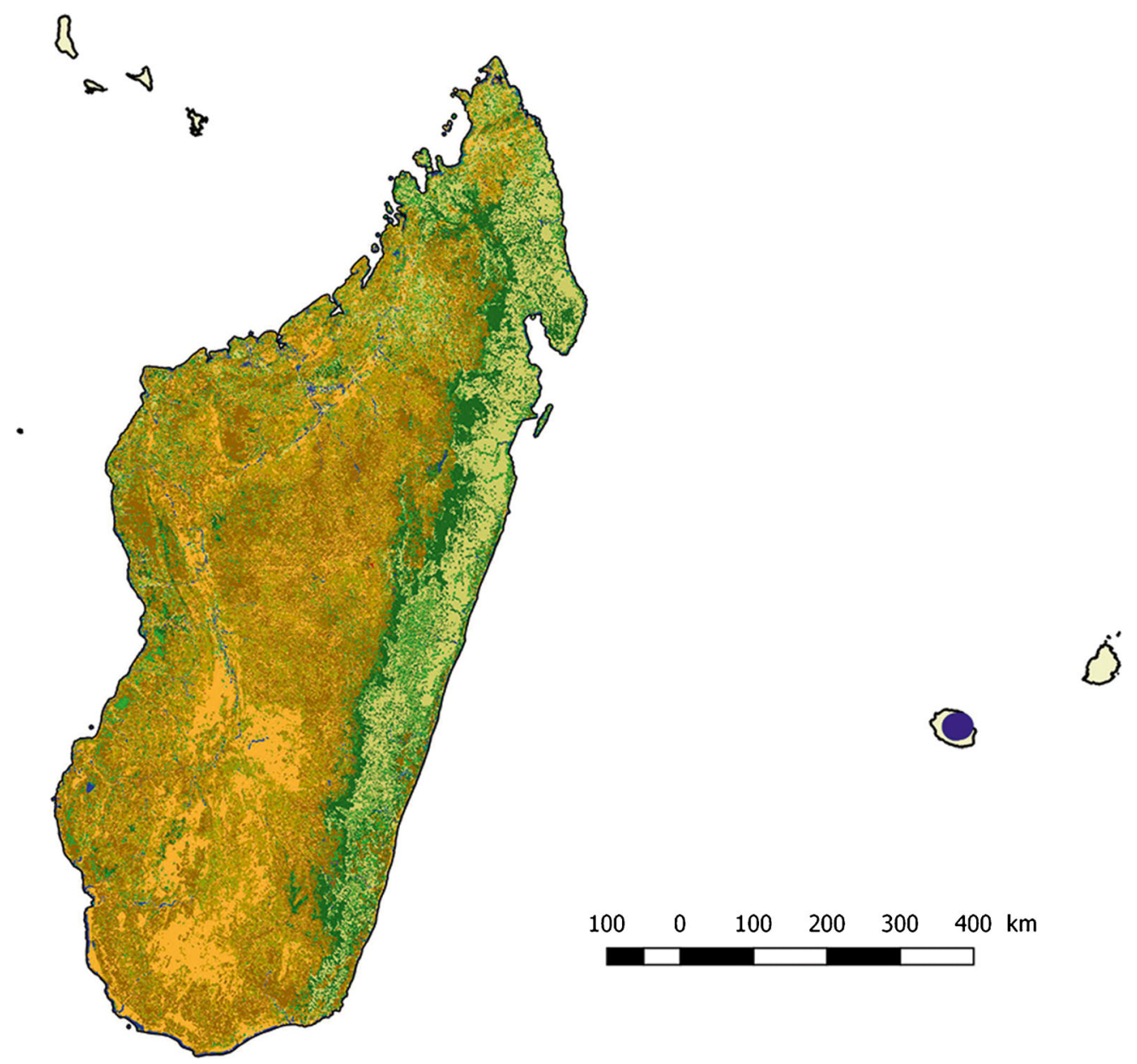

Map 9. Distribution of Liparis bernieri. 
also found herbarium material in the Réunion Museum where it was labelled as Liparis elegans Bernier, a name that had already been used five years earlier by Lindley for an Asian species. This group of unmounted plants, presumably collected by Bernier, found its way into the Cordemoy herbarium in Marseille where it is accompanied by labels of its origin and the same manuscript text used in Frappier's description. This is most likely the original material seen by the author; it has corresponding labelling and is close to the original description and is therefore without doubt the holotype of the species and has priority, according to ICN article 9.19 , over the lectotype chosen by Margonska (2009: 92) as outlined below.

Finet (1909: 98, pl.1) included a description and illustration of the species and mentioned that the plant was found mixed with Liparis purpurascens (now L. salassia), citing both Commerson and Boivin collections.

Margonska may well have been unaware of Cordemoy's Marseille herbarium material and lectotypified the species in error using Boivin's specimens kept in P. The Cordemoy material from MARS had been on loan for many years to $\mathrm{P}$ and not directly accessible, lately it has been on loan to the University of Réunion (REU). In the same paper Margonska (2009: 92) also considered Liparis danguyana to be synonymous with $L$. bernieri citing their similar characteristics. As explained above, there is a strong case for keeping these species separate.

Boivin collections in $\mathrm{P}$ and $\mathrm{W}$ were annotated by Reichenbach f. as 'Liparis boivini', the W sheet give 'Madagaskar?' as origin; Reichenbach f. never published L. boivini and both are clearly L. bernieri.

ILLUSTRATIONS: Fig. 7; Finet (1909: 98, pl.1); Bernet (2010a: 84); Szelengowicz \& Tamon (2013: 352).

Liparis bicornis Ridl. (Ridley 1885: 458; 1886b: 260); Schlechter (1924: 136); Perrier (1939: 280); Hermans et al. (2007: 215); Cribb \& Hermans (2009: 150). Type: Madagascar, Imerina, Jan. 1881, Hildebrandt 3849 (holotype BM; isotypes G, K, M, P, W, WU). Leptorkis bicornis (Ridl.) Kuntze (1891: 671).

Medium to small erect terrestrial or lithophyte plant 10 $22 \mathrm{~cm}$ tall, normally consisting of a single new growth and a disintegrating short rhizome, pseudobulb and sheaths from the previous season, roots thin and soft. Pseudobulbs elongate-conical, $8-15 \times 6-8 \mathrm{~mm}$, covered by brownish-grey fibrous sheaths, generally carrying 3 leaves (rarely 2 or 4 ) with the base overlapping and without a distinct petiole. Leaves lanceolate, fairly rigid, erect, a little attenuate, plicate, contracted, acute, 6 - 12 $\times 1.5-5.2 \mathrm{~cm}$. Inflorescence up to $28 \mathrm{~cm}$ long, carrying $10-$ 25 flowers. Peduncle extending above the leaves, carrying $2-3$ peduncle sheaths, $3-5 \times 1.5 \mathrm{~mm}$. Rachis $1 / 3$ to $1 / 4$ of the inflorescence, densely to sub-densely flowered. Floral bracts linear-lanceolate acute, a little shorter than the ovary, $2-6 \times 0.8-1.5 \mathrm{~mm}$. Flowers small, overall c. $7 \times 6$ $\mathrm{mm}$, greenish becoming reddish on wilting, petals and sepals somewhat transparent, lip reddish-brown. Pedicel and ovary $6-9 \times 1-1.2 \mathrm{~mm}$, obscurely winged. Dorsal sepal oblong-lanceolate obtuse recurved at the tip, $4.2-$ $6.5 \times 1.2-2 \mathrm{~mm}$. Lateral sepals oval-lanceolate obtuse, 3.9 $-4.2 \times 2-2.7 \mathrm{~mm}$. Petals linear-obtuse folded backwards, $4.5-5.3 \times 0.5-0.8 \mathrm{~mm}$. Lip ovate-obcuneate, emarginate, somewhat depressed in the centre and the margins thickened and rounded, with three distinct central veins, slightly auriculate at the base, carrying a distinct 2-horned callus near the base, flanking the column, $3.4-4 \times 2.9 \times 41 \mathrm{~mm}$, the horn-like calli c. $0.8 \mathrm{~mm}$ long. Column thick, very slightly curved, broadened at the apex, slightly winged, $2-2.8 \times 0.7-1 \mathrm{~mm}$. Anther ovate-obtuse c. $1 \times 1 \mathrm{~mm}$. Pollinia c. $0.5 \mathrm{~mm}$.

RECOGNITION. Liparis bicornis is distinguished by having a single flowering growth with the previous year's growth disintegrated, erect leaves, a tall inflorescence with many small flowers, with an obcuneate emarginated lip with two small but distinct calli at the base and an anther with a rounded margin.

In habit it is similar to Liparis densa but that differs in its lip shape (ovate-obcuneate vs obovate-oblong) and lack of distinct calli at the base of its lip. Its lip is similar to that of $L$. perrieri but the anterior lip margin in that species is dentate rather than rounded.

DISTRIBUTION. Endemic to Madagascar: mainly in the highlands of Antananarivo province with a few colonies in the Eastern forests (Map 10).

SPECIMENS EXAMINED. MADAGASCAR. Imerina, Jan. 1881, Hildebrandt 3849 (holotype BM; isotypes G, K, M, P, W, WU); Interior, Central, Manandona valley, Feb., Scott Elliot 2004 (BM, K); Central, s. loc., Baron 4228 (K); Ambatolaona, June 1906, d'Alleizette 854 (P); Central, Ankatso near Antananarivo, March 1923, Perrier 15753 (P); Ankazifotsy, cliff above Tsimbazaza, Antananarivo, Jan. 1960, Bosser 13482 (TAN); Ambohimirahavavy Mts, N of Mangindrano, 1999, Hermans 2448 (K); Toamasina, Périnet area, 1999, Hermans 2455 (K); Manjakatompo area, 1997, Hermans 2590 (K); Toamasina, road to Lakato $1041 \mathrm{~m}$, Feb. 2000, Hermans 1007 (K).

HABITAT. Wet marshy slopes, rocky outcrops. Altitude: $1300-1500 \mathrm{~m}$

CONSERVATION STATUS. Category VU: the extent of occurrence (EOO) of Liparis bicornis is estimated to be $32,601 \mathrm{~km}^{2}$ (which exceeds the limits for Vulnerable status under criterion B1) whereas its minimal area of occupancy (AOO) is estimated to be $28 \mathrm{~km}^{2}$ (which falls within the limits for Endangered status under the criterion B2). With seven known subpopulations representing seven locations (sensu IUCN), this species has been preliminarily assessed as VU using the green listing method. This species is threatened by 

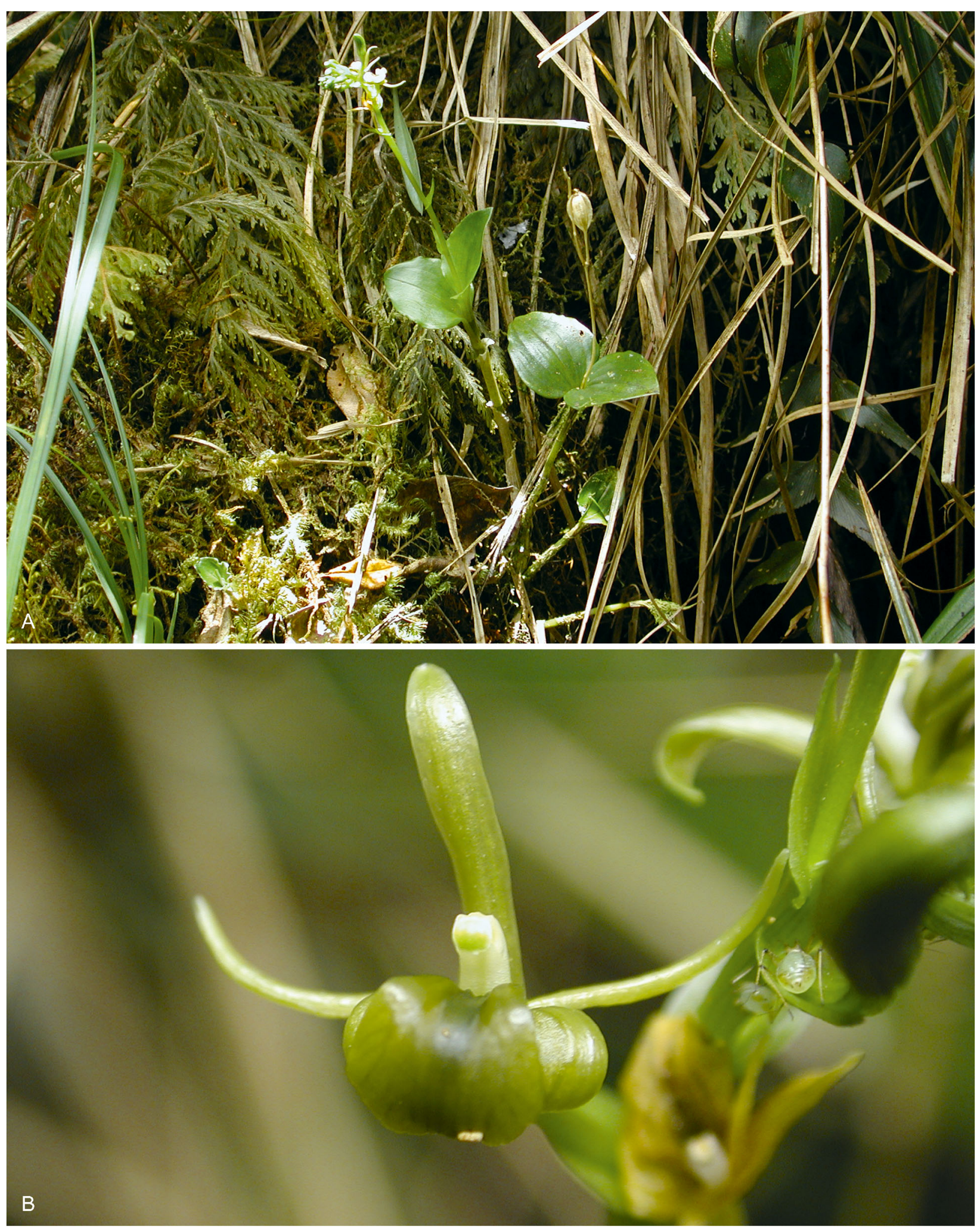

Fig. 7. Liparis bernieri. A habit; B flower. PHOTOS: PATRICE BERNET.

selective logging, timber harvesting for small-scale subsistence and tavy (slash-and-burn farming), resulting in habitat reduction and habitat quality reduction. The Ankatso habitat was destroyed for building and Eucalyptus plantations. The habitats near Ambatolaona and Lakato were burnt for cultivation. 
0 $100 \quad 200 \mathrm{~km}$

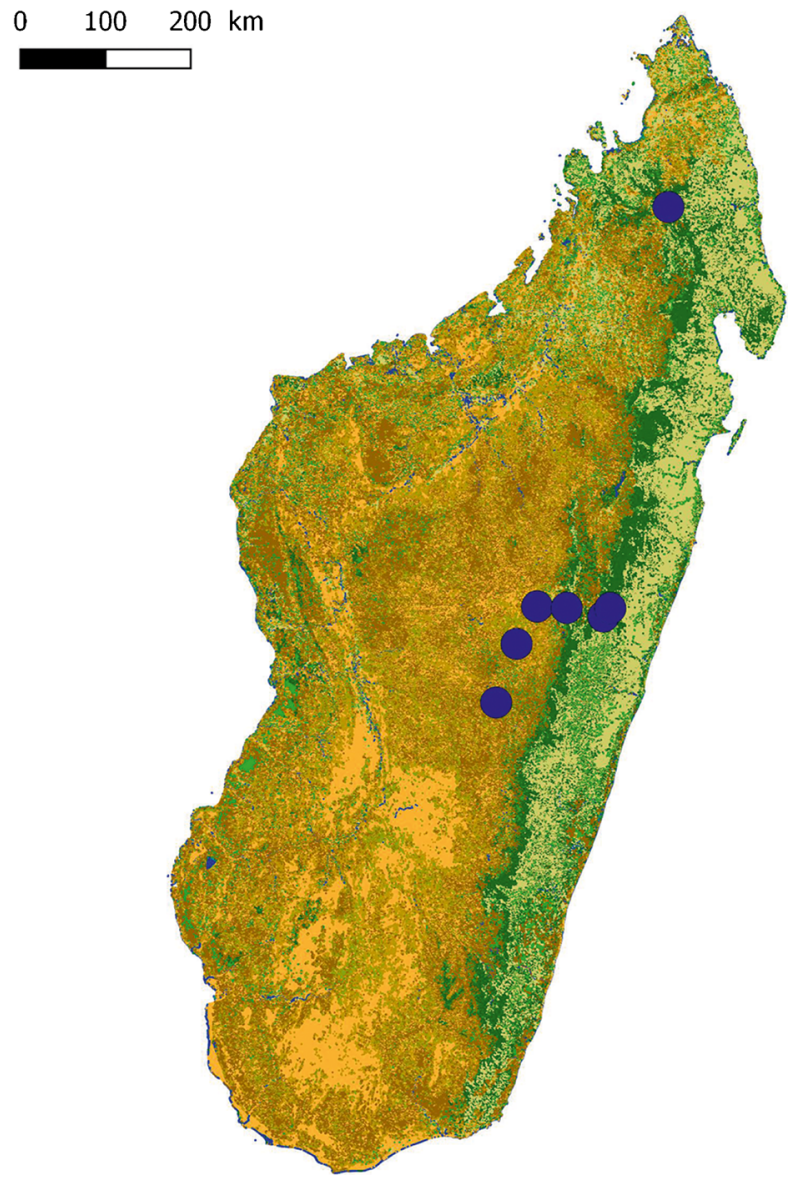

Map 10. Distribution of Liparis bicornis.

FLOWERING TIME. January to June.

ETYMOLOGY. The name refers to the two distinct horns at the base of the lip.

NOTES. The species was first found on wet mountain slopes by the German collector Johann Hildebrandt in 1881, a few months before he died in Madagascar. The type locality of the 'Imerina' area normally refers to the Madagascan Highlands around the capital Antananarivo. Henry Ridley acquired some of Hildebrandt's herbarium and described the new species four years later and is clearly based on the BM specimen. In line with much of Hildebrandt's herbarium the collections were widely sold or distributed around Europe, in this instance G, K, M, P, W and WU. A detailed drawing of the flowers by Ridley is in the orchid herbarium at $\mathrm{K}$ (Fig. 8).

ILLUSTRATIONS. Fig. 8; Perrier (1939: 283).

Liparis bosseri Hermans sp. nov. Type: Madagascar, near Betroka, Feb. 1963, Bosser 17910 (holotype P).

http://www.ipni.org/urn:lsid:ipni.org:names:77201713-1

Very small, squat terrestrial or lithophytic plant up to
$6 \mathrm{~cm}$ high, on a very short to almost non-existent rhizome, roots wiry. Pseudobulbs turbinate, whitish, $10-$ $18 \times 7-15 \mathrm{~mm}$, covered with $2-3$ thin membranous sheaths, carrying 2 leaves, very rarely only one, the previous year's pseudobulbs without leaves. Leaves spreading, ovate, apex acute, base cuneate to obtuse, thin, strongly veined, $4-6.2 \times 2.2-4.3 \mathrm{~cm}$. Inflorescence erect, much taller than the leaves, up to $13 \mathrm{~cm}$, c. $1.5 \mathrm{~mm}$ diam., with $2-10$ flowers, opening in succession. Peduncle about $1 / 2$ the length of the inflorescence, with 3 -4 prominent peduncle sheaths, $6-9 \times 2-3 \mathrm{~mm}$. Rachis loosely racemose. Floral bracts lanceolate, decreasing in size towards the apex of the rachis, $3-6 \times 2-2.9 \mathrm{~mm}$. Flowers medium in size, $10-12 \times 6-7 \mathrm{~mm}$, greenish, becoming yellow with age. Pedicel and ovary slender, grooved, $7-12 \times$ $0.7-1.6 \mathrm{~mm}$. Dorsal sepal erect, recurved towards the apex, narrowly lanceolate, $6.1-9.2 \times 1-1.9 \mathrm{~mm}$. Lateral sepals broadly falcate, obtuse, $6.1-8.9 \times 2.8-3.2 \mathrm{~mm}$. Petals linear, obtuse, $6.3-9 \times 0.2-0.3 \mathrm{~mm}$. Lip obovate, acuminate at the tip, anterior margin a little undulate, longly auriculate at the base, thickened ridges at the base becoming a canaliculate longitudinal ridge along the disk, $6.1-7.5 \times 4.2-6.1 \mathrm{~mm}$. Column almost straight, wings longly rounded, $3.2-4.3 \times 1.1 \times 1.7 \mathrm{~mm}$. Anther with a distinct spathulate beak, c. $0.8 \mathrm{~mm}$ long, rounded at the apex and narrowed towards the base, overall c. $1.7 \times 0.9$ mm. Pollinia pyriform c. $0.9 \times 0.6 \mathrm{~mm}$.

RECOGNITION. A very squat plant with broad, spreading leaves, a relatively long inflorescence and proportionately large flowers. Its lip is acuminate at the tip, longly auriculate at the base and lacks a distinct callus but has a thickened ridge formed of the three raised central veins.

Liparis bosseri has a number of characteristics overlapping with other species but none in the same combination. It is closest to $L$. trulliformis but the lip of $L$. bosseri is obovate (vs ovate-trullate), lacks a distinct callus at the base of the lip and has an anther with a spathulate (vs a sharp beak). In habit, flower size and lip shape it resembles $L$. andringitrana but $L$. bosseri is much squatter and smaller, the inflorescence shorter and the anther has a spathulate beak (vs short and rounded). It also resembles $L$. bathiei in habit and shape of the anther but the rachis of $L$. bosseri is less dense, the flowers are about double the size, the lip obovate (vs oval-lozenge-shaped). The habit and flowers of $L$. nephrocardia are similar in size but the inflorescence of $L$. bosseri far surpasses the leaves (vs about the same length) and lacks the distinct rounded callus of the lip. It shares the spathulate beak of the anther with $L$. zaratananae but the plant of $L$. bosser is is $1 / 3$ the size, without a distinct stem and also has smaller flowers and an obsolete callus vs ridges at the base of the lip.

DISTRIBUTION. Endemic to Madagascar, South-Central, Toliara and Fianarantsoa provinces (Map 11).

SPECIMENS EXAMINED. MADAGASCAR. Near Betroka, Feb. 1963, Bosser 17910 (holotype P); Ihorombe Region, Ihosy 


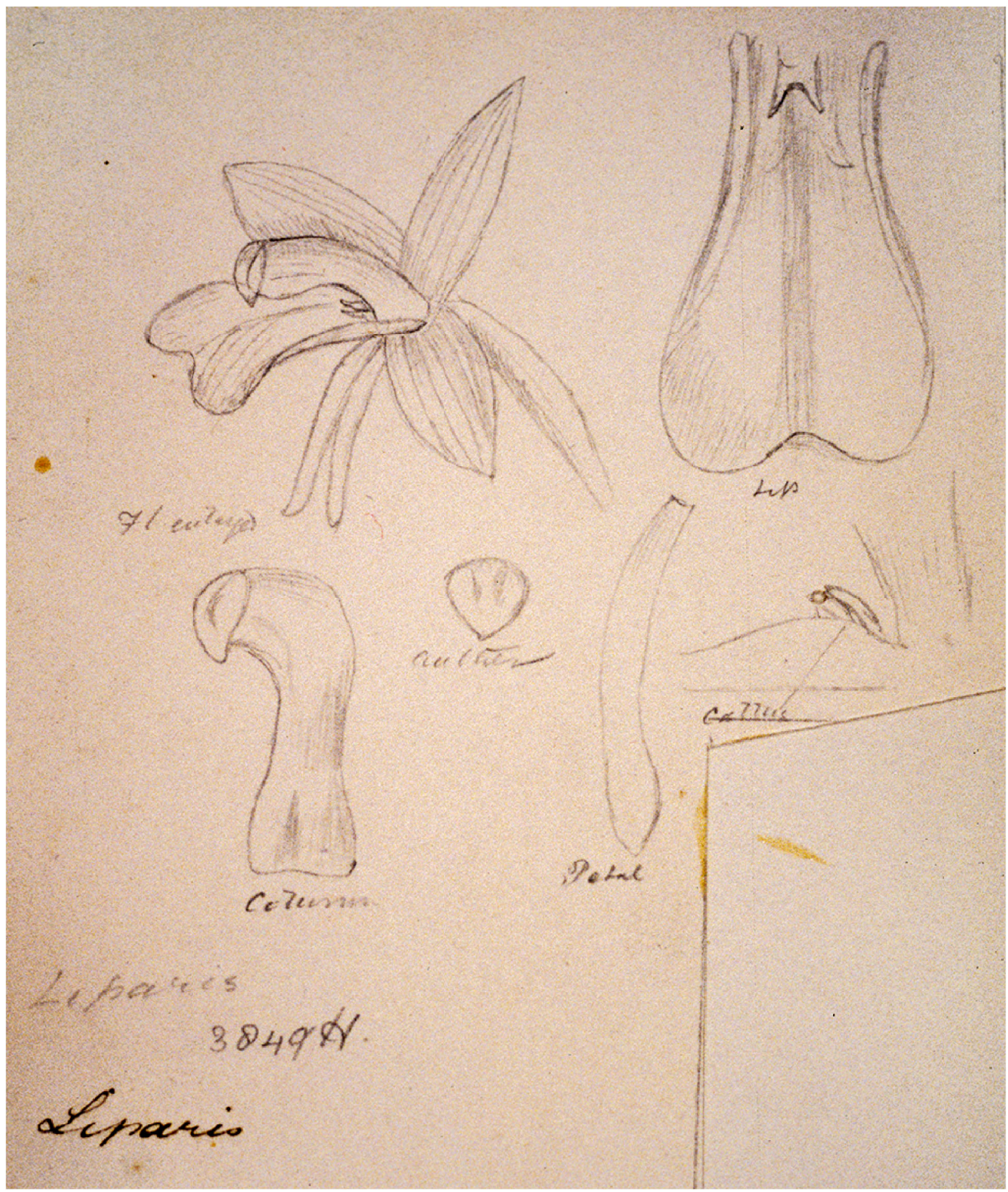

Fig. 8. Drawing by Henry Ridley of the type specimen of Liparis bicornis. Reproduced by kind permission of the Trustees of the Royal Botanic Gardens, Kew.

Distr., Bonnet du Pape, Ifandana, Zazafotsy, on inselberg, 1133 m, March 2010, Ramandimbisoa et al. 110 (MO, P, TAN). HABITAT. Forest remnants, in shade, in thin layer of humus and humus on inselberg. Altitude: $800-1100 \mathrm{~m}$.
CONSERVATION STATUS. Category EN: the extent of occurrence (EOO) of Liparis bosseri cannot be estimated since it is only known from two remaining subpopulations whereas its minimal area of occupancy 
$0 \quad 100 \quad 200 \mathrm{~km}$

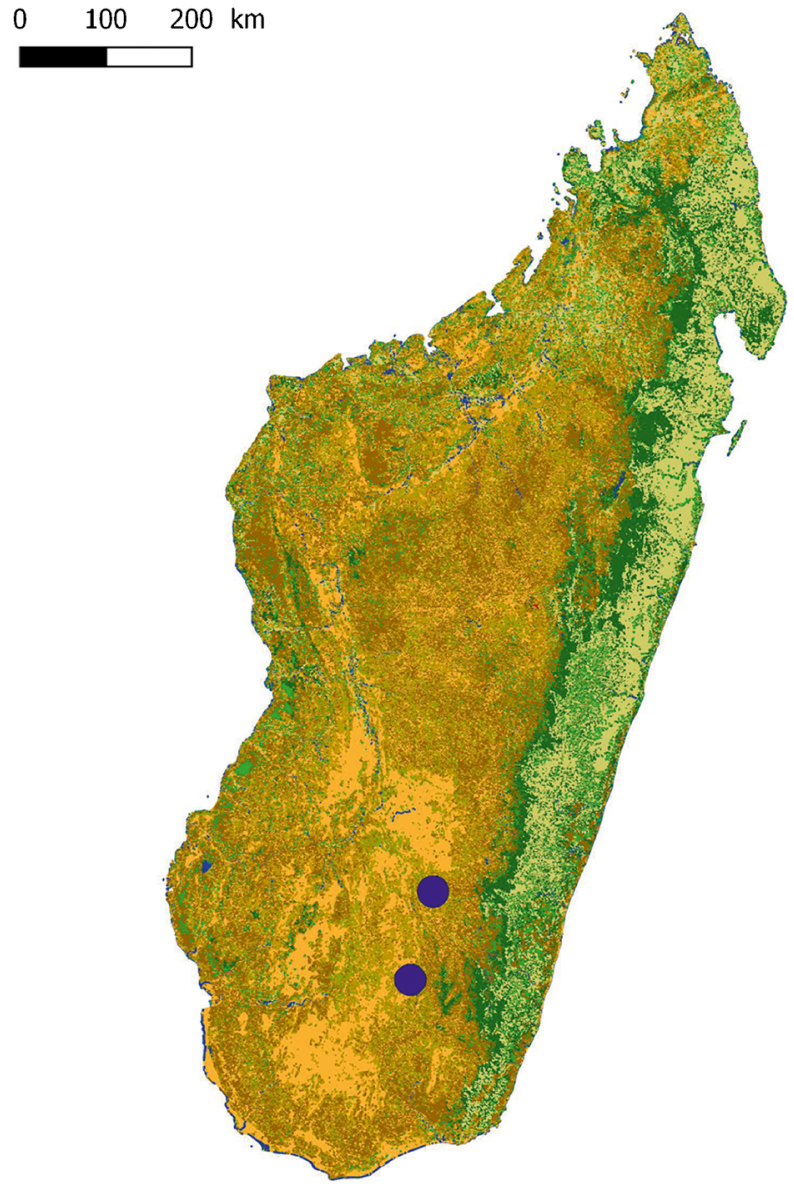

Map 11. Distribution of Liparis bosseri.

(AOO) is estimated to be $8 \mathrm{~km}^{2}$ (which falls within the limits for Critically Endangered status under the criterion B2). With only two known subpopulations representing two locations (sensu IUCN), this rare species has been preliminarily assessed as EN using the green listing method. This species is threatened by selective logging, timber harvesting for small-scale subsistence and tavy (slash-and-burn farming), resulting in habitat reduction and habitat quality reduction.

FLOWERING TIME. February and March.

ETYMOLOGY. Named for Jean Bosser (1922 - 2013), a great authority on the Flora of Madagascar and the Mascarenes.

\section{ILLUSTRATIONS. Fig. 9.}

Liparis bulbophylloides H.Perrier (1936: 242; 1939: 263); Hermans et al. (2007: 216); Cribb \& Hermans (2009: 145). Type: Madagascar, Toamasina, confl. Onive \& Mangoro, 1925, Perrier 16998 (holotype P).

Very small epiphytic plant up to $2.5 \mathrm{~cm}$ high, caespitose, rhizomatous epiphyte up to $10-15 \mathrm{~cm}$ long, the growths $5-25 \mathrm{~mm}$ apart, rhizome $1-3 \mathrm{~mm}$ diam. covered in brownish papery sheaths, roots $0.3-$ $1 \mathrm{~mm}$ diam., somewhat hairy, the tips glabrous. Pseudobulbs, small, oval, 8 - $16 \mathrm{~mm}$ long, c. $5 \mathrm{~mm}$ diam., base covered by a membranous sheath $5 \times 4$ $\mathrm{mm}$, carrying 2 leaves at the apex. Leaves ovate subsessile, rounded at the base and shortly acute at the apex, $10-18 \times 8-15 \mathrm{~mm}$. Inflorescence erect from the centre of the new growth, $3-10 \mathrm{~cm}$ tall carrying 3 - 10 flowers and buds. Peduncle with several bract-like sheaths. Rachis somewhat twisted, flowers 4-12 mm apart. Floral bracts green, with rounded wings, acute at the tip, single-veined and about $1 / 3$ the length of the pedicellate ovary, $4-6 \times 3-4 \mathrm{~mm}$. Flowers small, overall c. $8 \times 5 \mathrm{~mm}$, opening in succession, all segments recurved at the margins, pale yellow-green with the lip darker yellow-green, column white, pollinia yellow, flowers becoming brownish-orange with age, flower buds bulging at the base. Pedicel and ovary ridged, $5.5-8 \times 0.6-1.2 \mathrm{~mm}$. Dorsal sepal folded backwards, lanceolate, slightly acute, $4.2-6.8 \times 1-1.6$ $\mathrm{mm}$. Lateral sepals folded underneath the lip, oblong to oval, obtuse $3.1-5 \times 1.8-2.5 \mathrm{~mm}$. Petals linear, single veined, $4-6 \times 0.4-0.8 \mathrm{~mm}$. Lip suborbicular, trisinuate, narrowed and slightly auriculate at the base and incurved from the middle, the blade opaque with a few obscure veins, a distinct $(0.5 \mathrm{~mm})$ rounded cylindrical or bilobed callus at the base, $3-4.1 \times 3.1-$ $4 \mathrm{~mm}$. Column arched, the wings strongly expanded at the side of the stigmatic surface into prominent angular membranous lobes, then decurrent lower down, rostellum with a very small central tooth, 3 $3.8 \times 1 \mathrm{~mm}$. Anther extended at the front by a rounded semi-cylindrical beak almost the same size as the cap, 1 $-1.3 \times 0.5-0.7 \mathrm{~mm}$. Pollinia four, fused together in two pairs, oblong, $0.3-0.4 \times 0.2 \mathrm{~mm}$.

RECOGNITION. The species is one of the few truly epiphytic Liparis in the region. In habit it resembles species of Bulbophyllum Thouars (1822: t.3) with two small oval apical leaves and a small rounded pseudobulb on a long rhizome. The flowers are small, the lip is suborbicular with a rounded callus at the base, the column has obtuse transparent wings, the anther cap has a semi-cylindrical obtuse beak almost as large as the cap itself; somewhat resembling a baseball cap.

Liparis ambohimangana is similar but has a true stolon rather than a rhizome, a single leaf vs two and the anther is not beaked.

DISTRIBUTION. Endemic to Madagascar, fairly widespread in Eastern forests; Toamasina, Antsiranana and Toliara provinces (Map 12).

SPECIMENS EXAMINED. MADAGASCAR. Toamasina, confl. of Onive \& Mangoro, 1925 Perrier 16998 (holotype P); Toliara, SE, Manampanihy basin, Mt Vohimavo, March 1947, Humbert 20693 (P); Ambatovy, March 1998, McPherson 17526 (TAN); Toamasina, road 


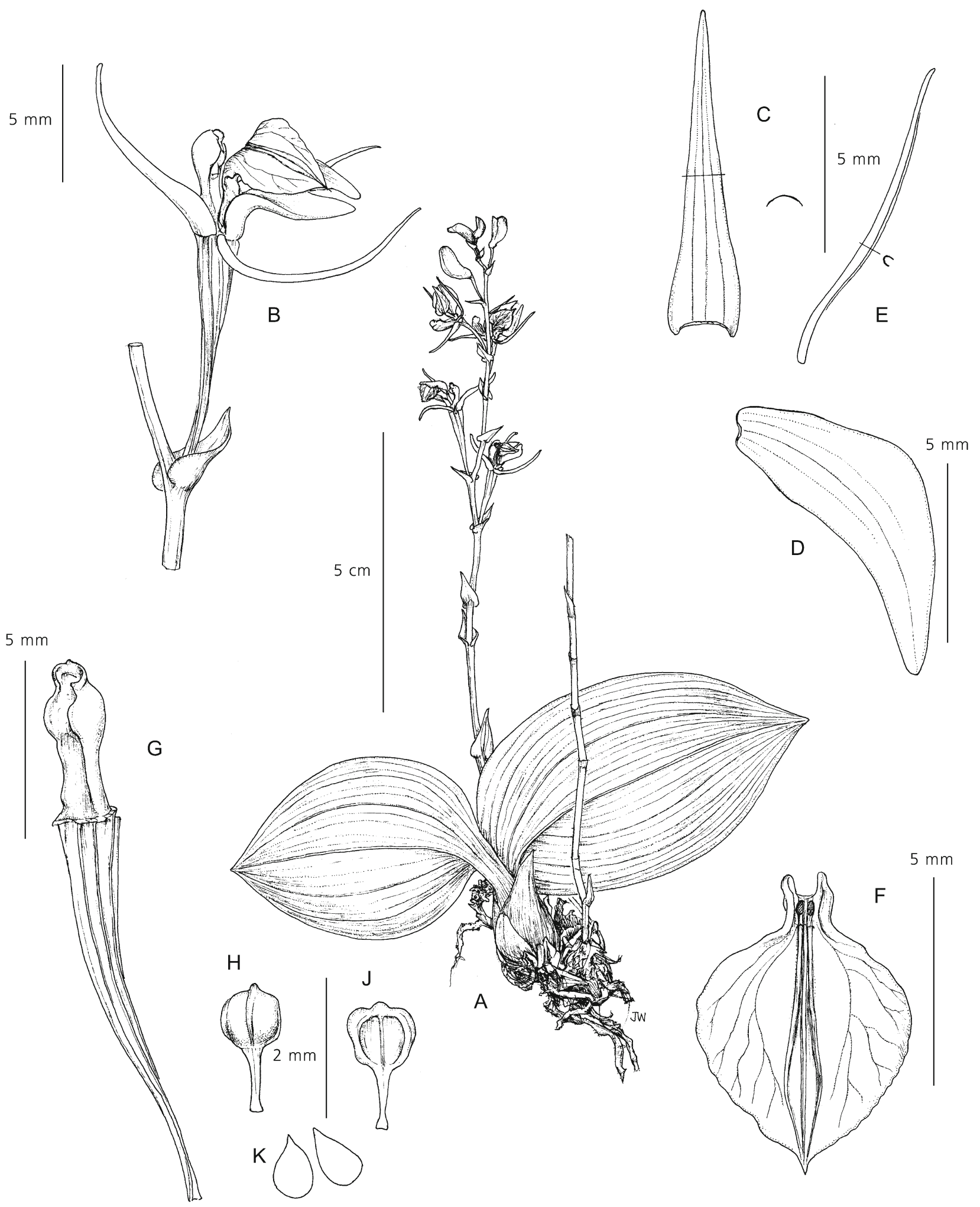

Fig. 9. Liparis bosseri. A habit; B flower, side view; C dorsal sepal; D lateral sepal; E petal; $\mathbf{F}$ lip; G column and ovary; $\mathrm{H}$ anther cap from above; J anther cap, below; K pollinia. From Bosser 17910 (P). DRAWN BY JULIET BEENTJE.

to Lakato, Feb. 2000, Hermans 4894 \& 5570 (K); Antsiranana, Vohemar, Daraina, Binara forest, 1030 m, 17 March 2003, Gautier et al. LG 4415 (G);
Antsiranana, Vohemar, Daraina, Antsahabe forest, 2004, Nusbaumer LN1034 (G, P); Toamasina, Alaotra Mangoro, Moramanga, Ambohibary, Ampitabe, 

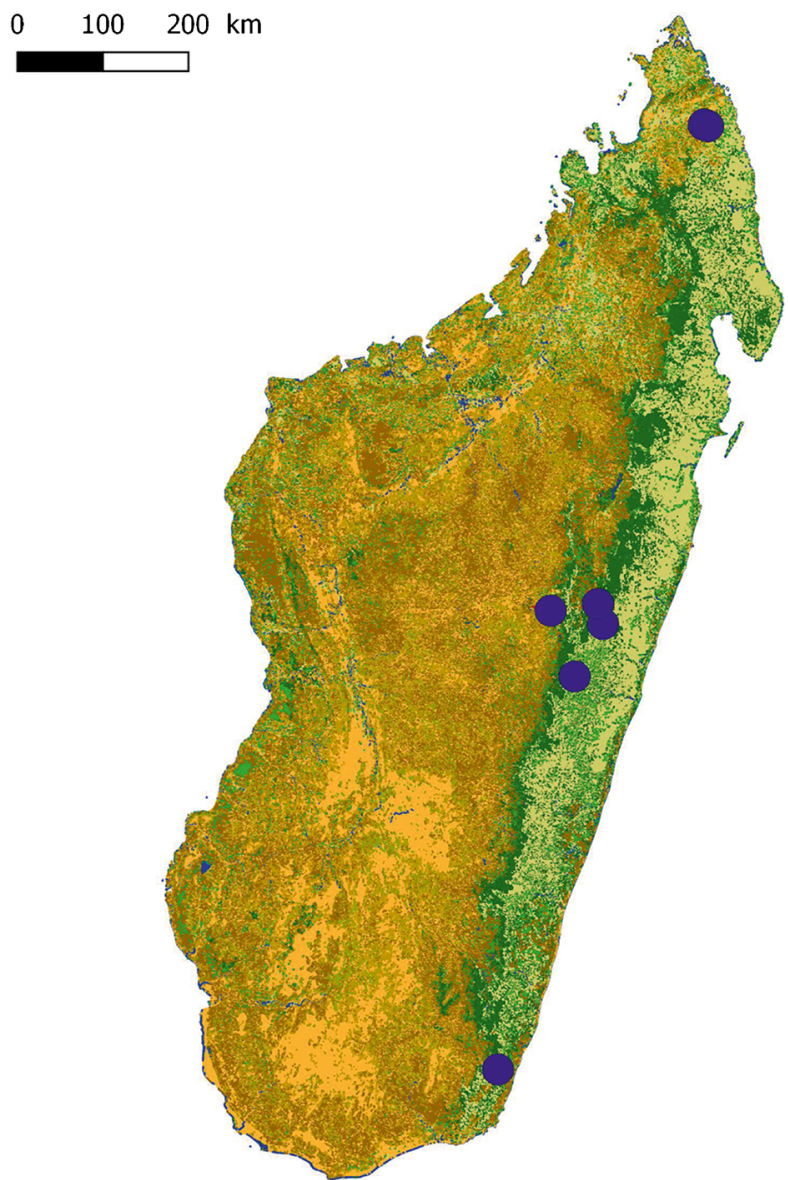

Map 12. Distribution of Liparis bulbophylloides.

Ambatovy, 1135 m, March 2005, Antilahimena et al. 6788 (MO, P, TAN); Toamasina, Ambavaniasy, Feb. 2015, Sieder 6759, Hermans 8067 (K, WU); near Carion, 1997, Hermans 2588 (K); Toamasina, Ambatovy, Ambohibary, Moramanga distr., Razanatsoa 145 (MO, TAN); Toamasina, Ampitambe, Ambatovy c. $22 \mathrm{~km} \mathrm{~N} \mathrm{E} \mathrm{of} \mathrm{Moramanga,} \mathrm{Analamahy,} 1058 \mathrm{~m}$, March 2005, Andriantiana E Razafindasy 172 (TAN); Toamasina, Ambohibary, Ampitabe, Ambatovy, 1102 $\mathrm{m}$, May 2008. Rakotondrafara 730 (MO, TAN); Toamasina, Andasibe, Menalamba, Ambatovy, Forêt de Berano, 1007 m, Sept. 2008, Andriantiana 452 (MO, TAN); Toamasina, Alaotra Mangoro, $1040 \mathrm{~m}$, May 2010, Ramahenina et al. 28 (K, MO, P, TAN); Toamasina, Distr. Moramanga, Ambatovy, 890 - 1117 m, Sept. 2014, Ambatovy Shade House 4492 (TAN).

HABITAT. Exclusively as an epiphyte in humid evergreen forest, amongst mosses on tree branches. Altitude: 600 - $1100 \mathrm{~m}$.

CONSERVATION STATUS. Category VU: the extent of occurrence (EOO) of Liparis bulbophylloides is estimated to be $71,015 \mathrm{~km}^{2}$ (which exceeds the limits for Vulnerable status under criterion B1) whereas its minimal area of occupancy (AOO) is estimated to be $44 \mathrm{~km}^{2}$ (which falls within the limits for Endangered status under the criterion B2). With 11 known subpopulations of this species representing 11 locations (sensu IUCN), L. bulbophylloides has been preliminarily assessed as VU using the green listing method. This species is threatened by mining activities, selective logging, timber harvesting for small-scale subsistence and tavy (slash-and-burn farming), resulting in habitat reduction and habitat quality reduction.

FLOWERING TIME. January to March.

ETYMOLOGY. Refers to the shape of the pseudobulbs and plant habit similar to some species of the orchid genus Bulbophyllum.

NOTES. The species was first described by Perrier from a collection made by Henri Humbert in Eastern Madagascar. It has since been found in a wide area along the Eastern mountain range of the Island.

ILLUStrations. Figs 10, 11; Perrier (1939: 255); Hermans et al. (2007: pl.45); Cribb \& Hermans (2009: 147).

Liparis caulescens Frapp. ex Cordem. (Frappier in Cordemoy 1895: 186). Types: Réunion, Les Hauts du Boucan Launay, 1847 - 1852, Boivin 1035 (P00112460) (lectotype P, designated here); Réunion, Boivin 1035 (P00112455), (P00112456), (P00112460) \& (K000718243) (isolectotypes designated here $\mathrm{P}, \mathrm{K}$, REU). Réunion, Boivin s.n. (P00112461) (lectoparatype $\mathrm{P}$ ).

Liparis caulescens Frappier (1880: 15) nom. nud.

Liparis vaginata in herb. Richard (K-Lindl, W) nom. nud.

Liparis longa Rchb.f. (Reichenbach f. 1877: 98) synon. nov.

Medium to large erect terrestrial or lithophytic plant, $14-33 \mathrm{~cm}$ high, rhizome short, ascending, roots wiry, more or less pilose, c. $1 \mathrm{~mm}$ diam. Pseudobulbs slender, stem-like, a little inflated at the base, up to $25 \mathrm{~cm} \times 6-$ $15 \mathrm{~mm}$, partly covered by $4-5$ thin amplexicaul sheaths, partly overlapping, up to $5 \mathrm{~cm}$ long, with $2-3$ (rarely 4) apical sub-petiolate leaves. Leaves spreading, asymmetric, lanceolate to elliptical-lanceolate, acuminate, undulate, the veins obliquely convergent, more or less glossy, contracted into a $10-25 \mathrm{~mm}$ petiole at the base, overall $8-10 \times 4-5.5 \mathrm{~cm}$, the third leaf usually smaller, dark green. Inflorescence erect, a little longer than the leaves, carrying up to 15 flowers but usually fewer, up to $11 \mathrm{~cm}$. Peduncle with a few linearlanceolate peduncle sheaths becoming sterile bracts, 7 - $10 \mathrm{~mm}$ long. Rachis loosely racemose in the upper half of the inflorescence, up to $7 \mathrm{~cm}$ long. Floral bracts spreading, linear-lanceolate, acuminate, the lower ones considerably longer than apical ones, up to $13 \times$ $3 \mathrm{~mm}$, green. Flowers medium in size, up to $15 \times 10$ $\mathrm{mm}$, ovary green, sepals and petals yellowish-brown, 


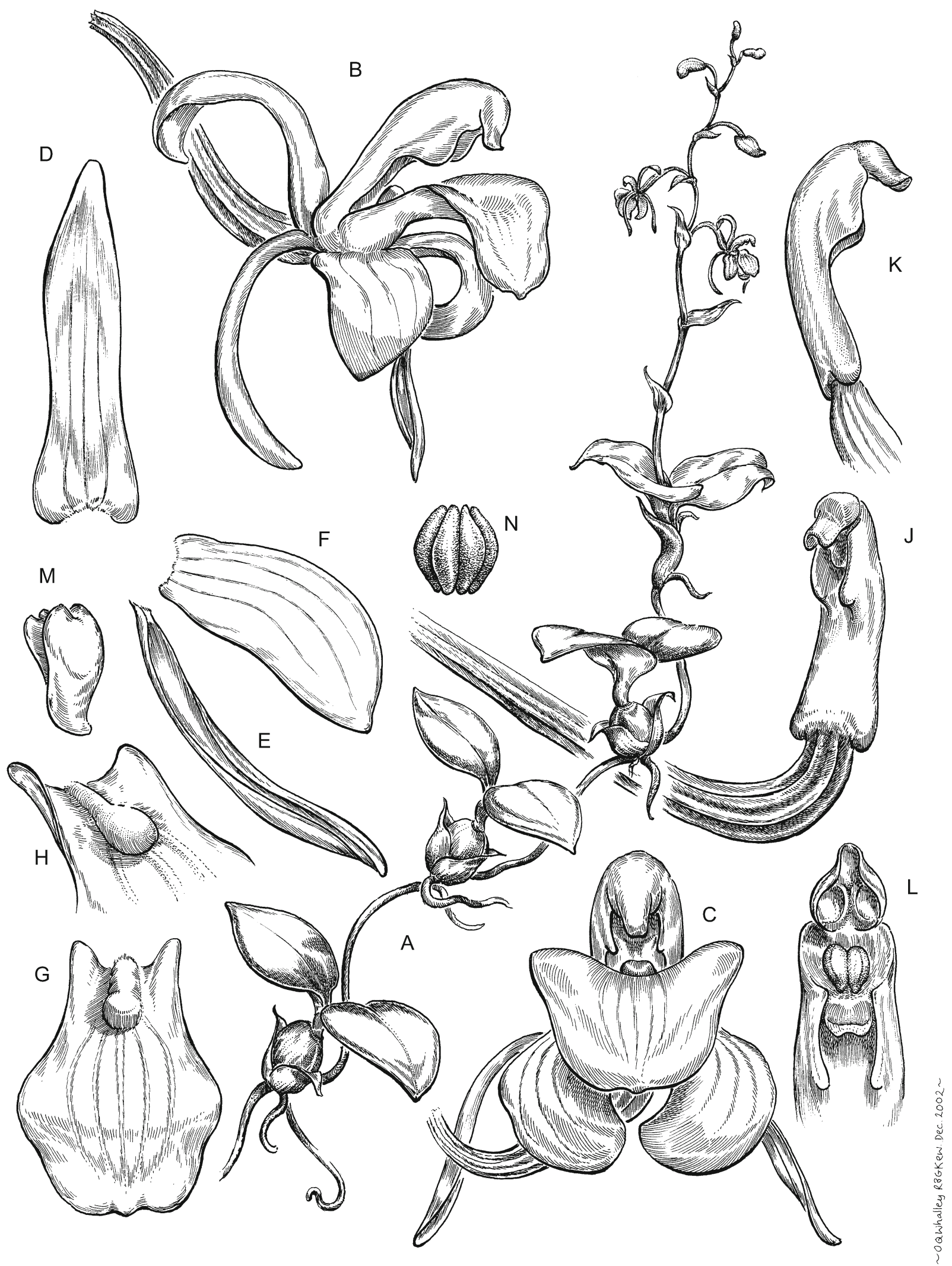

Fig. 10. Liparis bulbophylloides. A habit $\times 3$; B flower, side/front view $\times 15$; C flower, front view $\times 15$; D dorsal sepal $\times 15$; E petal $\times$ 15; F lateral sepal $\times 15 ; \mathrm{G}$ lip $\times 15 ; \mathrm{H}$ lip basal callus $\times 21$; J column, front view $\times 15 ; \mathrm{K}$ column, side view $\times 15 ; \mathrm{L}$ top of column with anther cap lifted $\times 15$; M anther cap $\times 27$; N pollinia $\times 38$. From Hermans 4894 (K). DRAWN BY OLIVER WHALLEY. 

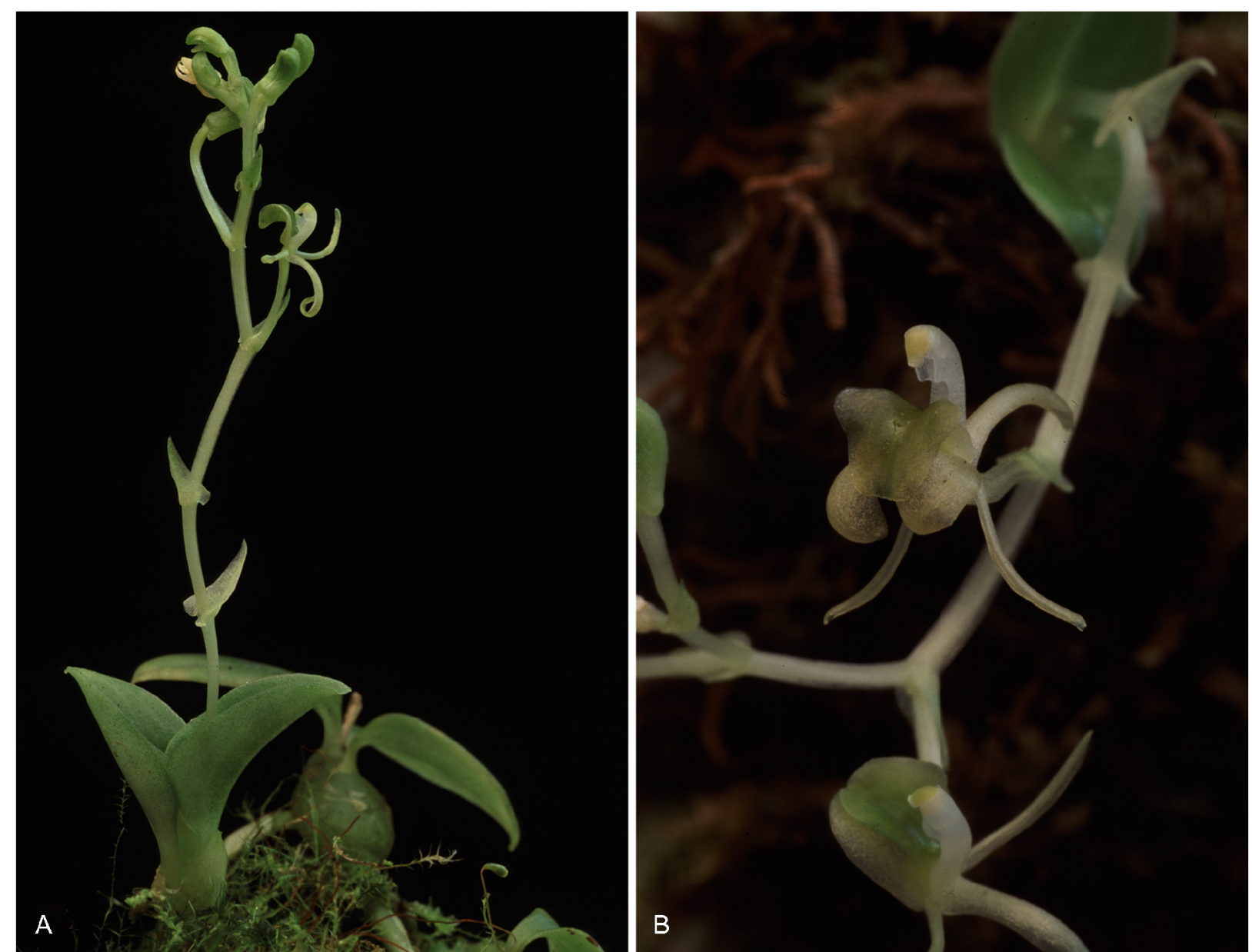

Fig. 11. Liparis bulbophylloides. A habit; B flower. PHOTOS: JOHAN HERMANS.

lip dark brown to ochre, darker towards the middle becoming a dark orange-red on the disk and base of column, column white becoming brown towards the base; the whole flower turning more orange with age. Pedicel and ovary glabrous, costate, $12-14 \times 0.8-1.1$ $\mathrm{mm}$. Dorsal sepal reclining, ligulate-lanceolate, $8-12.5$ $\times 1.5-2.1 \mathrm{~mm}$. Lateral sepals curved beneath the lip, ovate to lanceolate, $7.5-9.9 \times 3.6-4.5 \mathrm{~mm}$. Petals margins incurved, spreading and curved upwards, obliquely linear $9-10.5 \times 1.2-1.6 \mathrm{~mm}$. Lip strongly curved towards the base, broadly obovate, with very small auricles at the base, rounded to emarginate at the anterior margin, the margins undulate, with a distinct two-horned callus at the base, $7.1-8.9 \times 6.3-$ $8.6 \mathrm{~mm}$. Column relatively short, $3-4.5 \times 1-1.5 \mathrm{~mm}$, curved at the apex, with small triangular wings towards the apex. Anther oblate, rounded at the front, c. $0.8 \times$ $0.6 \mathrm{~mm}$. Pollinia in 2 pairs, ovoid, c. $0.5 \times 0.3 \mathrm{~mm}$.

RECOGNITION. A medium-sized to large plant with a long slender pseudobulb, two to three sub-petiolate asymmetric leaves, a loosely racemose rachis and medium-sized flowers, with a brown, broadly ovate lip with a two-horned callus at base and a rounded anther.

The species shares a similar habit, including the somewhat asymmetric leaves, its brownish-yellow flower colour and lip shape with Liparis rivalis from Madagascar but plants of $L$. caulescens are a little shorter, the spike habit is laxly racemose (vs densely racemose), fewer and with larger flowers, the lip with a more distinct callus, a larger, differently shaped column with angular vs rounded wings (Table 6). They may well have evolved from a common ancestor. It is somewhat similar in habit to Liparis gracilipes and L. danguyana from Madagascar but the leaves are considerably longer and asymmetric lanceolate vs elliptic-oval, while its flowers are at least $1 / 3$ larger and the lip broadly obovate vs suborbicular.

DISTRIBUTION. Réunion: all the cantons, mainly SaintDenis (le Brûlé), Saint-Pierre (Tampon), Saint-Louis (Cilaos) (Map 13). Humblot s.n. P00209845 (P) from the Comoro Islands, identified as this species, is possibly a misidentification and there appear to be two different species on the sheet both bearing only seed-pods. However, a sterile plant collected on 
Table 6. Comparison of Liparis caulescens and L. rivalis.

\begin{tabular}{lll}
\hline \hline & L. caulescens & L. rivalis \\
\hline Plant height $(\mathrm{cm})$ & up to 33 & up to 35 \\
Leaf size $(\mathrm{cm})$ & up to $10 \times 5$ & up to $15 \times 5$ \\
Leaf shape & asymmetric, lanceolate to elliptical-lanceolate & asymmetric, lanceolate to elliptical-lanceolate \\
Inflorescence length $(\mathrm{cm})$ & up to 11 & up to 15 \\
Number of flowers per inflorescence & up to 15 & up to 30 \\
Inflorescence type & loosely racemose & densely racemose \\
Dorsal sepal $(\mathrm{mm})$ & $8-11 \times 1.5-2$ & $5.5-7.2 \times 0.3-1$ \\
Lateral sepals $(\mathrm{mm})$ & $7.5-9.9 \times 3.6-4.5$ & $4.5-6.3 \times 1.9-2.2$ \\
Petals $(\mathrm{mm})$ & $9-10.5 \times 1.2-1.6$ & $5.5-7.0 \times 0.3-1$ \\
Lip shape & broadly obovate & broadly obovate \\
Lip size $(\mathrm{mm})$ & $7.1-8.9 \times 6.3-8.6$ & $4.1-5.4 \times 3.8-4.6$ \\
Lip callus & distinct, two-horned & small thickening \\
Column $(\mathrm{mm})$ & $3-4.5 \times 1-1.5$ & c. $2 \times 0.5$ \\
Anther & rounded at anterior margin & with small obtuse beak \\
Distribution & Réunion & N Madagascar \\
Altitude $(\mathrm{m})$ & $800-1500$ & $800-1600$ \\
\hline
\end{tabular}

Grande Comore by Brionnaud et al. (75) in 2000 seems to belong to this species. Boivin s.n. $1846-1848$ (W) from Mauritius is based on a later inscription and could also be an error.

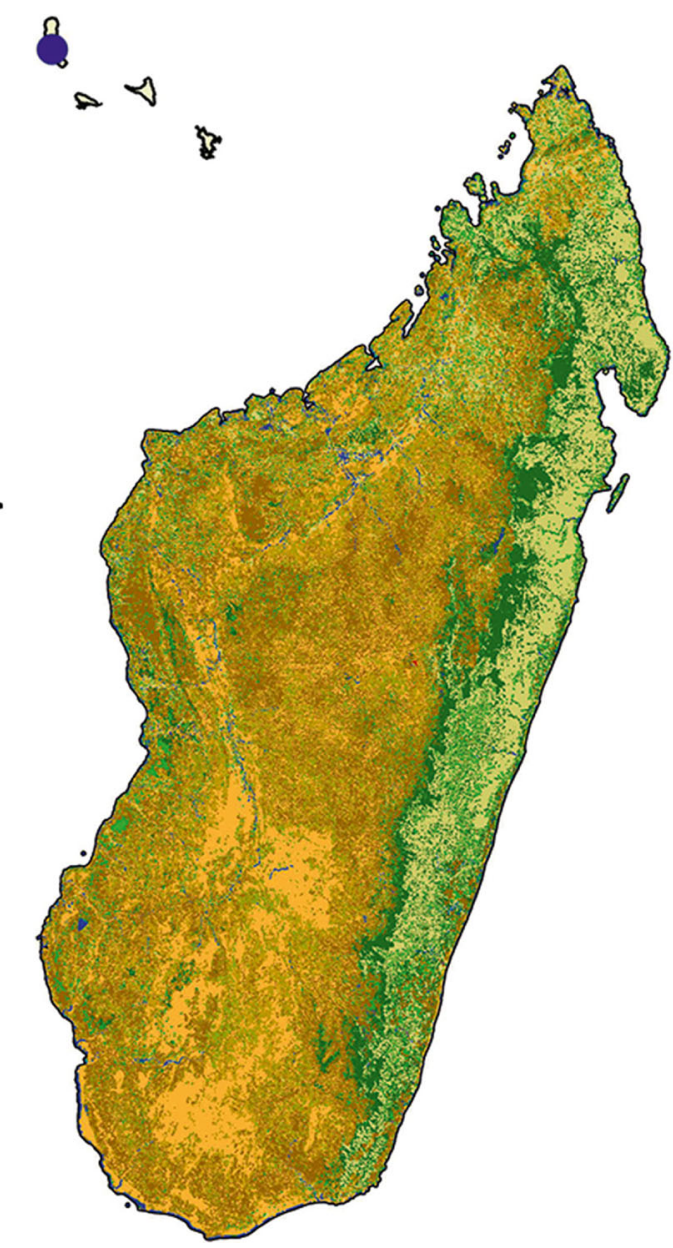

Map 13. Distribution of Liparis caulescens.
SPECIMENS EXAMINED. COMOROS. Grande Comore, Karthala, 1190 m, dense forest, Aug. 2000, Brionnaud et al. 75 (BR, CNDRS, K, MO, P). MAURITIUS:?, s. loc. Boivin, s.n. 1846 - 1848 (W). RÉUNION. Les Hauts du 
Boucan Launay, 1847 - 1852, Boivin 1035 (P00112460) (lectotype P); s. loc., Boivin 1035 (P00112455), (P00112456), (P00112460) \& (K000718243) (isolectotypes P, K); s. loc., Boivin s.n. (P00112461) (lectoparatype P); s. loc., 1853, Boivin 1045 (G); s. loc. 1846-1852 Boivin s.n. in Herb Delessert (G); s. loc., 1837, Richard 402 (P); s. loc., herb. Richard s.n. (KLindl.), s. loc., herb. Richard 643 (W); s. loc. Balfour s.n. rec. Oct. 1875 (K); s. loc., Cordemoy s.n (MARS); s. loc., Armange s.n. 1847 (P); Plaine des Cafres, March 1872, Potier s.n. (P); s. loc., 1875 De L'Isle 72 (P); Plaine des Palmistes, Aug. 1888 Cordemoy s.n. (MARS); Plaine des Palmistes, 1400 - 1500 m, June 1957, Bosser 11674 (P); Montée Plaine des Palmistes, Ilet à Patience, April 1971, Bosser 22470 (P); Cirque de Tacamaca, Hauts de St. Benoit, c. 800 m, April 1971, T. Cadet 3203 (P, REU); Montée de l'Ilet Patience, Bras Cabot path, Feb. 1971, Bosser 20581 (P); Plaine des Palmistes, l'Ilet Patience path, c. 1300 m, March 1973, T. Cadet 3173 (P); Morne des Patates à Durand, March 1974, Bosser 21653 (P); Les Trois Bras, Hauts de Sainte Anne, May 1974, Bosser 22075 (P); Takamaka, May 1974, Bosser 22051 \& 22051bis (P); Takamaka, June 1976, Bosser 22112 (P); Haute de Sainte Rose, April 1978, Bosser 22519 (P); Petite Plaine des Palmistes, 1300 m, March 1982, Cadet 6359 (REU); Takamaka, 820 m, Jan. 1990, R. Lavergne 1725 (REU); La Tanguiere, 850 m, Dec. 2003, Ferard et al. 982 (CBNM); Source Nouvelle Bras-Sec, 1036 m, Feb. 2004, Grondin 1036 (CBNM); Saint-Denis, Ravine, 1010 m, April 2006, Hivert 1989 (CBNM); Dimitile Bayonne, April 2009, Martos 629 (REU); Bois Blanc, 691 m, Sept. 2014, Ferard Ẽ Lacoste 4126 (CBNM); Plaine des Palmistes, Ravine seche, c. 800 m, Jan. 2007, Martos 19 \& 20 (REU); s. loc. Lavallée 269 (P).

HABITAT. Terrestrial or lithophyte in forest, common on rocky cliffs of shady ravines. Usually in dark and wet places in the rainforest at medium elevation. Altitude: 800 - $1500 \mathrm{~m}$.

CONSERVATION STATUS. Category EN: the extent of occurrence (EOO) of Liparis caulescens is estimated to be $172,983 \mathrm{~km}^{2}$ (far exceeding the limits for Vulnerable status under criterion B1) whereas its minimal area of occupancy (AOO) is estimated to be $36 \mathrm{~km}^{2}$ (which falls within the limits for Endangered status under the criterion B2). With only five known subpopulations representing five locations (sensu IUCN), this species has been preliminarily assessed as EN using the green listing method. This species is threatened by selective logging, timber harvesting for small-scale subsistence, slash-and-burn farming, grazing and anthropogenic fires, resulting in habitat reduction and habitat quality reduction. Previously assessed and published in the IUCN Red data listing for Réunion as LC (Picot 2013: 17).
FLOWERING TIME. February to May. ETYMOLOGY. Refers to the stem-like pseudobulbs. NOTES. The history of the species is complex, it appears to have been known by various botanists working at the end of the $19^{\text {th }}$ century and consequently several different names have been found in herbaria. The earliest herbarium sheets referring to this species are from Achille Richard's herbarium: two sheets in Paris (Richard 402) labelled as 'Malaxis flavescens', dated 1837 from Bourbon [Réunion] and one sheet in the Kew Lindley herbarium labelled as ' $L$. vaginata A.R. m. sp. Sp. nova. Ile Bourbon Richard'. Most of the early collections (e.g. Lavallée 269, Armange s.n. in P) were misidentified as M. flavescens, now Liparis flavescens, which was described and illustrated by Du PetitThouars (Thouars 1822: t.25) and was one of the few Liparis then known and similar, at first sight, to L. caulescens. Further Richard herbarium material found its way to the Reichenbach herbarium in W (643) where it is annotated 'Liparis vaginata nob. sp. nov.'. From the above it seems that Richard intended to describe the species as Liparis vaginata but never did so. The Richard specimen at K-Lindl. was traced on paper by Reichenbach $\mathrm{f}$. (now in W) and the tracing is annotated 'Liparis vaginata A. Rich. sp. nov' but additionally as 'Lip. caulescens Boiv. Isle Bourbon' and also labelled as 'L. longa Rchb.f cf. Linnaea". Liparis longa was described by Reichenbach in Linnaea (1877: 98) at the end of a lengthy series of novelties, most with a reference to type material except for $L$. longa which was the last in the series. The description is fairly detailed and mentioned a plant with a long stem, sub-opposite leaves and a lip with two teeth at the base of the lip. It is likely that Reichenbach was referring to the Richard material and decided to apply his own epithet and not the one suggested by Richard. Liparis longa is an earlier name for the species but under the rules of nomenclature (ICN article 7.9) Reichenbach's name cannot be accepted as it lacks any type material. In 1887, Ridley included L. longa in his monograph but added no further information.

Liparis caulescens first appeared in Frappier's listing of the plants of Réunion (1880: 15) as 'Liparis caulescens Frappier (ex. Boivin)'. It was finally validly described in 1895 by Cordemoy (1895: 186). Frappier did not specify a holotype in his description apart from indicating that it was based on a name given by Boivin on a herbarium specimen: 'Frapp, ex Boiv. hb. Mus. Réun.'. There are a number of herbarium sheets from the 1847 - 1852 Oise expedition to Réunion in $\mathrm{P}$ and in K: some give Les Hauts du Boucan Launay as a more specific locality, most have the collecting number '1035'. The most representative sheet of original material used by Frappier is P00112460 and was 

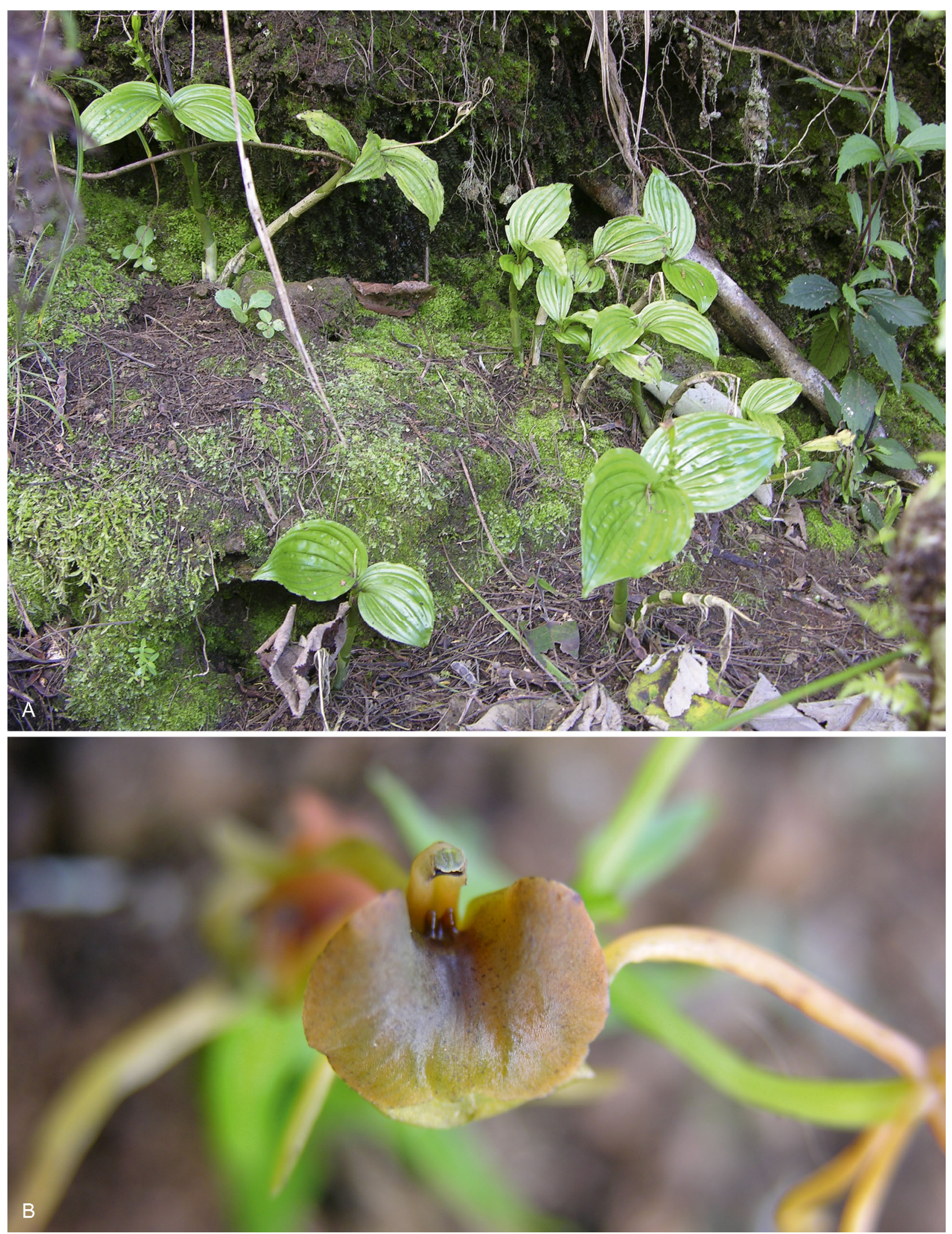

Fig. 12. Liparis caulescens. A habit; B flower. PHOtOS: PATRICE BERNET.

designated here as lectotype. Sheets P00112455, P00112456 and K000718243 are isolectotypes. The P specimen P00112461 has no collecting number and is treated as a lectoparatype. A specimen in the Paris 
herbarium of Boivin 1035 (P409214) is labelled L. caulescens and was annotated by Finet as L. polycardia Rchb.f but the plant habit and flowers are very different and it is L. ochracea. Boivin 1045 (G), identified by Kraenzlin as L. purpurascens, is L. caulescens. It is possible that it could be a transcription error of Boivin 1035 and therefore could be part of the type collection.

ILLUSTRATIONS. Fig. 12; Cadet (1989: 53); Bernet (2010a: 86); Szelengowicz \& Tamon (2013: 354).

Liparis cespitosa (Lam.) Lindl. (Lindley 1825: sub t. 882); Moore in Baker (1877: 342); Ridley (1885: 458; 1886b: 290); Frappier in Cordemoy (1895: 180); Perrier (1936: 241; 1939: 262); Hermans et al. (2007: 216); Cribb \& Hermans (2009: 146); Lebrun \& Stork (2017: 112). Type: Réunion, Lamarck ex Herb. Jussieu s.n. (holotype P-LA P00382094; isotype: herb. Jussieu 3830 (P00672996) P).

Epidendrum cespitosum Lam. (Lamarck 1783: 187).

Stichorkis cespitosa (Lam.) Thouars (Thouars 1809: 318) referring to Epidendrum cespitosum of Lam.

Malaxis caespitosa (Lam.) Thouars (Thouars 1822: t.90).

Cestichis caespitosa (Lam.) Ames (Ames 1908: 132).

Leptorchis caespitosa (Lam.) Kuntze (Kuntze 1891: 671)

Liparis cespitosa var. cleistogama Schltr. (Schlechter 1911a: 17).

Stichorkis cespitosa (Lam.) Thouars ex Marg. (emen in Szlachetko et al. 2008: 420 \& Margonska \& Szlachetko 2010: 61).

Malaxis minima Blume (Blume 1825: 391).

Liparis minima (Blume) Lindl. (Lindley 1830a: 32).

Leptorkis minima (Blume) Kuntze (1891: 671).

Liparis minima var. neoguineensis Schltr. (Schlechter 1905a: 105).

Malaxis angustifolia Blume (Blume 1825: 393).

Liparis angustifolia (Blume) Lindl. (Lindley 1830a: 31).

Liparis revoluta Hook. \& Arn. (Hooker \& Arnott 1832: $70)$.

Leptorkis revoluta (Hook. \& Arn.) Kuntze (1891: 671).

Liparis auriculata Rchb.f. (Reichenbach f. 1872: 277), non Miq.

Liparis pusilla Ridl. (Ridley 1886b: 294).

Leptorkis pusilla (Ridl.) Kuntze (1891: 671).

Stichorkis pusilla (Ridl.) Marg., Szlach. \& Kułak (in Szlachetko et al. 2008: 39).

Liparis obscura Hook.f. (Hooker 1889: t.1886).

Leptorkis obscura (Hook.f.) Kuntze (1891: 671).

Liparis prainii Hook.f. (Hooker 1889: t.1857).

Leptorkis prainii (Hook.f.) Kuntze (1891: 671).

Liparis duthiei Hook.f. (Hooker 1889: 1857b).

Leptorkis duthiei (Hook.f.) Kuntze (1891: 671).

Liparis comosa Ridl. (Ridley 1896).

Liparis neoguineensis (Schltr.) Schltr. (Schlechter 1911b: 209).
Liparis poilanei Gagnep. (Gagnepain 1929: 514).

Very small tufted epiphyte, lithophyte or terrestrial plant, $4-8 \mathrm{~cm}$ high on a short rhizome $1-2 \mathrm{~mm}$ diam., roots wiry, whitish, $1-2 \mathrm{~mm}$ diam. Pseudobulbs approximate, ovoid, green when young, becoming brown and wrinkled with age, with few scarious sheaths, up to $25 \mathrm{~mm}$ high and $10 \mathrm{~mm}$ in diam., single or very rarely 2-leaved, bearing a single terminal inflorescence. Leaf coriaceous, lanceolate sub-spathulate, widest towards the tip, gradually tapering to a narrow base joint, apex rounded to acute, pale to dark green, $18-59 \times 3-$ $9 \mathrm{~mm}$. Inflorescence erect, about the same length as the leaf, up to $8 \mathrm{~cm}$ but usually shorter, 5 - 20flowered. Peduncle somewhat flattened, with 1 or 2 short, thin sheaths. Rachis $10-32 \mathrm{~mm}$, densely to laxly flowered. Floral bracts acuminate, variable in length amongst specimens and within the inflorescence, $2.5-6 \times 0.3-0.9 \mathrm{~mm}$. Flowers very small, pale green to creamy yellow, the lip often a little darker, anther white, non resupinate, c. $4-5 \times 2-$ $3 \mathrm{~mm}$. Pedicel and ovary up to $4 \mathrm{~mm}$ long, smooth to somewhat ridged, thickened and rounded at the base, then becoming thin. Dorsal sepal reflexed, ovate, obtuse, single-veined, $1.5-2.9 \times 0.8-1.2$ $\mathrm{mm}$. Lateral sepals ovate, obtuse, $1.9-2.9 \times 0.9-$ $1.25 \mathrm{~mm}$. Petals angustate, linear reflexed, $1.5-2.5$ $\times 0.3-0.5 \mathrm{~mm}$. Lip oblong obtuse, the base erect and slightly winged, distal part bending downwards, margins retuse to minutely denticulate, with two veins, increasing at the base sometimes becoming thicker and callus-like, $1.9-2.5 \times 1.1-1.7 \mathrm{~mm}$. Column arcuate, slender, the edges a little expanded towards the apex, $1.1-1.6 \times$ c. $0.5 \mathrm{~mm}$. Anther small, obtuse, slightly expanded at the front, 0.4 $0.6 \mathrm{~mm}$ diam. Pollinia elliptic, $0.2 \mathrm{~mm}$. Seed capsule globular, ovate, c. $2 \mathrm{~mm}$ diam. with 3 strong ridges.

RECOGNITION. A small plant with rounded-ovoid pseudobulbs, bearing a single leaf, an inflorescence generally a little longer than the leaves, with up to 20 flowers, with $3 \mathrm{~mm}$ long sepals, an oblong and recurved lip, lightly denticulate at the anterior margin, and lacking a distinct callus, an unwinged column only slightly expanded towards the tip and an anther obtusely expanded at the front. The length of the floral bracts is variable, sometimes exceeding the length of the flower. Seed capsules are persistent on the rachis.

It shares the small pseudobulb and leaf-shape with Liparis ambohimangana but is very different in lacking a stolon while its flower, lip and anther are much smaller and a different shape with a suborbicular vs oblong-obtuse lip and a distinct callus. It is similar in habit to L. scaposa but has considerably smaller flowers and its lip callus is less apparent (Table 1). 
DISTRIBUTION. Widespread in Madagascar throughout Antananarivo, Fianarantsoa, Toamasina, Mauritius, Réunion and a few locations on the Comoro Islands (Map 14). Also in E tropical Africa (Uganda, Tanzania, Malawi, Mozambique), Sri Lanka, NE India to the Philippines, New Guinea, Solomon Islands and Fiji.

SPECIMENS EXAMINED: COMOROS. Grande Comore, Maoueni, La Grille Forest, 830 m, July 2000, Brionnaud et al. 11 (BRLU, CNDRS, K, MO, P). MADAGASCAR. Imerina, 1881, Deans Cowan s.n. BM0090077 (BM); s. loc., 1880's, Fox 28 (K ex LDS); Central, Andasibe forest, Onive valley, c. $1000 \mathrm{~m}$, Feb. 1925, Perrier 17125 (P); Sandrangato, S of Moramanga, March 1942, Decary 17787 (P); Mt Andriambavibe, July 1942, Decary 18134 (P); Toamasina, Bay of Antongil, Nosy Mangabe, April 1989, sea level, D. DuPuy E B. DuPuy MB154 spirit 56130 (K); Nosy Mangabe, Island of Nosy Mangabe, 0 - 10 m, April 1990, Carlson 161 (MO, SZU); NE, Masoala peninsula, Ratsianarana R., Oct. 1993, Lance 73 (K); Masoala Peninsula, Ambanizana R., W coast of Masoala, Nov. 1993, Lance 78 (K); Fianarantsoa, Ranomafana, 1100 - 1250 m, March 1993, Turk et al. 335 (MO, P); Fianarantsoa,
1272 m, 2003, Fischer OR370 (SZU); Sava, Andapa, Doany, Andranomololo, May 2006, Rakotovao et al. 3186 (MO, TAN). MAURITIUS. s. loc. Commerson s.n. (G); s. loc. Herb. Maire s.n. (P); s. loc. Bojer BM0088118 (BM); s. loc. Bouton s.n. (K); s. loc. April 1946, Edgerley 12193 (MAU, P); Bel Ombre, Oct. 1964, Vaughan 11360 (MAU, P); Bel Ombre, May 1959, Vaughan s.n. (MAU, P); Bassin Blanc, April 1974, Bosser 21852-3 (P); Tampoketsa of Ankazobe, 2001, Malala Orchidées Hort., Hermans 5387 (K); Toliara, Alaotra Mangoro, Moramanga, Ambatovy. Sahavaharina forest, $1034 \mathrm{~m}$, Sept. 2008, Antilahimena et al. 6541 (MO, P, TAN); Toliara, Alaotra Mangoro, Moramanga, Ambatovy. Sahavaharina forest, 1047 m, Sept. 2008, Antilahimena et al. 6542 \& 6542bis (MO, P, TAN); s. loc., Hermans 8068 (K, WU). RÉUNION. s. loc. Lamarck ex Herb. Jussieu s.n. (holotype P00382094 (P-LA); herb. Jussieu 3830 isotype P00672996 (P); s. loc. Thouars 18 (P); s. loc. Commerson s.n. P112446 (P); s. loc. Cordemoy s.n. (MARS); s. loc. March 1875, De L'Isle 227 (P); s. loc. 1875, De L'Isles.n (P); Herbier Drake s.n. (P); s. loc. Des Vaux s.n. (P); s. loc. Bernier s.n. (K, P); s. loc. Boivin 1036 (P); s. loc. 1837, Richard 401 (P); s. loc. Richards.n. (K-Lindl.); St. Philippe,

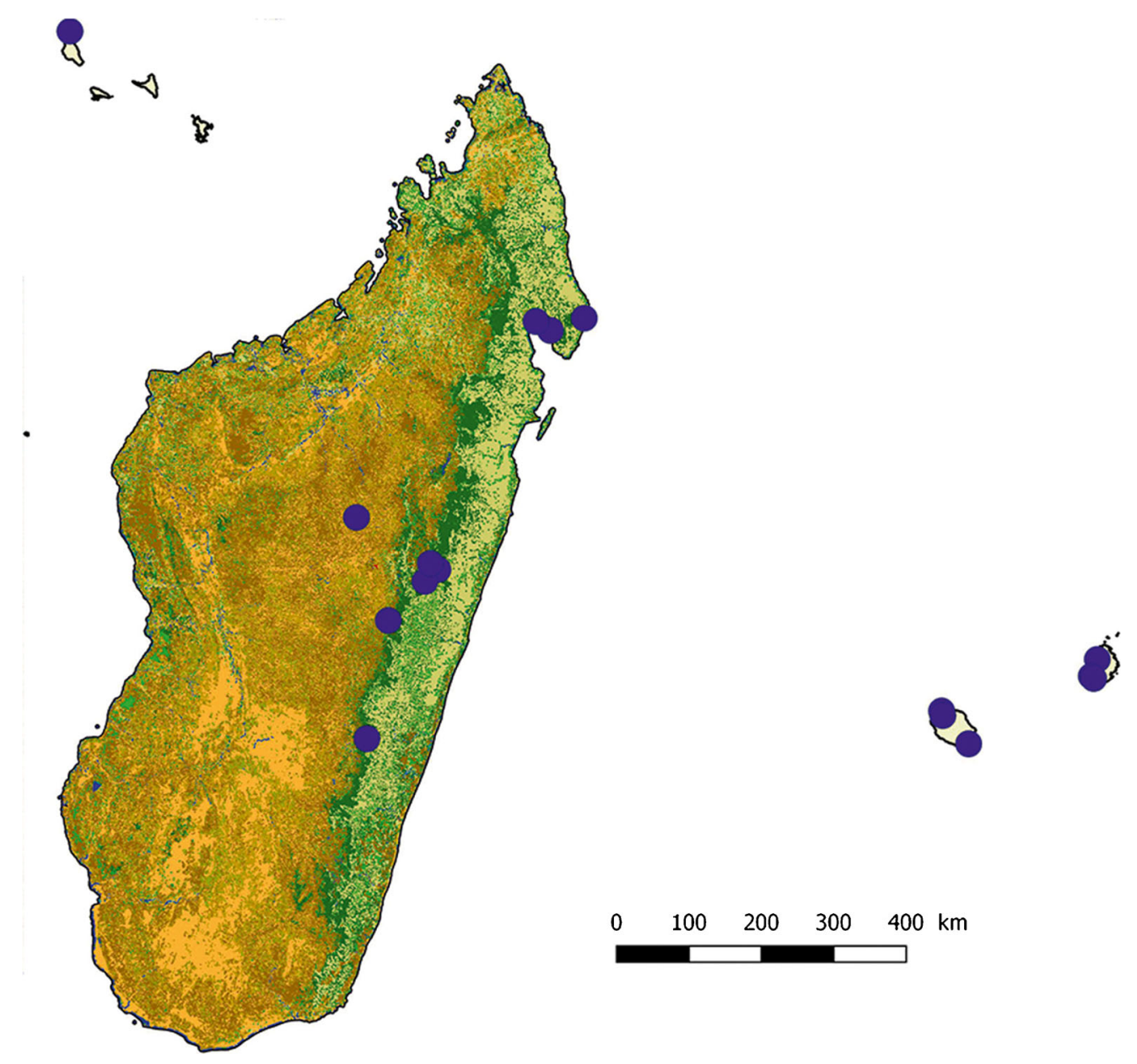

Map 14. Distribution of Liparis cespitosa. 
high Bara valley, Feb. 1971, T. Cadet 3058 (P); Dos d'Âne, Feb. 1971, ORSTOM 142 (P); La Grande Chaloupe, La Montagne, March 1974, Bosser 21638 (P); Cap Noir path, Dos d'Âne, Oct. 1972, Bosser 21252 (P); Dos d'Âne, Cap Noir, March 1976, Bosser 21721-2 (P); Ravine de la Grande Chaloupe, March 1978, Bosser 22351 (P); Plaine des Palmistes, 1200 m, Feb. 2003, Pailler TP67 (P); Bétan, 1200 m, Feb. 2003, Pailler TP68 (P); Herbier Cogniaux, 597L \& 948L (BR). Without Origin. Herb de Candolle, in part, as Epidendrum ophioglossiodes $(\mathrm{G})$.

HABITAT. Moss forest, secondary forest, humid forest. Altitude: 0 - $1400 \mathrm{~m}$.

CONSERVATION STATUS. Category LC: the extent of occurrence (EOO) of Liparis cespitosa is estimated to be $700,161 \mathrm{~km}^{2}$ (far exceeding the limits for Vulnerable status under criterion B1) whereas its minimal area of occupancy (AOO) is estimated to be $64 \mathrm{~km}^{2}$ (which falls within the limits for Endangered status under the criterion B2). With 14 known subpopulations representing 15 locations (sensu IUCN), this widespread species has been preliminarily assessed as LC using the green listing method. In Madagascar, this species is threatened by mining activities, selective logging, timber harvesting for small-scale subsistence and tavy (slash-and-burn farming), resulting in habitat reduction and habitat quality reduction

Previously assessed and published in the IUCN Red data listing for Réunion as CR (Picot 2013: 11)

FLOWERING TIME. January to April.

ETYMOLOGY. Referring to the tufted habit of the plant, as first described by Lamarck.

NOTES. Lamarck (1783: 187) first described Liparis cespitosa as Epidendrum cespitosum based upon a Bourbon [Réunion] specimen from de Jussieu's herbarium: he refers to it as 'Angrec en gazon' and likens its habit to E. ophioglossoides Jacq. (Jacquin 1760: 29) (= Stelis ophioglossoides (Jacq.) Sw. (Swartz 1800: 239)). The holotype specimen, as used by the author, is in the Lamarck Herbarium in P (P00382694), it consists of a fruiting plant. Later labelling on the sheet refers to Stelis and E. ophioglossioides and also to 'Martinica' obviously referring to the Antillean Stelis species in error. In addition, the de Jussieu herbarium has a sheet with five fruiting plants and one gap with the pin-holes of a previous mounting still in place, it again is annotated Stelis and E. ophioglossioides and also as Malaxis caespitosa Thouars. The Lamarck holotype specimen was without much doubt removed from this de Jussieu sheet which is, therefore, considered to be an isotype. It is likely that the original material came from Commerson but it is inconclusive whether the 'Comm' annotation on the Jussieu sheet refers to Commerson or to its communication. It is also interesting to note that a specimen sheet of unknown origin in the de Candolle Herbarium in G, has a mixture of two plants labelled as E. ophioglossiodes with one plant of L. cespitosa and another of a plant similar to $S$. ophioglossoides.

In 1809 Du Petit-Thouars referred to Lamarck's description in error under his new genus 'Stichorkis' as Angraecum caespitosum. In 1822 he referred to it both in the text and in the illustration as Malaxis caespitosa; there is no reason to believe he would not be referring to Lamarck's Epidendrum cespitosum. Lindley placed it in the genus Liparis in 1824.

Margonska (in Szlachetko et al. 2008: 35) rejected Rasmussen's (1979: 392) interpretation of Du Petit Thouars' work (1809 \& 1822) and re-typified and created Stichorkis cespitosa (Lam.) Thouars ex Marg. The nomenclature system allows a number of interpretations under the nomenclatural code (McNeill et al. 2012 \& Turland et al. 2018) but this is superfluous: Liparis cespitosa is clearly based on Lamarck's ex de Jussieu's original material as used by the author and not on any of Du Petit-Thouars' material.

Both the epithets caespitosa and cespitosa have been used in the literature, under the rules of nomenclature and as discussed by Rasmussen (Rasmussen 1979: 392) cespitosa is correct, keeping Lamarck's orthography.

This is one of the few Liparis in the Madagascar area with small bulbous pseudobulbs and a single leaf. It was first recorded in the area from the Mascarenes but has since also been recognised from Madagascar where it seems to be fairly widespread. It is also one of the few species with a much wider distribution in Africa and in Asia. Percival (1965: 11), mentioned that it is cleistogamous in the wet and misty rainforest but chasmogamous in the drier air outside of that environment.

Illustrations. Fig. 13. Du Petit-Thouars (Thouars 1822: t. 90); Seidenfaden \& Wood (1992: 234); Bernet (2010a: 87); Szelengowicz \& Tamon (2013: 373).

Liparis chantaliae Hermans $\mathcal{E}$ Hervouet sp. nov. Type: Madagascar, Toamasina, near Andasibe, Vakôna forest, 1020 - 1100 m, Jan. 1997, Hermans 3997 (holotype K).

http:/ /www.ipni.org/urn:lsid:ipni.org:names:77201716-1

Large terrestrial or rarely epiphytic plant up to $26 \mathrm{~cm}$ tall, rhizome scrambling, sometimes new growths emerge from the stem of previous growth, roots glabrous, white, c. $2 \mathrm{~mm}$ diam. Pseudobulbs stem-like, round, up to $23 \mathrm{~cm}$ long, $8-15 \mathrm{~mm}$ diam., with $3-6$ white sheaths along its length not much overlapping, attenuate at the apex, white-grey, strongly veined, dotted with ochre-brown, carrying two (rarely 3) leaves at the apex. Leaves broadly ovate, obtuse or shortly acute at the apex, undulate, crenulate along the 

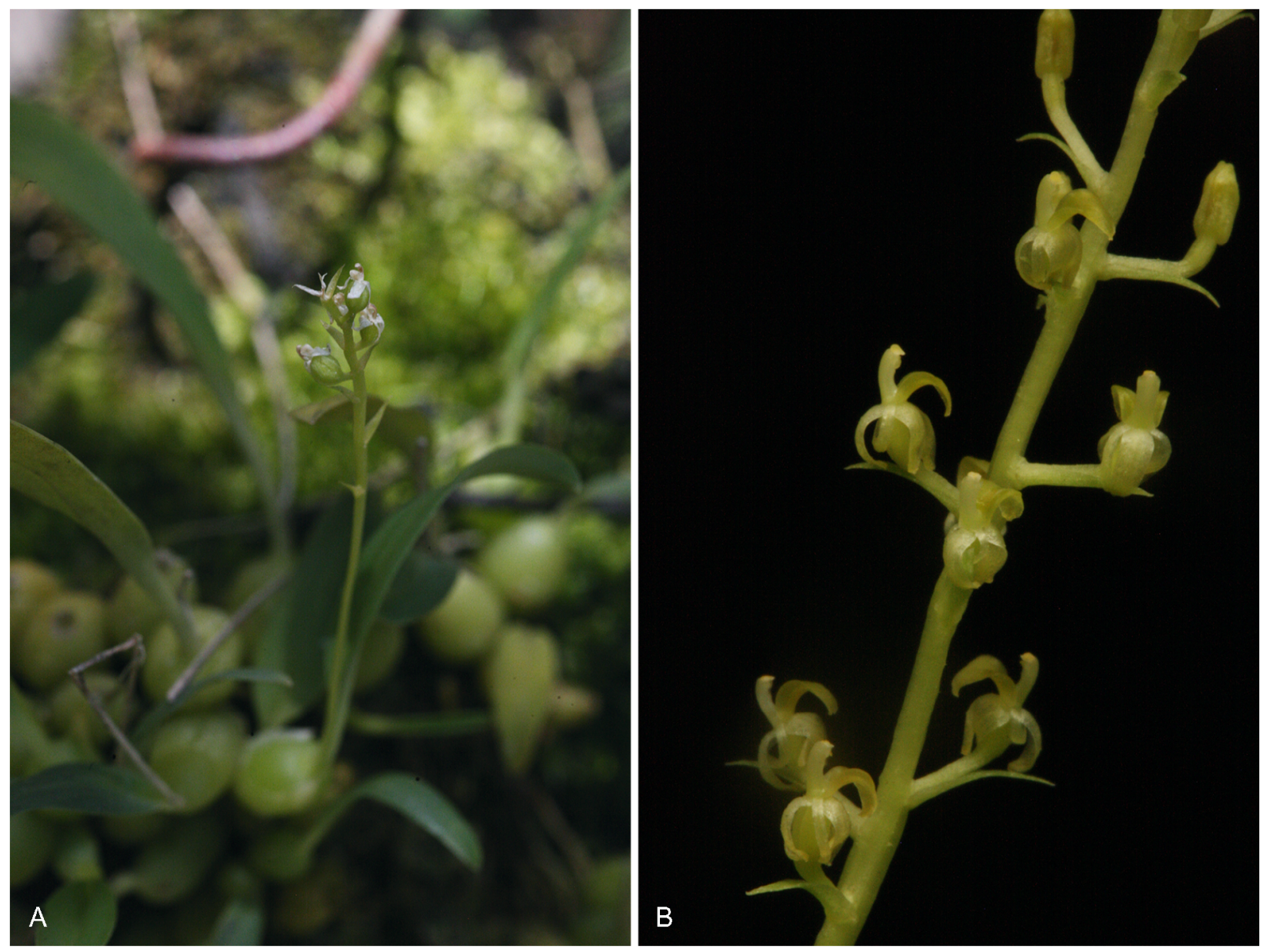

Fig. 13. Liparis cespitosa. A habit with wilting flowers; B rachis. PHOTOS: JOHAN HERMANS.

margins, subsessile or shortly petiolate, pale to dark green, often a little paler underneath, $5-8.5 \times 2-4.5$ $\mathrm{cm}$. Inflorescence erect, $8-15 \mathrm{~cm}$ long, carrying up to 14 flowers but generally fewer. Peduncle about the same length as the rachis, with one or two peduncle sheaths enveloping the base and one or two higher up, c. $2 \mathrm{~mm}$ diam. Rachis laxly 2 - 14-flowered. Floral bracts lanceolate, the base somewhat cordate, $5-15 \times 1.5-3$ $\mathrm{mm}$. Flowers large, up to $41 \times 23 \mathrm{~mm}$, pale green to viridian, the lip dark olive green with a darker longitudinal ridge, column and ovary white, anther green, pollen yellow, scented. Pedicel and ovary somewhat ridged, thickened at both ends, $11-16 \times 1-1.2$ $\mathrm{mm}$. Dorsal sepal erect, linear, obtuse, margins recurved, $13-23 \times 1.1-2 \mathrm{~mm}$. Lateral sepals folded below the lip, falcate, broadly lanceolate, $13-19 \times 3.5$ - $7.1 \mathrm{~mm}$. Petals narrow linear, curved downwards, the margin incurved, $13-19 \times 0.3-0.8 \mathrm{~mm}$. Lip broadly oval-lanceolate, the base with short rounded wings and two elongate lamellar-triangular calli, generally with a furrow of smaller, irregularly rounded calli in-between, anterior lobe almost triangular with dentate margins, $11.5-15 \times 5.8-8 \mathrm{~mm}$. Column slender, slightly arching, wings narrow and obtuse, $4.5-7 \times 1-$
$1.3 \mathrm{~mm}$. Anther with a cuspidate to linear beak, $1.1-$ $1.8 \times 0.8-1.3 \mathrm{~mm}$. Pollinia ovoid, c. $0.6 \times 0.5 \mathrm{~mm}$.

RECOGNITION. Liparis chantaliae is easily recognised by its tall pseudobulbs, circular in cross-section and partly covered by papery sheaths, with two broadly oval, corrugate leaves at the top. The large flowers have a characteristic broadly oval-lanceolate lip, with short rounded wings and two elongate lamellar-triangular calli at the base, and an almost triangular anterior lobe with dentate margins. The anther has a cuspidate to linear beak.

Liparis chantaliae is similar to L. gracilipes but the leaves are much thinner in texture and broadly oval vs elliptic, the lip broadly oval-lanceolate vs suborbicular and the callus bi-lamellar vs tridentate. There are some superficial similarities with L. zaratananae but the pseudobulbs are shorter, less leafy, the lip is ovallanceolate with the anterior margin angular vs broadly oval and rounded, the anther has a shorter, less spathulate beak. It shares the tall habit, somewhat corrugate leaves, lax inflorescence and large flowers with $L$. longicaulis with which it has frequently been confused in herbaria and in field-observations 
Table 7. Comparison of Liparis chantaliae and L. longicaulis.

\begin{tabular}{|c|c|c|}
\hline & L. chantaliae & L. longicaulis \\
\hline Plant habit & scrambling & compact \\
\hline Plant height & up to 26 & up to 35 \\
\hline Pseudobulb-stem & $\begin{array}{l}\text { round in cross-section, partly covered } \\
\text { by papery bracts }\end{array}$ & $\begin{array}{l}\text { angular in cross-section, covered by } \\
\text { papery bracts }\end{array}$ \\
\hline Inflorescence height $(\mathrm{cm})$ & $8-15$, shorter than the pseudobulbs & up to $10-24$, as long as the pseudobulbs \\
\hline No. flowers per inflorescence & up to 14 & up to 10 \\
\hline Lip & $\begin{array}{l}\text { broadly oval-lanceolate, anterior lobe } \\
\text { almost triangular and attenuate }\end{array}$ & oval to broadly ovate, anterior lobe obtuse \\
\hline Lip callus & bi-lamellar / triangular & indistinctly bi-lobed / rounded \\
\hline Flowering Time & Jan. - June & Dec. - April \\
\hline Distribution & $\begin{array}{l}\text { Madagascar: Antananarivo, Antsiranana, } \\
\text { Fianarantsoa, Mahajanga, Toamasina, } \\
\text { Toliara prov. }\end{array}$ & $\begin{array}{l}\text { Madagascar: Antananarivo, } \\
\text { Antsiranana, Fianarantsoa, } \\
\text { Mahajanga, Toamasina prov. }\end{array}$ \\
\hline Altitude (m) & $700-1700$ & $800-1800$ \\
\hline
\end{tabular}

(Table 7), but the latter differs by the angular stem which is completely covered by overlapping papery sheaths (vs partly covered), generally longer inflorescence, larger flowers, a lip with an attenuate anterior lobe (vs rounded), a distinct bilobed callus on the lip (vs rounded swelling) and a more acutely beaked anther. The two species have a wide and overlapping
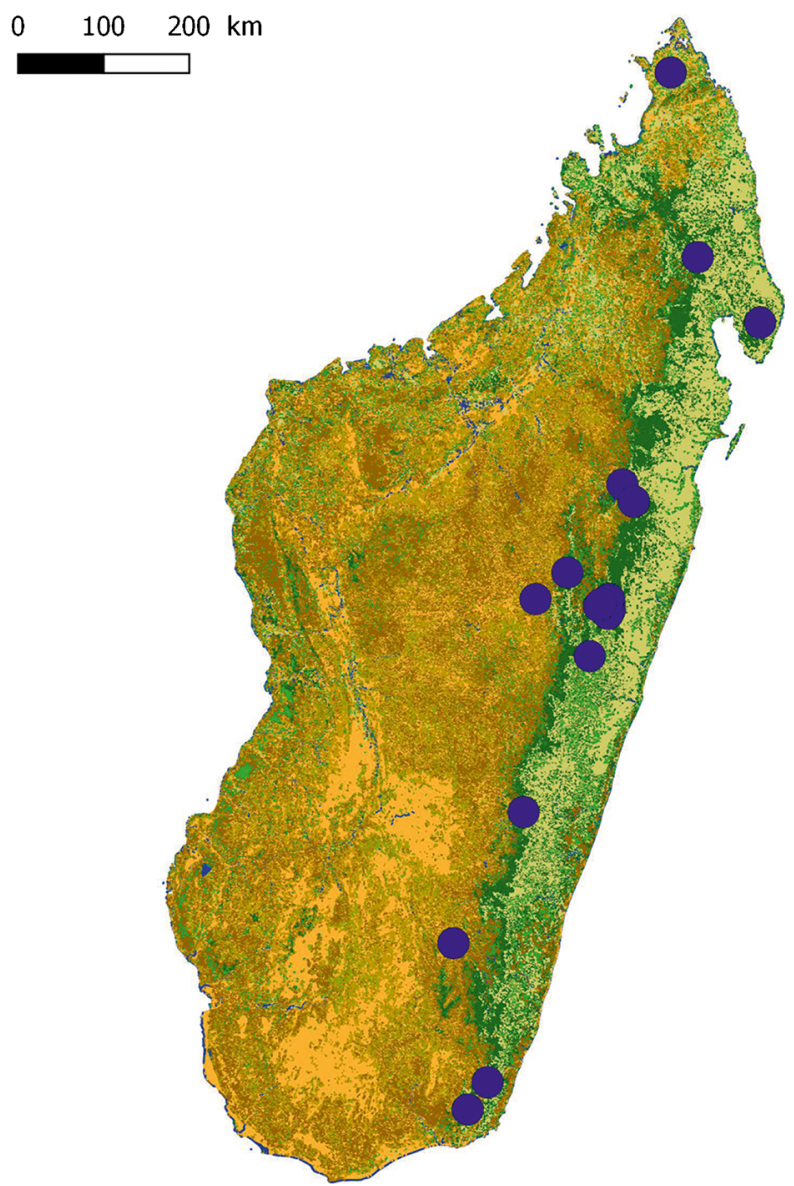

Map 15.. Distribution of Liparis chantaliae. distribution but $L$. chantaliae has been recorded from Toliara province, where L. longicaulis is absent. The species overlap in distribution in Andasibe (Toamasina prov.) and Ranomafana (Fianarantsoa prov.), they grow at similar elevations in wet evergreen forest, flower at similar times and both are scented.

DISTRIBUTION. Widespread and endemic to Madagascar: Antananarivo, Antsiranana, Fianarantsoa, Mahajanga, Toamasina and Toliara provinces (Map 15).

SPECIMENS EXAMINED. MADAGASCAR. Toamasina, near Andasibe, Vakôna forest, alt. 1020 - 1100 m, Jan. 1997, Hermans 3997 (holotype K); Ambohimanga, June 1906, Alleizette 351bis (P); Andohahela massif, upper valley of the Sakamalio, 1500 - 1700 m, Jan. 1934, Humbert 13562 (P); Zahamena, March 1941, Decary 16789 (P); Atsanga, Imerimandrosa, $750 \mathrm{~m}$, April 1941, Cours 1549 (P, TAN); Mts S of Tanandava, Manampanihy tributary, Mandrere valley, 600 - 700 m, March 1947, Humbert 20531 (G, P, TAN); Anjozorobe, March 1959 Bosser 12358 (P); Ranotsara, near Ihosy, March 1964, Bosser 17869 (P); Mt d'Ambre, June 1970, Bosser 20337 (P); Masoala, 700 m, May 1975, Morat 4933 (P); Mt d'Ambre, 1400 - 1475 m, April 1993, Andrianantoanina et al. 41 (K); SW of Antsiranana, near Joffreville, Parc National Mt d'Ambre, 1993, Malcomber et al. 2380 (MO); Andranotsarabe, 1050 m, Nov. 1994, Hermans 1002 \& 2292 (K); Tanandava area, in forest, $600 \mathrm{~m}$, 1999, Hermans 2423 (K); near Ranomafana, May 2001, 1016 m, Hermans 5243, 5250 \& 6607 (K); Mantadia, Belakato, Nov. 2003 (in fruit), Roberts et al. TPPO24 (K); Toamasina, Ambohibary, Ambatovy, $1144 \mathrm{~m}$, June 2008, Antilahimena et al. 6266 (MO, P, TAN); Toamasina, firaisana Ambohibary, fokontany Ampitabe, Ambatovy, $1026 \mathrm{~m}$, June 2008, Rakotondrajaona et al. 448 (MO, P, TAN); Toamasina, Andasibe, Menalamba, Ambondromasay, $1016 \mathrm{~m}$, April 2009, Bernard et al. 1416 (MO, P, TAN); Toamasina, Alaotra-Mangoro, Ambatovy, Sept. 2009, Antilahimena et al. 7158 (K, MO); Toamasina, Anosibe 
an'ala, April 2010, Rajavelona et al. 235 (K, TAN); Toamasina, Ambatovy: Région Alaotra-Mangoro, Distr. Moramanga. 1161 - 1186 m, Nov. 2011, Ambatovy Shade House 539 (BRLU, MO, TAN); Toamasina, Moramanga, Andasibe, Bekalakody, April 2012, Razafindrahaja E Antilahimena 225 (MO, P, TAN); Toamasina, Andasibe, Andasifahatelo, Ambatoaranana., 1005 m, April 2012, Rasoazanany $\mathcal{E}^{\circ}$ Ratolojanahary 104 (MO, P, TAN); Toamasina, Ambatovy: Région Alaotra-Mangoro, Moramanga, April 2013, Ambatovy Spirit Collection 858 (BRLU, MO, TAN); Moramanga, Andasibe, Analamazaotra, $817 \mathrm{~m}$, Dec. 2013, Razafindraibe et al. 633 (MO, TAN); Commune Andasibe, Réserve Spéciale Analamazaotra, site Anivokely, 1012 m, Dec. 2013, Razafindraibe 575 (MO, TAN); Andasibe, Fokontany Falierana, Mantadia, 915 m, Dec. 2013, Antilahimena et al. 8744 (MO, TAN); Fianarantsoa, Ranomafana area, April 2018, Hermans 8217 \& 8221 (K).

HABITAT. Evergreen forest undergrowth, riverine forest. Altitude: $700-1700 \mathrm{~m}$.

CONSERVATION STATUS. Category LC: the extent of occurrence (EOO) of Liparis chantaliae is estimated to be $145,327 \mathrm{~km}^{2}$ (which exceeds the limits for Vulnerable status under criterion B1) whereas its minimal area of occupancy (AOO) is estimated to be $96 \mathrm{~km}^{2}$ (which falls within the limits for Endangered status under the criterion B2). Liparis chantaliae is known from 13 subpopulations representing 15 locations (sensu IUCN), this species has thus been preliminarily assessed as LC using the green listing method. This species is threatened by mining activities, selective logging, timber harvesting for small-scale subsistence and tavy (slash-and-burn farming), resulting in habitat reduction and habitat quality reduction.

FLOWERING TIME. January to June.

ETYMOLOGY. Named in honour of Mme Chantal Hervouet, who with her husband, Jean-Michel Hervouet, is an ardent explorer of Madagascar.

ILlUStrations. Figs 14, 15. Cribb \& Hermans (2009: 149 as Liparis zaratananae).

Liparis cladophylax Schltr. (Schlechter 1916: 321; 1924: 136); Perrier (1939: 276); Hermans et al. (2007: 216); Cribb \& Hermans (2009: 150). Type: Madagascar, High Sambirano valley, 800 m, Oct. 1912, Perrier 11360 (139) (holotype P).

Very small epiphytic plant $6-8 \mathrm{~cm}$ high, rhizome short, roots glabrous, filiform. Pseudobulbs oval, small, 8 - $10 \mathrm{~mm}$ high, covered in thin membranous sheaths and a leaf-like $1 \mathrm{~cm}$ sheath, the flowering bulb carrying 2 larger leaves. Leaves erect to sub-erect, soft, oblong-ligulate, subacute and narrowed towards the base, $3-4.5 \times 0.6-0.8 \mathrm{~mm}$. Inflorescence erect, slender, a little shorter than the leaves, up to $25 \mathrm{~mm}$ long, subdensely 6 - 8-flowered (Schlechter's original description has $15-20$ flowers but there is no evidence of this in the type material). Peduncle with a short acuminate sheath. Floral bracts narrow, lanceolate, acuminate, a little shorter than the ovary, $3-4 \times 1.5 \mathrm{~mm}$. Flowers very small, somewhat spreading, greenish at first, becoming brownish-yellow with age, c. $2.5 \times 3 \mathrm{~mm}$. Pedicel and ovary slender, glabrous, up to $6 \mathrm{~mm}$ long. Dorsal sepal recurved, lanceolate, obtuse $2.5-3 \times 0.4-$ $0.6 \mathrm{~mm}$. Lateral sepals oblong, obtuse, single-veined, 1.8 - $2.7 \times 1.1-1.4 \mathrm{~mm}$. Petals narrowly linear, obtuse, single-veined, a little rough at the apex, $1.9-2.3 \times 0.3$ $\mathrm{mm}$. Lip slightly recurved, suborbicular without obvious veins, the base slightly auriculate, indented at the anterior margin, with a transversal 'M'-shaped callus or thickening at the base extending into two lateral keels, carrying a few horn-like protrusions on the anterior half, $1.7-2 \times 1.4 \times 2 \mathrm{~mm}$. Column with the angular wings on each side of the stigmatic surface $1.5-1.8 \times$ $0.3 \mathrm{~mm}$. Anther truncate at the front $0.3 \times 0.3 \mathrm{~mm}$. Pollinia c. $0.2 \mathrm{~mm}$ diam.

RECOGNITION. The species is mainly known from Perrier's type collection from Northern Madagascar, consisting of two plants and fragments of an inflorescence and flowers. The small size of the plant and flowers combined with the lip shape, callus and tiny horn-like protrusions at the back of the lip make it distinct.

Schlechter, in his description, wrote that this species is similar to Liparis epiphytica Schltr. (Schlechter 1905b), from Western Africa: in several characteristics the plant and habit are similar although the leaves in L. epiphytica are blunter, the flowers of L. cladophylax are much smaller (about half the size), the lip basal formation is also different ('M'-shaped vs rectangular). There are some similarities to L. cespitosa but that has a single leaf, and there are also differences in the lip which is rounded in L. cladophylax and more expanded and dentate in L. cespitosa. It is also close to L. scaposa but the flowers are smaller, the column has smaller wings and a smaller callus on the lip. As the species is only known from limited material, it is difficult to assess its identity with any certainty. The original description calls for a dense spike of $15-20$ flowers but the herbarium material bears no resemblance to this, this characteristic would make it very different from similar small species; with this conflict between type material and the description the species will have to remain somewhat ambiguous.

DISTRIBUTION. Endemic to Madagascar: Antsiranana province only (Map 16).

SPECIMENS EXAMINED. MADAGASCAR. Madagascar, high Sambirano Valley, 800 m, Oct. 1912, Perrier 11360 (139) (holotype P); Hort., 2000, Hermans 5308 (K). 


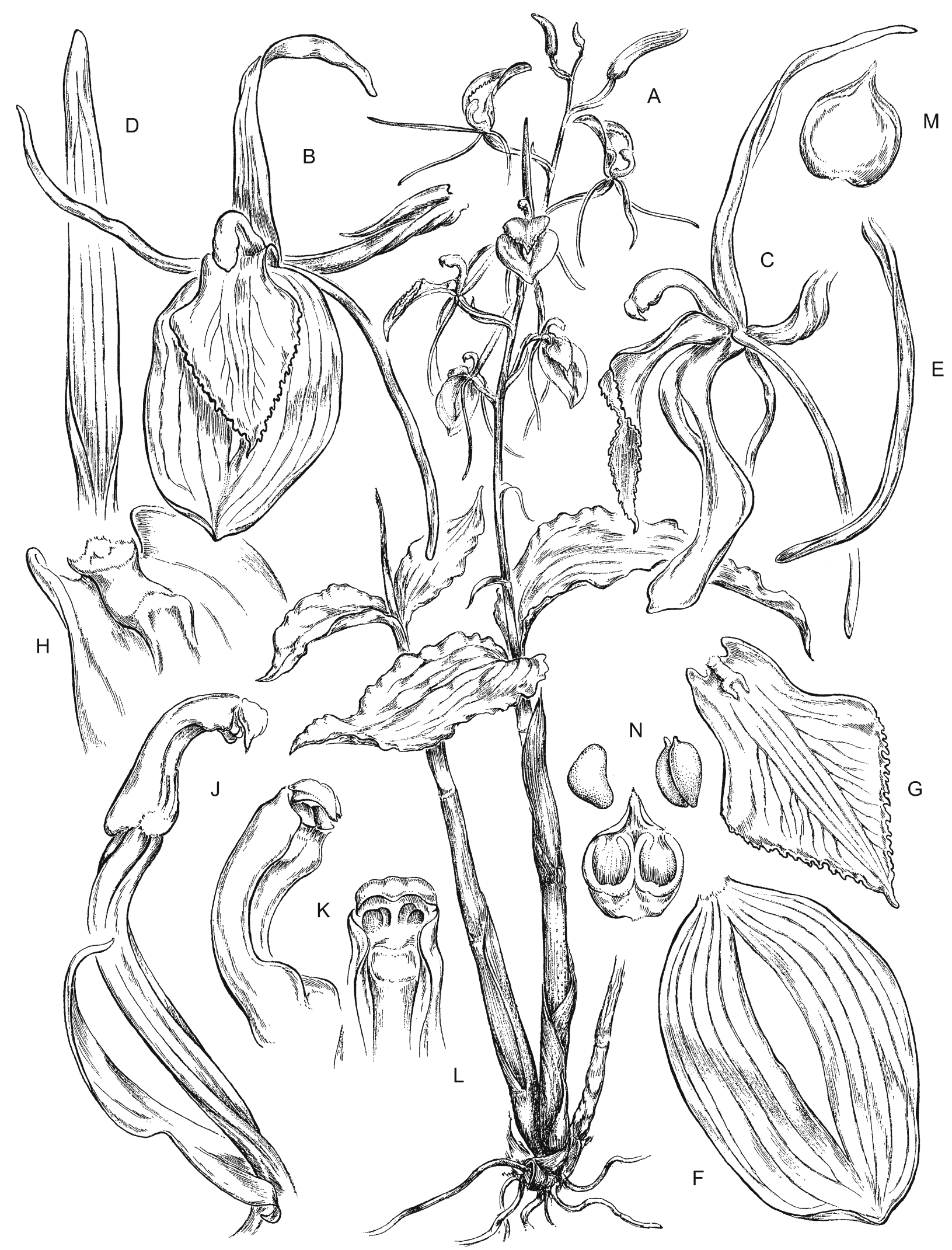

Fig. 14. Liparis chantaliae. A habit $\times 1$; B flower, front view $\times 3$; C flower, side view $\times 3$; D dorsal sepal $\times 5$; E petal $\times 3$; F lateral sepal $\times 5$; G lip $\times 5$; H lip basal callus $\times 10$; J column, side view $\times 8$; K column, side view $\times 19$; L top of column with anther cap lifted $\times 15$; $\mathbf{M}$ anther cap $\times 15$ (digitally altered); N pollinia $\times 15$. DRAWN BY OLIVER WHALLEY. 

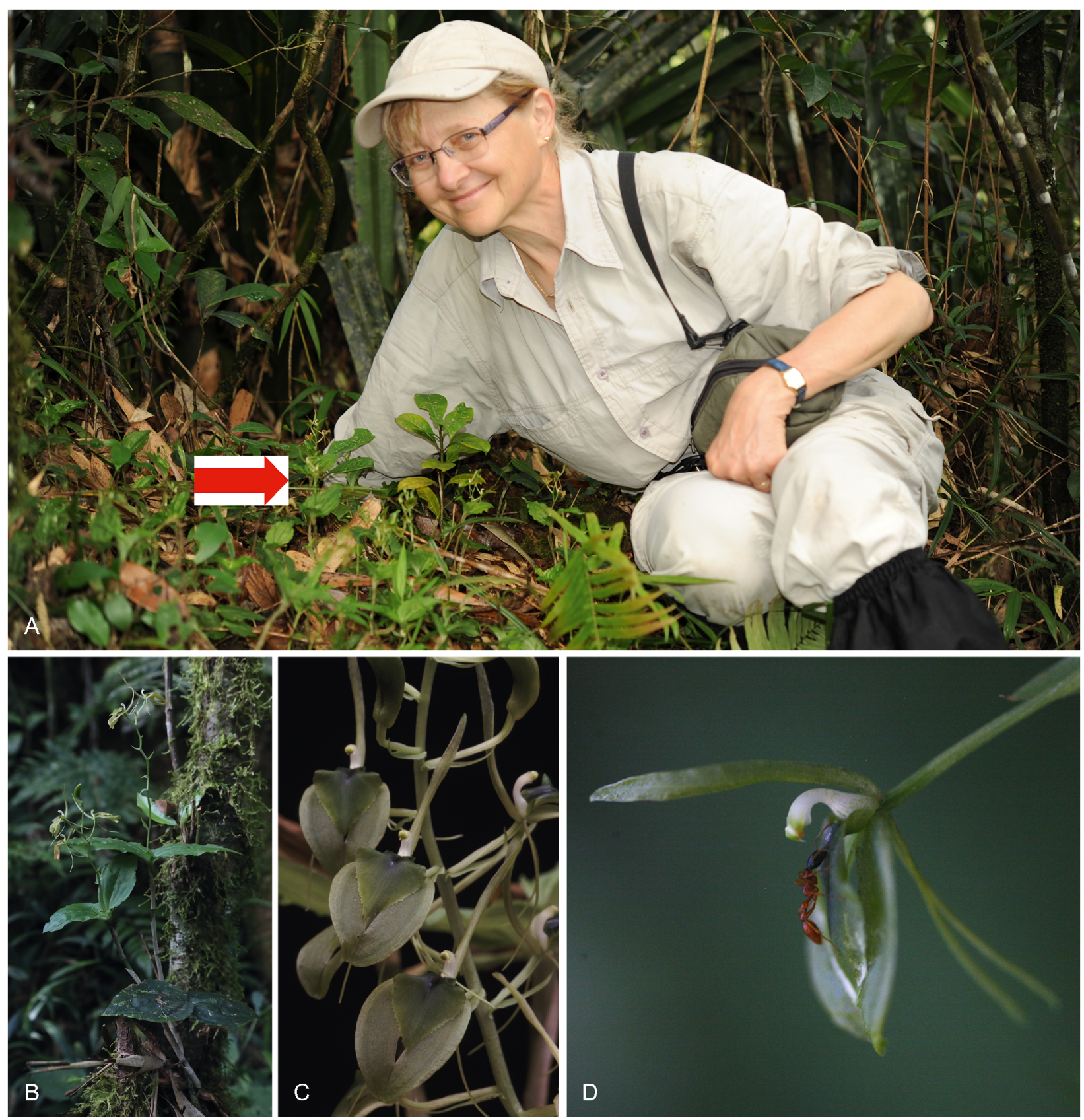

Fig. 15. A Liparis chantaliae with Chantal Hervouet for whom the species was named; B habit; C rachis; D flower visited by the ant Tetraponera grandidieri. PHOTOS: A JEAN-MICHEL HERVOUET; B - D JOHAN HERMANS.

HABITAT. Epiphyte in humid evergreen forest. Altitude: c. $800 \mathrm{~m}$

CONSERVATION STATUS. Category CR: the extent of occurrence (EOO) of Liparis cladophylax cannot be estimated since it is only known from one subpopulation whereas its minimal area of occupancy (AOO) is estimated to be $4 \mathrm{~km}^{2}$ (which falls within the limits for Critically Endangered status under the criterion B2).
The only known subpopulation represents one location (sensu IUCN). This species has thus been preliminarily assessed as CR using the green listing method. This species is threatened by selective logging, timber harvesting for small-scale subsistence and tavy (slashand-burn farming), resulting in habitat reduction and habitat quality reduction.

FLOWERING TIME. October. 


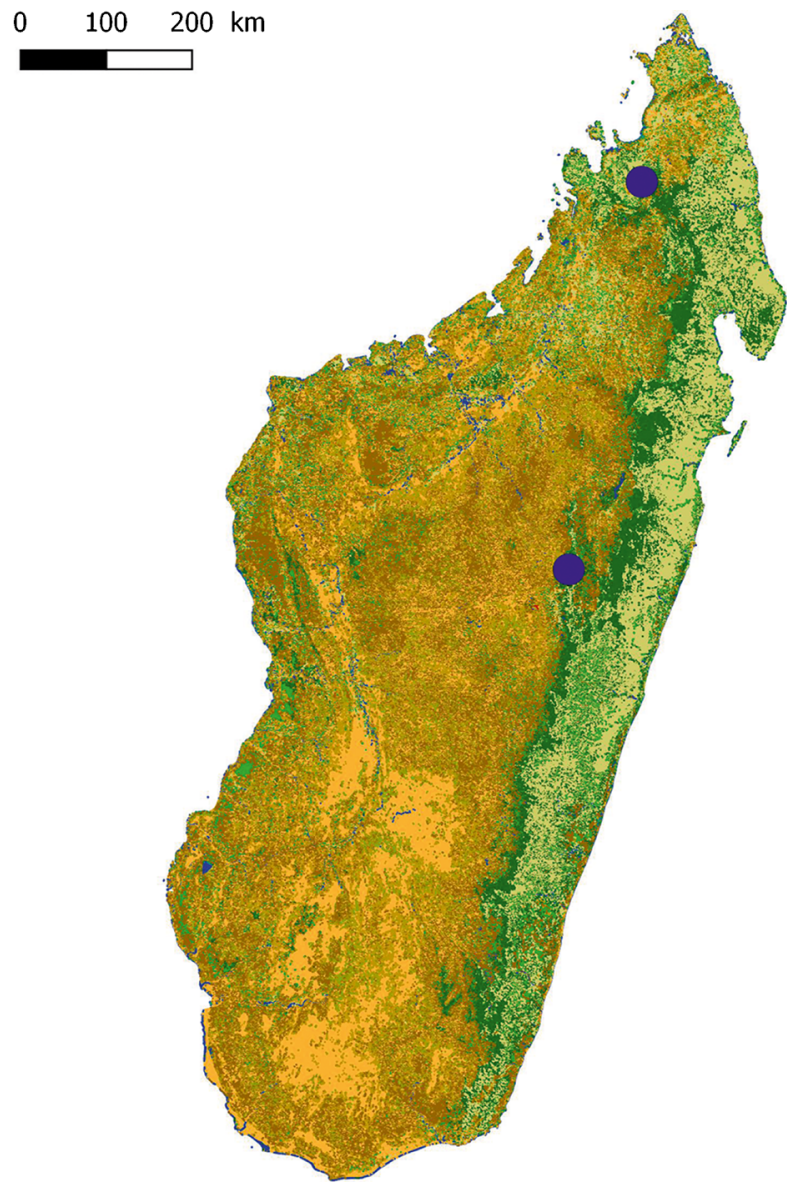

Map 16. Distribution of Liparis cladophylax.

ETYMOLOGY. Possibly referring to the dominant leaves or to the epiphytic habit of the species.

NOTES. The holotype, collected as Perrier 139, was then changed to Perrier 11360 and is lodged in Paris; this is sometimes cited as an isotype but it is clearly marked as Schlechter's type as used for the protologue and should therefore be considered the holotype of the species, especially as any other of Schlechter's material would be likely to have been destroyed in Berlin.

ILLUSTRATIONS. Schlechter (1932: t. 52).

Liparis clareae Hermans (in Hermans et al. 2007: 216); Cribb \& Hermans (2009: 146); Hervouet (2018: 406). Type: Madagascar, Mandraka Gorge, François in herb. Perrier 17797 (holotype P).

Liparis cardiophylla H.Perrier (1936: 244), non Ames (1908: 92); Perrier (1939: 268). Type as above.

Medium-sized epiphytic or terrestrial plant up to $18 \mathrm{~cm}$ tall, roots white c. $1.2 \mathrm{~mm}$ diam. Plant on a short linear rhizome, rhizome c. $5 \mathrm{~mm}$ diam., covered in fibrous sheaths, roots somewhat woolly. Pseudobulbs fleshy, $4-$ $11 \mathrm{~cm} \times 3-7 \mathrm{~mm}$, enveloped by $2-3$ papery sheaths, carrying a single leaf. Leaf more or less fleshy, persistent on the older pseudobulbs, broadly ovatecordate, acute, auriculate-imbricate at the base, blade leathery and rigid, green to blueish green, paler underneath, with several veins but mid-vein not prominent, especially in the living plant, $5.5-10 \times 4$ - $5.6 \mathrm{~cm}$. Inflorescence up to $20 \mathrm{~cm}$ long, erect to arching from the apex of the pseudobulb, carrying up to 10 flowers but generally fewer. Peduncle enveloped at the base by a single whitish sheath and $1-2$ bractlike sheaths similar to the floral bracts higher up. Rachis laxly flowered, successive along its length. Floral bracts cordate, a little shorter than the pedicellate ovary, $5-7 \times 1.5-2.1 \mathrm{~mm}$. Flowers large, overall $18 \times$ $15 \mathrm{~mm}$, olive green, the lip darker with a glossy dark green raised area from the base to the middle, column white, anther pale yellow, pollinia yellow, flowers turning yellow-orange with age, flower buds gibbose on each side of the base. Pedicel and ovary glabrous, round, $9-12 \times 6-7 \mathrm{~mm}$. Dorsal sepal lanceolate, subacute, narrowing towards the base faintly 3-veined, $6.5-11 \times 1.25-2.5 \mathrm{~m}$. Lateral sepals oblong to oval, obtuse $6-9.1 \times 2.2-4 \mathrm{~mm}$. Petals linear, $7-13 \times 0.4-$ $0.9 \mathrm{~mm}$. Lip ovate to sub-rectangular, base narrowed auriculate, the anterior margin denticulate, spreading into the margins, without a distinct callus but a swollen base spreading into the centre, $6.2-8.9 \times 4.1-7.6$ $\mathrm{mm}$. Column arched, $2.5-4.2 \times 1-1.5 \mathrm{~mm}$, with obtuse expanded wings towards the apex just below the rostellum. Anther with a distinct subacute beak almost as long as the anther chamber, $1.1-1.8 \times 0.7-$ $1.1 \mathrm{~mm}$. Pollinia one to rarely two per chamber, oval, $0.3-0.6 \times 0.2-0.5 \mathrm{~mm}$.

RECOGNITION. A medium-sized plant with a linear rachis and fleshy pseudobulbs and leaf. The leaf is flat, single, broadly ovate and clearly cordate at the base, the mid-vein is indistinct, the floral bracts cordate, and the flowers large for the genus, with an ovate to subrectangular lip with an indistinct callus, a column with rounded wings and an anther cap with a long sub-acute beak. It is long and successively flowering.

Liparis clarae is similar to $L$. warpurii but differs by the distinct habit with a short linear rachis (a longer scrambling habit in $L$. warpurii where new growths emerge from the lower nodes of the previous pseudobulb), the wider, flatter, heart-shaped leaf without a distinct central vein, cordate floral bracts and larger and more numerous flowers. As shown in Table 8 , it has similarities with several other species, including $L$. magnifica, described below but $L$. clareae is around three times the size in both plant and flower size and its callus is indistinct (vs bidentate). It is related to $L$. laurentii, described below, but the plant of $L$. laurentii is smaller, the leaf has a more distinct central vein and the base is rounded (vs cordate), it has $1-5$ flowers (vs $6-12$ ), the transversely elliptic or 
Table 8. Comparison of the larger single-leaved species: Liparis clareae, L. laurentii, L. magnifica, L. superclareae and L. warpuri, floral parts based on average measurements.

\begin{tabular}{|c|c|c|c|c|c|}
\hline & L. clareae & L. laurentii & L. magnifica & L. superclareae & L. warpurii \\
\hline Rhizome & $\begin{array}{l}\text { short to medium, } \\
\text { straight }\end{array}$ & short, ascending & short, ascending & short, ascending & $\begin{array}{l}\text { short to long, } \\
\text { scrambling }\end{array}$ \\
\hline Pseudobulbs shape & erect, thin & erect, thin, short & erect & erect & $\begin{array}{l}\text { sometimes from } \\
\text { internode of previous } \\
\text { bulb }\end{array}$ \\
\hline $\begin{array}{l}\text { Pseudobulbs } \\
\quad \text { size }(\mathrm{cm})\end{array}$ & $4-11$ & c. 2 & $2-5$ & $5-9.5$ & $3-5$ \\
\hline Sheaths & few, papery & $\begin{array}{l}\text { covering } \\
\text { pseudobulb }\end{array}$ & $\begin{array}{l}\text { almost covering } \\
\text { pseudobulb, } \\
\text { papery }\end{array}$ & $\begin{array}{l}\text { almost covering } \\
\text { pseudobulb, with } \\
\text { brown specks }\end{array}$ & $\begin{array}{l}\text { almost covering } \\
\text { pseudobulb, papery }\end{array}$ \\
\hline Leaf shape/colour & $\begin{array}{l}\text { ovate, flat } \\
\text { mid-vein } \\
\text { indistinct, green }\end{array}$ & broadly ovate, green & $\begin{array}{l}\text { lanceolate, with } \\
\text { silvery } \\
\text { markings }\end{array}$ & $\begin{array}{l}\text { lanceolate, } \\
\text { strongly veined }\end{array}$ & $\begin{array}{l}\text { lanceolate, distinct } \\
\text { mid-vein, sometimes } \\
\text { silvery }\end{array}$ \\
\hline Leaf size $(\mathrm{cm})$ & $7 \times 4.5$ & $5 \times 3$ & $4 \times 1.5$ & $10.5 \times 3.5$ & $5 \times 2$ \\
\hline Flowers (number) & $4-10$ & $1-5$ & $1-5$ & $4-7$ & $2-4$ \\
\hline Floral bract shape & cordate, & $\begin{array}{c}\text { lanceolate - } \\
\text { cordate, }\end{array}$ & lanceolate, & slender, & cordate, \\
\hline $\begin{array}{l}\text { Floral bract } \\
\text { size }(\mathrm{mm})\end{array}$ & $6 \times 1.8$ & $5 \times 1.5$ & $4.5 \times 1.5$ & $8 \times 1.5$ & $7 \times 2.5$ \\
\hline Dorsal sepal (mm) & $8 \times 1.5$ & $8 \times 1.5$ & $7.5 \times 1.5$ & $17 \times 1.6$ & $9.5 \times 1$ \\
\hline Lateral sepal (mm) & $8 \times 2.5$ & $6.5 \times 5$ & $6 \times 2.7$ & $17 \times 5.5$ & $9.5 \times 3.5$ \\
\hline Petal $(\mathrm{mm})$ & $9 \times 0.6$ & $8 \times 0.4$ & $7.5 \times 0.3$ & $18 \times 0.7$ & $8.5 \times 0.5$ \\
\hline Lip size $(\mathrm{mm})$ & $7 \times 6$ & $5 \times 6.5$ & $5.5 \times 4.4$ & $16 \times 11$ & $8.5 \times 7.5$ \\
\hline Lip shape & $\begin{array}{l}\text { ovate to } \\
\text { subrectangular, } \\
\text { margin } \\
\text { denticulate }\end{array}$ & $\begin{array}{l}\text { transversely } \\
\text { elliptic } \\
\text { to reniform, } \\
\text { emarginated, } \\
\text { margin } \\
\text { entire }\end{array}$ & $\begin{array}{l}\text { obovate, anterior } \\
\text { margin } \\
\text { undulate }\end{array}$ & $\begin{array}{l}\text { angular, } \\
\text { margin } \\
\text { dentate }\end{array}$ & margin slightly serrate \\
\hline Lip callus & indistinct swelling & two, horn-like & $\begin{array}{l}\text { shortly } \\
\text { bi-dentate }\end{array}$ & slight swelling & angular bilobed \\
\hline Anther & $\begin{array}{l}\text { long subacute } \\
\text { beak }\end{array}$ & long sharp beak & short sharp beak & $\begin{array}{l}\text { long sharp } \\
\text { beak }\end{array}$ & short obtuse beak \\
\hline Distribution & $\begin{array}{l}\text { Madagascar: N, } \\
\text { Central and E }\end{array}$ & Madagascar: NE & Madagascar: E & $\begin{array}{l}\text { Madagascar: } \\
\text { NE }\end{array}$ & $\begin{array}{l}\text { Madagascar: } \\
\text { E - Central }\end{array}$ \\
\hline
\end{tabular}

reniform lip is much wider (vs ovate), the margins are not serrate, the anterior margin is emarginate (vs entire), the basal calli consisting of horn-like calli (vs slight swellings) and the column wings are elongate (vs short and obtuse). It is also close to L. superclareae, described below, with which it shares its general habit and lip shape but $L$. superclareae has much longer pseudobulbs, the leaves of the previous growth disintegrate before the new ones develop (vs persistent), the leaves are lanceolate (vs ovate) and at least $2.5-3$ times longer than wide (vs 2 times), the floral bracts are less cordate at the base, the flowers and all its segments much larger, the column shorter with broad long wings (vs short-auriculate) and the anther more sharply beaked (Table 8).

DISTRIBUTION. Endemic and widespread in Madagascar: Antananarivo, Antsiranana, Fianarantsoa, Mahajanga \& Toamasina provinces (Map 17).

SPECIMENS EXAMINED. MADAGASCAR. N \& C, 1899, Warpur s.n. (K); Mandraka Gorge, François in herb. Perrier 17797 (holotype P); RN 1, Betampona, evergreen forest, Sept. 1963, Bosser 17226 (P); Antananari- vo, NW of Ambohitsaratelo-Bebao; c. $1200 \mathrm{~m}$, Jan. 1985, Barnett et al. 377 (MO, P, TAN); Majunga province, c. $16 \mathrm{~km} \mathrm{NW}$ of Ambohitsaratelo-Bebao, Jan. 1985, Barnett et al. 3484 (MO, P, TAN); Majunga, $15.4 \mathrm{~km} \mathrm{NW}$ of Ambohitsaratelo-Bebao, Jan. 1985, Barnett et al. 3510 also as Dorr et al. 3510 (K, MO, P, TAN); Toamasina, Masoala Peninsula, E of Ambanizana, May 1989, Schatz et al. 2717 (K, MO, P, TAN); Masoala peninsula, Ambanizana, $600 \mathrm{~m}$, June 1993, Zjhra E Hutcheon 331 (K, TAN); NE, Masoala Peninsula, W coast, May 1994, Lance 109 (K); Antsiranana, towards Anjanaharibe, 1994, Hermans 6542 (K): Fianarantsoa, Ranomafana area, 2001, 1095 m, Hermans 5215 \& 6677 (K); Antsiranana, Ambilobe, Beramanja, 617 m, Feb. 2005, Wohlhauser et al. 747 (P); Maroantsetra, Ambinanitelo, 224 m, May 2007, Ranarivelo 680 (K); Antsiranana, Bongomihiravavy forest, 700 m, Nov. 2007, Nusbaumer LN2558 (G); Antsiranana, Mt d'Ambre, 800 m, May 2008, Razanajatovo et al. MHR143 (G, P); Antsiranana, Mt d'Ambre, 833 m, April 2008, Ramandimbimanana 516 (G, P); Antsiranana, Mt d'Ambre, 1070 m, April 2008, 
$0 \quad 100 \quad 200 \mathrm{~km}$
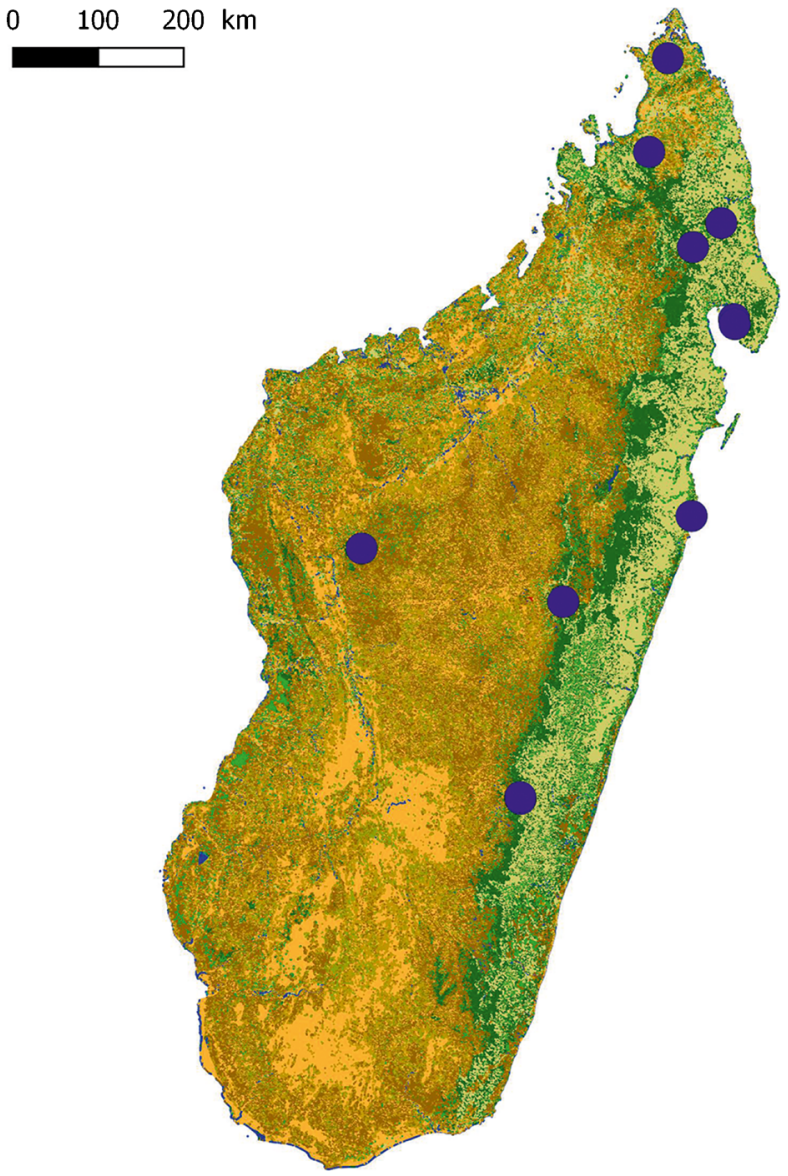

Map 17. Distribution of Liparis clareae.

Ramandimbimanana et al. SDR 049 (G); Mt d'Ambre, 920 m, 2012, Ramandimbimanana 479 (G, P); Saloka, 980 m, 2016, Hermans 8065 (K, WU).

HABITAT. Evergreen forest, moss-forest, on moss or moss-covered trees. Altitude: $600-1500$ m.

CONSERVATION STATUS. Category EN: the extent of occurrence (EOO) of Liparis clareae is estimated to be $217,057 \mathrm{~km}^{2}$ (far exceeding the limits for Vulnerable status under criterion B1) whereas its minimal area of occupancy (AOO) is estimated to be $44 \mathrm{~km}^{2}$ (which falls within the limits for Endangered status under the criterion B2). This species is known from nine subpopulations representing 10 locations (sensu IUCN), and has thus been preliminarily assessed as EN using the green listing method. This species is threatened by selective logging, timber harvesting for small-scale subsistence and tavy (slash-and-burn farming), resulting in habitat reduction and habitat quality reduction.

FLOWERING TIME. January to May.

ETYMOLOGY. The original name given by Perrier refers to the heart-shaped leaf, the name now refers to 'bright-shining' and to Clare Hermans.

NOTES. The species was first described by Perrier in his monograph on the Liparidinae of Madagascar in 1936, based on a specimen collected by Edmond François in the Mandraka Gorge. There is an earlier use of Liparis cardiophylla Ames (1908: 92), based on a plant from Jamaica that precludes the use of this name for the Madagascan plant, it was therefore named L. clareae in 2007 (Hermans et al. 2007: 216). Liparis cardiophylla var. angustifolia H.Perrier ex Hermans (in Hermans et al. 2007: 289) was described by Perrier in 1936 as a tentative variety of the species, it is only known from the type specimen which corresponds well with the characteristics of $L$. warpurii and is included and discussed under this species.

Perrier, in his description, noted that single pollinia were found in each of the two anther chambers in the type, this peculiarity seems to vary between specimens with some showing the normal two pollinia per chamber.

ILLUSTRATIONS. Fig. 16; Hermans et al. (2007: pl.45); Cribb \& Hermans (2009: 147); Hervouet (2018: 406).

Liparis danguyana H.Perrier (1936: 248; 1939: 274); Hermans et al. (2007: 217); Cribb \& Hermans (2009: 148); Bosser \& Lecoufle (2011: 406). Type: Madagascar, Mt Angavokely, E of Antananarivo, Perrier 16064 (holotype P).

Medium-sized, erect terrestrial or epiphytic plant, 11 $18 \mathrm{~cm}$, rhizome ascending, c. $5 \mathrm{~mm}$ diam., roots fibrous, wiry. Pseudobulbs $1-2 \mathrm{~cm}$ apart, stem-like, 7 $12 \mathrm{~cm} \times 1.5-5 \mathrm{~mm}$ diam., carrying two leaves at the apex, enveloped by $5-8$ scarious sheaths. Leaves dark green, broadly oval, subsessile, shortly acute at the apex, rounded at the base, petiole c. $8 \times 1.5 \mathrm{~mm}$, blade strongly veined, $2.4-4.5 \times 1.8-3 \mathrm{~cm}$. Inflorescence up to $7 \mathrm{~cm}$ long. Peduncle with $3-4$ bract-like sheaths. Rachis erect, subdensely 4 - 12-flowered. Floral bracts acute, about $1 /{ }_{3}$ of the length of the pedicellate ovary, $4 \times 2.1 \mathrm{~mm}$. Flowers small, c. $6 \times 8 \mathrm{~mm}$, green. Pedicel and ovary $8-9 \times 0.8-1.8 \mathrm{~mm}$, faintly winged. Dorsal sepal lanceolate, not auriculate at the base, $7-10 \times 1.2$ - $2 \mathrm{~mm}$. Lateral sepals semi-oval, rolled below the lip, $5.5-7 \times 3-3.5 \mathrm{~mm}$. Petals linear, 3-veined at the base, $7.5-10 \times 0.8-1.2 \mathrm{~mm}$. Lip ovate to orbicular, obscurely veined, the basal wings obtuse and divaricate, slightly attenuate at the anterior margin, with 2 small but distinct rounded calli at the base, $6-6.5 \times 4$ - $5.5 \mathrm{~mm}$. Column curved at the apex, $4-4 \times 1 \mathrm{~mm}$, wings thin and small. Anther suborbicular, very rounded at the front, $1-2$ pollinia per chamber, $1 \times 0.8$ mm. Pollinia ovate, c. $0.2 \mathrm{~mm}$ diam.

RECOGNITION. Distinct by its long and thin stem, with two broadly oval leaves, an ovate to orbicular lip with two indistinct calli at the base and a short apicule at the anterior margin and its suborbicular, rounded anther cap. 

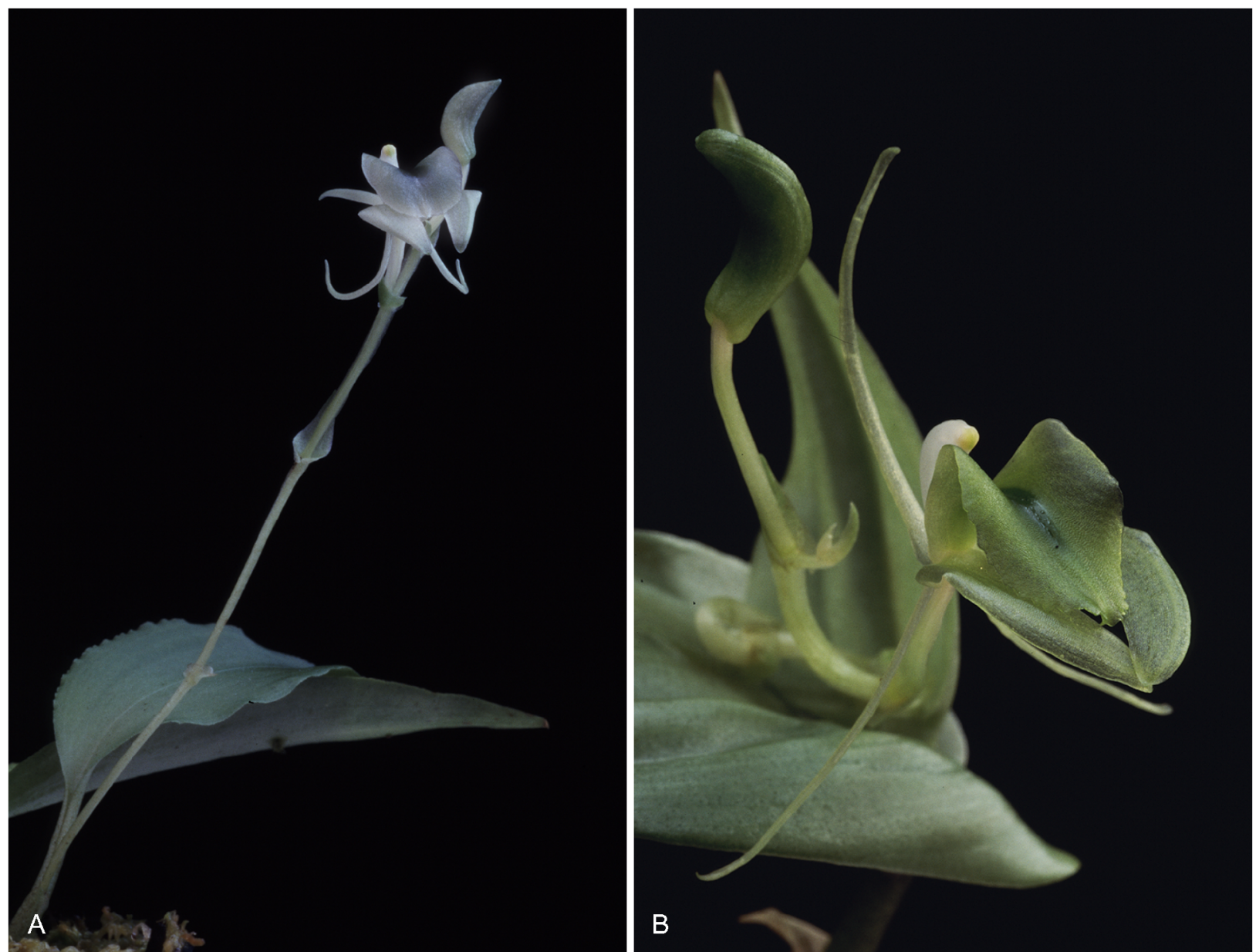

Fig. 16. Liparis clareae. A habit; B flower. PHOTOS: JOHAN HERMANS.

Margonska (2009: 97) mistakenly considered this species to be conspecific with Liparis bernieri. As shown in Table 5, there are a number of superficially similar species with an equally long fleshy stem and two leaves from the area, including: L. bernieri from Réunion and $L$. danguyana and $L$. listeroides from Madagascar but there are substantial differences: The leaves of $L$. danguyana are thinner in texture and have a more cordate base than those of $L$. bernieri and $L$. listeroides which are more leathery and have indistinct veins, the leaf shape of L. listeroides is oval petiolate vs broadly oval and sessile. The flowers of $L$. listeroides are generally smaller than the other two. The lip of $L$. danguyana has two small but distinct calli at the base, that of $L$. bermieri is cushion-like, those of $L$. listeroides are long and tooth-like, the anterior margin of $L$. danguyana is apiculate at the anterior margin, the others have a more or less denticulatesinuate margin. The anther of $L$. danguyana is rounded at the front and suborbicular, that of $L$. listeroides is slightly beaked. Considering these differences and specific geographical distribution it is correct to recognise all three species (Table 5).
DISTRIBUTION. Endemic to Madagascar, until recently known from the type locality of Angavokely in Antananarivo province only. It has now also been recorded from Ambondrombe in Fianarantsoa prov. (J.-M. Hervouet pers. comm.) (Map 18).

SPECIMENS EXAMINED. MADAGASCAR. Madagascar, Mt Angavokely (E of Antananarivo), Perrier 16064 (holotype P); Antananario, Angavokely forest reserve, March 1992, Pettersson $\mathcal{E}$ Nilsson 563 (P); Manjakandriana distr., SE of Nandihizana, Angavokely forest reserve, $1600 \mathrm{~m}$, March 1992, Pettersson E Nilsson 586 (P, UPS).

HABITAT. Moss forest, on moss and lichen-covered trees. Altitude: $1600-1800 \mathrm{~m}$.

CONSERVATION STATUS. Category CR: the extent of occurrence (EOO) of Liparis danguyana cannot be estimated since it is only known from one remaining subpopulation whereas its minimal area of occupancy (AOO) is estimated to be $4 \mathrm{~km}^{2}$ (which falls within the limits for Critically Endangered status under the criterion B2). Liparis danguyana is only known from one subpopulation representing one location (sensu IUCN), this rare species has thus been preliminarily 

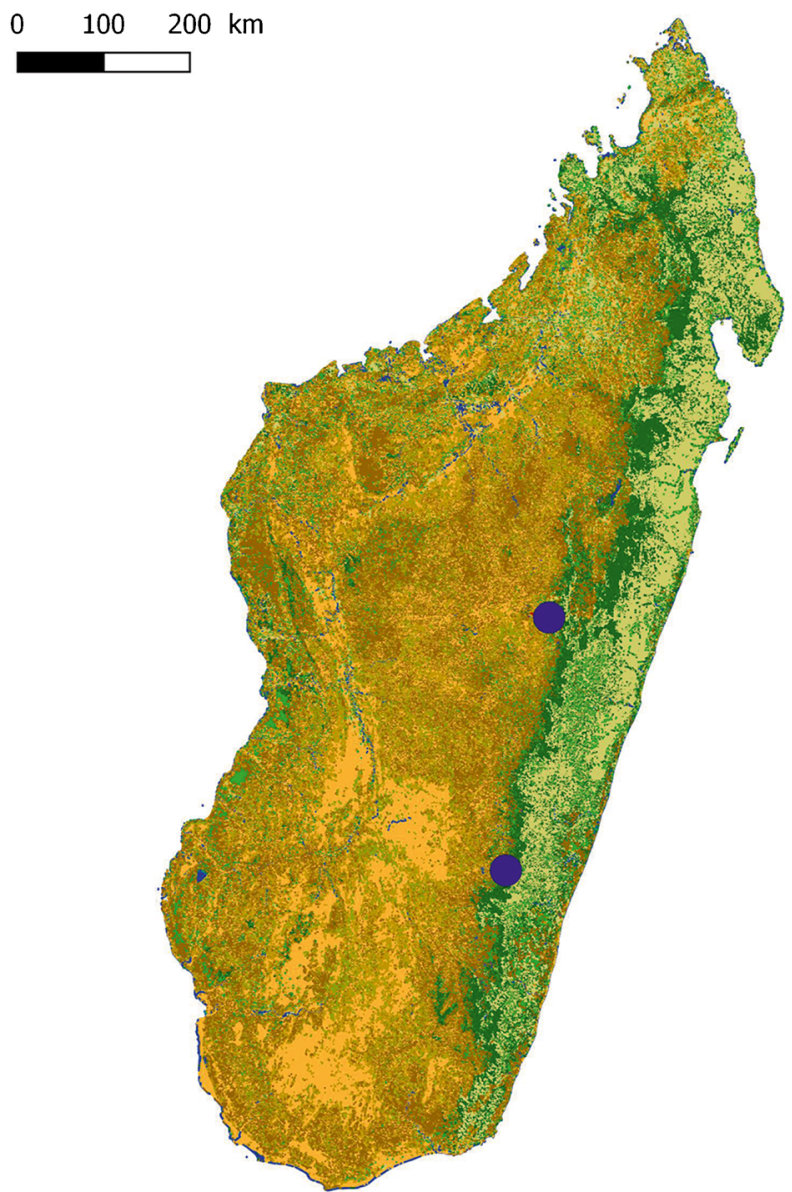

Map 18. Distribution of Liparis danguyana.

assessed as CR using the green listing method. This species is threatened by selective logging, timber harvesting for small-scale subsistence and tavy (slashand-burn farming), resulting in habitat reduction and habitat quality reduction. The type locality now has only remnants of forest and little surrounding habitat. FLOWERING TIME. February to March.

ETYMOLOGY. The name refers to Paul Auguste Danguy (1862 - 1942) who worked with Humbert and Perrier and later became deputy director of the Laboratoire de Phanérogamie at the Paris Museum, France.

ILLUSTRATIONS. Figs 17, 18; the plant labelled as Liparis danguyana in Bosser \& Lecoufle (2011: 406) is not this species and resembles $L$. imerinensis.

Liparis densa Schltr. (Schlechter 1924: 137); Perrier (1939: 281); Hermans et al. (2007: 217); Cribb \& Hermans (2009: 152); Hervouet (2018: 408). Type: Madagascar, Andringitra massif, Perrier 14358 (P00094972) (lectotype P, designated here; isolectotype Perrier 14358 (P00094973) P).

Small, compact, erect terrestrial or lithophytic plant, $10-15 \mathrm{~cm}$ tall, rhizome very short, roots wiry, glabrous. Pseudobulbs oblong, almost completely submerged in soil and humus, 2-edged, compressed, 2 $3 \times 1.2-1.4 \mathrm{~cm}$, watery, turning into pulp under finger pressure, carrying $2-5$ leaves, the base enveloping the pseudobulbs. Leaves erectly to suberectly spreading, oblong-ligulate, acute or somewhat obtuse, a little fleshy, $6-8 \mathrm{~cm}$ long, $1.2-2.5 \mathrm{~cm}$ wide. Inflorescence up to $11 \mathrm{~cm}$ long, with none or one thin sheath towards the base, carrying up to 15 flowers. Peduncle ridged, up to $6 \mathrm{~cm}$, hardly longer than the leaf sheaths. Rachis densely flowered, cylindrical, much longer than the peduncle, up to $8 \mathrm{~cm}$ long, $1.7 \mathrm{~mm}$ diam. Floral bracts narrowly lanceolate, acuminate, the lower ones as long as the ovary or longer, the upper ones shorter, up to $10 \times 2.1 \mathrm{~mm}$. Flowers small, $10 \times 5$ $\mathrm{mm}$, uniformly pale yellow to yellow. Pedicel and ovary rounded, slightly ridged, $8 \times 0.8 \mathrm{~mm}$. Dorsal sepal erect, ligulate-lanceolate, obtuse, $6.5-8 \times 1-1.3 \mathrm{~mm}$. Lateral sepals subfalcate, oblong, obtuse, spreading, curled backwards, $4.8-5 \times 2.2-2.7 \mathrm{~mm}$. Petals erect or semierect, linear, somewhat obtuse, $6.5-8 \times 0.8-1 \mathrm{~mm}$. Lip distinctly geniculate, recurved, obovate-oblong, very obtuse, margins sub-crenulate, basal margins minutely triangular-auriculate, creating a deep gutter at the base, without a callus on the disk and base, $4.5-6 \times 2-3.7 \mathrm{~mm}$ when flattened. Column curved, wings small and rounded, $3-4 \times 1.2 \mathrm{~mm}$. Anther with a small triangular beak, $0.6 \times 0.7 \mathrm{~mm}$. Pollinia ovate, c. $0.2 \mathrm{~mm}$ diam.

RECOGNITION. The species is distinct by the compact plant and inflorescence with the rachis longer than the peduncle, the semi-erect petals and the kneeshaped lip without a callus. Schlechter pointed out in his description that this species is related to Liparis capensis Lindl. (Lindley 1840: 314) known from the Western and Eastern Cape of South Africa. Although related, plants of $L$. capensis are generally shorter, normally have two narrower leaves, flowers about $1 / 4$ smaller, a slightly different lip (elliptic vs obovate) with a small conical callus at its base vs ecallose. There are similarities in plant habit to L. bathiei but the flowers are almost double the size, the lip is obovate vs ovallozenge shaped and the anther is triangular vs rounded. In plant habit it is similar to L. bicornis but the flowers are very different with the lip obovate vs ovate-obcuneate and without callus at the base vs distinctly two-horned. It is closest to L. lutea and they could well be the same species but the pseudobulbs are longer, the leaves bigger, the inflorescence and rachis more compact and the flower segments a little larger. Due to the limited nature of the type material of $L$. lutea it is impossible to effectively compare the two species.

DISTRIBUTION. Endemic to Madagascar: Fianarantsoa, in the Andringitra massif and Toliara province in the Andohahela massif, at a similar altitude but several hundred km South from the type locality (Map 19). 

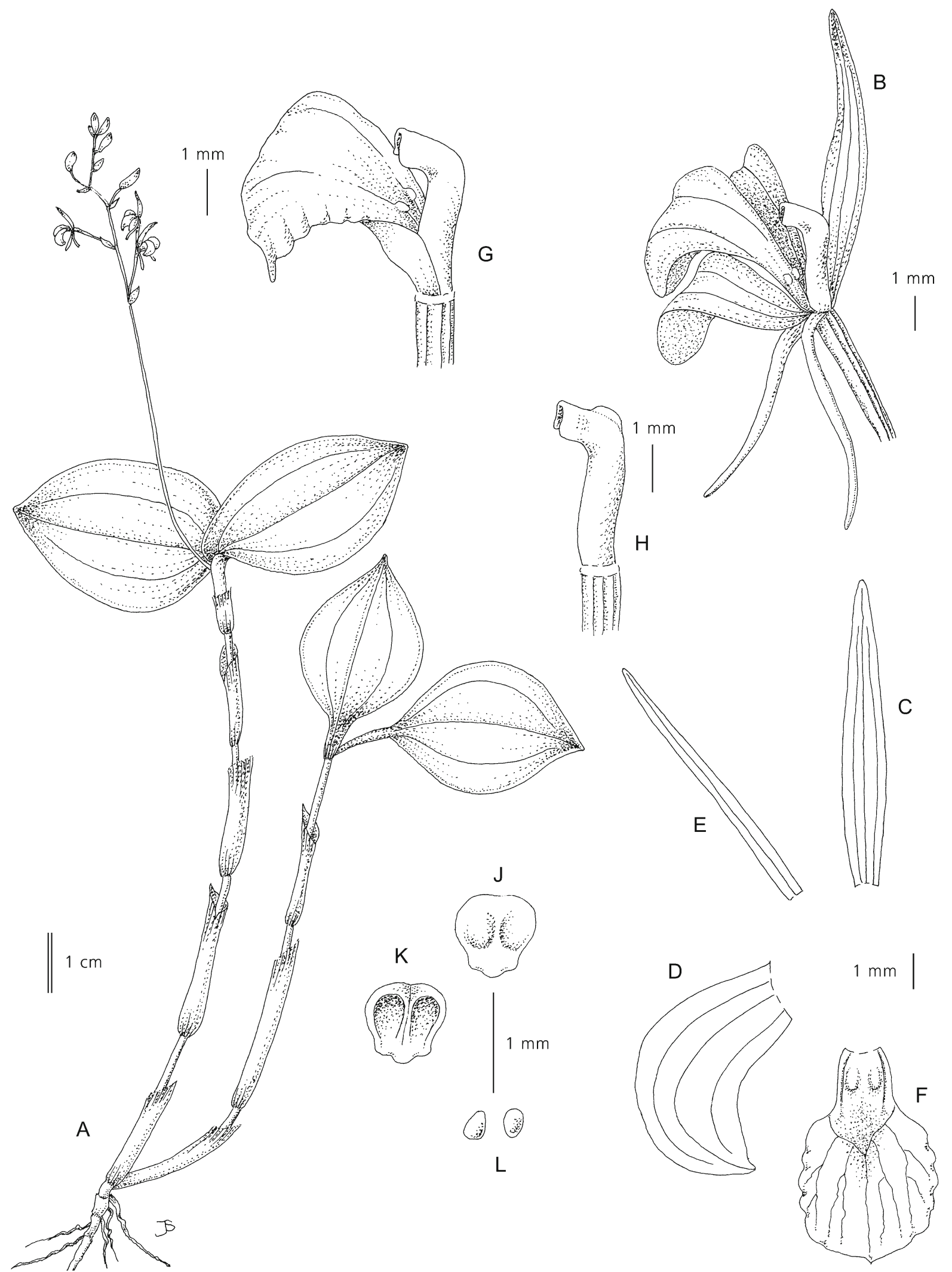

Fig. 17. Liparis danguyana. A habit; B flower; C dorsal sepal; D lateral sepal; E petal; F lip; G column and lip, side view; H column, anther cap removed; J anther cap, dorsal view; K anther cap, ventral view; L pollinia. From Perrier 16064 (P). DRAWN BY JUDI STONE. 


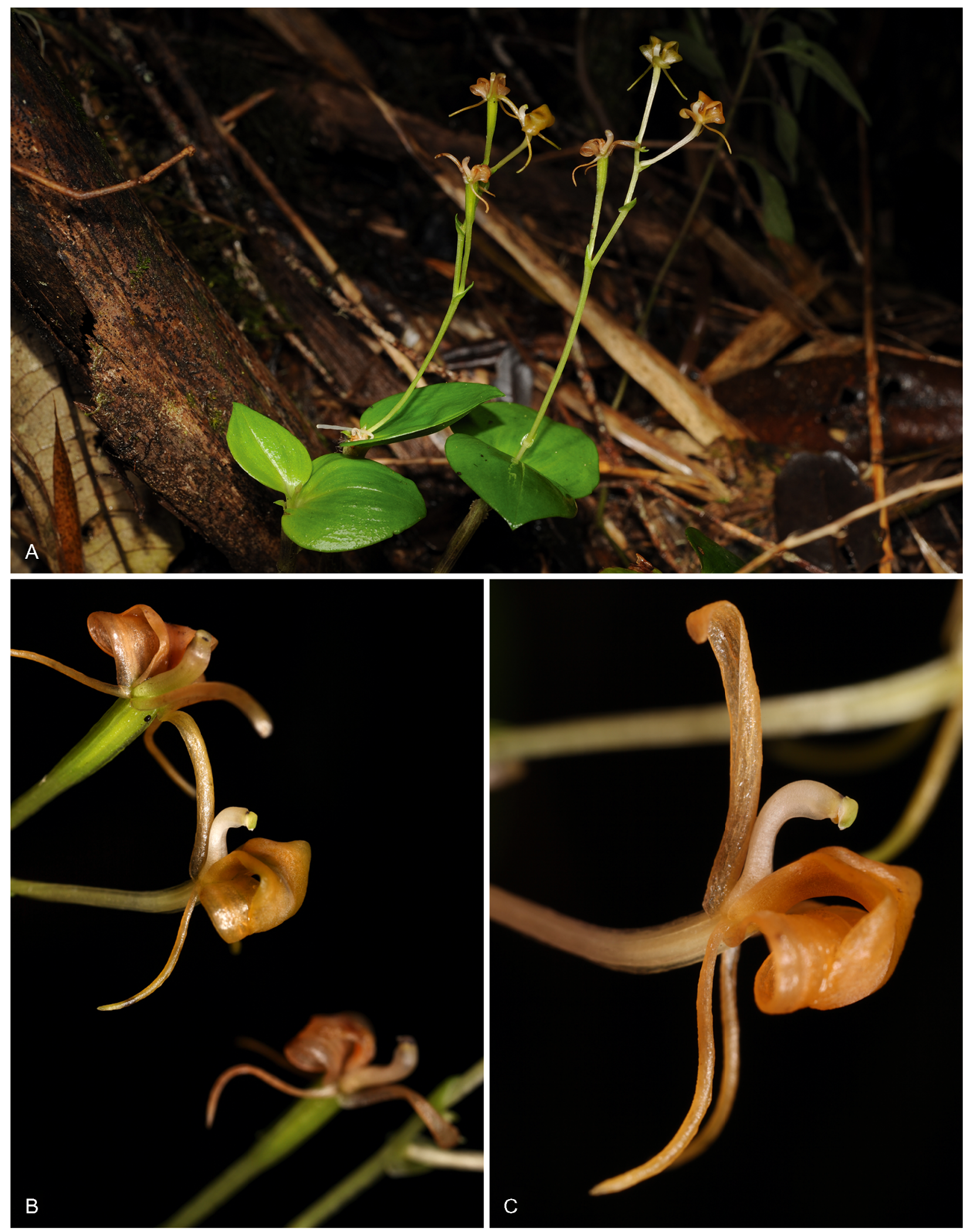

Fig. 18. Liparis danguyana. A plant habit; B flowers; C flower detail. PHOTOS: JEAN-MICHEL HERVOUET.

SPECIMENS EXAMINED. MADAGASCAR. Ankeramadinika, Nov. 1885, Fox 78 (K ex LDS); Andringitra massif,
Perrier 14358 (P00094972) (lectotype P); Perrier 14358 (P00094973) (isolectotype P); Andohahela massif, high 

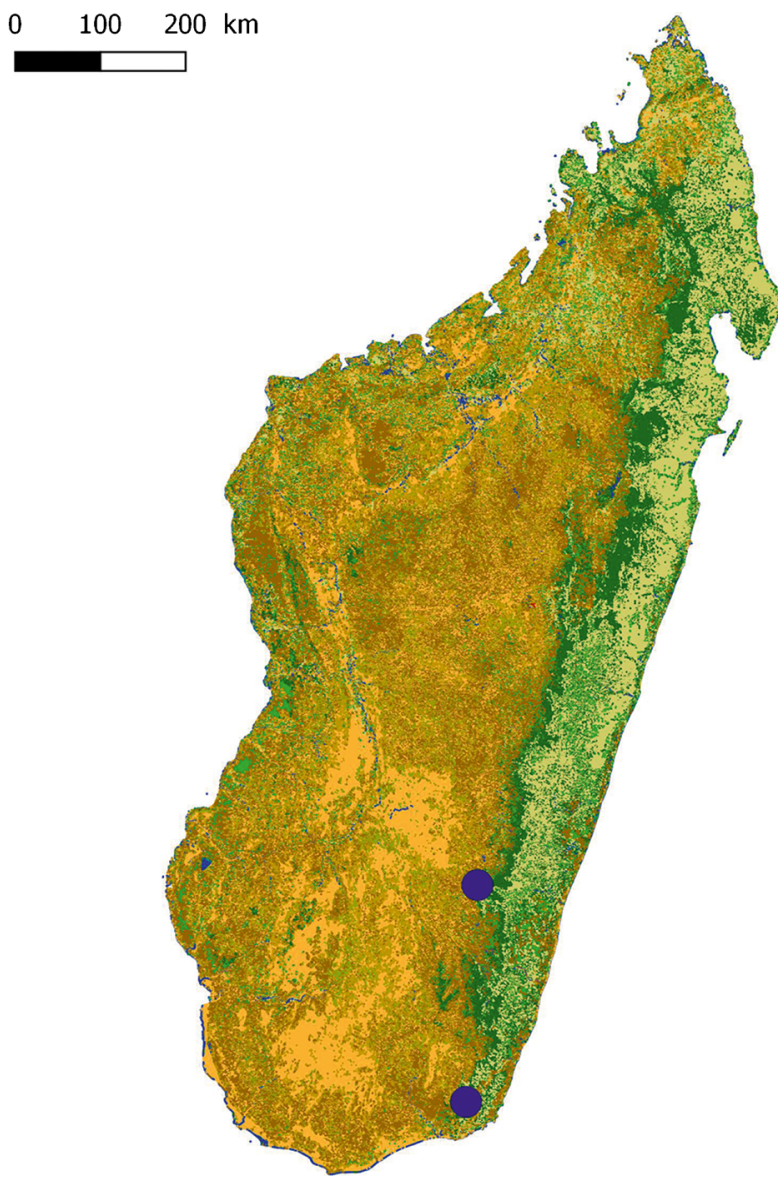

Map 19. Distribution of Liparis densa.

valley of the Sakamalio evergreen forest, $1500-1900$ m, Jan. 1934, Humbert 13559 (P); Andohahela Massif, RN11, Jan. 1974, Morat 4404 (P); Andohahela area, 1999, Hermans 2884 (K).

HABITAT. Terrestrial or lithophyte on shaded and humid rocks, partly submerged in humus. Altitude: c. $2400 \mathrm{~m}$.

CONSERVATION STATUS. Category EN: the extent of occurrence (EOO) of Liparis densa cannot be estimated since it is only known from two subpopulations whereas its minimal area of occupancy (AOO) is estimated to be 4 $\mathrm{km}^{2}$ (which falls within the limits for Critically Endangered status under the criterion B2). Liparis densa is only known from two subpopulations representing two locations (sensu IUCN), this rare species has thus been preliminarily assessed as EN using the green listing method. This species is threatened by selective logging, timber harvesting for small-scale subsistence and tavy (slash-and-burn farming), resulting in habitat reduction and habitat quality reduction.

FLOWERING TIME. January.

ETYMOLOGY. Presumably refers to the compact habit of plant and inflorescence.

NOTES. The species was first collected by Perrier in the Andringitra Massif in SE Madagascar in 1922. It was described by Schlechter in Germany two years later and the type specimens were returned to Paris. There are two herbarium sheets of Perrier 14358 in P marked as 'type': the sheet with barcode P00094972 is the most complete with characteristic clumps of plants and is therefore chosen here as the lectotype, with sheet P00094972 being the isolectotype.

Humbert 13559 shows some differences from the type, as noted by Perrier: its pseudobulb and leafshape are similar, but its lip is a little larger and has a different shape but this is difficult to confirm in the dried specimens.

ILLUSTRATIONS. Figs 19, 20. Schlechter (1932: T.52); Perrier (1939: 283); Guérin \& Hervouet (2013: 326); Hervouet (2018: 408).

Liparis dryadum Schltr. (Schlechter 1924: 138); Perrier (1939: 278); Hermans et al. (2007: 218); Cribb \& Hermans (2009: 152). Type: Madagascar, Mt Tsaratanana, lichen forest, 1200 - 1600 m, Jan. 1923, Perrier 15245 (P00094977) (holotype P); Mt Tsaratanana, 1200 - 1600 m, Feb. 1923, Perrier 15245 (P00094978) (topotype P).

Platystyliparis dryadum (Schltr.) Margonska (2009: 94) synon. nov.

Very small, erect epiphytic plant, up to $6 \mathrm{~cm}$, forming small clumps, rhizome very short, roots rounded, filiform, glabrous, $1-2 \mathrm{~mm}$ diam. Pseudobulbs distinctly flattened-rounded, normally with $2-3$ leaves, $4-16 \times 8$ $-15 \mathrm{~mm}$, covered in degrading sheaths and the base of the lower leaf. Leaves lanceolate, erectly spreading, obtuse to subacute, more or less corrugate especially at the margins, a little narrowed at the base, forming a short petiole, overall $1.5-5.5 \times 0.4-2.1 \mathrm{~cm}$, the third one generally smaller. Inflorescence erect or arching, up to $9 \mathrm{~cm}$, laxly 3 - 30-flowered. Peduncle winged, barbellate, with one or two sheaths $4-6 \times 1-1.2 \mathrm{~mm}$. Rachis $3-4$ $\mathrm{cm}$, costate, with the lower flowers opening before the upper ones. Floral bracts lanceolate to ovate, rounded at the base, about the same size as the ovary, entire to dentate at the margins, $2.1-4.9 \times 1.8-2 \mathrm{~mm}$. Flowers very small, overall $5-8 \times 3-6 \mathrm{~mm}$, yellow-green to yellowbrown. Pedicel and ovary rounded, winged, distinctly echinate especially towards the base, $3-7 \times 0.3-0.8$ $\mathrm{mm}$. Dorsal sepal erect, lanceolate-ovate, obtuse, margins strongly recurved, $3-4.9 \times 0.9-1.9 \mathrm{~mm}$. Lateral sepals deflexed, obliquely-ovate, obtuse, $2.7-3.9 \times 1.4-2.5$ $\mathrm{mm}$. Petals deflexed, narrowly subfalcate-linear, obtuse, $3.1-3.7 \times 0.2-0.4 \mathrm{~mm}$. Lip curved, very broadly suborbicular-obtrapezoid, the anterior margin with a slightly obtuse apicule, emarginate, base broadly rounded truncate, at the base with a short bilobed rounded callus at the base, partly covered by a basal lobe, $1.9-2.8$ $\times 1.8-2.8 \mathrm{~mm}$. Column a little curved, the margins extended into a short acute triangle alongside the 


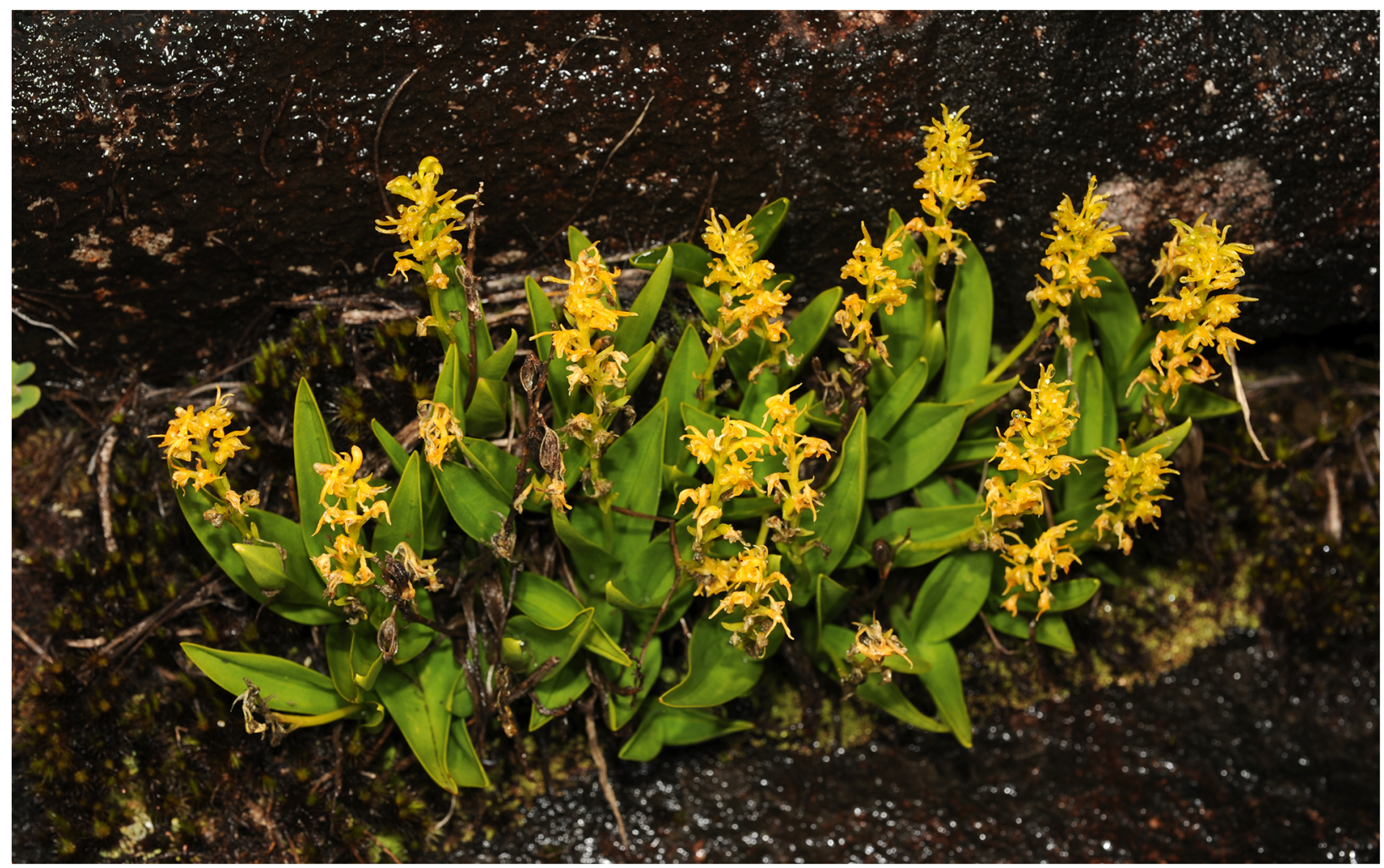

Fig. 19. Liparis densa. Plant habit. PHOtO: JeAN-MiCheL HeRVOUET.

stigmatic surface, $2-3.5 \times 0.8-1.3 \mathrm{~mm}$. Anther obtriangular with two ridges, c. $0.4 \mathrm{~mm}$ diam. Pollinia c. $0.3 \mathrm{~mm}$ diam.

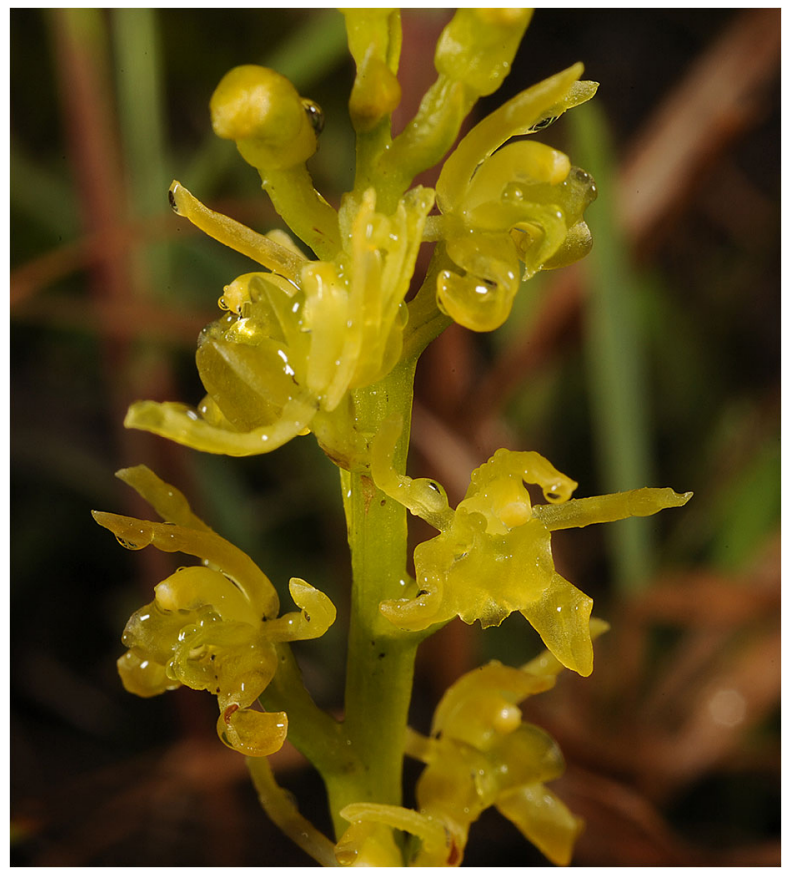

Fig. 20. Liparis densa. Rachis. PHOto: JeAN-MiCHEL HeRVOUET.
RECOGNITION. Liparis dryadum is one of the smallest species of the genus. The inflorescence is somewhat longer than the lanceolate leaves, of which it has two to three leaves with wavy margins and a short petiole. The lip disk has a short, bilobed callus at the base. The broadly inverse-trapezoid lip with rounded corners is also characteristic.

Liparis dryadum is similar to L. xanthina but the leaves are shorter and narrower, the differences in flower characteristics are difficult to ascertain with only Deans Cowan's rudimentary watercolour as evidence. It is somewhat different from L. cladophylax which has wider leaves that are not corrugate at the margins and an narrower lip with an ' $M$ ' shaped callus vs shortly bilobed. Schlechter mentioned a similarity with L. epiphytica Schltr. (Schlechter 1905b) from West Africa, but it is easily distinguished by being more than half the size both in plant and flower and a bilobed lip callus vs rectangular.

Perrier seems to have made another collection in the same locality one month after collecting the type specimen and gave it the same collection number. The later collection is a topotype of the species (P00094978). It is also possible that an error was made on the specimen labels. The species was re-classified as Platystyliparis dryadum (Schltr.) Marg. by Margonska in Richardiana (2009: 94) but there is no evidence or necessity for this. 
DISTRIBUTION. Endemic to Madagascar: Antsiranana, Fianarantsoa, Mahajanga, Toamasina Provinces (Map 20). Confusingly Perrier indicated 'Centre' on collection labels; the Tsaratanana mountain range is in Antsiranana province in Northern Madagascar. Szelengowicz \& Tamon (2013: 355); reported this species from Réunion but there is no evidence for this. Their description transcribes Perrier's original text and is accompanied by a fuzzy photograph of an unidentifiable plant.

SPECIMENS EXAMINED. MADAGASCAR. Mt Tsaratanana, 1200 - 1600 m, Jan. 1923, Perrier 15245 P00094977 (holotype P); Mt Tsaratanana, 1200 - 1600 m, Feb. 1923, Perrier 15245 P00094978 (topotype P); Mahajanga, NW of Ambohitsaratelo-Bebao, 1200 m, Jan. 1985, Barnett et al. 312 (MO, TAN); Mahajanga, NW of AmbohitsarateloBebao, NW of Tsiroanomandidy; c. 1200 m, Jan. 1985, Dorr et al. 3575 (K, MO, P, TAN); Antsiranana, Sava, Sambava, Beventro, Tsaratanana, 1143 m, Feb. 2007, Rakotovao et al. 3560 (K, MO); Toamasina, Andrangato R., March 2011, 660 m, Antilahimena 7578 (MO, TAN); Toamasina, Ankerana NE, 28 Jan. 2012, Ravelonarivo 4215 (TAN); Mahajanga, S of Bealanana, $1307 \mathrm{~m}$, Jan. 2018, Gamisch et al. SA7547 (WU); Fianarantsoa, Ranomafana area, Jan. 1992, 1130 m, Hermans 8285 (K).

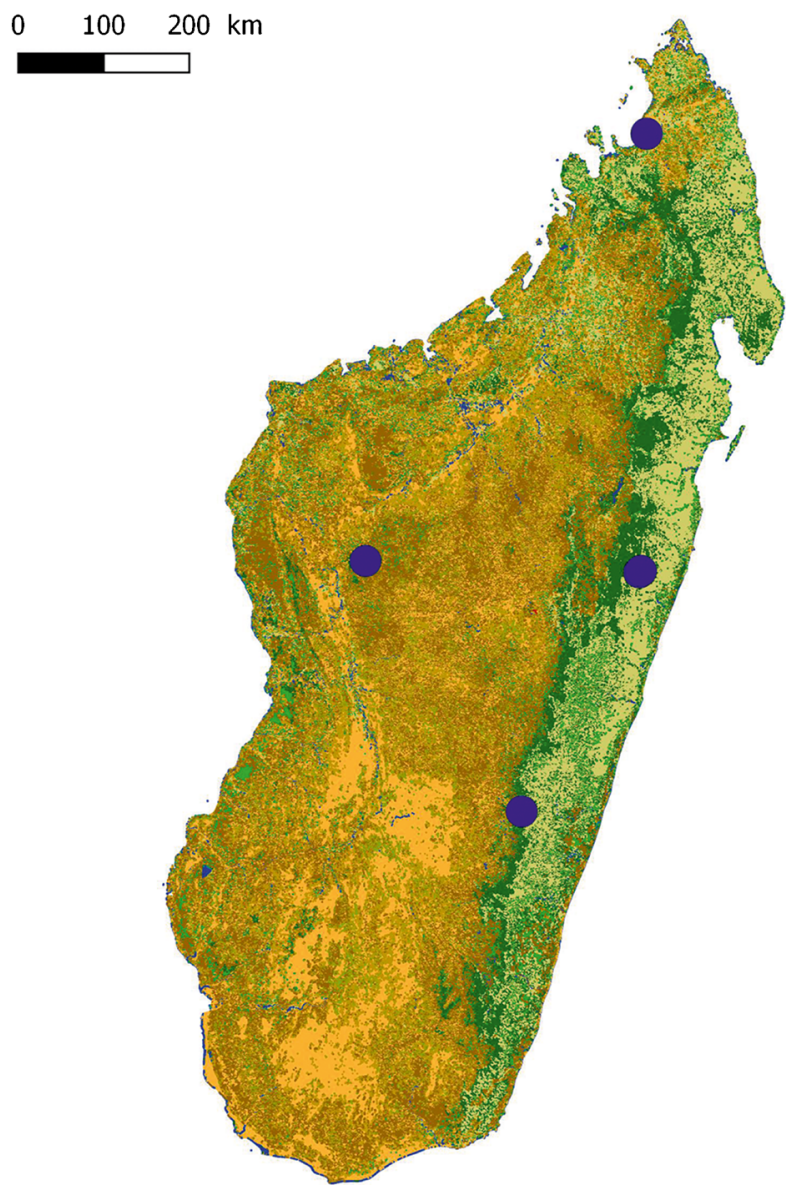

Map 20. Distribution of Liparis dryadum.
HABITAT. Epiphyte in lichen forest, or dense humid evergreen forest, moss and lichen-covered trees. Altitude: 660 - $1600 \mathrm{~m}$.

CONSERVATION STATUS. Category EN: the extent of occurrence (EOO) of Liparis dryadum is estimated to be $151,497 \mathrm{~km}^{2}$ (far exceeding the limits for Vulnerable status under criterion B1) whereas its minimal area of occupancy (AOO) is estimated to be $20 \mathrm{~km}^{2}$ (which falls within the limits for Endangered status under the criterion B2). With only four known subpopulations representing four locations (sensu IUCN), this species has been preliminarily assessed as EN using the green listing method. This species is threatened by selective logging, timber harvesting for small-scale subsistence and tavy (slash-and-burn farming), resulting in habitat reduction and habitat quality reduction.

FLOWERING TIME. January to March.

ETYMOLOGY. Referring to the Dryads, tree dwelling mythological nymphs.

ILlUStrations. Figs 21, 22; Perrier (1939: 283); Cribb \& Hermans (2009: 151).

Liparis flavescens (Thouars) Lindl. (Lindley 1825: sub t. 882); Moore in Baker (1877: 342); Ridley (1885: 460; 1886b: 271); Frappier in Cordemoy (1895: 185); Perrier (1936: 253; 1939: 287); Hermans et al. (2007: 218); Cribb \& Hermans (2009: 154); Bernet (2010a: 84); Robert (2019: 350). Type: s. loc., Thouars s.n. (P00112469) (holotype P).

Malaxis flavescens Thouars (1822: t. 25).

Leptorkis flavescens (Thouars) Kuntze (1891: 671).

Malaxis flexuosa nom. nud. in ms. herb. G, Neraud s.n.

Very small to small, terrestrial or epiphytic plant, squat, 6 - $11 \mathrm{~cm}$, rhizome very short, older pseudobulb leafless and porrect to horizontal, the flowering one erect, roots glabrous, thin and wiry. Pseudobulbs $1-5 \mathrm{~cm}, 8-19 \mathrm{~mm}$ diam., covered by membranous leaf sheaths, carrying $2-$ 4 erectly-spreading leaves but generally with 2 prominent leaves. Leaves lanceolate or ovate, acute, $5.6-6.5 \times$ $1.2-3.9 \mathrm{~cm}$, membranous, normally strongly 7-veined, pale green. Inflorescence erect up to $22 \mathrm{~cm}$ long but usually shorter, thin, laxly $2-15$-flowered in the upper half. Peduncle carrying $2-4$ ovate-lanceolate, acuminate peduncle sheaths, slightly auriculate at the base, $3.8-8 \times$ $2-3.1 \mathrm{~mm}$. Rachis laxly flowered, $5-8 \mathrm{~cm}$. Floral bracts ovate-lanceolate, acuminate, about $1 / 2$ the length of the pedicellate ovary, $2.5-5 \times 1.2-1.8 \mathrm{~mm}$. Flowers small to medium in size, av. $11 \times 8 \mathrm{~mm}$, greenish-yellow, turning orange with age, the disk of the lip darker green, column paler. Pedicel and ovary $5-11 \times 0.5-1.5 \mathrm{~mm}$, slightly ridged, rounded. Dorsal sepal linear-ligulate, margins recurved, $4.7-8.4 \times 0.9-1.8 \mathrm{~mm}$. Lateral sepals broadly oblong-falcate, obtuse, $4.8-8.1 \times 2.7-3 \mathrm{~mm}$. Petals linear $5.8-8 \times 0.3-0.9 \mathrm{~mm}$. Lip broadly ovate, sinuate to 


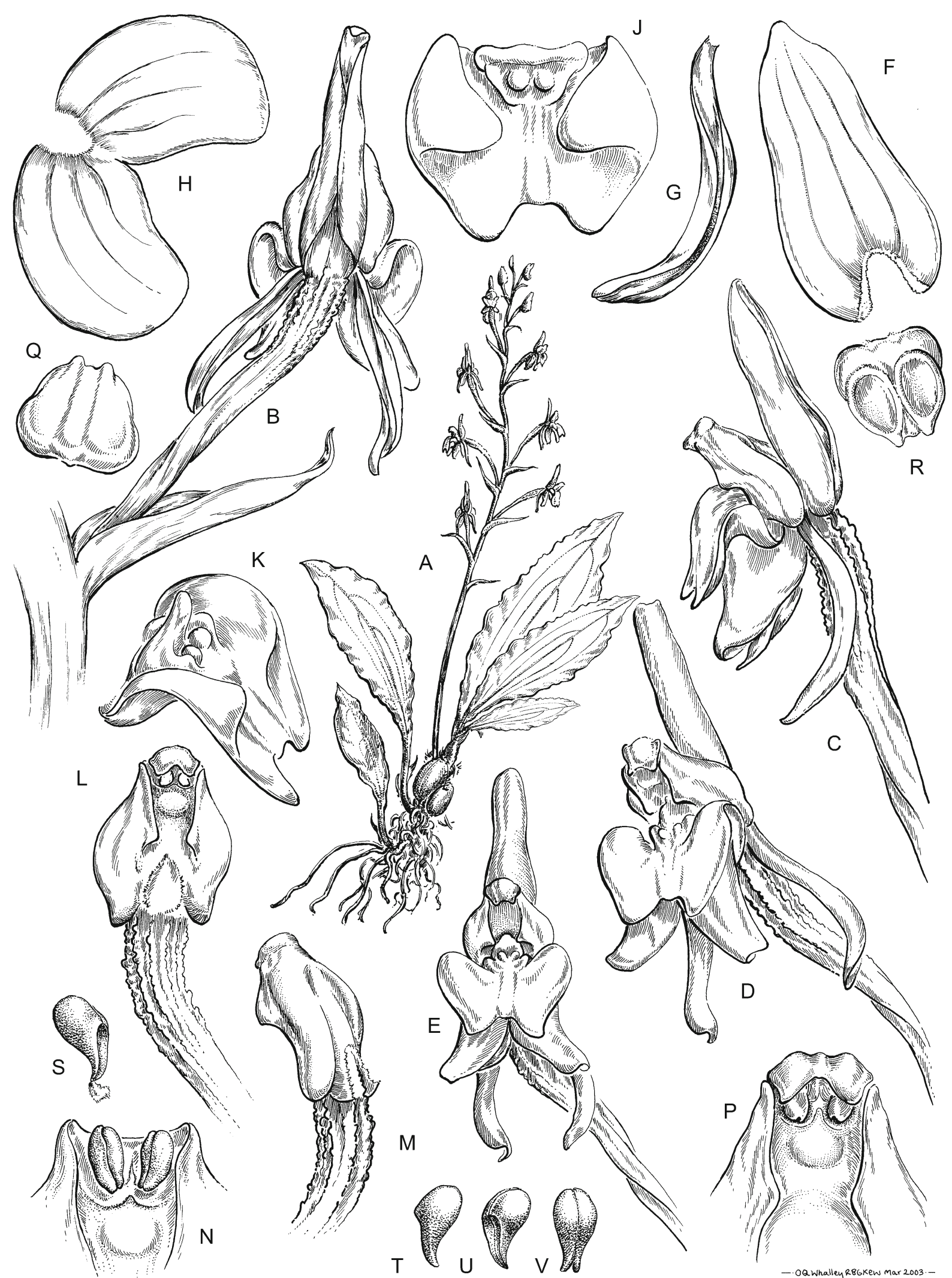

Fig. 21. Liparis dryadum. A habit $\times 1$ (two leaves digitally added); $\mathrm{B}$ flower, behind and bract $\times 12 ; \mathrm{C}$ flower from side $\times 12 ; \mathrm{D}$ flower $3 / 4$ view $\times 12$; E flower from front $\times 12$; $\mathrm{F}$ dorsal sepal (flattened) $\times 15 ; \mathrm{G}$ petal $\times 15 ; \mathrm{H}$ lateral sepals (joined) $\times 15$; J lip from above $\times 21 ; \mathrm{K}$ lip from side and above $\times 21$; L column from front $\times 15 ; \mathrm{M}$ column from side and behind $\times 15 ; \mathrm{N}$ top of column, anther cap removed $\times 36 ; \mathrm{P}$ top of column $\times$ 30; Q anther cap top $\times 36$; R anther cap underside $\times 36$; S pollinia side/behind $\times 39$; T pollinia side view $\times 39$; U pollinia side/behind $\times 39$; V pollinia from above $\times 39$. From Hermans 5575, plant habit after Hermans drawings and description. DRAWN BY OLIVER WHALLEY. 

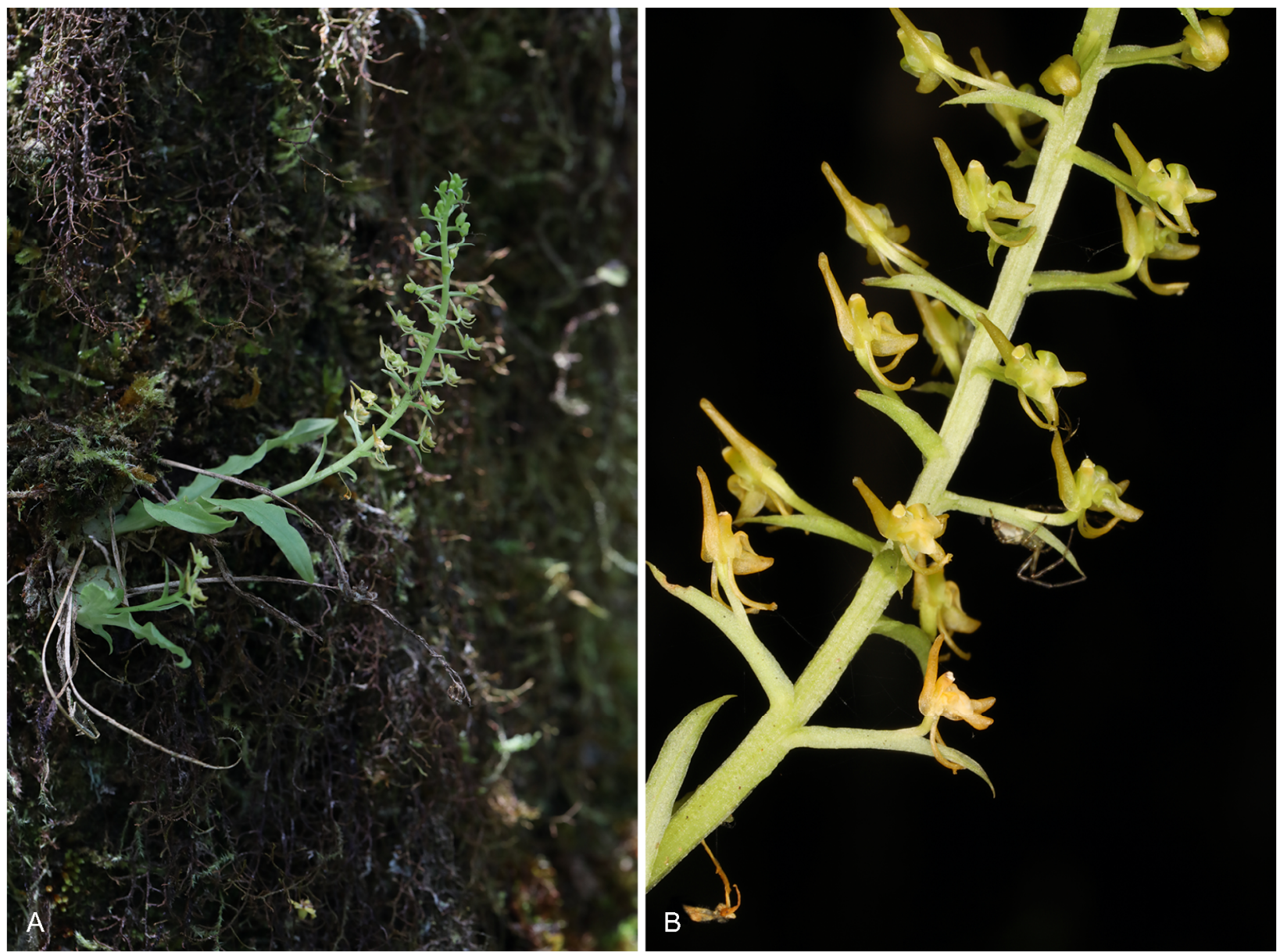

Fig. 22. Liparis dryadum. A plant habit; B rachis. PHOTOS: JOHAN HERMANS.

crenate at the margins, base with two small to very small rounded calli at the base forming a saddle-shape, $5-6.3$ $\times 4.9 \times 5.5 \mathrm{~mm}$. Column strongly arched, narrowed in the middle, with the wings obtuse-triangular, $1.8-3.9 \times 0.8-$ $1.2 \mathrm{~mm}$. Anther rounded with a small acute apicule at the anterior margin, c. $1.1 \times 0.9 \mathrm{~mm}$. Pollinia ovoid, c. $0.4 \times$ $0.3 \mathrm{~mm}$.

RECOGNITION. Liparis flavescens is a small and squat plant, with the pseudobulb covered by sheaths and leaf base, the previous year's pseudobulb being leafless and porrect. It bears three to four lanceolate to ovate, strongly veined leaves with a short petiole. Somewhat cordate, sterile bracts, auriculate at the base, are found along the lower half of spike. The medium to small flowers have a rounded lip, slightly crenate at front, with two small calli at base in a saddle shape and a short, sharply beaked anther.

Most, if not all records from Madagascar of Liparis flavescens are based on misidentifications. Liparis andringitrana seems to be its closest relative in Madagascar but generally its pseudobulbous stem is shorter and thicker, the leaf petiole longer, the flowers a little smaller and the callus more distinctly bilobed.
It is also similar to L. nephrocardia but it has a much longer inflorescence and rounded column wings (vs triangular in L. nephrocardia). It is close to L. nectarina in habit and lip shape but the leaves of L. flavescens are membranous not leathery, strongly many-veined (vs 3veined), the lip margin is entire (vs clearly emarginate and more deeply undulate), and the lateral sepals overlap (vs spreading). It shares the habit, inflorescence and flower habit of L. bowkeri from Southern Africa but L. flavescens is considerably larger, with more and larger flowers (Tables $2 \& 3$ ).

DISTRIBUTION. Its main distribution is in Réunion and Mauritius but there is one record from the Seychelles: Moore in Baker (1877: 343) listed 'Horne!'. A specimen from Mahé at K, possibly Horne 602 is this species and is noted to be common in moist shady forest of Mahé, Praslin and Silhouette. The species is also listed by Robertson (1989: 223), Summerhayes (1931: 291) cited several specimens and recorded the species as common (Map 21). A record from the Comoros (Humblot 1509 at BM \& P) is clearly not this species but Liparis sambiranoensis. Collections from Madagascar are generally of other species or difficult to ascertain because of the quality of the herbarium 


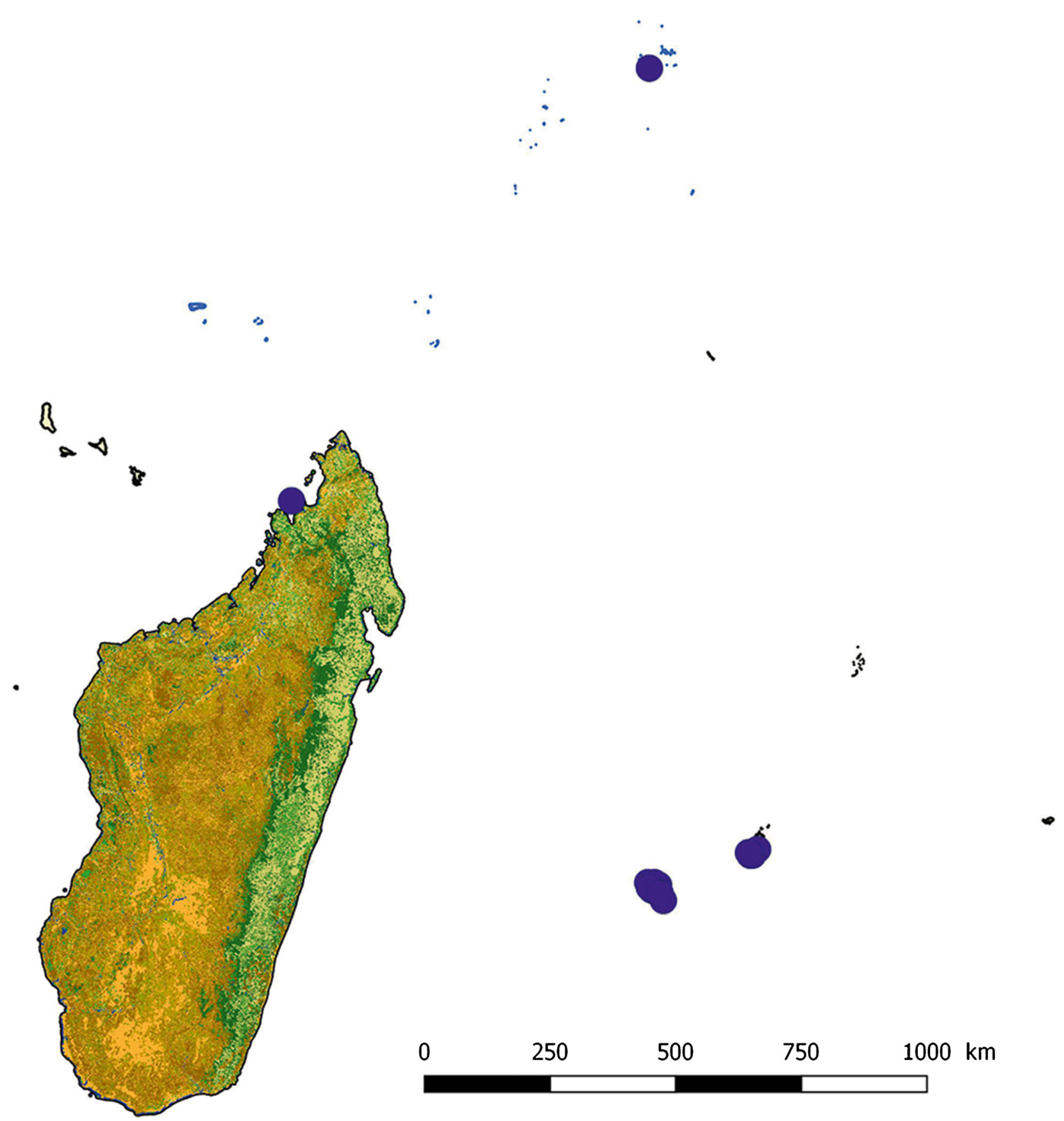

Map 21. Distribution of Liparis flavescens.

material. It is likely that much of the earlier herbarium material (e.g. Baron 1110 \& 227, Deans Cowan s.n. (BM00090072), Parker s.n. (1880), all at K) was identified on the basis of Du Petit-Thouars' (1822: t. 25) drawing which has limited detail. Only Pervillé 143 from 'Nossi-Bé' bears some resemblance to the species. SPECIMENS EXAMINED. MADAGASCAR. Nossi- Bé Island, 1841, Pervillé 143 (K-Lindl.). MAURITIUS. s. loc. 1821, Bory s.n. (G); s. loc., Bory s.n. (G); s. loc. 1847, Huguenin s.n. (G); Hort. July 1863, Blackburn 46 (K); s. loc., Commerson s.n. (P); Herb. Bescherelle s.n (P);
Grand Bassin 1929, Vaughan 694 (MAU, P); s. loc., 1966, Guého 11715 (P); Macabé Cima forest, 1971, Julien s.n. (P); Macabé Cima forest, May 1972, Vaughan 15481 (MAU, P); Noire, 1995, W. Page 22609 (P); Bel Ombre forest, 1931, Vaughan 739 (MAU, P); Milieu path, 1999, Poonaasamy et al. 23285 (P); s. loc. Neraud s.n. (G). RÉUNION. s. loc. July 1837 Gaudichaud s.n. (P); s. loc. 1846, Armange 163 (P); s. loc., 1847-, Boivin 1034 (G, P); s. loc., Balfour s.n. (K); s. loc., Richard s.n. (KLidl.); s. loc., Bory s.n. Herb. Richard. Rchb.f. 15288 (W); Salazi, Cordemoy s.n (MARS); Ilet à Baune cliff, 
Dec. 1970, Friedmann 804 (P); Marquat ravine, Dos d'Âne, 700 m, Feb. 1972, Friedmann 1542 (P); Haut de Bras Panon, 600 - 700 m, Oct. 1972, Bosser 21211 (P); Cirque de Cilaos, March 1974, Bosser 21704 (P); Bébour forest, Aug. 1975, Bosser 22358 (P); Basse Vallée, May 1976, Bosser 22180 (P); Col de Bellevue, Bosser 22551 (P); Oct. 1981, Renz 13026 (RENZ); Haut de Sainte-Marie, 800 m, Dec. 1971, Bosser 20989 (P); St Joseph, Hauts de Jacques Payet, 1300 m, March 1972, T. Cadet 3590 (P, REU); Ilet Solitude, Hauts de la Possession, $600 \mathrm{~m}$, March 1973, T. Cadet 4184 (P, REU); la Nouvelle, Mafate, 1500 m, June 1980, J. Cadet 6157 (P, REU); Plaine des Palmistes, $1300 \mathrm{~m}$, June 1980, J. Cadet 6162 (P, REU); Heureuse valley, 2004, Pailler TP134 (P); Eden, May 2004, 600 m, Fournel JF108 (P); Les Avirons, 1020 m, March 2004, Fontaine $\mathcal{E}$ Boullet 1065 (CBNM); Piton Textor March 2004, 1200 - 1600 m, ex Bernet, Hermans 8166 (K); Sainte-Marie, June 2006, 900 m, Hivert $\mathcal{E}^{\circ}$ Grondin 2078 (CBNM); Takamaka 900 m, Sept. 2007, ex Bernet, Hermans 8159 (K). SEYCHELLES. Mahe, 1874, Horne ?602 (K). WITHOUT LOCALITY. Thouars s.n. P00112469 (holotype P); ex Herb. Richard (R15287) (W); 502, (R29770) (W).

HABITAT. In moist shady places on the sides of ravines and cascades, open ground or forest. Amongst mosses, terrestrial or rarely epiphytic on large branches and tree trunks. Altitude: $400-1500 \mathrm{~m}$.

CONSERVATION STATUS. Category VU: the extent of occurrence (EOO) of Liparis flavescens is estimated to be $919,021 \mathrm{~km}^{2}$ (far exceeding the limits for Vulnerable status under criterion B1) whereas its minimal area of occupancy (AOO) is estimated to be $68 \mathrm{~km}^{2}$ (which falls within the limits for Endangered status under the criterion B2). Because L. flavescens is known from nine subpopulations representing eight locations (sensu IUCN), this species has been preliminarily assessed as VU using the green listing method. This species is threatened by selective logging, timber harvesting for small-scale subsistence slash-and-burn farming, grazing and anthropogenic fires, resulting in habitat reduction and habitat quality reduction. Previously assessed and published in the IUCN Red data listing for Réunion as LC (Picot 2013: 17)

FLOWERING TIME. February to August.

ETYMOLOGY. Refers to the yellowish colour of the flowers.

NOTES. Du Petit-Thouars (1822) first described and illustrated Liparis flavescens as Malaxis flavescens. He was not specific as to where it was found but mentioned Îles de France [Mauritius] and Bourbon [Réunion] in his descriptive table. Du Petit Thouars' holotype in Paris has no indication of locality and is fragmentary, the flowers consisting of partly damaged parts only and it is difficult to see distinct features but is without doubt the original material used by the author. His description and illustration also provide limited infor- mation. In 1825, Lindley transferred the species to the genus Liparis, Richard in 1828 also included it in Liparis but marked it as his own transfer, three years after Lindley's reclassification. In 1891 Kuntze placed it in Leptorchis. Ames (1908: 127) made the combination of Malaxis flavescens for an Asian species in error.

Du Petit-Thouars, in his description, indicated the width of the leaves at $1 / 4$ pouce wide $($ c. $6 \mathrm{~mm})$, this is different from what is shown in his drawing. Perrier, in his revision of Liparis (1936: 256), was not certain of the existence of the species in Madagascar. He mentioned that a Lyall specimen quoted by Ridley (1885: 460) seems to be another species (this is L. imerinensis at $\mathrm{K}$ with a drawing in K-Lindl.). Pervillé 710 (P), identified as L. flavescens, is in part L. foliosa: it seems to be a mixed sheet of different species, with duplicates at K. A collection by Neraud (G) from Réunion has a contemporary label of Malaxis flexuosa, but this is likely to be a transcription error.

ILLUSTRATIONS. Figs 23, 24; Du Petit-Thouars (Thouars 1822: t. 92); Bernet (2010a: 90); Cadet (1989: 55); Szelengowicz \& Tamon (2013: 357); Robert (2019: 350). Photographs captioned as Liparis flavescens in Bosser \& Lecoufle (2011: 407) and in Cribb \& Hermans (2009: 157) are all L. ochracea.

Liparis foliosa $\mathrm{Lindl}$. (Lindley 1825: t. 882); Loddiges (1825: t. 1097); Hooker (1827: t. 2709); Moore in Baker (1877: 343). Types: Île de France? [Mauritius], Hort. Barclay, 1824 (holotype K-Lindl.); Hort. Bot. Gard. Glasgow (paratype K-Lindl.); Bot. Reg. t. 882 (1825) para-iconotype.

Cestichis foliosa (Lindl.) Hoffmanns. (Hoffmannsegg 1842a: 38).

Alipsa foliosa Schltdl. (Schlechtendal 1842: 228).

Liparis flammula Frapp. (Frappier 1880: 15) nom. nud. Liparis flammula Frapp. in Cordem. (Frappier in Cordemoy 1895: 183). Type missing. synon. nov.

Small to medium epiphytic plant up to $17 \mathrm{~cm}$, on a very short rhizome, roots fleshy, very long, up to $20 \mathrm{~cm}$ $\times 2-3 \mathrm{~mm}$ in diam., growths in small clusters of $3-5$ pseudobulbs. Pseudobulbs at first elongate then becoming distinctly globular to ovoid, fleshy, somewhat glossy, a few acute whitish-yellow sheaths with prominent veins at the base when mature, generally carrying 3 (rarely 2) leaves at the apex, 12 - $25 \mathrm{~mm}$ diam. Leaves, erect to erectly spreading when mature ligulate-lanceolate, more or less longitudinally corrugate (strongly veined in the herbarium), with a distinct central recess, narrowed into a conduplicate petiole, $4.5-16 \times 1.5-2.6 \mathrm{~cm}$, dark green to yellowish-green. Inflorescence elongate, laxly racemose emerging from the new growth, $8-16 \mathrm{~cm}$ long, 3-4 mm in diam., with up to 16 flowers but generally fewer. Peduncle with $1-3$ peduncle sheaths up to $14 \times 3.5 \mathrm{~mm}$. Rachis in 


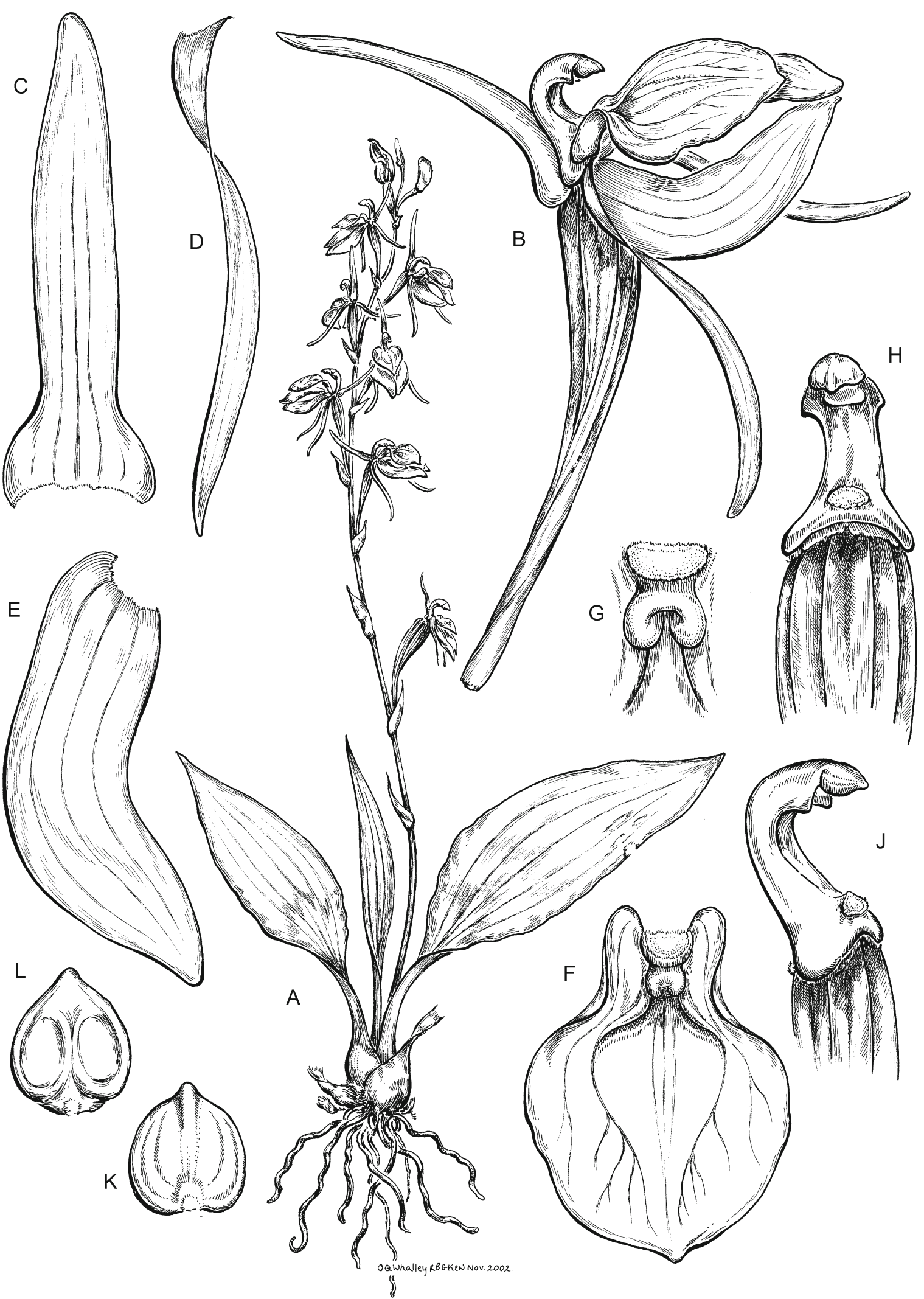

Fig. 23. Liparis flavescens. A habit $\times 1$; B flower $\times 9$; C dorsal sepal $\times 12$; D petal $\times 12$; E lateral sepal $\times 12 ; \mathrm{Flip} \times 12$; $\mathrm{G}$ lip callus $\times$ 36; $\mathrm{H}$ column, front view $\times 12$; J column, side view $\times 12 ; \mathrm{K}$ anther cap, top $\times 30$; L anther cap, bottom $\times 30$. From Pervillé 143 (KLindl.). DRAWN BY OLIVER WHALLEY. 

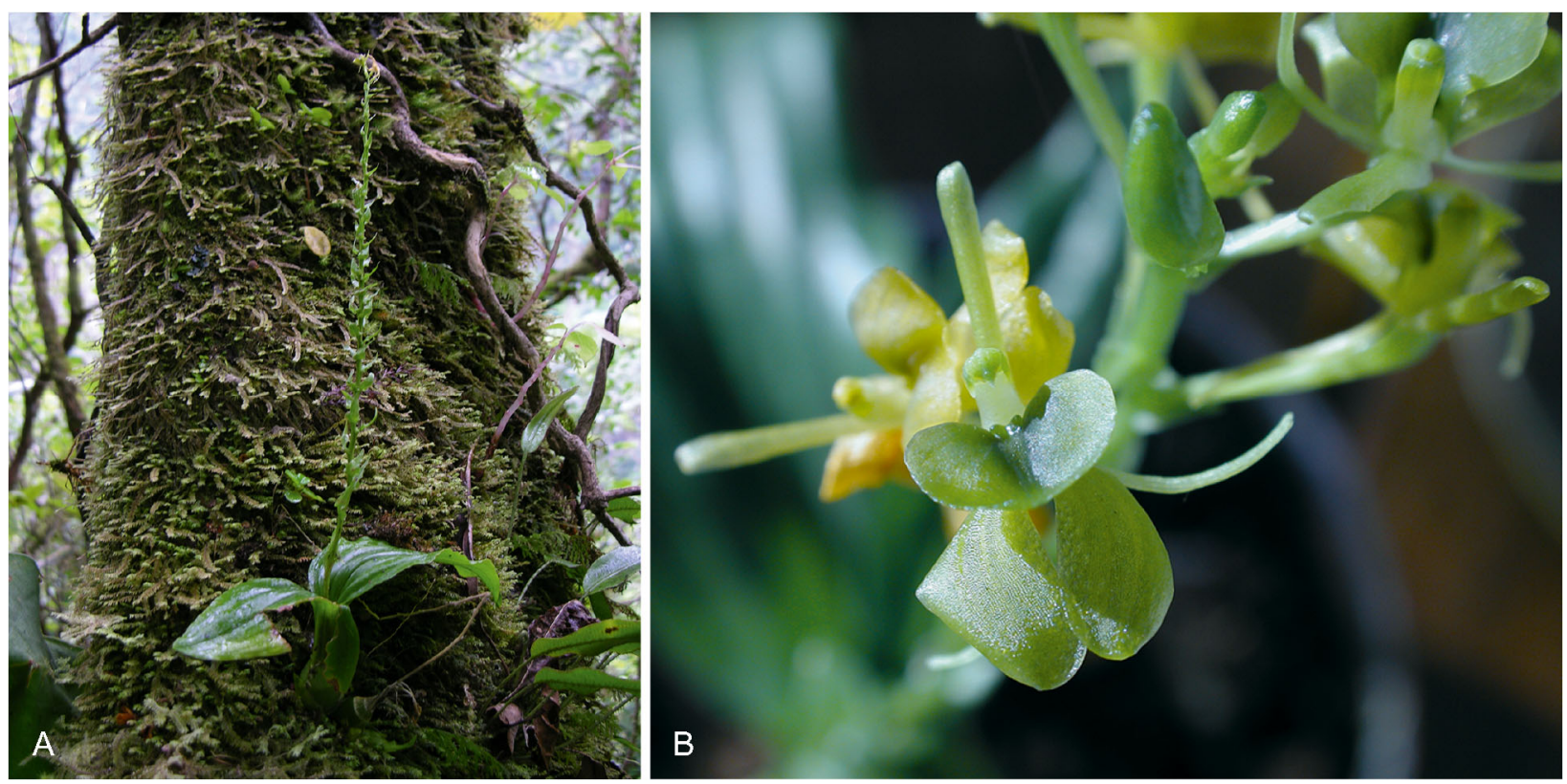

Fig. 24. Liparis flavescens. A habit; B flower. PHOtOS: PATRICE BERNET.

the upper $1 / 3$ of the inflorescence, becoming more lax as the flowers open. Floral bracts lanceolate, attenuate, more or less auriculate at the base, becoming smaller towards the apex of the rachis, $4.1-9.8 \times$ $0.8-1.6 \mathrm{~mm}$. Flowers small, erectly spreading $8-10 \times 6$ $-8 \mathrm{~mm}$, characteristically the dorsal sepal strongly reflexed, the lip blade and lateral sepals in an almost vertical plane, petals and sepals pale yellowish green, lip darker green with a yellow-green disk becoming orange with age, column white, anther green. Pedicel and ovary erect, somewhat ridged, $9.5-14 \times 0.8-1.8$ $\mathrm{mm}$. Dorsal sepal erect to strongly recurved, margins incurved ligulate, apex obtuse, $7.8-10 \times 1.5-2.1 \mathrm{~mm}$. Lateral sepals lanceolate with the apex narrowed and more strongly incurved, strongly down-curved and parallel with the blade of the lip, $6.1-8.1 \times 2.3-3.9$ $\mathrm{mm}$. Petals recurved, margins incurved, linear, $6.3-$ $8.7 \times 0.3-0.6 \mathrm{~mm}$. Lip ovate, strongly down-curved just below the base, base barely winged with two rounded, thickened ridges especially obvious in living plants, blade margins rounded more or less irregularly dentate, apex with a distinct protruding lobule, disk thickened, $5.8-6.7 \times 4.8-5.5 \mathrm{~mm}$. Column linear clavate, curved, the front margins with small angular wings towards the apex, $3.9-6.4 \times 0.8-1.9 \mathrm{~mm}$. Anther obovoid with a distinct rounded lobe at the anterior margin and sometimes with a miniscule sharp beak, c. $1 \times 1 \mathrm{~mm}$. Pollinia 2 fused pairs, narrowly ovoid, bipartite, c. $0.6 \times 0.4 \mathrm{~mm}$.

RECOGNITION. A small to medium-sized plant, with distinctly rounded pseudobulbs, persistent, ligulatelanceolate leaves, a laxly flowered inflorescence and small flowers with reflexed segments, lateral sepals in a vertical plane with the lip, lip strongly decurved from the base, ovate with rounded ridges at the base, anterior margin lobed, disk thickened, darker green becoming orange, column with indistinct wings, anther roundly lobed or minutely beaked at the front margin.

Liparis foliosa is similar to the Australian L. reflexa but the lip is larger in $L$. reflexa, oblong (vs ovate), the anterior margin which is emarginate with a small central lobe in $L$. reflexa (vs a larger single lobe in L. foliosa). In Liparis reflexa the lip is thickened at the base into a single callus, whereas $L$. foliosa has thickened callus-like ridges, the orange colouring is linear on the former and covers the entire disc of the lip in the latter. It is similar to the Madagascan $L$. longipetala but the pseudobulbs in L. foliosa are larger, the leaves thicker, not longly acuminate, the lip callus smaller and the anther rounded and not beaked as in L. longipetala.

DISTRIBUTION. This species may well be endemic to Réunion: S and Central, Cirque de Cilaos and Mafate, Saint-Pierre, Bébour forest, Plain des Palmistes (Map 22). The collection from Madagascar (Pervillé 710 in $\mathrm{P}$ ) is poor and may be another species. Records from Mauritius, including the type, Barclay 1824 (KLindl.), may be an error in the recording and could have originated from Réunion. There are no other records from the island but its habitat may have disappeared since the $19^{\text {th }}$ century.

SPECIMENS EXAMINED. MADAGASCAR. NW, March 1841, Pervillé 710 (P). MAURITIUS. Île de France? [Mauritius], Hort. Barclay, 1824 (holotype K-Lindl.); Hort. Bot. Gard. Glasgow (paratype K-Lindl.). RÉUNION. Plaine des Palmistes, Cordemoy (MARS); photo. Cordemoy watercolour of Liparis reflexa (K); Bébour Plateau, 

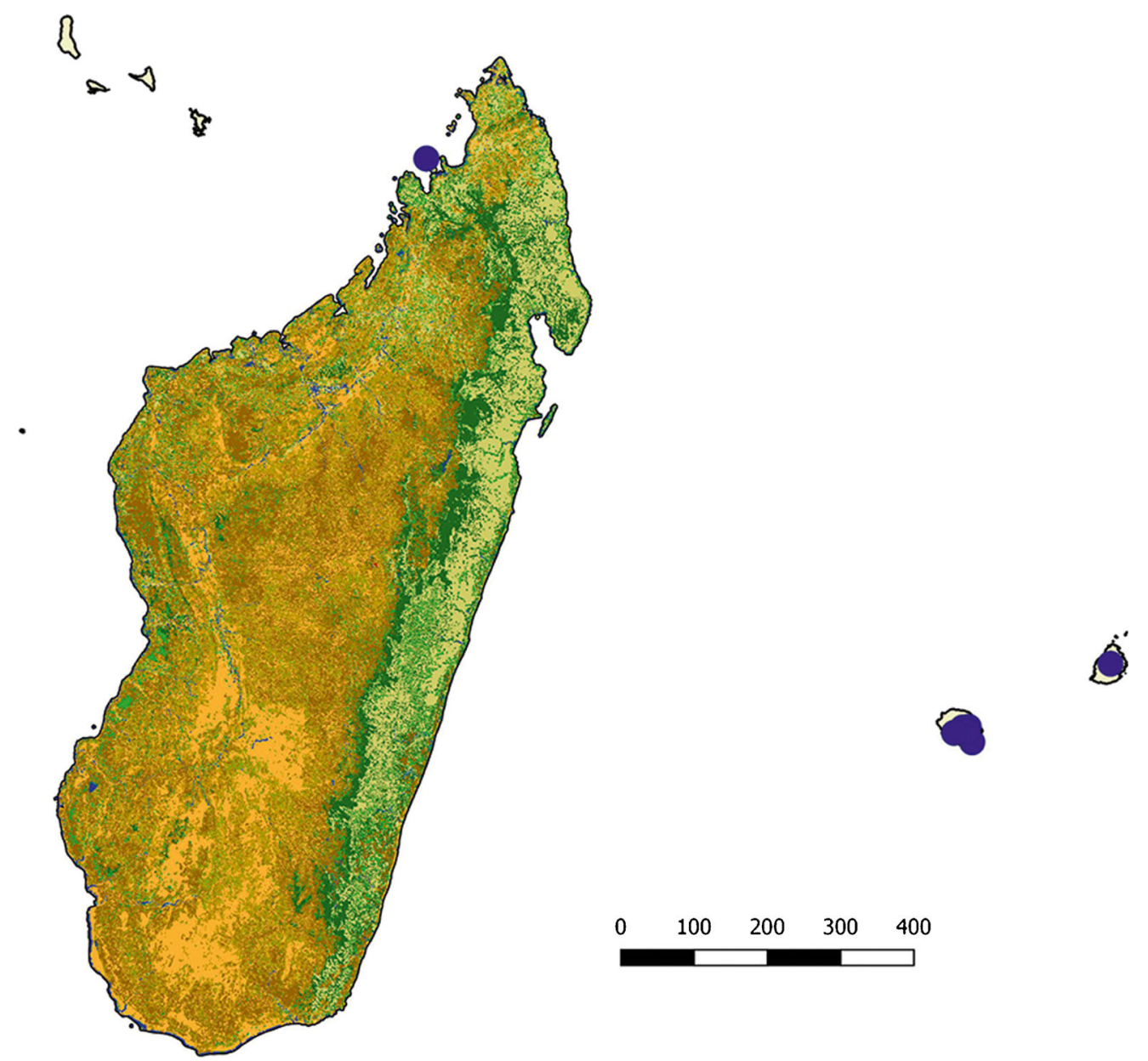

Map 22. Distribution of Liparis foliosa.

April 1970, Bosser 20072 (P); Hauts de Basse Vallée, 1400 m, Feb. 1971, T. Cadet 3059 (P); Bébour forest, April 1971, Guého 14743 (MAU, P); Bébour, 1300 m, March 1973, Lorence R23 (P); Piton Mare à Boue, Plaine des Cafres, March 1974, Bosser 21779 (P); Petite Plaine des Palmistes, March 1974, Bosser 21784 (P); Bébour forest, March 1982, Bosser 22711 (P); Hort. 1987, Bosser F58 (P); Plaine des Palmistes, 1400 m, Feb. 2002, Paillier TP28 (P); Piton Textor, $1600 \mathrm{~m}$, Bélouve, Feb. 2004 ex Bernet, Hermans 8155 (K); Belouve forest, Salazie, 1620 m, Dec. 2003, Ferard et al 923 (CBNM); Piton Textor, 1600 m, Feb. 2004, ex Bernet, Hermans 8156 (K); Dimitile, Cilaos Bébour Bélouve, 1200 m, Jan. 2003, ex Bernet $\mathcal{E}$ Rivière, Hermans 8157 (K); Piton Textor, 1500 m, Feb. 2004, ex Bernet Ẽ Rivière, Hermans 8164 (K); Bélouve, 1600 m, March 2004, ex Bernet, Hermans 8163 (K). WITHOUT LOCALITY. Hort. mixed sheet including Hort Glasgow, type of Curtis. Bot. t.2709 (K); Hort 183 P02118440 (P); Herb. Richard 409 (P).

HABITAT. Epiphyte in high altitude evergreen forest, in semi-xerophytic forest. On high branches. Altitude: $500-1600 \mathrm{~m}$.
CONSERVATION STATUS. Category EN: The extent of occurrence (EOO) of Liparis foliosa is estimated to be $139,396 \mathrm{~km}^{2}$ (far exceeding the limits for Vulnerable status under criterion B1) whereas its minimal area of occupancy (AOO) is estimated to be $36 \mathrm{~km}^{2}$ (which falls within the limits for Endangered status under the criterion B2). With only five known subpopulations representing four locations (sensu IUCN), this species has been preliminarily assessed as EN using the green listing method. This species is threatened by grazing and anthropogenic fires, resulting in habitat reduction and habitat quality reduction. Previously assessed and published (as Liparis flammula) in the IUCN Red data listing for Réunion as DD (Picot 2013: 25).

FLOWERING TIME. January to April.

ETYMOLOGY. Lindley's name refers to the leafy nature of the plant (he called it the 'Many leaved Liparis' (1825: t.882)). Liparis flammula refers to the flame-like appearance of the newly emerging leaves

NOTES. Lindley first described and illustrated Liparis foliosa in 1825 in Edwards' Botanical Register (t.882), based on a cultivated plant from Robert Barclay Esq. said to have come from Île de France [Mauritius]. On 


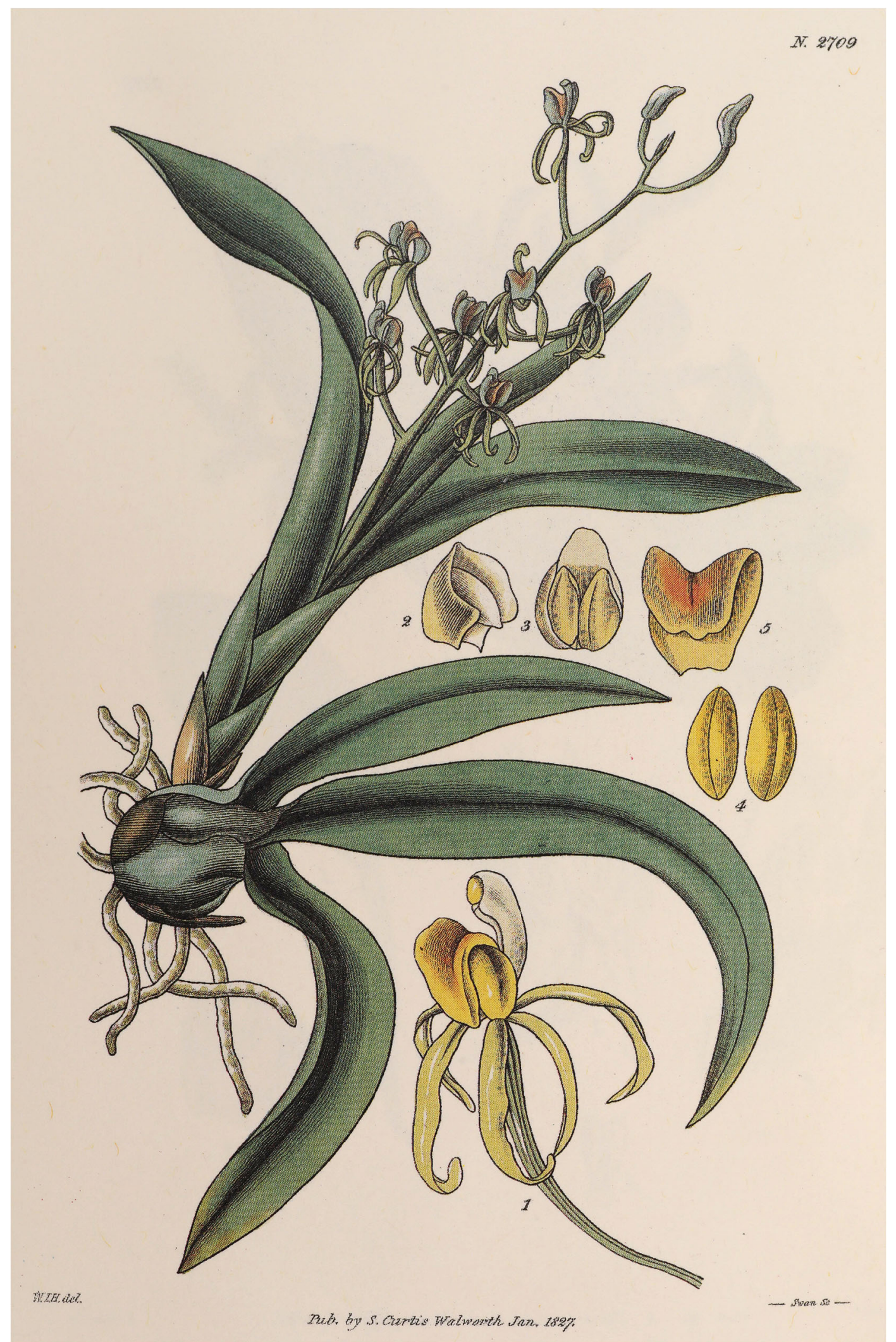

Fig. 25. Liparis foliosa. Engraving from Hooker 1827: t.2709. 
the same sheet there is a preparatory pencil drawing for the illustration in the Lindley Herbarium at $\mathrm{K}$ and together with the plant material there is no doubt that this is the original material used by Lindley. The same year another illustration appeared in The Botanical Cabinet (Loddiges 1825: t.1097), here it is mentioned that the plant '...was lately introduced from Mauritius, by our worthy friend, Mr. Barclay, of Bury Hill, who kindly imparted it to us. It flowered in November, and is a curious and interesting plant, although not very showy...'. The text is presumably by George Loddiges, no author is mentioned of $L$. foliosa but one must assume it refers to Lindley's newly published name. Robert Barclay Esq. of Bury Hill (near Dorking in Surrey) (1751 - 1830), a wealthy collector, grower and student of plants, was well connected in the botanical world and had a number of overseas contacts who supplied him with plant novelties. One of these contacts was Dr Charles Telfair (1778 - 1833) a naval surgeon resident in Mauritius but also known to have collected plants in Madagascar, Réunion and the Seychelles (Dorr 1997: 468). W. J. Hooker refers to this in Barclay's obituary and also reproduced his last letter to Barclay (Hooker 1830: 122). Telfair also had a great interest in botany, working with Wenceslas Bojer, corresponding with several botanists in Europe and introducing a number of plants from the region. Loddiges cultivated several of them, presumably obtained via Barclay. The Horticultural Register of 1831 (Paxton \& Harrison 1831: 190) recorded the species flowering at the Loddiges \& Sons Nursery in Hackney. Another plant from the Barclay collection is illustrated and described in Curtis' Botanical Magazine in 1827 (t.2709) (Fig. 25) by W. J. Hooker who noted that it is '...drawn from a plant presented by Mr. Barclay, to the Glasgow Botanic Garden, which flowered in the month of Oct. 1826. It is a native of the Mauritius, and there, in all probability, grows upon trees. The figure given in Botanical Register being drawn from a young specimen, the bulbs were not formed, and hence, probably, Mr Lindley was induced to suppose the plant was terrestrial...'. There is a specimen that flowered at Kew, annotated by Robert Rolfe that may be the type of the illustration in Curtis' Botanical Magazine t.2709, there is another specimen at $\mathrm{K}$ of the plant that originally flowered at Glasgow Botanic Garden. Another plant of unknown origin, flowered in the Botanical Garden in Paris in the 1830s (P02118440) and was identified by Achille Richard as this species.

Considering the origin of the Liparis described by Lindley, there is no evidence that it actually came from Mauritius. Barclay may have noted the origin as having been sent by Telfair from Mauritius but it is possible that it could have been collected on Réunion. In 1828, Achille Richard included Lindley's species in his Monograph of the orchids of Mauritius and Réunion; he likened it to L. flavescens differing in its longer, narrower leaf and more flowers.

Five years after his original description, Lindley, in his Genera and Species of Orchidaceous Plants (1830a: 29) listed 'Liparis foliosa Lindley' but also has 'Liparis? reflexa Lindl. 1.c.' and 'Cymbidium reflexum R.Br. Prodr.331' and had the species coming from Mauritius, New Holland and Port Jackson, the last two referring to an Australian origin. In his observations Lindley wrote that the plants from Mauritius were found to have an entire clinandrium and the Australasian one to have a dentate one but otherwise not different. This re-classification is explained further by Lindley in The Transactions of the Horticultural Society of London (1830b: 68), where he gave the same nomenclature arrangement and referred to a plant collected in New Holland by Captain McArthur in 1825 and described by Brown as Cymbidium reflexum. He goes on to say that 'Upon comparing it with the Ile de France Liparis foliosa, described by me in the Botanical Register, fol. 882, I see no reason to doubt its being the same species; that plant which flowered in Mr Barclay's stove, and which I there described, was destitute of bulbs, but the plant of the Garden was furnished with large ovate oblong bulbs, each of which was terminated by three ligulate acuminate channelled leaves indistinctly five-nerved. The scape was about the same length as the leaves of that shoot which produced it, but much shorter than the full grown leaves of the old bulb. The differences that seem to exist I am disposed to believe depend upon the age of the plant, which, when old, would have bulbous stems, of which it would be destitute when young ...' De Candolle in his Géographie Botanique Raisonnée (De Candolle 1855: 1036) used the variability and distribution given by Lindley for $L$. reflexa, to illustrate the geographical variance in species. Lindley's decision of putting the Mauritius plant into synonymy with Brown's Australian L. (Cymbidum) reflexa was followed by subsequent authors, including Ridley's monograph of the genus (1887: 287).

Moore in Baker (1877: 343) in the Flora of Mauritius and the Seychelles noted that 'Liparis foliosa Lindl. given as Mauritius on the authority of Barclay, is in all probability, not a native of this region. Du PetitThouars makes no mention of it, and it was not seen by either Richard or Bojer. On the other hand, carefully dissecting it will, I believe, show that it is identical with the Australian L. reflexa Lindl.'

Frappier in Cordemoy in the Flora of Réunion of 1895 accepted Lindley's Liparis reflexa with a question mark after the name. He gave a description and cited plants from 'Plaine des Cafres et des Palmistes. An uncommon epiphyte in semi-shade between 1500 - $1500 \mathrm{~m}$, Flowering in Oct. (according to Cordemoy), seen dried and alive.' He also noted that this plant partly belongs in the herbarium of J. M. C. Richard where it is labelled 
Table 9. Comparison of the type material of Liparis foliosa from Mauritius / Mascarenes and L. reflexa from Australia.

\begin{tabular}{lll}
\hline \hline & L. foliosa & L. reflexa \\
\hline Specimen & Hort. Barclay, 1824 (K-Lindl.) & Brown $5506(\mathrm{~K})$ \\
Pseudobulbs shape & globular to ovoid & longly ovoid \\
Pseudobulb size $(\mathrm{mm})$ & c. $25 \times 25$ & $25-40 \times 2-30$ \\
Leaves number & 3 & $1-3$ \\
Leaves size $(\mathrm{cm})$ & up to $16 \times 2.6$ & up to $30 \times 3.5$ \\
Inflorescence height $(\mathrm{cm})$ & c. 15 & $10-30$ \\
Inflorescence type & loosely racemose & fairly densely racemose \\
No. flowers per inflorescence & $8-15$ & $5-30$ \\
Flower size $(\mathrm{mm})$ & $8-10 \times 6-8$ & $10-15 \times 8-10$ \\
Dorsal sepal $(\mathrm{mm})$ & $7.8-10 \times 1.5-2$ & $7-10 \times$ c. 2 \\
Lateral sepals $(\mathrm{mm})$ & $6.1-8.1 \times 2.3-3.9$ & $6.5-9.5 \times$ c. 2 \\
Petal $(\mathrm{mm})$ & $6.3-8.7 \times 0.3-0.6$ & $6.5-9.5 \times$ c. 1 \\
Lip size $(\mathrm{mm})$ & $5.8-6.7 \times 4.8-5.5$ & $7-10 \times 3-4$ \\
Lip shape/colour & ovate, yellow green with an orange & oblong, base deeply channelled with \\
& spot on the disc, thickened & 2 orange ridges about 4 mm long \\
Anther & roundly lobed & slightly beaked \\
Habitat & epiphyte & generally on rock \\
\hline
\end{tabular}

L. foliosa Lindl.; the other in the Cordemoy herbarium. The Cordemoy herbarium (MARS), has a sheet labelled L. reflexa from Plaine des Palmistes and is clearly L. foliosa as described by Lindley; there also is a black \& white photograph at $\mathrm{K}$ of one of Cordemoy's watercolours showing the same plant.

Examining the literature and all the material available it is clear that Liparis foliosa, as described by Lindley in 1825 is a valid species and is different from L. reflexa (R.Br.) Lindl. from Australia, SE Queensland to E New South Wales.

The possible confusion of the origin of Barclay's plants is questionable as the provenance from Telfair is solid and there are no records of Barclay importing plants from Australia (as explained above and also see (Hooker 1830: 122)); the only question is over its origin from Mauritius or Réunion. The cultivated plants from Kew and Glasgow have the same origin, as have the illustrations in the Botanical Register, Botanical Cabinet and Curtis' Botanical Magazine.

There are undoubted similarities between Liparis foliosa and L. reflexa from Australia; they both have bulbous pseudobulbs, linear-lanceolate leaves, greenish-yellow flowers with orange marking on the lip and reflexed sepals and petals but so do several other Liparis from around the world. It is not surprising that Lindley thought them to be the same species, at a time when only limited material was available. There are a number of differences between the two species (Table 9): the plant habit is somewhat different with the pseudobulbs more elongate in L. reflexa, the leaves and inflorescence longer. The principal differences are in the oblong lip (vs ovate) which is larger in L. reflexa, the anterior margin which is emarginate with a small central lobe in L. reflexa (vs a larger single lobe in L. foliosa), a single thickened callus in L. reflexa (vs thickened callus-like ridges), its orange coloured stripe (vs entirely orange disc). The column of $L$. foliosa is more acutely winged.

The name Liparis flammula first appeared in Frappier's 1880 listing of the plants of Réunion on p. 15 as 'Liparis flammula Fr.'. It was subsequently described in detail by Cordemoy (Frappier in Cordemoy (1895: 183)). Cordemoy's description is clear and describes a plant around $15-20 \mathrm{~cm}$ high with distinct pseudobulbs, lanceolate leaves resembling flames and a mucronate lip. Frappier did not indicate a type nor is there any reliable contemporary herbarium material available. There are a number of more recent collections (Bosser 22711, T. Cadet 3059, Lorence R23, Hermans ex Bernet 8155-7, 8163-4) and combined with the description, these indicate that this is the same species as Lindley's L. foliosa. They all match the Barclay's plants, especially the more complete cultivated ones. The photographs in Bernet (2010a: 102) of his Liparis sp. 1 \& 2 match this species.

A similar specimen has been recorded from Madagascar (Lavango Surveillant 6031 in P) but as the specimen has seed capsules only it is not possible to ascertain its identity.

ILLUSTRATIONS. Figs 25, 26; Lindley (1825: t.882); Loddiges (1825: t.1097); Hooker (1827: t.2709) (Fig. 25); Bernet (2010a: 102, as sp. 1 \& 2); Szelengowicz \& Tamon (2013: 356).

Liparis gracilipes Schltr. (Schlechter 1924: 138); Perrier (1939: 266); Hermans et al. (2007: 218); Cribb \& Hermans (2009: 150). Type: Madagascar, Mt Tsaratanana, Perrier 15747 (P00094979) (lectotype P, designated here; isolectotype Perrier 15747 (P00094980) P)).

Medium to large slender plant, erect terrestrial, 

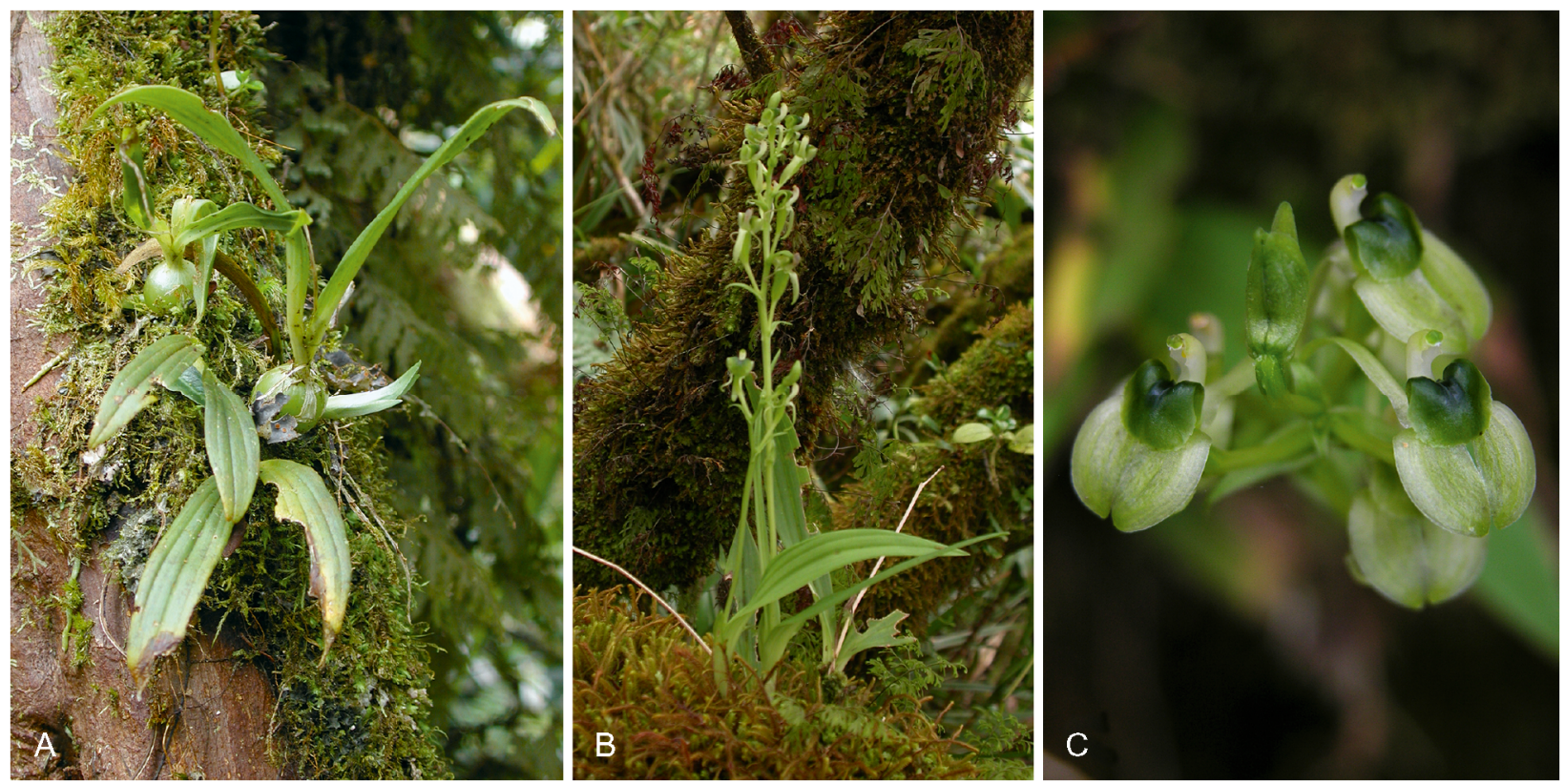

Fig. 26. Liparis foliosa. A habit; B inflorescence; C flower. PHOTOS: PATRICE BERNET.

lithophyte or epiphyte, up to $22 \mathrm{~cm}$ tall growing in dense clumps, the older pseudobulbs retaining their leaves, rhizome woody, short c. $8 \mathrm{~mm}$ diam., roots slender, filiform, more or less pilose. Pseudobulbs very slender av. $3 \mathrm{~mm}$ diam., up to $15 \mathrm{~cm}$ long, woody, in 3 -5 sections each carrying a $10-12 \mathrm{~mm}$ acute sheaths. Leaves $2-3$ (rarely 4), erectly spreading, thin, elliptic to lanceolate elliptic, acuminate, base rounded with a petiole $6-15 \mathrm{~mm}$ long, margins slightly undulate, with 5 strong veins, $7-10 \mathrm{~cm}$ long, $1.7-5 \mathrm{~cm}$ wide. Inflorescence slender, erect, up to $15 \mathrm{~cm}$ long, laxly 5 12-flowered. Peduncle up to $8 \mathrm{~cm}$, slender with $2-3$ lanceolate, acuminate erectly spreading sheaths up to $8 \mathrm{~mm}$ long, sometimes with a larger leaf-like bract. Rachis up to $7.5 \mathrm{~cm}$ long but normally shorter. Floral bracts lanceolate acuminate but wider than the peduncle sheaths, $4-9 \times 2-3.5 \mathrm{~mm}$. Flowers erectly spreading, greenish to greenish-white, becoming yellow on ageing, medium size, up to $11 \times 7 \mathrm{~mm}$. Pedicel and ovary slightly winged, up to $11 \times 1.2 \mathrm{~mm}$. Dorsal sepal somewhat reflexed, narrowly lanceolate to ligulatelanceolate, obtuse, $8-15 \times 2-3.1 \mathrm{~mm}$. Lateral sepals oval-obtuse $7.5-11 \times 4.1-5 \mathrm{~mm}$. Petals deflexed, narrowly linear, $8-12 \times 0.7-1.3 \mathrm{~mm}$. Lip curved, suborbicular, tip slightly indented, margins sub-crenulate, two strong curved veins running parallel with the margins, at the base with a distinct wedge-shaped, erect, tridentate callus, $6.5-10.1 \times 6.8-10 \mathrm{~mm}$. Column hardly curved at the tip, with very small thin triangular wings near the apex, $4.2-4.8 \times 1 \mathrm{~mm}$. Anther rounded without a beak c. $0.8 \times 0.9 \mathrm{~mm}$. Pollinia oval $0.3-0.5 \mathrm{~mm}$ diam.

RECOGNITION. It is likely that this species has been confused with other vegetatively similar species with a long stem but the medium-sized flowers with a distinct rounded lip with wavy edges, strong side veins and the dentate callus are characteristic.

In plant habit the species is similar to Liparis chantaliae (described above) but the leaves are much thicker in texture and elliptic vs broadly oval, the lip suborbicular vs broadly oval-lanceolate and the callus tridentate vs bi-lamellar, the flowers are also much smaller. It equally has similarities with $L$. longicaulis with its elongate stem but differs in that the stem is very thin and has two to rarely three leaves with short wavy margins. The flowers are distinct by the wide rounded lip with at the base an erect three pointed wedge-shaped callus. The species is also similar to L. caulescens from Réunion, but the leaves are more cordate, there are fewer flowers a quarter smaller and the lip is suborbicular vs broadly obovate with a tridentate vs bidentate callus.

DISTRIBUTION. Endemic to Madagascar in Antsiranana and Fianarantsoa provinces (Map 23).

SPECIMENS EXAMINED. MADAGASCAR. Mt Tsaratanana, Perrier 15747 (P00094979) (lectotype P); Perrier 15747 (P00094980) (isolectotype P); Anosibe an'ala ?, $850 \mathrm{~m}$, Hermans 5267 (K); Fianarantsoa, W of Ranomafana, May 2001, 746 m, Hermans 1010 (K); Andapa, Doany, Anjialavahely, March 2006, Ravelonarivo et al. 1809 (K, MO). HABITAT. Moss forest, river margins and shaded and humid rocks. Altitude: $800-1800 \mathrm{~m}$.

CONSERVATION STATUS. Category EN: the extent of occurrence (EOO) of Liparis gracilipes is estimated to be $45,562 \mathrm{~km}^{2}$ (which exceeds the limits for Vulnerable status under criterion B1) whereas its minimal area of occupancy (AOO) is estimated to be $16 \mathrm{~km}^{2}$ (which falls within the limits for Endangered 


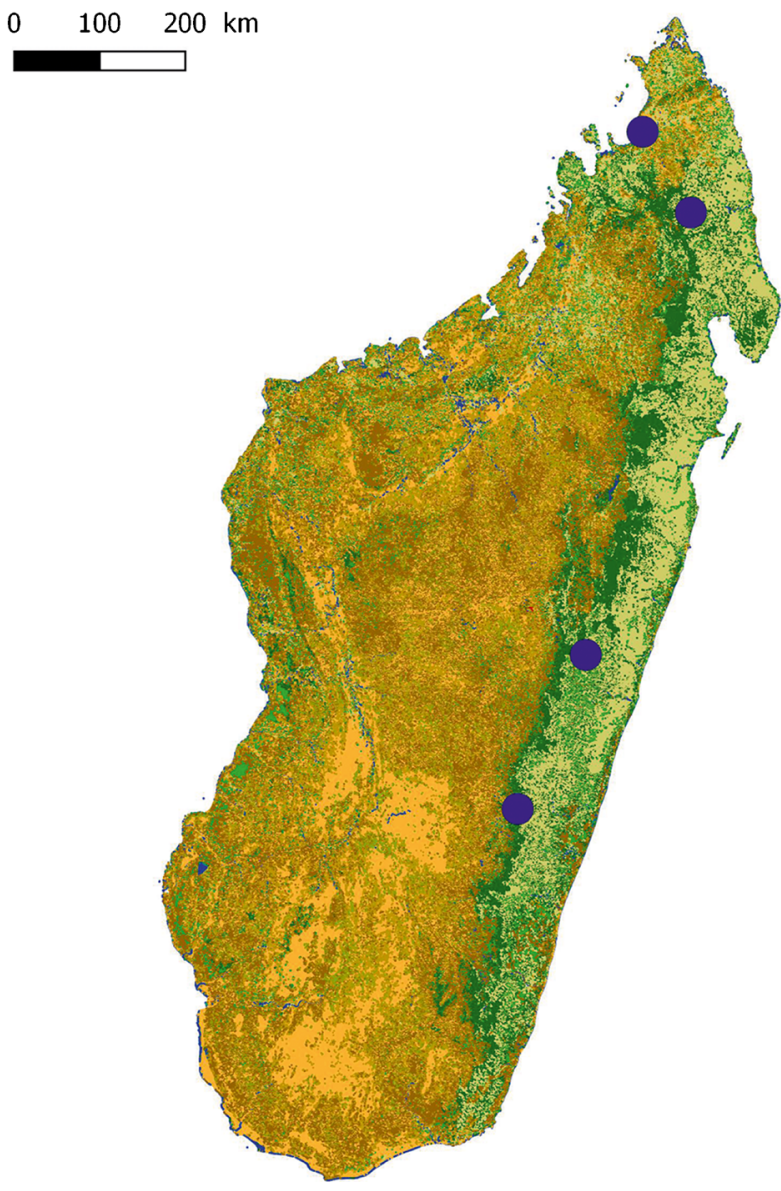

Map 23. Distribution of Liparis gracilipes.

status under the criterion B2). With only four known subpopulations representing four locations (sensu IUCN), L. gracilipes has been preliminarily assessed as EN using the green listing method. This species is threatened by selective logging, timber harvesting for small-scale subsistence and tavy (slash-and-burn farming), resulting in habitat reduction and habitat quality reduction. The habitat near Anosibe an'ala has been destroyed due to slash-and-burn.

FLOWERING TIME. January to May.

ETYMOLOGY. Referring to the long slender pseudobulbs.

NOTES. The species was described by Schlechter in Germany from herbarium material sent to him by Perrier and this was then returned to the Paris herbarium, as indicated on the herbarium label. In his description, Schlechter cited Perrier 15747 as the type, there are two sheets of this number and P00094979 is designated here as the lectotype and P00094980 is an isolectotype; the first specimen is more representative of the species and has more open flowers. Until recently known from the type only.

ILLUSTRATIONS. Perrier (1939: 255).
Liparis imerinensis Schltr. (Schlechter 1924: 141); Perrier (1936: 255; 1939: 294); Hermans et al. (2007: 218); Cribb \& Hermans (2009: 154); Hervouet (2018: 409). Type: Madagascar, near Manjakandriana, E Imerina, 1920, Perrier 12973 (P00094997) (lectotype P, designated here; Perrier 12973 (P00094998) isolectotype $\mathrm{P}$ ).

Large erect terrestrial plant, up to $25 \mathrm{~cm}$ tall, rhizome very short, roots wiry, flexuose more or less pilose. Pseudobulbs normally two; one erect, carrying $2-3$ leaves, the other leafless and almost divaricate at a right angle or almost horizontal, cylindrical, stem-like, enveloped by sheaths, $4.5-11 \mathrm{~cm}$ long, $2.2-5.1 \mathrm{~mm}$ diam. Leaves erectly spreading, oval-elliptic, shortly acuminate, slightly apiculate, semi-petiolate $(1-2 \mathrm{~cm})$ towards the base, soft, plicate and distinctly veined, $6-$ $12 \times 3-4 \mathrm{~cm}$. Inflorescence erect, somewhat exceeding the length of the leaves, sublaxly 5 - 16-flowered. Peduncle slender, ridged, up to $7 \mathrm{~cm}$, with $1-4$ slender sheaths. Rachis up to $5 \mathrm{~cm}$. Floral bracts erectly spreading, linear-lanceolate, acuminate, the lower ones slightly longer than the pedicellate ovary, the higher ones slightly shorter, up to $10 \times 2 \mathrm{~mm}$. Flowers erectly spreading, medium in size, greenish-yellow becoming ochre-coloured on ageing, overall up to 15 $\times 12 \mathrm{~mm}$. Pedicel and ovary, glabrous, slightly ridged becoming almost triangular in cross-section, $6-11 \times 1$ - $2 \mathrm{~mm}$. Dorsal sepal erect, narrowly lanceolate, somewhat obtuse, the base subauriculate-expanded, $7.2-10 \times 1.0-1.9 \mathrm{~mm}$. Lateral sepals porrect, semioval, obtuse, 4 - or 5-veined, $5.6-9.1 \times 2.2-3.5 \mathrm{~mm}$. Petals deflexed, narrowly linear, oblique, $5.7-8.5 \times 0.3$ $-0.5 \mathrm{~mm}$. Lip contracted, subrectangular, broadly oval or oval-rhomboid, narrowed-acute or apiculate at the apex, base obtusely triangular-auriculate, with a small two-horned thickening (c. $0.3 \mathrm{~mm}$ ) at the base, $5.3-$ $7.9 \times 4.1-5.5 \mathrm{~mm}$. Column semi-terete, angular-obtuse along the stigmatic surface, $3.2-4.5 \times 1.2-1.4 \mathrm{~mm}$. Anther triangular acute at the front, up to $1.3 \times 1.1$ mm. Pollinia oval c. $0.5 \times 0.6 \mathrm{~mm}$.

RECOGNITION. Its single erect flowering growth reaches up to $25 \mathrm{~cm}$, with the leafy pseudobulb up to $11 \mathrm{~cm}$ long, the other leafless and leaning to almost horizontal. Lip oval-rhomboid, with a bidentate callus, acute at the apex, with five veins and anther with a short beak at the front.

Similar to Liparis andringitrana in some respects but it is a somewhat larger plant with longer pseudobulbs, the older pseudobulb being almost divaricate. Its lip has an acute tip whilst that of $L$. andringitrana is rounder and indented, the callus consists of two horns (vs a rounded lobe).

DISTRIBUTION. Endemic to Madagascar: Antananarivo and Toliara provinces. The majority of collections are from the Highlands around the capital, a few are from much further South in Toliara province (Map 24). 

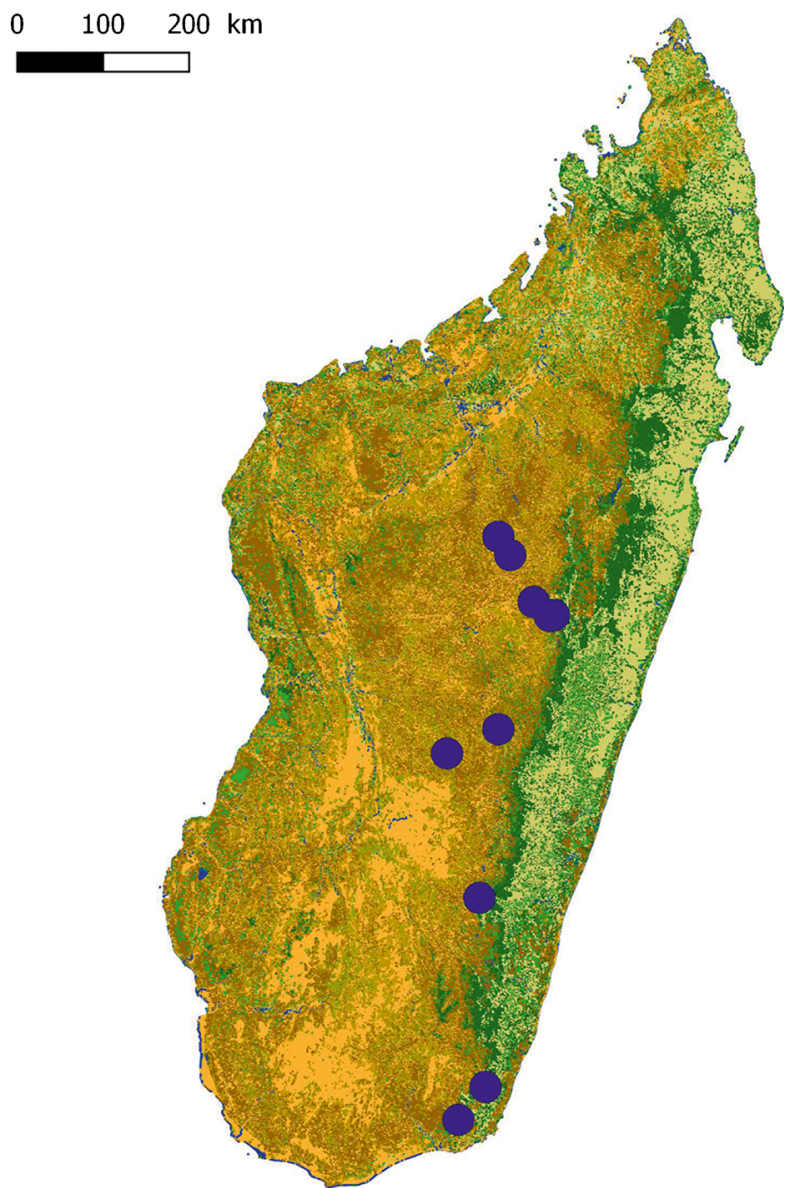

Map 24. Distribution of Liparis imerinensis.

SPECIMENS EXAMINED. MADAGASCAR. Imerina, Lyall s.n. K0002421140 (K); Ambatovory, Dec. 1886, Fox 21 (K ex LDS); Ambohimanga, June 1905, d'Alleizette 346 (P); near Manjakandriana (E Imerina), 1920, Perrier 12973 (P00094997) (lectotype P); Perrier 12973 (P00094998) (isolectotype P); Centre, Manerinerina, Tampoketsa between Ikopa and Betsibola, forest of the Eastern slopes, c. 1500 m, Dec. 1924, Perrier 16869 (P); Centre, Analabe N of Antananarivo, forest remnant, Feb. 1928, Perrier 18431(P); Ambohimanga, April 1928, Decary 6210 (P); Centre, Ambohimanga near Antananarivo, terrestrial in forest, Feb. 1932, Perrier 19010 (P); Toliara, lower basin of the Mananara, 700 900 m, Feb. 1934, Humbert 13929 (P); Toliara, lower basin of the Mananara, tributary of the Mandrare, 700 - 900 m, Feb. 1934, Humbert 13929bis (P); Forest S of Ambositra, rocks by a stream, Feb. 1942, Decary 17516 (P); Manerinerina (Ankazobe Tampoketsa) forest, Jan. 1942, Decary 17140 (P); Ambohitantely forest, Feb. 1945, Homolle s.n. (P); Mandrare valley, tributary of the Manampanihy (SE), Mts S of Tanandava, c. $850 \mathrm{~m}$, March 1947, Humbert 20559 (P); Ambohimanga, Feb. 1938, Jard. Bot. Tana. 3254 (P); W Betsileo, 1500 1700 m, Jan. - April 1955, Humbert 28171 (P); Ambohimanga, Jan. 1964, Bosser 18830 (P); Antananari- vo, SE of Nandihizano (Carion), Angavokely forest, Mt Ambatolava, 1700, Feb. 1988, Petterson E Nilsson 198 (K); Angavokely, Jan. - Feb. 1996, Ceplitis E B Brostrom 891 (P, TAN, UPS); Tampoketsa of Ankazobe, near Ambohitantely forest, May 2001, 1448 m, Hermans 2121 (K); Ambohimanga area, 2001, 1395 m, Hermans 5413 \& 5395 (K).

HABITAT. Epiphyte, terrestrial or lithophyte amongst moss, moss forest, evergreen forest. Altitude: $1200-1800 \mathrm{~m}$.

CONSERVATION STATUS. Category EN: the extent of occurrence (EOO) of Liparis imerinensis is estimated to be $53,247 \mathrm{~km}^{2}$ (far exceeding the limits for Vulnerable status under criterion B1) whereas its minimal area of occupancy (AOO) is estimated to be $40 \mathrm{~km}^{2}$ (which falls within the limits for Endangered status under the criterion B2). Liparis imerinensis is known from nine subpopulations representing nine locations (sensu IUCN), thus been preliminarily assessed as EN using the green listing method. This species is threatened by selective logging, timber harvesting for small-scale subsistence and tavy (slash-and-burn farming), resulting in habitat reduction and habitat quality reduction. The habitat in the Manjakandriana region has been destroyed and is now a Eucalyptus plantation.

FLOWERING TIME. December to May.

ETYMOLOGY. Referring to Imerina; an old kingdom and geographical area of the highlands of Madagascar.

VERNACULAR NAMES. 'Famany' (d'Alleizette 346 in P).

NOTES. Schlechter (1924) described Liparis imerinensis from a collection made by Perrier in 1920 in Manjakandriana to the $\mathrm{E}$ of Antananarivo. He mentioned that he had only little material available for his description. Perrier (1939: 294) added further information from other collections for his description in the Flore de Madagascar. Schlechter cited Perrier 12973 as the type; there are two sheets of this number in Paris and P00094997 is designated here as the lectotype and P00094998 is an isolectotype, the first specimen being more complete.

Liparis imerinensis seems to be a variable species both in plant and floral characteristics: the callus on the lip is obvious in some collections but hardly noticeable in others. Perrier 16869, 18431 and 19010 (all P) are all annotated by Perrier as 'var', perhaps confirming the variability of the species.

ILLUSTRATIONS. Fig. 27; Schlechter (1932: t.53), the drawing does not show a callus on the lip; Cribb \& Hermans (2009: 157); the photograph in Bosser \& Lecoufle (2011: 408) shown as Liparis imerinensis has the characteristics of $L$. ochracea.

Liparis jumelleana Schltr. (Schlechter 1916: 320; 1924: 142); Perrier (1939: 289); Hermans et al. (2007: 219); Cribb \& Hermans (2009: 156). Type: Madagascar, Sambirano valley, Perrier 11366 (133) (P00095450) (lectotype P, designated here; Perrier 11366 (133) (P00095451) isolectotype P). 

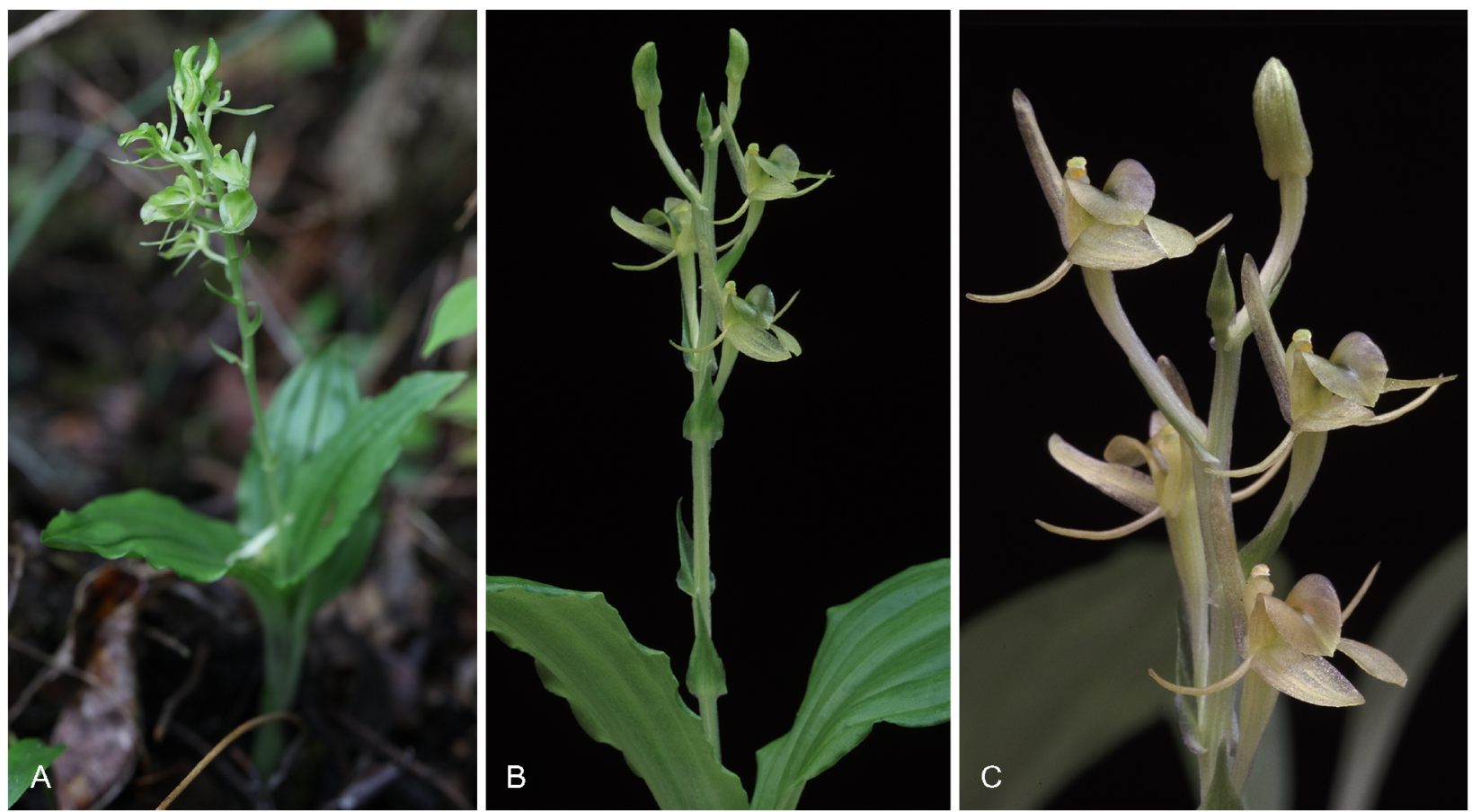

Fig. 27. Liparis imerinensis. A habit; B rachis; C flowers. PHOTOS: JOHAN HERMANS.

Small to large erect terrestrial plant, $8-24 \mathrm{~cm}$ high, rhizome very short or absent, roots wiry, somewhat woolly. Pseudobulbs 2, stem-like, elongate, fleshy, the old one leafless and at a wide angle to the flowering one or lying flat, enveloped by $2-3$ brown sheaths, sometimes with a large leaf-like sheath, up to $12 \mathrm{~cm}$ long, c. $5 \mathrm{~mm}$ diam. Leaves $2-3$, erectly spreading, thin, oval to obliquely elliptic, shortly acuminate, narrowed at the base into a short pleated-veined, petiole, $4-13 \times 1.5-6.5$ $\mathrm{cm}$. Inflorescence slender, erect, laxly 4 - 9-flowered. Peduncle up to $9 \mathrm{~cm}$, with a few sterile oval lanceolate bracts, av. $7 \times 3 \mathrm{~mm}$. Rachis c. $5 \mathrm{~cm}$ long. Floral bracts erectly spreading, lanceolate, around half the length of the ovary, $4.5-7 \times 2-3 \mathrm{~mm}$. Flowers medium size, pale greenish-yellow becoming brown with age, $12-15 \times 9.0-$ $12 \mathrm{~mm}$. Pedicel and ovary rounded at the base becoming angular towards the pedicel, up to $15 \times 1.3 \mathrm{~mm}$. Dorsal sepal recurved, lanceolate, subacute, $7.1-11 \times 1.5-2.1$ $\mathrm{mm}$. Lateral sepals porrect, semi-oblong, somewhat obtuse, $7.1-9 \times 3.5-5.1 \mathrm{~mm}$. Petals decurved, narrowly linear, subacute, $7.1-9.0 \times 0.3-0.6 \mathrm{~mm}$. Lip transversely elliptic, with proportionally small wings at the narrow base, the blade very rounded at the sides, the front margins almost straight ending in a small triangular cusp, with two small but distinct thickened calli at the base thinning out into three strong central veins, 5.1 $6.3 \times 6.9-10.1 \mathrm{~mm}$. Column almost straight, somewhat broadened towards the base, with two small wings at the apex, $3.0-3.3 \times 1.1-1.3 \mathrm{~mm}$. Anther rounded with a distinct acute beak, c. $1.0 \times 1.2 \mathrm{~mm}$. Pollinia pear-shaped, c. $0.5 \times 0.4 \mathrm{~mm}$.

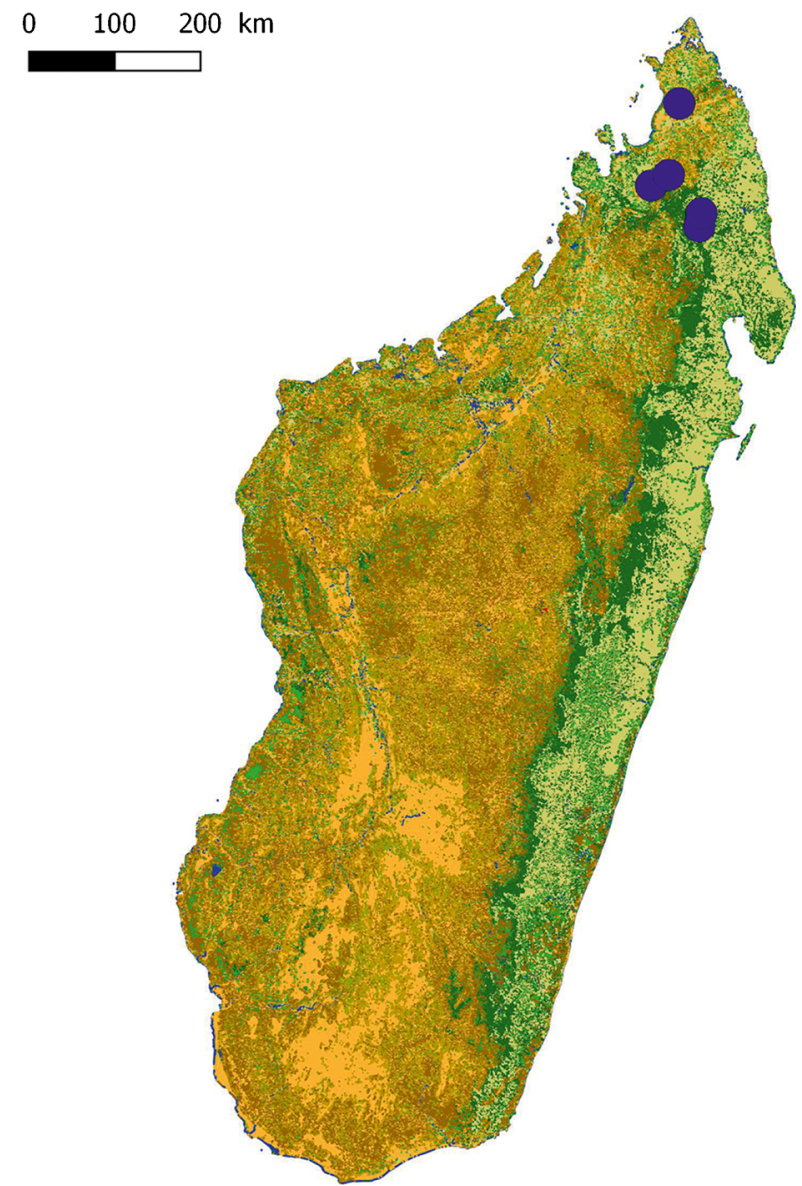

Map 25. Distribution of Liparis jumelleana. 
RECOGNITION. Usually a squat plant with $2-3$ thin leaves on the flowering growth, the previous growth being leafless and lying at an angle or flat on the ground. It has short, stem-like pseudobulbs, mediumsized flowers with a typically broad lip with a short triangular apex, small wings at the base and two small but distinct nipple-like calli at the base thinning out into the three central veins, and an anther with a sharp beak.

The only other species with a very broad lip is Liparis laurentii described below but L. laurentii has a single perennial leaf on a slender pseudobulb (vs 2 to 3 deciduous leaves of a different shape and size), the lip calli are shorter and blunter in L. jumelleana. In habit it somewhat resembles L. imerinensis but the lip shape and callus are very different with the lip transversally elliptic vs oval and the callus small and rounded vs two-horned.

DISTRIBUTION. Endemic to Madagascar: Antsiranana. The distribution is scattered from the Sambirano region in the North to Andapa in the NE (Map 25).

SPECIMENS EXAMINED. MADAGASCAR. Sambirano valley, Perrier 11366 (133) (lectotype P (P00095450); isolectotype P (P00095451); Marivorahona massif, SW Manambato, high Mahavavy to North, Ambilobe distr., 2200 m, March 1951, Humbert 25774 (P); Ankarana massif, Diego-Suarez, 30 - 350 m, Jan. - Feb. 1960, Humbert 32481 (P); Antsiranana, Anjialavabe, near Tsaralanto village, Feb. 2006, 1030 m, Antilahimena et al. 4604 (P, MO); Antsiranana, Andapa, Doany, SE of Andranomolo, 1489 m, April 2006, Rakotovao et al. 3139 (K, MO).

HABITAT. Epiphyte, terrestrial or lithophyte in humid evergreen forest at mid-altitude. On gneiss rock. Altitude: $300-2200 \mathrm{~m}$.

CONSERVATION STATUS. Category EN: the extent of occurrence (EOO) of Liparis jumelleana is estimated to be $4,675 \mathrm{~km}^{2}$ (within the limits for Endangered status under criterion B1) whereas its minimal area of occupancy (AOO) is estimated to be $20 \mathrm{~km}^{2}$ (which also falls within the limits for Endangered status under the criterion B2). With five known subpopulations representing five locations (sensu IUCN), L. jumelleana has been preliminarily assessed as EN using the green listing method. This species is threatened by selective logging, timber harvesting for small-scale subsistence and tavy (slash-and-burn farming), resulting in habitat reduction and habitat quality reduction.

FLOWERING TIME. October to May.

ETYMOLOGY. Named for Henri Jumelle (1866 - 1935), professor of botany and director of the Botanic Garden in Marseille (France). He did not work in Madagascar but collaborated extensively with Perrier.

NOTES. Some of Perrier's earlier collections followed an alternative numbering system: here the type has the old number 133 bracketed by Perrier, with the new number 11366. As often, Schlechter assigned more than one herbarium sheet to the name; from these the specimen P00095450, corresponding most closely to the description, has been designated as lectotype, the other (P00095451) as the isolectotype.

Plant size is quite variable as is obvious from the type specimens but lip size and shape seem to be consistent throughout its range.

ILLUSTRATIONS. Fig. 28; Schlechter (1932: t.54); Perrier (1939: 283).

Liparis laurentii Hermans $\mathcal{E}$ Nusb. sp. nov. Type: Madagascar, Antsiranana, Sava Region, Vohemar distr., Commune rurale de Nosibe, forêt de Bobankora, partie nord, 410 m, 3 March 2003, Gautier, Wohlhauser E Nusbaumer 4204 (holotype G (G00007152), isotypes K (K000395947), P (P00635637), TAN, MO, herbarium of Daraina).

http://www.ipni.org/urn:lsid:ipni.org:names:60479367-2

Small scrambling to ascending terrestrial plant of $2-3$ growths, up to $9 \mathrm{~cm}$ high, on a short rhizome, roots flexuose, somewhat woolly, c. $1 \mathrm{~mm}$ diam. Pseudobulbs slender, ascending, tubular, more or less thickened towards the base, $20-45 \times 5-10 \mathrm{~mm}$, dark green, entirely enveloped by $2-3$ long brownish papery attenuate sheaths, strongly ridged and with a few dark brown specks, the upper one caudate, up to $23 \times 7$ $\mathrm{mm}$, with a single leaf at the apex. Leaf somewhat fleshy, persistent on the older pseudobulbs, broadly ovate, acute, rounded to subcordate at the base, with a $1-2 \mathrm{~cm}$ sheathing petiole, blade leathery and rigid, pale green, with several darker veins, $3.1-7.5 \times 2.5-$ $4.5 \mathrm{~cm}$. Inflorescence erect from the apex of the pseudobulb, up to $9 \mathrm{~cm}$ long, carrying up to 5 flowers but generally fewer. Peduncle partly enveloped by the leaf petiole and with $1-2$ bract-like sheaths, $5.1-9 \times$ 3.2 - $4.6 \mathrm{~mm}$. Rachis loosely racemose, the older flowers fading before the new ones open. Floral bracts lanceolate, somewhat cordate at the base, $3.5-6 \times 0.9$ $-3.1 \mathrm{~mm}$. Flowers medium sized, c. $1.8 \times 1.5 \mathrm{~cm}$, facing upwards, the ovary and floral bracts pale whitishgreen, the petals and sepal brownish green, the lip pale green with the disk darker viridian, anther darker green. Pedicel and ovary slender, slightly winged, sometimes somewhat dentate, $10-16 \times 1.1-2.1$ $\mathrm{mm}$. Dorsal sepal erect, arching, the margins recurved, ligulate, acute, $7.2-10.3 \times 1.1-1.8 \mathrm{~mm}$. Lateral sepals falcate-oblong, obtuse, parallel with the lip, margins a little recurved, $5.1-9.8 \times 3.2-4.8 \mathrm{~mm}$. Petals spreading, curled upwards towards the apex, margins recurved, linear, $7.2-9 \times 0.3-0.5 \mathrm{~mm}$. Lip transversely elliptic to reniform, with small basal wings, the margin entire but the anterior tip emarginated with a small central lobule, base with two distinct hornlike calli, $4.1-6.5 \times 6.1 \times 7.8 \mathrm{~mm}$. Column slightly 

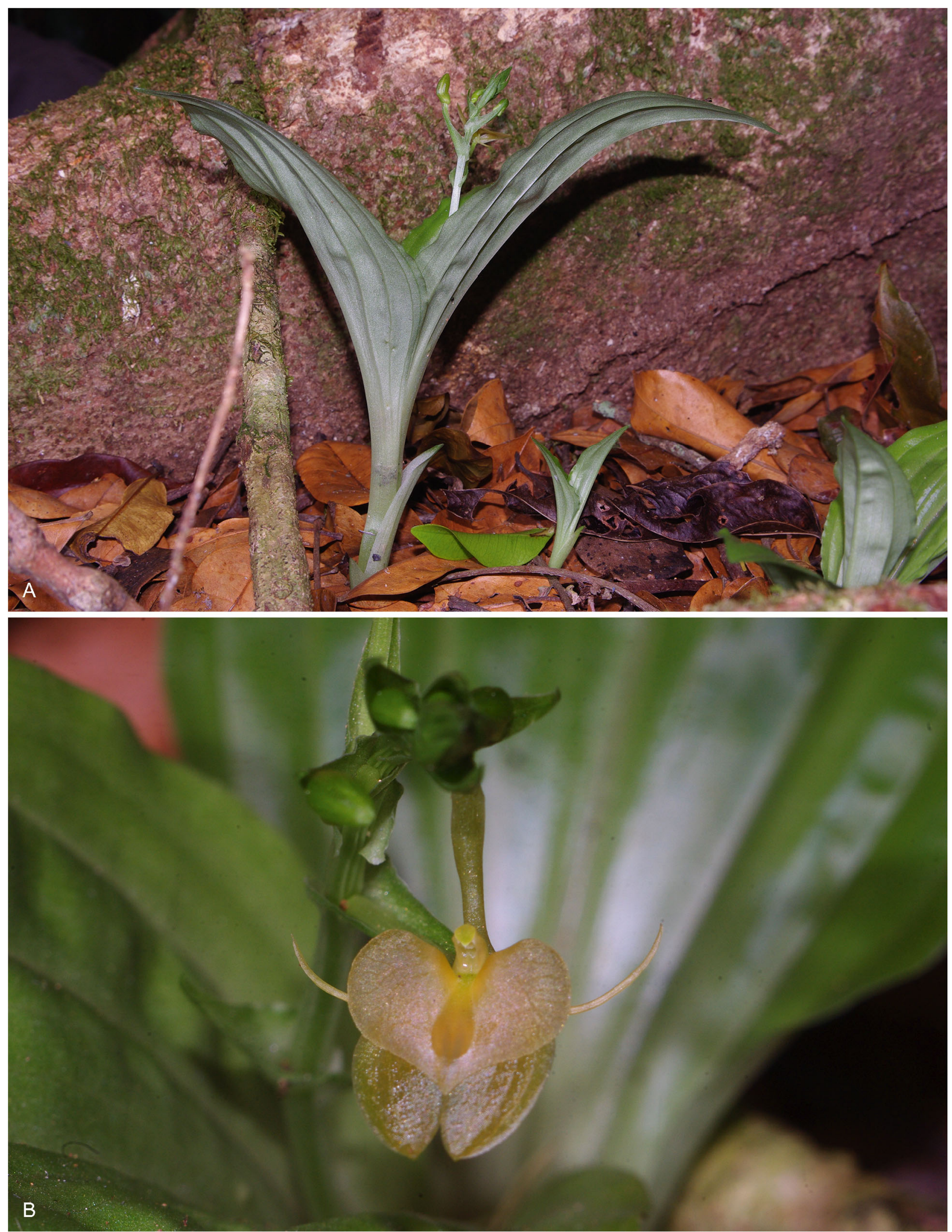

Fig. 28. Liparis jumelleana. A habit; B flower. PHOTOS: MARC MOREL (SFO).

arched towards the apex, wings long, membranous, rounded, $2.5-3.9 \times 1-1.3 \mathrm{~mm}$. Anther ovate with a distinct sharp beak upturned at the apex, sometimes a little verrucose on the exterior, remaining attached by 
a thin filament at the base after pollination, c. $2.2 \times 0.8$ $\mathrm{mm}$. Pollinia ovate c. $0.4 \times 0.3 \mathrm{~mm}$. Fruit: young capsule ovoid, $7 \times 4 \mathrm{~mm}$, with six longitudinal bands including three more protruding, mature capsule and seeds unknown.

RECOGNITION. Liparis laurentii is a small single-leaved plant with a slender pseudobulb, broadly ovate leaf, few-flowered inflorescence, and medium-sized flowers, with a transversely elliptic to reniform lip, the anterior tip emarginate with a small central lobule and a base with two distinct horn-like calli.

It is related to Liparis clareae but smaller, the leaf has a more distinct central vein and the base is rounded (vs cordate), has fewer flowers ( $1-5$ vs $6-$ 12), a much wider, transversely elliptic to reniform lip (vs ovate), with entire margins (vs serrate), an emarginate apex (vs entire), horn-like basal calli (vs slight swellings) and elongate column wings (vs short and obtuse). It has similarities with $L$. warpurii but the leaf of $L$. laurentii is broadly ovate (vs lanceolate), the flowers smaller and the lip not serrate at the margins and with horn-like calli (vs a single rounded callus). It is similar in size to L. magnifica described below but the lip is transversally elliptic (vs obovate), the anther beak is much longer and the lip callus is separate (vs joined). It differs from $L$. superclareae described below, by its diminutive size, and shape of the lip, callus and anther (Table 8 ). The only other species with a very broad lip is $L$. jumelleana but $L$. laurentii has a single perennial leaf on a slender pseudobulb (vs two to three deciduous leaves of a different shape and size on a ridged pseudobulb), and the lip calli are shorter and blunter in L. jumelleana.

DISTRIBUTION. Endemic to Madagascar: Antsiranana province only. The species has been found in the Loky-Manambato National Park (Daraina) area in the NW and another collection was made a little further South near Doany (Map 26).

SPECIMENS EXAMINED. MADAGASCAR. Diego Suarez, Vohemar, Daraina, Bobankora forest, $410 \mathrm{~m}$, March 2003, Gautier et al. 4204 (holotype G, isotypes K, P, TAN); Anjialavahely, Sava, Andapa, Doany, Anjialavahely, Feb. 2006, 1293 m, Ravelonarivo et al. 1606 (MO, P).

HABITAT. Terrestrial amongst leaves and humus in forest from $410-1293 \mathrm{~m}$ altitude. In the LokyManambato National Park (Daraina), a total of about 40 individuals were observed in one locality during the flora and vegetation survey of the region. The species was there growing on the ground, along a crest, close to the top of a granitic mountain reaching $607 \mathrm{~m}$ elevation with a non-climatic raw mineral soil (Riquier 1968; Jourde et al. 1974). It grows in a mesophilous forest surrounded by a matrix of dry deciduous forest. The vegetation of the Daraina locality reaches up to 10 - $15 \mathrm{~m}$ high with emergent trees up to 18 (-21) m, with a quite dense shrub stratum at $0.5-1 \mathrm{~m}$ high, with shrub strata increasing in density between $4-8 \mathrm{~m}$ high and with a very sparse stratum at $8-10 \mathrm{~m}$ high (Gautier et al. 2006; Nusbaumer 2011). Altitude: 410 $1293 \mathrm{~m}$.

CONSERVATION STATUS. Category EN: The extent of occurrence (EOO) of Liparis laurentii cannot be estimated since it is only known from two subpopulations, one included in the Loky-Manambato Category V Protected Area (Daraina) and the second one at 100 $\mathrm{m}$ exterior of the limit of the provisionally protected area of the Corridor Marojejy-Anjanaharibe-SudTsaratanana (COMATSA), whereas its minimal area of occupancy (AOO) is estimated to be $8 \mathrm{~km}^{2}$ (which falls within the limits for Critically Endangered status under the criterion B2). With only two known subpopulations representing two locations (sensu IUCN), this species has been preliminarily assessed as EN using the green listing method. This species is threatened by selective logging, timber harvesting for small-scale subsistence and tavy (slash-and-burn farming), resulting in habitat reduction and habitat quality reduction. In the Daraina region, this species was collected rather early during the floristic survey and we expected several subpopulations to be observed

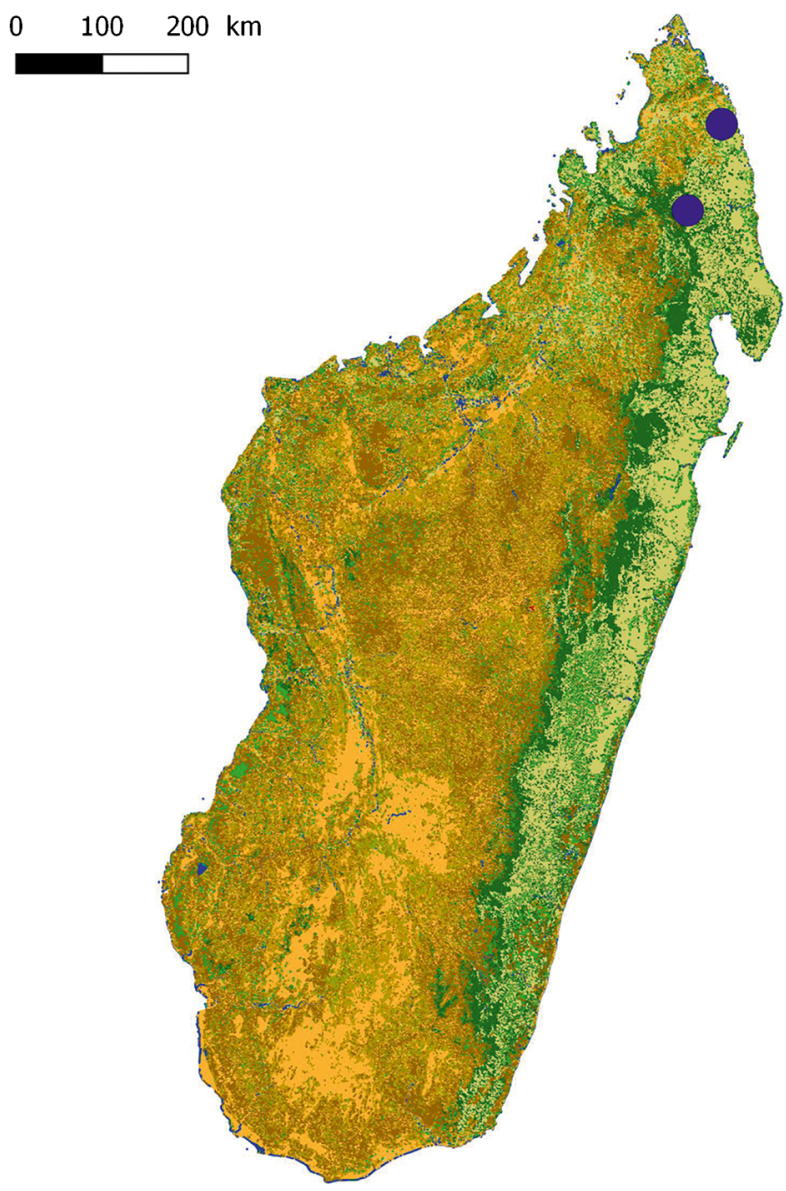

Map 26. Distribution of Liparis laurentii. 


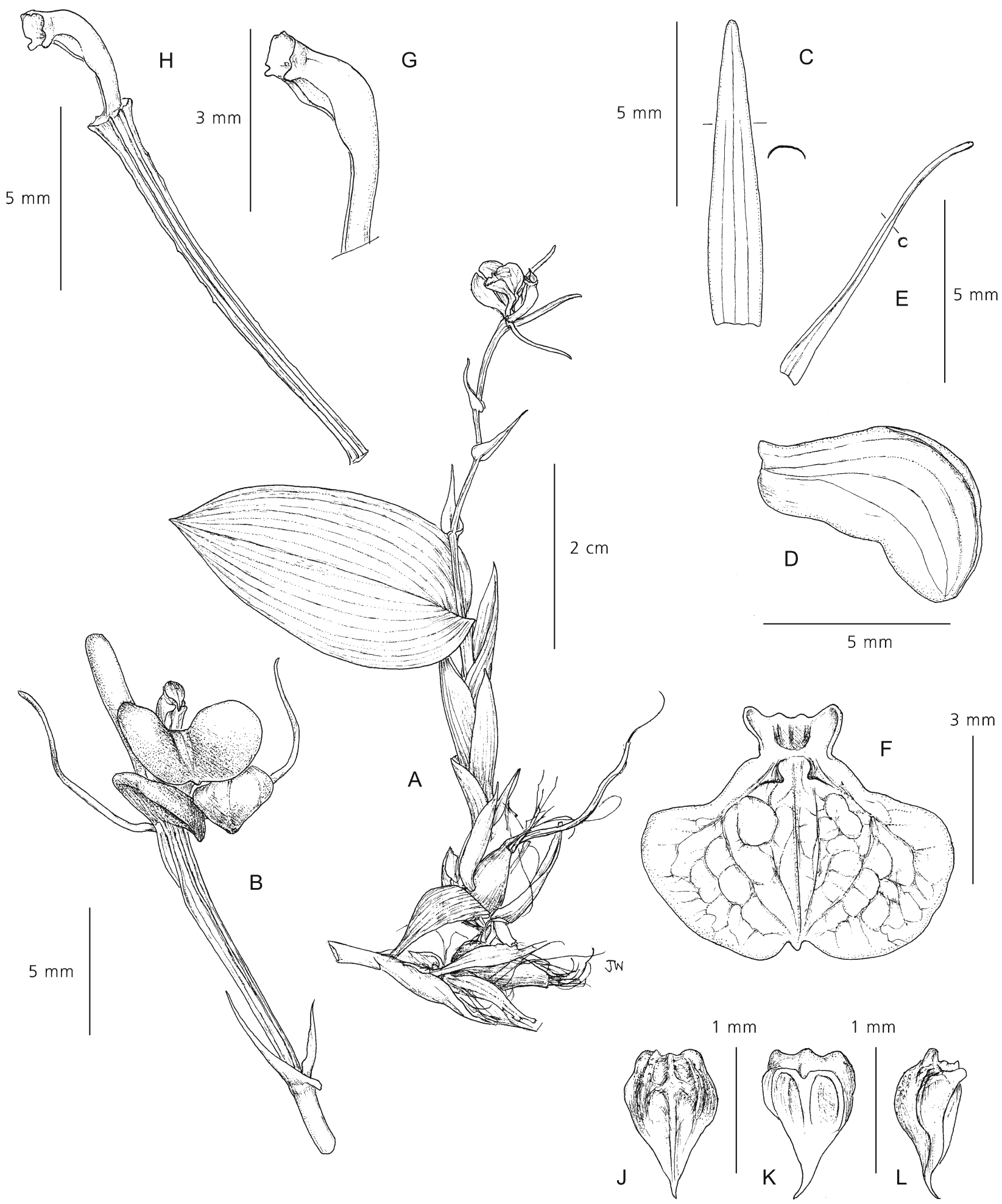

Fig. 29. Liparis laurentii. A habit; B flower; C dorsal sepal; D lateral sepal; E petal; F lip; G column, side view; H column and ovary; J anther cap from above; K anther cap from below; L anther cap, side view. From Nusbaumer LG4204 (G). DRAWN BY JULIET BEENTJE.

later, because its habitat, the mesophilous forest, is quite frequent in Loky-Manambato. Nevertheless, it turned out that no additional fertile or sterile material of this species was encountered among the more than
54,000 plant species occurrences recorded including about 5,000 herbarium specimen collections (Nusbaumer 2011).

FLOWERING TIME. February to March. 
ETYMOLOGY. Named for Dr Laurent Gautier of the Conservatoire et Jardin botaniques de Genève, one of the co-finders of the new species, the upturned petals also have a striking resemblance to his beautifully groomed moustache.

NOTES. The new species is known from two localities in North-Eastern Madagascar. Specimens in herbaria had either been unidentified or named as Liparis clareae with which it shares a number of features but is very different, as discussed above. The plant from the Doany area (Ravelonarivo et al. 1606) comes from a much higher elevation than those collected in the Bobankora forest near Daraina (Gautier et al. 4204), they also seem to consist of more mature and therefore larger plants and flowers; all other characteristics and proportions are otherwise identical.

ILLUSTRATIONS. Figs 29, 30.

Liparis listeroides Schltr. (Schlechter 1924: 143); Perrier (1936: 247; 1939: 273); Hermans et al. (2007: 219); Cribb \& Hermans (2009: 148); Hervouet (2018: 410). Type: Madagascar, Andringitra massif, March 1922, c. 1400 m, Perrier 14440 (P00095453) (lectotype P, designated here); Perrier 14440 (P00095454) (isolectotype P).
Medium sized, slender, erect terrestrial or epiphytic plant, up to $18 \mathrm{~cm}$ high, rhizome very short, roots wiry, more or less hairy. Pseudobulbs stem-like, thin, erect, fleshy, enveloped by thin grey striate sheaths overlapping each other, with two leaves at the apex (rarely 3), older growths retaining their leaves, up to $13 \mathrm{~cm}$, c. $5 \mathrm{~mm}$ diam. Leaves sub-opposite, erectly spreading to sub-erect, oval or elliptic-lanceolate, acute, base rounded or wedge-shaped, sessile or on a short petiole, fairly leathery and glossy, pale green becoming darker with age, $3.5-7.3 \times 1.5-3.0 \mathrm{~cm}$. Inflorescence erect, up to $15 \mathrm{~cm}$ long and almost as long as the pseudobulbs, sub-laxly 5 - 15-flowered. Peduncle almost as long as the raceme, slightly ridged, with two to three sheaths c. $5 \times$ $3 \mathrm{~mm}$. Rachis successive flowering, up to $9 \mathrm{~cm}$ long. Floral bracts erectly spreading, acuminate, about $1 / 3-1 / 2$ the length of the pedicellate ovary, c. $4 \times 2 \mathrm{~mm}$. Flowers small to medium in size $8-11 \times 6.5-7 \mathrm{~mm}$, greenishyellow becoming more yellow with age, the disk of the lip darker viridian green, lip generally appears darker in herbarium material. Pedicel and ovary glabrous, slender, a little ridged, $8-12 \times 0.7-3 \mathrm{~mm}$. Dorsal sepal reflexed (often remaining in herbarium material), narrowly lanceolate almost tubular, somewhat obtuse, base subcordate to auriculate, $5.5-8.0 \times 1.1$ - $1.5 \mathrm{~mm}$. Lateral sepals folded beneath the lip, semi-

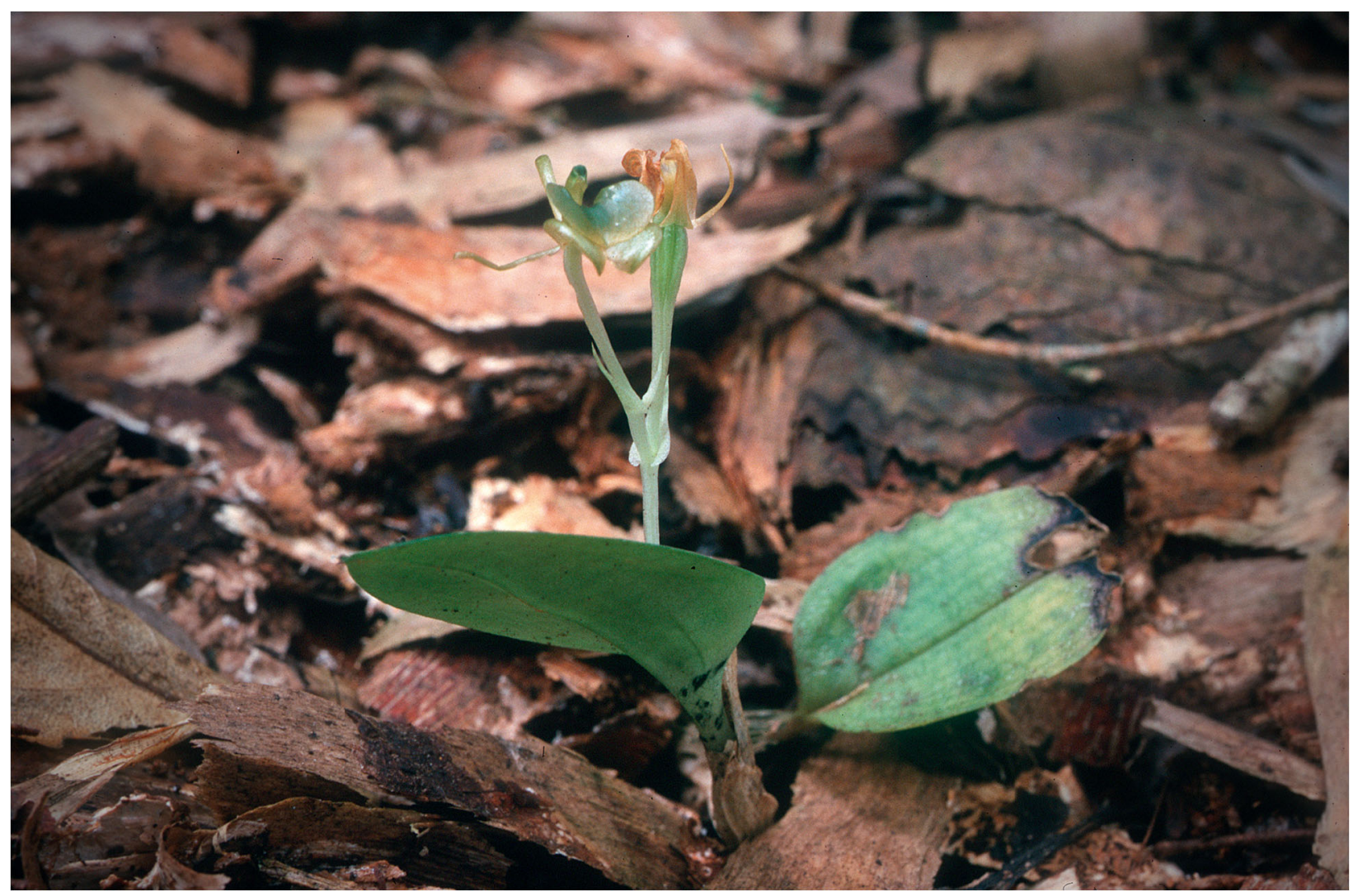

Fig. 30. Liparis laurentii. Habit of the type collection with fresh flower and wilted flower on a young fruit. PHOTO: LOUIS NUSBAUMER. 
oval, obtuse, $5.0-6.0 \times 2.5-3.9 \mathrm{~mm}$. Petals reflexed, linear almost tubular, subacute, slightly narrowing towards the base, $5.5-8.3 \times 0.5-0.8 \mathrm{~mm}$. Lip slightly curved, shortly auriculate at base, expanded into an obcordate blade sometimes covered by small viscous droplets in living plants, with two simple central veins and two branched lateral ones, the margins curved, the front margin a little denticulate-undulate, subtruncate or emarginated with a bicornate or 2horned callus at the base which can be up $1.4 \mathrm{~mm}$ long, $4.5-7.1 \times 5.0-6.9 \mathrm{~mm}$. Column slightly curved, up to $5 \times 1.5 \mathrm{~mm}$, somewhat angular wings. Anther with a short, obtuse beak, c. $1.0 \times 1.1 \mathrm{~mm}$. Pollinia 2 pairs, oval c. $0.5 \times 0.6 \mathrm{~mm}$.

RECOGNITION. Distinguished by its long stem with two somewhat leathery oval-lanceolate leaves at the top. Its lip is entire, slightly indented on the anterior margin and rounded with a distinct two-horned callus at the base. Its anther is slightly beaked. It is a very variable species both in shape of the lip and that of the two calli on the lip which can be more or less united or separate and up to $1.4 \mathrm{~mm}$ long, parallel or slanting. In herbarium specimens, the lip of the flowers often appear considerably darker and denser than the rest of the floral segments.

Both Liparis bernieri and L. danguyana are similar species but there are substantial differences (Table 5). The leaf of L. danguyana is thinner than those of L. bernieri and L. listeroides which are more leathery with indistinct veins. The flowers of L. listeroides are generally smaller than the other two. The lip of L. danguyana has two small but distinct calli at the base, those of $L$. bernieri are less distinct and rounded, those of L. listeroides are long and tooth-like. The front margin of the lip of L. danguyana is apiculate, the others have a slightly denticulate margin. The anther cap of L. danguyana is rounded at the front and suborbicular, that of L. listeroides is slightly beaked. Considering these differences and specific geographical distribution it is reasonable to recognise all three species. Vegetatively, there is some resemblance with L. stenophylla but the leaves are more lanceolate than elliptic. It shares the basal teeth of the lip with L. polycardia and L. imerinensis but the plant and flower are smaller, the leaves shorter and broader and the inflorescence shorter.

DISTRIBUTION. Endemic to Madagascar: Antananarivo, Antsiranana and Fianarantsoa provinces (Map 27).

SPECIMENS EXAMINED. MADAGASCAR. Andringitra massif, March 1922, c. 1400 m, Perrier 14440 (P00095453) (lectotype P); Perrier 14440 (P00095454) (isolectotype P); Centre, Mandraka, Ankeramadinika forest, François in Herb. Perrier 16966bis (P); Centre, Mt Tsaratanana, forest, c. 1500 m, April 1924, Perrier 16089 (P); Centre, Tsinjoarivo, forest, c. $1400 \mathrm{~m}$, Feb. 1925, Perrier 16970bis (P); Mandraka, undergrowth, evergreen forest, Feb. 1959, Bosser 12625 (P); Mandraka, Feb. 1959, Bosser 12723 (TAN); Antananarivo, Mandraka, PK69, March 1984, Dorr et al. 2918 (K, MO, P, TAN); E of Ankaramy, Manongarivo, Antsatrotro, 1470 - 1570 m, April 1992, Malcomber et al. 1498 (K, MO, TAN); Moramanga area, Fiheranana, 1999, Hermans 2867 (K); Antananarivo, near Mandraka, $1215 \mathrm{~m}$ alt., Jan. 2000, Hermans 4869 \& 5203 (K); Antananarivo, towards Anjozorobe along RN3, 1550 - 1600 m, Jan. 2000, Hermans 456 (K); Toamasina, near Andasibe, Jan. 2000, Hermans 4945 (K); Toamasina, road to Lakato $1041 \mathrm{~m}$, Feb. 2000, Hermans 1003 (K); Toamasina, Mantadia area, May 1997, 1089 m, Hermans 5598 (K); Toamasina, Anosibe an'ala, April 2010, Rajavelona et al. 235 (K, TAN); Sofia, Bandabe, Apr. 2007, Revelonarivo 2264 (P); Antsiranana, Ampasindava, Bongomihiravavy forest, Dec. 2008, Madiomanana et al. MAD 201 (G); Toamasina, Ambatovy, 1070 m, April 2014, Ambatovy Spirit Collection 1575 (TAN); Antsiranana, Mt d'Ambre, 890 m, Ramandimbimanana et al., SDR050 (G, K, P); Antsiranana, Mt d'Ambre, April 2008, Trigui et al. SMT263 (G, K, P).
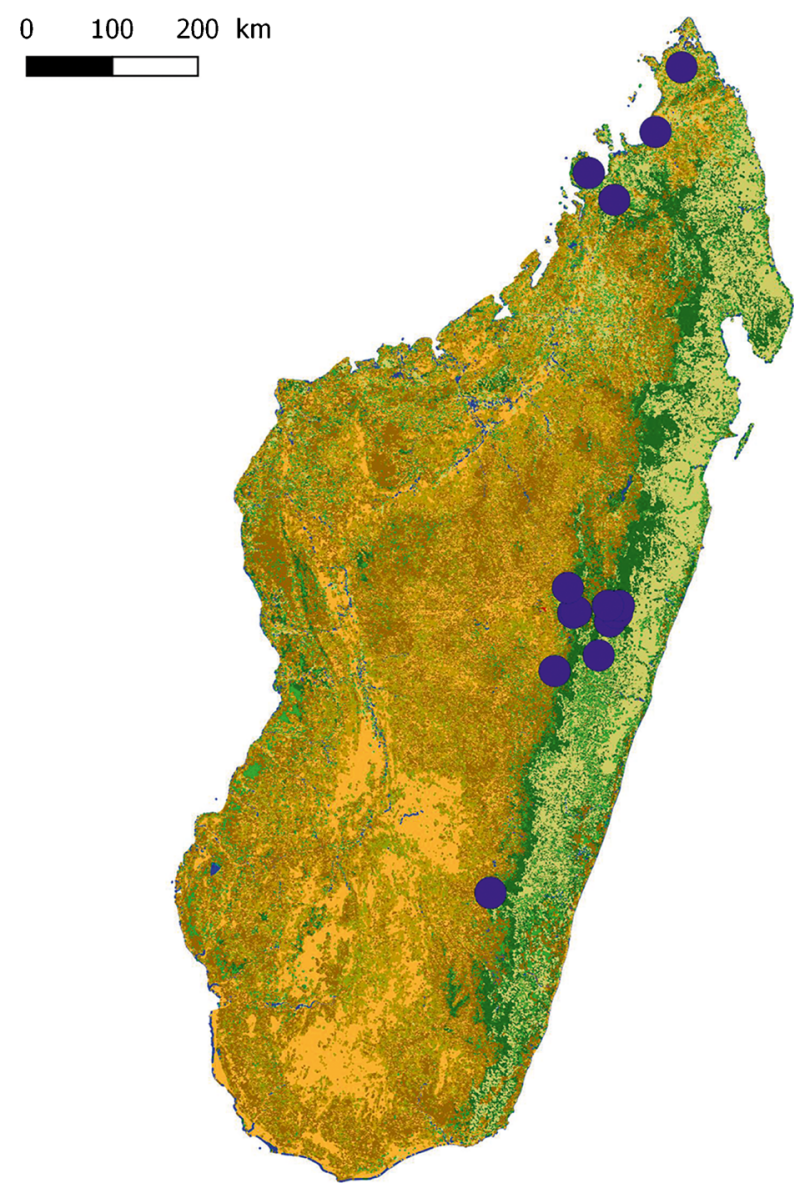

Map 27. Distribution of Liparis listeroides. 

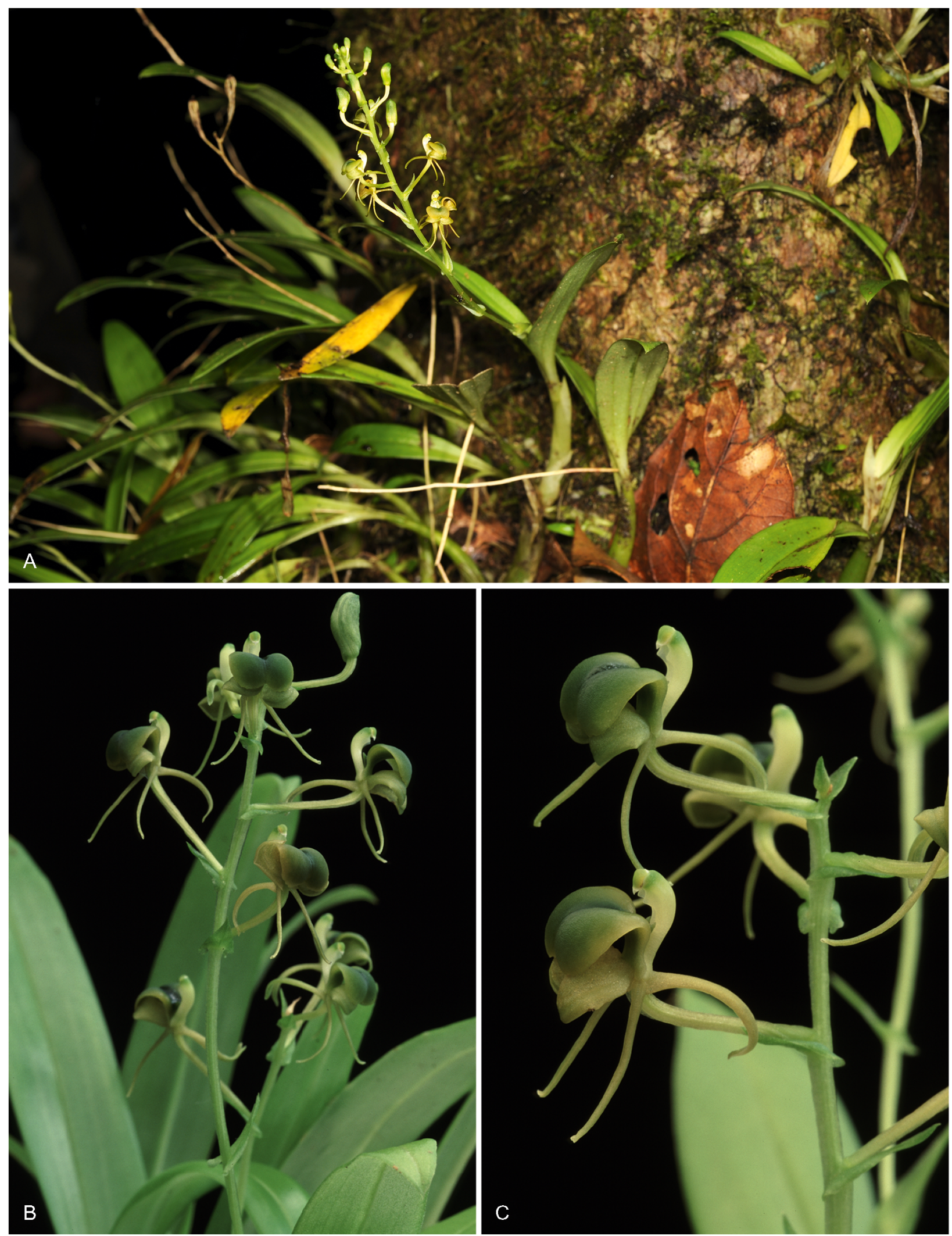

Fig. 31. Liparis listeroides. A habit; B inflorescence; C flowers. PHOTOS: A JEAN-MICHEL HERVOUET; B, C JOHAN HERMANS. 
HABITAT. Moss forest, evergreen forest in undergrowth, in shade, moss and lichen-covered trees. Altitude: 1040 - $1600 \mathrm{~m}$.

CONSERVATION STATUS. Category LC: the extent of occurrence (EOO) of Liparis listeroides is estimated to be $87,271 \mathrm{~km}^{2}$ (far exceeding the limits for Vulnerable status under criterion B1) whereas its minimal area of occupancy (AOO) is estimated to be $56 \mathrm{~km}^{2}$ (which falls within the limits for Endangered status under the criterion B2). Because L. listeroides is known from 12 subpopulations representing 14 locations (sensu IUCN), this species has been preliminarily assessed as LC using the green listing method. This species is threatened by mining activities, selective logging, timber harvesting for small-scale subsistence and tavy (slash-and-burn farming), resulting in habitat reduction and habitat quality reduction. More specifically the species has been affected by habitat loss due to land clearance by burning in the Manongarivo and Mandraka areas. Also affected by charcoal production in the Lakato area.

FLOWERING TIME. January to April.

ETYMOLOGY. The plant resembles a medium-sized Listera R.Br. in its habit (Schlechter 1924: 143). Listera, in turn, was named for Dr Martin Lister (c. 1638 1712), English physician and naturalist.

NOTES. Schlechter assigned more than one herbarium sheet to the type; the specimen (P00095453) corresponding most to the description and most complete was designated as the lectotype, the other (P00095454) being an isolectotype.

ILLUSTRATIONS. Fig. 31; Schlechter (1932: t.54); Cribb \& Hermans (2009: 151); Hervouet (2018: 410).

Liparis longicaulis Ridl. (Ridley 1885: 461; 1886b: 270); Perrier (1936: 246; 1939: 272); Hermans et al. (2007: 220); Cribb \& Hermans (2009: 148); Hervouet (2018: 411). Type: Madagascar, Ankafana, Hildebrandt 3979 (lectotype BM00090069, designated here; Hildebrandt 3979 isolectotypes G, K, M, P, WU, Z); Madagascar, Ankafana, Deans Cowan s.n. BM00090068 (lectoparatype BM), Hildebrandt 3979 P00095461 (lectoparatype $\mathrm{P})$.

Leptorkis longicaulis (Ridl.) Kuntze (1891: 671). Type as above.

Liparis longicaulis var. crassilabia in Herb. Perrier (16072) nom. nud. Type: Central, Mt Tsaratanana, April 1924, Perrier 16072 (P001778654-7).

Large terrestrial or rarely epiphytic plant up to $35 \mathrm{~cm}$ tall, rhizome short, repent or slightly ascending, roots more or less finely villous. Pseudobulbs often clustered, stem-like, up to $25 \mathrm{~cm}$ long, 5 - $11 \mathrm{~mm}$ diam., distinctly tetragonal or angular-winged when alive, enveloped by several overlapping greyish-white sheaths along its length, carrying two leaves (very rarely three) at the apex. Leaves broadly ovate, rounded to sub-cordate at the base, subsessile or shortly petiolate, attenuate to acuminate at the tip, undulate, crenulate along the margins, glaucous green to pale green, $5-9 \times 3.2-5.5 \mathrm{~cm}$. Inflorescence erect carrying up to 10 flowers but generally fewer, often exceeding the length of the stem, $10-24 \mathrm{~cm}$. Peduncle about twice the length of the rachis, c. $2 \mathrm{~mm}$ in diam., with one or two cordate to lanceolate peduncle sheaths up to $10 \times 5 \mathrm{~mm}$. Rachis about $1 / 2$ to $1 / 3$ of the inflorescence, laxly-flowered. Floral bracts lanceolate, the base more or less cordate, $7-10 \times 2-4.5 \mathrm{~mm}$. Flowers large, up to $24 \times 18 \mathrm{~mm}$, olive green to dark green becoming more yellow with age, the lip with a darker disk, column and ovary white, pollen yellow, flowers opening in succession, the upper ones sometimes cleistogamous or deformed. Pedicel and ovary somewhat ridged to winged, $11-17 \times 0.6-1.8 \mathrm{~mm}$. Dorsal sepal erect or curved forward a little at the apex, linear to ligulate, attenuate, margins recurved, $16-22$ $\times 1.5-3.5 \mathrm{~mm}$. Lateral sepals forming a platform below the lip, sometimes partly fused into one blade, broadly falcate, the outer margins curved upwards, $10-18 \times 5$ - $7.9 \mathrm{~mm}$. Petals narrow linear, recurved, the margin incurved, $10-15 \times 0.6-1.3 \mathrm{~mm}$. Lip oval to broadly ovate, the base with short rounded wings then broadening into an obtuse anterior lobe with an irregular dentate margin, callus at the base fairly indistinctly bilobed-rounded, $10-13.2 \times 5.5-9.9$ mm. Column slender, slightly arching, wings long, obtuse, $4.5-6.9 \times 1-1.9 \mathrm{~mm}$. Anther generally with a short angular-obtuse beak, $1.1-1.6 \times 0.6-1.3 \mathrm{~mm}$. Pollinia two pairs united at the tip by an obsolete viscidium, c. $0.7 \times 1 \mathrm{~mm}$.

RECOGNITION. This is a large plant with long angular (sometimes not obvious in herbarium material) pseudobulbs, almost entirely covered by white sheaths, broadly ovate leaves, and large flowers with an obtuse lip, crenulate at the front, and a small rounded callus at the base.

It bears some similarity to Liparis gracilipes but its leaves are much thinner and broadly oval vs elliptic, the lip ovate vs suborbicular, the callus indistinct vs tridentate. There is also some similarity to L. zaratananae but again the pseudobulbs are angular vs rounded, the leaves broadly ovate vs ovate-elliptic and the lip ovate vs oval. Historically it has been confused in the field and in herbaria with the newly described L. chantaliae but it is distinct because of its angular (vs rounded) pseudobulbs covered by papery sheaths, short rhizome, slightly smaller flowers, lip with an obtuse tip (vs attenuate), indistinct callus and the less acute beak of the anther (Table 7).

DISTRIBUTION. Widespread and endemic to Madagascar: Antananarivo, Antsiranana, Fianarantsoa, Mahajanga and Toamasina provinces (Map 28). 

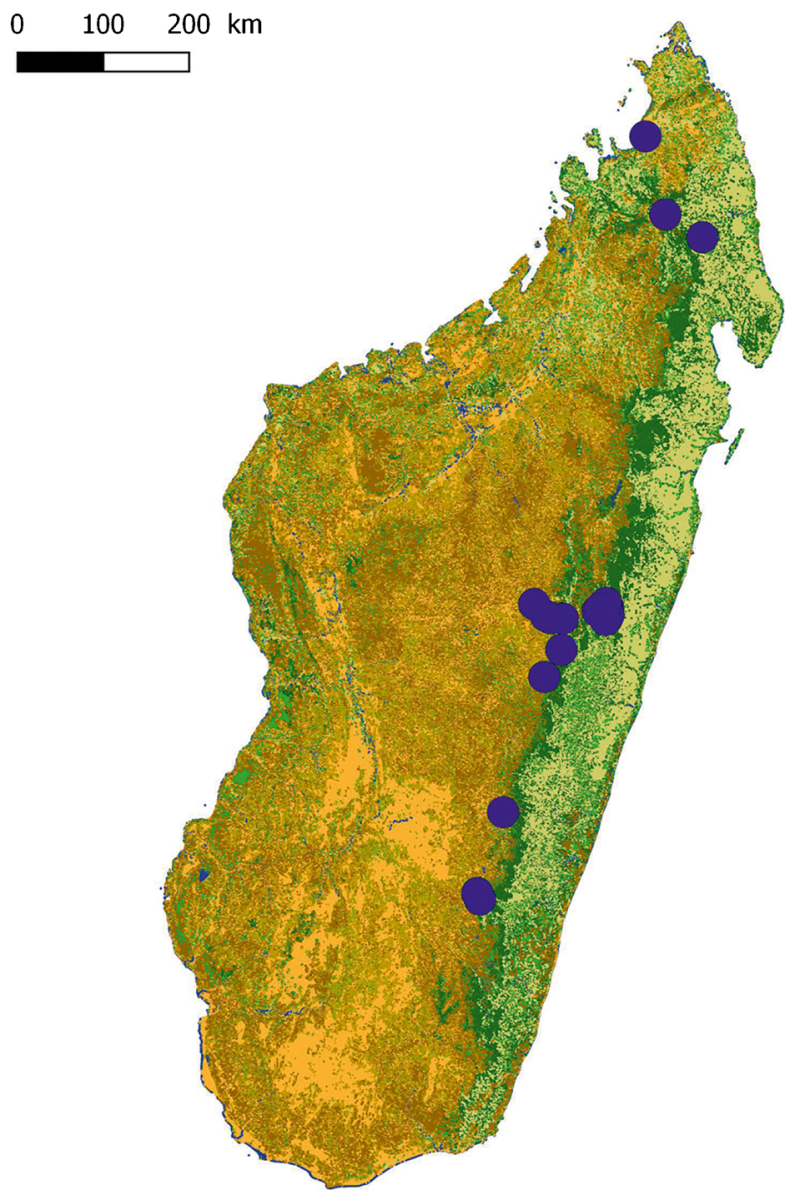

Map 28. Distribution of Liparis longicaulis.

SPECIMENS EXAMINED. MADAGASCAR. Ankafana, Hildebrandt 3979 (lectotype BM, isolectotypes G, K, M, P, WU, Z); Ankafana, Deans Cowan s.n. BM090068, P00095461 lectoparatypes BM, P); Imerina, Ankeramadinika, Fox 20 (BM, K); Central, Dec. 1883, Baron s.n (K); Betsileo-land, Baron 228 (K); s. loc. Warpur 20 (K); Ambohimanga, 1906, Alleizette 351bis (P); Ambatovory, June 1909, Alleizette 346bis (P); Central, Mt Tsaratanana, c. 1800 m, April 1924, Perrier 16072 (P); Andasibe forest, Onive valley, c. $1000 \mathrm{~m}$, Feb. 1925, Perrier 16969 (P); Central, Tsinjoarivo, c. 1400 m, Feb. 1925, Perrier 16966 (P); Analabe, forest remnant N of Antananarivo, Feb. 1928, Perrier 18430 (P); NE, Marojejy massif, 800 - 1200 m, Jan. Feb. 1949, Humbert 23158 (G, P); Anjozorobe, March 1959, Bosser 12858 (P); Eastern side of Lake Tsiazompaniry, $1600 \mathrm{~m}$, March 1970, Bosser E Morat 1432 (P); lake Tsiazompaniry, March 1970, Bosser 20010 (P); Angavokely, 1992, Petterson E Nilsson 562 (P, K); Mangindrano area, Ambohimirahavavy Mts, 1800 m, 1997, Hermans 2390, 2391, 2607 (K); Toamasina, near base of Col de Mantadia, $958 \mathrm{~m}$ alt., Feb. 2000, Hermans 4972 (K); Fianarantsoa, Andringitra, 1765 m, 2005 Fischer 2110 (WU); Toamasina, Ambatovy forest, $1086 \mathrm{~m}$, March 2005,
Antilahimena et al. 3659 (TAN); Toamasina, Moramanga, Ambohibary, Ampitambe, Ambatovy, 1135 m, March 2005, Andriantiana 95 (MO, P, TAN); Toamasina, Andasibe, 1157 m, March 2007, Antilahimena 5644 (TAN); Toamasina, Ambatovy, 1122 m, June 2008, Rakotondrajaona 441 (MO, P, TAN); Toamasina, Ambatovy, 959 m, July 2008, Radrianasolo et al. 756 (MO, P, TAN); Toamasina, Ambatovy, 1135 m, July 2008, Radrianasolo et al. 789 (TAN); Toamasina, Menalamba, Analamay, 1069 m, July 2008, Antilahimena et al. 6374 (MO, P, TAN); Toamasina, Ambavahadiala, 1091 m, June 2008, Rakotonandrasana 1344 (MO, TAN); Toamasina, Ambatovy, 1098 m, June 2008, Rakotovao et al. 4131 (MO, TAN); Toamasina, Ambatovy, Analamay, 1106 m, July 2008, Radrianasolo et al. 802 (TAN); Toamasina, Andasibe, Menalamba, Ambatovy, Forêt de Berano, 1032 m, Sept. 2008, Andriantiana 443 (K, MO, P, TAN); Toamasina, Ambatovy, Analamay côté Nord, 1069 m, Sept. 2008, Randrianasolo et al. 858 (TAN); Toamasina, Ambatovy, 1183 m, April 2010, Bernard et al. 1538 (MO, P); Toamasina, Andasibe, Menalamba, Ambatovy, Berano, 1030 m, Oct. 2011, Rakotovao et al. 5625 (MO, TAN); Andasibe, Andasifahatelo, Marinjo, 1017 m, April 2012, Rasoazanany et al. 160 (MO, P, TAN); Moramanga, Andasibe, Tsaravelona, $988 \mathrm{~m}$, April 2012, Razafindrahaja \& Antilahimena 198 (MO, P, TAN); Toamasina, Ambatovy April 2012, 1134 - 1151 m, Ambatowy Shade House 962 (MO, TAN); Toamasina, Mantadia, Sahanody, 944 m, March 2013, Razafindrahaja et al. 303 (MO, TAN); Toamasina, Ambatovy, March 2013, 1091 m, Ambatovy Spirit Collection 819Z1/1 (TAN); Toamasina, Mantadia, Sahandambo, March 2013, 982 m, Bernard et al. 2108 (P, TAN); Toamasina, Mantadia, Falierana, Ambodigoviala, March 2013, 948 m, Rasoazanany et al. 481 (MO, P, TAN); Toamasina, Ambatovy, 1103 - 1119 m, March 2013, Ambatovy Shade House 1098 (BRLU, MO, TAN); Toamasina, Mantadia, Falierana, Sahandambo, 1041 m, March 2013, Bernard et al. 2076 (MO, P, TAN); Toamasina, Mantadia, Falierana, Andranomanamponga, $995 \mathrm{~m}$, March 2013, Ramahenina et al. 206 (TAN); Andasibe, Analamazaotra, 1034 m, Dec. 2013, Ramandimbisoa et al. 359 (MO, TAN); Toamasina, Mantadia, Ambodigavoala-Barrière, 986 m, Dec. 2013, Razafindrahaja et al. 376 (TAN); Toamasina, Ambatovy, 1041 m, Oct. 2014, Ambatovy Shade House 4598 (BRLU, MO, TAN); Toamasina, Ambatovy, 1179 - 1227 m, Oct. 2014, Ambatovy Shade House 4649 (BRLU, MO, P, TAN); Toamasina, Ambatovy s.n., Feb. 2015, 1041 m, Ambatovy Spirit Collection 4598 (TAN); Toamasina, Ambatovy, 925 - 1054 m, Feb. 2015, Ambatovy Shade House 2359 (TAN); Toamasina, Ambatovy, 985 - 1054 m, March 2015, Ambatovy Shade House 2392 (MO); Toamasina, Ambatovy, April 2015, 1016 m, Ambatovy Spirit Collection 2435/4883 (TAN). 
HABITAT. Evergreen forest, moss forest, riverine forest, degraded forest. Often amongst dense undergrowth in deep shade in humus-rich and moist soil. Altitude: 800 - $1800 \mathrm{~m}$.

CONSERVATION StATUS. Category VU: the extent of occurrence (EOO) of Liparis longicaulis is estimated to be $95,273 \mathrm{~km}^{2}$ (which exceeds the limits for Vulnerable status under criterion B1) whereas its minimal area of occupancy (AOO) is estimated to be $104 \mathrm{~km}^{2}$ (which falls within the limits for Endangered status under the criterion B2). With 11 subpopulations representing 17 known locations (sensu IUCN), this species has been preliminarily assessed as VU using the green listing method. This species is threatened by mining activities, selective logging, timber harvesting for small-scale subsistence and tavy (slash-and-burn farming), resulting in habitat reduction and habitat quality reduction.

FLOWERING TIME. December to April.

ETYMOLOGY. Referring to the long distinct pseudobulb-stem.

NOTES. Henry Ridley (1885: 461) described the species from material he had received from the Rev. Deans Cowan and Johannes Hildebrandt in 1880 and 1881 respectively. The plant and flower are represented in Deans Cowan's sketchbook, kept at the Natural History Museum (BM) in London (Cowan 1880: 18). Ridley based the name on both collections. The Deans Cowan material is duplicated in $\mathrm{P}$ but both sheets are less typical than that of Hildebrandt which has five collections in different European herbaria. The latter was therefore chosen as the lectotype for the species. Perrier in 1924 annotated a specimen from Mt Tsaratanana in N Madagascar (16072) as Liparis longicaulis var. crassilabia, mentioning differences from the Imerina (Highland) forms in the lip lacking visible veins and the anther having a very short rostrum. This varietal name was never published. The plant shows the typical characteristics of the species but the lip is a little broader and more acute at the apex.

It has been noted that the flowers are scented (Hermans 3997).

ILlUStRAtionS. Figs 32, 33; Cowan (1880: 18); Perrier (1939: 271); Cribb \& Hermans (2009: 151, the illustration labelled as Liparis zaratananae is this species); Hermans et al. (2007: pl.45); Hervouet (2018: 411).

Liparis longipetala Ridl. (Ridley 1885: 459; 1886b: 275); Perrier (1936: 243); Hermans et al. (2007: 220); Cribb \& Hermans (2009: 152). Type: Madagascar, Ankafana (S Betsileo), Hildebrandt 3980 (holotype BM; isotypes G (partly mislabelled as Hildebrandt 3981), K, W).

Leptorkis longipetala (Ridl.) Kuntze (1891: 671). Types as above.
Liparis anthericoides H.Perrier (1936: 243) synon. nov.; Perrier (1939: 263); Hermans et al. (2007: 215); Cribb \& Hermans (2009: 145); Bosser \& Lecoufle (2011: 405); Hervouet (2018: 405). Types: Madagascar, Central, Andasibe forest (Onive basin), c. 1300 m, Feb. 1925, Perrier 17103 (lectotype P, designated here); Madagascar, Central, Andasibe forest, 1000 m, Feb. 1925, Perrier 17104; Madagascar, E, Analamazoatra forest, $800 \mathrm{~m}$, July 191, Perrier 10981 (lectoparatype P).

Medium-sized epiphytic or terrestrial plant, $5-25 \mathrm{~cm}$ tall, rhizome short, roots wiry, thin, glabrous av. $1 \mathrm{~mm}$ diam. Pseudobulbs fleshy, whitish-green, spherical or oval, $10-18 \times 9-16 \mathrm{~mm}$, enveloped by thin bract-like sheaths, with $2-3$ leaves generally persisting on the previous growths. Leaves pale green, erect to erectly spreading, ligulate to oblanceolate, the lower $1 / 3$ somewhat narrowing, becoming longly attenuate, the basal sheaths papery and enveloping the petiole, 6 $16 \mathrm{~cm} \times 8-20 \mathrm{~mm}$. Inflorescence erect, from the side of the pseudobulbs, somewhat curved at the tip, up to $22 \mathrm{~cm}$ long, $1-2 \mathrm{~mm}$ in diam., $8-25$ flowers. Peduncle with $2-4$ scales or narrowly acute sterile bracts, $6-8 \times$ $1.5-2 \mathrm{~mm}$, in the lower half. Rachis loosely racemose, flowers $8-12 \mathrm{~mm}$ apart, $4-6.5 \mathrm{~cm}$. Floral bracts thin, narrowly acute, $3-9 \times 1.3-2 \mathrm{~mm}$, becoming shorter towards the apex of the inflorescence. Flowers small, overall av. $7 \times 10 \mathrm{~mm}$, pale green to yellow with the lip often darker, olive-green, the column almost white, anther pale green, overall becoming more yellowbrown with age. Pedicellate ovary subfiliform to slightly ridged, becoming a distinct thicker and twisted ovary towards the base, $6-16 \mathrm{~mm}$ long. Dorsal sepal broadly linear to lanceolate, subacute, curved backwards, 3veined, $5.6-8 \times 1.1-1.9 \mathrm{~mm}$. Lateral sepals oblong to almost oval, falcate, $4.1-6.1 \times 1.4-3.2 \mathrm{~mm}$. Petals linear, sometimes a little wider towards the tip, 5.2 $8.5 \times 0.4-1.1 \mathrm{~mm}$. Lip with a narrow auriculate base then expanding into an obovate to broadly oval blade, emarginated with a small apicule at the tip, with a long rounded ridge-like basal callus with a more or less bilobed or thickened tip, $3.5-5.5 \times 2.3-4.1 \mathrm{~mm}$. Column slender, curved towards the apex, expanded below the rostellum into distinct, long, angular pointed wings, $3-4.9 \times 0.8-1.2 \mathrm{~mm}$. Anther suborbicular with a long curved acute beak, $0.8-1.3 \times 0.7 \times 1$. Pollinia 2 , generally bipartite, without viscidium. The anther chambers sometimes contain one or sometimes two pollen masses; this variation occurs even in individual flowers on the same inflorescence, c. $0.4 \times 0.3 \mathrm{~mm}$. Seed capsule sub-spherical $5-6 \mathrm{~mm}$ diam.

RECOGNITION. A medium-sized plant with rounded pseudobulbs enveloped by thin white papery sheaths, two long lanceolate leaves, a laxly-flowered inflores- 


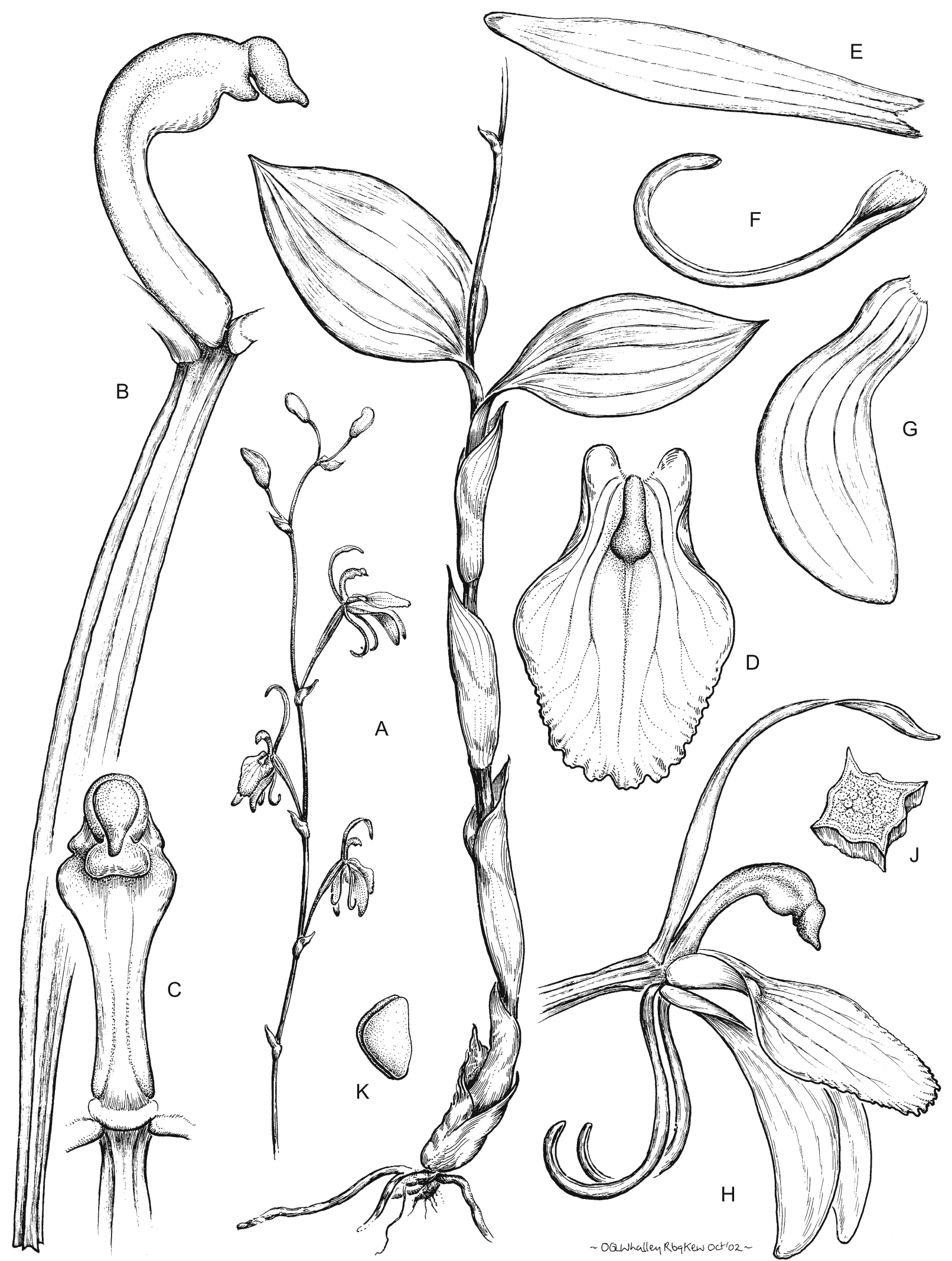

Fig. 32. Liparis longicaulis. A habit $\times 1$ (the stem is likely to be that of Liparis chantaliae); B column and ovary $\times 9 ; \mathbf{C}$ column $\times 9$; D lip $\times 6$; E dorsal sepal (flattened) $\times 6$; F petal $\times 6$; G lateral sepal $\times 6$; H flower $\times 6$; J T/S through stem $\times 9 ; \mathrm{K}$ pollinium $\times 30$. From Hildebrandt 3979 (K). DRAWN BY OLIVER WHALLEY. 

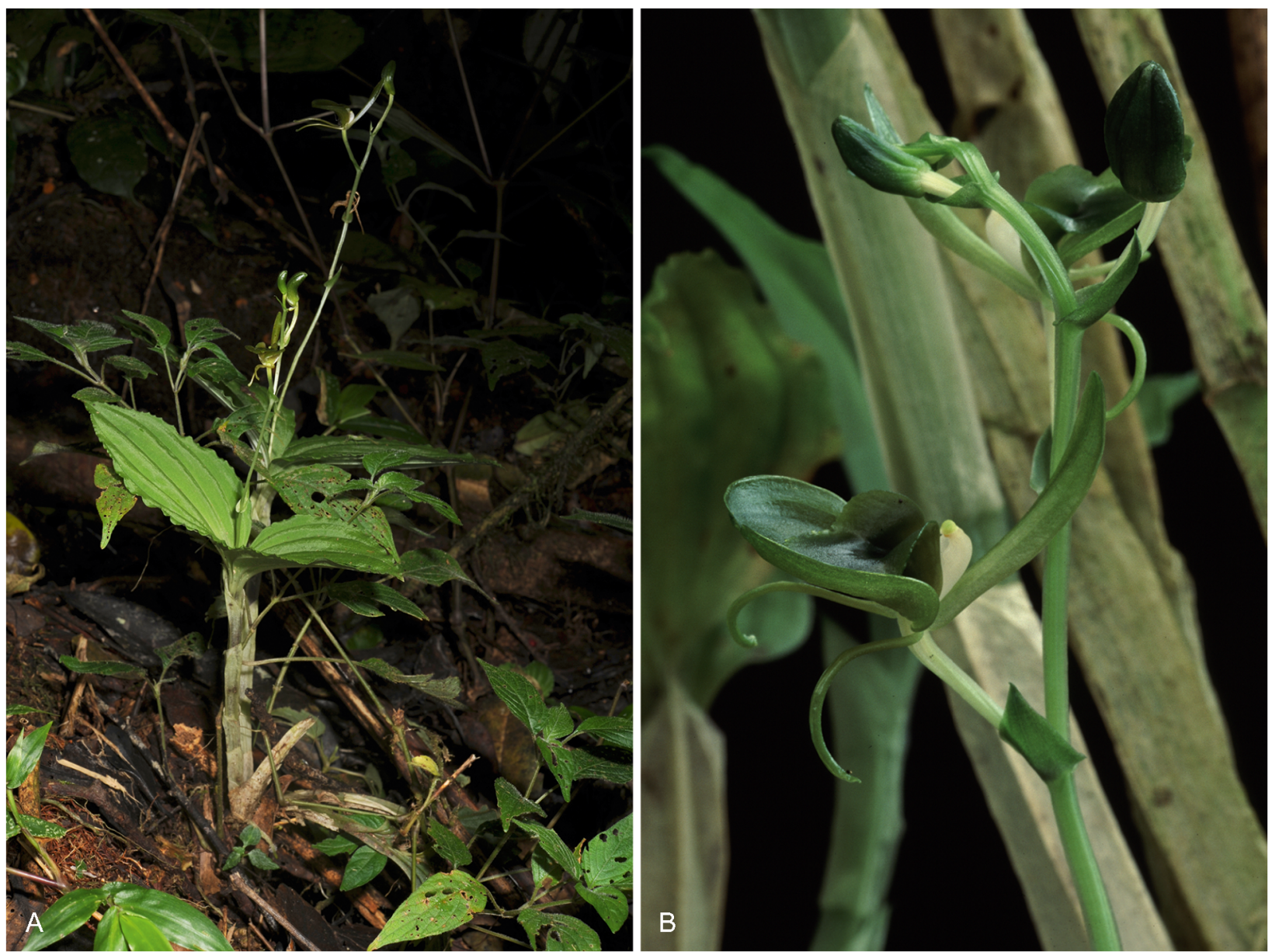

Fig. 33. Liparis longicaulis. A habit; B flower. PHOtOS: A JEAN-MICHEL HERVOUET; B JOHAN HERMANS.

cence and flowers with a long rounded callus at the base of the lip, long and angular column wings, and an anther with a very acute beak. The lip often appears darker than the rest of the flower in herbarium material.

It is similar to Liparis foliosa from Réunion but the pseudobulbs of $L$. longipetala are smaller, the leaves longly acuminate, the lip callus more pronounced and the anther beaked and not rounded as in L. foliosa. The flower is somewhat similar to those of L. bulbophylloides but the plant is caespitose vs longly rhizomatous, the leaves ligulate vs ovate, and the flowers almost half the size.

DISTRIBUTION. Endemic to Madagascar: mainly in the Eastern forests of Antananarivo, Toamasina and Fianarantsoa province but also in the North in Antsiranana province. The Ankafana area referred to in the type is the old mission post near Fianarantsoa (Map 29). Szelengowicz \& Tamon (2013: 361), cited and illustrated this species from Réunion but its habit, leaf and shape of the lip are different; the plant illustrated belongs to a different species and is probably Liparis foliosa.
SPECIMENS EXAMINED. MADAGASCAR. Ankafana (S Betsileo), Hildebrandt 3980 (holotype BM, isotypes G, K, W); Central, Andasibe forest (Onive basin), c. 1300 m, Feb. 1925, Perrier 17103 (lectotype P); Central, Andasibe forest, 1000 m, Feb. 1925, Perrier 17104; East, Analamazoatra forest, 800 m, July 191, Perrier 10981 (lectoparatypes P): Analamazoatra, July 1935, Herb. Jard. Bot. Tan. 3387 (TAN); Angavokely, May 1937, Herb. Jard. Bot. 2474 (TAN); Analamazoatra, June 1941, Jard. Bot. 4853 (TAN); SE, Mandrare valley, tributary of the Manampanihy (SE), Mts S of Tanandava, March 1947, Humbert 20546 (G, P); Ampandrandava area, 1943, Seyrig 791b (P); s. loc., Mason 144 (K-spirit); s. loc., 1959, Rauh E् Buchloh M658(251961) (HEID); Périnet, Aug. 1962, Bosser 16447 (P); Mt d'Ambre, Bosser 13539 (TAN); Mt d'Ambre, Jard. Bot. 624 (P, TAN); SW of Périnet, between Antananarivo and Tamatave, Oct. 1969, Stewart 1158 (K); Ranomafana, S of Namorona R., 1100 - 1250 m, March 1992 Malcomber E Rakoto 1346 (G, MO, K, P, TAN); Fianarantsoa, Ranomafana, $1100-1250 \mathrm{~m}$, March 1993 Turk et al. 332 (K, MO. TAN); Antsiranana, near Mt d'Ambre, 1999, Hermans 2865 (K); 
$0 \quad 100 \quad 200 \mathrm{~km}$

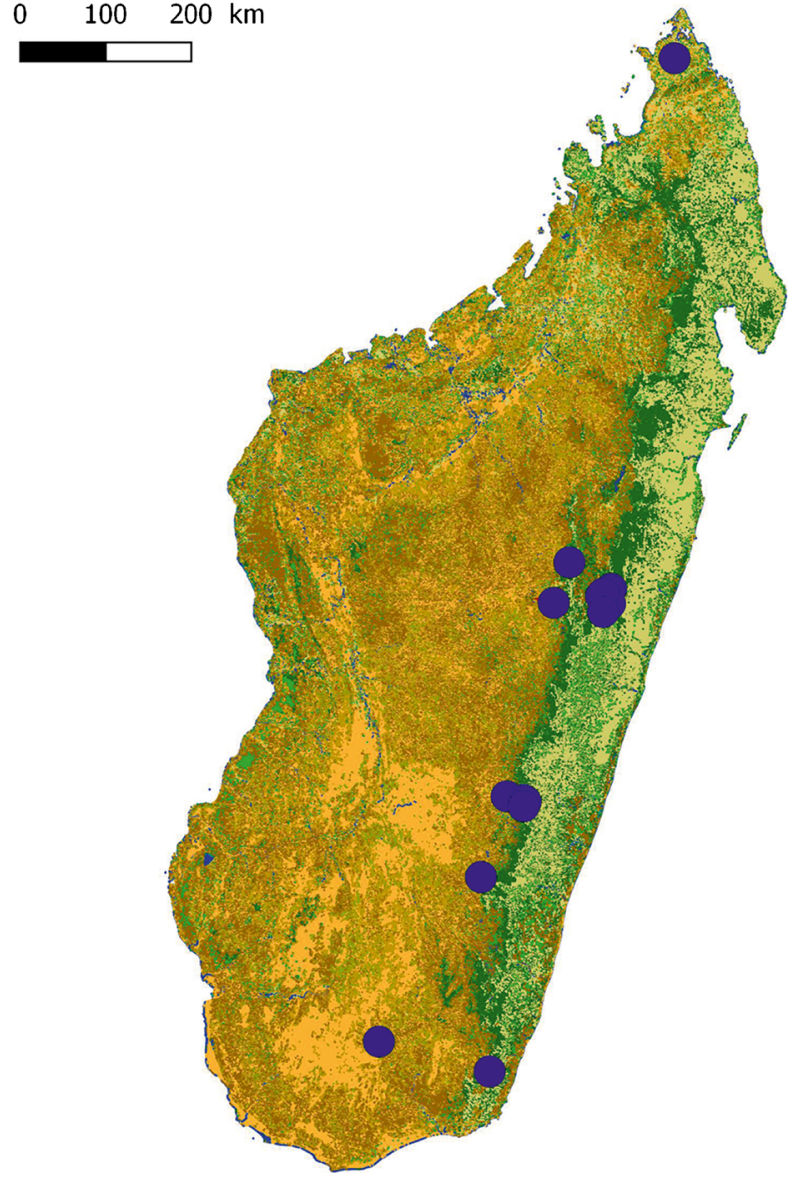

Map 29. Distribution of Liparis longipetala.

Andasibe area, Andriamaharo, Hort 2000, Hermans 5202 (K); Toamasina, road to Lakato, $1041 \mathrm{~m}$ alt., Feb. 2000, Hermans 1005 (K); Anjozorobe, Malala Hort, 2000, Hermans 6716 (K); Fianarantsoa, W of Ranomafana, May 2001, 1135 m, Hermans 118 (K); s. loc., Hort., Aug. 2005, Hermans 6672 (K); Fianarantsoa, near Andringitra, 2005, Fischer et al. FS2043 (SZU); Toamasina, Andasibe, Menalamba, Analamay forest, 1056 m, Jan. 2007, Bernard 542 (G); Mt d'Ambre, May 2008, 1055 m, Trigui et al. 384 (G); Toamasina, Ambatovy, Sahavaharina forest, 1047 m, Sept. 2008, Antilahimena et al. 6542 \& 6542bis (MO, P, TAN); Toamasina, Ambatovy, Aug. 2010, 1029 m, Antilahimena et al. 7526 (MO, P); Toamasina, Andasifahatelo, Marinjo, Mantadia, $968 \mathrm{~m}$, April 2012, Rasoazanany E $\mathcal{E}$ Ratolojanahary 157 (MO, P); Toamasina, Andasibe, Faliriana, Bekalakody, 1038 m, May 2012, Antilahimena $\mathcal{E}$ Razafindrahaja 8401 (MO, P, TAN); s. loc., Feb. 2016, Sieder 6930, Hermans 8062 (WU); Toamasina, Mantadia area, May 2018, Hermans 8219 (K).

HABITAT. Wet evergreen forest, in forest on mossy ground or epiphytic in evergreen forest. Altitude: 800 $-1500 \mathrm{~m}$.
CONSERVATION STATUS. Category LC: the extent of occurrence (EOO) of Liparis longipetala is estimated to be $117,936 \mathrm{~km}^{2}$ (which exceeds the limits for Vulnerable status under criterion B1) whereas its minimal area of occupancy (AOO) is estimated to be $52 \mathrm{~km}^{2}$ (which falls within the limits for Endangered status under the criterion B2). Liparis longipetala is known from seven subpopulations representing 12 locations (sensu IUCN), this species has been preliminarily assessed as LC using the green listing method. This species is threatened by mining activities, selective logging, timber harvesting for small-scale subsistence and tavy (slash-and-burn farming), resulting in habitat reduction and habitat quality reduction.

FLOWERING TIME. February to August.

ETYMOLOGY. Referring to the petals which are said to be longer than in other species. Liparis anthericoides refers to the vegetative similarities with Anthericum (Liliaceae).

NOTES. Liparis longipetala was described by Henry Ridley in 1885 based on specimens collected by Johannes Hildebrandt (3980) in Central Madagascar; there are several sheets of this collection (BM, G, K and $\mathrm{W})$. Some sheets in $\mathrm{G}$ are labelled and identified in error as Hildebrandt 3981 which is the type number of Cynorkis hispidula Ridl. (Ridley 1885: 517). More than 50 years after the description of L. longipetala Perrier described L. anthericoides based on several of his own collections from the Andasibe area in Eastern Madagascar. He cited Perrier 17103 and 17104 (both in P). Perrier 17103 was collected at $1300 \mathrm{~m}$ and has a good range of plants and also has small drawings by Perrier of floral detail, it is therefore designated as the lectotype. Perrier 17104 comes from the same locality but was collected at c. $1000 \mathrm{~m}$ and is a lectoparatype. He also cited Perrier 10981 in his description and this is also to be treated as a lectoparatype. There is no doubt that L. longipetala and L. anthericoides are the same which unfortunately means that Perrier's appropriate epithet, lacking precedence, becomes synonymous with Ridley's less appropriate epithet (Table 10). Plant size of this locally common species is variable but the shape of pseudobulb, leaves and inflorescence are consistent. The lip-shape with its characteristic narrowed base, oblong blade and long rounded ridge-like basal callus with a more or less bilobed end are identical, the sharply beaked anther and small triangular pointed column wings are also the same. It is unlikely that Perrier saw any of the type material of $L$. longipetala and he repeated some of Ridley's limited description in his own texts (Perrier 1936: 243 \& 1939: 263). He mistakenly placed L. longipetala in sect. Coriifoliae and L. anthericoides in sect. Moliifoliae. 
Table 10. Comparison of type specimens of Liparis anthericoides and L. longipetala.

\begin{tabular}{lll}
\hline \hline & L. anthericoides & L. longipetala \\
\hline Specimen & Hildebrandt $3980(\mathrm{BM}, \mathrm{K}, \mathrm{W})$ & Perrier $17103-4$ \& $10981(\mathrm{P})$ \\
Plant height $(\mathrm{cm})$ & $6-17.5$ & $7-15$ \\
Pseudobulb $(\mathrm{mm})$ & $12-16 \times 10-11$ & $11-15 \times 10-12$ \\
Leaf shape & ligulate to oblanceolate & ligulate \\
Leaf size & $7-17 \mathrm{~cm} \times 6-18 \mathrm{~mm}$ & $7-14 \mathrm{~cm} \times 9-14 \mathrm{~mm}$ \\
Inflorescence size $(\mathrm{cm})$ & $6-18$ & $8-15$ \\
No. flowers per inflorescence & $8-15$ flowers & $10-12$ flowers \\
Floral bract $(\mathrm{mm})$ & $4-5 \times 1-2$ & $3-4 \times 1-1.3$ \\
Dorsal sepal $(\mathrm{mm})$ & $5.5-6 \times 1.2-1.6$ & $7-8 \times 1-1.1$ \\
Lateral sepals & $4.1-4.8 \times 1.9-2.5$ & $5.2-6.0 \times 2.4-3$ \\
Petal $(\mathrm{mm})$ & $5.1-6.8 \times 0.4-0.6$ & $7.0-8.5 \times 0.5-0.7$ \\
Lip shape & oblong & $5.2-5.5 \times 3.9-4.0$ \\
Lip size $(\mathrm{mm})$ & $3.9-5.1 \times 2.9-3.9$ & long, obtuse-bi-lobed at end \\
Lip callus & truncate to rounded & wings short triangular, \\
Column wing shape & wings rectangular & $2.8-4 \times 1.0-1.2$ \\
Column wing size $(\mathrm{mm})$ & $2.5-3.4$ & sharply beaked \\
Anther shape & sharply beaked & $0.9-1.3 \times 0.7 \times 1$ \\
Anther size $(\mathrm{mm})$ & $0.8-1.1 \times 0.7-0.8$ & Madagascar: Ankafina, Fianarantsoa prov. \\
Distribution & Madagascar: Andasibe, Toamasina prov & March \\
Flowering & Feb. & \\
\hline
\end{tabular}

Liparis longipetala is a widespread species in the humid evergreen forest of Madagascar above $800 \mathrm{~m}$ and its flowering time from February to August is quite long. Ridley cited long petals as one of the characteristics of his L. longipetala but these are variable and not unusually long for the genus.

ILLUSTRATIONS. Figs. 34, 35 and 36; Perrier (1939: 255); Cribb \& Hermans (2009: 147); Bosser \& Lecoufle (2011: 405); Guérin \& Hervouet (2013: 320); (Hervouet 2018: 405).

Liparis lutea Ridl. (Ridley 1885: 458; 1886b: 274); Perrier (1939: 279); Hermans et al. (2007: 220); Cribb \& Hermans (2009: 152). Type: Madagascar, Ankafana, Deans Cowan s.n. BM000090073 (holotype BM).

Leptorkis lutea (Ridl.) Kuntze (1891: 671). Type as above.

Very small, up to $8 \mathrm{~cm}$, erect terrestrial plant, on a short rhizome with the previous growth deciduous, roots wiry, c. $1 \mathrm{~mm}$ diam. Pseudobulbs almost stem-like, with three leaves, the petiolate base enveloping the elongate pseudobulb, two to three membranous sheaths at the base, $16 \times 6 \mathrm{~mm}$. Leaves ovate to lanceolate, $5-6.5 \times 1.6-2.3 \mathrm{~cm}$ with a c. $25 \mathrm{~mm}$ petiole. Inflorescence c. $11 \mathrm{~cm}$ long, $1 \mathrm{~mm}$ diam., with three sheaths along its length, with c. 10 flowers. Peduncle 2 - 3, sheaths lanceolate acuminate, $7-8 \times$ $2.5-3 \mathrm{~mm}$. Rachis dense, flowers appressed to the rachis, c. $3.5 \mathrm{~cm}$. Floral bracts ovate, lanceolate acuminate, $3.8-4.3 \times 1.2-1.7 \mathrm{~mm}$, about half the length of the ovary. Flowers small c. $9 \times 7 \mathrm{~mm}$, yellow to pale green. Pedicel and ovary somewhat ridged, $6-9 \times 0.8-$
$1.2 \mathrm{~mm}$. Dorsal sepal narrowly linear, wider at the base, acuminate obtuse at the apex, $4.8-6.1 \times$ c. $0.9 \mathrm{~mm}$. Lateral sepals ovate, a little falcate, $4.1-4.6 \times 2.1-2.2$ mm. Petals narrowly linear almost subulate, $4.5-5.4 \times$ c. $0.3 \mathrm{~mm}$. Lip ovate cordate, obtuse, with three strong veins in the middle, slight swelling towards the base but without obvious callus, auriculate at the base, $2.9-$ $4.1 \times 2.0-3.1 \mathrm{~mm}$. Column short and thick, curved towards the apex, shortly winged $2.2-2.9 \times 0.5-1.1$ $\mathrm{mm}$. Anther cordiform $0.7-0.9 \mathrm{~mm}$ diam. Pollinia ovate c. $0.3 \times 0.2 \mathrm{~mm}$.

RECOGNITION. A very small plant with a dense raceme, the flowers not spreading much and almost appressed to the rachis, relatively large floral bracts, and small, yellow flowers with lip with three central veins, lacking a callus, a slightly winged column and heart-shaped anther.

The type material and the drawing by Deans Cowan (Cowan 1880: 22) provide limited evidence of the morphology of the species; it is similar to Liparis densa but the pseudobulbs are shorter, the leaves smaller, the inflorescence and rachis more elongate, carrying at least two lanceolate sheaths low on the peduncle (not present or smaller in L. densa) and the flower segments smaller. Due to the limited nature of the type material of L. lutea, it is difficult to compare the two species. It is also similar to L. bathiei but the floral bracts are smaller and narrower, the anther is beaked (vs cordiform) and the column has more pronounced wings.

DISTRIBUTION. Endemic to Madagascar: the Fianarantsoa area only (Map 30). The type locality of Ankafana refers the highland area in-between Antsirabe and Ambalavao. 


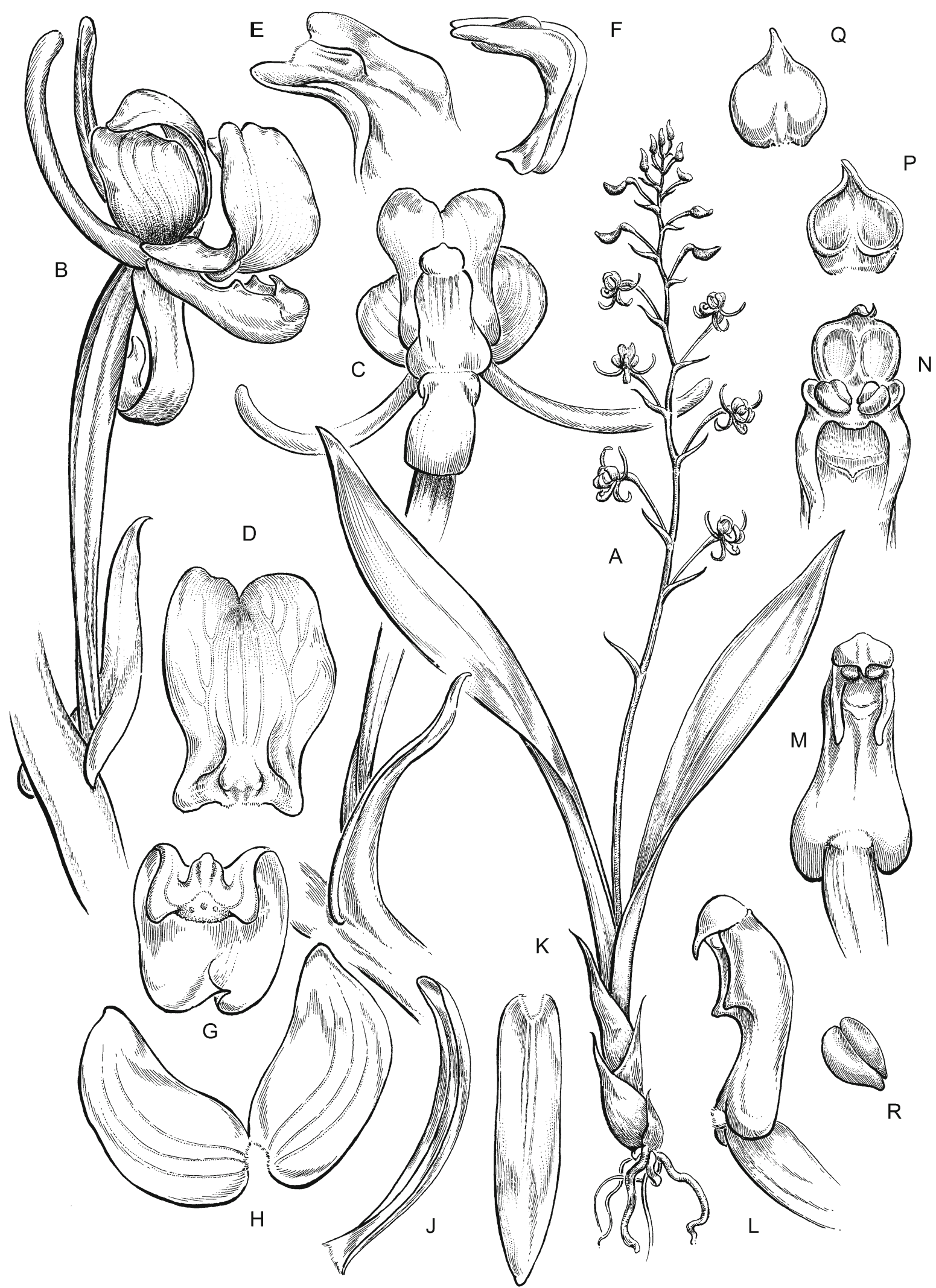

Fig. 34. Liparis longipetala. A habit $\times 1 ; \mathbf{B}$ flower, ovary, bract from side $\times 9 ;$ C flower, ovary, bract from front $\times 9 ; \mathrm{D}$ lip $\times 12 ; \mathrm{E}$ lip basal callus showing lateral basal thickening $\times 12$; F lip from side $\times 9$; G lip from behind $\times 12$; H lateral sepals $\times 9$; J petal $\times 9$; $\mathrm{K}$ dorsal sepal $\times 9$; L column from side $\times 12 ; \mathbf{M}$ column front $\times 12 ; \mathbf{N}$ top of column, anther cap lifted $\times 21$; $\mathbf{P}$ anther cap underneath $\times$ 21; Q anther cap above $\times 21$; R pollinia $\times 36$. From Hermans 5202 \& Stewart $1158($ K). DRAWN BY OLIVER WHALLEY. 


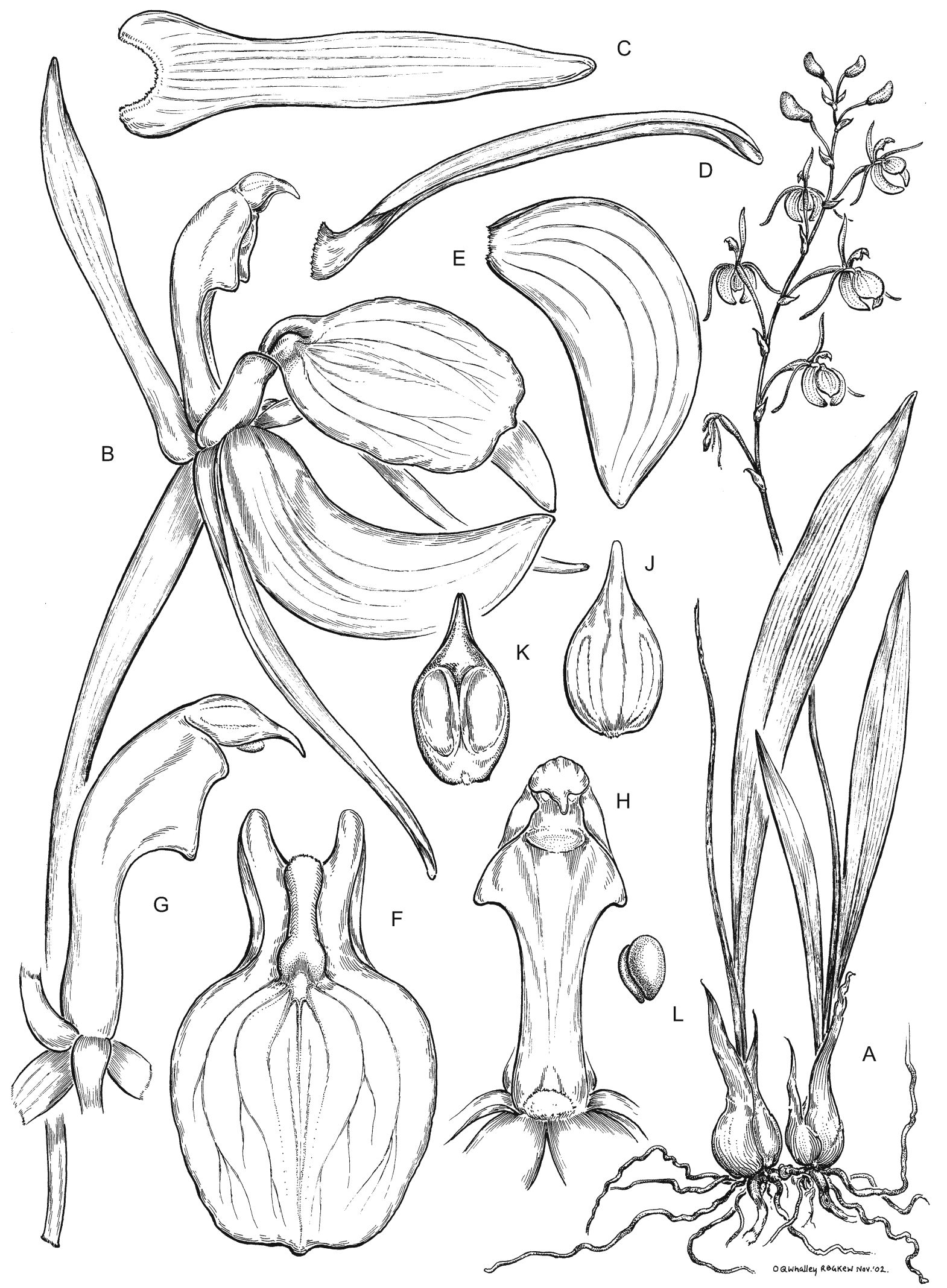

Fig. 35. Liparis longipetala. A habit $\times 1$ (inflorescence 1.5); B flower $\times 12 ; \mathrm{C}$ dorsal sepal $\times 12$; D petal $\times 12 ; \mathrm{E}$ lateral sepal $\times 12 ; \mathrm{F}$ lip $\times$ 9; G column side $\times 21 ; \mathrm{H}$ column front $\times 21$; J anther cap top $\times 30 ; \mathrm{K}$ anther cap underside $\times 30 ; \mathrm{L}$ pollinia $\times 30$. From Hildebrandt 3980 (K). DRAWN BY OLIVER WHALLEY. 

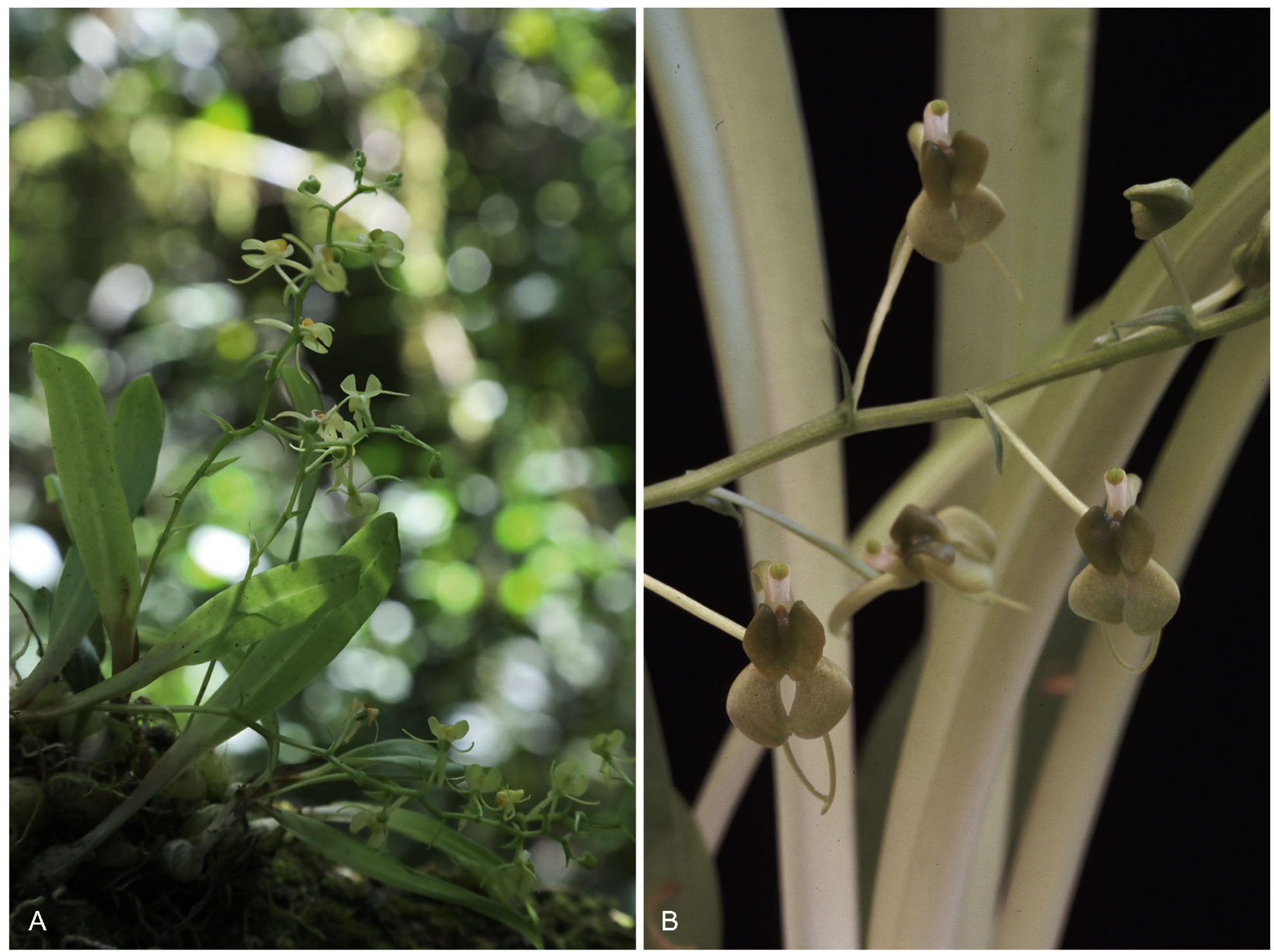

Fig. 36. Liparis longipetala. A habit; B flowers. PHOTOS: JOHAN HERMANS.

SPECIMENS EXAMINED. MADAGASCAR. Ankafana, in marsh, 1880, Deans Cowan s.n. (holotype BM); Ankiseve, Sendrisoa, Ambalavao, Feb. 1953, Rakoto 5570 (P, TAN); s. loc., Lawrance s.n. Spirit 34514 (K).

HABITAT. In marshland. Altitude: c. $1500 \mathrm{~m}$.

CONSERVATION STATUS. Category EN: the extent of occurrence (EOO) of Liparis lutea cannot be estimated since it is only known from two subpopulations whereas its minimal area of occupancy (AOO) is estimated to be $4 \mathrm{~km}^{2}$ (which falls within the limits for Critically Endangered status under the criterion B2). With only two known subpopulations representing two locations (sensu IUCN), this species has been preliminarily assessed as EN using the green listing method. Liparis lutea is threatened by selective logging, timber harvesting for small-scale subsistence and tavy (slash-and-burn farming), resulting in habitat reduction and habitat quality reduction.

FLOWERING TIME. February.

ETYMOLOGY. Presumably referring to the yellow colour of the flowers.

NOTES. Henry Ridley (1885) described Liparis lutea from a plant collected by the Rev. William Deans
Cowan. The type consists of a single growth only but Deans Cowan, in his sketchbook of Madagascar orchids (Cowan 1880: 22 no 48) (Fig. 37) shows a fairly detailed watercolour sketch of a plant plus some detail of a flower. The species is only known from the holotype and two other collections at present and it is likely that this species will remain somewhat ambiguous because of the limitations of the description and type material. If further material comes to hand it should be compared with Liparis densa, of which it may well prove to be an unusual or smaller form.

ILlUStrations. Cowan (1880: 22 no 48) (Fig. 37).

Liparis magnifica Hermans sp. nov. Type: Madagascar, Toamasina, Andasibe area, 1997, Hermans 2575 (holotype $\mathrm{K}$ ).

http://www.ipni.org/urn:lsid:ipni.org:names:77201800-1

Very small epiphytic or terrestrial plant, up to $8 \mathrm{~cm}$, ascending, clustered on a short to sometimes extended rhizome, roots villous. Pseudobulbs stem-like, terete, 

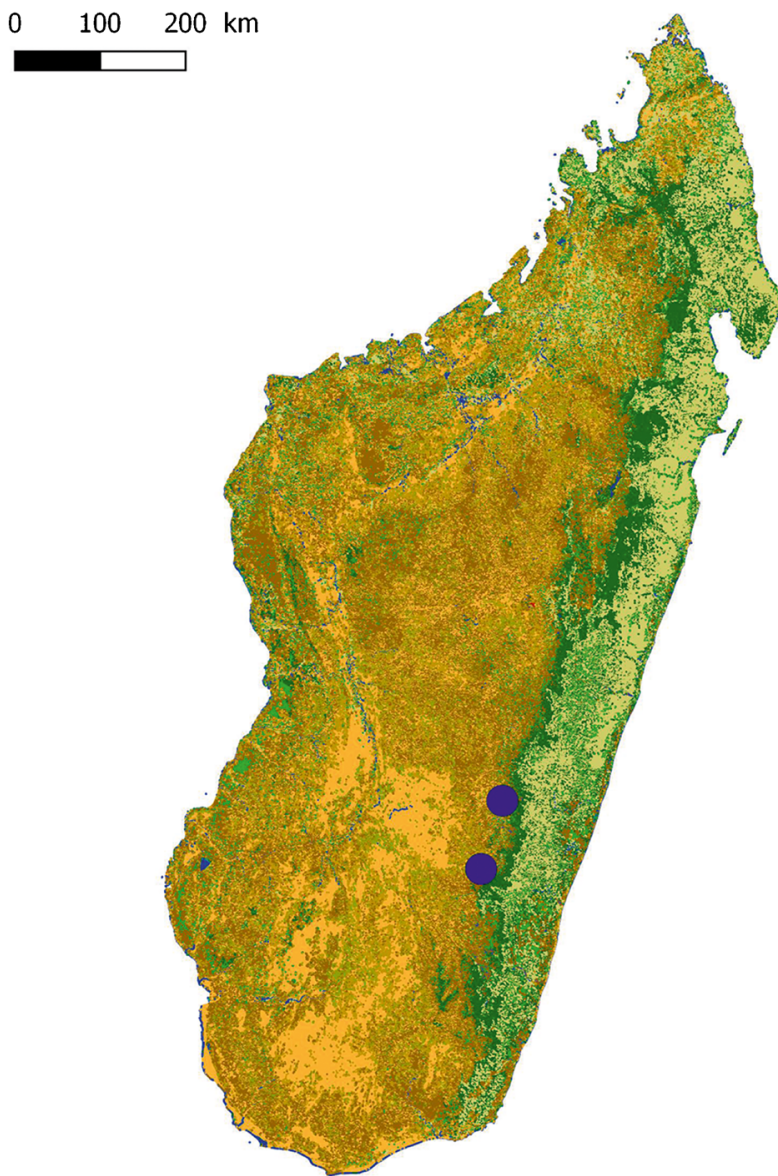

Map 30. Distribution of Liparis lutea.

greenish brown to dark red, $12-51 \times 2-7 \mathrm{~mm}$, almost completely covered by $2-3$ papery, partly overlapping sheaths which are strongly acuminate at the apex, $11-23 \times 3-5 \mathrm{~mm}$, carrying a single semierect to divergent leaf at the apex. Leaf persistent, lanceolate, rounded to subcordate at the base, attenuate at the tip, pale to dark green, distinctly marked with silvery-white longitudinal interrupted streaks or continuous bands, $3-5 \times 1.3-2 \mathrm{~cm}$. Inflorescence erect, apically racemose, with $1-5$ flowers, $4-6.5 \mathrm{~cm}$ long. Peduncle somewhat angular to corrugate, about $\% 3$ of the inflorescence, pale green, with $1-2$ lanceolate peduncle sheaths up to $7 \times 2 \mathrm{~mm}$. Rachis apical, extending as the flowers open. Floral bracts narrowly lanceolate, $3.6-5.1 \times 1.1-1.7 \mathrm{~mm}$. Flowers medium in size, erectly spreading, up to $14 \times 9 \mathrm{~mm}$, petals and sepals whitish-green to pale green becoming yellowishgreen when maturing, lip green with the disk, column white. Pedicel and ovary ridged, $7.5-10.3 \times 0.6-0.9$ $\mathrm{mm}$. Dorsal sepal erect, recurved towards the apex, ensiform, margins recurved, $6.9-8.2 \times 1.2-1.9 \mathrm{~mm}$. Lateral sepals strongly recurved beneath the lip, elliptic, acute at the tip, $5.9-6.5 \times 2.5-2.9 \mathrm{~mm}$. Petals parallel or slightly divergent to the pedicellate ovary, linear, margins recurved, $7.1-7.9 \times 0.3-0.4 \mathrm{~mm}$. Lip strongly recurved around the middle, obovate, auriculate at the base, anterior margin retuse, undulate, disk a little thickened, callus shortly bidentate to ' $\mathrm{M}$ 'shaped, $5.2-5.8 \times 4.3-4.5 \mathrm{~mm}$. Column curved towards the middle, wings longly, roundly-lobed, $3.3-$ $4.4 \times 1.1-1.4 \mathrm{~mm}$. Anther roundly ovoid with a short triangular beak, base indented, $1-1.2 \times 0.9-1 \mathrm{~mm}$. Pollinia in two pairs, pyriform, c. $0.5 \times 0.4 \mathrm{~mm}$. Seed capsule fusiform, c. $15 \times 5 \mathrm{~mm}$.

RECOGNITION. This small new species is distinct by the single lanceolate leaf, marked with silvery white longitudinal bands, the short pseudobulbous stem, lanceolate floral bracts, the obovate lip with an undulate anterior margin and a distinct bidentate callus at the base. The species is distinct from all the other single-leaved Liparis of the region by the longitudinal silvery markings on the lanceolate leaf. It is closest to $L$. warpurii but differs by the lanceolate peduncle sheaths and floral bracts narrowly lanceolate vs cordate in $L$. warpurii, the leaf with an overall silvery upper surface vs banded, the flowers about half the size, the lip is more curved and obovate vs angular, the lip margin undulate vs dentate-serrate and the more sharply beaked anther. There are also similarities with $L$. clareae but the new species is much smaller in both plant and flower and the callus is bidentate vs indistinct. It is similar in size to L. laurentii described above but the lip is obovate vs transversally elliptic, the anther beak is much shorter and the lip callus is joined vs separate, it differs from $L$. superclareae described below by the much smaller plant and flower, the shorter anther and the lip callus bidentate vs obscure (Table 8).

DISTRIBUTION. Endemic to the Eastern forests of Madagascar in Fianarantsoa and Toamasina provinces (Map 31).

SPECIMENS EXAMINED: MADAGASCAR. Toamasina, Andasibe area, c. 1000 m, 1997, Hermans 2575 (holotype K); Toamasina, Ambatovy, Ambohibary, 1055 m, Oct. 2005, Razanatsoa et al. 502 (TAN); Toamasina, Ambatovy: Région Alaotra-Mangoro, April 2013, Ambatovy Spirit Collection 860Z17 (MO, TAN); Toamasina, near Anosibe an 'Ala, Feb. 2018, Gamisch et al. 7655 WU); Fianarantsoa, Ranomafana area, 970 m, April 2018, Hermans 8220 (K).

HABITAT. Epiphyte or terrestrial in wet mediumaltitude forest, often amongst leaf-litter and mosses. Altitude: 950 - $1350 \mathrm{~m}$.

CONSERVATION STATUS. Category EN: the extent of occurrence (EOO) of Liparis magnifica is estimated to be $1,999 \mathrm{~km}^{2}$ (which falls within the limits for Endangered status under criterion B1) whereas its minimal area of occupancy (AOO) is estimated to be $12 \mathrm{~km}^{2}$ (which also falls within the limits for Endangered status under the criterion B2). Liparis magnifica is known from three subpopulations representing three locations (sensu IUCN), this 


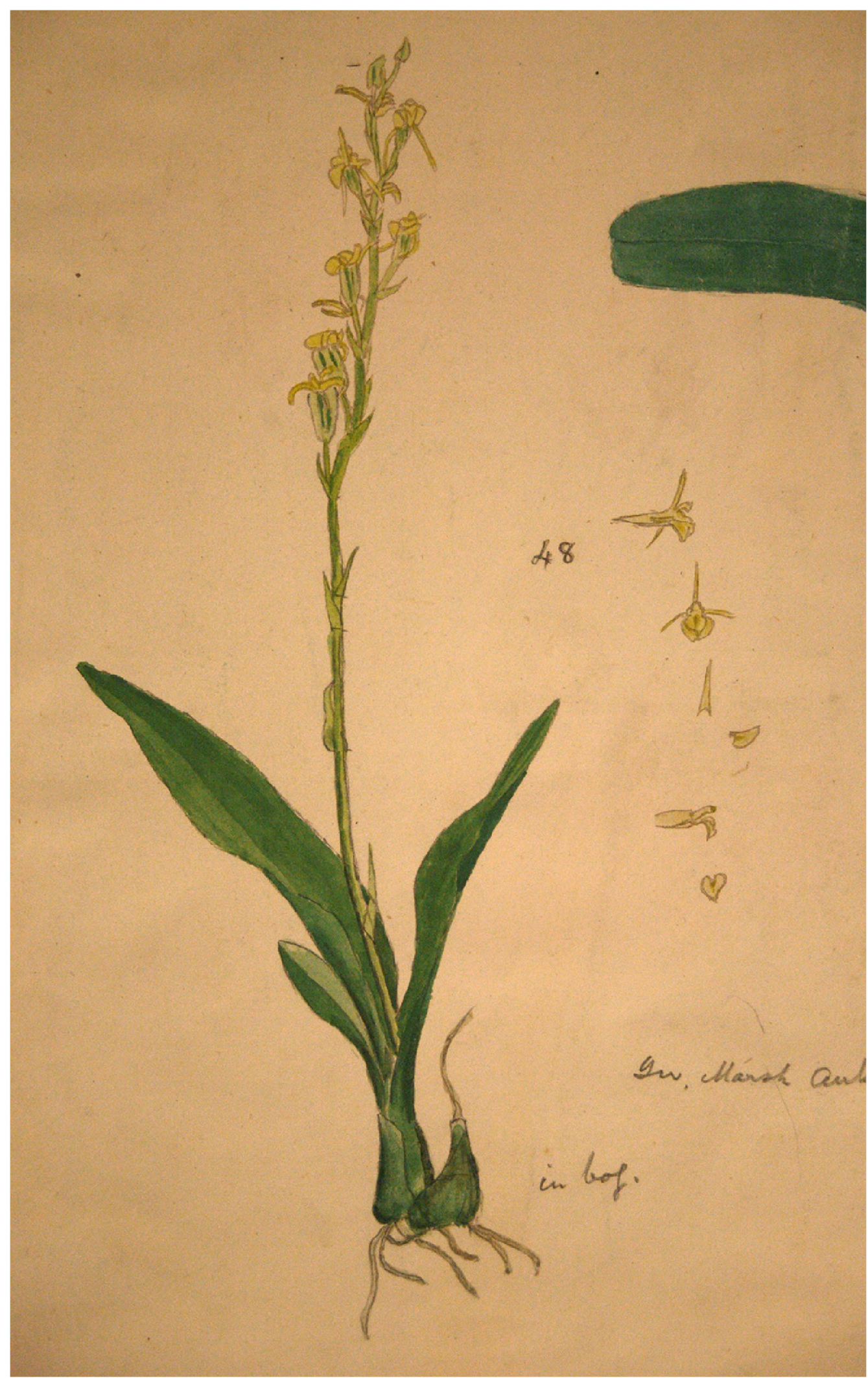

Fig. 37. Liparis lutea. Watercolour by Deans Cowan 1880: 19. @ The Trustees of the Natural History Museum, London. 


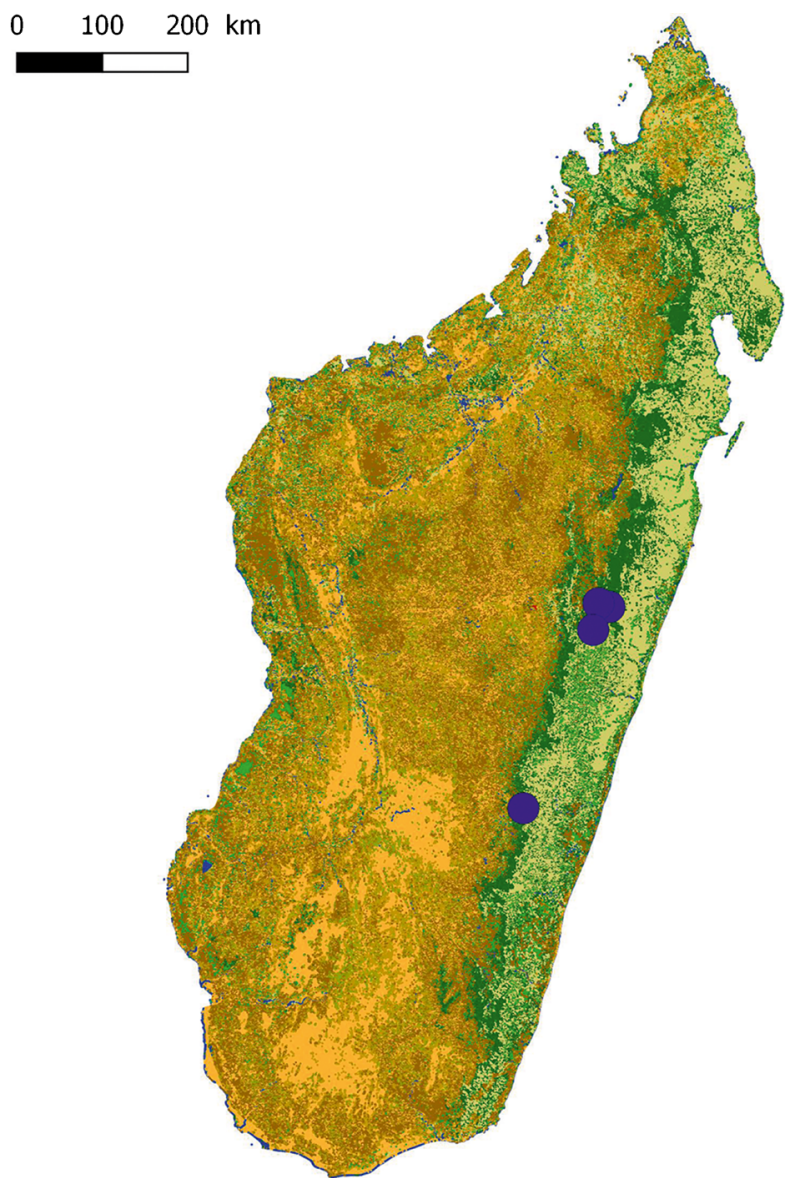

Map 31. Distribution of Liparis magnifica.

species has been preliminarily assessed as EN using the green listing method. This species is threatened by selective logging, timber harvesting for small-scale subsistence and tavy (slash-and-burn farming), resulting in habitat reduction and habitat quality reduction.

FLOWERING TIME. April and May.

ETYMOLOGY. The epithet refers, firstly, to Madame Mag Izouard of Vakôna Lodge in Madagascar, who brought this species to our attention and, secondly, to the magnificence of the markings on the foliage.

NOTES. For some time the new species was only known from photographs of its leaves which had been found in forest around Vakôna Lodge near Andasibe in Eastern Madagascar by its owner Mme Izouard. On recent flowering it was possible to match the species to several herbarium collections from the same area. Since then the new species has also been found in the Ranomafana area in the SE of the island.

Liparis cardiophylla var. angustifolia, mentioned by Perrier (1936: 244) and only known from the type specimen, also has whitish leaves with darker veins. It was initially thought that it could be the same as L. magnifica but its flowers are very different and correspond well with the characteristics of $L$. warpurii. It is discussed under that species.
ILLUSTRATIONS. Figs 38, 39.

Liparis nectarina Frapp. ex Cordem. (Frappier in Cordemoy 1895: 184); Bernet (2010a: 92). Type: Réunion, Entre Deux, 800 m, 22 April 2012, Bernet in Hermans 8153 (neotype K, designated here) Liparis nectarina Frappier (1880: 15) nom. nud.

Very small to small epiphytic or terrestrial plant 4.5 $10 \mathrm{~cm}$ high, on a very short rhizome, roots wiry, slightly villous, c. $1 \mathrm{~mm}$ diam. Pseudobulbs ovoid to elliptic $15-20 \times 7-10 \mathrm{~mm}$, covered by $3-4$ whitish brownish amplectant, scarious sheaths, with $2-3$ leaves, the third smaller and sheath-like number of leaves, the older pseudobulbs without leaves. Leaves erectly spreading, elliptic-lanceolate, in living plants corrugate into three distinct veins, in herbarium material several-veined, overall $3.2-7.5 \times 1-1.9 \mathrm{~cm}$, acuminate, with a short $5-12 \mathrm{~mm}$ petiole, somewhat leathery, pale green. Inflorescence erect, relatively thick for the genus, corrugate up to $12 \mathrm{~cm}$ long but generally shorter, c. $2 \mathrm{~mm}$ in diam., with $5-7$ flowers. Peduncle about $2 / 3$ of the inflorescence, with $1-2$ elongate peduncle sheaths $8-15 \times 3-5 \mathrm{~mm}$. Rachis densely racemose becoming more spreading as the flowers open. Floral bracts lanceolate, acuminate, 6 $8.5 \times 1.2-1.8$. Flowers parallel with the rachis, small to medium in size, overall c. $11 \times 7 \mathrm{~mm}$, segments pale green becoming yellow and then orange with age, anther paler, the lip darker green with the central ridge and callus almost olive-green. Pedicel and ovary elongate, twisted, sharply ridged, $7.1-8 \times 1.3-1.8$ $\mathrm{mm}$. Dorsal sepal erect, narrowly lanceolate, acuminate, the margins infolded, $7.8-8.1 \times 1.2-1.8 \mathrm{~mm}$. Lateral sepals ovate, obtuse, folded beneath the lip, spreading and only overlapping near the base $5.6-5.8 \times 2.6-3.8$ $\mathrm{mm}$. Petals descending, more or less curved, linear, margins infolded, $8.2-9 \times 0.6-0.9 \mathrm{~mm}$. Lip distinctly auriculate at base, then very strongly curved and expanded into an obcordate blade, the margins curved, the anterior margin undulate, broadly emarginated, a bilobed rounded callus at the base becoming a longitudinal swollen ridge on the disc, covered by small sticky droplets in living plants, overall $5.5-6.1 \times 5.3-6.4 \mathrm{~mm}$. Column curved and roundly bilobed at the apex, $3.8-4 \times 1.4-1.5 \mathrm{~mm}$. Anther oval with a distinct acute beak at the anterior margin, $0.9-$ $1 \times 0.9-1 \mathrm{~mm}$. Pollinia (2) ovoid c. $0.5 \times 0.4 \mathrm{~mm}$. Seed capsule obovate, erect, c. $6 \times 5 \mathrm{~mm}$.

RECOGNITION. Liparis nectarina is a small plant with an ovoid pseudobulb covered by sheaths, two ellipticlanceolate corrugate leathery leaves with three distinct recessed veins, an inflorescence with one or two elongate sheaths, few-flowered towards the tip, and 


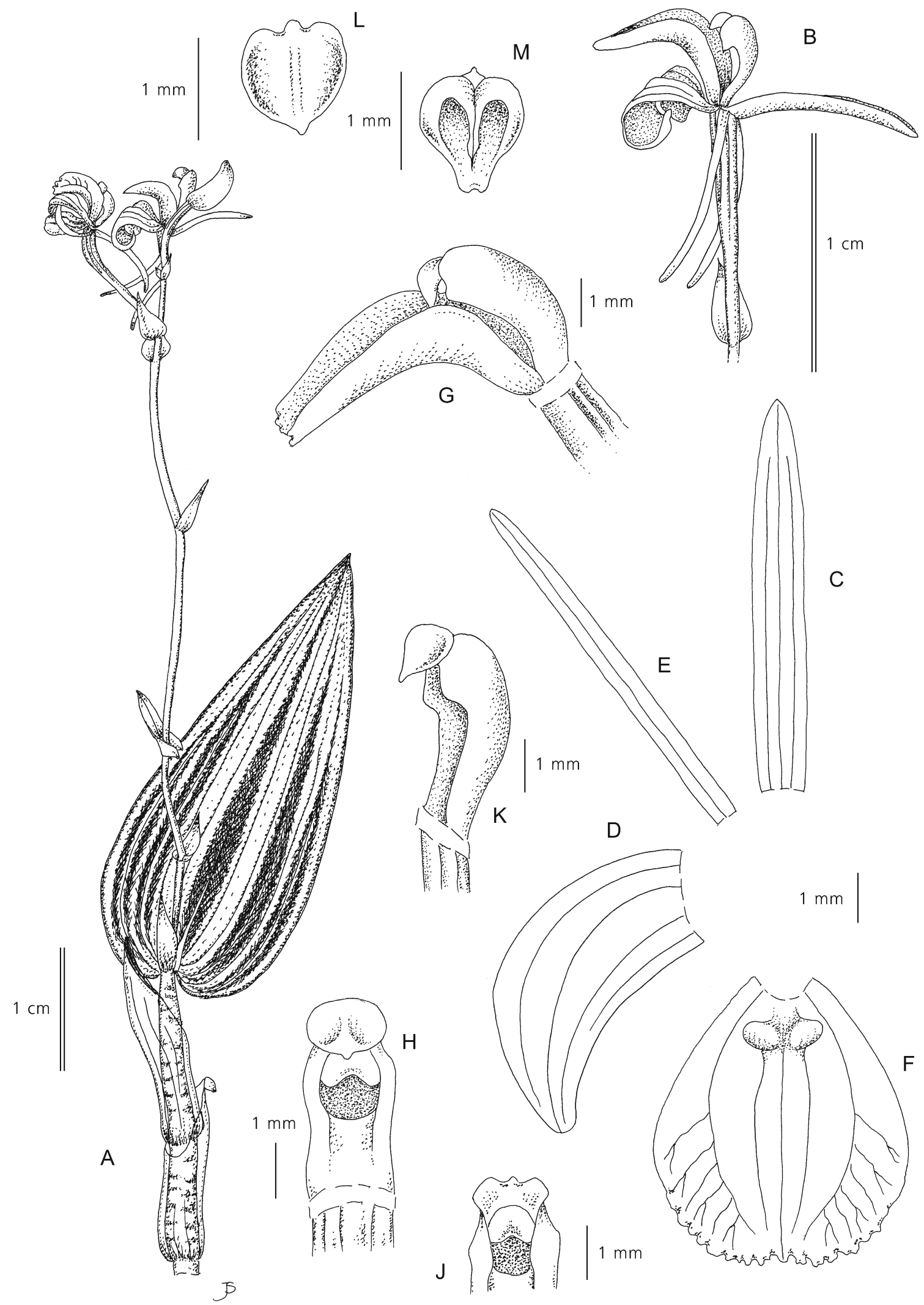

Fig. 38. Liparis magnifica. A habit; B flower; C dorsal sepal; D lateral sepal; E petal; F lip; G column and lip, side view; H column, front view; J top of column, anther removed; K column, side view; L anther cap, dorsal view; M anther cap, ventral view. From Hermans 2575 (K). DRAWN BY JUDI STONE. 

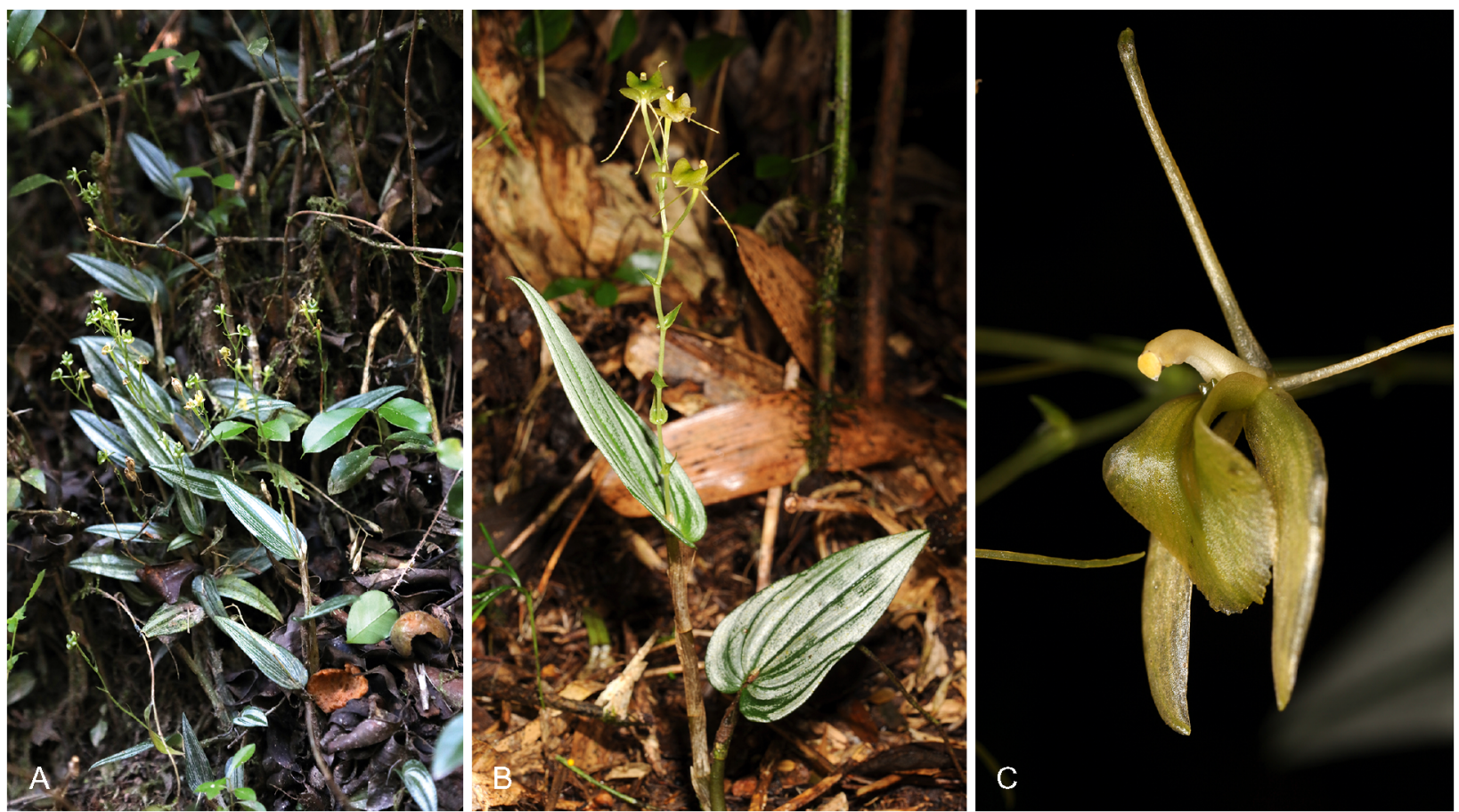

Fig. 39. Liparis magnifica. A \& B habit; C flower. PHOTOS: A JOHAN HERMANS; B, C JeAN-MiChel HERVOUet.

small to medium-sized flowers, with a lip strongly auriculate at the base, with an emarginate apex, undulate, with a rounded bilobed callus and swollen longitudinal disk, nectar-like droplets (in living plants) on the surface, and a sharply beaked anther.

Liparis nectarina is closest to L. flavescens in habit and lip shape but the leaves of L. nectarina are leathery (vs membranous), strongly three-veined (vs manyveined), the lip margin is clearly emarginate (vs entire) and more deeply undulate. It is also similar to $L$. scaposa but the flowers of $L$. nectarina are at least a third larger, it has two leaves (vs one) and the anther is sharply beaked (vs roundly lobular). The lateral sepals overlap in both of the above species whilst they are divergent in $L$. nectarina, the distinct viscous droplets on the lip also seem to be particular to this species.

DISTRIBUTION. Endemic to Réunion. Frappier refers to 'Hab. Saint-Pierre (Tampon)'. It has now also been found in nearby localities at the Entre Deux and Takamaka in the S Central mountains of the Island. Szelengowicz \& Tamon (2013: 363) also report it from the more Westerly Cirque de Mafate (Map 32).

SPECIMENS EXAMINED: RÉUNION. Entre Deux, $800 \mathrm{~m}$, April 2012, Bernet in Hermans 8153 (neotype K); Cilaos, April 1974, Bosser 22479 (P); Takamaka 900 m, Sept. 2007, Bernet in Hermans 8160 (K); Feb. 2002, Plaine des Palmistes, Bernet in Hermans 8167 (K).

HABITAT. Epiphyte or terrestrial in shaded forest; 800 $2000 \mathrm{~m}$.

CONSERVATION STATUS. Category EN: the extent of occurrence (EOO) of Liparis nectarina is estimated to be $164 \mathrm{~km}^{2}$ (which falls within the limits for Endangered status under criterion B1) whereas its minimal area of occupancy (AOO) is estimated to be $16 \mathrm{~km}^{2}$ (which also falls within the limits for Endangered status under the criterion B2). Liparis nectarina is known from three subpopulations representing two locations (sensu IUCN), this species has been preliminarily assessed as EN using the green listing method. This species is threatened by grazing and anthropogenic fires, resulting in habitat reduction and habitat quality reduction. Previously assessed and published in the IUCN Red data listing for Réunion as category DD (Picot 2013: 25).

FLOWERING TIME. March to April.

ETYMOLOGY. Frappier, in his description, refers to the nectar-like droplets on the disk of the lip. A viscous substance on the lip is not unique to this species and can be found in others, such as Liparis listeroides, but the distinct droplets are unusual.

NOTES. Liparis nectarina first appeared in Frappier's list in 1880, without a description. It was then formally described by Cordemoy (1895) which incorporated Frappier's text on the Orchidaceae. Frappier did not indicate a type but gave the locality of 'Tampon SaintPierre'. It is assumed that Frappier's herbarium was lost (Bosser 2011) and there are no plants in Cordemoy's herbarium that are labelled as such or fit the description. It was therefore decided to assign a new type from a more recent and well-documented collection (neotype Bernet in Hermans 8153). It originated from a similar area in the South-central mountains of Réunion. There are 


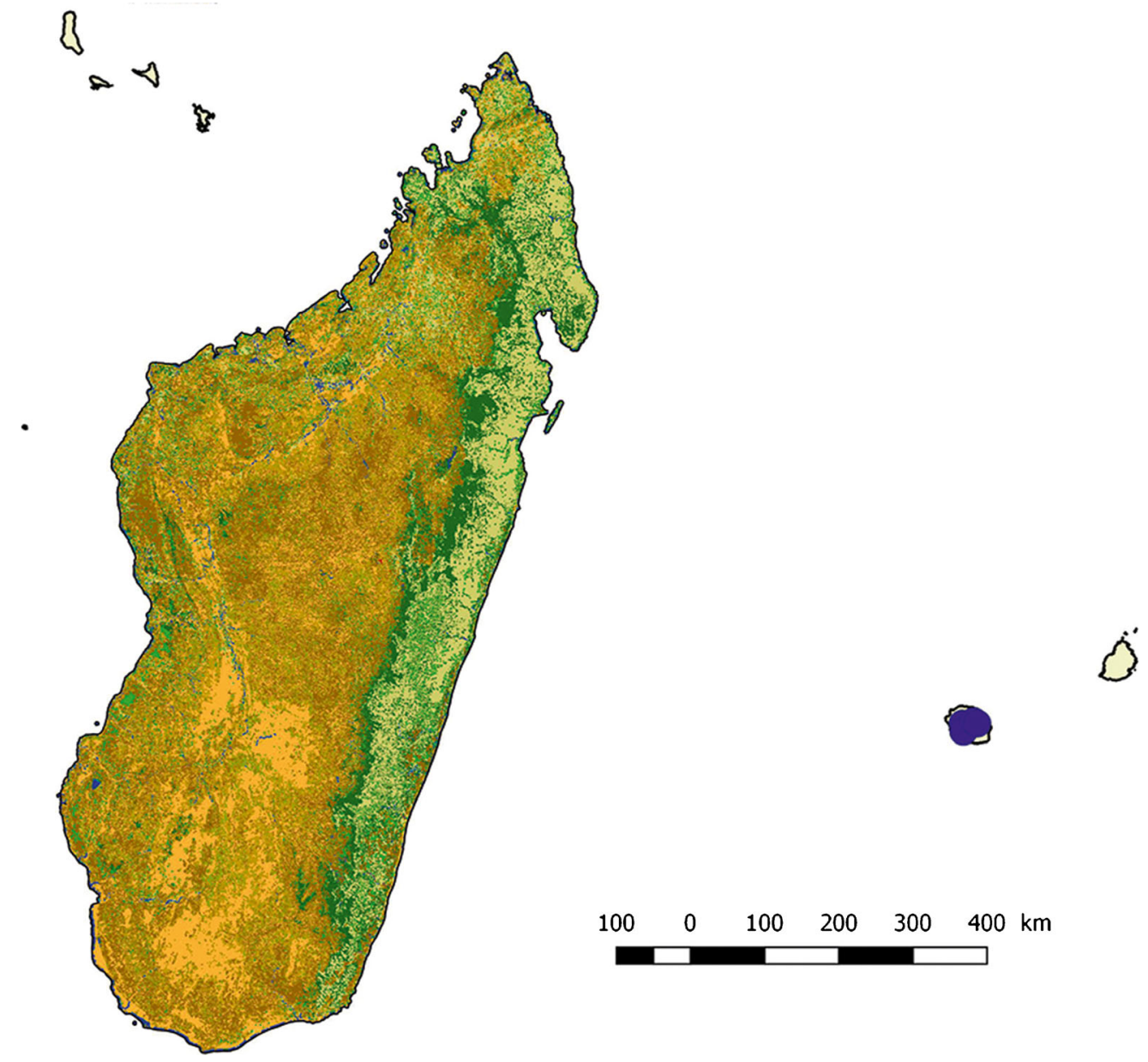

Map 32. Distribution of Liparis nectarina.

several fruiting specimens in herbaria, currently filed under L. flavescens, that could be this species (e.g. Bosser 20989, 21211, 21310, 22180 (P), Balfour 1875 (K) etc.)

ILLUSTRATIONS. Figs 40, 41 and 42; Bernet (2010a: 92); Szelengowicz \& Tamon (2013: 363).

Liparis nephrocardia Schltr. (Schlechter 1924: 145); Perrier (1936: 253; 1939: 288); Hermans et al. (2007: 220); Cribb \& Hermans (2009: 154); Bosser \& Lecoufle (2011: 409); Hervouet (2018: 414). Types: Madagascar, Mt Tsaratanana, Jan. 1923, Perrier 15746 (P00095479) (lectotype $\mathrm{P}$, designated here); Mt Tsaratanana, Dec. 1922, Perrier 15246 (P00095476) paratype P).

Small to medium, erect epiphyte, lithophyte or humicole plant, $9-17 \mathrm{~cm}$ high, rhizome very short, roots flexuose c. $1.5 \mathrm{~mm}$ diam. Pseudobulbs short, broadly ovoid to conical, $10-24 \mathrm{~mm}$ high, 7 $13 \mathrm{~mm}$ wide, entirely covered by $2-3$ sheaths and the leaf petioles, with two larger leaves and a third smaller one. Leaves elliptic-lanceolate, acute or acuminate, narrowed into a petiole (up to $2.5 \mathrm{~cm}$ ), plicate, erectly spreading, margins slightly undulate, $6.2-15 \times 2-3.5$ $\mathrm{cm}$. Inflorescence up to $17 \mathrm{~cm}$; variable in size, shorter or the same length as the leaves in the high altitude form, exceeding the length of the leaves in the lowland form, slightly ridged, with up to 14 flowers. Peduncle with a single sheath towards the base and 2 5 broadly-lanceolate sterile leaf-like bracts below the rachis, $7-9 \times 2-3.5 \mathrm{~mm}$. Rachis laxly flowered, $3-$ $6 \mathrm{~cm}$ long. Floral bracts erectly spreading, initially similar to the sterile bracts below but then decreasing in size, lanceolate-acuminate, $5.4-8 \times 1-3 \mathrm{~mm}$. Flowers small, up to $10 \times 8 \mathrm{~mm}$, erectly spreading, greenish-yellow at first becoming brownish-yellow with age. Pedicel and ovary somewhat ridged, c. $5 \times 1.5 \mathrm{~mm}$. Dorsal sepal narrowly lanceolate, obtuse, base subcordate-auriculate, $6.5-8 \times 1.1-1.7 \mathrm{~mm}$. Lateral sepals porrect, elliptic-oblong, obtuse, $5.1-6.5 \times 2.3-$ $2.7 \mathrm{~mm}$. Petals deflexed, obliquely linear, $5.1-7.9 \times$ $0.3-0.5 \mathrm{~mm}$. Lip strongly curved in the middle, the base subrectangular, basal wings short and rounded, with a rounded callus at the base forming a crescent or ' $\mathrm{V}$ ' or ' $\mathrm{M}$ ' shape, abruptly expanded in the middle into a kidney-shaped obcordate blade, rounded to 


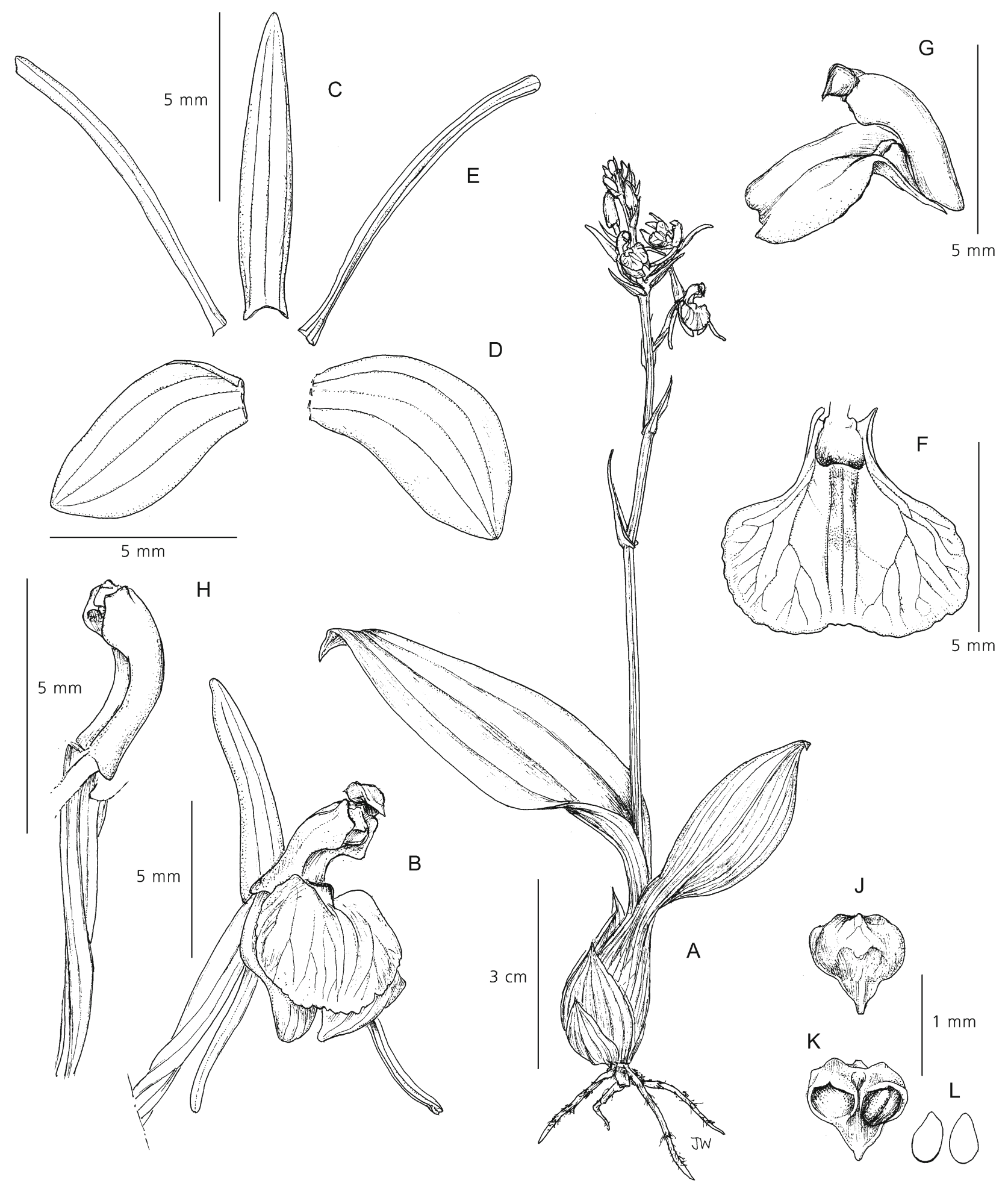

Fig. 40. Liparis nectarina. A habit; B flower; C dorsal sepal; D lateral sepal; E petal; F lip; G lip and column; H column; J anther cap, front view; K anther cap, rear view; L pollinia. From Hermans 8153 \& 8160 (K). DRAWN BY JULIET BEENTJE.

undulate at the anterior margin, $4.1-5.6 \times 3.8-5.4$ $\mathrm{mm}$. Column curved at the apex with subrectangular wings, $2.3-4.1 \times 0.8-1.2 \mathrm{~mm}$. Anther obtusely beaked at the front, c. $1 \times 0.9 \mathrm{~mm}$. Pollinia oval c. $0.4 \times 0.3 \mathrm{~mm}$.
RECOGNITION. A squat, broad-leaved plant normally with one flowering growth and a short conical pseudobulb, several broadly lanceolate sterile bracts below the rachis with similar floral bracts but becom- 

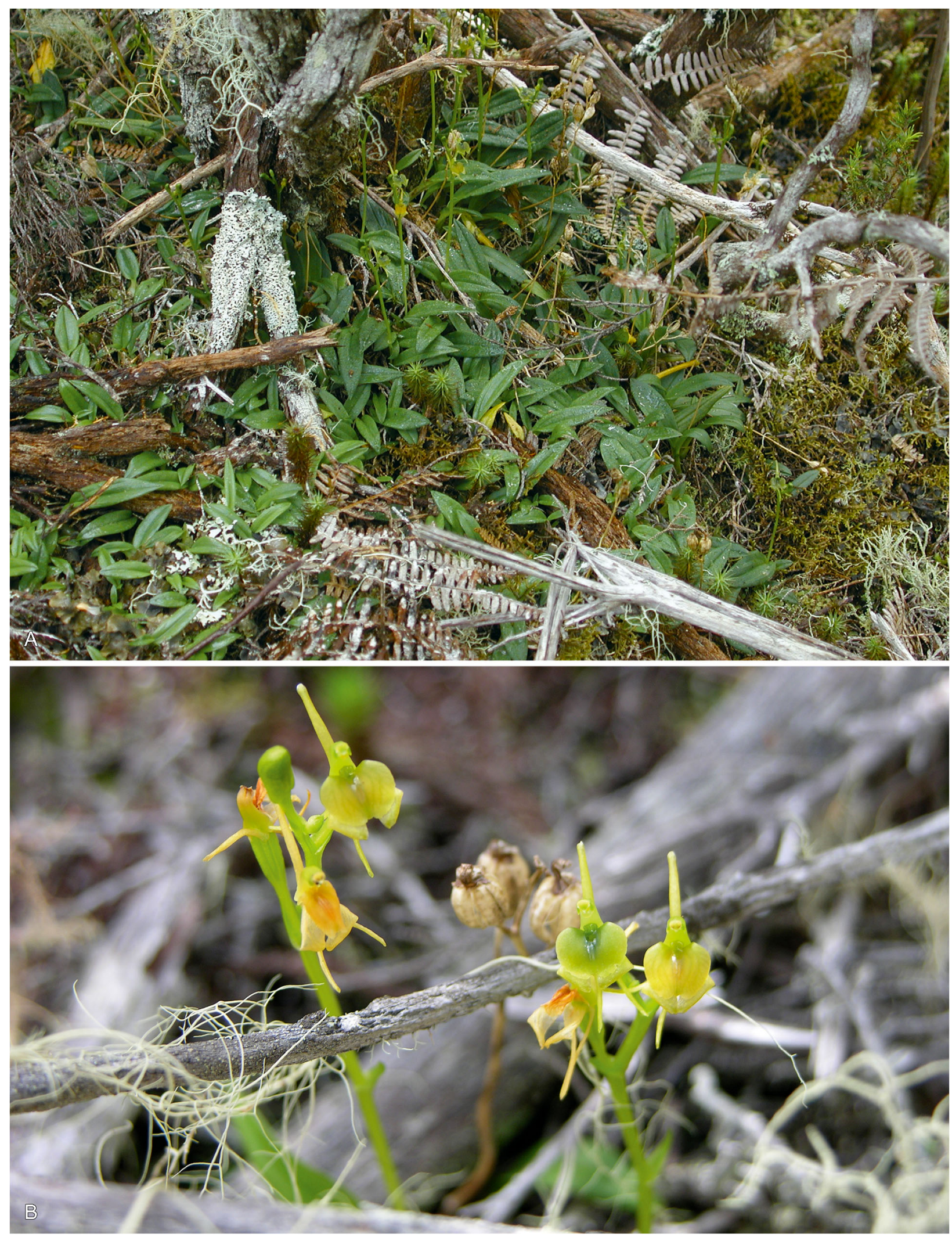

Fig. 41. Liparis nectarina. A habit; B flowers. PHOTOS: PATRICE BERNET. 


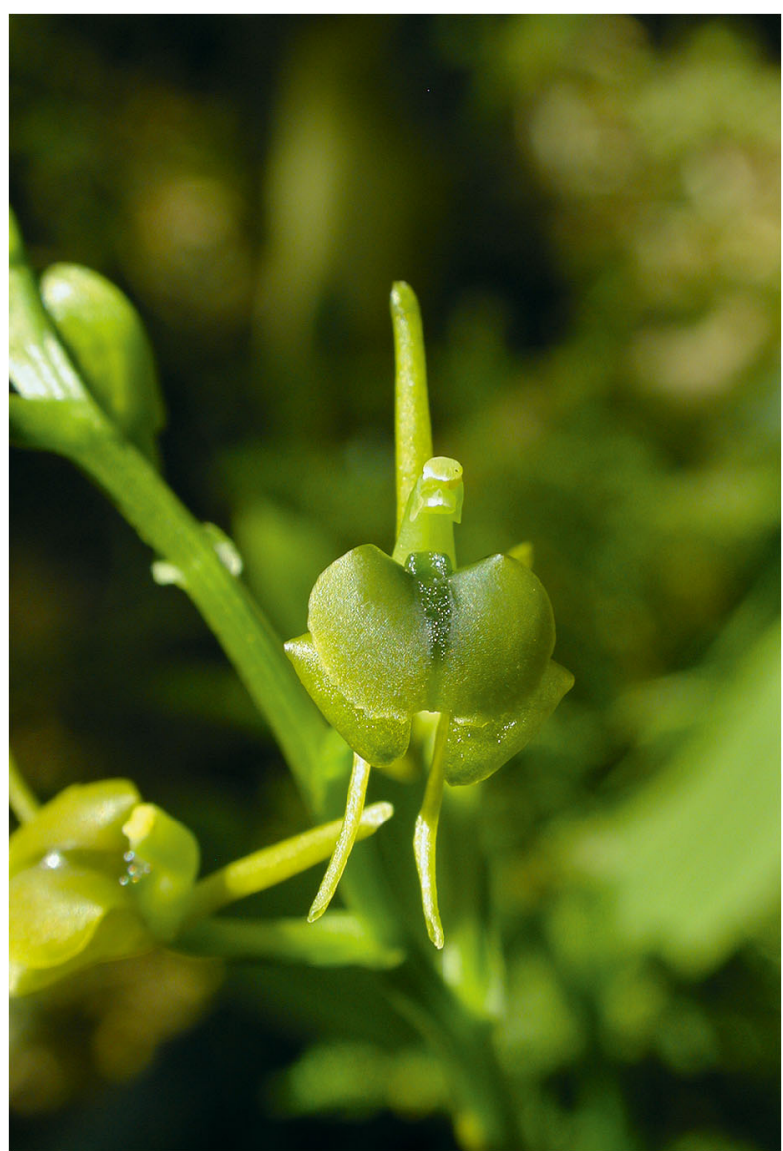

Fig. 42. Liparis nectarina. Flower. PHOTO: PATRICE BERNET.

ing smaller, a lip with a large rectangular base and then expanded into a broad rounded subcordate blade with and entire, semi-circular to 'M'-shaped callus and an obtusely beaked anther cap.

Schlechter compared Liparis nephrocardia with L. jumelleana but it is very different in habit and in having a somewhat longer and kidney-shaped blade of the lip. Liparis bosseri described above is similar in plant and flower size but the inflorescence of $L$. bosseri far surpasses the leaves (vs about the same length) and lacks the distinct rounded callus. It is similar to L. andringitrana in both habit and flower but L. nephrocardia is a little smaller and squatter, its lip is sub-rectangular near the base and the callus is lobed and much more obvious vs obscure, it also has more prominent column wings (Table 2).

DISTRIBUTION. Endemic to Madagascar: Antsiranana, Fianarantsoa and Toamasina provinces only (Map 33). SPECIMENS EXAMINED. MADAGASCAR. Mt Tsaratanana, Jan. 1923, Perrier 15746 (P00095479) lectotype (P); Mt Tsaratanana, Dec. 1922, Perrier 15246 (P00095476), paratype (P); Sambirano, Northern slopes of the Sambirano valley, 600 m, Dec. 1922, Perrier 15745 (P); East, near the confluence of the Onive and the Mangoro, c. 700 m, Feb. 1925, Perrier 17135 (P); Mts $\mathrm{N}$ of Mangindrano, Ambohimirahavavy, $1800 \mathrm{~m}$,

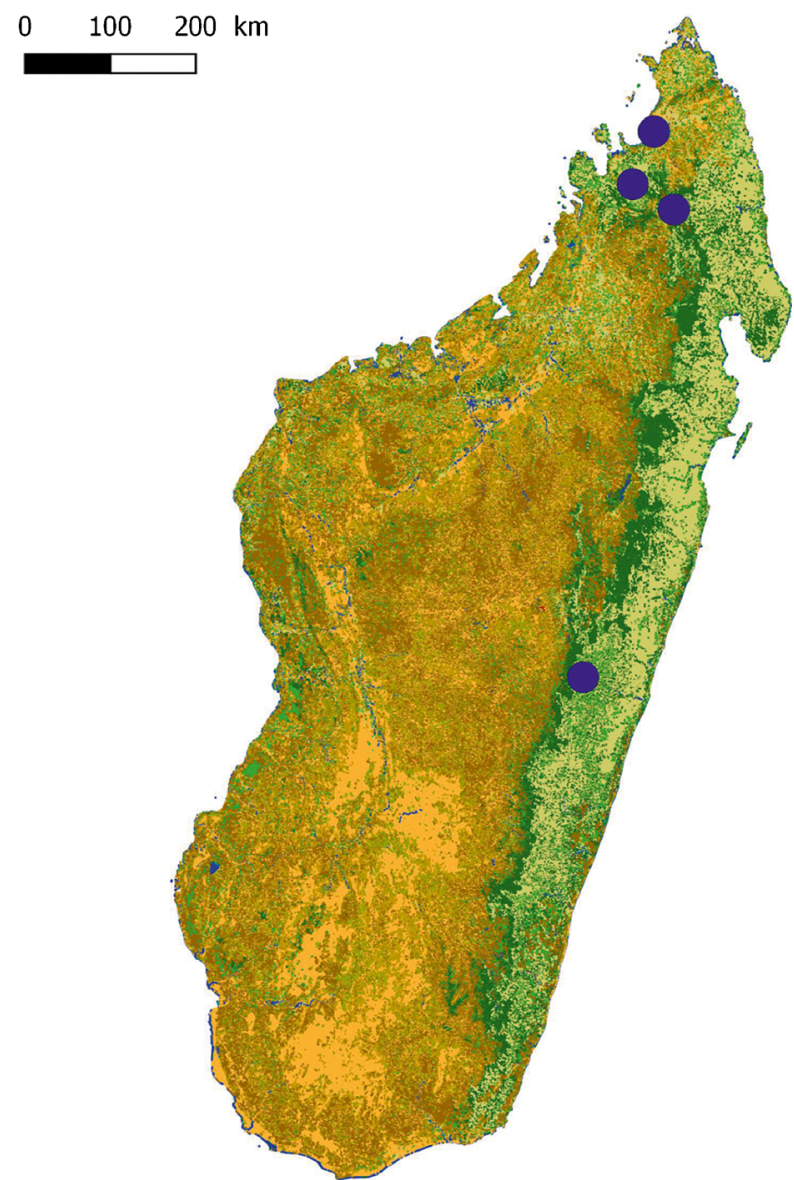

Map 33. Distribution of Liparis nephrocardia.

Jan. 1951, Humbert 24887 (P); Fianarantsoa, Ranomafana area, Jan. 1992, Hermans 8286 (K).

HABITAT. Humid evergreen forest and moss-forest. Altitude: 600 - $1800 \mathrm{~m}$.

CONSERVATION STATUS. Category EN: the extent of occurrence (EOO) of Liparis nephrocardia is estimated to be $20,007 \mathrm{~km}^{2}$ (which exceeds the limits for Vulnerable status under criterion B1) whereas its minimal area of occupancy (AOO) is estimated to be $16 \mathrm{~km}^{2}$ (which falls within the limits for Endangered status under the criterion B2). Liparis nephrocardia is known from four subpopulations representing four locations (sensu IUCN), this species has been preliminarily assessed as EN using the green listing method. This species is threatened by selective logging, timber harvesting for small-scale subsistence and tavy (slash-and-burn farming), resulting in habitat reduction and habitat quality reduction.

FLOWERING TIME. December to March.

ETYMOLOGY. Refers to the kidney / heart shape of the blade of the lip.

NOTES. This is one of the few species where Schlechter indicated a holotype specimen (Perrier 15746) '...to avoid future confusion' but, even then, there are two sheets with the same number, collected at the same 
locality but at a different time, the better specimen is designated here as the lectotype. Perrier (1936: 253) mentioned that Perrier 17135 differs a little from the holotype in that it has 3-veined sepals (not 5-veined), petals shorter than the dorsal sepal and with two veins only, a smaller lip and the callus which is narrowly ' $\mathrm{V}$ ' shaped. But there is some variability in all the specimens recorded by Schlechter.

There seem to be two distinct forms of this species, a smaller one from Mt Tsaratanana and the Sambirano region and a lusher lower altitude form from the Eastern forests where the plant is almost double the size and the inflorescence much longer.

ILLUSTRATIONS. Figs 43, 44; Bosser \& Lecoufle (2011: 409) but the flowers do not look like this species; Hervouet (2018: 414).

Liparis ochracea Ridl. (Ridley 1885: 461; 1886b: 270); Hermans et al. (2007: 221); Cribb \& Hermans (2009: 158); Bernet (2010a: 94; 2010b: 69); Bosser \& Lecoufle (2011: 410); Hervouet (2018: 415). Type: Madagascar, Ankafana, Deans Cowan watercolour no. 581.9 (691), p.17 no 36, 1880 (holotype BM).

Leptorkis ochracea (Ridl.) Kuntze (1891: 671).

Liparis connata Ridl. (Ridley 1885: 462; 1886b: 270).

Type: Madagascar, Imerina, Deans Cowan s.n. BM000090067 (holotype BM).

Leptorkis connata (Ridl.) Kuntze (1891: 671).

Liparis hildebrandtiana Schltr. (Schlechter 1924: 140); Perrier (1936: 251; 1939: 286). Type: Madagascar, Mt Tsiafajavona, Perrier 13511 (holotype P).

Large, erect, terrestrial, epiphytic or rarely lithophytic plant, up to $28 \mathrm{~cm}$ tall but generally between $15-20 \mathrm{~cm}$, rhizome very short, repent, roots filiform, flexuose more or less pilose. Pseudobulbs stem-like, narrowly cylindricalovoid to subcylindrical but bulbous at the base, up to $6 \mathrm{~cm}$ long, $2 \mathrm{~cm}$ wide, covered by 2 - 3 long and overlapping stem-sheaths, sometimes the older leafless pseudobulb obliquely divergent, with up to 5 leaves starting half-way up the stem and ending with $2-3$ larger ones towards the apex. Leaves erectly spreading, obliquely elliptic to ovateelliptic, apiculate to obtuse, base rounded-cuneate and then narrowed into a $1.5-4 \mathrm{~cm}$ petiole, overall $7-15 \times 3-$ $5 \mathrm{~cm}$, plicate, margins a little undulate to crenulate. Inflorescence erect, up to $15 \mathrm{~cm}, 2-3 \mathrm{~mm}$ in diam., laxly with up to 11 flowers but generally fewer. Peduncle costate, with $2-4$ peduncle sheaths, the basal ones amplectant, the higher spreading, up to $35 \times 4 \mathrm{~mm}$. Rachis up to $8 \mathrm{~cm}$ long. Floral bracts erectly-spreading, variable but generally the lower ones lanceolate-acuminate, the higher ones shorter, ovate-acuminate to cordate and almost leaf-like, 6 $-14 \times 2.5-5 \mathrm{~mm}$. Flowers large, erectly spreading, up to 20 $\times 15 \mathrm{~mm}$, sepals and petals greenish-white to more or less greenish yellow becoming more yellow-orange with age, the lip a little darker and sometimes with a darker patch on the disk, column white, anther white to greenish-white, pollinia yellow. Pedicel and ovary slightly ridged to costate, 9 - $14 \times 2-5 \mathrm{~mm}$. Dorsal sepal arching over the column, narrowly-triangular, base cordate, tip obtuse to acuminate, $12-17 \times 2-3.5 \mathrm{~mm}$. Lateral sepals porrect below the lip, frequently fused or part fused with one another, subfalcate, oblong-lanceolate, somewhat obtuse, 11.5 - 16 $\times 3.5-5 \mathrm{~mm}$. Petals pendent and recurved towards the tip, narrowly linear narrowing towards the apex, margins incurved, $10-15 \times 0.5-1.2 \mathrm{~mm}$. Lip elliptic, apex truncate-obtuse and shortly indented, anterior margins undulate to dentate, strongly curved just above the middle, base shortly cordate-auriculate, with two distinct parallel calli at the base, more or less longitudinally semi-obovate to lobular, overall $9.6-14.2 \times 5-7.4 \mathrm{~mm}$, generally about half as wide as long. Column slightly curved, semi-terete, the margins extended into rounded wings along the apical half, $4-7 \times 1.5-2.5 \mathrm{~mm}$. Anther shallow, broadly obovate with a tiny apicule at the anterior margin, $1.0-1.2 \times 1.1-$ $1.3 \mathrm{~mm}$. Pollinia ovate, c. $0.5 \times 0.6 \mathrm{~mm}$. Seed capsule costate.

RECOGNITION. This is a variable species both in habit and flower but there are a number of distinguishing characteristics. It is a large plant with three to five broad ovate-elliptic leaves along a bulbous stem, a costate peduncle, broad, almost leaf-like floral bracts, large flowers with a long narrowly triangular dorsal sepal, a strongly curved lip almost twice as long as wide with a denticulate anterior margin, with parallel calli at the base and a rounded anther.

There are some strong similarities with Liparis sambiranoensis but that has a longer pseudobulb and a more distinct rounded epichile and angular hypochile of the lip (vs almost pandurate), a curved column with small angular wings make the latter species also distinct. Similar to L. ornithorrhynchos but the latter is generally shorter in growth, has a more rounded leaf, somewhat smaller flowers with narrower bracts, a narrower dorsal sepal, much rounder lip without distinct calli and an anther without a distinct beak. A number of Hildebrandt specimens from the same locality were confused with L. ornithorrhynchos. DISTRIBUTION. Widespread in Madagascar in the highlands and Eastern forests. Antananarivo, Antsiranana, Fianarantsoa and Toamasina provinces (Map 34). There is a record from Toliara (Rakotoson 9421) and they seem to be more compact elongate plants growing in a drier environment. Herbarium material collected by Boivin in 1850 - 51 (P00095480-2) on Nosy-Be in Northern Madagascar could be a misidentification, the plants mainly consist of damaged or fruiting specimens; the floral bracts are not typical for this species. The species is rare on Réunion and records are relatively modern (Bernet 2010b: 69).

SPECIMENS EXAMINED. MADAGASCAR. Ankafana, Deans Cowan watercolour 1880: London, Natural History Museum, no. 581.9 (691), p.17 no 36, 1880 (holotype 


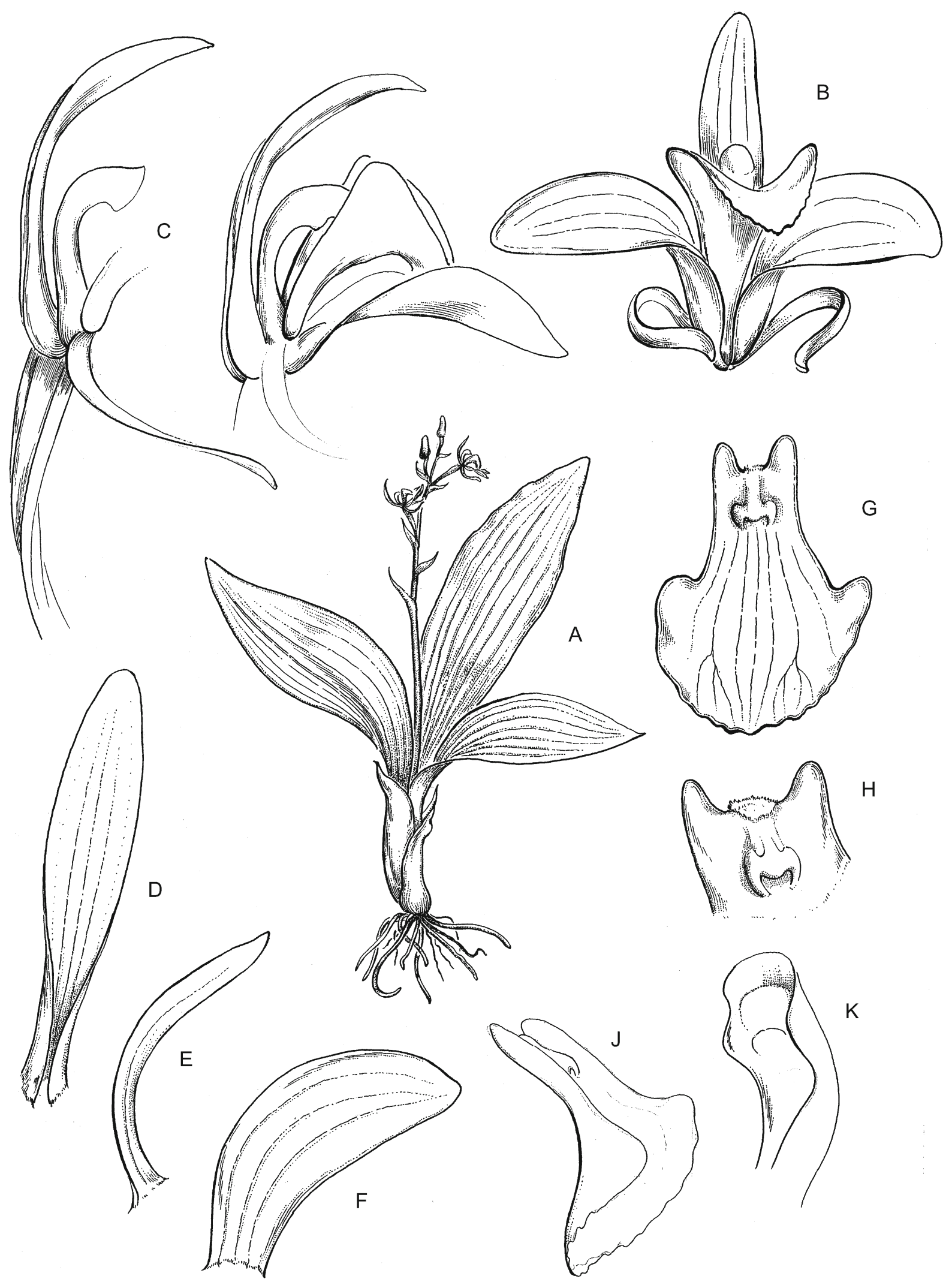

Fig. 43. Liparis nephrocardia. A habit $\times 1$; B flower, front $\times 8$; C flower, side view $\times 10$; D dorsal sepal $\times 10$; E petal $\times 10$; F lateral sepal $\times 10$; G lip $\times 10$; $\mathrm{H}$ lip basal callus $\times 15$; J lip, side view $\times 10 ; \mathrm{K}$ column, side view $\times 15$. UNFINISHED DRAWING BY OLIVER WHALLEY. 

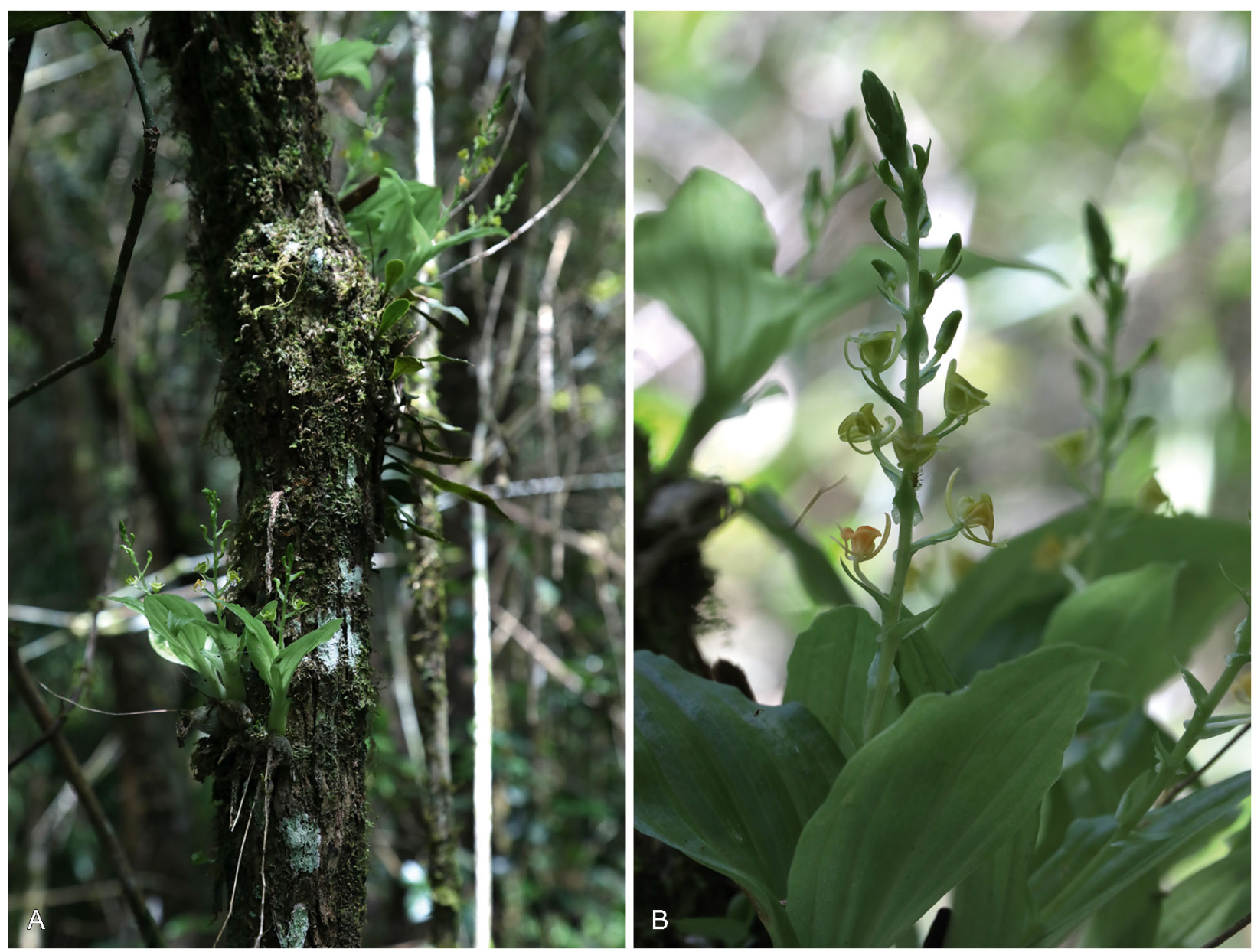

Fig. 44. Liparis nephrocardia. A habit; B rachis. PHOTOS: JOHAN HERMANS.

BM); Nossi-Bé, Lokobe (Loucoube), Jan. 1850 March 1851, Boivin s.n. P00095480-2 (P); Fianarantsoa, Scott Elliot 2065 (P); Ankafana forest, S Betsileo, March 1881, Hildebrandt 4048 (W); S Betsileo, Ankafina forest, Hildebrandt 3985b (W); Centre, Tsinjoarivo, Feb. 1925, Perrier 16971-3 (P); Centre, Andasibe forest, Feb. 1925, Perrier 17133 (P); Centre, Andasibe forest, Feb. 1925, Perrier 17134 (P); Mandraka, March 1925, François 17206 (P); Mandraka, Ankeramadinika forest, Perrier 15953 (P); Mandraka, Ankeramadininika forest, Perrier 17134bis (P); Carion, Feb. 1938, Jard. Bot. Tana., 3370 (P); E, near the confluence of the Onive and the Mangoro, Perrier 17195 (P); S of Ambositra, Feb. 1942, Decary 17574 (P); W of Itremo, Humbert s.n (P-spirit); Ambatofitorahana, Betsileo, 1350 - 1600, Jan. 1955, Humbert 28417 (P); Road Antananarivo-Fianarantsoa, Jan. 1957, Descoings 2159 (P, TAN); Behara, Isilitsily, Amboasary, March 1957, Rakotoson 9421 (P, TAN); between Ambositra and Fianarantsoa, Aug. 1963, Rauh 10681 (HEID); Mt Tsaratanana, Jan. 1964, Rakotozafy 1289 (P); S of Ambositra, Jan. 1964, Bosser
18841 (P); S of Ambositra, PK300, Jan. 1965, Bosser 18937 (P); PK 290 main road S of Tana towards Fianarantsoa, Sept. 1969, Stewart 1060 (K); Fianarantsoa, Ambatofitorahana, Jan. 1996, Hermans 5372 (K); Fianarantsoa, Ambatofitorahana, 1996, Hermans 3738 \& 3739 (K); Angavokely, 1500 m, Jan. 1996, Hermans 5377 (K); Antananarivo, Manjakatompo, 1800 m, 1997, Hermans 3939 (K, Kspirit); Manjakatompo, Dec. 1997, Hermans 2585, 4269 (K); Tsiazompaniry area, 1997 Hermans 2556 (K); Ambatovory, 1997, Hermans 2598 (K); Manjakatompo, 1999, Hermans 2476 (K); Ambatofitorahana, towards Fianarantsoa, 1999, Hermans 2881 (K); Antananarivo, Anjozorobe forest, 2000, Hermans 4257.1 (K); Ankaratra Massif, 2001, Hermans 5405 (K); road towards Ambatofinandrahana, before Anjomam Ankona, April 2001, Hermans 2111 (K); Toamasina, Ampitambe, Ambatovy, 1123 m, March 2005, Rakotovao et al. 1411 (TAN); Toamasina, Antsakabary, Andapanomby, Mikara, 1021 m, April 2007, Birkinshaw et al. 1677 (K); Toamasina, Antaniditra, côté Ouest de Analamay, 1078 m, Oct. 2008, 


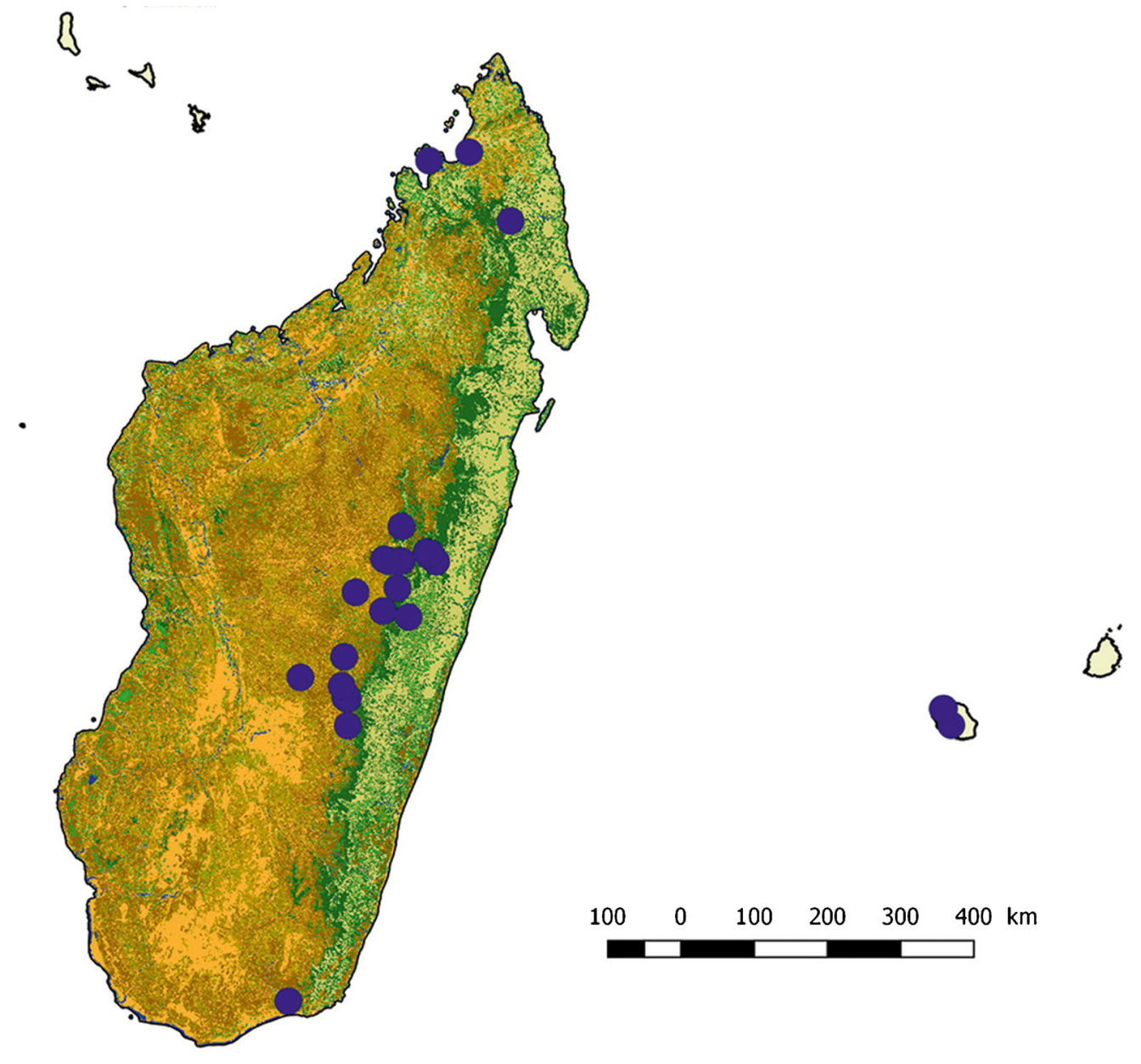

Map 34. Distribution of Liparis ochracea.

Radrianasolo 943 (MO, P, TAN); Toamasina, Morarano, Marovoay, 1030 m, April 2009, Ravelonarivo 3277 (MO, P, TAN); Antanarivo, Ambatolampy, Ambatotsipihina, Dec. 2009, Rajaovelona 100 (K, TAN); Toamasina, Antaniditra, Ambatovy forest, 1035 m, Oct. 2008, Antilahimena et al. 6627 (MO, P, TAN); s. loc. (K Spirit 21018.000); s. loc., Plazon s.n. R7523 (W). RÉUNION. s. loc. Boivin 1035 P409214 (P); Boivin, s.n. P409246 (P); Marquat ravine, Clos d'Âne, 700 m, March 1973, Friedmann 2145 (P); Ilet Solitude, Hauts de la Possession, $600 \mathrm{~m}$, March 1973, T. Cadet 4183 (P, REU); Dimitile, 2000 m, March 2003, Bernet Ẽ Rivière in Hermans 8165 (K).

HABITAT. Humid Eastern forest, highland forest, lichen forest, in damp shade in moss, on rocks and on moss-covered trees. Altitude: $600-2000 \mathrm{~m}$.

CONSERVATION STATUS. Category LC: the extent of occurrence (EOO) of Liparis ochracea is estimated to be $783,412 \mathrm{~km}^{2}$ (far exceeding the limits for Vulnerable status under criterion B1) whereas its minimal area of occupancy (AOO) is estimated to be $132 \mathrm{~km}^{2}$ (which falls within the limits for Endangered status under the criterion B2). Liparis ochracea is known from 24 subpopulations representing 29 locations (sensu IUCN), this species has been preliminarily assessed as LC using the green listing method. This species is threatened by mining activities, selective logging, timber harvesting for small-scale subsistence and tavy (slash-and-burn farming), resulting in habitat reduction and habitat quality reduction.

Previously assessed and published (as Liparis hildebrandtiana) in the IUCN Red data listing for Réunion as CR (Picot 2013: 11).

FLOWERING TIME. January to April.

ETYMOLOGY. The name presumably refers to the ochre colour of the flower, especially the ochre area in the lamina of the lip mentioned by Ridley in his description. This is not often seen in this species; Ridley's description relied on Deans Cowan's fairly rudimentary watercolour which shows this feature.

NOTES. The species was described in 1885 by Henry Ridley based upon a watercolour drawing in William Deans Cowan's sketchbook of Madagascan orchids (Cowan 1880: 17), now kept at the Natural History Museum, London. Ridley confirmed in his description that there was no herbarium specimen of it. Deans Cowan was not one of the most accomplished botanical artists but the watercolour shows the plant and also some 
detail of the flower and its parts; together with Ridley's description, the species is fairly well defined. In the same publication Ridley also described Liparis connata which he admitted is likely to be a monstrous form of another species where the lateral sepals are fused together; otherwise it shows all the characteristics of L. ochracea. In 1924 Rudolf Schlechter described L. hildebrandtiana; 'named in memory of the Madagascar researcher Johann Maria Hildebrandt', it has all the characteristics of L. ochracea. Perrier (1936: 242, 251; 1939: 286) reduced both $L$. ochracea and $L$. connata to the synonymy of L. hildebrandtiana: in his reasoning he mentioned that he thought $L$. hildebrandtiana is nothing else but the Liparis named by Ridley as L. ochracea and L. connata but that it was impossible to verify this synonymy as L. ochracea was only described from a watercolour by Deans Cowan and L. connata is an abnormal cleistogamous form. He proposed therefore to conserve, notwithstanding its later publication, the name of Schlechter which, he said, is at least applied to a clearly defined species and is represented by several herbarium specimens, showing clearly the variability of the species and the cleistogamous forms that exist. This statement may well be true but is not valid under the rules of nomenclature and therefore the name $L$. ochracea has priority under ICN article 11.4.

Both Ridley and Perrier mentioned the great variability of the species plus the tendency to produce cleistogamous or deformed flowers, this is also confirmed by observations in the field. Perrier (1936: 251) gave a detailed analysis of the different variants and abnormalities found in plants from different localities, he also annotated a number of herbarium specimens; fusion of the lateral sepals seems to be quite common and the absence or deformity of anther and stigma are also frequent, especially the flowers at the apex of the inflorescence. He mentioned that the shape of the lip can also vary but the number of veins (seven) and their disposition (three median undivided and four branched laterals) are always present.

A specimen in the Paris herbarium (Boivin 1035 P00409214) from Réunion, misidentified as Liparis caulescens, is annotated as L. polycardia Rchb.f. but is in fact $L$. ochracea.

ILLUSTRATIONS. Fig. 45; Cowan (1880: 17); Schlechter (1932: T.211); Cribb \& Hermans (2009: 157); Bernet (2010a: 94; 2010b: 69), (Bosser \& Lecoufle 2011: 410); Hervouet (2018: 415). Photographs shown in Bosser \& Lecoufle (2011) as Liparis flavescens (p. 407) and as L. imerinensis (p. 408) both have the characteristics of L. ochracea.

Liparis ornithorrhynchos Ridl. (Ridley 1885: 460; 1886b: 270); Perrier (1939: 293); Hermans et al. (2007: 221); Cribb \& Hermans (2009: 158). Types: Madagascar, Ankafana, Deans Cowan 35 (BM00090064) (lectotype BM, designated here); Madagascar, Ankafana, Deans Cowan watercolour 1880: London, Natural History Museum, no. 581.9 (691), p.17 no 35, 1880 (BM); lectoparatype Madagascar, Ankafana, S Betsileo Hildebrandt 4049 BM, G, K (pro parte), LE, M).

Leptorchis ornithorrhynchos (Ridl.) Kuntze (1891: 671).

Small erect to arching terrestrial plant on a short to repent rhizome, rhizome up to $5 \mathrm{~cm}$ long covered with thin sheaths, roots filiform more or less villous 3 $5 \mathrm{~mm}$ diam., overall up to $15 \mathrm{~cm}$ but often smaller. Pseudobulbs stem-like, up to $5 \mathrm{~cm}$ long, $7-10 \mathrm{~mm}$ diam., completely covered by $2-3$ papery sheaths up to $45 \mathrm{~mm}$ long, with 2 or rarely 3 leaves at the top, disintegrating when the new growth emerges. Leaves shortly petiolate, ovate, acute, somewhat plicate, $3.5-$ $7.5 \times 1.5-3.5 \mathrm{~cm}$, green. Inflorescence erect, laxly $8-$ 12-flowered, overall between 6 and $12 \mathrm{~mm}$ long, 3 $4 \mathrm{~mm}$ diam. Peduncle angular, with $2-3$ acutely lanceolate peduncle sheaths, $8-9 \times 3-4 \mathrm{~mm}$. Rachis between 4 and $6 \mathrm{~cm}$. Floral bracts ovate-lanceolate, the upper ones more acutely-lanceolate, $4.2-11.5 \times 1.8-$ $2.9 \mathrm{~mm}$, decreasing in size towards the apex. Flowers large, spreading, up to $16 \times 10 \mathrm{~mm}$, overall pale green becoming more yellowish-green with age, the column white, with a darker green longitudinal band on the disk of the lip. Pedicel and ovary long and thin, up to 15 $\times 1.5 \mathrm{~mm}$. Dorsal sepal linear, erect to arching, margins incurved, 8.5 - $11.1 \mathrm{~mm}$. Lateral sepals ovate-lanceolate, obtuse, folded underneath the lip, $9.3-9.5 \times 3.8-5.2$ $\mathrm{mm}$. Petals narrowly linear, spreading, $10.8-10.6 \times 0.6$ - $1 \mathrm{~mm}$. Lip rounded to cordate with a short, narrow auriculate base, margins slightly undulate, a short apicule at the tip, with a broad disk and without calli, $7.9-9.2 \times 8.0-8.3 \mathrm{~mm}$. Column arching, almost straight, with long elongate wings, up to $5 \mathrm{~mm}$ long, $1.5 \mathrm{~mm}$ wide. Anther ovate with an elongate-rostrate obtuse beak, $0.9-1.0 \times 1.0-1.2 \mathrm{~mm}$. Pollinia ovate, c. $0.5 \mathrm{~mm}$. Seed capsule obovate, slightly ridged, up to $15 \times$ $8 \mathrm{~mm}$.

RECOGNITION. The plant has a creeping rhizome, a short thin stem covered with two to three long papery sheaths, two ovate, plicate leaves, ovate-lanceolate floral bracts becoming narrower and shorter towards the apex of the inflorescence, a long and thin pedicellate ovary, and relatively large flowers, with the lateral sepals folded beneath the lip and about twice as long as wide, a roundly to broadly cordate lip with a narrow base, no calli and a distinctly beaked anther cap.

In his description Ridley compared it with Liparis bowkeri from mainland Africa but that has a different habit, rounded vs stem-like pseudobulbs and also has two distinct calli at the base of the lip. In habit and lipshape L. ornithorhynchos is similar to both L. imerinensis and L. andringitrana but it does not have the flattened 

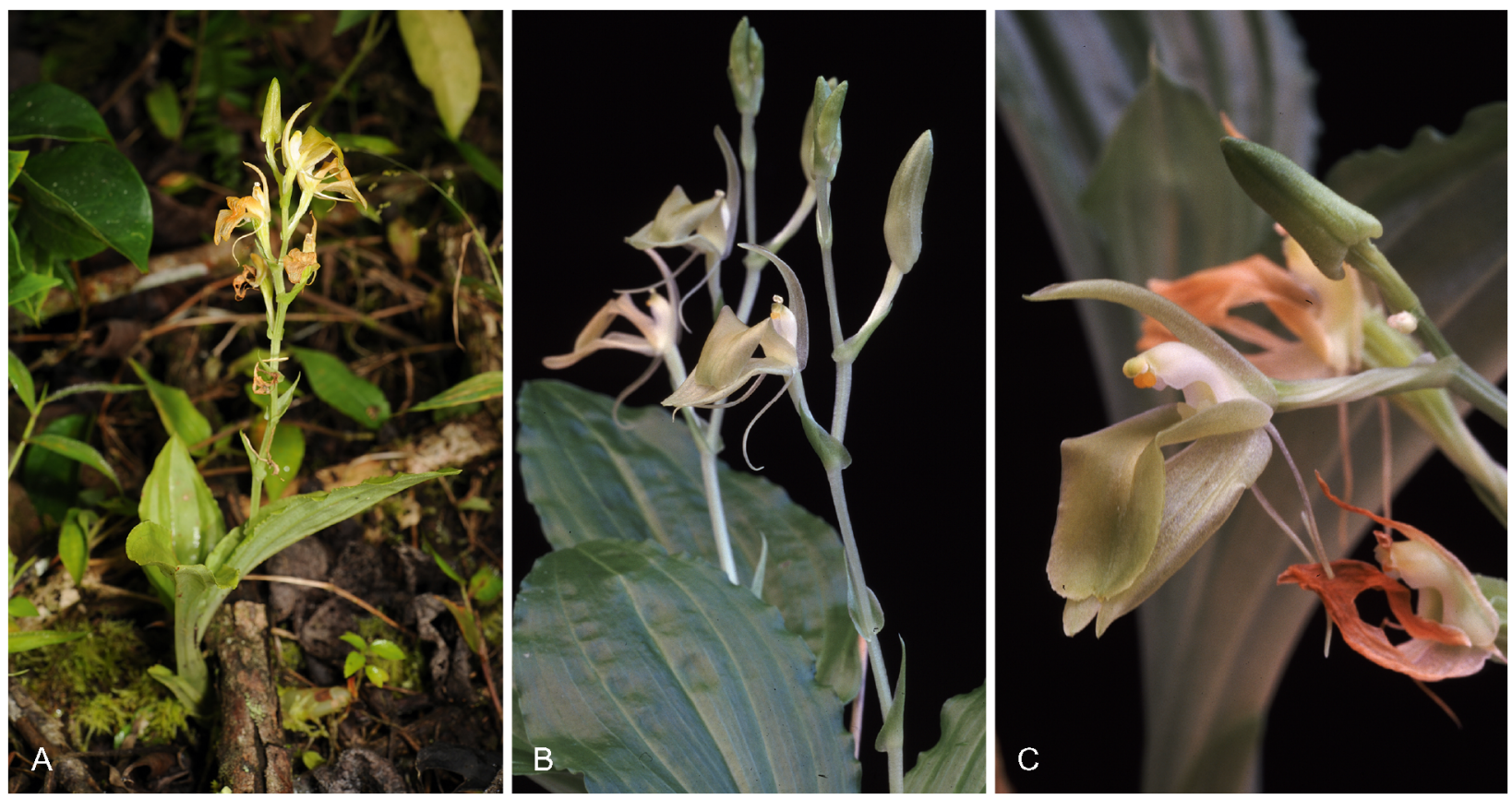

Fig. 45. Liparis ochracea. A habit; B inflorescence; C flower. PHOTOS: A JEAN-MICHEL HERVOUET; B, C JOHAN HERMANS.

pseudobulbs of L. andringitrana, the flowers almost $1 / 3$ larger and lack a callus at the base of the lip. It is often confused in herbaria with L. ochracea but its habit, smaller and rounder lip lacking a callus and its beaked anther cap make it distinct. The syntype or lectoparatype (Hildebrandt 4049) at $\mathrm{K}$ differs in its lip shape from that at $\mathrm{W}$ and elsewhere; the collection is a mixed group containing L. ochracea.

DISTRIBUTION. Endemic to Madagascar: Antananarivo and Fianarantsoa provinces (Map 35).

SPECIMENS EXAMINED. MADAGASCAR. Madagascar, Ankafana, Deans Cowan 35 (BM00090064) (lectotype BM); Ankafana, Deans Cowan watercolour 1880: London, Natural History Museum, no. 581.9 (691), p.17 no 35, 1880 (drawing of lectotype BM); Ankafana, S Betsileo, Hildebrandt 4049 (lectoparatypes BM, G, K (pro parte), LE, M); Central, 1880's Baron 1221 (K); Betsileo-land, 1880's Baron 196 (K); s. loc., Baron s.n., rec. July 1880 (K); Fianarantsoa, Jan. - Feb. 1890, Scott Elliot 2065 (BM, K); Road to Lakato, April 1964, Bosser 17753 (P); Fianarantsoa, Ranomafana, vicinity of Ampasina, March 1995, Turk et al. 741 (K, P); Angavokely area, 1997, Hermans 2700 (K).

HABITAT. Highland evergreen forest, in shade, damp places. Altitude: $1000-1500 \mathrm{~m}$.

FLOWERING TIME. January to April.

CONSERVATION STATUS. Category EN: the extent of occurrence (EOO) of Liparis ornithorrhynchos is estimated to be $11,163 \mathrm{~km}^{2}$ (which exceeds the limits for Endangered status under criterion B1) whereas its minimal area of occupancy (AOO) is estimated to be $16 \mathrm{~km}^{2}$ (which also falls within the limits for Endangered status under the criterion B2). Liparis ornithorrhynchos is known from four subpopulations representing four locations (sensu IUCN), this species has been preliminarily assessed as EN using the green listing method. This species is threatened by selective logging, timber harvesting for small-scale subsistence and tavy (slash-and-burn farming), resulting in habitat reduction and habitat quality reduction.

ETYMOLOGY. Presumably referring to the resemblance of the anther to the beak of a bird.

NOTES. Ridley (1885) described Liparis orthorrhynchos and cited two distinct collections: material collected by the Rev. William Deans Cowan in 1880 and specimens collected in 1881 by Johann Hildebrandt from a similar area. The Deans Cowan material consists of a single herbarium sheet of several plants kept at BM, it is annotated '35' in Ridley's hand which refers to one of Dean's Cowans watercolours (Cowan 1880: 17, no 35). Hildebrandt's collection is represented in several European herbaria. The Deans Cowan specimen was selected as the holotype because it corresponds well to Ridley's description and also matches Dean's Cowan's illustration. The Hildebrandt material is a mixed group containing some atypical plants that do not correspond well with the description, the majority of plants being in seed. They are considered to be syntypes or lectoparatypes.

ILLUSTRATIONS. Fig. 46; Cowan (1880: 17 no 35); Cribb \& Hermans (2009: 157) is Liparis ochracea.

Liparis parva (Kuntze) Ridl. (Ridley 1885: 462); Ridley (1886b: 275); Perrier (1936: 249); Perrier (1939: 277); Hermans et al. (2007: 221); Cribb \& Hermans (2009: 


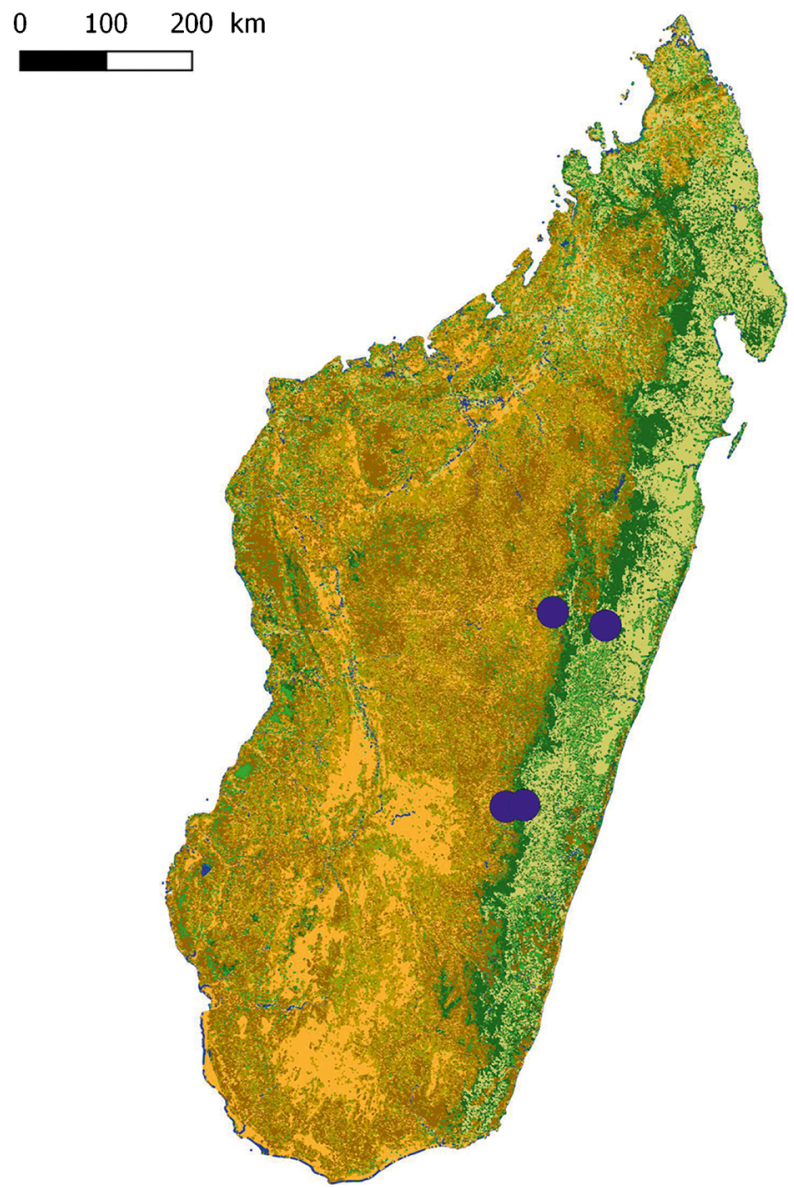

Map 35. Distribution of Liparis ornithorrhynchos.

153). Types: Madagascar, Ankafana, trees, Deans Cowan 38 (BM000090074) (holotype BM); Madagascar, Ankafana, Deans Cowan watercolour 1880: London, NHM, no. 581.9 (691), p.19 no 38, 1880 (illustration of holotype BM).

Leptorkis parva Kuntze (1891: 671).

Very small epiphytic plant on a very short rhizome, roots villous, overall $2.5-3.9 \mathrm{~cm}$ high without the inflorescence. Pseudobulbs adjoining, at first elongate then globular when mature, very pale green, with a few membranous sheaths around the base, a pair of leaves at the apex. Leaves opposite, lanceolate to lanceolate-ovate, c. $3 \times 1 \mathrm{~cm}$ acuminate, on a short 5 $-8 \mathrm{~mm}$ petiole. Inflorescence erect, up to $8 \mathrm{~cm}$ long, laxly 6 -12-flowered. Peduncle with one or two c. $6 \times$ $1.5 \mathrm{~mm}$ spreading peduncle sheaths. Rachis slightly angular, c. $3 \mathrm{~cm}$ long. Floral bracts cordate, lanceolate to ovate apiculate, $3.3-6.0 \times 1.4-2 \mathrm{~mm}$. Flowers medium size, erectly spreading, c. $12 \times 7 \mathrm{~mm}$, petals and sepals greenish yellow, the lip olive green, column green becoming white towards the apex, anther yellowish green, all parts becoming orange yellow on ageing with the lip orange. Pedicel and ovary at first straight then acutely curved upwards towards the column, a little angular, $5.5-9.1 \times 0.5-0.8 \mathrm{~mm}$. Dorsal sepal narrowly lanceolate, margins incurved, $5.2-6.8 \times 0.8-1.2 \mathrm{~mm}$. Lateral sepals lanceolate, falcate, obtuse, deflexed, $3.6-$ $5.5 \times 2-3.1 \mathrm{~mm}$. Petals spreading, linear, $5.9-7.1 \times 0.3-$ $0.5 \mathrm{~mm}$. Lip narrowly auriculate at the base, then ovate to suborbicular, obtuse a little indented at the anterior margin, with a longitudinal raised disk (not obvious in dried specimens) ending in an obtuse sub-rectangular callus at the base, $4.1-5.1 \times 3-3.6 \mathrm{~mm}$. Column thick, semiterete, wings broad, angular and strongly incurved, c. $4 \times 1 \mathrm{~mm}$. Antherwith a short sharp apicule at the front, c. $1 \times 0.8 \mathrm{~mm}$. Pollinia ovate, c. $0.3 \mathrm{~mm}$ diam.

RECOGNITION. Liparis parva is a very small two-leaved plant with relatively large flowers, orbicular pseudobulbs, long and narrow leaves, a loosely flowered and zig-zag inflorescence, and flowers with a lip with a large sub-rectangular callus at the base, wide and angular, incurved column wings, a pedicellate ovary and column at an acute angle.

The species has some similarities with Liparis cladophyllax and L. dryadum but neither have the distinct globular pseudobulbs and have a column that is indistinctly winged vs distinctly angular, and a lip almost half the size. Liparis parva bears some similarity to $L$. cespitosa but that species has a single leaf and flowers half the size (Table 1).

DISTRIBUTION. Endemic to Madagascar: Fianarantsoa and Toamasina provinces (Map 36). Szelengowicz et al. (2011: 11) and Szelengowicz \& Tamon (2013: 367), cited and illustrated this species from Réunion: it is not possible to verify the identity of the plant from the photographs but it is unlikely to be this species.

SPECIMENS EXAMINED. MADAGASCAR. Ankafana, trees, Deans Cowan 38 (BM000090074) (holotype BM); Ankafana, Deans Cowan watercolour 1880 (illustration of holotype BM); Mandraka, Ankeramadinika, 1930's Perrier 16966 bis \& ter (P); Toamasina, Maromizaha area, 1100 - 1200 m, 1997, Hermans 3987 (K); s. loc., May 2018, Hermans 8218 (K).

HABITAT. In wet Eastern and highland evergreen forests, in deep shade, on moss and lichen-covered trees. Altitude: 1100 - $1500 \mathrm{~m}$.

CONSERVATION STATUS. Category EN: the extent of occurrence (EOO) of Liparis parva is estimated to be $7,631 \mathrm{~km}^{2}$ (which exceeds the limits for Endangered status under criterion B1) whereas its minimal area of occupancy (AOO) is estimated to be $12 \mathrm{~km}^{2}$ (which falls within the limits for Critically Endangered status under the criterion B2). With only three known subpopulations representing three locations (sensu IUCN), this species has been preliminarily assessed as EN using the green listing method. This species is threatened by selective logging, timber harvesting for small-scale subsistence and tavy (slash-and-burn farming), resulting in habitat reduction and habitat quality reduction. 

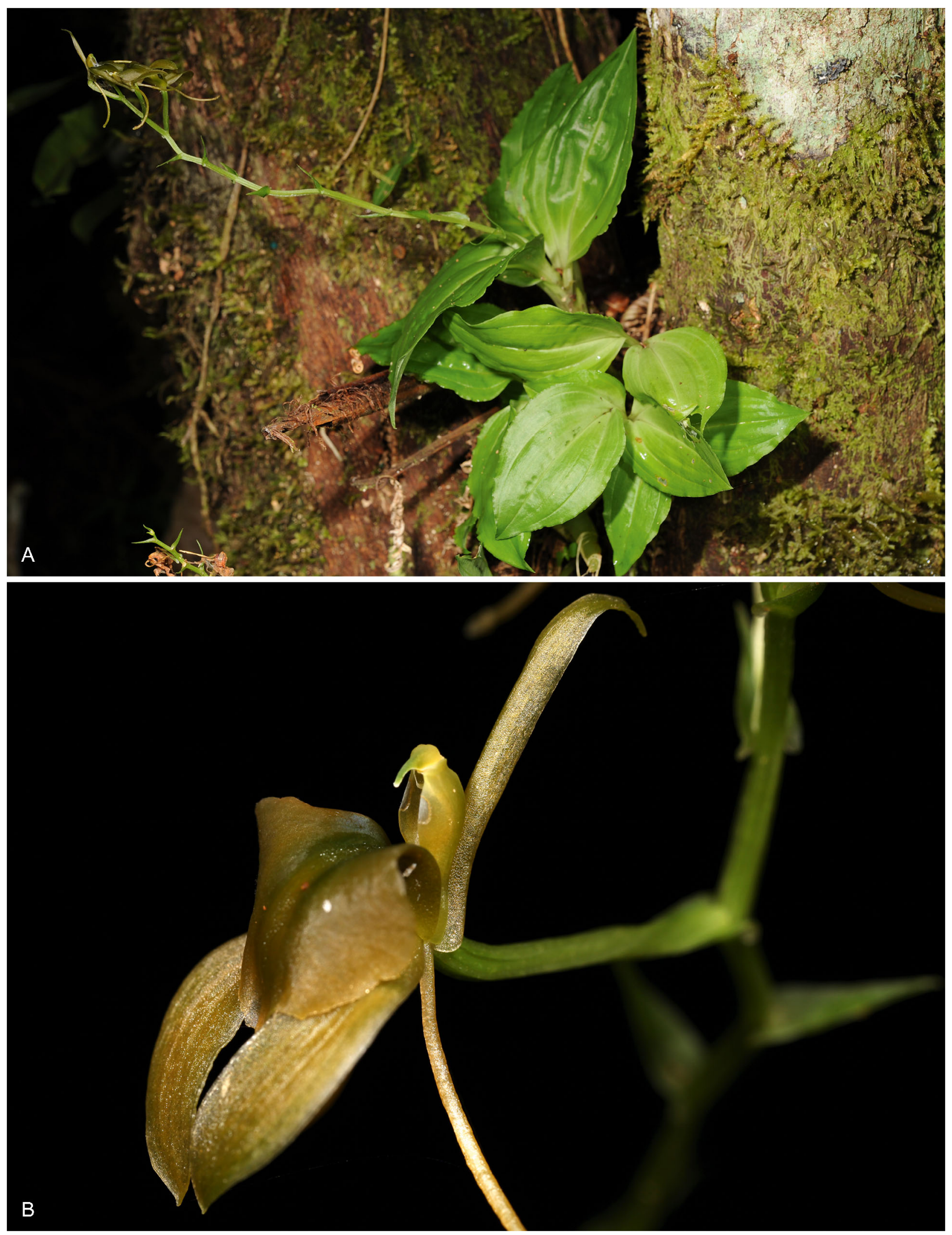

Fig. 46. Liparis ornithorrhynchos. A habit; B flower. PHOTOS: JEAN-MICHEL HERVOUET.

FLOWERING TIME. February.

ETYMOLOGY. Refers to the small size of the plant.
NOTES. Liparis parva was described by Henry Ridley, based on a plant found by the Rev. William Deans 
$0 \quad 100 \quad 200 \mathrm{~km}$

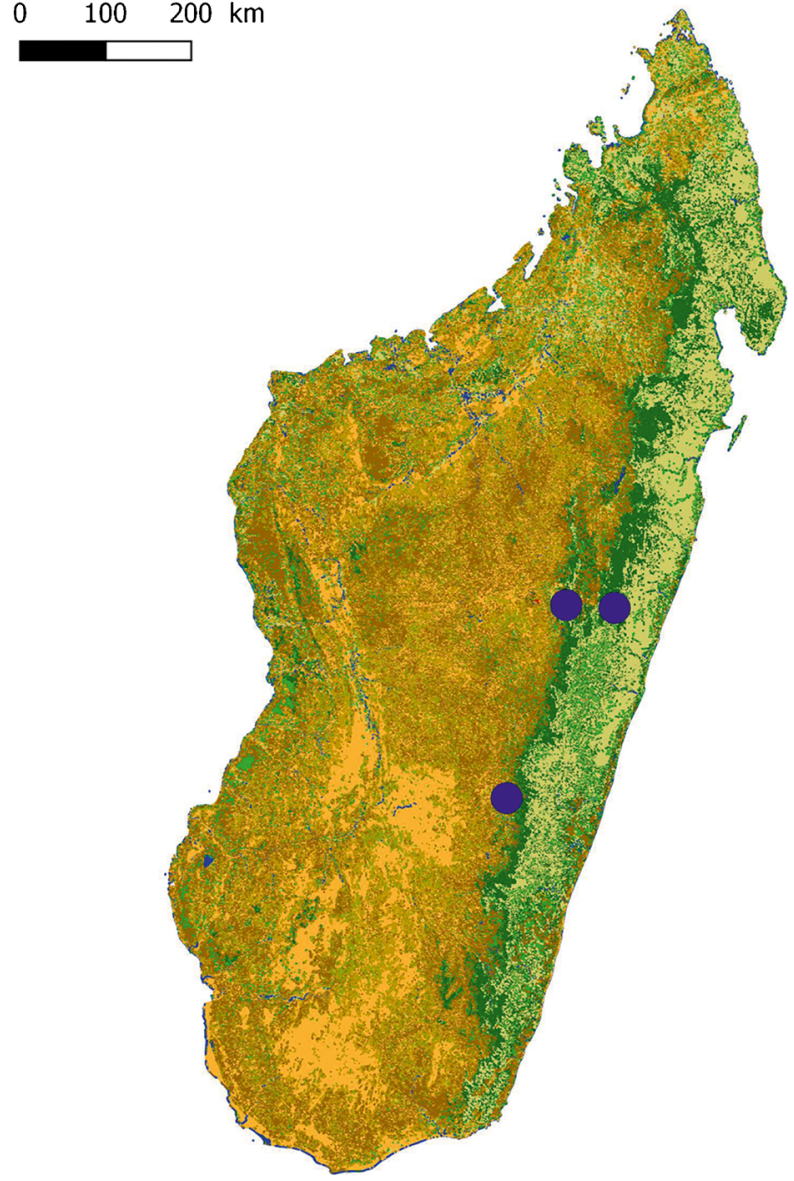

Map 36. Distribution of Liparis parva.

Cowan in the Highland forest of Madagascar. The same specimen was also drawn by Deans Cowan in his sketchbook, the drawing number (38) is given in Ridley's hand on the herbarium specimen. The plant seems to shrink greatly when dried and herbarium specimens lose the globular shape of the pseudobulbs.

Perrier (1939: 283) mentioned that the plant produces short white stolons but this is not reflected in the herbarium material.

ILlUStRATIONS. Figs 47, 48; Cowan (1880: 19); Perrier (1939: 283); Cribb \& Hermans (2009: 155).

Liparis perrieri Schltr. (Schlechter 1913: 164, 21 of extract; 1924: 146); Perrier (1936: 250; 1939: 285); Hermans et al. (2007: 222); Cribb \& Hermans (2009: 154). Types: Madagascar, Firingalava (Boina), Perrier 499 (P00095497) lectotype P, designated here; Perrier 499 (P00095498) isolectotype P; West, Bemarivo valley, Dec. 1906, Perrier 1886 (Schlechter 45) syntypes P).

Liparis perrieri Schltr. var. trinervia H.Perrier ex Hermans (in Hermans et al. 2007: 289); Perrier (1939: 285); Hermans et al. (2007: 222); Cribb \& Hermans (2009: 154) synon. nov. Type: Madagascar, Toamasina, E, Savoka, near the confluence of the
Onive \& Mangoro, terrestrial, 700 m, Feb. 1925, Perrier 17136 (holotype $\mathrm{P}$ (P00095499); isotype (P90005500) $\mathrm{P})$.

Liparis perrieri Schltr. var. trinervia H.Perrier (1936: 251) nom. nud. Based upon Perrier 17136.

Large erect lithophytic or rarely epiphytic plant, up to 28 $\mathrm{cm}$, on a very short rhizome, roots filiform, flexuose, woolly, 3-4 mm diam. Pseudobulbs solitary or with a smaller growth or with $1-2$ leafless oblique remnants, 1 $-3 \mathrm{~cm}$, generally carrying 3 leaves, rarely 4 , base with a smaller stem sheath. Leaves erectly-spreading, somewhat leathery, plicate, broadly elliptic, acute, base contracted into a $6-11 \mathrm{~cm}$ long sheath-like petiole, blade $8-25 \times 3$ $-8 \mathrm{~cm}$, pale green and somewhat glossy, strongly veined, especially in dried specimens. Inflorescence erect, up to $30 \mathrm{~cm}$ tall, ridged, purplish-green, 10 - 40-subdensely flowered in the upper half. Peduncle with $1-2$ membranous sheaths and $2-5$ sterile decurved bracts up to $5 \mathrm{~mm}$ long. Rachis sub-dense, up to $15 \mathrm{~cm}$. Floral bracts decurved, lanceolate-acute, about half the length of the pedicellate ovary, $2.8-7 \times 1.2-1.8 \mathrm{~mm}$, pale green, brown at the base. Flowers small, erectly-spreading, opening in succession with the lower ones fading well before the upper ones open, overall up to $10 \times 9 \mathrm{~mm}$, ovary, sepals and petals green tinted more or less with purple, lip pink-violet to purple (rarely entirely green), green in the upper margins, column white becoming green towards the tip, anther cap pale green. Pedicel and ovary twisted and strongly roundly ridged, up to $12 \times 0.6-$ $1.1 \mathrm{~mm}$. Dorsal sepal strongly incurved and recurved, oblong-ligulate, obtuse, broadening towards the base, $4-$ $6.3 \times 0.8-2 \mathrm{~mm}$. Lateral sepals obliquely ovate-obtuse, strongly recurved to revolute below the lip, $3.0-5.4 \times 1.8$ - $2.8 \mathrm{~mm}$. Petals linear to spathulate, incurved, spreading, 3.8 - 5.8 $\times 0.4-0.9 \mathrm{~mm}$. Lip ovate to flabellate-dilate, the base rectangular strongly auriculate, anterior margin recurved, retuse, more or less denticulate, carrying 2 more or less prominent horn-like calli at the very base, $3.1-4.5 \times 3-4.6 \mathrm{~mm}$. Column curved forward in the upper half, strongly roundly winged towards the apex, 2 $-3.2 \times 0.8-1.2 \mathrm{~mm}$. Anther obovoid, often with a long apicule at the tip, $0.8-1.1 \times 0.7-0.9 \mathrm{~mm}$. Pollinia ovoid $0.3-0.5 \times 0.5-0.7 \mathrm{~mm}$. Seed capsule narrowly obovate, up to $12 \times 5 \mathrm{~mm}$.

RECOGNITION. This is a large, somewhat variable species with one flowering growth with many small flowers and the remnants of the previous year's growth. It has a ridged peduncle, strongly decurved floral bracts, green flowers tinted with purple, a much darker violet to purple lip with two separate horn-like calli at the very base, calli that are easily missed in dissection of herbarium material, a column winged near the apex and an obovoid anther without a distinct apicule.

The species is similar to Liparis nervosa and its numerous variants which has a widespread distribu- 


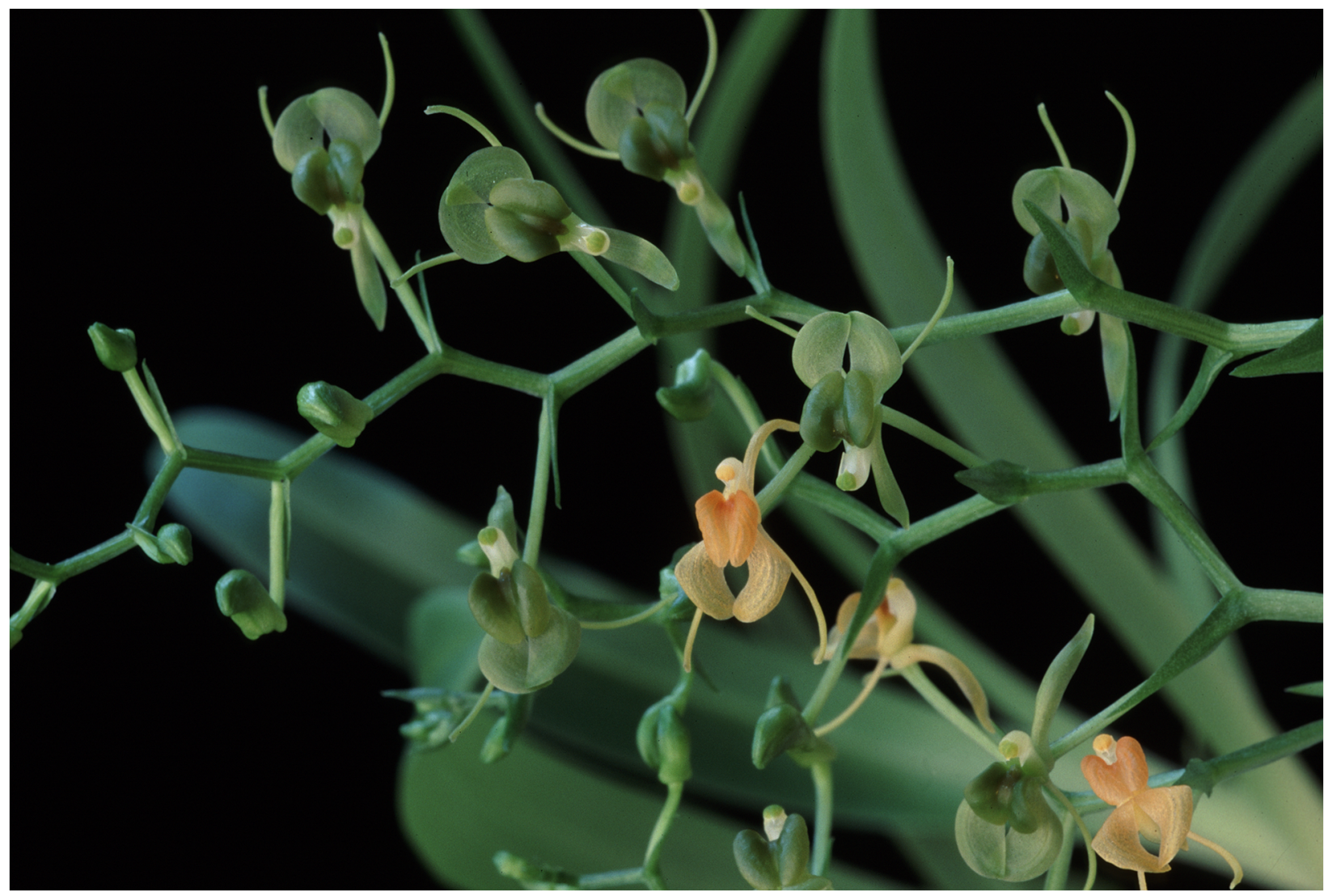

Fig. 47. Liparis parva. Inflorescence. PHOTO: JOHAN HERMANS.

tion in tropical Africa and also India and Japan extending to the Philippines and in Central and South America. The two species are very similar and both are very variable. Plants of $L$. nervosa are generally more compact, the inflorescence denser and the callus on the lip more pronounced. The main consistent difference is in the floral bract: in $L$. nervosa it is parallel with the ovary or erect and about $3 / 4$ the length of the pedicellate ovary whereas, in L. perrieri, it is always deflexed or recurved and about half the length of the ovary. This is seen in both dried specimens and in living plants. Schlechter (1913: pl. VII) drew L. perrieri to show erect bracts that do not correspond with the herbarium material and is, therefore, likely to be an error. Amongst the Madagascan species, L. perrieri is not easily confused. Liparis rivalis is also a large plant with a dense raceme of small flowers but the plant has a distinct stem and the lip is ovateflabellate vs broadly obovate obtuse, the callus is very prominent vs obscure. Some forms of it have a very compact stem, others more elongate; the latter tend to come from drier habitats in the $\mathrm{W}$ of the Island. It is vegetatively close to $L$. bemarahensis described above but the flowers of $L$. bemarahensis are larger by a third, the rachis lax (vs sub-dense) and the anther distinctly beaked.

DISTRIBUTION. Found mainly in Western Madagascar in the provinces of Antsiranana, Mahajanga and Toliara
(Map 37). The variant trinervia is found in Toamasina Province. Records from Fianarantsoa province (Perrier 11475 in P) are of fruiting specimens with a dubious identity. For Réunion there are photographs of this species, labelled as Liparis nervosa in Szelengowicz et al. (2011: 11) and Szelengowicz \& Tamon (2013: 364) but there are no vouchers available, it is said to have been found in one location on Réunion.

SPECIMENS EXAMINED. MADAGASCAR. Firingalava (Boina), Perrier 499 (P00095497) (lectotype P), Perrier 499 (P00095498) (isolectotype P); Nossi Be, Jan. 1850, Boivin s.n. (P); West, Bemarivo valley (Boina), Dec. 1906, Perrier 1886 (Schlechter 45) (syntypes P); Sambirano, slopes of the Sambirano valley, Jan. 1923, Perrier 15336 (P) Sambirano, slopes of the Sambirano valley, Manongarivo Massif, Jan. 1923, Perrier 8032 (P); East, Savoka, near the confluent of the Onive \& Mangoro, 700 m, Feb. 1925, Perrier 17136 (P); Ambodiriana, E of Antsalova, 100 - 150, Dec. 1952, Léandri E Capuron 2078 (P); Diego Suarez, Anivorano N, Antenampandrana forest, Ankarana Tsingy, Feb. 1960, Cours E $\mathcal{F}^{2}$ Humbert 5561 (P); Diego Suarez, Ankarana Tsingy, Feb. 1960, 30 - 350 m, Humbert $\mathcal{E}^{\circ}$ Cours 32690 (P); vicinity of Tsiandro, 5 - $600 \mathrm{~m}$, Jan. 1953, Léandri 2366 (P); Mahajanga, Ankarafantsika, Service Forestière 31 (P); NW of Ambohitsaretelo, 1100 - 1200 m, Jan. 1985, Dorr 3505 


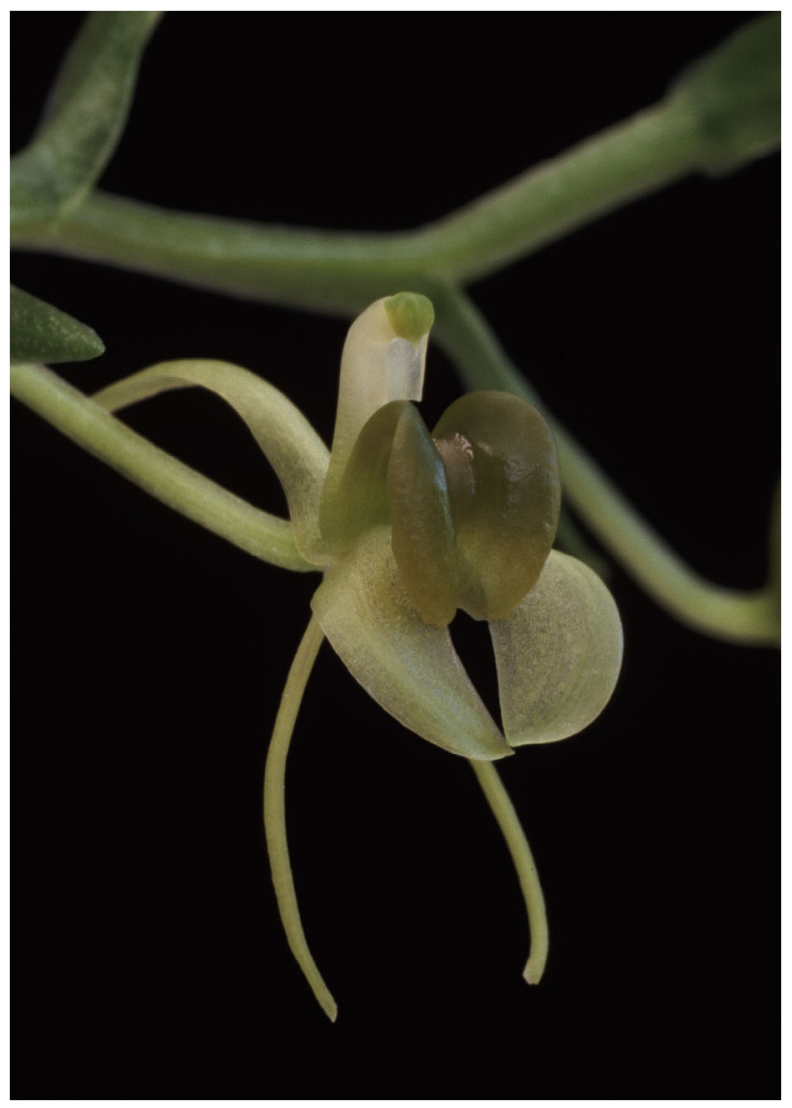

Fig. 48. Liparis parva. Flower. PHOTO: JOHAN HERMANS.

(G, K); Anjanaharibe, near Andranotsarabe, $1050 \mathrm{~m}$, 1994, Hermans 117 (K); Mahajanga, Tsiandro area, 1999, Hermans 2460 (K); Antsiranana, Ankarana area, 1999, Hermans 2443 (K); E of Ankaramibe, Manongarivo reserve, Bekolosy, $800-100 \mathrm{~m}$, Dec. 1992, Malcomber et al. 2000 (K, P); Tsingy of Antsalova, 1999, Hermans 2464 (K); Sakaraha, Zombitse, Feb. 2007, Ranarivelo et al. 598 (K, P, TAN); Ampasaindava, Bongomihiravavy forest, 415 m, Dec. 2008, Madiomanana et al. 191 (G, K, P); Antsiranana, Ampasindava, Bongomihiravavy forest, Dec. 2008, Madiomanana et al. MAD191 (G); Ampasindava, Andranomatavy forest, $405 \mathrm{~m}$, Jan. 2010, Ammann et al. 503 (G, K, P); Beana, Ambahaky, 217 m, Jan. 2012, Bolliger et al. 102 (G, K); Antsiranana, Mt d'Ambre, 879 m, Jan. 2012, Randimbiarison E Ramandimbimanana RCH089 (G); Antsiranana, Sava, $713 \mathrm{~m}$, Bone 219 (K); road to Bealanana, Jan. 2016, Sieder E̋ Andriantiana SKA6961 (WU); Ambanja, Beentje et al. 4584 (K); s. loc. Chabonis P01778646 (P).

HABITAT. The species is mainly restricted to the Western forest where it is found in the more humid areas growing on granite, calcareous rock or the base of trees on humus in moderate shade. Also in evergreen humid forest. Altitude: $500-1200 \mathrm{~m}$.
CONSERVATION STATUS. Category LC: the extent of occurrence (EOO) of Liparis perrieri is estimated to be $252,553 \mathrm{~km}^{2}$ (far exceeding the limits for Vulnerable status under criterion B1) whereas its minimal area of occupancy (AOO) is estimated to be $76 \mathrm{~km}^{2}$ (which falls within the limits for Endangered status under the criterion B2). Liparis perrieri is known from 18 subpopulations representing 18 locations (sensu IUCN), this species has been preliminarily assessed as LC using the green listing method. This species is threatened by selective logging, timber harvesting for small-scale subsistence and tavy (slash-and-burn farming), resulting in habitat reduction and habitat quality reduction.

FLOWERING TIME. December to February.

ETYMOLOGY. Named for Henri Perrier de la Bâthie $(1873$ - 1958).

NOTES. It was described and illustrated by Schlechter (1913) based on several specimens collected by Perrier. In the description, he referred to Perrier 479 as the type, this is a typographical error and it should be Perrier 499 which is from the correct locality and on the type sheet in $\mathrm{P}$ confirmed by Perrier and Schlechter. The type consists of two sheets and sheet $\mathrm{P} 00095497$ is designated as the lectotype because it is

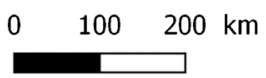


more complete, P00095498 is an isolectotype. Schlechter also mentioned Perrier 45 (1886 of Perrier) and this is labelled as a 'co-type 'or syntype. Liparis perrieri is a variable and widespread species and exhibits a considerable range in plant and flower size and shape. Perrier (1936: 251) described var. trinervia without a Latin diagnosis but the name was later validated by Hermans (in Hermans et al. 2007: 289). It is said to differ from the typical form by the "lateral sepals with five veins; the lip being shortly apiculate in the middle of the front indentation, with three veins, the middle one simple, and with a well separated callus, in a conical swelling and very pronounced; the anther with the front lip subrectangular". It comes from the Eastern side of the island and is a local variant within the morphological range of the species. Although it is said to differ in having lateral sepals with five veins this is not consistent and can also be found in the syntype of the typical variety (Perrier 1886), the different lip, callus and anther shape can also be observed in other specimens of the typical Western form.

Perrier 1885 (P00095491) mentioned an abnormal form where the inflorescence emerges from the old leafless growth. This seems to be an oddity not observed in other specimens.

ILLUSTRATIONS. Figs 49, 50; Schlechter (1913: pl.7); Schlechter (1932: T.55).

Liparis polycardia Rchb.f. (Reichenbach f. 1885: 543). Type: Madagascar, Fôret d'Anhaya?, Humblot s.n. (R16689) (holotype W).

Leptorchis polycardia (Rchb.f.) Kuntze (1891: 671), as Leptorkis.

Large epiphyte or terrestrial plant up to $23 \mathrm{~cm}$ tall but usually smaller, on a short ascending rhizome up to $15 \mathrm{~mm}$ long, 3 - $4 \mathrm{~mm}$ diam., partly covered by disintegrating sheaths, roots fleshy $1-2 \mathrm{~mm}$ diam. Pseudobulbs stem-like, thin, swollen towards the base, becoming thinner towards the apex, fleshy 3.1 $-7 \times$ $0.5-1 \mathrm{~cm}$, enveloped by $3-5$ papery lanceolatelongly attenuate sheaths, partly overlapping each other, up to $4 \mathrm{~cm}$ long and $15 \mathrm{~mm}$ wide, with one to two opposite or sub-opposite leaves on top, older growths retaining their leaves. Leaves sometimes single but generally 2, erectly spreading, ligulate, longly attenuate, strongly veined, $5.5-16 \times 1.2-3.2 \mathrm{~cm}$, with a short $1-2 \mathrm{~cm}$ petiole. Inflorescence generally as long as the plant or longer, $7-24 \mathrm{~cm} \times 1.1-1.5 \mathrm{~mm}$ in diam., with up to 15 flowers. Peduncle carrying $2-4$ somewhat cordate bract-like sheaths $12-18 \times 3-5$ mm. Rachis laxly racemose, up to $15 \mathrm{~cm}$ long. Floral bracts lanceolate, becoming smaller towards the apex, $2.8-9 \times 1-3 \mathrm{~mm}$. Flowers small to medium in size 6.5 $-9 \times 5.5-8 \mathrm{~mm}$, pale green becoming yellow to brownish yellow, the lip a little darker with the disk dark green, column white. Pedicel and ovary terete to somewhat grooved, $7-12 \times 0.4-0.9 \mathrm{~mm}$. Dorsal sepal ligulate-ensiform, strongly recurved, $5.8-9.2 \times 0.9-$ $1.2 \mathrm{~mm}$. Lateral sepals obovate, recurved below the lip, $4.8-7.8 \times 2.2-3.2 \mathrm{~mm}$. Petals filiform, curved, $6.3-$ $8.8 \times 0.2-0.6 \mathrm{~mm}$. Lip obcordate to cuneate to expanded flabellate, anterior margin slightly undulate to almost dentate, base hardly winged with two distinct, more or less flattened horn-like calli at the base, $5.1-6.9 \times 4.2-6.6 \mathrm{~mm}$. Column slightly curved at the apex a little thickened at the apex and then with two small but distinct triangular wings, $3.5-4 \times 0.7-$ $1.1 \mathrm{~mm}$. Anther more or less sharply beaked, the pollen chambers only slightly divided, $1-1.3 \times 0.7-0.9 \mathrm{~mm}$. Pollinia obovoid, bipartite, on a common viscidium, 0.5 $\times 0.4 \mathrm{~mm}$.

RECOGNITION. A large plant with a very long inflorescence and small to medium-sized flowers, the stem-like pseudobulbs covered with long attenuate, papery sheaths, longly ligulate and attenuate leaves, an obcordate lip lacking wings at the base and with two sharplyhorned calli at the base, and a strongly beaked anther.

In his description Reichenbach mentioned that the flowers are like those of Liparis foliosa, referring, as explained above, to L. reflexa (R.Br.) Lindl. (Lindley 1825: t.882) from Australia, but plant habit, length of the inflorescence and the shape of the lip are different with the leaves about half the size, the flowers a little smaller with the lip obcordate vs oblong and the callus horn-like vs indistinct. It shares the basal teeth of the lip with L. listeroides and L. imerinensis but the plant and flower are bigger, the leaves longer and narrower (ligulate vs oval-elliptic) and the inflorescence longer by a third.

The most closely allied species is Liparis stenophylla which is similar in habit, flower size and shape but its leaves are more horizontal rather than erectly spreading, the leaves are narrowly lanceolate (vs lanceolate in L. polycardia), the petiole shorter, the inflorescence generally shorter, the petals shorter and the lip obovate to suborbiculate rather than obcordate.

Some forms have larger than average flowers and a less distinctly heart-shaped lip with a more denticulate anterior margin (Hermans 6737 and Antilahimena 4753), the drawing by Reichenbach accompanying the type also shows a denticulate lip.

DISTRIBUTION. Endemic to Madagascar: Antsiranana, Fianarantsoa and Toamasina provinces (Map 38). The label on the type specimen in $\mathrm{W}$ indicates Comores as a locality but this has been corrected to Madagascar which corresponds with Humblot's travels as shown in his notebooks (Humblot 1882 - 1885). The label indicated 'Forêt d'Anhaya' as the collecting locality but no reference has been found to this name. A specimen in the Paris herbarium (Boivin 1035 


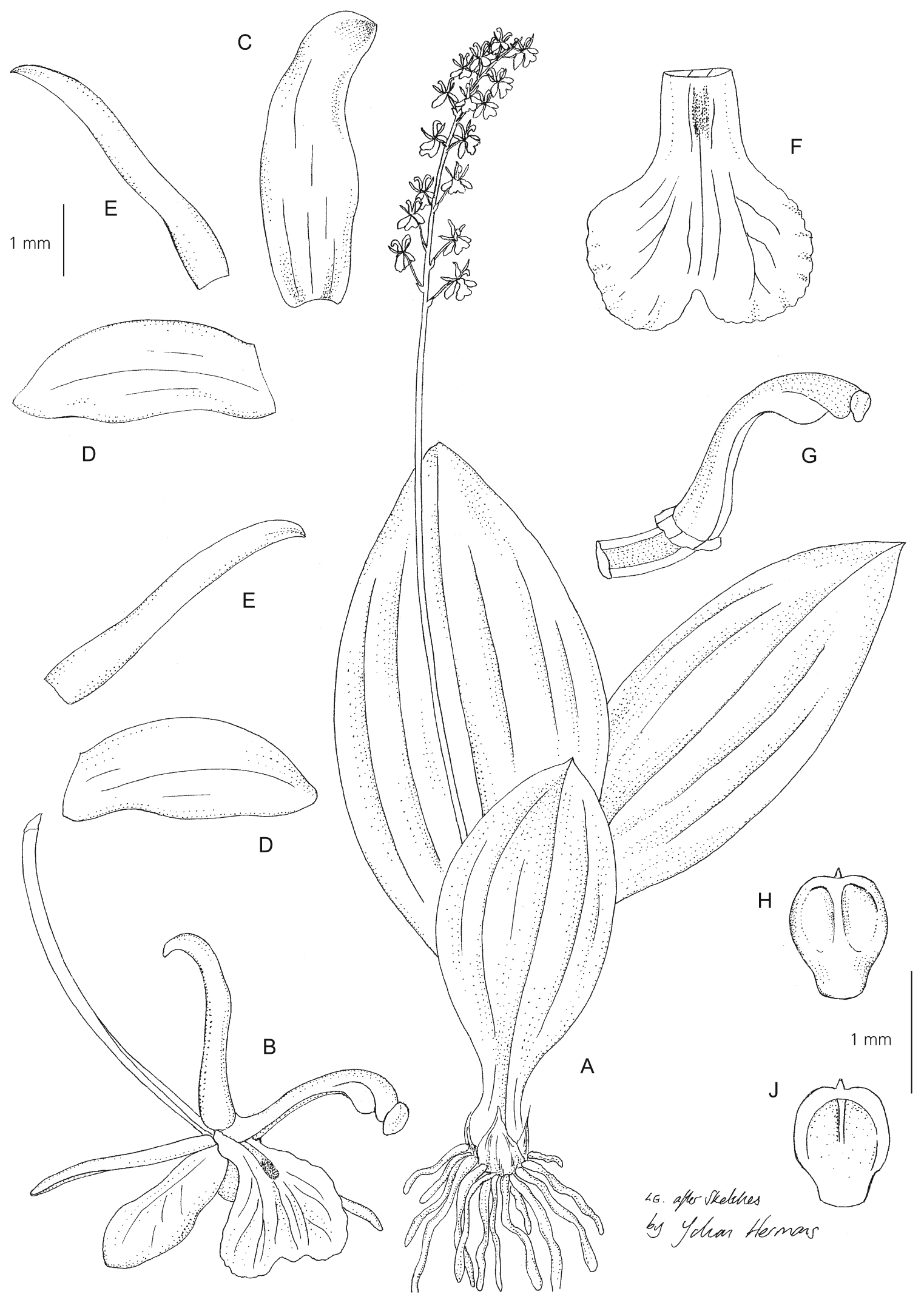

Fig. 49. Liparis perrieri. A habit; B flower; C dorsal sepal; D lateral sepal; E petal; F lip; G column; H anther cap exterior; J anther cap interior. Based on $H$. Perrier 17136. DRAWN BY LINDA GURR, BASED ON SKETCHES BY J. HERMANS.

P409214) from Réunion labelled as Liparis caulescens is annotated to be 'Liparis polycardia Reichenb. f." by 

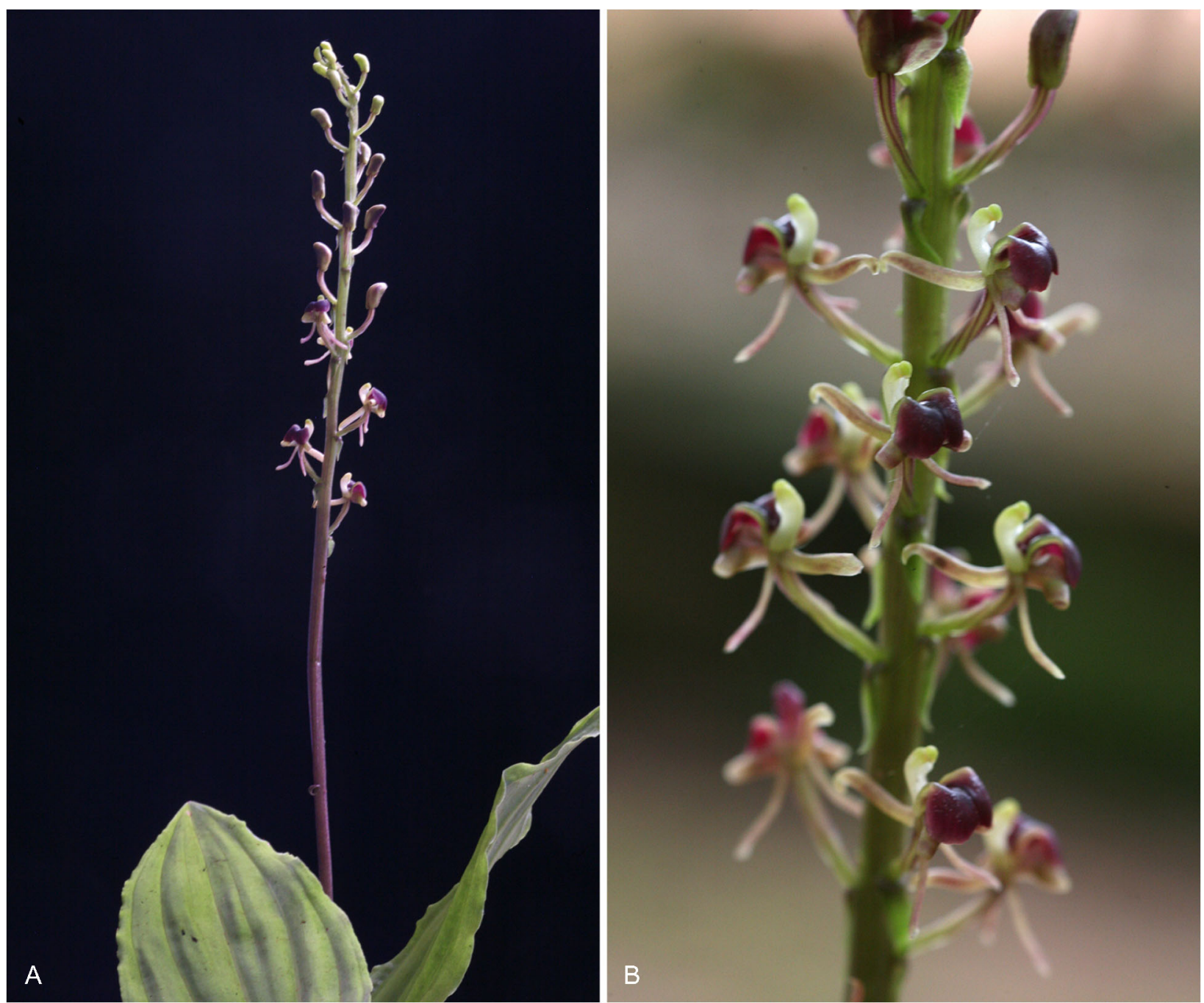

Fig. 50. Liparis perrieri. A habit; B flower. PHOTOS: JOHAN HERMANS.

Achille Finet but the plant habit and flowers are very different; it is in fact $L$. ochracea.

SPECIMENS EXAMINED: MADAGASCAR. Forêt d'Anhaya, Humblot s.n., (Rchb.f. 16689) (holotype W); North \& Central, Tanambe, Warpur s.n. (K); s. loc., 1959, Rauh E Buchloh M658 (HEID); Antsiranana province, Anjanaharibe, 1050 m, 1994, Hermans 2293 (K); Masoala PN., Anjahana, Maroatsetra, 383 - 400 m, May 1996, Aridy et al. 273 (K); Toamasina, $1041 \mathrm{~m}$, Feb. 2000, Hermans 1008 (K); Fianarantsoa, Ranomafana area, Ambatolahy, May 2001, 1046 m, Hermans 5396, 5399, 5582 \& 6690 (K); Mantadia, Belakato, $1080 \mathrm{~m}$, Nov. 2003, Roberts et al. TPPO21 (K); Antsiranana, Andapa, Doany, Anjialavahely, Ankarongameloka forest, $1546 \mathrm{~m}$, March 2006, Antilahimena E Tianina 4753 (K, MO, P); Toamasina, Andasibe area, c. 968 m, Sept. 2007, Hermans 6737 (K); Toamasina, Alaotra-Mangoro region, $1107 \mathrm{~m}$, May 2008, Rakotovao 4054 (K, MO, P, TAN); Toamasina, Ambatovy, 1088 m, Aug. 2008, Bernard 1057
(TAN); Toamasina, Moramanga, Analamay, $1063 \mathrm{~m}$, Sept. 2008, Rakotondrajaona et al. 566 (TAN); Toamasina, Moramanga, Andasibe, Andasifahatelo, Marinjo, April 2012, Rasoazanany E Ratolojanahary 154 (MO, P); Toamasina, Andasibe, Faliriana, Bekalakody, 962 m, May 2012, Antilahimena E Razafindrahaja 8405 (MO, P, TAN); Toamasina, Ambohibary, Ampitambe, Ambatovy, Antampimbato forest, 1299 m, June 2012, Antilahimena E Ravelonarivo 8410 (MO, P, TAN); Toamasina, Ambatovy, 1146 m, April 2015, Ambatovy Shade House 5060 (MO, TAN); Moramanga, Andasibe, Maromizaha, $1001 \mathrm{~m}$, March 2018, Gamisch et al. 7738 (WU).

HABITAT. Epiphyte or terrestrial in wet forest at medium elevation, in deep leaf litter. Altitude: 400 $1500 \mathrm{~m}$.

CONSERVATION STATUS. Category VU: the extent of occurrence (EOO) of Liparis polycardia is estimated to be $44,008 \mathrm{~km}^{2}$ (which exceeds the limits for Vulnerable status under criterion B1) whereas its 


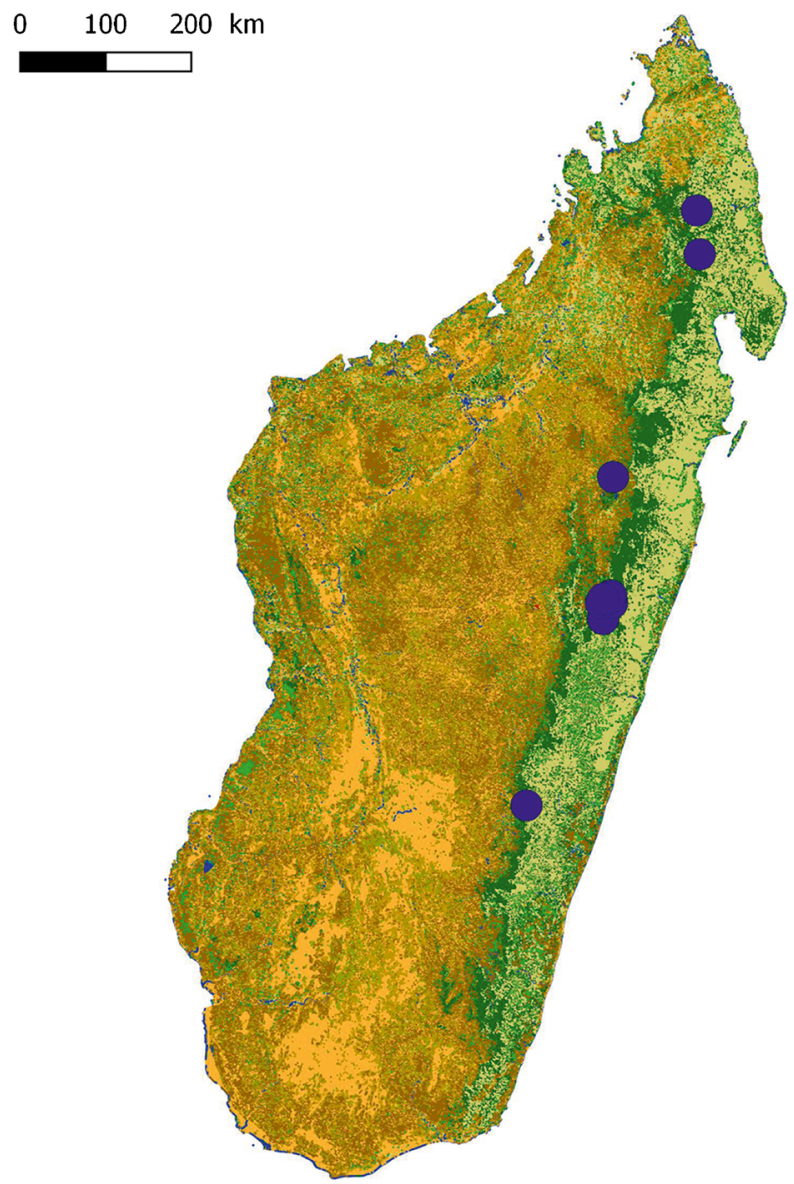

Map 38. Distribution of Liparis polycardia.

minimal area of occupancy (AOO) is estimated to be $48 \mathrm{~km}^{2}$ (which falls within the limits for Endangered status under the criterion B2). Liparis polycardia is known from nine subpopulations representing 10 locations (sensu IUCN), this species has been preliminarily assessed as VU using the green listing method. This species is threatened by mining activities, selective logging, timber harvesting for small-scale subsistence and tavy (slash-and-burn farming), resulting in habitat reduction and habitat quality reduction.

FLOWERING TIME. February to June.

ETYMOLOGY. Probably referring to the many heartshaped lips on the flowers.

NOTES. Liparis polycardia has remained somewhat enigmatic for some time. Reichenbach f. (1885) validly described it, together with a number of other new species discovered by Leon Humblot. It was included in Ridley's 1887 monograph of the genus where Reichenbach's description was repeated and marked as 'unseen' and possibly related to $L$. puncticulata, and said to have come from SE Africa. Kuntze (1891: 671) transferred it to his new genus Leptorchis together with other Liparis. It is not included in subsequent litera- ture except for a listing in Durand \& Schinz (1895: 9) and repeated by Voeltzkow (1917: 444) as coming from Africa. It is recorded in Govaerts (2017) as an unplaced name.

ILLUSTRATIONS. Figs 51, 52 and 53.

Liparis puncticulata Ridl. (Ridley 1886a: 119; 1886b: 270); Perrier (1936: 245; 1939: 266); Hermans et al. (2007: 222); Cribb \& Hermans (2009: 150); Hervouet (2018: 461). Types: Madagascar, Baron 4334 (K000242144) lectotype K, designated here; isolectotypes Baron 4334 BM (BM00090071), P (P0095501)).

Leptorkis puncticulata (Ridl.) Kuntze (1891: 671).

Large slender, erect plant, terrestrial or rarely epiphytic up to $40 \mathrm{~cm}$ tall, often forming clumps of 5 or more growths, on a short $0.3-2 \mathrm{~cm}$ rhizome, roots flexuose, woolly. Pseudobulbs slender, stem-like, hardly thickened at the base, $16-38 \mathrm{~cm}$ long, $5-9 \mathrm{~mm}$ diam. Covered by $6-9$ membranous sheaths slightly overlapping in the lower half and becoming more distant towards the apex, keeled and acuminate at the tip, characteristically spotted with more or less visible dark dots, with 3 - 4 somewhat distant leaves at the apex. Leaves narrowly lanceolate to ligulate, on a short $3-8 \mathrm{~mm}$ petiole, acute, margins generally a little undulate, sometimes irregularly serrate, $5.5-8 \times 1.2-2.5 \mathrm{~cm}$, pale green. Inflorescence erect, thin c. $2-3 \mathrm{~mm}$ diam., up to $30 \mathrm{~cm}$ tall but generally shorter, carrying up to 11 flowers but most often far fewer. Peduncle somewhat ridged, with a few $8-14 \times 3-4 \mathrm{~mm}$ sterile bract-like sheaths. Rachis up to $18 \mathrm{~cm}$, laxly racemose, the lower flowers fading or disappearing well before the apical ones open. Floral bracts erectly spreading, lanceolate acute $7.2-11 \times 2-3 \mathrm{~mm}$. Flowers medium size, up to 19 $\times 12 \mathrm{~mm}$, erectly spreading, pedicellate ovary pale greenish white becoming darker towards the base of the flower, sepals and petals pale to olive green, lip olive green, the basal lobes paler, with a characteristic very dark green disk, column white, anther greenish-yellow, all parts becoming yellow to pale orange with age. Pedicel and ovary slender erect, $10-21 \times 1.1-1.8 \mathrm{~mm}$. Dorsal sepal lanceolate to ligulate-angustate, the base strongly lobed and for the most part strongly incurved, $7.7-14.5$ $\times 1-1.8 \mathrm{~mm}$. Lateral sepals broadly lanceolate, obtuse, curved alongside or under the lip, $6-12.5 \times 3-4 \mathrm{~mm}$. Petals oblanceolate to linear, strongly incurved along their length, $9-15 \times 0.5-1 \mathrm{~mm}$. Lip cuneate, the base thickened, longly auriculate, at first hollowed into a narrow gutter then widened into an obtriangular blade, bilobed to obscurely obcordate at the anterior margin which is distinctly dentate. Without a distinct callus at the base but with a thickened bilobed ridge with a rhomboid depression in-between, overall $8-13 \times 4-6.7 \mathrm{~mm}$. Column suberect, the tip curved, wings short and obscure, $3.5-6 \times 0.6-1.5 \mathrm{~mm}$. Anther rounded, with a 


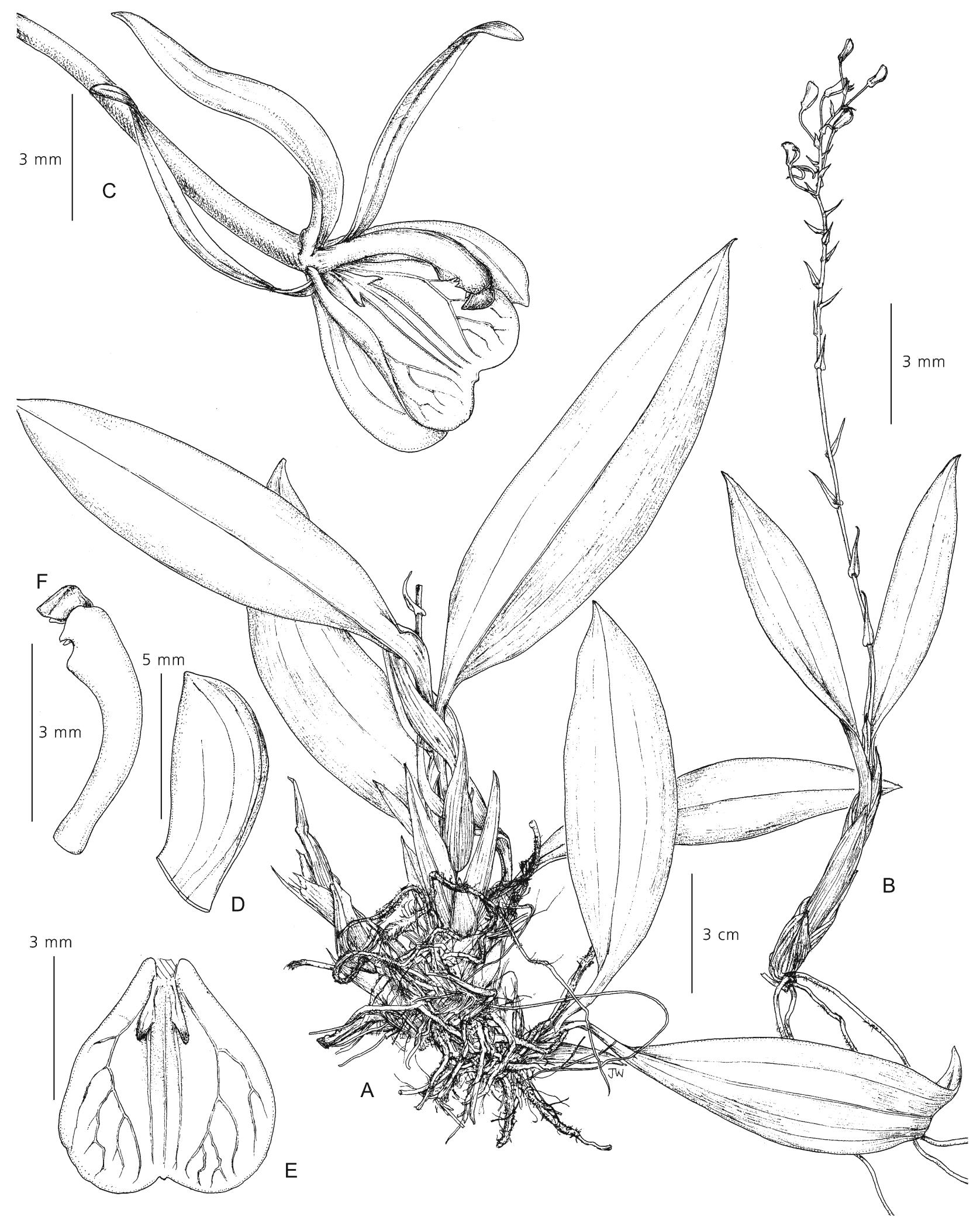

Fig. 51. Liparis polycardia. A main habit; B small flowering habit; C flower; D lateral sepal; E lip; F column. From Rakotovao 4054 \& Warpur S.n. (K). DRAWN BY JULLET BEENTJE. 


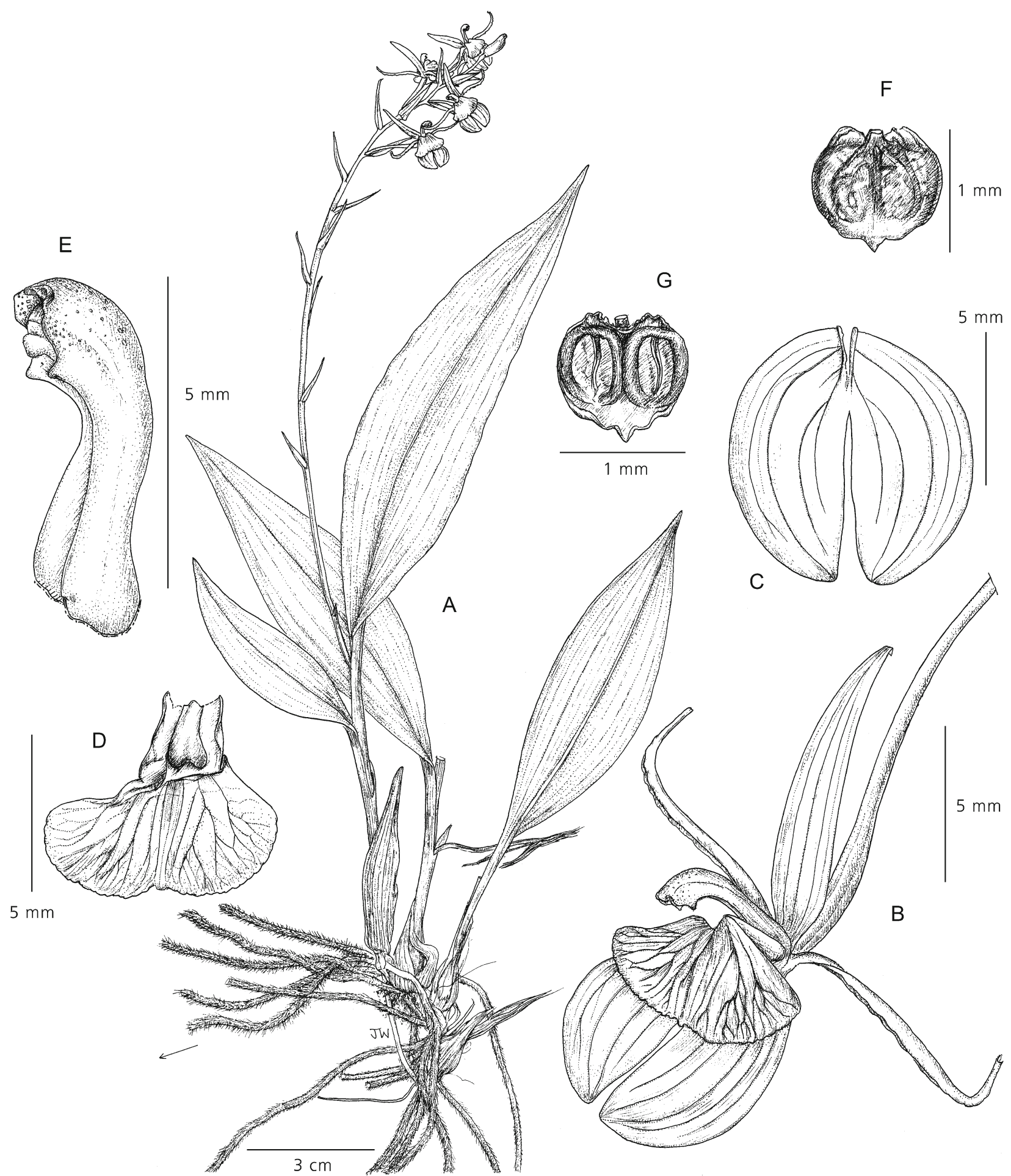

Fig. 52. Liparis polycardia. A habit; B flower $3 / 4$ view; C lateral sepals; D lip; E column; F anther cap, top view; G anther cap, underside. From Antilahimena 4753 (K). DRAWN BY JULIET BEENTJE.

short beak-like apicule at the front, c. $1 \times 0.9 \mathrm{~mm}$. Pollinia ovoid c. $0.5 \times 0.4 \mathrm{~mm}$. Seed capsule fusiform, c. $12 \times 6 \mathrm{~mm}$.

RECOGNITION. This is a large plant characterised by its long, thin pseudobulbs covered by pale sheaths slightly overlapping towards the base but more distant towards the apex, the sheaths often carrying dense, dark spots. It has three to four somewhat distant leaves, an elongate inflorescence with bracts along its length and a few medium-sized flowers towards the apex. The flowers have a wedge-shaped lip with a thickened ridge-like callus at the base 

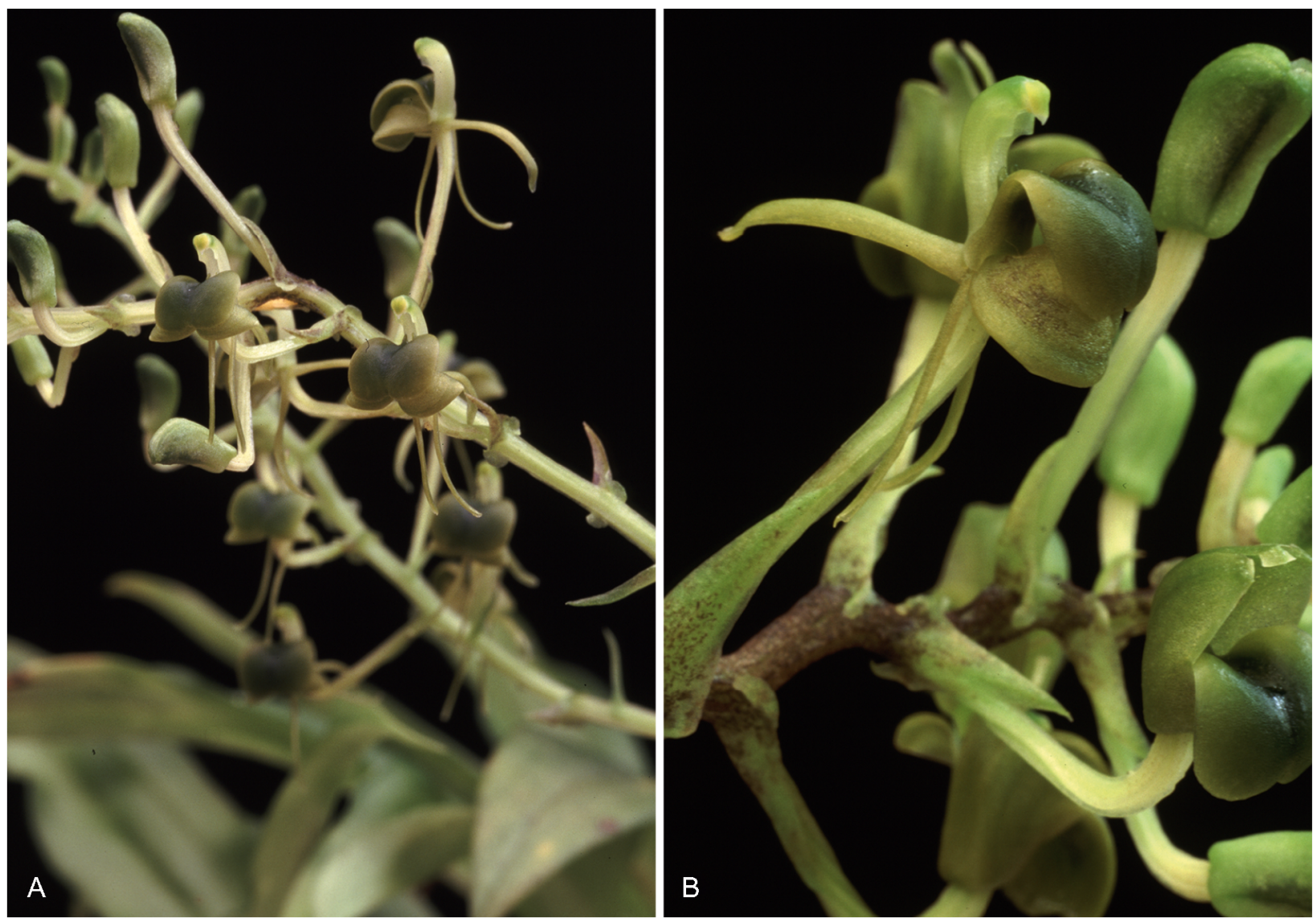

Fig. 53. Liparis polycardia. A inflorescence; B flower. PHOTOS: JOHAN HERMANS.

and dentate anterior margin and a much darker coloured base.

The long thin stem of Liparis puncticulata is also found in L. gracilipes but its leaves are much narrower (narrowly lanceolate vs elliptic) and the lip wedgeshaped vs suborbicular. The closest species is L. sambiranoensis but its stem is more slender, not angular, the stem sheaths do not overlap all along the stem, the leaves are fewer, more distant, much narrower: narrowly lanceolate vs elliptic and not as thin, the peduncle longer, and the flowers a little smaller with the lip wedge-shaped vs broadly oval.

DISTRIBUTION. Endemic and fairly widespread in Madagascar, provinces of Antananarivo, Antsiranana, Toamasina, Fianarantsoa (Map 39). There is a dubious record from Toliara (Humbert 20689 in P). Its main distribution is in the humid Eastern forest around Mandraka on the border of Antananarivo and Toamasina province.

SPECIMENS EXAMINED. MADAGASCAR. Central, Baron 4334 (lectotype K, isolectotypes BM, P); Nidy forest, Catat 1793 (P); s. loc. Baron 2306 (K); Central, July 1894, Baron 6752 (K); Mt Tsaratanana, April 1923, Perrier 16485 (P); Ankaizinana, April 1923, Decary 2020 (P); Central, Mandraka, 1925? François in herb. Perrier 16965bis (P); Central, Analabe (N Imerina), N of Antananarivo, c. 1300 m, Feb. 1928, Perrier 18432
(P); Central, Ankeramadinika forest, c. 1400 m, April 1928, Perrier 18549 (P); Mandraka, June 1938, Herb. Jard. Bot. Tan. 3670 (P); Toliara, Manampanihy basin, Mt Vohimavo, $\mathrm{N}$ of Ampasimena, c. $600 \mathrm{~m}$, March 1947, Humbert 20689 (P); Lokoho Valley, Jan. 1949, Humbert 22946 (P); Ambatoharanana, March 1951, Cours 4022 (P); Marivorahaona Massif, SW of Manambato, c. 1200 m, March 1951, Humbert $\mathcal{E}^{\circ}$ Capuron 25722 (K, P, REU, TAN); Andrambovato, Jan. 1959, Humbert E Capuron 28468 (P); Mandraka, April 1960, Bosser 14254 (P); Mandraka, Feb. 1960, Bosser 13540 (TAN); Central, Tsinjoarivo, Feb. 1964, Bosser 18978 (P); Mandraka forest, April 1964, Bosser 19690 (P); Andringitra, April 1964, Bosser 19495 (P); Lake Mantasoa, March 1970, Bosser 20002 (P); Andrianany, 1560 m, Oct. 1970, Guillaumet 3357 (TAN); Antananarivo, Mandraka, 1984, Dorr et al. 2922 (MO, TAN); Marivorahona Mts, Ambilobe, 1999, Hermans 2446 (K); near Mandraka Jan. 2000, Hermans 4919 (P); Alaotra-Mangoro, Ampitabe, Ambatovy, $1140 \mathrm{~m}$, May 2008, Antilahimena et al. 6192 (K, MO, P); Alaotra-Mangoro region, 1107 m, May 2008, Rakotovao 4054 (MO, TAN); Fivondronana Moramanga, Ambatovy, June 2008, $1121 \mathrm{~m}$, Antilahimena et al. 6248 (MO, TAN); Ambatolampy, Sahatorendrika, $1535 \mathrm{~m}$ alt, 
$0 \quad 100 \quad 200 \mathrm{~km}$

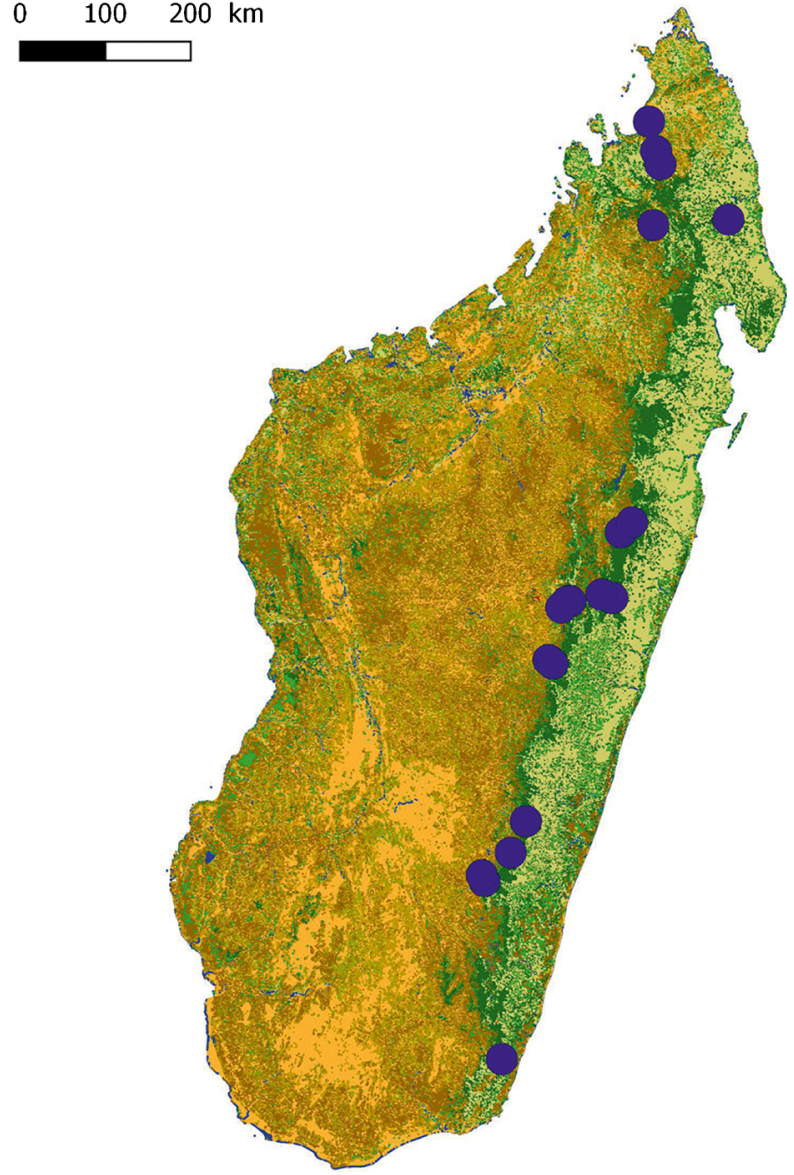

Map 39. Distribution of Liparis puncticulata.

Jan. 2010, Rajaovelona RJL62 (K, TAN); Ambatovy, Andriantiana 618 (MO).

HABITAT. Terrestrial in humus and in moss-rich forest or on the base of moss-covered trees. Altitude: $800-$ $2500 \mathrm{~m}$.

CONSERVATION STATUS. Category VU: the extent of occurrence (EOO) of Liparis puncticulata is estimated to be $101,847 \mathrm{~km}^{2}$ (which exceeds the limits for Vulnerable status under criterion B1) whereas its minimal area of occupancy (AOO) is estimated to be $64 \mathrm{~km}^{2}$ (which falls within the limits for Endangered status under the criterion B2). Liparis puncticulata is known from 14 subpopulations representing 14 locations (sensu IUCN), this species has been preliminarily assessed as VU using the green listing method. This species is threatened by mining activities, selective logging, timber harvesting for small-scale subsistence and tavy (slash-and-burn farming), resulting in habitat reduction and habitat quality reduction. The main concentration of colonies is in the Mandraka area which has now been greatly eroded and only few forest remnants remain.

FLOWERING TIME. January to July but mainly January and February.
ETYMOLOGY. Refers to the black spots, more or less visible, on the stem sheaths.

VernaCULAR NAMES. Avonala (Herb. Jard. Bot. Tan. 3670 in $\mathrm{P}$ ).

NOTES. Three herbarium sheets of Baron's type material exist, one in BM which has no flowers, one at $\mathrm{P}$ with flower fragments only and one at $\mathrm{K}$ which has several good flowers; for this reason the $\mathrm{K}$ specimen has been designated as the lectotype, the others are isolectotypes. There also is a tracing by Reichenbach of the Kew type at W.

ILLUStRATIONS. Figs 54, 55; Perrier (1939: 271); Hermans et al. (2007: pl.46); Cribb \& Hermans (2009: 151); Guérin \& Hervouet (2011: 96); Hermans (2013: 293); Hervouet (2018: 416).

Liparis punctilabris Frapp. ex Cordem.(Frappier in Cordemoy 1895: 184); Bernet (2010a: 96). Type: Réunion, Dimitile, Palmistes, $1800 \mathrm{~m}$, March 2002, Bernet in Hermans 8161. (neotype, designated here, K). Liparis punctilabris Frappier (1880: 15) nom. nud.

Very small epiphytic or terrestrial plant $5-7 \mathrm{~cm}$ high, on a short rhizome, roots wiry, woolly, c. $3 \mathrm{~mm}$ diam. Pseudobulbs ovoid to conical $12-15 \times 9-10 \mathrm{~mm}$, the base covered by membranous sheaths without strong veins, carrying $2-3$ erectly-spreading leaves. Leaves ovate to lanceolate, acute, narrowed into a short petiole at the base, blade corrugate, $3.8-6 \times 1.5-$ $2.1 \mathrm{~cm}$, pale green. Inflorescence erect, up to $95 \mathrm{~mm}$, corrugate, with up to 13 flowers. Peduncle with $2-3$ small narrowly lanceolate bracts. Rachis loosely racemose, in the upper third of the inflorescence. Floral bracts narrowly lanceolate $3.5-5.5 \mathrm{~mm}$, about $1 / 3$ the length of the ovary, minutely erose at the base. Flowers small, erectly spreading, av. $9 \times 7 \mathrm{~mm}$, floral segments overall pale and translucent, with minute dark spots within the structure, especially the lip (not always obvious in dried specimens). Pedicellate ovary green, perianth yellowish green, becoming yellow-orange with age, lip and column green, anther white-brown. Pedicel and ovary cylindrical corrugate, $8-13 \times 0.7-$ $0.8 \mathrm{~mm}$. Dorsal sepal erect, linear-ligulate, more or less widened at the base, margins recurved, $6.8-7 \times 1.1-$ $2 \mathrm{~mm}$. Lateral sepals broadly oblong-falcate, obtuse, curved below the lip and overlapping, $4.7-5.2 \times 2.3-$ $2.8 \mathrm{~mm}$. Petals linear, spreading, margins incurved, 6.3 - $6.5 \times 0.4-0.6 \mathrm{~mm}$. Lip transversally elliptic to reniform, with distinct short wings at the base then abruptly broadened into the blade which is slightly undulate at the anterior margin and minutely mucronate at the apex, two distinct calli (appearing as an angular cushion in living material) at the base ending in longitudinal rounded ridges along the central vein, $3.2-3.5 \times 5-5.1 \mathrm{~mm}$. Column slightly curved, hunchbacked, broadened in the upper half with 


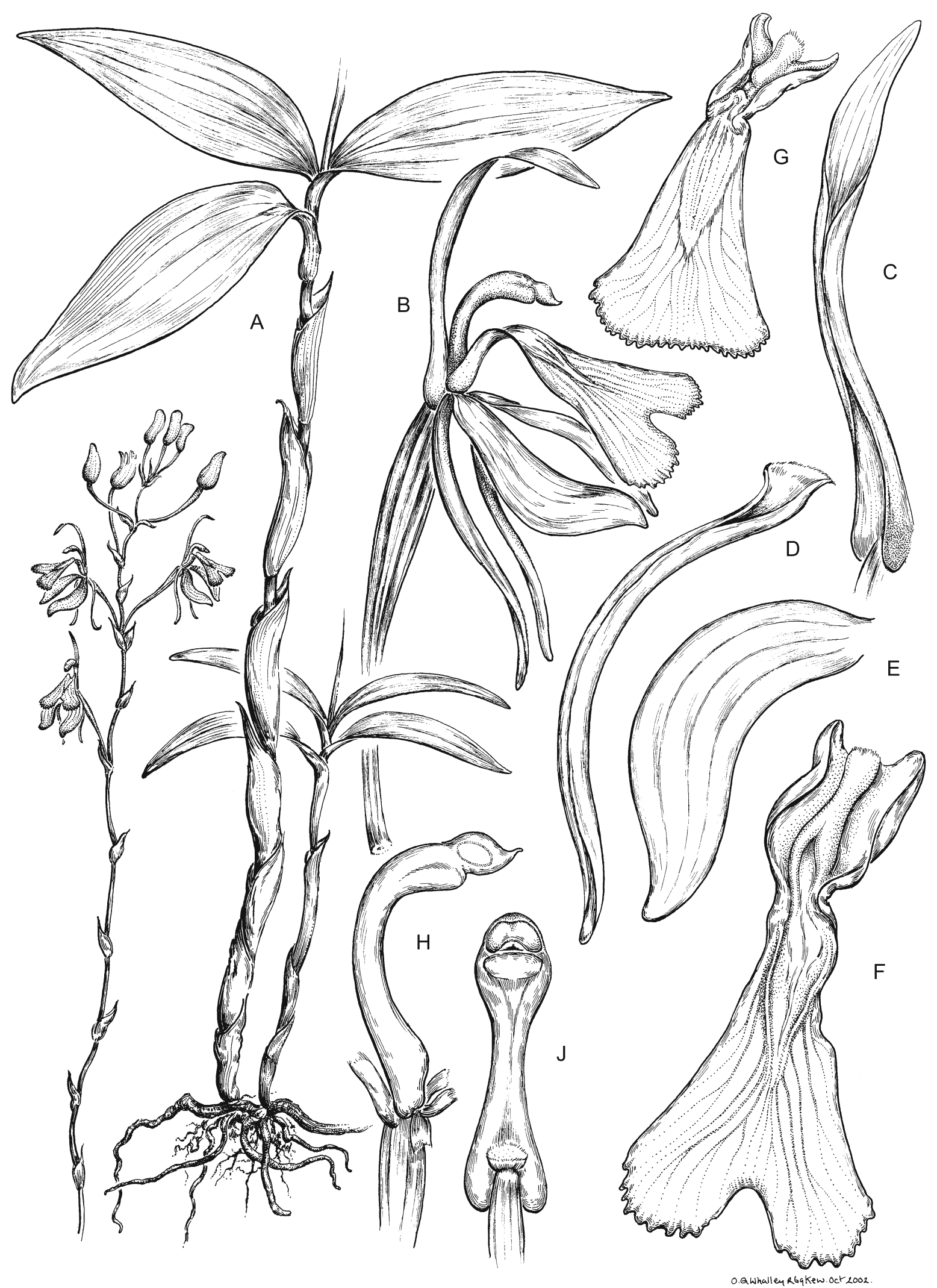

Fig. 54. Liparis puncticulata. A habit $\times 1$; B flower $\times 6$; C dorsal sepal $\times 12$; D petal $\times 12$; E lateral sepal $\times 12 ; \mathbf{F}$ lip of type $\times 12 ; \mathrm{G}$ lip of Baron $6752 \times 10 ; \mathrm{H}$ column, side view $\times 8$; J column, front view $\times 8$. From Baron 4334 \& Baron 6752 (K). DRAWN BY OLIVER WHALLEY. 

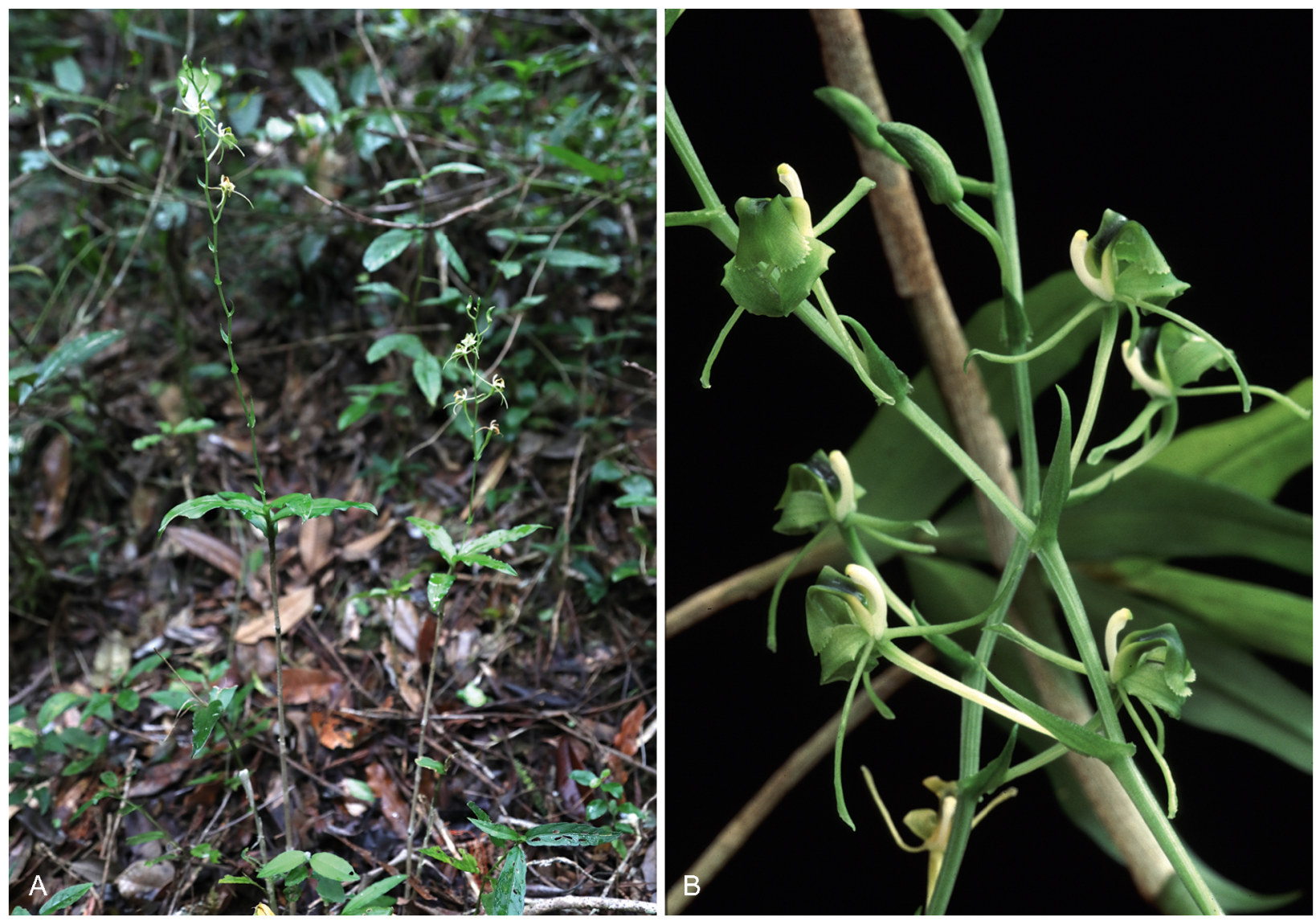

Fig. 55. Liparis puncticulata. A habit; B rachis. PHOTOS: JOHAN HERMANS.

elongate rounded wings, $2.1-2.3 \times 0.8-0.9 \mathrm{~mm}$. Anther ovoid, with a short rounded lobe at the anterior margin. Pollen 2, ovate c. $0.5-0.3 \mathrm{~mm}$. Seed capsule obovate, erect c. $10 \times 5 \mathrm{~mm}$.

RECOGNITION. This is a very small plant, with ovoidconical pseudobulbs, ovate, corrugate leaves, and small flowers with translucent and punctate segments, a transversally elliptic to reniform lip wider than long (Frappier, in his key, referred to the lip being orbicular but this may have been a misinterpretation especially as he also described it as very obtuse, all other characteristics correspond with his description), shortly auriculate at the base, mucronate at the tip, and with an angular bilobed callus at the base, a short column and thickened at the apex, wings long and indistinct, and an anther with a small lobule in front.

The plant has some similarities with Liparis bathiei, L. flavescens and L. lutea but their inflorescences are denser, their lip ovate (vs transversally elliptic), their column wings more angular and their anther with a more acute beak.

DISTRIBUtION. Endemic to Réunion: Saint Pierre (Tampon: Piton Hyacinthe); Saint-Benoit (Bébour); Plaine des Palmistes (Map 40).
SPECIMENS EXAMINED. RÉUNION. Dimitile, Palmistes 1800 m, March 2002, Bernet in Hermans 8161, neotype (K); Piton Hyacinthe, Plaine des Cafres, herb. Cordemoy s.n. (MARS); Basse Vallée, Oct. 1972, Bosser 21310 (P); Descente Plaine des Sables, Ravine Langevin, May 1975, Bosser 22128 (P); Bébour Bélouve, 1400 m, Jan. 2003, Bernet Ẽ Rivière in Hermans 8152 (K).

HABITAT. Very moist shaded forest of the interior of the island. Altitude: $1000-1800 \mathrm{~m}$.

CONSERVATION STATUS. Category EN: the extent of occurrence (EOO) of Liparis punctilabris is estimated to be $169 \mathrm{~km}^{2}$ (which falls within the limits for Endangered status under criterion B1) whereas its minimal area of occupancy (AOO) is estimated to be $20 \mathrm{~km}^{2}$ (which also falls within the limits for Endangered status under the criterion B2). With only three known subpopulations representing two locations (sensu IUCN), this species has been preliminarily assessed as EN using the green listing method. This species is threatened by grazing and anthropogenic fires, resulting in habitat reduction and habitat quality reduction.

Previously assessed and published in the IUCN Red data listing as EN (Picot 2013: 12).

FLOWERING TIME. January to April.

ETYMOLOGY. Referring to the punctate lip (mainly visible in living flowers). 


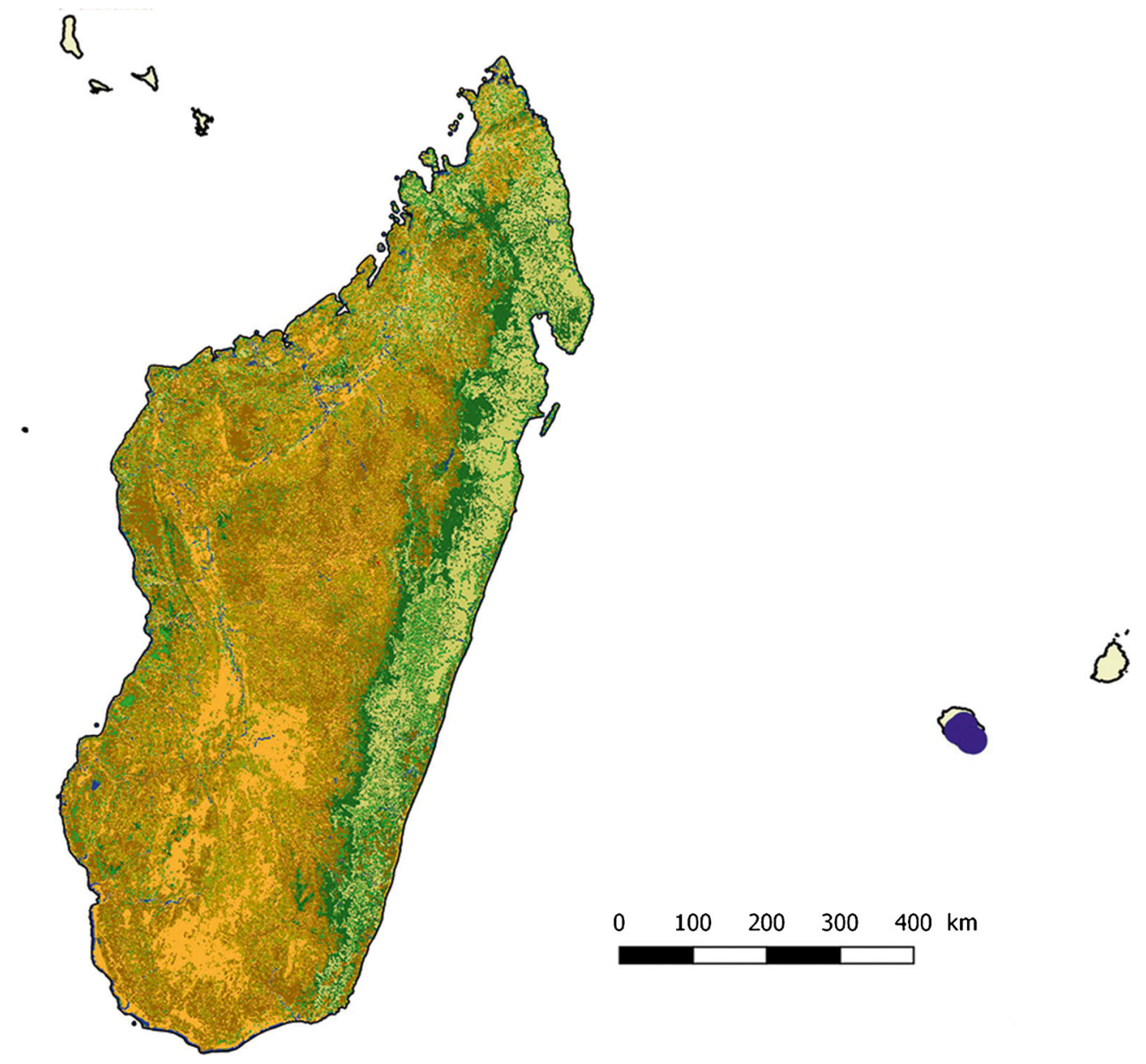

Map 40. Distribution of Liparis punctilabris.

NOTES. Liparis punctilabris first appears in Frappier's listing of Réunion plants in 1880 but without a description. It was then described by Cordemoy (1895) who incorporated Frappier's manuscript.

Frappier indicated several localities in Réunion but there is no clear type material. A fruiting specimen is in the Cordemoy herbarium (MARS) corresponds with the description and comes from Piton Hyacinthe which is one of the localities mentioned by Frappier in Cordemoy. There is no direct proof that this specimen is part of the type material and the fruiting plant is a poor representation of the species. As there is no other historical representative material available it was decided to assign a new type from a more recent and well-documented collection (Bernet in Hermans 8161). The new type originates from a similar area in the South-central mountains of the island.

ILLUSTRATIONS. Figs 56, 57; Bernet (2010a: 96); Szelengowicz \& Tamon (2013: 368).

Liparis rivalis Schltr. (Schlechter 1924: 146); Perrier (1939: 267); Hermans et al. (2007: 223); Cribb \& Hermans (2009: 150); Hervouet (2018: 417). Types:
Madagascar, Mt Tsaratanana, Perrier 15244 (P00095517) (lectotype $\mathrm{P}$, designated here; isolectotype Perrier 15244 (P00095518).

Large erect terrestrial plant, up to $35 \mathrm{~cm}$ tall; rhizome very short; roots more or less pilose, c. $1 \mathrm{~mm}$ diam. Pseudobulbs slender, stem-like, up to $22 \mathrm{~cm} \times 3-6 \mathrm{~mm}$, partly covered by $4-8$ amplectant sheaths, sometimes with a leaf-like bract just below the leaves, with $3-5$ apical sub-petiolate leaves. Leaves asymmetric, somewhat falciform, thin, lanceolate to elliptical-lanceolate, acuminate, up to $5-15-2-5 \mathrm{~cm}$ but usually in the smaller range, pale green. Inflorescence erect, longer than the leaves, carrying up to 30 flowers, up to $15 \mathrm{~cm}$. Peduncle with a few short costate peduncle sheaths sizes and several sterile bracts. Rachis densely-flowered, racemose, up to $14 \times 2 \mathrm{~cm}$ diam. Floral bracts spreading, linear-lanceolate, acuminate, the lower ones a little longer than the pedicellate ovary, the apical ones shorter, $5.2-7 \times 0.9-1.6 \mathrm{~mm}$, green. Flowers small, up to $9 \times 6 \mathrm{~mm}$, erectly-spreading, lower ones fading before the upper ones open, ovary and column green, sepals and petals brownish-green, lip pale orange and becoming darker towards the middle 


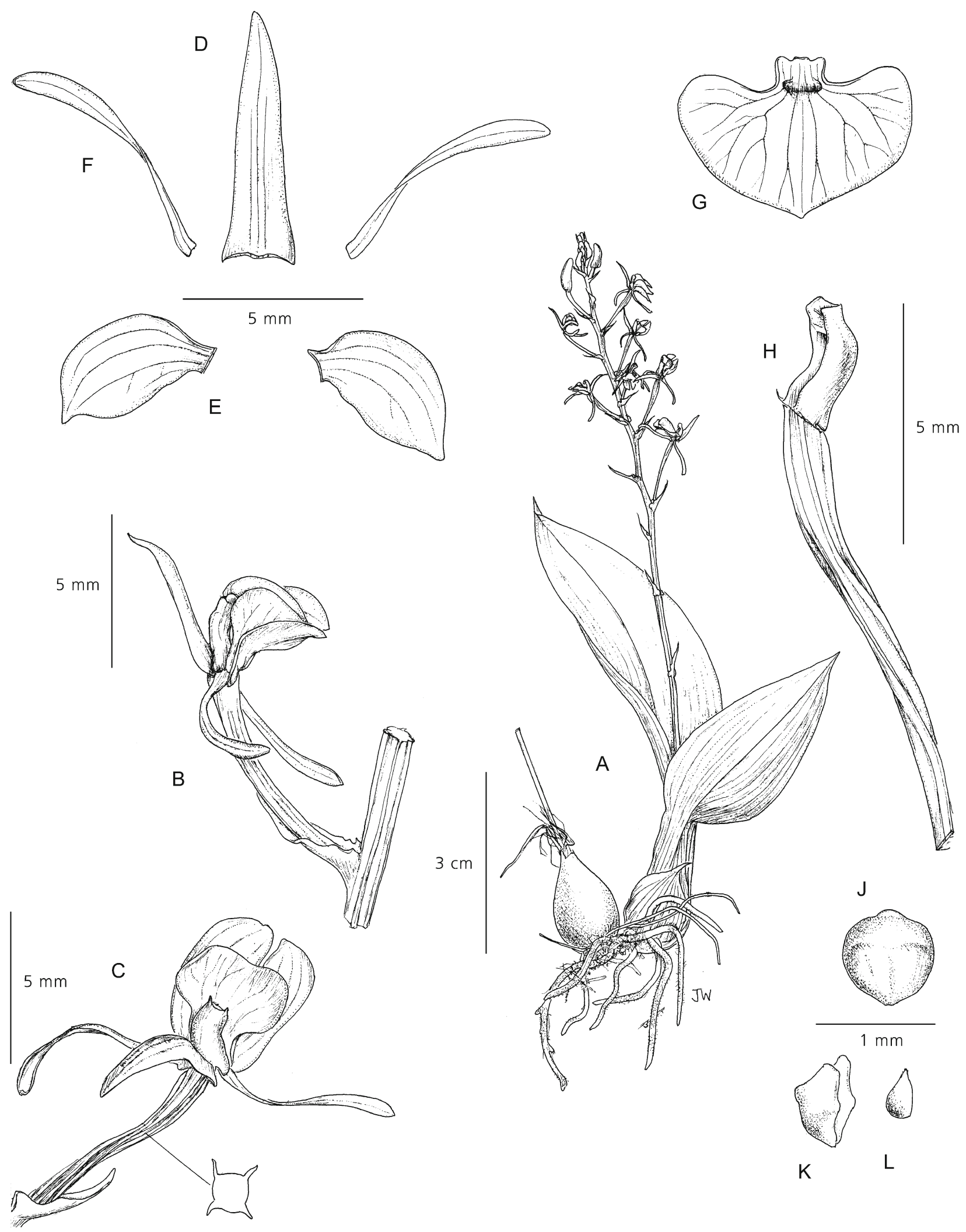

Fig. 56. Liparis punctilabris. A habit; B flower, side view; C flower from above; D dorsal sepal; E lateral sepal; F petal; G lip; H column, side view; J anther cap; K anther cap; L pollinium. From Hermans 8152 \& 8161 (K). DRAWN BY JULIET BEENTJE. 

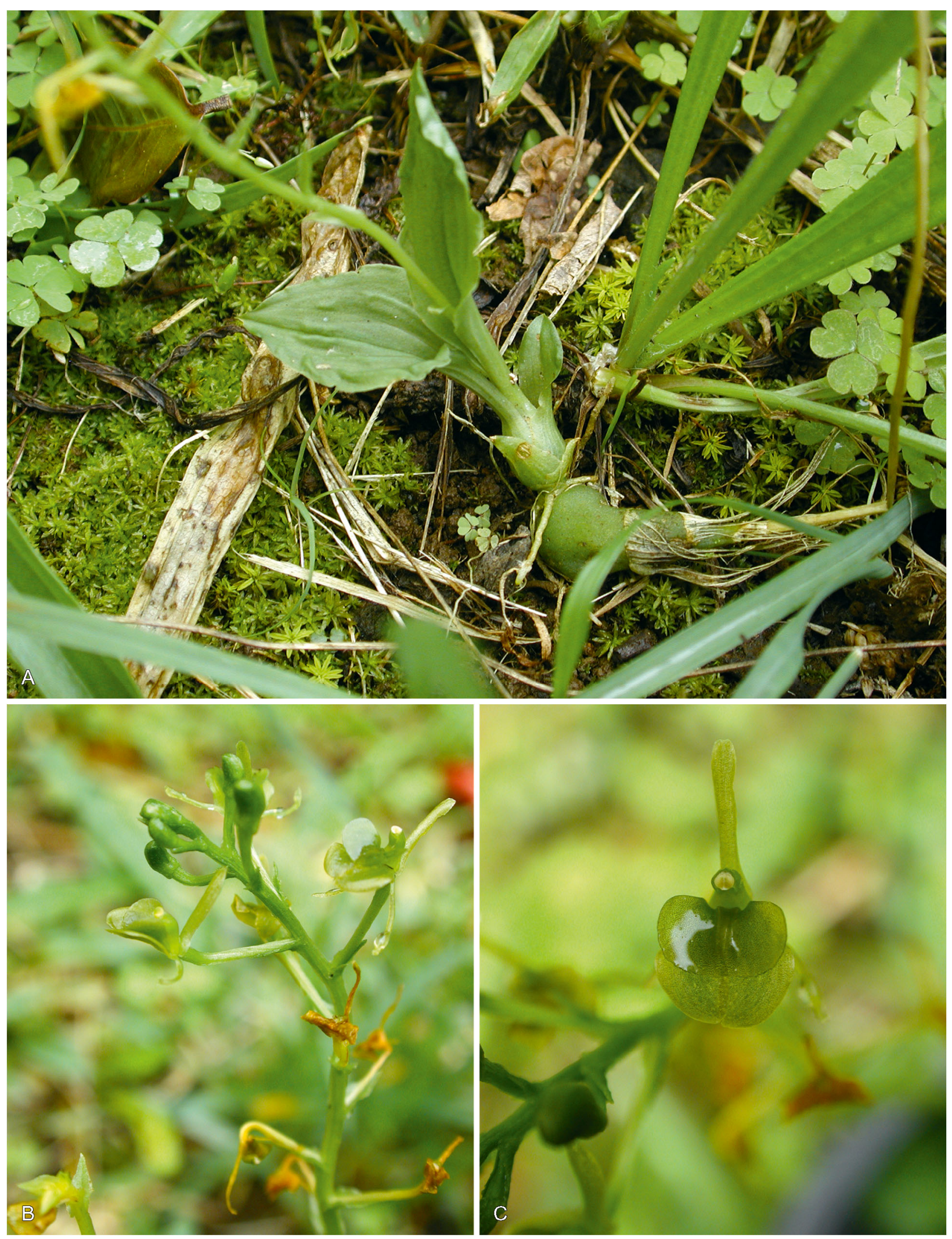

Fig. 57. Liparis punctilabris. A habit; B inflorescence; C flower. PHOTOS: PATRICE BERNET. 
to a dark orange-red on the disk; the whole becoming more yellow with age. Pedicel and ovary glabrous, costate, $4.5-7 \times 0.5-1.1 \mathrm{~mm}$. Dorsal sepal erect, ligulate-lanceolate, $5.5-7.2 \times 0.3-1 \mathrm{~mm}$. Lateral sepals porrect, forming a platform beneath the lip, narrowly oblong, $4.5-6.3 \times 1.9-2.2 \mathrm{~mm}$. Petals margins incurved, curved upwards, obliquely linear $5.4-7.0 \times$ $0.3-1 \mathrm{~mm}$. Lip slightly curved, broadly obovate, with very small auricles at the base, very obtuse to almost truncate at the front, the margins undulate to crenulate, with a small callus-like thickening at the base, $4.1-5.4 \times 3.8-4.6 \mathrm{~mm}$. Column very small $1.2-$ $2.8 \times 0.4-0.5 \mathrm{~mm}$, curved at the apex, with small wings. Anther oblate with a small obtuse beak at the front, c. $0.5 \times 0.5 \mathrm{~mm}$. Pollinia ovoid, c. $0.3 \times 0.2 \mathrm{~mm}$.

RECOGNITION. This is a very distinct species with a long, slender stem-like pseudobulb with asymmetric falciform leaves at the apex, and a dense rachis of small flowers. Its flowers are yellow orange with the centre of the lip dark orange to red, a broadly ovate lip, obtuse at the front and with very small auricles at the base, a scarcely visible basal callus and a very small column.

It is somewhat similar in habit to Liparis gracilipes, $L$. listeroides, $L$. puncticulata and $L$. danguayana but the asymmetric leaves, long inflorescence with many small flowers and very small column sets it apart. It shares with $L$. caulescens from Réunion a similar habit, including the somewhat asymmetric leaves, the brownish-yellow flower colour and lip shape but plants of $L$. caulescens are generally shorter, the spike laxly racemose (vs densely racemose), fewer flowered, the flower segments almost double the size, the lip with a distinct callus and the column larger and with angular vs rounded wings (Table 6). Some forms have slightly larger flowers than average and a lip without distinct wings but are still the same species (e.g. Humbert 25132).

DISTRIBUTION. Endemic mainly to the North of Madagascar in Antsiranana and Toamasina provinces (Map 41).

SPECIMENS EXAMINED. MADAGASCAR. Mt Tsaratanana, Perrier 15244 lectotype (P); Perrier 15244 isolectotype (P); NE, foothills of the Marojejy massif, near col Doanyanala, 1949, Humbert 23143 (G, K, P); Anjanaribe, rd to Andapa, c. 1200 m, Dec. 1950, Cours 3699 (P, TAN); Mt Rahobevava, 960 m, March 1951, Cours 4278 (P, TAN); Mts N of Mangindrano, $1800-$ 2100 m, Jan. 1951, Humbert 25132 (P); Mt d'Ambre, Dec. 1967, L. B. 12034 (G); Antsiranana, near Anjanaharibe, Jan. 1994, Hermans 2119, 2885 (K); near Andranotsarabe, $1050 \mathrm{~m}$, Nov. 1994, Hermans 1001 (K); Rahobevava area, 1999, Hermans 2425 (K); Antsiranana area, 1999, Hermans 2439 (K); Anjanaribe, 1999, Hermans 2444 (K); Andapa area, 1999, Hermans 2468 (K); Masoala, E slope of Ambohitsitondroinan, 1125 m, Feb. 2003, Lowry et al. 6170 (P, TAN);
Antsiranana, near Mt d'Ambre, Jan. 2017, Hermans 8106 (K).

HABITAT. Terrestrial at the edge of streams or damp places, in undergrowth in evergreen forest of gneiss and laterite. Often in deep leaf litter and moss. Altitude: 800 - $1600 \mathrm{~m}$.

CONSERVATION STATUS. Category VU: the extent of occurrence (EOO) of Liparis rivalis is estimated to be $40,636 \mathrm{~km}^{2}$ (exceeding the limits for Vulnerable status under criterion $\mathrm{B} 1$ ) whereas its minimal area of occupancy (AOO) is estimated to be $32 \mathrm{~km}^{2}$ (which falls within the limits for Endangered status under the criterion B2). With only eight known subpopulations representing eight locations (sensu IUCN), L. rivalis has been preliminarily assessed as $\mathrm{VU}$ using the green listing method. This species is threatened by selective logging, timber harvesting for small-scale subsistence and tavy (slash-and-burn farming), resulting in habitat reduction and habitat quality reduction.

FLOWERING TIME. December to March.

ETYMOLOGY. Refers to the habitat, near the margin of streams, where the type specimen was found.

NOTES. Rudolf Schlechter (1924: 146) described Liparis rivalis from material collected by Perrier on Mt Tsaratanana. There are two sheets of type material:

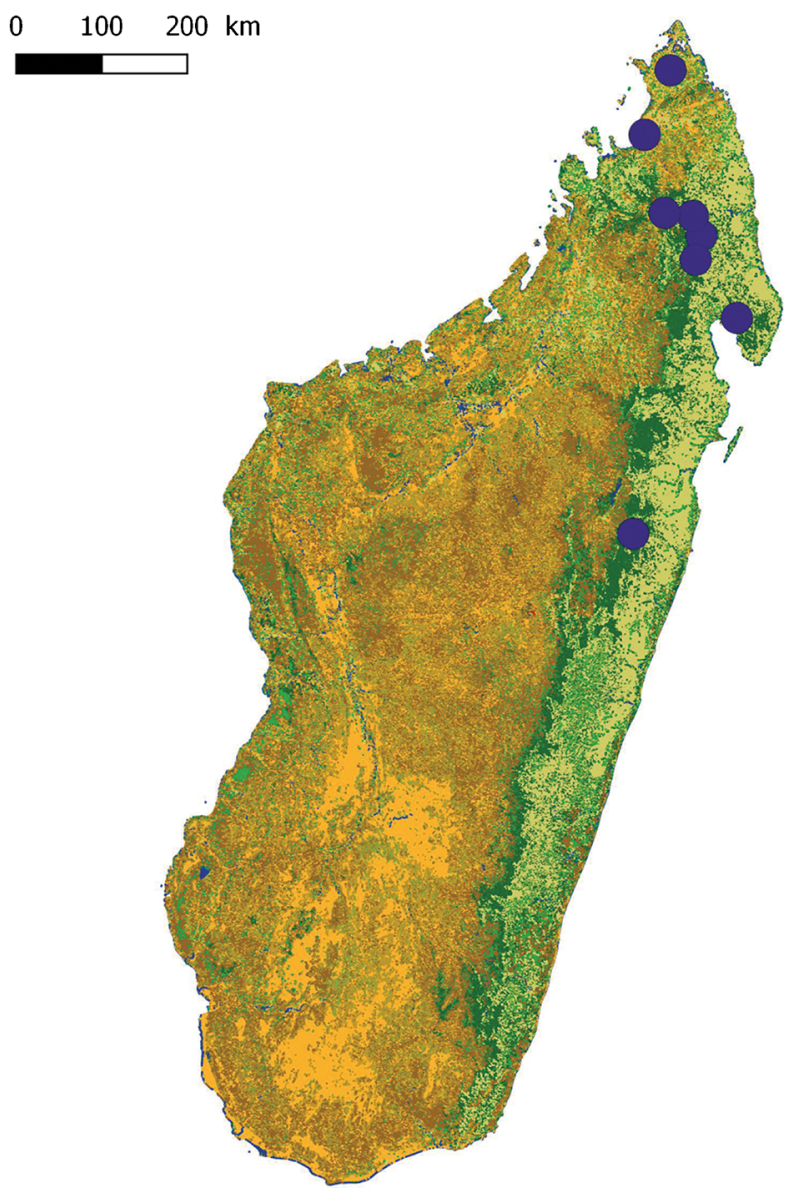

Map 41. Distribution of Liparis rivalis. 
the specimen with barcode P00095517 corresponds best to the description and is more complete than P00095518 and is designated as the lectotype.

ILlUStRAtions. Fig. 58; Perrier (1939: 271); Hervouet (2018: 417).

Liparis salassia (Pers.) Summerh. (Summerhayes 1953: 133); Hermans et al. (2007: 223); Cribb \& Hermans (2009: 156); Bernet (2010a: 98); Bosser \& Lecoufle (2011: 409); Hervouet (2018: 418). Type: Île de Bourbon [Réunion], Montes Salassii, Commerson in Herb. Jussieu 3770. (P00672904) (holotype P in Herb Jussieu).

Epipactis salassia Pers. (Persoon 1807: 513).

Ophrys salassia ms. in Herb. Commerson sec. A.Rich.

(Richard 1828: 53).

Serapias salassia (Pers.) Steud. (Steudel 1821: 767).

Neottia salassia (Pers.) Steud. (Steudel 1841: 189).

Malaxis purpurascens Thouars (1822: tt. 26 \& 27). Type:

s. loc. Thouars s.n. (P00112470) (holotype P).

Liparis purpurascens (Thouars) Lindl. (Lindley 1825: t.882); Moore in Baker (1877: 343); Ridley (1886b: 279); Frappier in Cordemoy (1895: 183); Perrier (1939: 267).
Leptorkis purpurascens (Thouars) Kuntze (1891: 670). Liparis salassia (Pers.) Summerh. var. mieroslawskiana Marg. \& Szeleng. (Margonska \& Szelengowicz 2011: 15), synon. nov. Types: Réunion, E Coast, at Takamaka, March 2011, Szelengowicz 0311 (holotype UGDA-HBM, isotype UGDA-HBM spirit coll.).

Small erect or divergent terrestrial or rarely epiphytic or lithophytic plant on a short ascending up to $16 \mathrm{~cm}$ tall but generally around $10 \mathrm{~cm}$, completely reddish to violet-red when alive, rhizome c. $3 \mathrm{~mm}$ diam., roots thin, villous. The most recent 2 or 3 growths retaining their leaves, older pseudobulbs becoming reptant. Pseudobulbs stem-like, fusiform to somewhat angular, purple-red, $5-10 \mathrm{~cm} \times 3-6 \mathrm{~mm}$, partly covered by $2-$ 4 sheaths (10 - $15 \mathrm{~mm}$ long), generally carrying 2 apical leaves and sometimes a $3^{\text {rd }}$ smaller leaf a little lower. Leaves somewhat coriaceous, cordate to ovate, abruptly contracted into a short petiole $(5-12 \mathrm{~mm})$, margins more or less undulate, $2-6 \times 1.5-3.5 \mathrm{~cm}$, dark green, glossy, the veins and petiole dark redpurple, purple-brown underneath. Inflorescence up to $10 \mathrm{~cm}$ long, generally shorter, somewhat grooved, dark red-brown. Peduncle with $1-2$ cordate to
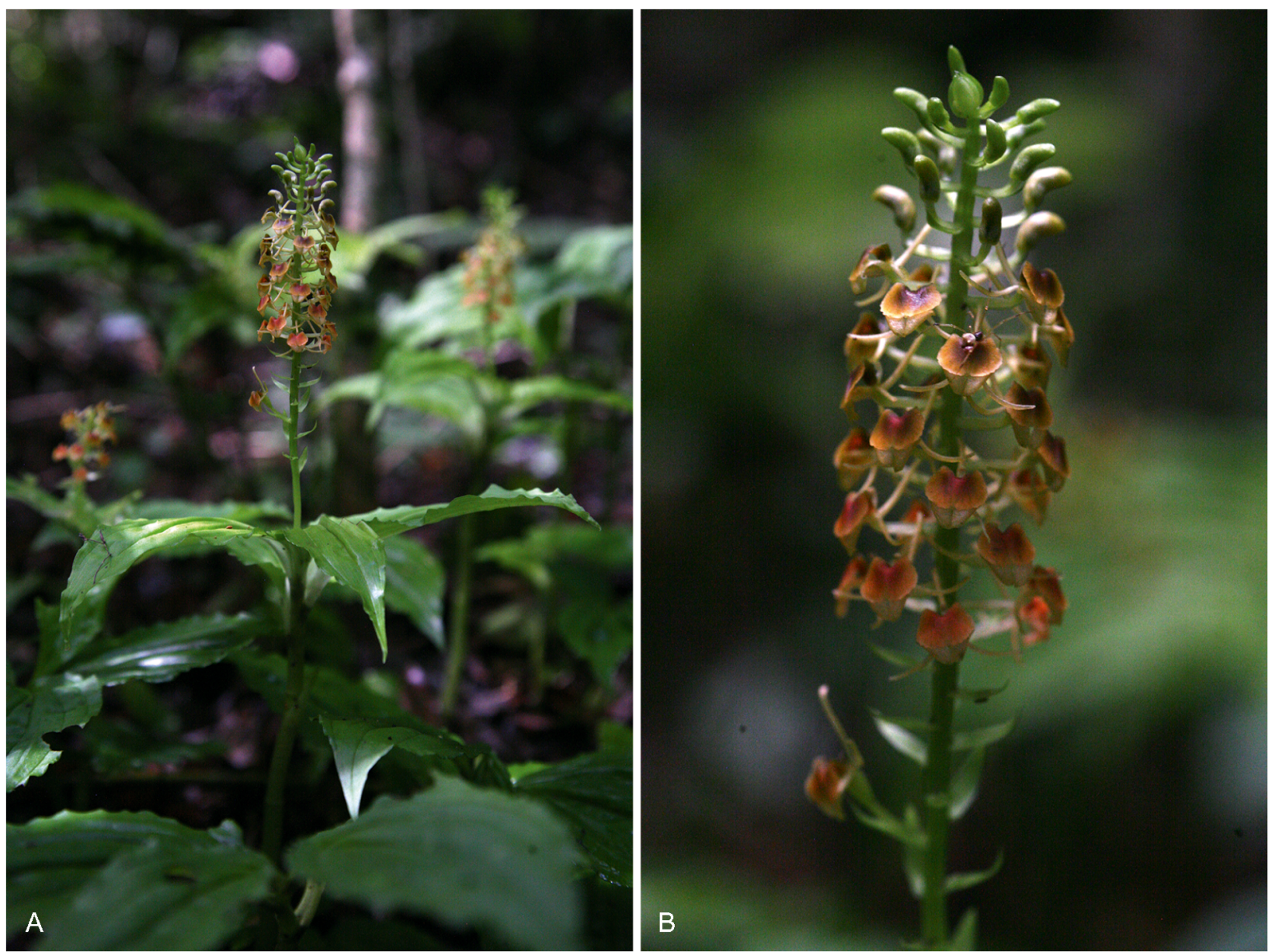

Fig. 58. Liparis rivalis. A habit; B inflorescence. PHOTOS: JOHAN HERMANS. 
lanceolate peduncle sheaths c. $5 \times 2 \mathrm{~mm}$. Rachis subcorymbose, elongating with age, with up to 16 flowers, generally fewer. Floral bracts lanceolate, $5-5.8 \times 1.2-$ $1.5 \mathrm{~mm}$, much shorter than the pedicellate ovary, reddish-brown. Flowers medium in size, up to $1.4 \times 1.5$ $\mathrm{mm}$, ovary, dorsal sepal and petals burgundy, lateral sepals yellow-brown more or less marked with burgundy, lip pale-yellow with the veins dark burgundy, column white marked with purple, anther pale yellow, pollinia orange to brown. Pedicel and ovary tubular to fusiform, twisted, sulcate, up to $12 \times 1.5 \mathrm{~mm}$, elongating with age. Dorsal sepal recurved, subulate to linear, margins incurved, subapiculate, $5.5-8 \times 0.7-$ $1.4 \mathrm{~mm}$. Lateral sepals oblong ovate, obtuse, connate at the base, folded underneath the lip, $4.7-6.7 \times 2 \times 2.9$ $\mathrm{mm}$. Petals descending to divergent, subulate to linear, the margins more or less incurved, subapiculate, obtuse, $4.5-5.6 \times 0.2-0.3 \mathrm{~mm}$. Lip suborbicular to obcordate-triangular, curved downwards toward the middle, base with long upturned lobes entire at the margins, forming small auricles at the base, emarginated to apiculate at the front, anterior margins serrate to laciniate, with a more or less pro- nounced basal callus which can be divided, $3.5-5.9 \times$ $4.2-4.9 \mathrm{~mm}$. Column elongate, arcuate toward the apex, wings at the tip obtusely triangular, $2-3.4 \times 0.7$ - $1.5 \mathrm{~mm}$. Anther ovoid, strongly beaked, c. $1.1 \times 0.9$ $\mathrm{mm}$. Pollinia ovoid c. $0.4 \times 0.3 \mathrm{~mm}$. Seed capsule oblong, a little narrowed from the apex to the base, pedicel slender, c. $12 \times 3.5 \mathrm{~mm}$.

RECOGNITION. A distinctive small plant with a short thin pseudobulb and two to three, cordate to ovate, purplered leaves, with undulate margins, at the top. Its inflorescence is subcorymbose and bears medium-sized, more or less burgundy coloured flowers, with a paler lip with a serrate anterior margin and indistinct rounded callus. The anther is distinctly beaked. It is quite distinct from all the other Madagascan and Mascarene species in its typical habit, lip shape and colour.

DISTRIBUTION. Widespread in Madagascar, Antsiranana, Fianarantsoa, Mahajanga and Toamasina provinces. Réunion and Mauritius (Map 42). Possibly also on Grande Comore in the Comoro Islands but there is some doubt over these records: this probably stems from a Humblot specimen in the Reichenbach

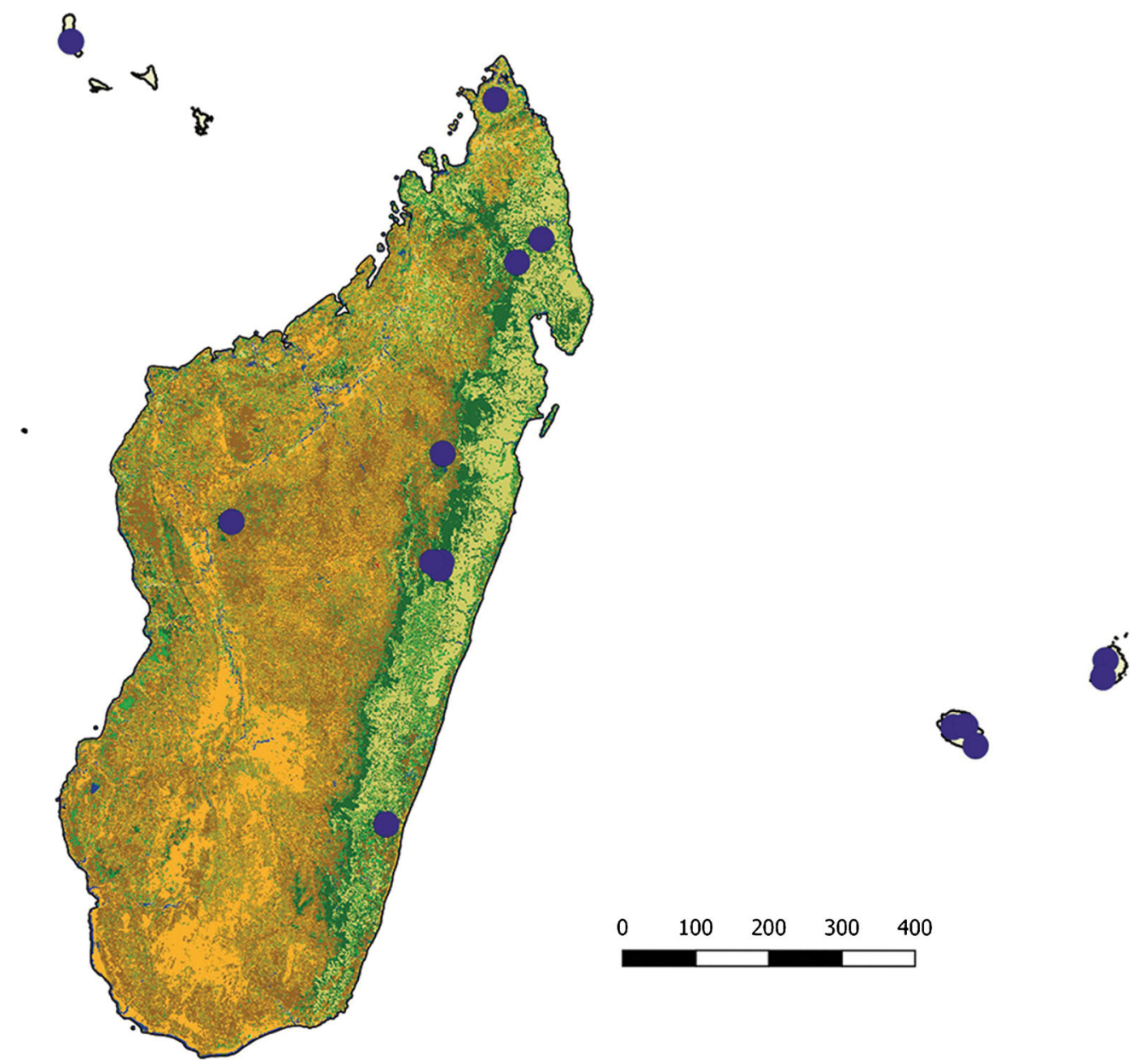

Map 42. Distribution of Liparis salassia. 
herbarium in W (R39766), marked as coming from the Comoros. There are no other indications of the origin and Humblot collected not only in the Comoros but also in Madagascar, it is therefore difficult to ascertain its origin. It is this specimen that probably was the reason Voeltzkow (1917: 444) included the Comoros in its distribution. This was subsequently copied by others. With its wide distribution it would be no surprise if the species was found there but there are currently no reliable records.

SPECIMENS EXAMINED. COMOROS. Grande Comore?, Humblot R39766 (W). MADAGASCAR. North \& Central, 1899, Warpurs.n.(K); Central-North, Mt d'Ambre, 1200 m, Sept. 1926, Perrier 17724 (P); Matitanana basin, Tsianovoka forest, Sept. 1934, Heim s.n. (P); Moramanga forest, Sept. 1942, Decary 18189 (P); NE, Marojejy massif, E of Ambalamanasy, 1000 - 1500 m, Dec. 1958, Humbert E Capuron 22248 (P); Mt d'Ambre, Dec. 1964, Morat 1227 (P); Andasibe, May 1984, Dorr 3120 (TAN); NW of Ambohitsaratelo-Bebao, c. 1100 m, Jan. 1985, Dorr 3461 (K, MO, P, TAN); Anjanaharibe, 1050 m, 1994, Hermans 3555 (K); Mantadia, Belakato, 1090 m, Nov. 2003, Roberts et al. TPPO26 (K); Antsiranana, Mt d'Ambre, Nov. 2007, 1200 m, Nusbaumer et al. 2362 (G, P); Mt d'Ambre, 1040 m, April 2008, Ramandimbimanana et al. SDR056 (G, K); Alaotra Mangoro, Ambohibary, Ambatovy, Marohonkona, June 2012, Ramahenina et al. 81 (P); Moramanga, Analamazaotra, site Andranomadio, Dec. 2013, 927 m, Razafindraibe et al. 606 (TAN); s. loc. Academ. Mal. 984 (TAN). MAURITIUS. s. loc., Commerson s.n. P00738600 (P), (G); s. loc., Bouton (KLindl); s. loc., Bouton in herb. Lemann (CGE); Piton Grand Bassin, May 1966, Vaughan 12204 (MAU, P); Mt Louis, March 1971 Bosser 21158 (P); s. loc., Léman P00738598 (P); s. loc. Wiehe 1704 (MAU, P). RÉUNION. Île de Bourbon, Montes Salassii, Commerson in Herb. Jussieu 3770. (P00672904) (holotype $\mathrm{P}$ in Herb Jussieu); sur les hauts de St Louis de la rivière de St Etienne, Commerson s.n. MPU017853 (MPU) 1771 (G); St. Etienne river, Aug. 1771, Commerson s.n. P001124714 (P); s. loc. Thouars s.n. P00112470 (P); on the Bonita, July 1837, Gaudichaud s.n. (P); s. loc., ex herb. Richard, R15286 (W); Richard, R39765 (W); s. loc. Herb. Desvaux (P); Mare Longue, St Phillippe, Oct. 1972, Bosser 21278 (P); Takamaka, 650 m, April 2002, Bernet 1 (P); Takamaka, 700 m, April 2002, Bernet 2 (P); Piton Mare d'Azule, April 2004, Pause E Fontaine 1145 (CBNM); Sain-Benoit, Grand Etang, April 2008, Fontaine 2455 (CBNM); Sainte-Rose, Mourouvin, 256 m, Sept. 2014, Ferard E Lacoste 4127 (CBNM); s. loc. Léman 824, Herb. Maire, P00409226 (P).

HABITAT. In humid evergreen forest on gneiss and laterite. In shady and damp places, in humus or moss, on moss-covered trees. Altitude: $1000-1500 \mathrm{~m}$ in Madagascar, generally lower $(300-900 \mathrm{~m})$ on the Mascarenes.
CONSERVATION STATUS. Category LC: The extent of occurrence (EOO) of Liparis salassia is estimated to be $967,522 \mathrm{~km}^{2}$ (far exceeding the limits for Vulnerable status under criterion B1) whereas its minimal area of occupancy (AOO) is estimated to be $64 \mathrm{~km}^{2}$ (which falls within the limits for Endangered status under the criterion B2). Liparis salassia is known from 24 subpopulations representing 29 locations (sensu IUCN), this species has been preliminarily assessed as LC using the green listing method. This species is threatened by mining activities, selective logging, timber harvesting for small-scale subsistence and tavy (slash-and-burn farming), resulting in habitat reduction and habitat quality reduction. Previously assessed and published in the IUCN Red data listing for Réunion as LC (Picot 2013: 17).

FLOWERING TIME. December to April in Madagascar, generally March to May in the Mascarenes.

ETYMOLOGY. The type description refers to Mt Salass in the middle of Réunion, referring to les Salazes, $\mathrm{N}$ of the Cirque de Cilaos (Jean-Michel Hervouet, pers. comm. 2017).

NOTES. For a long time, this species appeared in literature as Liparis purpurascens, mainly because an earlier description by Persoon was overlooked by $\mathrm{Du}$ Petit-Thouars and subsequent authors. The typification of the species has also been confused with various Commerson specimens located in Paris, Montpellier and private herbaria. It is interesting to note that all the type material consists of fruiting plants. Persoon, in his description refers to a Commerson collection in the Jussieu herbarium (now in $\mathrm{P}$ ); it was therefore decided to confirm sheet P00672904 from 'Mont Salassii' in the Jussieu herbarium as the holotype because it is the original material used by the author. Another Commerson specimen in the Jussieu herbarium (Jussieu 3770 P00672922) labelled 'Ophrys salassiae' may not be this species. The other Commerson sheets in the Paris herbarium (P00112471-4, P00738600) come from another locality on Réunion and were not mentioned by Persoon in his description.

Liparis salassia (Pers.) Summerh. var. mieroslawskiana Marg. \& Szeleng., from Réunion, is said to differ by the sepals which are initially connate from their base for most of their length, as the flower develops only at the basal part, and the lip with upturned margins, giving it a piriform shape. These characteristics can be observed more or less in other colonies in Réunion and Madagascar and are well within the range of variability of the species. It is, therefore, considered a synonym.

The species was first described in 1807 by Christiaan Hendrik Persoon (1761 - 1836) in his Synopsis plantarum, as Epipactis salassia, based on specimens collected by Phillibert Commerson (1727 - 1773) in 1771 on Réunion who, in manuscript on the 
herbarium sheet, had named them Ophrys salassia. Commerson had sent various large collections to France where they were distributed to herbaria, including that of Abbé Pourret (1754 - 1818), whose collection was later acquired by Baron JosephAthanase Barbier (1767 - 1846). His herbarium ended up in P but also in Montpellier (Dorr 1997: 93). In 1821 Ernst Gottlieb Steudel (1821: 767) transferred the species to the genus Serapias.

In 1822 du Petit-Thouars (tt. 26 \& 27) described Malaxis purpurascens, based on his own collection, it is unclear if it originated from Mauritius or Réunion. His illustration in t.26 shows a typical plant in flower, but t.27 shows a very different plant with a much longer stem, long rhizome, and may well be a different Liparis. The type material of $M$. purpurascens in P correspond to t.26, there is no material that matches t.27.

Unaware of Persoon's original description, Achille Richard noted in his Monograph of the Orchids of Réunion and Mauritius (1828: 53) the existence of the name Ophrys salassia written on the Commerson herbarium sheet in $\mathrm{P}$ and put it as a synonym of $\mathrm{Du}$ Petit-Thouars' Liparis purpurascens. This was repeated by John Lindley who transferred Du Petit Thouars' Malaxis to the genus Liparis in 1825 (sub. t. 882). Steudel transferred it to the genus Neottia (1841: 189), before Kuntze (1891: 670) put it into Leptorkis, together with other species. It is puzzling why the species was not mentioned in Perrier (1936). Finally, Summerhayes (1953: 133) summarised the confusion and established Liparis salassia (Pers.) Summerh.

ILLUSTRATIONS. Fig. 59; Du Petit-Thouars (Thouars 1822: t.26); Du Puy et al. (1999 pl. 31); Hermans et al. (2007: pl. 46); Cribb \& Hermans (2009: 157); Bernet (2010a: 98); Bosser \& Lecoufle (2011: 411); Margonska \& Szelengowicz (2011: 15); Szelengowicz \& Tamon (2013: 369); Hervouet (2018: 418).

Liparis sambiranoensis Schltr. (Schlechter 1924: 147); Perrier (1939: 290); Hermans et al. (2007: 224); Cribb \& Hermans (2009: 158); Hervouet (2018: 419). Type: Madagascar, Sambirano Valley, Perrier 15194 (holotype P). Liparis panduriformis H.Perrier (1936: 253); Perrier (1939: 289); Hermans et al. (2007: 221); Cribb \& Hermans (2009: 158), synon. nov. Type: Madagascar, Manongarivo massif, Perrier 1946 (holotype P).

Large erect terrestrial, lithophyte or rarely epiphytic plant $15-40 \mathrm{~cm}$ high, emerging directly from the base of the previous growth, roots filiform, more or less villous. Pseudobulbs cylindrical, narrowly elongate, sometimes somewhat flattened-angular, almost entirely covered by membranous sheaths and by the sheathlike petiole of the lower leaves, with 3 or 4 to rarely 5 leaves towards the top, growth emerging from the previous leafless growth which is divaricate, older pseudobulbs disintegrating and merging in the substrate, without obvious rhizome, $7-18 \times 2-3 \mathrm{~cm}$. Leaves erectly spreading, variable in size, often in two pairs 15 - $30 \mathrm{~mm}$ apart, blade elliptic-acuminate, corrugate, narrowed into a long petiole amplectant to the pseudobulb, overall $10-18.5 \times 5-7.5 \mathrm{~cm}$, pale green, more or less glossy. Inflorescence erect, up to $30 \mathrm{~cm}$ long, from the centre of the growth, much longer than the leaves, carrying up to 25 flowers, the lower ones fading before the upper ones open. Peduncle costate, with a few ovate-lanceolate sterile bracts. Rachis laxly racemose, up to $15 \mathrm{~cm}$. Floral bracts shorter than the pedicellate ovary, porrect, ovatelanceolate, strongly attenuate at the tip, almost cordate at the base, $8-12 \times 3.8-4.1 \mathrm{~mm}$, green Flowers large, erectly spreading, up to $29 \times 14 \mathrm{~mm}$, ovary pale green, sepals and petals pale greenishyellow, lip darker olive green to orange, column and anther white, all parts becoming paler and more yellow with age, tepals and lip a little glossy. Pedicel and ovary porrect, slightly upturned toward the base of the flower, cylindrical, somewhat grooved, $10-17 \times$ $1.5-2 \mathrm{~mm}$. Dorsal sepal erect to incurved, linearlanceolate, base cordate-auriculate, margins more or less recurved, 12.5 - $18 \times 1.2-3.8 \mathrm{~mm}$. Lateral sepals parallel, descending below the lip, obliquely oblong, obtuse, $11-16 \times 3.4-5.9 \mathrm{~mm}$. Petals divaricate, obliquely linear, margins recurved, obtuse, $11.4-17 \times$ $0.5-1.5 \mathrm{~mm}$. Lip strongly curved in the middle forming a gutter-like hypochile, shortly auriculate at the base and a broadly oval hypochile serrate to crenate at the anterior margin, with a bi-gibbose callus at the base, $9.1-14 \times 5.4-8.8 \mathrm{~mm}$. Column strongly curved towards the apex, with distinct sharply triangular wings, $4.1-6 \times 1.1-1.5 \mathrm{~mm}$. Anther ovoid, with a short acute beak at the tip, $1.1-1.5 \times 0.9-1.0 \mathrm{~mm}$. Pollinia ovoid c. $0.5 \times 0.7 \mathrm{~mm}$.

RECOGNITION. This is a large plant, up to $40 \mathrm{~cm}$ tall, with a distinct thin stem and about four glossy leaves borne a few centimetres apart, old pseudobulb divaricate, large flowers in a many-flowered lax raceme. Its lip is longer than wide, narrowed around the middle, serrate or crenate on the front margin and with a bigibbose callus at the base, and its column has sharply triangular wings and a shortly beaked anther.

It is closest to Liparis ochracea but L. sambiranoensis has longer pseudobulbs, generally a longer inflorescence, a longer lip with a rounded epichile and angular hypochile (vs almost pandurate) and short angular vs elongate column wings. There are similarities with L. ornithorrhynchos but this species has a different habit with shorter pseudobulbs, fewer flowers, the lip is almost pandurate vs rounded and the anther sharply triangular vs elongate-obtuse. It is also similar to L. bemarahensis described above but it 

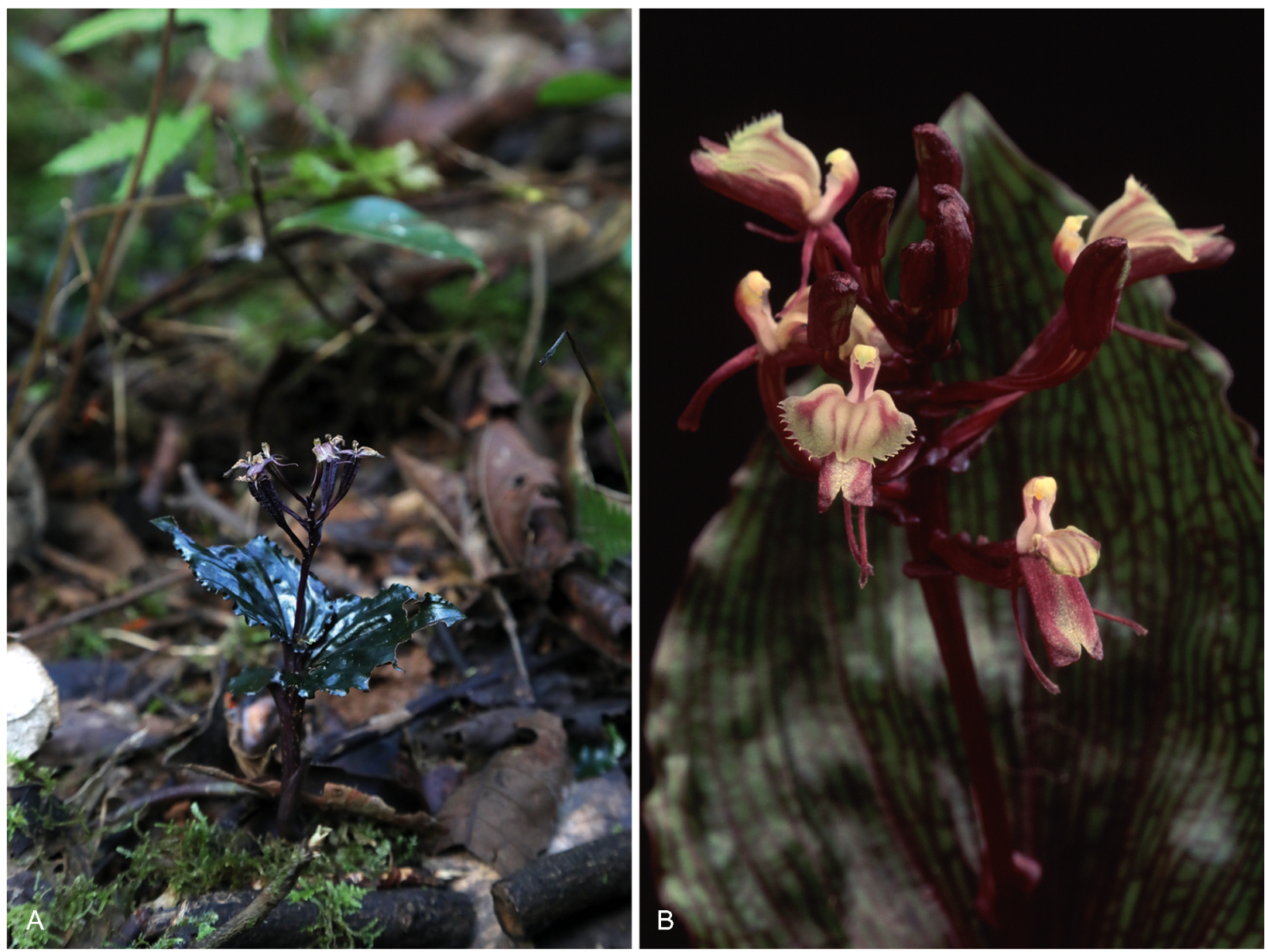

Fig. 59. Liparis salassia. A habit; B inflorescence. PHOTOS: JOHAN HERMANS.

differs by the plant habit, shape of the lip, callus and anther, as shown in Table 4.

DISTRIBUtION. Comoros: Moheli, Grande Comore, Mayotte, Anjouan. Madagascar: Antsiranana province and Mahajanga province where it partly overlaps with Liparis bemarahensis (Map 43). Possibly also Réunion (Szelengowicz et al. (2011: 11); Szelengowicz \& Tamon (2013: 371)), where the plant is illustrated and resembles the species but there are no vouchers for this.

SPECIMENS EXAMINED. COMORO ISLANDS. Anjouan, March 1886, Humblot 1509 (BM, P); Moheli, Miringeni, Chalet St Antoine, Feb. 1975, Floret 1246 (P); Grande Comore, Karthala, below Madjou Madjou, $1300 \mathrm{~m}$, March 1975, Floret 1302 (P); Mayotte, Benara Massif, 580 m, Dec. 1996, Labat E Pascal 2903 (MAYOTTE, P); Mayotte, Tchaourembo, 450 m, Feb. 1996, Pascal 387 (K, P); Hort, 2001-2, Pignal 1871 (P-spirit); Mayotte, Grande Terre, Chirongui, Feb. 2004, Barthelot et al. 1303 (MAO, P). MAdAGASCAR. Sambirano Valley, Perrier 15194 (holotype P); Manongarivo massif, Perrier 1946 (holotype P); Sambirano Valley, c. 200 m, Oct. 1922, Perrier 15122 (P); near Tsiandro, 300 - 600 m, Nov. 1932, Capuron Ẽ Léandri
1910 (P); NE, mid valley of the Andraronga, Feb. 1949, Humbert 23218 (P); NE, Western foothills of the Marojejy massif, near col Doanyanala, Feb. 1949, Humbert 23232 (P); Mangandrano, Belanana, April 1953, Rabatoto 5078(P); Mangandrano, Belanana, April 1953, Rabatoto 5245 (P); Diego Suarez, Anivorano, Antenampandrana Feb. 1960, Cours 5557(P); Siandro, Behandrao, Dec. 1952, Capuron et al. 1997 (P); Mt d'Ambre, 1000 m, Dec. 1959 Jan.1960, Humbert 32118 (P); Diego Suarez, Ankaranana, 300 - 350 m, Jan. - Feb. 1960, Humbert 37690 (P); Diego Suarez, Akarana, Jan. 1969, Morat 3059 (P); Mt d'Ambre, March 1971, Bosser 21170 (P); Nossi Be, Jan. 1971, Cremers 1324 (TAN); Andapa, Bealampona, 75 m, April 1995, Ravelonarivo 740 (MO, P, TAN); Marojejy, March 1995, Rasoavimbahoaka 556 (K, MO, P, TAN); s. loc., 1997, Hermans 3602 (K); N of Mangindrano, 800 m, 1999, Hermans 2475 (K); North, Antsiranana area, 1999, Hermans 2429 (K); Ankarana area, 1999, Hermans 2442 (K); Manongarivo, Ambahatra, March 1999, Gautier et al. LG3443 (G, K, P); Ambanja area, 1999, Hermans 2715 (K); Ambanja area, 2000, Hermans 1011 (K); Andapa, Anjialavabe, $\mathrm{N}$ of Ambodivohitra Antsahabalika, Feb. 2006, Antilahimena et al. 4579 (P); Sava, Andapa, 

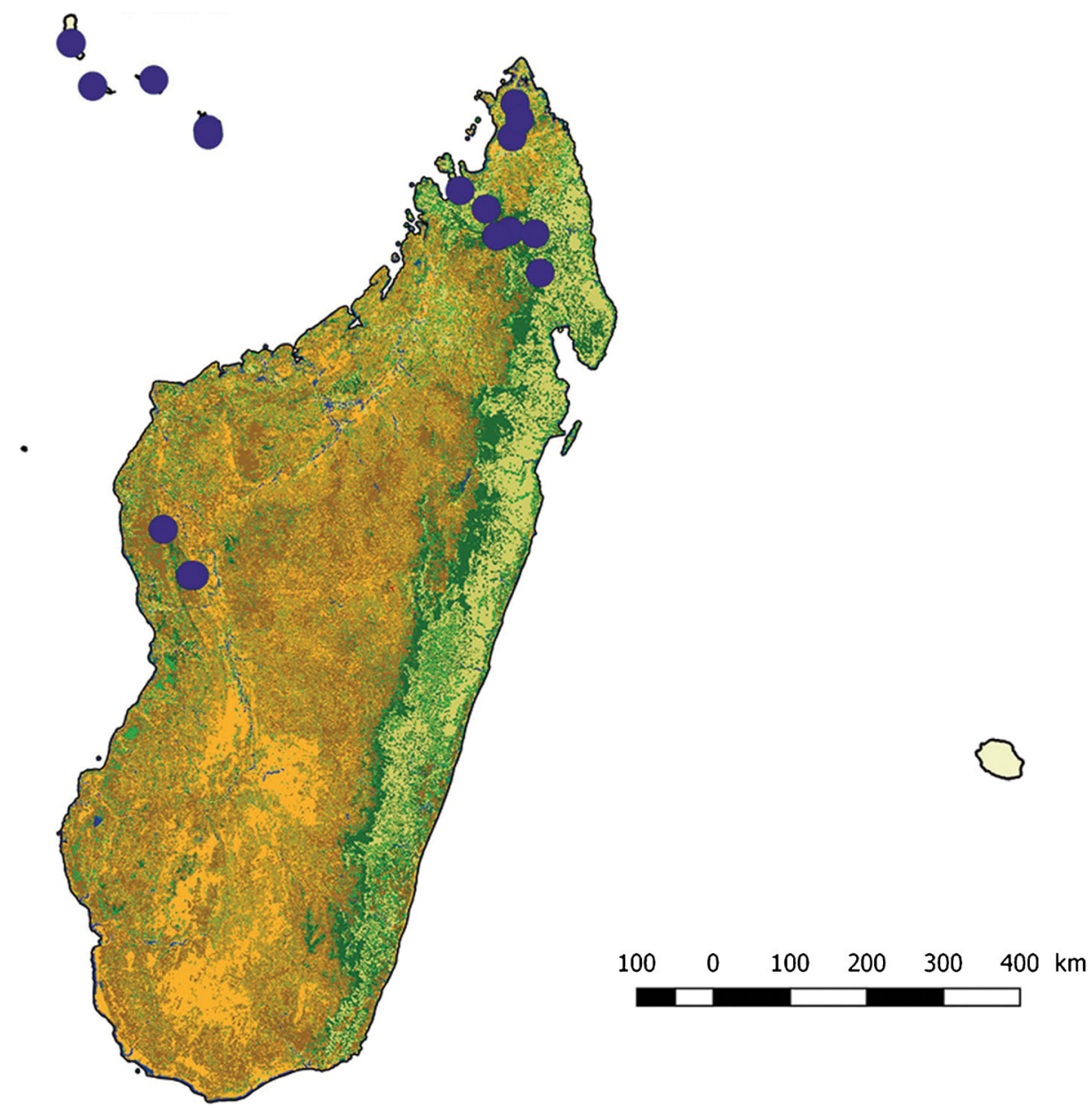

Map 43. Distribution of Liparis sambiranoensis.

Ambodivohitra, Anjialavabe, Feb. 2006, Rakotovao 2687 (G, P, TAN); Sava, Sambava, Feb. 2007, Rakotovao et al. 3524 ( K, MO); Mt d'Ambre, May 2008, Ramandimbimanana et al. 106 (G); Mt d'Ambre, May 2008, Trigui et al. 304 (G); Mt d'Ambre, March 2012, Ramandimbimanana 472 (G); Ambanja, Beentje et al. 4584
(K); Mahajanga, Beanka, S of Kimanambolo, 390 m, Nov. 2012, Gautier et al. LG5843 (G).

HABITAT. Wet, dense evergreen forest in N \& NW Madagascar and Mayotte in humid soil and humus or rarely epiphytic in thick moss on fallen trees or the base of trees. Chalky outcrops in deciduous forest. Altitude: $200-1000 \mathrm{~m}$.

Table 11. Comparison of the type specimens of Liparis panduriformis and L. sambiranoensis, based on average measurements.

\begin{tabular}{lll}
\hline \hline & L. panduriformis & L. sambiranoensis \\
\hline Specimen & Perrier $1946(\mathrm{P})$ & Perrier $15194(\mathrm{P})$ \\
Plant height $(\mathrm{cm})$ & 18 & 18.5 \\
Pseudobulb stem length $(\mathrm{cm})$ & 7 & 6.5 \\
Leaves $(\mathrm{cm})$ & $14 \times 8$ & $11 \times 5$ \\
Inflorescence $(\mathrm{cm})$ & 22 & 14.5 \\
Floral bract $(\mathrm{mm})$ & c. $9 \times 2-3$ & c. $11 \times 4$ \\
No of Flowers & 16, large & 12, large \\
Dorsal sepal $(\mathrm{mm})$ & $14 \times 2.1$ & $12 \times 1$ \\
Lateral sepals $(\mathrm{mm})$ & $10 \times 3.1$ & $12 \times 3.5$ \\
Petal $(\mathrm{mm})$ & $11 \times 0.4$ & $13 \times 0.4$ \\
Lip $(\mathrm{mm})$ & $9.8 \times 5.2$ & $9.5 \times 4.7$ \\
Column $(\mathrm{mm})$ & $3.9 \times 0.5$ & $5 \times 1$ \\
Anther $(\mathrm{mm})$ & $0.9 \times 0.8$ & $1.3 \times 1$ \\
Distribution & Madagascar: Antsiranana prov., Manongarivo & Madagascar: Antsiranana prov., Sambirano \\
\hline
\end{tabular}


CONSERVATION STATUS. Category LC: the extent of occurrence (EOO) of Liparis sambiranoensis is estimated to be $332,359 \mathrm{~km}^{2}$ (far exceeding the limits for Vulnerable status under criterion B1) whereas its minimal area of occupancy (AOO) is estimated to be $72 \mathrm{~km}^{2}$ (which falls within the limits for Endangered status under the criterion B2). With 16 known subpopulations representing 17 locations (sensu IUCN), this species has been preliminarily assessed as LC using the green listing method. This species is threatened by selective logging, timber harvesting for small-scale subsistence and tavy (slash-and-burn farming), resulting in habitat reduction and habitat quality reduction.

Previously assessed and published in the IUCN Red data listing for Mayotte as VU D2 (Mercks 2013).

FLOWERING TIME. October to May.

ETYMOLOGY. Refers to the Sambirano river and area in Madagascar where the species was first found. Liparis panduriformis refers to the three-lobed, lute-shaped lip. VERNACULAR NAMES. A local name for the species is said to be 'Ahijajavy' (Rabatoto 5078 (P)).

NOTES. Liparis sambiranoensis was described by Schlechter in 1924 from material collected by Perrier in the Sambirano area of Northern Madagascar; it has since been found to have a wide distribution in the North of the island and on the Comoros. Liparis panduriformis was described by Perrier in 1936 from plants collected in 1909 in the Manongarivo also from the Sambirano region; a specimen without flowers had been sent to Schlechter at the time and Perrier subsequently found more herbarium material on which he based his description. On close examination it is clear that these two species are identical, with L. sambiranoensis having precedence (ICN article 11.4). Table 11 shows the similarities of the characteristics. The pandurate lip of $L$. panduriformis is given as distinct from other species but the lip of $L$. sambiranoensis shows the same characteristics with a contracted winged base, a narrowed part below then an expanded part where the lip is naturally curved in living specimens, then a slightly narrowed part and ending in an oblong epichile. In flattened, dried specimens these parts become less distinct and are variable. The plant and flower size are also identical, the floral bracts are relatively large and cordate at the base, the lip has two rounded calli at the base, a more or less crenate anterior margin, small rounded column wings and a beaked anther cap.

It is interesting to note that the species was collected as early as 1886 by Léon Humblot on the Comoros (Humblot 1509 at BM \& P). The specimens at BM were misidentified by Ridley as Liparis flavescens. ILLUSTRATIONS. Fig. 60; Hermans et al. (2018: 20); Hervouet (2018: 419).

Liparis scaposa Frapp. ex Cordem. (Frappier in Cordemoy 1895: 183); Bernet (2010a: 100); Hervouet
(2018: 403) as Liparis ambohimangana. Types: Réunion, Plaine des Cafres, 6 June 1851, Boivin s.n. (P00112475 upper seven specimens only) (holotype P); Réunion, 1847 - 1852, Boivin s.n. (P00112476) (isotype P).

Liparis verrucosa Frapp. ex Cordem. (Frappier in Cordemoy 1895: 185). Type: Réunion, Plaine des Palmistes, Aug. 1895, Cordemoy s.n. (lectotype MARS). Liparis verrucosa var. plana Cordem. (Frappier in Cordemoy 1895: 185). Without Type.

Liparis verrucosa var. undulata Cordem. (Frappier in Cordemoy 1895: 185). Without Type.

Liparis microcharis Schltr. (Schlechter 1924: 144) synon. nov.; Perrier (1939: 279); Hermans et al. (2007: 220); Cribb \& Hermans (2009: 152); Hervouet (2018: 413). Type: Madagascar, Mt Vohitrakidahy S of Ambositra (W Betsileo), Feb. 1919, Perrier 12423 (holotype P).

Very small to small terrestrial or epiphytic plant, very variable in size, $3-8 \mathrm{~cm}$ tall at most, few wiry roots, generally in small tufts on a short rhizome. Pseudobulbs completely or partly submerged in the soil or humus, broadly oval to subcylindrical-conical, single- or 2-leaved, very small, $3.1-10 \times 2.3-8 \mathrm{~mm}$, covered with $2-3$ thin white sheaths, one larger than the others, up to $10-18 \times 4$ - $5 \mathrm{~mm}$. Leaves emerging from the apex of the pseudobulb, mainly carried on the flowering bulb, lanceolate, acute, margins sometime slightly undulate or minutely dentate, with a prominent central vein, narrowed into a short petiole at the base, somewhat fleshy, pale to dark green, with a prominent central vein, overall $15-60 \times 4-15 \mathrm{~mm}$. Inflorescence erect, wiry, much longer than the leaf, up to $12 \mathrm{~cm}$ long, with $3-7$ flowers towards the apex. Peduncle disproportionally long, generally well over half the length of the inflorescence, carrying an occasional peduncle scale $4-6 \mathrm{~mm}$ long, sometimes with one or two sterile bracts. Rachis densely racemose, up to $2-5 \mathrm{~cm}$ long. Floral bracts half the length of the ovary at most, lanceolate, acute, $2.1-3.9 \times 0.5-1.3 \mathrm{~mm}$. Flowers variable in size, very small to small, thin, green, yellowishgreen to orange-pale yellow, the petals often a little paler, the lip with a darker green glossy central groove, the callus also darker green, apex of the column white, anther white, 5-10 $\times 4-8 \mathrm{~mm}$. Pedicel and ovary conical, slender, $4.5-7.5 \times 0.3-1.1 \mathrm{~mm}$. Dorsal sepal erect, lanceolate, margins incurved, more or less cordate at the base, $4.8-7$ $\times 1.2-2.1 \mathrm{~mm}$. Lateral sepals curved beneath the lip, oblong-falcate, $3.5-5.1 \times 1.8-2.5 \mathrm{~mm}$. Petals deflexed to spreading, linear, subulate, $4.4-6.7 \times 0.3-0.4 \mathrm{~mm}$, slightly spathulate at the apex. Lip broadly oval to suborbicular, rounded or slightly emarginated-auriculate at the base, anterior margin more or less crenulate, a hollow triangular groove runs from the base towards the anterior margin which is glossy and shiny in living plants, with a comparatively large bilobed, slightly depressed callus at the base, overall $2.8-5.5 \times 3.1-5.5 \mathrm{~mm}$. Column broadened at the base, acutely curved at the apex with 

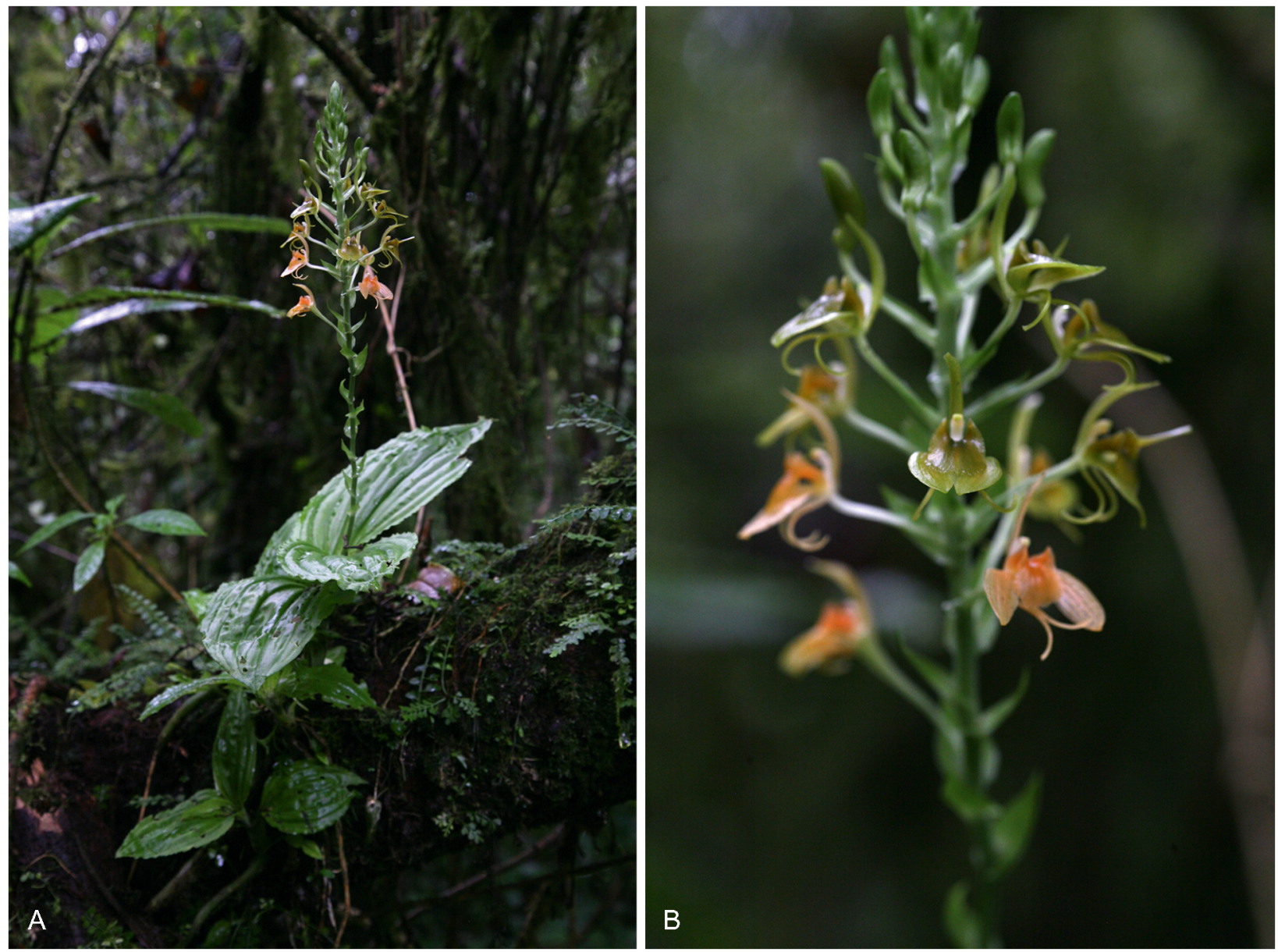

Fig. 60. Liparis sambiranoensis. A habit; B rachis. PHOTOS: JOHAN HERMANS.

pronounced auriculate wings at the apex, $2.2-4 \times 0.5-1$ $\mathrm{mm}$. Anther comparatively small and sitting at the very apex of the column, broadly obovate with a small rounded lobule at the anterior margin, $0.3-0.5 \times 0.4-0.6 \mathrm{~mm}$. Pollinia in two pairs, ovate - flattened on one side c. $0.3 \times$ $0.2 \mathrm{~mm}$. Seed capsule oblong or oblanceolate, ridged, $8-9$ $\times 3.5-4 \mathrm{~mm}$.

RECOGNITION. This small, variable plant has a roundedconical pseudobulb, lanceolate leaves, small flowers, a disproportionately long, few- flowered inflorescence, and flowers with a wide to fan-shaped lip, a prominent rounded bilobed notched callus on lip and a longitudinal groove. Its column is distinctly lobed at the apex, and its small anther has a small lobule at the anterior margin.

It is close to Liparis ambohimangana which has stolons, always a single leaf and generally a shorter inflorescence. Also similar is $L$. cespitosa in habit but L. scaposa is larger in plant size and has a larger flower, different lip-shape and a more prominent callus. Liparis parva has a somewhat similar lip but with a more elongate callus. The four species are compared in Table 1. It is also similar to L. nectarina but the plant and flowers of
L. scaposa are much smaller, overlapping lateral sepals (divergent in L. nectarina), and a roundly lobular anther (vs sharply beaked). In its small size it is similar to the ambiguous L. xanthina which is a little larger in all aspects, the lip is wider and a different shape (broadly oval vs oblong). It is also similar to L. lutea but the prominent callus on the lip is distinct.

Distribution. Madagascar: Antananarivo, Fianarantsoa and Toamasina provinces. More widespread on Réunion (Map 44).

SPECIMENS EXAMINED. MADAGASCAR. Mt Vohitrakidahy S of Ambositra (W Betsileo), Feb. 1919, Perrier 12423 (holotype of L. microcharis, P); Ankeramadinika forest, May 1928, Perrier 18548 (P); Ankeramadinika forest, François 4 in Herb. Perrier 17548bis, larger plant without stolon only (part, as syntype of L. monophylla P); Imerina, Ambohimanga, April 1928, Decary 6222 (P00095463 - 4) (as syntype of L. monophylla, P); Ilafy, Oct. 1905, d'Alleizette 611 M (P); Mandraka forest, March 1907, herb. Rotereau (P02222824) (P); SE of Nandihizana (Carion), Angavokely, 1600 m, Feb. 1988, Pettersson $\mathcal{E}^{2}$ Nilsson 197 (K, P, UPS); SE of Nandihizana (Carion), Angavokely, 1600 m, March 1992, 1600 m, Pettersson $\mathcal{E}$ Nilsson 587 (K, P); Angavokely area, 


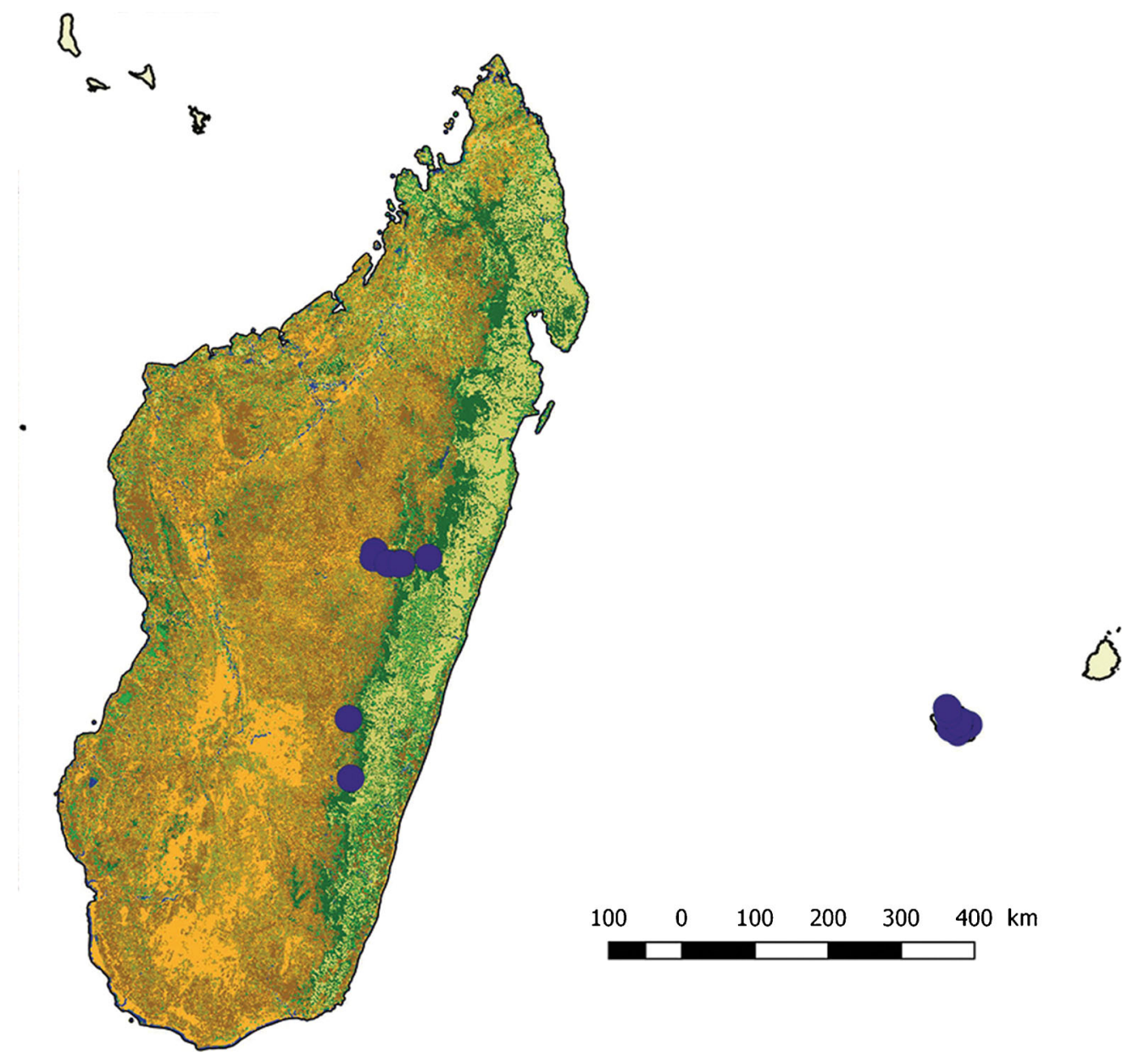

Map 44. Distribution of Liparis scaposa.

Dec. 1997, Hermans 2108 (K); Angavokely area, 1999, Hermans 2858 (K); near Mandraka, 1139 m, 2000, Hermans 4973 (K); Toamasina, Andasibe, near Vakôna, $1101 \mathrm{~m}$ alt., Jan. 2000, Hermans 455 (K); Andasibe, Menalamba, Ambatovy, Behontsa, June 2009, 1000 m, Antilahimena et al. 7133 (MO, P, TAN); Ambatovy, Région, Alaotra-Mangoro, 1080 - 1098 m, April 2012, Ramandimbisoa 207 (BRLU, MO, TAN); Ambatovy, May 2012, Ambatovy Shade House 1174; Antananarivo, Anjozorobe, May 2018, Hermans 8214 (K); s. loc. (TAN). RÉUNION. Plaine des Cafres, June 1851, Boivin s.n. holotype P (P00112475 upper 7 specimens only); Réunion, 1847 - 1852, Boivin s.n. isotype $\mathrm{P}$ (P00112476); Plaine des Palmistes, Aug. 1895, Cordemoy s.n. (MARS); Plaine des Palmistes, forest, Aug. 1895, Cordemoy s.n. (MARS); s. loc., Cordemoy s.n. (P); Petite Plaine, 1500 m, 17 July 1963, Rauh 10147 (HEID 251968); Montée de la Plain de Chicots, Feb. 1971, Bosser 20685 (P); East river, April 1971, T. Cadet 3177 (P, REU); Plaine des Cafres, March 1974, Bosser 21775 (P); Petite Plaine des Palmistes, March 1974, Bosser 21785 (P); Morne des Patates à Durand, April 1975, 1000 - 1100 m, Bosser 22452 (P); Bébour forest, March 1978, Bosser 22356 (P); Haut des Tampons,
Notre Dames de la Paix, 1982, Bosser 22577 (P); Brûlé de St Denis, March 1994, Bosser 21659 (P); Ilet de Patience, Bras Cabot path, April 1978, Bosser 22461 (P); Delteil ex Drake s.n. P00409209 (P); Dimitile, 1900 $\mathrm{m}$, March 2012, Bernet in Hermans 8158 (P); Sainte Marie, Sentier Piton Fougères, 1570 m, Feb. 2017, Ferard E Lacoste 5002 (CBNM); Plaine des Palmistes, 800 m, May 2004, Grondin E Ferard 1176 (CBNM).

HABITAT. Terrestrial on embankments, forest remnants, on humus and moss-covered rock and forest floor. On granite and gneiss rocky outcrops to quartzrich sandy banks in shade or semi-shade limestone, laterite. Epiphyte on branches and at the base of trees, in moss. In shade of Philippia, ericaceous vegetation. Altitude: 1000 - $2000 \mathrm{~m}$.

CONSERVATION STATUS. Category VU: the extent of occurrence (EOO) of Liparis scaposa is estimated to be $132,719 \mathrm{~km}^{2}$ (which exceeds the limits for Vulnerable status under criterion B1) whereas its minimal area of occupancy (AOO) is estimated to be $76 \mathrm{~km}^{2}$ (which falls within the limits for Endangered status under the criterion B2). With 10 known subpopulations representing eight locations (sensu IUCN), this species has been preliminarily assessed as VU using 
the green listing method. In Madagascar, this species is threatened by selective logging, timber harvesting for small-scale subsistence and tavy (slash-and-burn farming) while in Réunion island, it is threatened by grazing and anthropogenic fires, resulting in habitat reduction and habitat quality reduction

Previously assessed and published in the IUCN Red data listing for Réunion as LC (Picot 2013: 17).

FLOWERING TIME. January to May.

ETYMOLOGY. Liparis scaposa is thought to refer to the long rachis, L. verrucosa is said by Frappier to refer to the uneven groove in the centre of the lip. Liparis microcharis refers to the small dainty appearance of the plant.

NOTES. Liparis scaposa was first collected by Boivin during his 1847 - 1852 expedition, on Réunion. Frappier found it in the Paris Herbarium and his notes were posthumously published by Cordemoy (1895: 183) who mentioned that there was some doubt about the identity of L. scaposa and its similarity to L. verrucosa which was described just two pages later; the main difference given in the key being the absence or presence of calli on the lip. There is no doubt that the two species are the same and have been recognised as such by recent authors (Bernet 2010a: 100). Frappier also mentioned two varieties: 'plana' and 'undulata' which are only different in the shape of the leaf margins and are well within the variability of the species. It was thought to be endemic to Réunion but close examination of living and herbarium material shows that there are a number of reliable records of this species from Madagascar which were previously identified as L. microcharis, now considered a synonym. Finet (1909: pl.1) described and illustrated it based on the Boivin type. Liparis microcharis was described by Schlechter (1924: 144) and based on a Perrier collection from $\mathrm{S}$ of Ambositra in central Madagascar; it shares all the characteristics of L. scaposa apart from its sometimes smaller flower size. Generally, the plants and flowers from Réunion are a little larger than the ones found in Madagascar but are well within the variability of the species. Szelengowicz et al. (2011: 11) reported $L$. microcharis from Réunion; the description and photographs confirm that this is L. scaposa.

The type sheet, Boivin s.n. P00112475 has seven small fruiting plants on the top of the sheet and two different plants below. The upper plants correspond well with Frappier's description; the lower plants resemble Liparis punctilabris and should therefore not be considered part of the type. Another specimen Boivin s.n. (P00112476), without precise provenance shows the typical species and can be considered an isotype.

ILLUSTRATIONS. Figs 61, 62; Finet (1909: pl.1: 20 - 27); Cribb \& Hermans (2009: 157); Bernet (2010a: 100); Szelengowicz \& Tamon (2013: 372); Hervouet (2018: 403).
Liparis stenophylla Schltr. (Schlechter 1924: 148); Perrier (1939: 266); Hermans et al. (2007: 224); Cribb \& Hermans (2009: 148); Hervouet (2018: 420). Types: Madagascar, Manongarivo massif, Perrier 8048 (lectotype P (P000955524), designated here); Perrier 8045 (P00095525) lectoparatype P).

Erect, medium to large $(15-32 \mathrm{~cm})$ terrestrial or rarely lithophytic or epiphytic plant on a short $1-2 \mathrm{~cm}$ tufted rhizome, the leading 2 or 3 growths retaining their leaves, roots flexuose, more or less villous. Pseudobulbs slender, terete, up to $16 \times 10 \mathrm{~mm}$, olive green, the flowering one partly enveloped by $3-5$ brownish-white carinate, acute sheaths, disintegrating on the older growths, with two sub-opposite leaves at the apex. Leaves erectly spreading to almost horizontal, narrowly lanceolate to ligulate attenuate, margins almost parallel, with a short petiole, somewhat fleshy, $9-16 \times 0.9-2 \mathrm{~cm}$, pale green with the veins darker, more or less glossy. Inflorescence erect, flexuose, up to $20 \mathrm{~cm} \times 2 \mathrm{~mm}$, with up to 25 flowers. Peduncle about $1 / 3$ of the inflorescence with a few bract-like lanceolate-acuminate sheaths. Rachis laxly several-flowered becoming thinner towards the apex. Floral bracts lanceolate acuminate, somewhat amplexicaul, shorter than the pedicellate ovary, $3-6 \times$ $0.75-1.5 \mathrm{~mm}$. Flowers small, erectly spreading, c. $12 \times 8$ $\mathrm{mm}$, ovary, petals and sepals pale yellowish-green, lip pale greenish-yellow with the disk darker green, becoming darker towards the middle, basal teeth green, column whitish with the apex becoming green, anther pale yellow. Pedicel and ovary slightly twisted, slender, more or less ridged, $4.7-11 \times 0.4-0.8 \mathrm{~mm}$. Dorsal sepal erect or slightly reflexed especially at the apex, narrowly lanceolate acute, margins recurved except at the apex, broadening towards the base and shortly subcordate, 6.5 - $7.5 \times 0.6$ - $1.3 \mathrm{~mm}$. Lateral sepals curved parallel beneath the lip, obliquely oblong-ovate, obtuse, $4-5.8 \times$ $2-3 \mathrm{~mm}$. Petals divergent, semi-erect or descendant, margins strongly recurved, linear obtuse, $4.9-7 \times 0.4-$ $0.7 \mathrm{~mm}$. Lip a little curved towards the base, obovate to suborbicular, the anterior margin crenate to serrate, indented in the middle, the base narrowed and auriculate, with two distinct horn-like calli (c. $0.7 \mathrm{~mm}$ long), 4.8 - $6.2 \times 4-5.2 \mathrm{~mm}$. Column a little incurved, shortly winged towards the apex, $2.7-4.9 \times 0.6-1.3 \mathrm{~mm}$. Anther ovoid, strongly beaked, c. $1 \times 0.7 \mathrm{~mm}$. Pollinia ovoid c. 0.6 $\times 1.2 \mathrm{~mm}$.

RECOGNITION. Liparis stenophylla is a medium-sized to large plant with a long thin pseudobulb partly covered with long carinate sheaths, two long ligulate leaves with darker veins, a long thin, laxly-flowered inflorescence. It has small flowers, with an obovate to suborbicular lip, with two distinct horn-like teeth at the base, and an indented and crenate-serrate anterior margin.

The most closely allied species is Liparis polycardia which is similar in habit, flower size and shape but its 


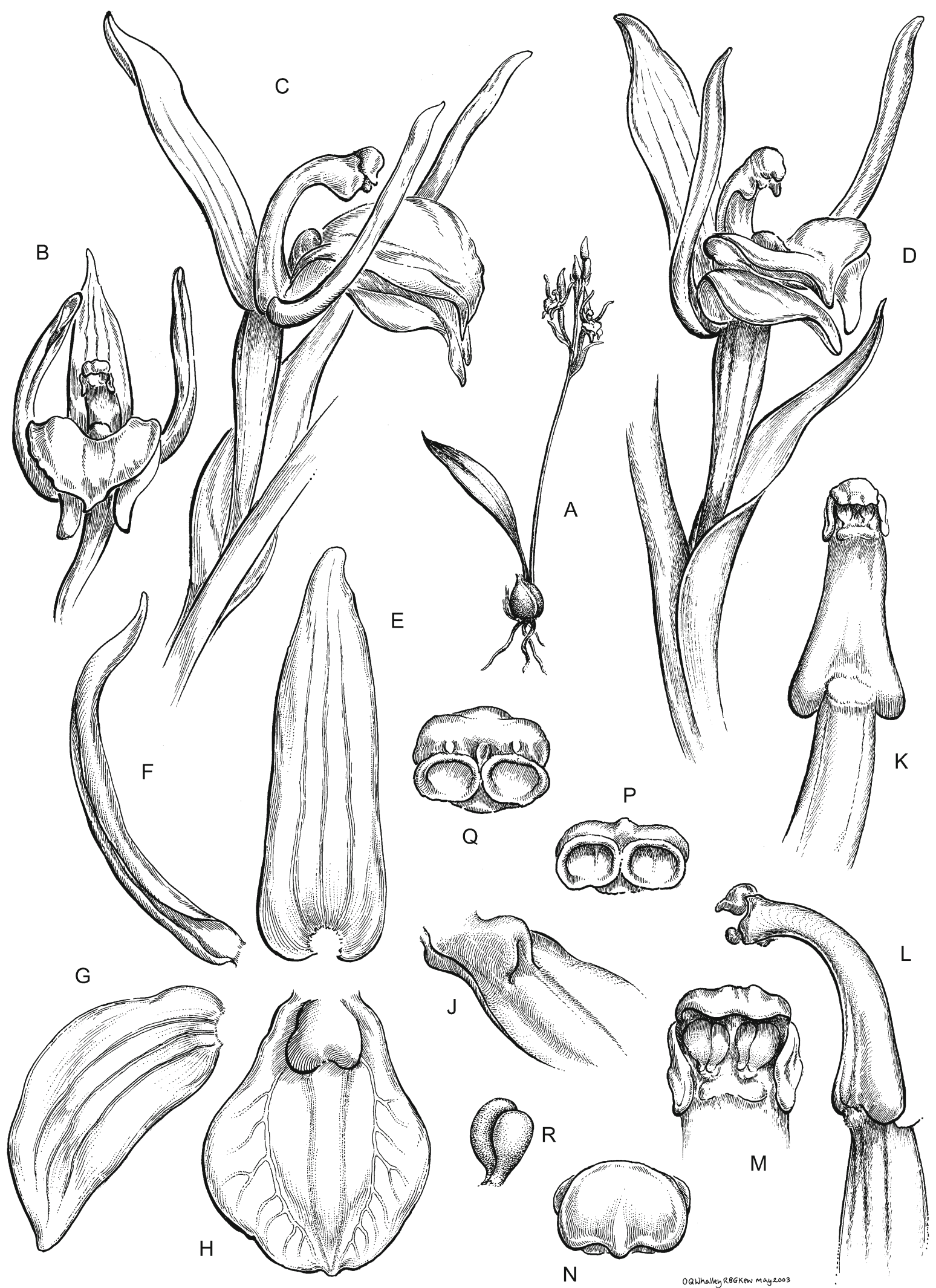

Fig. 61. Liparis scaposa. A plant habit $\times 1$.3; B flower, front view $\times 9$; C flower, side view $\times 12$; $\mathbf{D}$ flower, side front view $\times 12 ; \mathbf{E}$ dorsal sepal $\times 15 ; \mathrm{F}$ petal $\times 15$; G lateral sepal $\times 15 ; \mathrm{H}$ lip $\times 15$; J lip basal callus, side view $\times 15 ; \mathrm{K}$ column, front view $\times 15 ; \mathrm{L}$ column, side view $\times 15 ; \mathrm{M}$ column anther/stigma $\times 36$; $\mathbf{N}$ anther cap above $\times 39$; P anther cap behind $\times 39$; Q anther cap front underside $\times$ 39; R pollinia $\times$ 39. From Hermans $4973($ K). DRAWN BY OLIVER WHALLEY. 


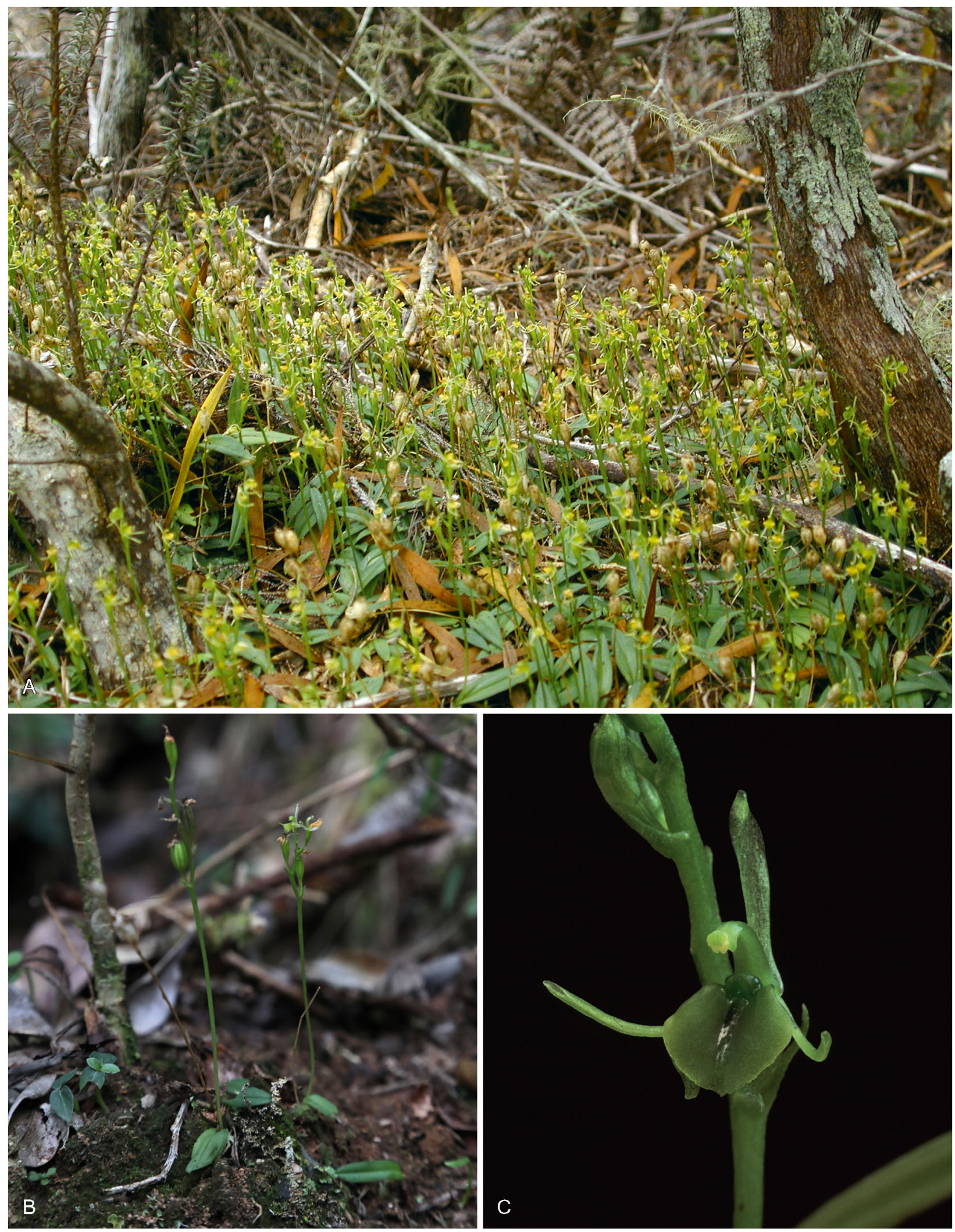

Fig. 62. Liparis scaposa. A plant habit in Réunion; B plants in Madagascar; C flower. PHOTOS: A PATRICE BERNET; B JEAN-MICHEL HERVOUET; C JOHAN HERMANS. 
leaves are more erectly spreading rather than horizontal, the leaves are ligulate (vs narrowly lanceolate in L. polycardia), the petiole longer, the inflorescence generally longer, the petals longer and the lip obcordate rather than obovate to suborbiculate. The species is similar in many respects to $L$. listeroides but differs in its longer pseudobulbs and the much longer ligulate leaves (vs oval-elliptic to broadly ligulate in L. listeroides), the lip is also broader in L. listeroides. It is also similar to L. danguyana but the plant is almost double the size, the leaves are narrowly lanceolate vs broadly oval and the anther is beaked vs rounded. Liparis stenophylla was until recently only known from the lower elevations of Northern Madagascar but has recently also been found in Eastern Forest near Ranomafana (Hermans 8213). Its distribution overlaps with $L$. listeroides which is usually confined to higher elevations.

DISTRIBUTION. Endemic to Northern Madagascar: Antsiranana, Fianarantsoa and Toamasina provinces (Map 45).

SPECIMENS EXAMINED. MADAGASCAR. Manongarivo massif, Perrier 8048 (lectotype P) \& Perrier 8045 (lectoparatype P); Andranompany, Brickaville distr., Ambalarondra, April 1951, 350 m, Cours 4514 (P); Toamasina, Ambanizana, Masoala Peninsula, $450 \mathrm{~m}$, May 1988, Lowry E Schatz 4487 (MO); NE, Masoala Peninsula, c. 470 m, Sept. 1993, Lance 14 (K); NE, Masoala Peninsula, 280 m, Lance 110 (K); Antsiranana, Anjanaharibe, Nov. 1994, Hermans 6544 \& 6547 (K); near Brickaville, Andranampony, 1999, Hermans 2426 (K); Toamasina, Ambohibary, Ambatovy, Analamay, 1074 m, Aug. 2011, Miandrimanana 514 (MO, P, TAN); Toamasina, Ambatovy: Alaotra-Mangoro Région, Moramanga Distr., 1080 - 1098 m, April 2012, Ramandimbisoa 207 (AMB843) (BRLU, MO, TAN); Fianarantsoa, Mahakajy, April 2018, Hermans 8213 (K). HABITAT. Dense, wet, evergreen forest, either terrestrial in shady undergrowth, in humus and mosses, lithophytic on moss-covered rocks or epiphytic. Altitude: $280-1100 \mathrm{~m}$.

FLOWERING TIME. November to August but mainly November to May.

CONSERVATION StATUS. Category VU: the extent of occurrence (EOO) of Liparis stenophylla is estimated to be $66,448 \mathrm{~km}^{2}$ (exceeding the limits for Vulnerable status under criterion B1) whereas its minimal area of occupancy (AOO) is estimated to be $24 \mathrm{~km}^{2}$ (which falls within the limits for Endangered status under the criterion B2). With six known subpopulations representing six locations (sensu IUCN), L. stenophylla has been preliminarily assessed as VU using the green listing method. This species is threatened by selective logging, timber harvesting for small-scale subsistence and tavy (slash-and-burn farming), resulting in habitat reduction and habitat quality reduction.

ETYMOLOGY. The name refers to the slender leaves.
NOTES. Schlechter (1924: 148) cited both Perrier 8045 and 8048 as types. Both are from the same locality in the Manongarivo Massif but collected a month apart. As Perrier 8048 is more complete it was chosen as the lectotype.

ILLUSTRATIONS. Figs 63, 64; Hervouet (2018: 420).

Liparis superclareae Hermans sp. nov. Type: Madagascar, Maroantsetra, Anjahana, Ambanizana, 120 m, June 2002, Antilahimena 1054 (holotype K; isotypes $\mathrm{MO}, \mathrm{P})$.

http:/ /www.ipni.org/urn:lsid:ipni.org:names:77201936-1

Erect, ascending, medium-sized, terrestrial plant, 15 $18 \mathrm{~cm}$ tall; rhizome woody c. $5-8 \times 4 \mathrm{~mm}$, covered in sheaths up to $2 \mathrm{~cm}$ long; roots somewhat villous, c. $2 \mathrm{~mm}$ diam. Pseudobulbs tubular, in a linear series, a single leaf at the apex, the previous year's growth leafless and carrying long fibrous remnants at the apex, apart from some short gaps, enveloped by brownish sheaths covered in brown specks, $5-9.5 \mathrm{~cm}$ long $2-5 \mathrm{~mm}$ diam. Leaf lanceolate, unequally cordate at the base, attenuate at the tip, strongly veined, $7.9-9.8 \times 2.9-4.1 \mathrm{~cm}$.

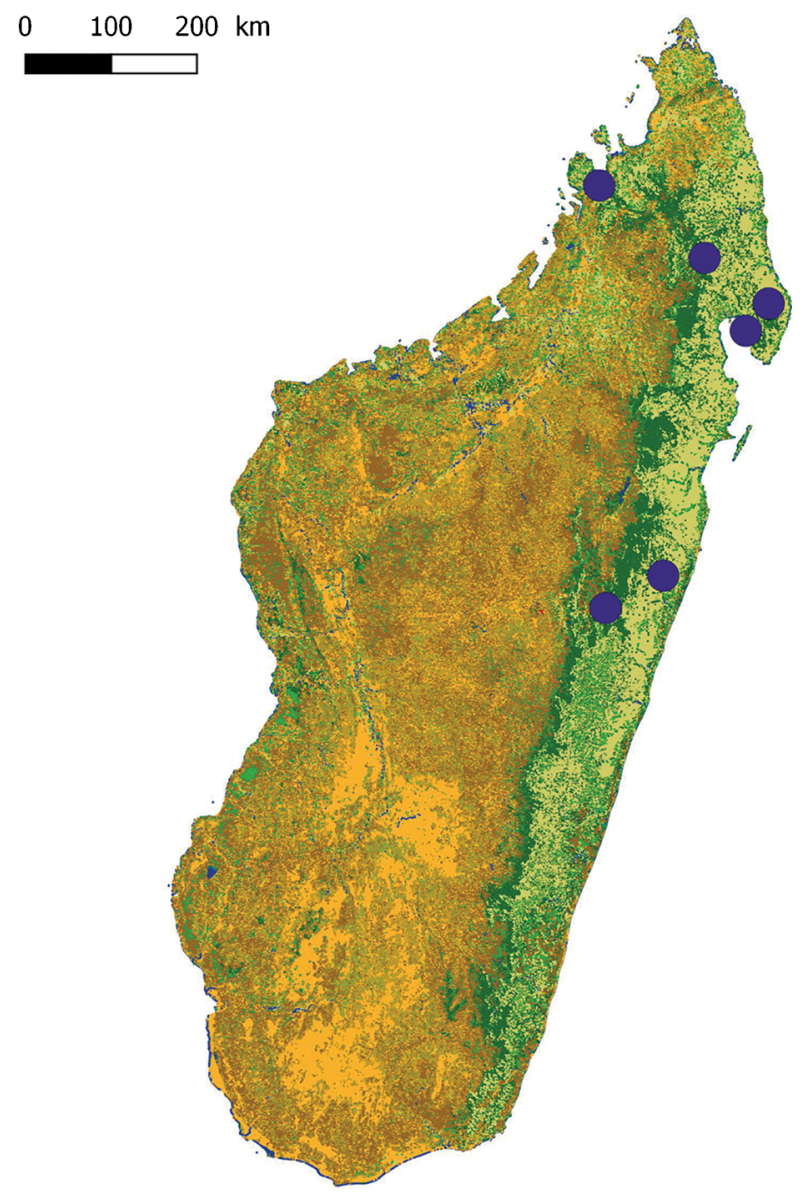

Map 45. Distribution of Liparis stenophylla. 

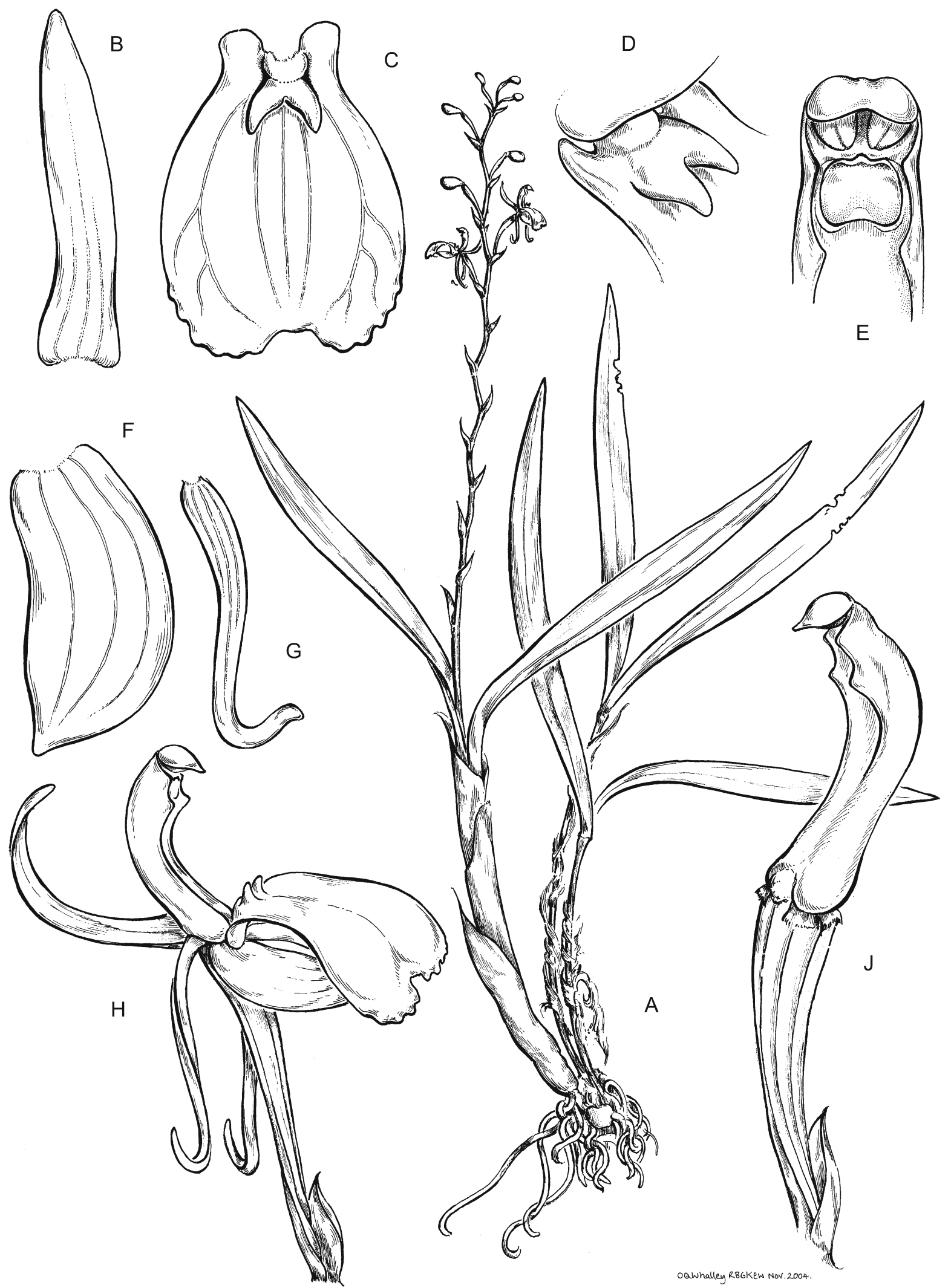

Fig. 63. Liparis stenophylla. A habit $\times 1$; B dorsal sepal $\times 12 ; \mathrm{C}$ lip $\times 12 ; \mathrm{D}$ lip with basal callus $\times 21$; $\mathrm{E}$ anther and stigma (top of column) $\times 21$; F lateral sepal $\times 12$; G petal $\times 12$; H flower $\times 12$; J column and ovary $\times 12$. From Perrier 8045 (P) \& Hermans 6547 (K). DRAWN BY OLIVER WHALLEY. 


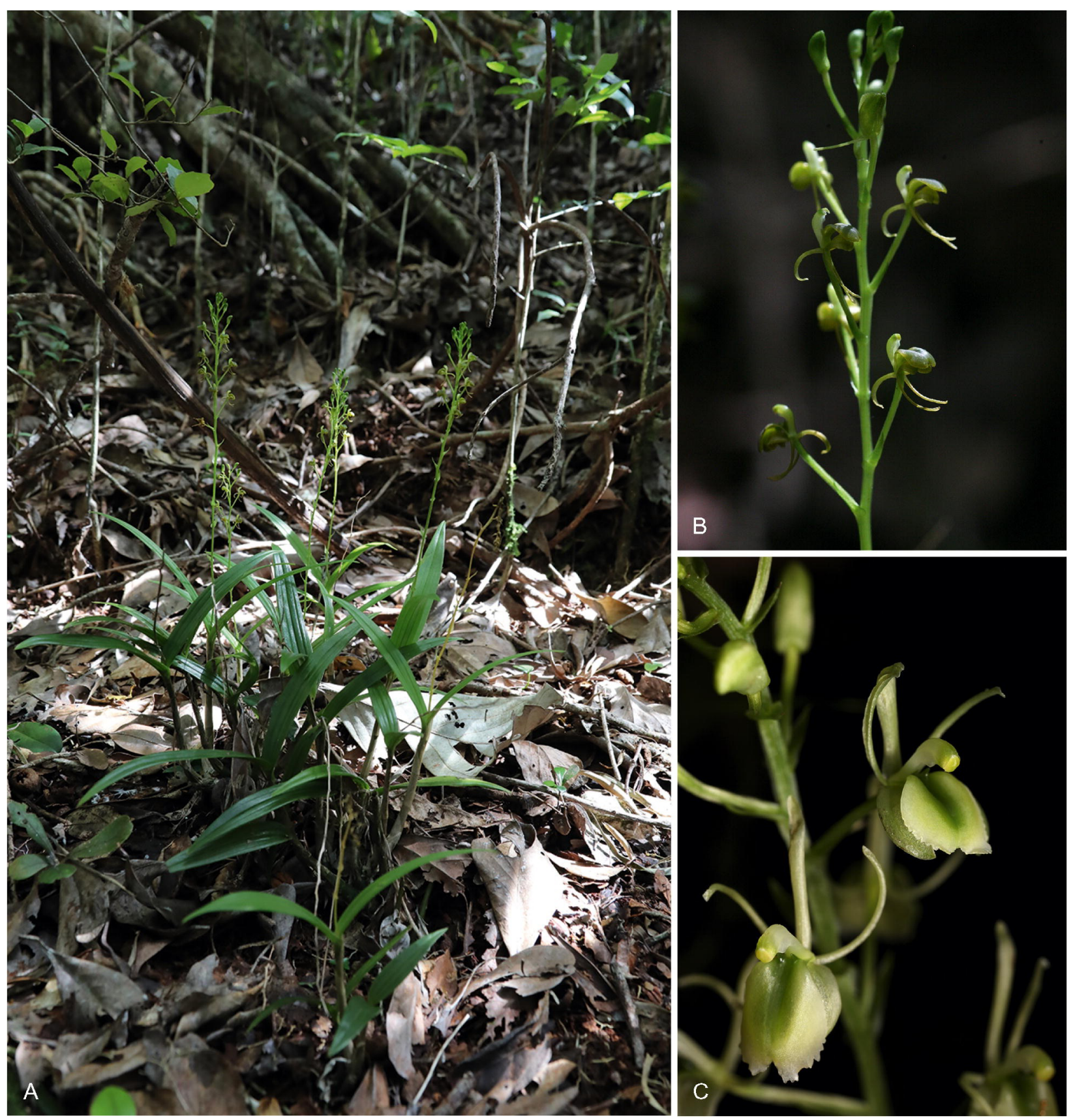

Fig. 64. Liparis stenophylla. A habit; B rachis; C flowers. PHOTOS: A, B JOHAN HERMANS; C JEAN-MiCHEL HERVOUET.

Inflorescence erect, far exceeding the leaf, 9 - $16 \mathrm{~cm}$ long, $1-2 \mathrm{~mm}$ in diam., carrying up to 6 flowers. Peduncle up to $10 \mathrm{~cm}$, about double the length of the raceme with $2-$ 4 sterile bracts, $9-11 \times 3-4 \mathrm{~mm}$. Rachis loosely racemose, up to $7 \mathrm{~cm}$ long, the lower flowers fading before the apical ones open. Floral bracts narrowly lanceolate, a little cordate at the base, $6-10 \times 1.2-2.8$ $\mathrm{mm}$. Flowers large, erectly spreading, up to $25 \times 18 \mathrm{~mm}$, sepals, petals and lip yellow, anther green, ovary white. Pedicel and ovary thin, curved, slightly winged, $12-16 \times$ $1.1-1.5 \mathrm{~mm}$. Dorsal sepal ligulate, narrowed towards the base, incurved, obtuse at the tip $15.5-18.2 \times 1.4-1.8$ $\mathrm{mm}$. Lateral sepals longly ovate, curved-falcate, $15.8-18.3$ $\times 4-6.3 \mathrm{~mm}$. Petals spreading, linear, expanded at the base, $17.6-19.1 \times 0.5-0.9 \mathrm{~mm}$. Lip longly-auriculate at the base, expanded into an elliptic blade angular at the base and dentate in the anterior margin, a short thickened central ridge at the base and slight swelling along the central vein, $15.2-16.1 \times 11-11.4 \mathrm{~mm}$. Column relatively short and thick for the genus, slightly curved, with very broad thin rounded wings, $4.9-6.1 \times$ $2.5-3.1 \mathrm{~mm}$. Anther strongly sharply beaked, around 
twice as long as wide, $1.5-2 \times 0.8-0.9 \mathrm{~mm}$. Pollinia 2 , ovoid, c. $5 \times 3 \mathrm{~mm}$.

RECOGNITION. Liparis superclareae has tubular pseudobulbs, covered by brown sheaths, a single, lanceolate leaf, disintegrated on previous growth, and very large flowers, with an elliptic lip, dentate at the margins with a thickened ridge at the base, and a relatively short and broad, widely winged column, with a very long sharp beaked anther.

Liparis superclareae is close to $L$. clareae with which it shares the general habit and lip shape but the new species has much longer pseudobulbs, the leaves of the previous growth disintegrate before the new ones develop (vs persistent), its leaves are lanceolate (vs ovate) and are at least $2.5-3$ times longer than wide (vs 2 times), the floral bracts are less cordate at the base, the flowers and all its segments much larger, the column shorter with broad long wings (vs shortauriculate) and the anther much more sharply beaked. It is also similar to $L$. warpurii with which it shares the leaf and lip shape but the new species has a more linear plant habit (vs scrambling), the leaves of the previous growth disintegrate before the new ones develop (vs persistent), the floral bracts are less cordate at the base, the flowers and all its segments much larger, the lip has a thickened ridge (vs rounded callus), the column is short and broadly winged (vs shortly obtuse) and the anther much more beaked. It differs from L. magnifica and L. laurentii, described above, by its much larger size, shape of the lip, callus and anther, as shown in Table 8.

DISTRIBUTION. Endemic to Madagascar: known from the type only from Maroantsetra in Toamasina province (Map 46).

SPECIMENS EXAMINED. MADAGASCAR. Maroantsetra, Anjahana, Ambanizana, 120 m, June 2002, Antilahimena 1054 (holotype K, isotypes $\mathrm{P}, \mathrm{MO}$ ).

HABITAT. Humid forest. Altitude: c. $120 \mathrm{~m}$.

CONSERVATION STATUS. Category CR: The extent of occurrence (EOO) of Liparis superclareae cannot be estimated since it is only known from one subpopulation whereas its minimal area of occupancy (AOO) is estimated to be $4 \mathrm{~km}^{2}$ (which falls within the limits for Critically Endangered status under the criterion B2). Liparis superclareae is only known from one subpopulation representing one location (sensu IUCN), this rare species has thus been preliminarily assessed as CR using the green listing method. This species is threatened by selective logging, timber harvesting for small-scale subsistence and tavy (slash-and-burn farming), resulting in habitat reduction and habitat quality reduction.

FLOWERING TIME. May to June.

ETYMOLOGY. Referring to the much larger size of plant and flower compared with Liparis clareae.

NOTES. Liparis superclareae is currently only known from the type specimen collected by Patrice Antilahimena in Maroantsetra. The collection consists of several flowering plants with type material in $\mathrm{K}, \mathrm{P}$ and $\mathrm{MO}$. The species overlaps in distribution with $L$. clareae which is more common in central Eastern forests. It could be considered a lower altitude, larger-flowered local form of this species but the pronounced deciduous habit, pseudobulb, leaf-shape and the shape of the column and anther make it distinct enough to be considered a distinct species.

ILLUSTRATION. Fig. 65.

Liparis trulliformis Schltr. (Schlechter 1924: 149); Perrier (1939: 293); Hermans et al. (2007: 224); Cribb \& Hermans (2009: 156). Type: Madagascar, Mt Tsaratanana, Perrier 15744 (holotype P).

Small erect epiphytic plant up to $7 \mathrm{~cm}$ high, flowering growth emerging directly from the base of the leafless previous growth which is divergent to decumbent, roots flexuose, more or less villous. Pseudobulbs short, oblong, cylindrical, covered by sheaths and the base of the lower leaf, less than $2 \mathrm{~cm}$ tall and $10 \mathrm{~mm}$ diam., with $2-3$ leaves in the upper half. Leaves erectly spreading, plicate, elliptic-acuminate, with a long

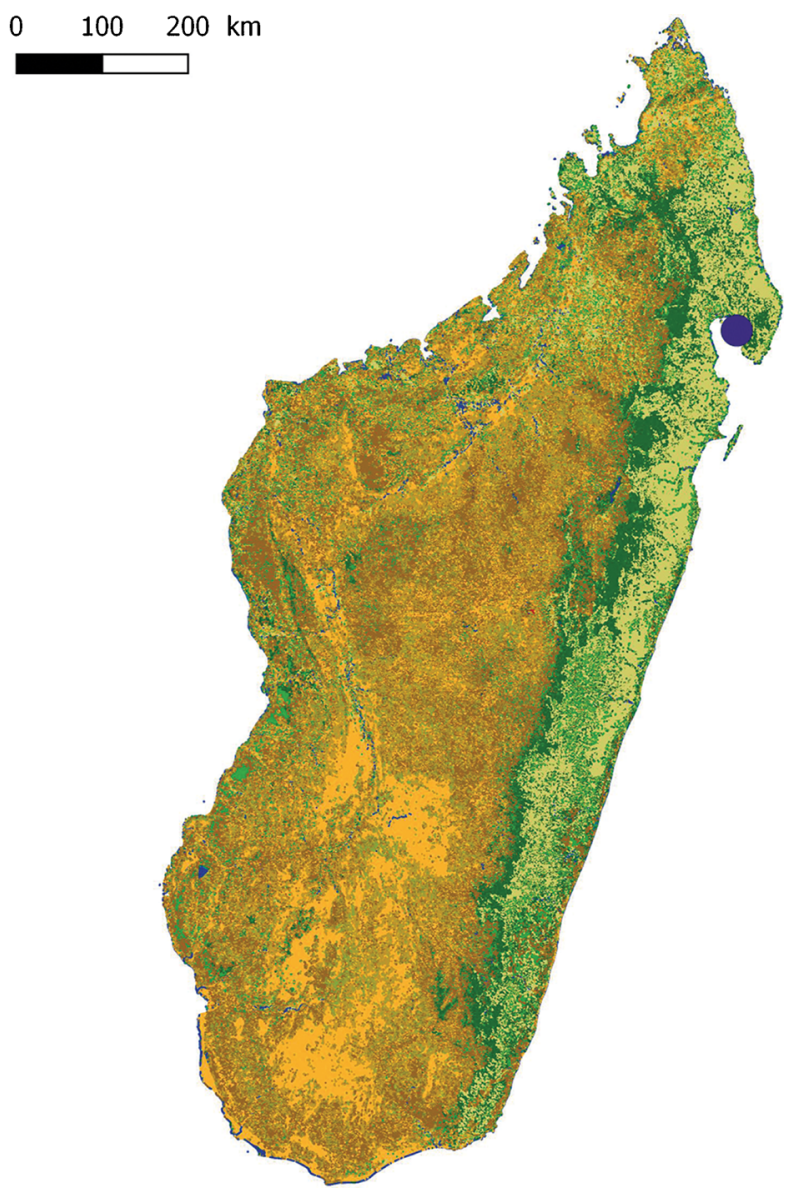

Map 46. Distribution of Liparis superclareae. 


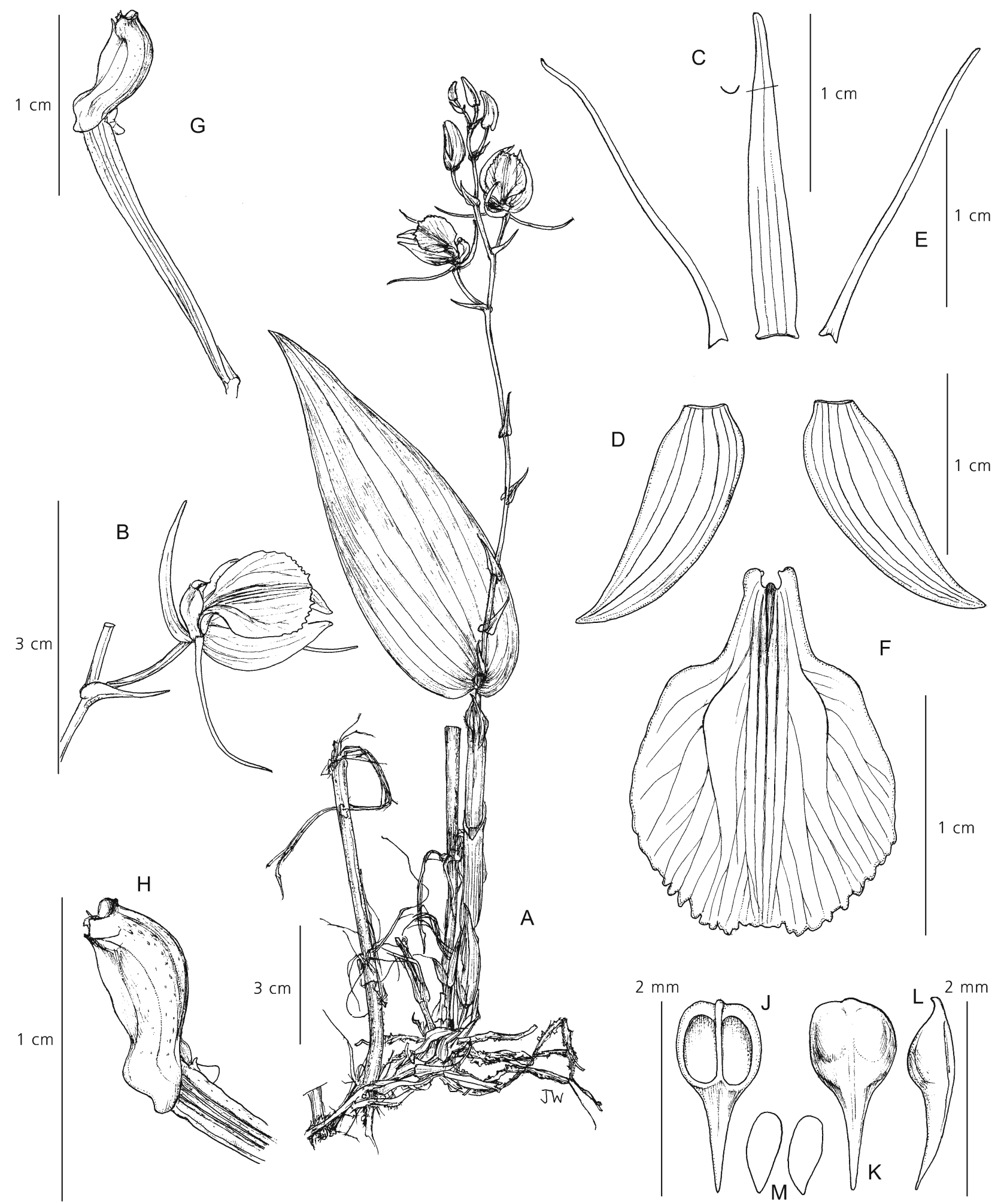

Fig. 65. Liparis superclareae. A habit; B flower; C dorsal sepal; D lateral sepal; E petal; F lip; G column and ovary; $\mathrm{H}$ column, side view; J anther cap from below; K anther cap from above; L anther cap from side; M pollinia. From Antilahimena 1054 (K). DRAWN BY JULIET BEENTJE.

sheath-like narrow petiole, $3.4-4.9 \times 1.3-2.1 \mathrm{~cm}$. Inflorescence up to $8 \mathrm{~cm}$ long, surpassing the leaves. Peduncle about half the length of the inflorescence, with $2-3$ lanceolate bracts. Rachis sub-densely $5-6$ flowered. Floral bracts erectly spreading, lanceolate acute to acuminate, lower one longer than those at 
the apex, $4-6.1 \times 2.3-2.6 \mathrm{~mm}$. Flowers erectly spreading, small, c. $14 \times 8 \mathrm{~mm}$, greenish-yellow. Pedicel and ovary glabrous, a little ridged, c. $9 \times 1 \mathrm{~mm}$. Dorsal sepal erect, ligulate-lanceolate, obtuse with the base shortly auriculate, $7.1-8.1 \times 0.9-1 \mathrm{~mm}$. Lateral sepals porrect, obliquely-oblong, obtuse, $6.8-7.1 \times 2.3-2.5$ $\mathrm{mm}$. Petals narrowly linear, margins recurved, a little spathulate at the apex, $6.3-6.5 \times 0.4-0.6 \mathrm{~mm}$. Lip slightly curved, ovate-trullate, a little expandedangular towards the lower third, then slightly contracted towards the upper third and rounded at the top, a little dentate around the margins, base very slightly auriculate, on top with a small bipartite flattened callus, $6-6.3 \times 3.1-3.3 \mathrm{~mm}$. Column curved, wings indistinct, $3 \times 0.8 \mathrm{~mm}$. Anther ovoid, distinctly beaked, a little blunt at the tip, c. $1 \times 0.6 \mathrm{~mm}$.

RECOGNITION. Liparis trulliformis is a small squat plant with elliptic plicate leaves, the new growth emerges from the disintegrating divergent or decumbent previous growth, an inflorescence with a few small flowers. Its flowers have an ovate-trullate lip, almost twice as long as wide, with a flattened bifold callus at the base, and a strongly and bluntly beaked anther.

Liparis trulliformis is somewhat similar to L. bathiei but different by the longer pseudobulbs, prominent plicate leaves, trowel-shaped lip which is almost twice as long as wide. It is also close to L. bosseri described above but the lip of $L$. bosseri is obovate (vs ovatetrullate), lacks a distinct callus at the base of the lip and has an anther with a spathulate beak vs a sharp beak.

DISTRIBUTION. Endemic to Madagascar: Antsiranana province only (Map 47).

SPECIMEN EXAMINED. MADAGASCAR. Mt Tsaratanana, Perrier 15744 (holotype P).

HABITAT. Epiphyte in forest. Altitude: c. $1800 \mathrm{~m}$.

CONSERVATION STATUS. Category CR: the extent of occurrence (EOO) of Liparis trulliformis cannot be estimated since it is only known from one subpopulation whereas its minimal area of occupancy (AOO) is estimated to be $4 \mathrm{~km}^{2}$ (which falls within the limits for Critically Endangered status under the criterion B2). Liparis trulliformis is only known from one subpopulation representing one location (sensu IUCN), this rare species has thus been preliminarily assessed as CR using the green listing method. This species is threatened by selective logging, timber harvesting for small-scale subsistence and tavy (slashand-burn farming), resulting in habitat reduction and habitat quality reduction.

FLOWERING TIME. January.

ETYMOLOGY. Referring to the trowel shape of the lip.

NOTES. Known from the type specimen only, collected by Perrier in 1923 on Mt Tsaratanana close to the type locality of Liparis zaratananae (the collecting numbers are consecutive). Only four plants grew in the colony and two were collected and sent to Schlechter in 1923 who described it a year later together with several other Liparis. These might be juvenile plants of another species, but as it comes from a fairly underexplored area it has been decided to recognise the species until more information becomes available.

ILLUSTRATION: Fig. 66.

Liparis vulturiceps Hermans $\mathcal{E}$ P.J.Cribb (2014: 9517: 4); Hervouet (2018: 421). Type: Madagascar, Toamasina, Akanin'ny Nofy (Lake Ampitabe), Nov. 1997, Hermans 4187 (holotype K).

Medium-sized erect terrestrial or epiphytic plant, up to $20 \mathrm{~cm}$, with a short rhizome; roots $2-3 \mathrm{~mm}$ diam., woolly. Pseudobulbs 8 - $18 \mathrm{~cm}$ long, 5 - $7 \mathrm{~mm}$ diam., caespitose, 2 - 3-leaved, largely covered by thin overlapping greenish-brown sheaths, $20-25 \mathrm{~mm}$ long. Leaves ovate, $2-8.2 \times 1.5-4 \mathrm{~cm}$, glossy, dark green with a short $5-10 \mathrm{~mm}$ petiole. Inflorescence terminal from the centre of the leaves of the new growth, 50 - $65 \mathrm{~mm}$ long, with $2-6$ flowers. Peduncle ridged, 2 - $3 \mathrm{~mm}$ diam., pale green, with a scale $8 \times 2-3$

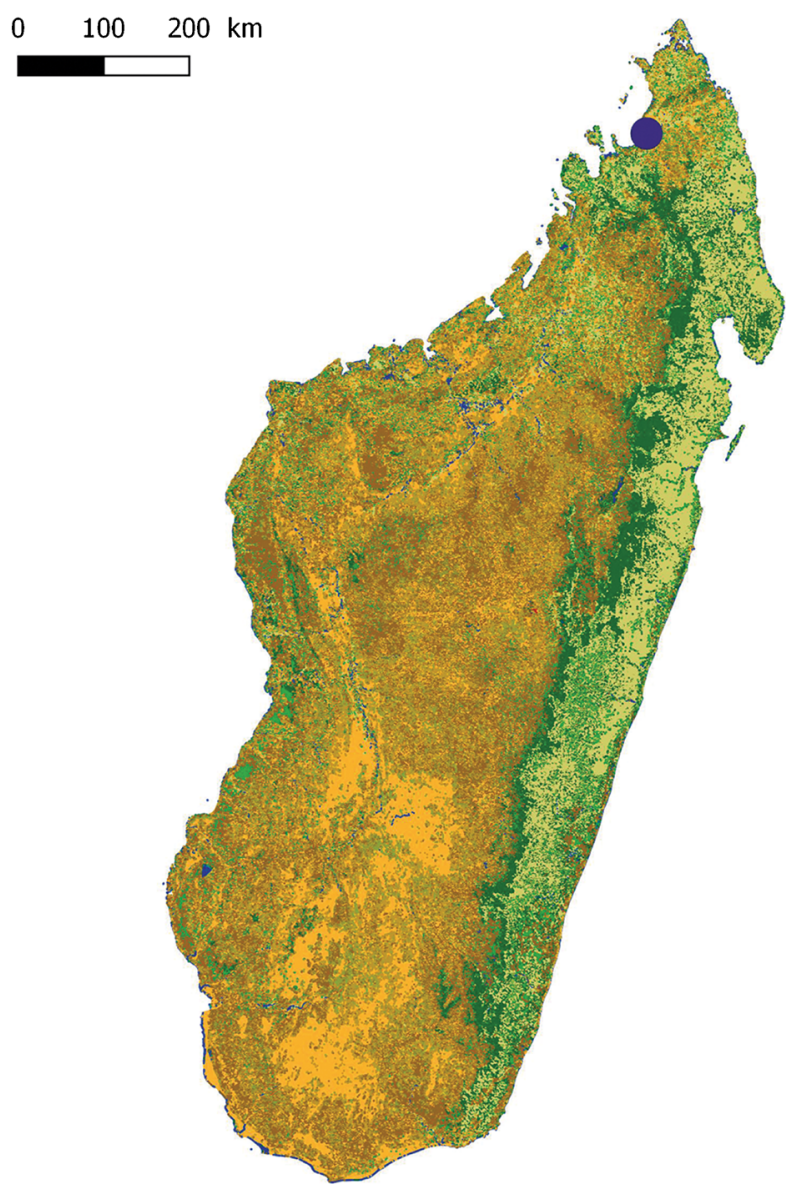

Map 47. Distribution of Liparis trulliformis. 


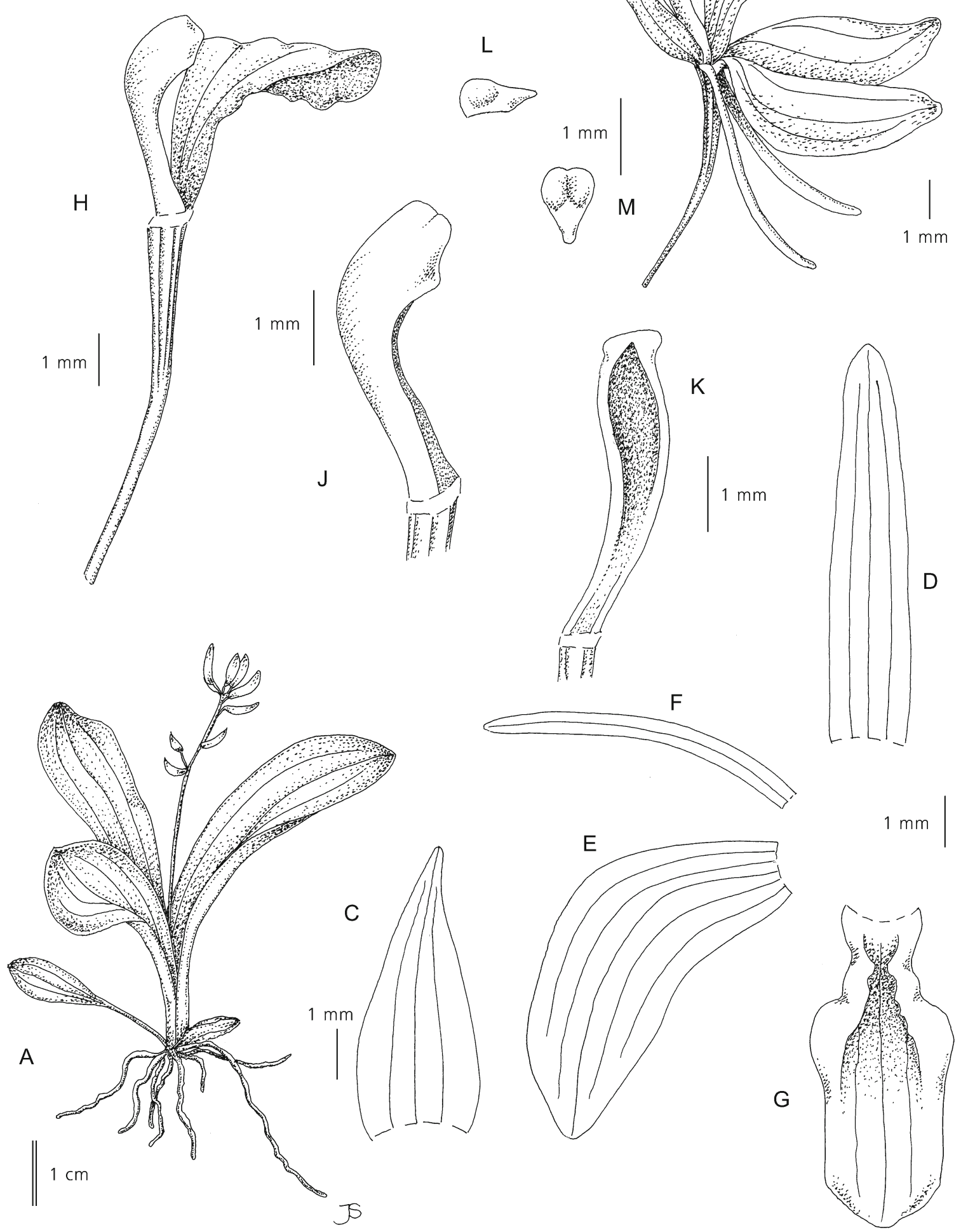

Fig. 66. Liparis trulliformis. A habit; B flower: C floral bract; D dorsal sepal; E lateral sepal; F petal; G lip; H column and lip, side view anther cap removed; J column, side view, anther cap removed; K column, front view; L anther cap, side view; M anther cap, dorsal view. From Perrier 15744. DRAWN BY JUDI STONE. 
$\mathrm{mm}$. Rachis $3-5 \mathrm{~cm}$ long. Floral bracts lanceolate $5-$ $6 \times 2-2.5 \mathrm{~mm}$. Flowers medium in size, $14 \times 9 \mathrm{~mm}$, pale green becoming ochre with age, petals and column paler, main callus on lip dark green, the anther white, pollinia yellow. Pedicel and ovary twisted, smooth, pale green, $13-16 \times 1-1.5 \mathrm{~mm}$. Dorsal sepal strongly recurved against the ovary, linear, acuminate, $12-15 \times 2-2.5 \mathrm{~mm}$. Lateral sepals auriculate, the outer margin distinctly recurved, $10-13 \times 5.5-6 \mathrm{~mm}$. Petals folded against the back of the flower, linear, acuminate, $12-14 \times$ $1-1.2 \mathrm{~mm}$, margins recurved. Lip pandurate, 11 $13 \times 7-8 \mathrm{~mm}$; lateral lobes rounded, small; midlobe flabellate, large with the anterior margin distinctly undulate; callus basal, large, 3-lobed, 3 $5 \mathrm{~mm}$ long, its basal lobes rounded, erect, the midlobe clavate. Column erect, incurved in the apical half, wings expanded over the upper third becoming distinctly falcate at the tip, $4.5 \times 2.3 \mathrm{~mm}$. Anther oblanceolate, strongly ridged, with a short beak, $2 \times$ $0.7 \mathrm{~mm}$. Pollinia 2, pyriform, elongate, $0.9 \times 0.3 \mathrm{~mm}$.

RECOGNITION. This is a medium-sized plant with a long thin pseudobulb and two (rarely three) fleshy leaves at the top, around five medium flowers with strongly recurved petals and dorsal sepals, petals auriculate and parallel with the lip, lip pandurate with a long rounded callus at the base, column with falcate wings.

The habit of the plant is somewhat similar to other bifoliate Liparis, including L. bernieri, L. listeroides and L. longicaulis, but its pseudobulbs are generally shorter and the leaves thicker. The lip shows some similarity to that of $L$. ochracea, L. longicaulis and $L$. puncticulata but the habit, flower, lip calli and falcate column wings are all very different, as explained in Hermans \& Cribb (2014: 4).

DISTRIBUTION. Endemic to Madagascar: Toamasina and Fianarantsoa provinces (Map 48).

SPECIMENS EXAMINED. MADAGASCAR. Toamasina, Akanin'ny Nofy (Lake Ampitabe), 1 Nov. 1997, Hermans 4187 (holotype K); Toalanara, N of Ezoanbo, Beentje et al. 4602 (K).

HABITAT. Found in Eastern Madagascar, in degraded humid evergreen forest in leaf litter in dense shade. In leaf litter or on moss-covered tree-trunk. Altitude: around $1000 \mathrm{~m}$.

CONSERVATION STATUS. Category EN: the extent of occurrence (EOO) of Liparis vulturiceps is estimated to be $38,236 \mathrm{~km}^{2}$ (exceeding the limits for Vulnerable status under criterion B1) whereas its minimal area of occupancy (AOO) is estimated to be $16 \mathrm{~km}^{2}$ (which falls within the limits for Endangered status under the criterion B2). With only four known subpopulations representing four locations (sensu IUCN), this rare species has been preliminarily assessed as EN using the green listing method. This species is threatened by selective logging, timber harvesting for small-scale subsistence and tavy (slash-and-burn farming), resulting in habitat reduction and habitat quality reduction.

FLOWERING TIME. November to March.

ETYMOLOGY. Refers to the vulture-like appearance of the flower.

ILLUSTRATIONS. Figs 67, 68 and 69; Hermans \& Cribb (2014: 69-9517), Hermans (2015: 247), Hermans (2016: 4); Hervouet (2018: 421).

Liparis warpurii Rolfe as L. warpuri (Rolfe 1908: 69); Perrier (1939: 262); Hermans et al. (2007: 224); Cribb \& Hermans (2009: 146). Types: Madagascar, 10 June 1900, Warpur s.n. (lectotype K, designated here; lectoparatypes Warpur 473 (K000242145) K; drawing of Warpur 473, 1906 K.)

Liparis clareae Hermans var. angustifolia H.Perrier ex Hermans (in Hermans et al. 2007: 217, 289); Cribb \& Hermans (2009: 146); (Hervouet 2018: 406), synon. nov. Type: Madagascar, confl. Mangoro \& Onive, Perrier 17018 (holotype P).

Liparis cardiophylla var. angustifolia H.Perrier (1936: 244; 1939: 269) nom. nud.

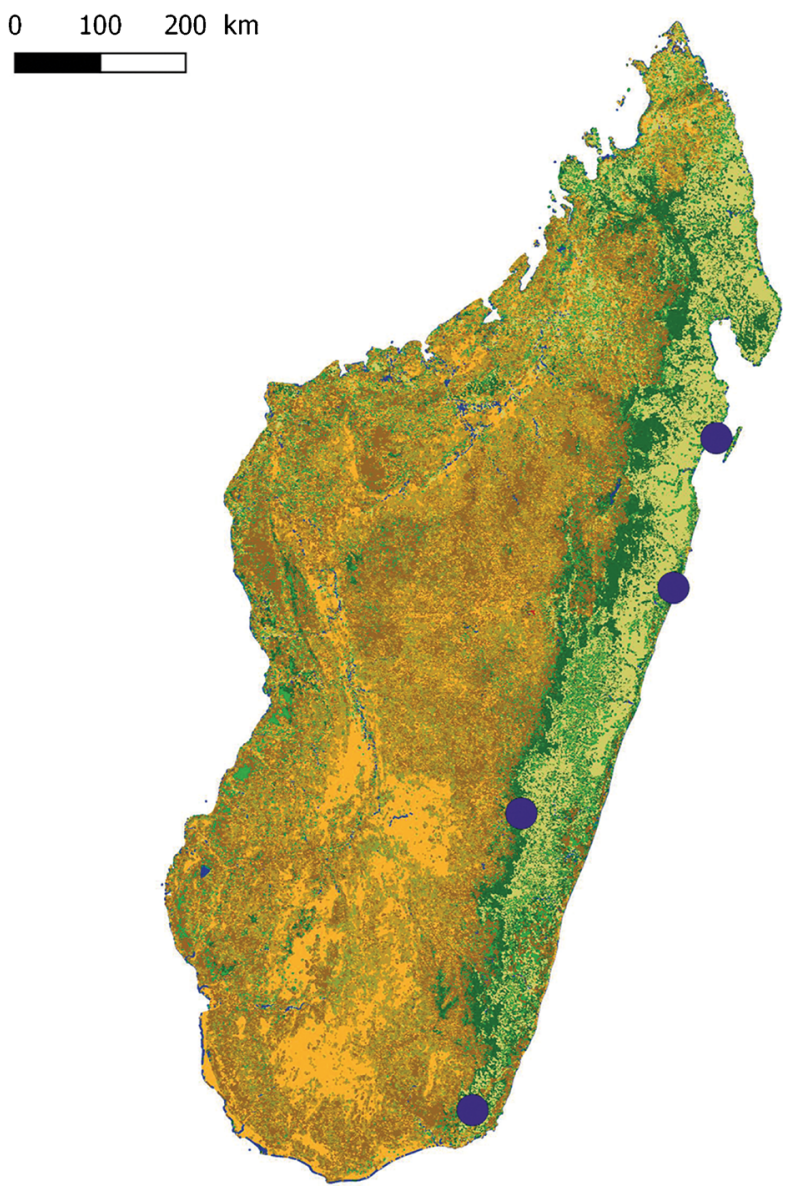

Map 48. Distribution of Liparis vulturiceps. 


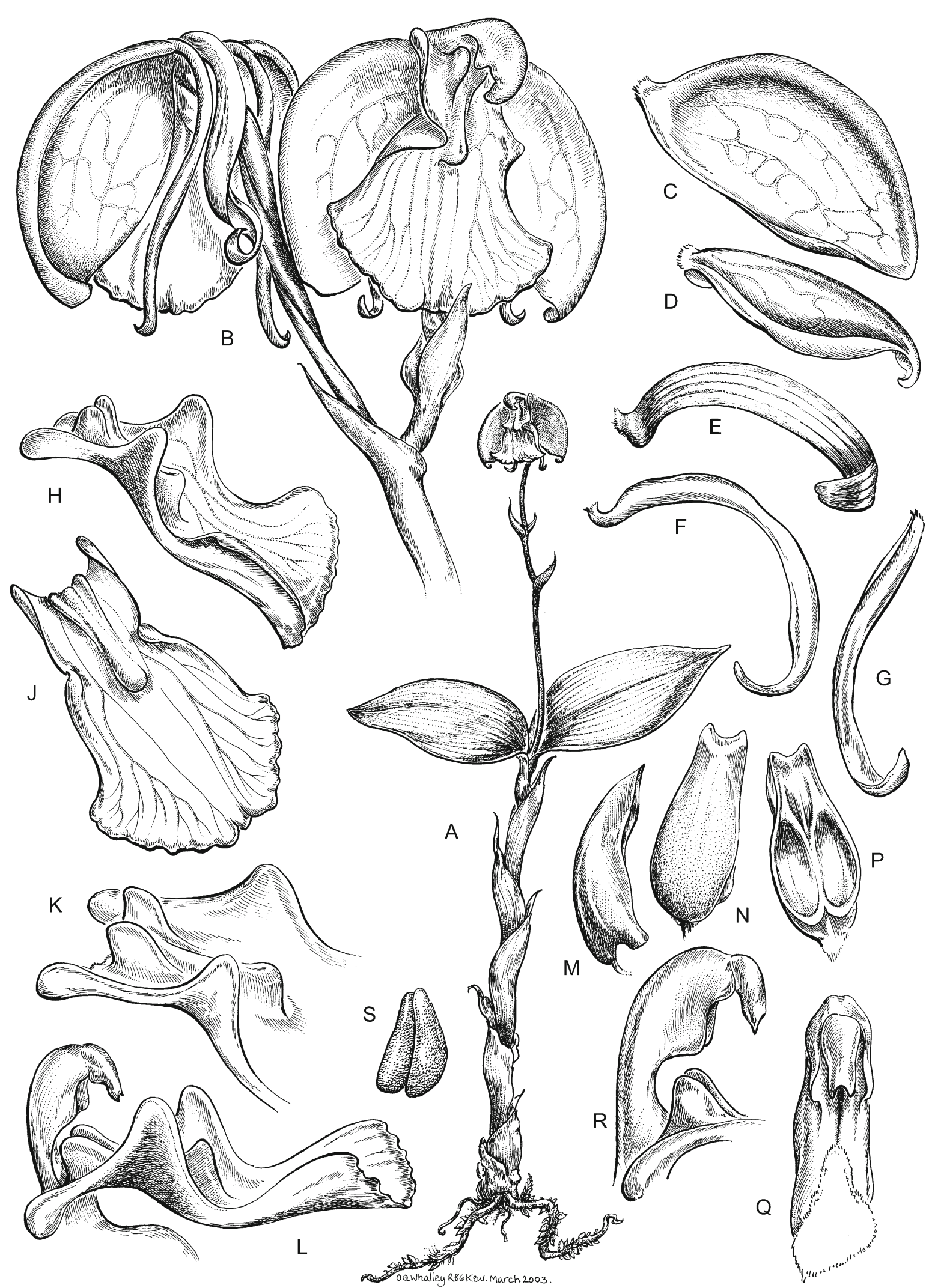

Fig. 67. Liparis vulturiceps. A habit $\times 1.3 ; \mathbf{B}$ inflorescence $\times 4.5 ; \mathrm{C} \& \mathrm{D}$ lateral sepal $\times 6$; $\mathrm{E}$ dorsal sepal $\times 6$; $\mathrm{F}, \mathrm{G}$ petal $\times 6$; $\mathrm{H}$ lip, side view $\times 6$; J lip from above $\times 6$; K lip basal callus $\times 9$; L lip and column from side $\times 6$; M anther cap, side view $\times 21 ; \mathrm{N}$ anther cap from above $\times 21$; $\mathbf{P}$ anther cap underneath $\times 21$; Q column, front view $\times 9$; R column and callus, side view $\times 9$; $\mathbf{S}$ pollinia $\times 21$. From Hermans 4187 (K). DRAWN BY OLIVER WHALLEY. 


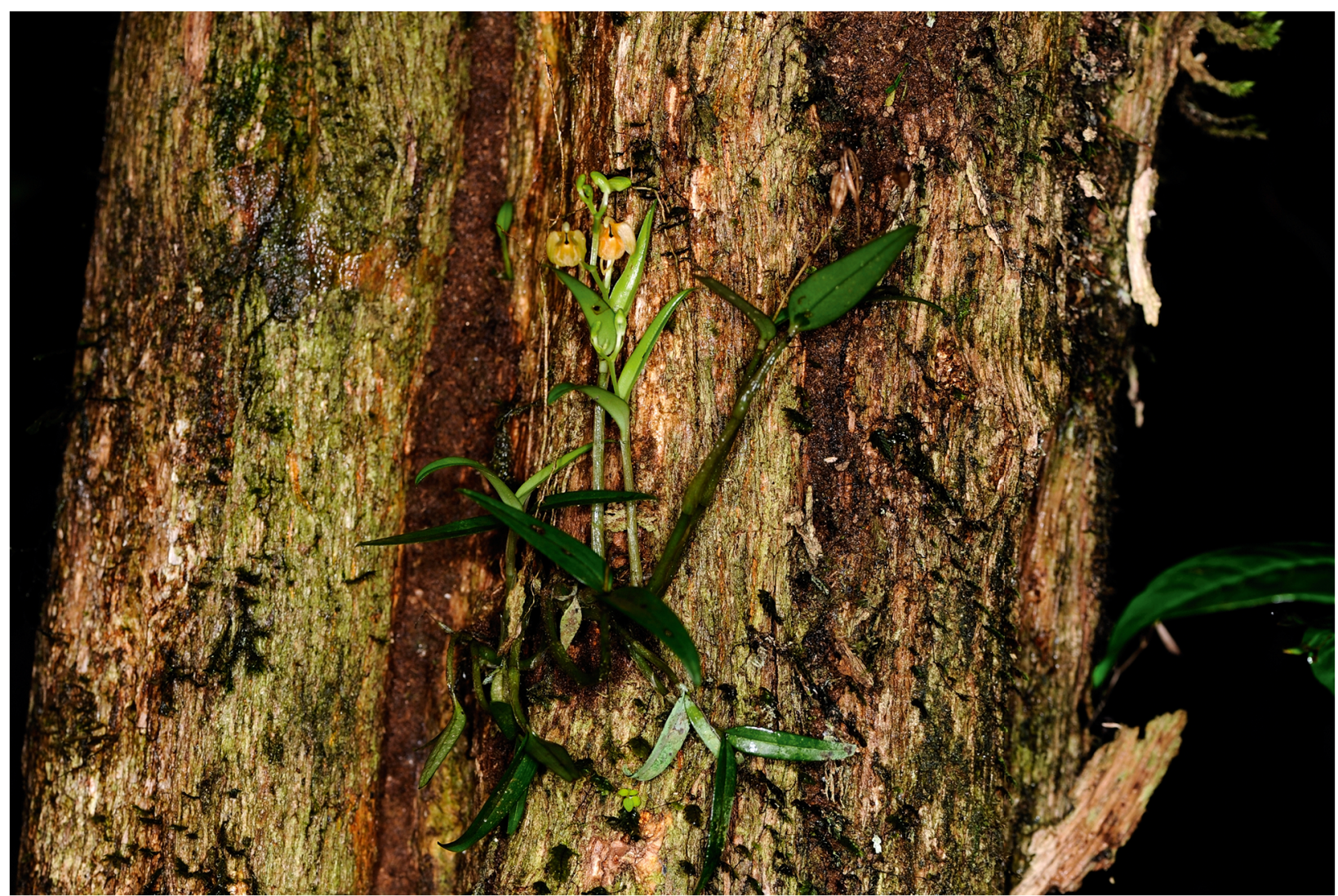

Fig. 68. Liparis vulturiceps. Habit. PHOTO: MORITZ GRUBENMANN.

Small scrambling terrestrial plant up to $10 \mathrm{~cm}$ high, on a long rhizome with new growths often from internodes of the previous pseudobulb, roots flexuose, hairy. Pseudobulbs slender, dark green, sometimes speckled dark brown, almost entirely enveloped by several long brownish papery imbricate sheaths, overall up to $50 \times 7$ $\mathrm{mm}$, with a single leaf at the apex. Leaf almost sessile, narrowly ovate, acute, subconduplicate, a little cordate at the base, glaucous on the upper surface, green underneath, sometimes partly mottled or entirely silvery, 2.5 $6.5 \times 1-2.5 \mathrm{~cm}$. Inflorescence slender, erect, up to $6 \mathrm{~cm}$ long, up to 4 flowers towards the apex but usually fewer. Peduncle about $1 / 2$ the length of the inflorescence, with one or two sterile bracts. Rachis loosely few-flowered. Floral bracts sessile, cordate, acuminate, $4.1-8 \times 1.6-3.5$ $\mathrm{mm}$. Flowers large, up to $21 \times 18 \mathrm{~mm}$, all segments pale yellowish-green except for the lip which has a much darker emerald green disk, column cream, anther cap pale yellow. Pedicel and ovary slender, slightly winged, 8 $12 \times 1.5-2 \mathrm{~mm}$. Dorsal sepal linear, erect, the margins recurved, $9.3-9.9 \times 0.8-1.6 \mathrm{~mm}$. Lateral sepals falcateoblong, obtuse, parallel with the lip, margins a little recurved, $8.5-12 \times 3.1-4.1 \mathrm{~mm}$. Petals divergent, filiform, margins recurved, $7.7-10.4 \times 0.3-1 \mathrm{~mm}$. Lip slightly curved, shortly unguiculate, obovate, denticulate at the anterior margin, disk thickened, with a small rounded, often bilobed or trilobed callus at the base, 6.9 - $10 \times 5.9-9.2 \mathrm{~mm}$. Column incurved, wings shortly obtuse, $4.1-6 \times 0.8-0.9 \mathrm{~mm}$. Anther obovoid, obtusely beaked at the front, c. $1.2 \times 1 \mathrm{~mm}$. Pollinia 2, bipartite, obovoid c. $0.7 \times 0.6 \mathrm{~mm}$

RECOGNITION. Liparis warpurii is a small scrambling plant with a thin pseudobulb and a single narrowly ovate leaf, few-flowered inflorescence and floral bracts that are cordate at the base. It has large flowers, with a shortly unguiculate, obovate lip, serrate at the front, small rounded callus at base, and a bluntly beaked anther.

Rolfe indicated that Liparis warpurii was close to L. parva but it is very different being a much larger plant (L. parva is c. $4 \mathrm{~cm}$ ), single-leaved (vs two-leaved) and has a different inflorescence and flowers. The closest species is L. magnifica, described above, but it differs by the foliage which is not longitudinally streaked with silverywhite, the cordate peduncle sheaths and floral bracts (vs lanceolate in L. magnifica), the flowers about double the size, a less curved and angular lip (vs obovate), with a dentate margin (vs undulate), and a less sharply beaked anther. It is similar to $L$. clareae but differs in having narrower leaves, more numerous flowers (three to five), longer sepals, a larger lip, with a rectangular blade and a disk with a more distinct rounded callus at the base, a taller column and a smaller anther, the beak being wider 


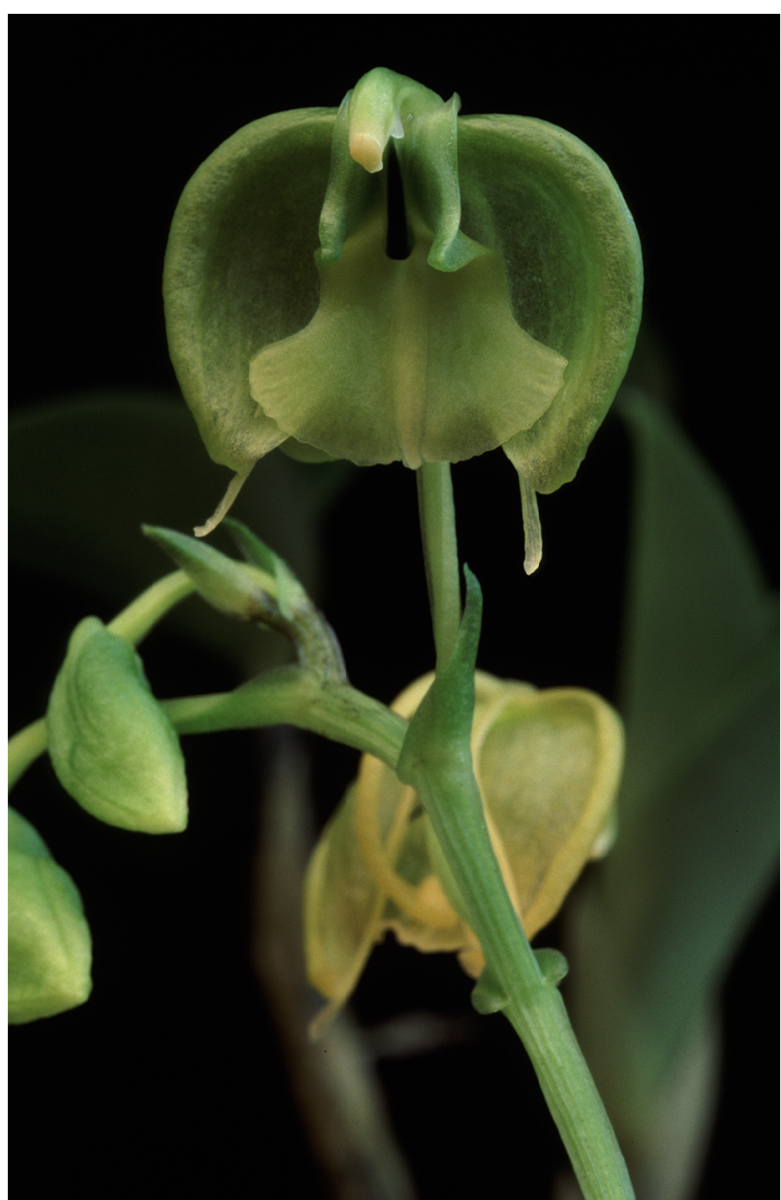

Fig. 69. Liparis vulturiceps. Flower. PHOTO: JOHAN HERMANS.

and more obtuse. It is similar to L. laurentii, described above, but the leaf of $L$. laurentii is broadly ovate (vs lanceolate), the flowers are smaller, the lip not serrate at the margins and with horn-like calli (vs a single rounded callus) (Table 8).

DISTRIBUTION. Endemic to Madagascar: Toamasina Province (Map 49).

SPECIMENS EXAMINED. MADAGASCAR. Warpur s.n., 10 June 1900 (lectotype K); Warpur 473 (K000242145) (lectoparatype K); drawing of Warpur 473, 1906 (K); s. loc., Oct. 1899, Warpur s.n. (K); Tamambe, Tsilohan'ala, June 1900, Warpur s.n. (K); Eastern forest, near the confluence of the Mangoro \& Onive, c. 700 m, Feb. 1925, Perrier 17018 (P); s. loc., Bogner s.n. (K-spirit 31440); Toamasina, fokontany Ampitabe, Ambatovy, 1051 m, July 2008, Randrianasolo et al. 760 (MO, P, TAN); Toamasina, Ambohibary, Ampitambe, Forêt d'Ampangadiantrandraka, 1010 m, Oct. 2009, in fruit, Ravelonarivo et al. 3283 (MO, P, TAN); Toamasina, Ambatovy, $1050 \mathrm{~m}$, March 2012, Stévart et al. 4119 (BRLU, K, MO, TAN); Ambatovy: Région AlaotraMangoro, Distr. Moramanga, 1054 - 1119 m, March 2013, Ambatovy Spirit Collection 765 (TAN).

HABITAT. Epiphyte or terrestrial in wet Eastern forest, moss and lichen-covered trees, in soil. Altitude: $700-$ $1100 \mathrm{~m}$.

CONSERVATION STATUS. Category EN: the extent of occurrence (EOO) of Liparis warpuri is estimated to be $1,812 \mathrm{~km}^{2}$ (which falls within the limits for Endangered status under criterion B1) and its area of occupancy (AOO) is estimated to be $12 \mathrm{~km}^{2}$ (which falls within the limits for Endangered status under the criterion B2). With only three subpopulations representing three locations (sensu IUCN), this species has been preliminarily assessed as EN using the green listing method. This species is threatened by mining activities, selective logging, timber harvesting for small-scale subsistence and tavy (slash-and-burn farming), resulting in habitat reduction and habitat quality reduction.

FLOWERING TIME. September to July.

ETYMOLOGY. Refers to Mr Warpur (fl. 1890 - 1901), a Belgian collector, who first imported the species into Europe. Rolfe, in his description, has the name ending in one ' $i$ ' but this is an error to be corrected to ' $i$ ' according to the Botanical Code (Turland et al. 2018: 60.14).

NOTES. The type material of Liparis warpurii had not been fully understood and consists of a sheet of sterile

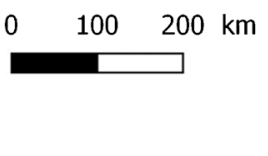


plants collected by Warpur, an inflorescence with one flower only, lacking its lip from a cultivated plant from the Warpur collection, plus an unsigned watercolour from a cultivated plant from the Warpur collection showing the plant and a close-up of a flower (Fig. 70). This combination of material clearly shows that L. clareae var. angustifolia, described by Perrier in 1936 and known only from the type specimen, is also the same taxon and quite distinct from L. clareae.

Plants were collected by Warpur in Madagascar in June 1900 and herbarium material of plants without flower arrived at Kew in December; the herbarium sheet has a label by Warpur stating that the specimen came from Tananbe (or Tamambe) and grew in soil on dry slopes in forest. One can assume that at the same time living plants from the same origin also came to Kew where they were cultivated for several years. During this time Warpur supplied great quantities of orchids from Madagascar to European orchid growers, either directly or through auctions at Protheroe \& Morris. Some of these were also grown at Kew. It is not entirely certain where the plants were collected: Tananbe could be Tanambe near Lake Aloatra in Toamasina province but there are several other possibilities, the name meaning 'big village' in Malagasy. The plants flowered at Kew on several occasions, a plant and flower were painted in 1906 (in the style of Matilda Smith, Fig. 70) and a flower without a lip is also preserved on a herbarium sheet in 1907 , both are annotated with the Kew accession number 437. Rolfe finally described the new species in 1908. The herbarium sheet and watercolour are both annotated by Rolfe as being 'close to L. parva'. Rolfe, in his description, just referred to 'Warpur' as the type specimen but mentioned that the plant was introduced about 7 years ago'. The K herbarium sheet Warpur from 'Tananabe' 10 June 1900 is chosen here as the lectotype with the single imperfect flower Warpur 437 (K0002452145) being an lectoparatype plus the watercolour of Warpur 437 of September 1906 being an additional lectoparatype. Additional material without a number, dated October 1899, is also at K. Liparis cardiophylla H.Perrier var. angustifolia H.Perrier was described by Perrier in 1936 but lacked a Latin diagnosis, the name was validated in 2007 Hermans et al. (2007: 289).

ILLUSTRATIONS. Figs 70, 71 and 72; Cribb \& Hermans (2009: 147).

Liparis zaratananae Schltr. (Schlechter 1924: 151); Perrier (1936: 253; 1939: 269); Hermans et al. (2007: 224); Cribb \& Hermans (2009: 148). Types: Madagascar, Mt Tsaratanana, Oct. 1922, Perrier 15743 (P00095528) (holotype P); Madagascar, Mt Tsaratanana, Dec. 1922, Perrier 15743 (P00095529) (lectoparatype. P).

Medium-sized terrestrial plant up to $17 \mathrm{~cm}$ high, rhizome very short, pseudobulbs retain leaves for two seasons, roots flexuose, more or less pilose.
Pseudobulbs stem-like, up to $9 \mathrm{~cm}$ long, c. $5 \mathrm{~mm}$ in diam., enveloped by several sheaths and the lower leaf petiole, with $2-3$ leaves at the apex. Leaves somewhat papery, erectly spreading, ovate-elliptic, blade $5.5-9.5 \times 2.5-5 \mathrm{~cm}$, acuminate, pleatedveined, rounded and abruptly contracted into a 1 $2 \mathrm{~cm}$ petiole. Inflorescence erect longer than the leaves up to $12.5 \mathrm{~cm}$. Peduncle costate, $5-7 \mathrm{~cm}$ with $2-3$ bracts. Rachis sublaxly $6-8$-flowered. Floral bracts lanceolate acuminate, 5 - $7.1 \times 1.1$ $1.8 \mathrm{~mm}$. Flowers large, erectly spreading up to $18 \times$ $11 \mathrm{~mm}$, green becoming brown-yellow with age. Pedicel and ovary slender, glabrous, slightly ridged, up to $17 \times 2 \mathrm{~mm}$. Dorsal sepal reflexed, ligulatelanceolate, somewhat obtuse and bi-auriculate at the base, $12-15.5 \times 1.5-1.8 \mathrm{~mm}$. Lateral sepals porrect, falcate-oblong, obtuse, 11.3 - $12.8 \times 3.8-$ $4.1 \mathrm{~mm}$. Petals deflexed, narrowly linear, obtuse, $12.5-13.2 \times 0.5-0.6 \mathrm{~mm}$. Lip curved, with the base contracted and shortly biauriculate, abruptly expanded into a very broadly oval blade, apiculate at the apex and the front margins almost subdenticulate, base with a small rounded-subcordate, sometimes obsolete callus, $9.2-10.1 \times 7.5-7.7$ mm. Column slightly curved, short and thick, a little expanded above the middle, 4 - $5 \mathrm{~mm}$ long, somewhat winged. Anther with a spathulate beak, $1 \mathrm{~mm}$ long, rounded at the apex and narrowed towards the base, overall c. $1.9 \times 1.1 \mathrm{~mm}$. Pollinia ovoid, united by a thin membrane, c. $0.6 \times 0.4 \mathrm{~mm}$.

RECOGNITION. Liparis zaratananae is a medium-sized plant with fairly short, slender pseudobulb and two or rarely three, ovate-elliptic leaves, with a $1-2 \mathrm{~cm}$ petiole, the leaves being retained on at least two growths. It has large flowers with a broadly oval lip narrowed at the base and slightly serrulate at the anterior margin, a rounded and indistinct callus, an anther with a distinct spathulate, $1 \mathrm{~mm}$ long beak, rounded at the apex and narrowed towards the base, and a short and thick column.

Liparis zaratananae is somewhat similar in habit and inflorescence to L. jumelleana but it is well characterised by the more ovate leaves with a more sharply defined petiole, larger flowers, smaller petals and the lip oval vs transversally elliptic and the spathulate vs pointed beak of the anther. There are similarities with $L$. sambiranoensis but the plant is generally a little smaller, the leaf more petiolate, two years growth remain whilst L. sambiranoensis emerges from a repent pseudobulb, the bracts are smaller (not cordate), the lip a very different in shape (shortly auriculate vs distinctly auriculate) and much shorter dentate at the front and the anther has a spathulate beak vs triangular.

DISTRIBUTION. Endemic to Madagascar: Antsiranana province, Mt Tsaratanana only (Map 50). 


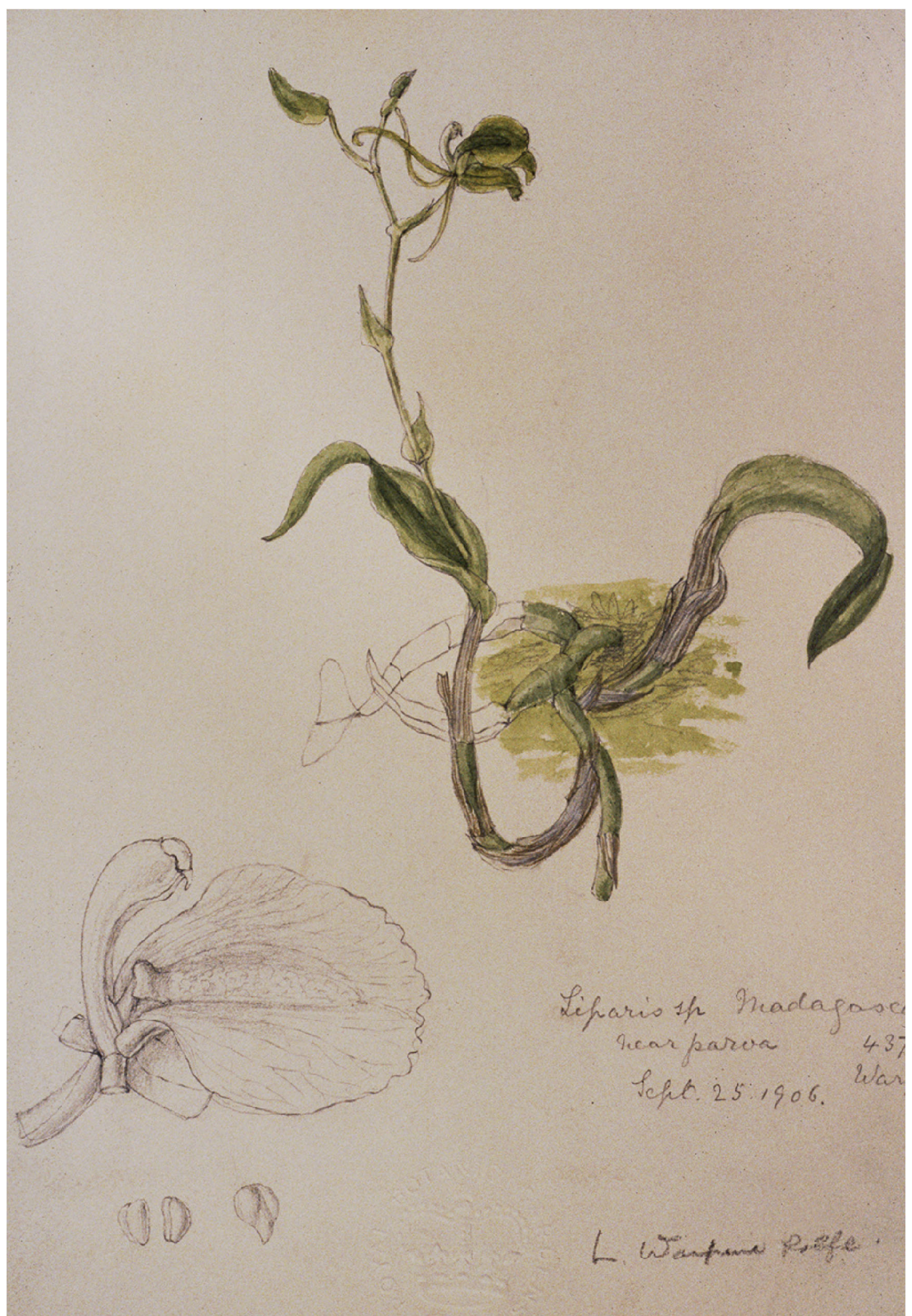

Fig. 70. Liparis warpuri. Watercolour by Matilda Smith of the type specimen. Reproduced by kind permission of the Trustees of the Royal Botanic Gardens, Kew. 


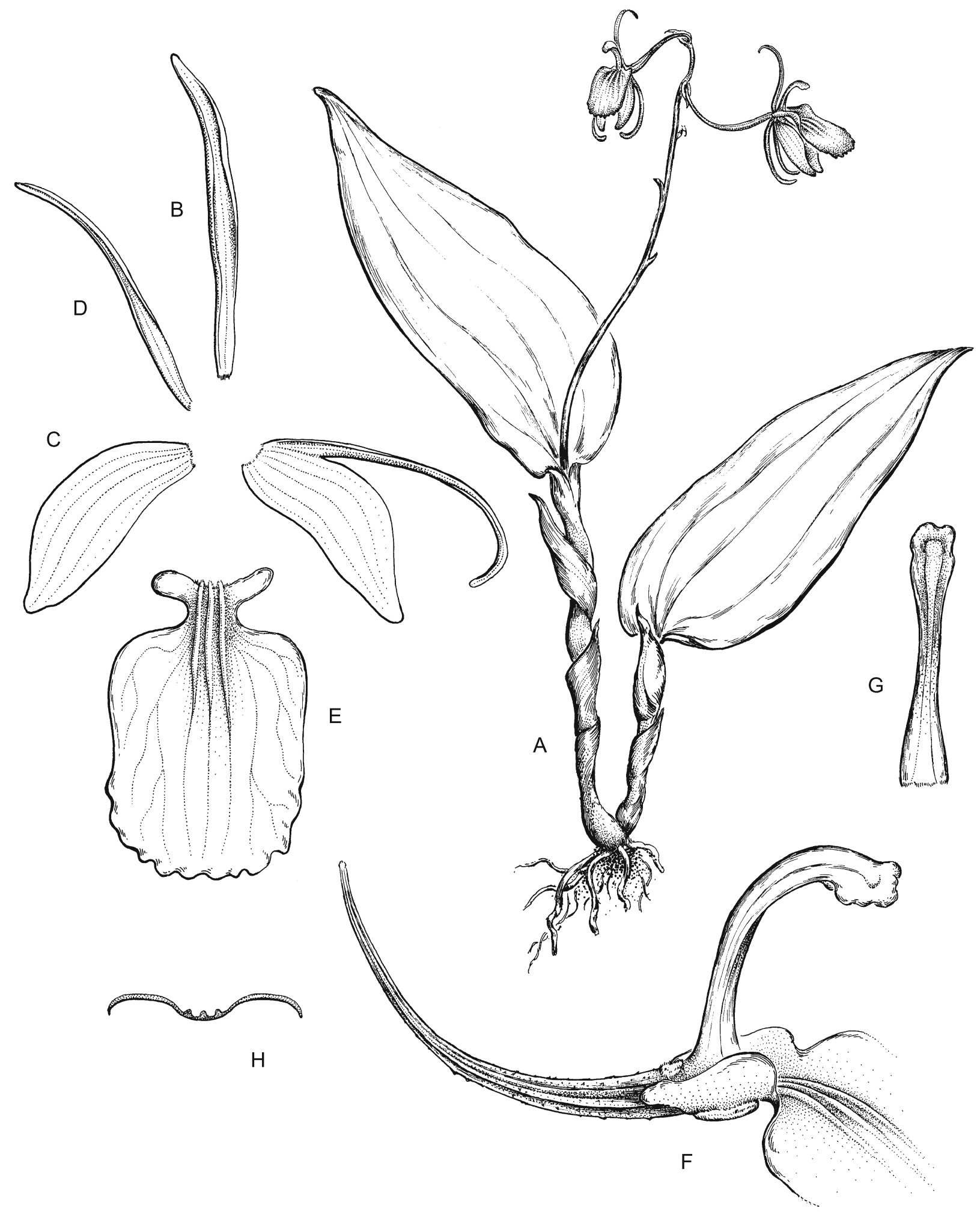

$O Q$. Whalley from drawing a J. Hermans (Rbakew. Oct 2002.)

Fig. 71. Liparis warpuri. A habit $\times 1$; B dorsal sepal $\times 6 ; \mathrm{C}$ lateral sepals $\times 6$; D petal $\times 6$; $\mathrm{E}$ lip $\times 6$, F column and ovary, side view $\times$ 9; G column, front view $\times 9$; H T/S through lip $\times 6$. Based on $H$. Perrier $17018(P)$. Unfinished drawing by Oliver Whalley from sketches by J. Hermans. The lip callus shown in E, $\mathrm{F}$ and $\mathrm{H}$ is based on dried specimens and does not show the more swollen bi- or tri-lobed callus. 

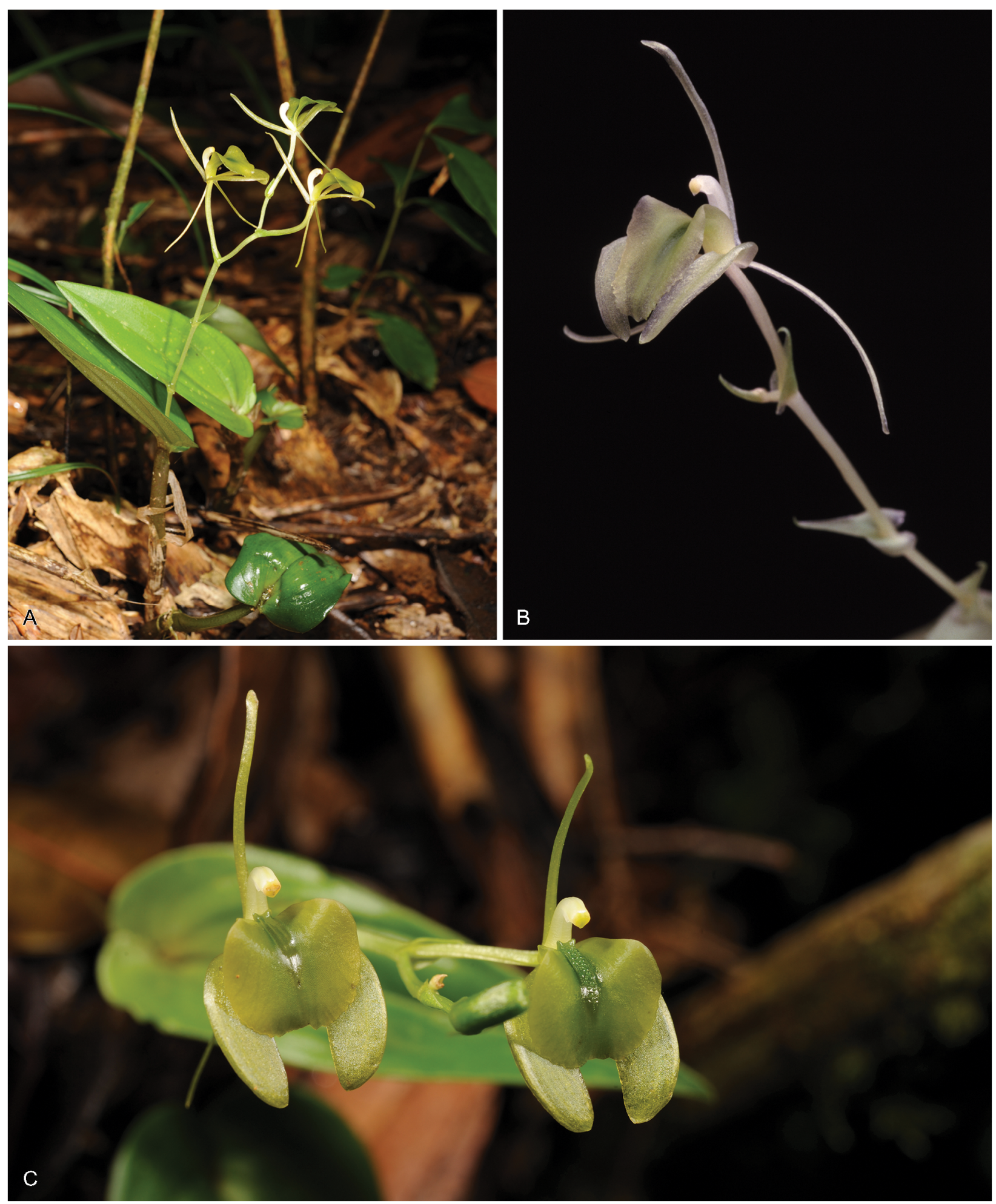

Fig. 72. Liparis warpuri. A habit; B flower; C flowers showing distinct callus. PHOTOS: A, C JEAN-MICHEL HERVOUET; B PHOTO: JOHAN HERMANS.

SPECIMENS EXAMINED. MADAGASCAR. Mt Tsaratanana, Oct. 1922, Perrier 15743 (P00095528) (holotype P); Mt Tsaratanana, Dec. 1922, Perrier 15743 (P00095529) (lectoparatype P); Centre, Mt Tsaratanana, c. 2000 m, April 1924, Perrier 16484.
HABITAT. Forest undergrowth, moss and lichen. Altitude: $1500-2000 \mathrm{~m}$.

CONSERVATION STATUS. Category CR: the extent of occurrence (EOO) of Liparis zaratananae cannot be estimated since it is only known from one subpopula- 
$0 \quad 100 \quad 200 \mathrm{~km}$

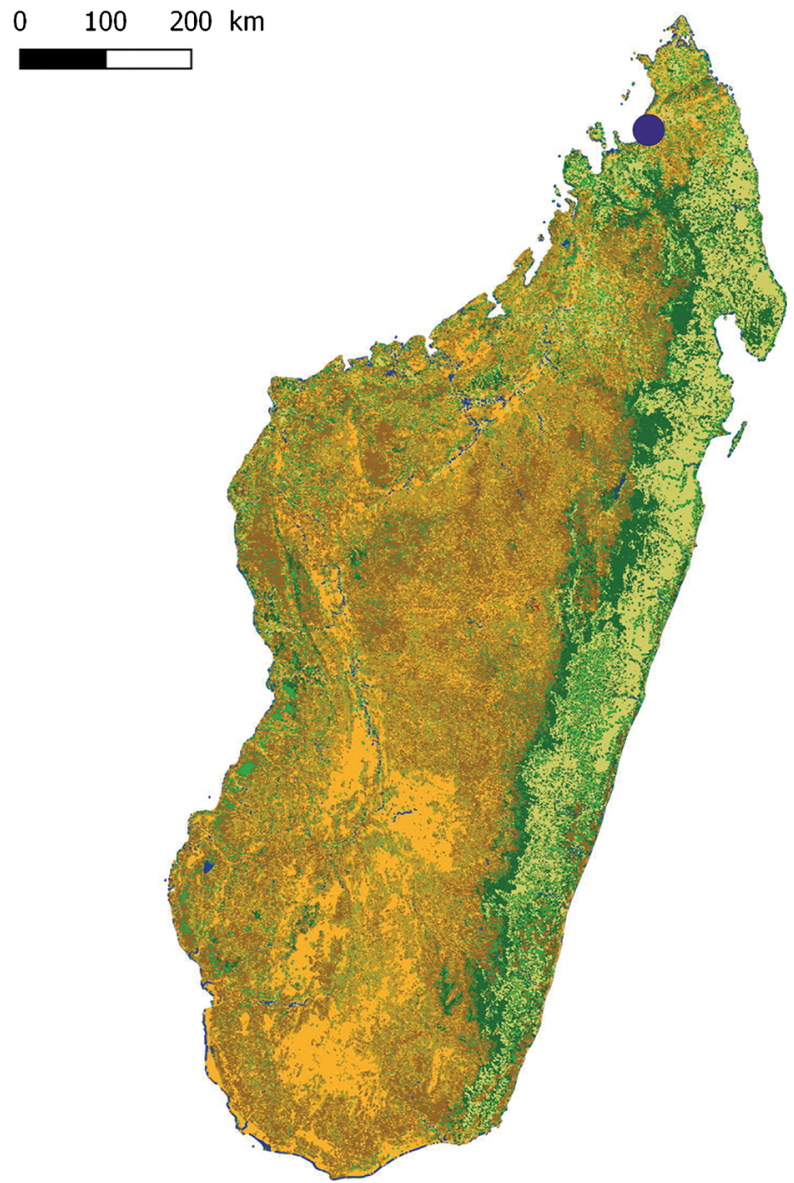

Map 50. Distribution of Liparis zaratananae.

tion whereas its minimal area of occupancy (AOO) is estimated to be $4 \mathrm{~km}^{2}$ (which falls within the limits for Critically Endangered status under the criterion B2). Liparis zaratananae is only known from one subpopulation representing one location (sensu IUCN), this rare species has thus been preliminarily assessed as CR using the green listing method. This species is threatened by selective logging, timber harvesting for small-scale subsistence and tavy (slashand-burn farming), resulting in habitat reduction and habitat quality reduction. At Mt Tsaratanana the habitat is particularly affected by clearance for cultivation of illegal drugs.

FLOWERING TIME. Perrier 15743 P00095528 has October, P00095529 has December and Perrier 16484 has April. ETYMOLOGY. Refers to Mt Tsaratanana (Zaratanana), the type locality in Northern Madagascar. Perrier (1939: 269) changed the epithet to tsaratananae believing Schlechter to have made a typographic error, but there is no basis for this as Schlechter used the German version of spelling.

NOTES. Liparis zaratananae is often confused in herbaria with other species. It was first collected in October 1922 by Perrier from a small colony of six plants on Mt Tsaratanana and sent to Schlechter for identification in May 1923. He returned it to the Paris herbarium in October of the same year and published the description a year later. There are two sheets from the same locality, one has a collecting date of October (X) and the other December, this could be an error but could equally be a collection from a later date. Perrier made another collection in 1924, from a different area of Mt Tsaratanana of a somewhat different form with a wider lip and more linear anther beak. No other reliable records exist of the species. ILLUSTRATION. Perrier (1939: 271). The photographs in Cribb \& Hermans (2009: 149) labelled Liparis zaratananae are of L. chantaliae.

\section{Ambiguous species and unplaced names Liparis xanthina Ridl. (Ridley 1886b: 275); Perrier (1939: 278); Hermans et al. (2007: 224); Cribb \& Hermans (2009: 153); Hervouet (2018: 422) nomen dubium. Type: Mada- gascar, Ankafana (S Betsileo), Deans Cowan s.n. (holotype BM (BM000090075); Deans Cowan watercolour 39 (illus- tration of holotype BM). \\ Leptorkis xanthina (Ridl.) Kuntze (1891: 671).}

Plant erect, very small, epiphyte, $6 \mathrm{~cm}$, rhizome very short, roots rounded, filiform, glabrous. Pseudobulbs oval-conical with 2 leaves, $4-7 \mathrm{~mm}$, covered in degrading sheaths. Leaves ovate, $5.5-6 \times 2.5-2.8 \mathrm{~cm}$. Inflorescence erect c. $7 \mathrm{~cm}$, laxly 13-flowered. Peduncle one or two sheaths $6 \times 1-1.2 \mathrm{~mm}$. Rachis $3-4 \mathrm{~cm}$, with the lower flowers before the upper ones open. Floral bracts lanceolate, c. $3 \times 1 \mathrm{~mm}$. Flowers very small, yellow, overall c. $7 \times 5 \mathrm{~mm}$. Pedicel and ovary rounded, winged, c. $3 \times 0.3 \mathrm{~mm}$. Dorsal sepal narrowly linear, obtuse, c. $3.5 \times 1 \mathrm{~mm}$. Lateral sepals ovate-oblong and obtuse, c. $3.5 \times 2 \mathrm{~mm}$. Petals narrowly linear c. $3.5 \times 0.3$ mm. Lip curved, oblong and obtuse, c. $2.5 \times 2 \mathrm{~mm}$. Column rather thick, c. $2 \times 1.3 \mathrm{~mm}$. Anther not known.

RECOGNITION. Liparis xanthina has an inflorescence that is longer than its leaves; two fairly broad leaves, small flowers and fairly long floral bracts.

It is similar in its inflorescence and flowers to Liparis dryadum but it has broader and larger leaves. It also resembles in size and habit $L$. densa, L. lutea, $L$. nephrocardia and L. bathiei but, without flowers, it is not possible to be certain from the type herbarium material if it differs sufficiently. The type plant at BM has one growth and no flowers, its habit matches several species but it is not possible to determine which. Deans Cowan's watercolour does not allow identification with any certainty and we, therefore, consider this name ambiguous (nomen dubium designated here) due to the lack of reliable type material. It shares many characteristics with L. bathiei which may be the same species but there is not enough reliable material to support this. 
DISTRIBUTION. Endemic to Madagascar: Fianarantsoa area (Ankafana; the highland area in-between Antsirabe and Ambalavao) (Map 51).

SPECIMENS EXAMINED. MADAGASCAR. Ankafana (S Betsileo), Deans Cowan s.n. (holotype BM). BM000090075 and Deans Cowan watercolour 39 (BM) (syntype BM).

HABITAT. In trees. Altitude: unknown.

CONSERVATION STATUS. Category CR: the extent of occurrence (EOO) of Liparis xanthina cannot be estimated since it is only known from one subpopulation whereas its minimal area of occupancy (AOO) is estimated to be $4 \mathrm{~km}^{2}$ (which falls within the limits for Critically Endangered status under the criterion B2). Liparis xanthina is only known from a single subpopulation representing one location (sensu IUCN), this rare species has thus been preliminarily assessed as CR using the green listing method. This species is threatened by selective logging, timber harvesting for small-scale subsistence and tavy (slash-and-burn farming), resulting in habitat reduction and habitat quality reduction.

FLOWERING TIME. Not known.

ETYMOLOGY. Refers to the yellow colour of the flowers. NOTES. Liparis xanthina was described by Henry Ridley based on a specimen collected by William Deans Cowan of the London Missionary Society who was sent out to Madagascar in 1874, settled in Fianarantsoa and returned to England in 1881. Deans Cowan provided a number of herbarium specimens to Ridley and also left an album of watercolours of his finds, these often help to illustrate the type material (Fig. 73). In his description Ridley refers to Deans Cowan's drawing 89 which must be mistranscription of 39, since 89 does not exist in the Deans Cowans' sketchbook (Cowan 1880).

ILLUSTRATION. Cowan (1880: 39) (Fig. 73).

Liparis pulchella Cordemoy ms.

Cordemoy s.n. from Réunion in the Marseille herbarium specimen was labelled by Cordemoy as Liparis pulchella. The name is unpublished and no other records have been found. It has similarities with L. flammula and L. nectarina but there are insufficient features left to identify with any certainty. The name L. pulchella was also used by Hooker $\mathrm{f}$. in 1889 for an Asian species (now L. petiolata).

\section{Liparis obliqua Frappier ms.}

This is an unpublished name on a Cordemoy herbarium sheet of L. caulescens May 1863 (MARS).

Liparis arno(ma)toides Cordemoy ms.

This name appears on a Cordemoy herbarium specimen that lacks flowers and provenance (MARS).
Liparis sp. nov.

Schlechter (1913: 22) mentioned a 'Liparis sp. nov. ?' from Madagascar, Manongarivo. This corresponds to a specimen without flowers in P (Perrier 11847) but it is not possible to identify and is likely to be a species of Malaxis.

\section{New species with insufficient material}

The following collections are insufficiently complete to describe but appear to represent a new species.

MADAGASCAR: Mangandrano, Bealanana, RN 4, June 1953, Levango Surveillant 6031 (P00409223), P001805101-2 (P); Antananarivo, c. $130 \mathrm{~km}$ towards Mahajunga, Hermans 2122 (K). A large bulbous plant related to Liparis foliosa but larger and more bulbous. The specimens are with fruit capsules only.

\section{Malaxis}

Malaxis Sol. ex Sw. (Swartz 1788: 119). Type species: Malaxis spicata Sw. (Swartz 1788: 119).

Achroanthes Raf. (Rafinesque 1819: 195).

Acroanthes Raf. (Rafinesque 1819: 261).

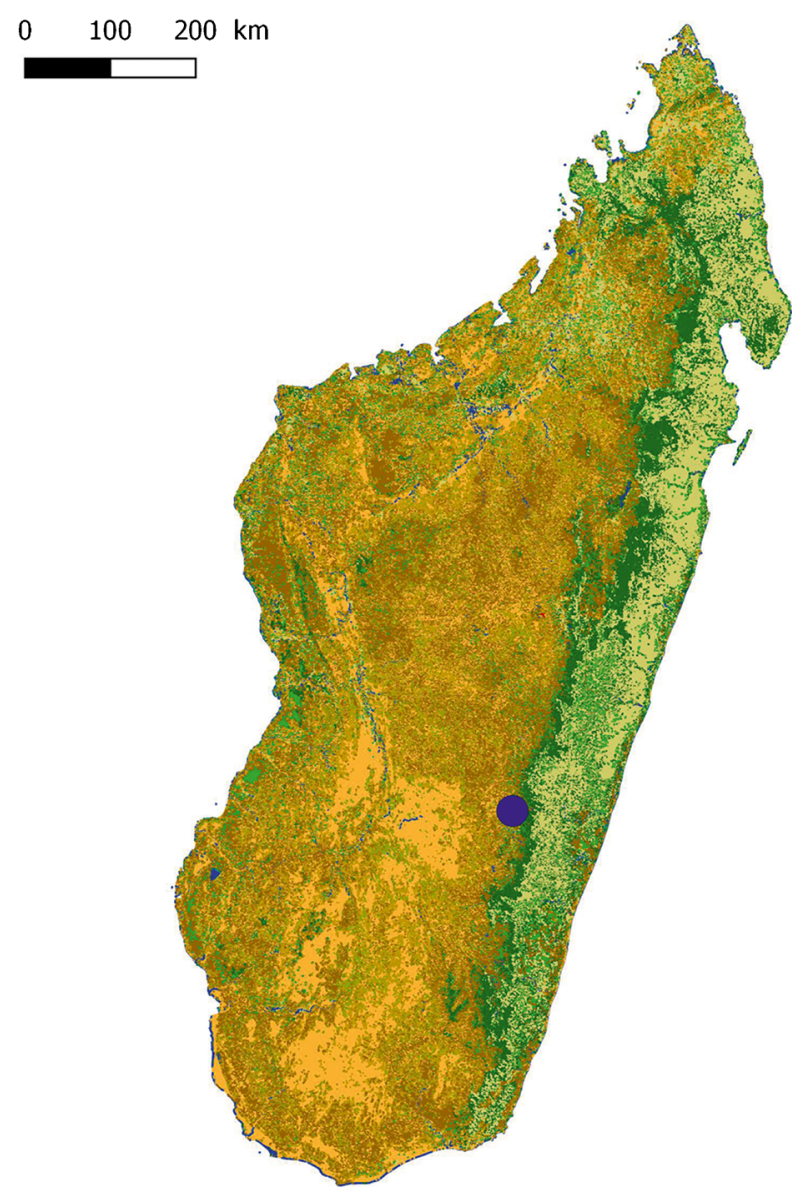

Map 51. Distribution of Liparis xanthina. 


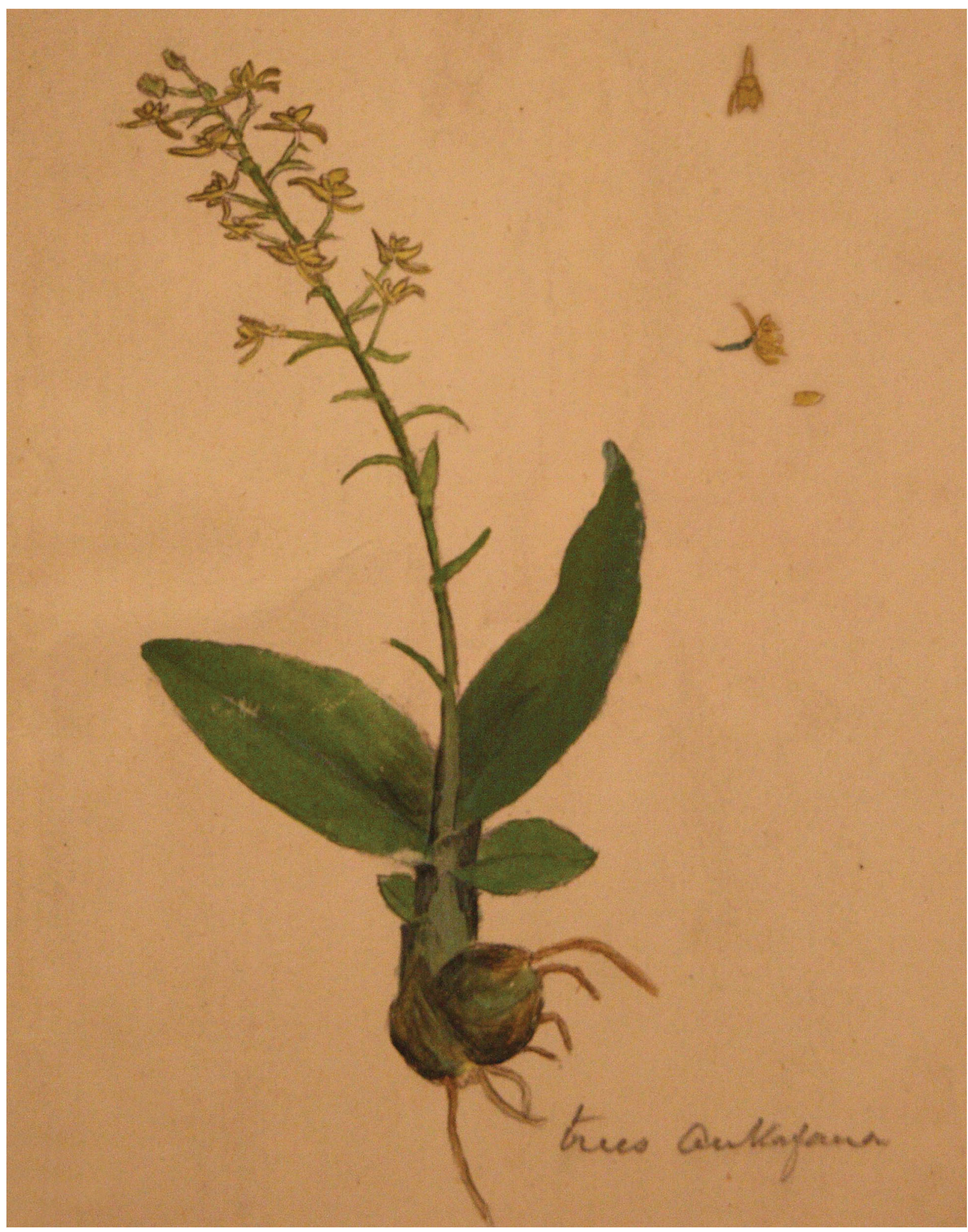

Fig. 73. Liparis xanthina. Watercolour by Deans Cowan 1880: 19. (C) The Trustees of the Natural History Museum, London. 
Microstylis (Nutt.) Eaton (1822: 115), nom. et orth. cons. Type species: Microstylis ophioglossoides (Muhl. ex Willd.) Nutt. ex Eaton (1822: 353).

Cheiropterocephalus Barb.Rodr. (Rodrigues 1877: 28). Glossochilopsis Szlach. (Szlachetko 1995: 122).

Kornasia Szlach. (Szlachetko 1995: 120).

Lisowskia Szlach. (Szlachetko 1995: 121).

Pycnantha Ravenna (2011: 30).

Terrestrial or rarely epiphytic, lithophytic herb. Roots hairy. Stem cylindrical to pseudobulbous, fleshy, often creeping and rooting in basal part. Leaves thin textured to fleshy, usually pleated, petiole sheathing at base. Inflorescence erect, racemose, unbranched. Floral bracts setose to lanceolate, persistent. Flowers non-resupinate or resupinate, green, brown, yellow, pink or purple. Dorsal sepal spreading, free. Lateral sepals free or fused, spreading. Petals often narrower than the sepals, free, spreading. Lip erect, flat but sometimes concave at base, entire to lobed, auriculate at base or lacking auricles, apical margins entire to toothed, lacking a spur, callus absent, cushion-like or obscurely transversely ridged. Column lacking a foot; anther dorsal, attached by a slender filament, locules opening ventrally, pollinia four, waxy, lacking appendages or rarely with one or two tiny viscidia, stigma semi-circular or ovate; rostellum often obtuse or emarginate at apex (adapted from Cribb in Pridgeon et al. 2005: 471).

DISTRIBUTION. A genus of about 300 species found throughout the tropics and subtropics of the Old and New World, with a few species in temperate regions of Europe, Asia and the Americas. Four species in Madagascar of which three endemic $(75 \%)$, one endemic to the Seychelles, one to the Comores, one with a wider distribution on main- land Africa. None on the Mascarenes. Ridley mentioned the W African Microstylis stelidostachya Rchb.f. (Reichenbach f. 1881: 118) (now Orestias stelidostachya (Rchb.f.) Summerh. (Summerhayes 1937: 460) from the Comoros in error.

TAXONOMIC NOTES. Most authors until recently have followed the treatments of Schlechter (1911a) and Seidenfaden (1978) in accepting a broadly defined Malaxis. However, in this sense, Malaxis is undoubtedly polyphyletic. More species need to be included in ongoing DNA studies to resolve the problems.

The systematic history of Malaxis is complex. Ridley (1888) produced the first infrageneric treatment of Microstylis (subsequently subsumed in Malaxis), recognising eight sections, six of which were confined to the New World, one to Africa, and two to Asia. Smith $(1909,1913)$ and Schlechter (1911a) recognised non infrageneric groupings in Microstylis. Seidenfaden (1978) included Microstylis in Malaxis and discussed previous infrageneric treatments, transferring five section established in Microstylis to Malaxis.

More recently, Szlachetko (1995), Szlachetko \& Margonska (2002) and Margonska et al. (2012) recognised a number of new genera in subtribe Malaxideae. Most of them were included in Malaxis by previous authors. Szlachetko \& Olsewski (2001) accepted the segregate genera Lisowskia and Kornasia in their account of the orchids of Cameroon.

Data from DNA sequence analysis shows that Malaxis s.l. is polyphyletic (Cameron 2005) but not along the lines defined by Szlachetko and his co-workers.

ETYMOLOGY. From the Greek malaxis (malasso), to soften, in allusion to the soft-textured leaves.

\section{Taxonomy of Malaxis}

\section{Artificial key to Malaxis in Madagascar, the Mascarenes, Comoros and Seychelles}

1. Plant large, more than $10 \mathrm{~cm}$ tall; leaves large, more than $7 \mathrm{~cm}$ long, borne along the stem $\ldots \ldots \ldots \ldots \ldots \ldots \ldots \ldots \ldots \ldots \ldots \ldots \ldots \ldots$ Malaxis seychellarum

1'. Plant small, less than $10 \mathrm{~cm}$ tall; leaves 2 , less than $7 \mathrm{~cm}$ long, borne at the apex of the pseudobulb or stem. . . 2 2. Flowers non-resupinate, with the $\operatorname{lip}$ uppermost in the flower $\ldots \ldots \ldots \ldots \ldots$ 2'. Flowers resupinate with the lip lowermost in the flower $\ldots \ldots \ldots \ldots \ldots \ldots \ldots$ 3. Lip distinctly 3-lobed, the basal auricles overtopping the column, the front margin entire . . M. madagascariensis 3'. Lip indistinctly 3-lobed, basal auricles not overtopping the column, anterior margin sinuate . . . M. physuroides

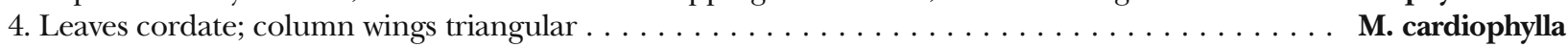
4 '. Leaves oval to oblong; column wings rounded. $\ldots \ldots \ldots \ldots \ldots \ldots \ldots$ 5. Leaf petiole short, less than $1 \mathrm{~cm}$ long; lip wider than long, the basal auricles lower than the column . . M. atrorubra 5'. Leaf petiole more than $1 \mathrm{~cm}$ long; lip suborbicular, the basal auricles folded around the column. . M. weberbaueriana

Malaxis atrorubra (H.Perrier) Summerh. (Summerhayes 1954: 578); Hermans et al. (2007: 225); Cribb \& Hermans (2009: 160). Type: Madagascar, Manerinerina, Tampoketsa, Perrier 16828 (holotype P). Microstylis atroruber H.Perrier (1936: 233; 1939: 259).
Small terrestrial plant, c. $10 \mathrm{~cm}$ high, on a short creeping rhizome with the new growth emerging from the base or node of the previous withered decumbent pseudobulb, covered in brown scarious sheath remnants; roots filiform, hairy. Pseudobulbs caulescent, 45 - 
$75 \times 3-7 \mathrm{~mm}$, completely covered with $3-5$ brownish amplectant sheaths, attenuate to caudate at the tip, 5 $22 \times 4-5 \mathrm{~mm}$, with 3 leaves at the apex generally with one smaller than the others. Leaves ovate acute, narrowed into a $5-8 \mathrm{~mm}$ petiole at the base, blade oblique, $3.5-5.6 \times 2.1-3.3 \mathrm{~cm}$. Inflorescence erect, lengthening with age, up to $88 \mathrm{~mm}$ long but generally shorter, thin, corrugate, with up to 12 flowers. Peduncle up to $40 \mathrm{~mm}$ with up to 5 bract-like sheaths. Rachis laxly racemose, up to $50 \mathrm{~mm}$, flowers opening in succession. Floral bracts narrowly lanceolate, acute, 1.9 $-2.3 \times 0.5-0.8 \mathrm{~mm}$. Flowers very small to small, erectly spreading, c. $5.5 \times 6 \mathrm{~mm}$, dark purple, almost black, lip sometimes greenish-yellow. Pedicel and ovary straight, corrugate to winged $2.2-2.5 \times 0.3-0.4 \mathrm{~mm}$. Dorsal sepal oval-lanceolate, obtuse, broad at the base $2.8-$ $3.5 \times 1.1-1.5 \mathrm{~mm}$. Lateral sepals ovate $2.7-3.1 \times 1.1-$ $1.6 \mathrm{~mm}$. Petals linear obtuse, $1.8-2.1 \times 0.3-0.5 \mathrm{~mm}$. Lip very shortly and narrowly winged at the base below the column then abruptly broadened into a subglobose to oval blade rounded at the anterior margin, with 2 longitudinal crescent-shaped swellings along a central vein, $1.9-2.2 \times 2.1-2.7 \mathrm{~mm}$. Column very short, with characteristic large rounded wings at the apex, $0.9-1.2 \times 0.4-0.5 \mathrm{~mm}$. Anther very small, broadly obovate, with two distinct chambers, c. $0.3 \times$ $0.35 \mathrm{~mm}$. Pollinia ovoid c. $2 \mathrm{~mm}$

RECOGNITION. A small plant with three leaves, small flowers with an obtuse dorsal sepal, widened at the base, a lip slightly wider than long, with a very narrow base not surrounding the column, two crescentshaped swellings on the blade along a central vein, and a very short column with large rounded wings at the apex.

The broad lip is similar to that of Malaxis cardiophylla but plant and leaf are different with the base of $M$. cardiophylla being more cordate than this species, the leaves of $M$. cardiophylla also have a distinct elongate petiole. The lip is broader in M. cardiophylla which also lacks the crescent-shaped swellings. The column has rounded apical wings (vs angular). The species is different from M. weberbaueriana (Kraenzl.) Summerh. (Summerhayes 1934: 208) in having leaves with a shorter petiole, flowers that are equally small, but have a lip with much smaller basal auricles that do not surround or surpass the column as in M. weberbaueriana. It differs from $M$. welwitschii from Angola by the less cordate ovate leaves, the entire ovate lip (vs three-lobed) and the large rounded wings (vs angular) of the column.

DISTRIBUTION. Endemic to Madagascar: Antananarivo province (Map 52).

SPECIMENS EXAMINED. MADAGASCAR. Manerinerina, Tampoketsa, Perrier 16828 (holotype P); Kitsamby forest, Jan. 1964, Thérézien s.n. P1778684. (P); Soavinandriana area, 1997, Hermans 3551 (K).
HABITAT. Terrestrial in humid evergreen forest on plateau. Altitude: $1000-1500 \mathrm{~m}$.

CONSERVATION STATUS. Category EN: the extent of occurrence (EOO) of Malaxis atrorubra cannot be estimated since it is only known from two subpopulations whereas its area of occupancy (AOO) is estimated to be $4 \mathrm{~km}^{2}$ (which falls within the limits for Critically Endangered status under the criterion B2). With only two known subpopulations representing two locations (sensu IUCN), M. atrorubra has been preliminarily assessed as EN using the green listing method. This species is threatened by selective logging, timber harvesting for small-scale subsistence and tavy (slash-and-burn farming), resulting in habitat reduction and habitat quality reduction.

FLOWERING TIME. October to January.

ETYMOLOGY. Refers to the dark-red to dark purple colour of the flowers.

NOTES. Perrier originally described it as Microstylis atroruber and it was transferred to the genus Malaxis by Summerhayes (1953). According to the ICN (Turland et al. 2018: 60.11) the use of a hyphen in this instance is to be treated as an error and corrected: therefore atro-rubra becomes atrorubra.

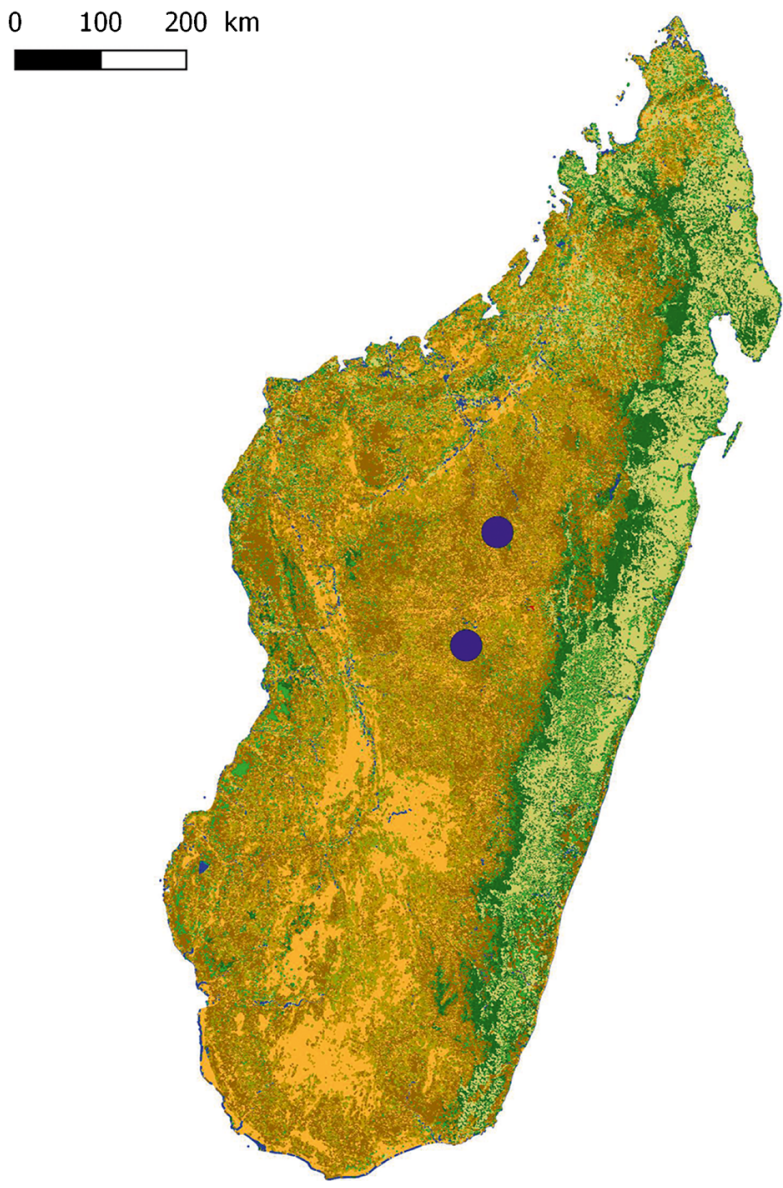

Map 52. Distribution of Malaxis atrorubra. 
Perrier's holotype is a young plant with few flowers. In his description he noted that the lip calli were verrucose which is not obvious in specimens.

Margonska (2009: 91) considered this species to be conspecific with Malaxis welwitschii from Angola (as Lisowskia welwitschii) together with $M$. francoisii (H.Perrier) Summerh. (Summerhayes 1954: 578) also from Madagascar but the plant, lip and column of M. atrorubra are considerably different as explained above. The species was described at the same time as M. francoisii and based on a collection by Perrier and François, who would have seen the living plants. It is unlikely that Perrier would have described the same species twice in the same paper.

ILLUSTRATIONS. Perrier (1939: 255).

Malaxis cardiophylla (Rchb.f.) Kuntze (1891: 673); Hermans et al. (2007: 225). Types: Comoros, Mayotte, Combani forest, Humblot 1437 (437) (holotype W, isotypes BM, LD, LG, P (P00094908-10)).

Microstylis cardiophylla Rchb.f. (Reichenbach 1885:

543); Ridley (1888: 66); Perrier (1939: 257).

Orestias cardiophylla (Rchb.f.) Marg. (Margonska \& Szlachetko 2006: 218), synon. nov.

Small, terrestrial, lithophytic or epiphytic tufted plant $5.5-10 \mathrm{~cm}$ high, on a very short, occasionally branching rhizome, roots fibrous. Pseudobulbs slender, caulescent, $20-60 \times 3-5 \mathrm{~mm}$, covered by $3-4$ membranous sheaths, generally carrying two leaves, sometimes accompanied by a third smaller leaf, leaves persistent on previous growths. Leaves thin, broadly cordate, more or less unequally lobed at the base, shortly acute at the tip, with a short $6-12 \mathrm{~mm}$ petiole, $1.8-3 \times 1.3-2 \mathrm{~cm}$. Inflorescence erect, thin, $6-10.5$ cm, with $7-23$ flowers. Peduncle short, with $3-5$ bractlike sheaths. Rachis loosely racemose, flowering in succession hardly $1-2 \mathrm{~cm}$ above the upper leaf. Floral bracts erectly spreading, narrowly lanceolate to cordate-triangular, $2.5-5 \times 0.9-1.1 \mathrm{~mm}$. Flowers small, 5 $-6 \mathrm{~mm}$ including the ovary, violet or purplish, the lip green with a yellow callus. Pedicel and ovary glabrous, 3 - $3.5 \times 1.1$ - $1.3 \mathrm{~mm}$. Dorsal sepal oval-lanceolate, obtuse, $1.9-2.8 \times 0.7-1.2 \mathrm{~mm}$. Lateral sepals ovate, obtuse, $2-2.8 \times 1-1.3 \mathrm{~mm}$. Petals linear, obtuse, narrowed towards the apex, $2.1-2.7 \times 0.5-0.6 \mathrm{~mm}$. Lip oblong, obtuse and sinuate at the anterior margin, broadly winged at the base not surpassing the column, the disk with two rounded minutely pubescent longitudinal ridges, $1.5-2.1 \times 1.6-2 \mathrm{~mm}$. Column slender, up to c. $1.1 \times 0.3 \mathrm{~mm}$, the apical wings triangularacute, ascending. Anther ovate with a rounded anterior lobe, c. $0.6 \times 0.8 \mathrm{~mm}$. Pollinia ovate $0.8 \times 0.5 \mathrm{~mm}$.

RECOGNITION. Malaxis cardiophylla is a small plant with two, broadly cordate, persistent leaves with a long petiole, a loosely racemose rachis, with up to 20 small flowers, an oblong, broadly lobed, obtuse lip, with two longitudinal vein-like ridges.

Malaxis cardiophylla is similar to M. weberbaueriana but the plant and flowers are distinct, especially the leaves which are cordate (vs lanceolate) and a lip which is broader and does not surpass or envelop the column. A drawing by Ridley (at K) based on Humblot 437 (presumably based on the BM specimen), shows differently shaped (not cordate) leaves. Perhaps M. cardiophylla is an aberrant or local form of $M$. weberbaueriana but based on current evidence it is left as a separate entity. It is also similar in lip-shape to $M$. atrorubra but it is broadly vs narrowly winged, its habit and leaf shape are slightly different with a broadly cordate leaf vs ovate with the base oblique, and its column structure with rounded (vs angular) lobes.

DISTRIBUTION. Comoro Islands, Mayotte. Perrier (1939: 257) gave 'Grande Comore, Combani' as the locality of this species but Humblot's Field Notebooks in P (1882 - 1885) clearly list the "plant growing next to rocks, flowers violet, from Mayotte, Combani forest". It is a common mistake to confuse Combani forest of Grande Comore with Combani on the island of Mayotte (Hervouet \& Barthelat 2014: 268) (Map 53).

SPECIMENS EXAMINED. COMOROS. Mayotte, Combani forest, Humblot 1437 (437) (holotype W, isotypes BM, LD, LG, P (P00094908-10)); Mayotte, Grande Terre, Tsararano, Benara, Dec. 2002, Barthelat 1116 (K, P); Mayotte, Summit of Petit Benara, Jan. 1990, Tinguy 1134 (P).

HABITAT. Near rock, in forest, terrestrial or epiphytic. Altitude: around $300-400 \mathrm{~m}$.

CONSERVATION STATUS. Category CR: The extent of occurrence (EOO) of Malaxis cardiophylla cannot be estimated since it is only known from one subpopulation whereas its minimal area of occupancy (AOO) is estimated to be $4 \mathrm{~km}^{2}$ (which falls within the limits for Critically Endangered status under the criterion B2). Malaxis cardiophylla is only known from a single subpopulation representing one location (sensu IUCN), this rare species has thus been preliminarily assessed as CR using the green listing method. This species is threatened by selective logging, timber harvesting for small-scale subsistence, slash-and-burn farming and urban development, resulting in habitat reduction and habitat quality reduction.

Previously assessed and published in the IUCN Red data listing for Mayotte as VU D2 (Mercks 2013).

FLOWERING TIME. December to January.

ETYMOLOGY. A reference to its heart-shaped leaves. NOTES. Reichenbach originally described it as Microstylis cardiophylla but it was transferred to the genus Malaxis by Kuntze (1891). The species was placed in the genus Orestias by Margonska \& 

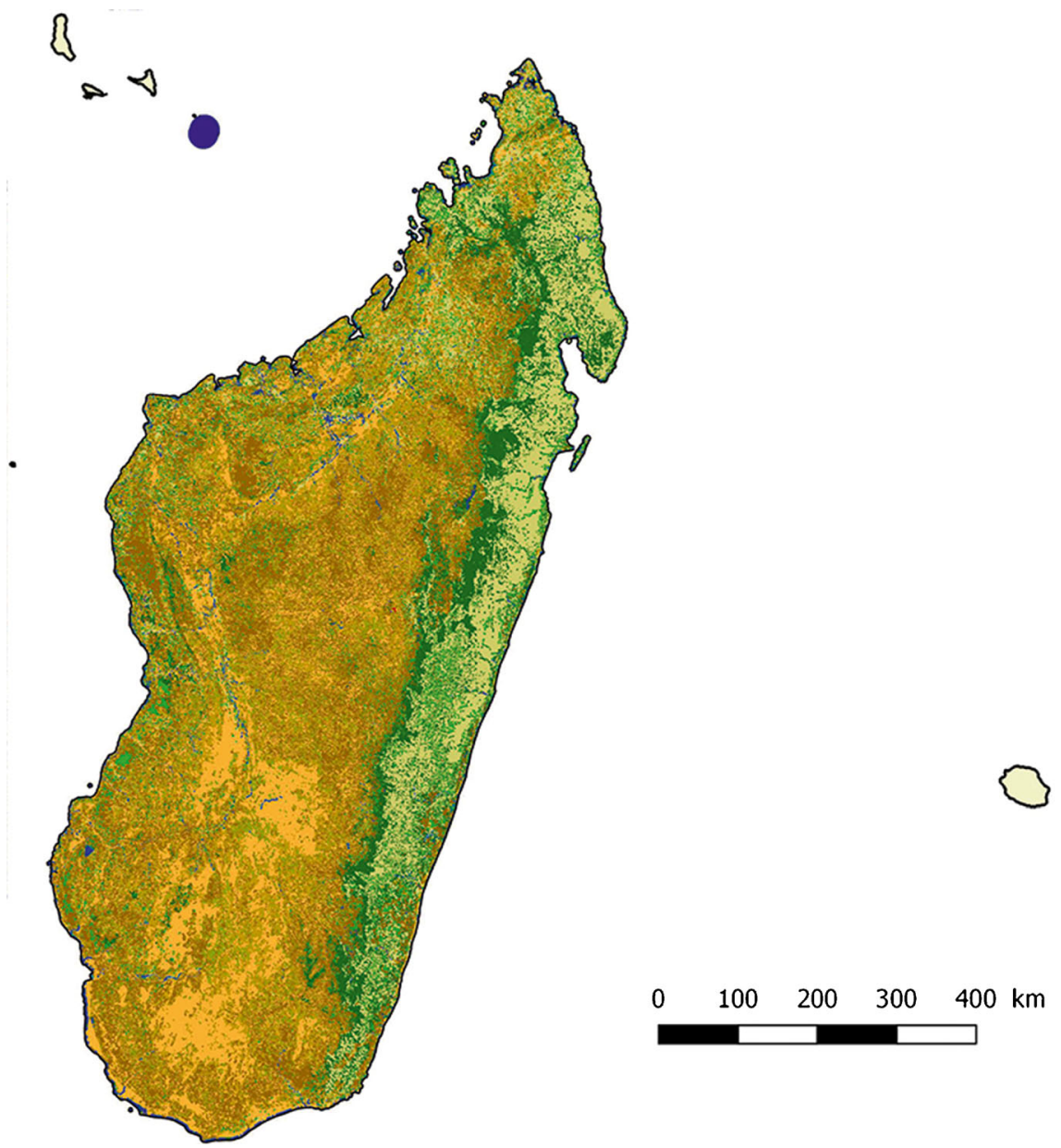

Map 53. Distribution of Malaxis cardiophylla.

Szlachetko (2006) in their revision of the mainland African genus Orestias Ridl. (Ridley 1887: 24). The main differences cited are the characteristics of the lip and gynostemium but these seem identical in several species of Malaxis from the same region. Ridley, in creating the genus based it mainly on the length and shape of the column especially the arched and expanded tip of the column: a similar length and shape can be found in many other species of Malaxis and the type material of $M$. cardiophylla shows no curvature of the column. Significantly, Ridley did not place $M$. cardiophylla in his new genus Orestias. The distinction between the genera seems to be exclusively based on morphological characteristics which overlap and are not exclusive, it is therefore prudent to leave them in the older genus Malaxis.

Margonska (in Margonska et al. 2012: 451) unnecessarily lectotypified Malaxis cardiophylla with Humblot 437 (R40906) and isolectotype (BM000088116). The holotype in $\mathrm{W}$ is clearly marked as such and there is, therefore, no need for lectotypification; she also overlooked the other isotypes.

ILLUSTRATIONS. Figs 74, 75; Margonska \& Szlachetko 2006: 218.
Malaxis madagascariensis (Klinge) Summerh. (Summerhayes 1954: 578); Hermans et al. (2007: 225); Cribb \& Hermans (2009: 160). Type: Madagascar, Hamelin s.n. (holotype LE $\dagger$ ); Iconotype: drawing in LE \& Klinge (1898: t.2).

Microstylis madagascariensis Klinge (1898: 140, t.2); Perrier (1939: 257).=

Small plant $10-12 \mathrm{~cm}$ high, on a short rhizome, the previous pseudobulb leafless. Pseudobulbs conicalcylindrical, partly covered by leaf-like bracts, with 4 5 leaves at the apex. Leaves oval-lanceolate, acuminate, pleated-undulate, spotted, the blade as long as the petiole, including sheath, $6-9 \times 2-4 \mathrm{~cm}$. Inflorescence erect, slender, angular, pale purple c. $15 \mathrm{~cm}$ long, with c. 30 flowers. Peduncle about $1 / 3$ the length of the inflorescence with a few bract-like sheaths. Rachis densely racemose, pyramidal-cylindrical, elongate. Floral bracts linear-lanceolate, as long as the pedicellate ovary. Flowers not resupinate, small, c. $9 \mathrm{~mm}$ long, $7 \mathrm{~mm}$ wide, dull brownish-purple, flower buds green. Dorsal sepal broadly oblong, rounded, obtuse convex, c. $4 \times 2.5 \mathrm{~mm}$. Lateral sepals oblong, obtuse, convex c. $4 \times 2 \mathrm{~mm}$. Petals spreading, linear, 


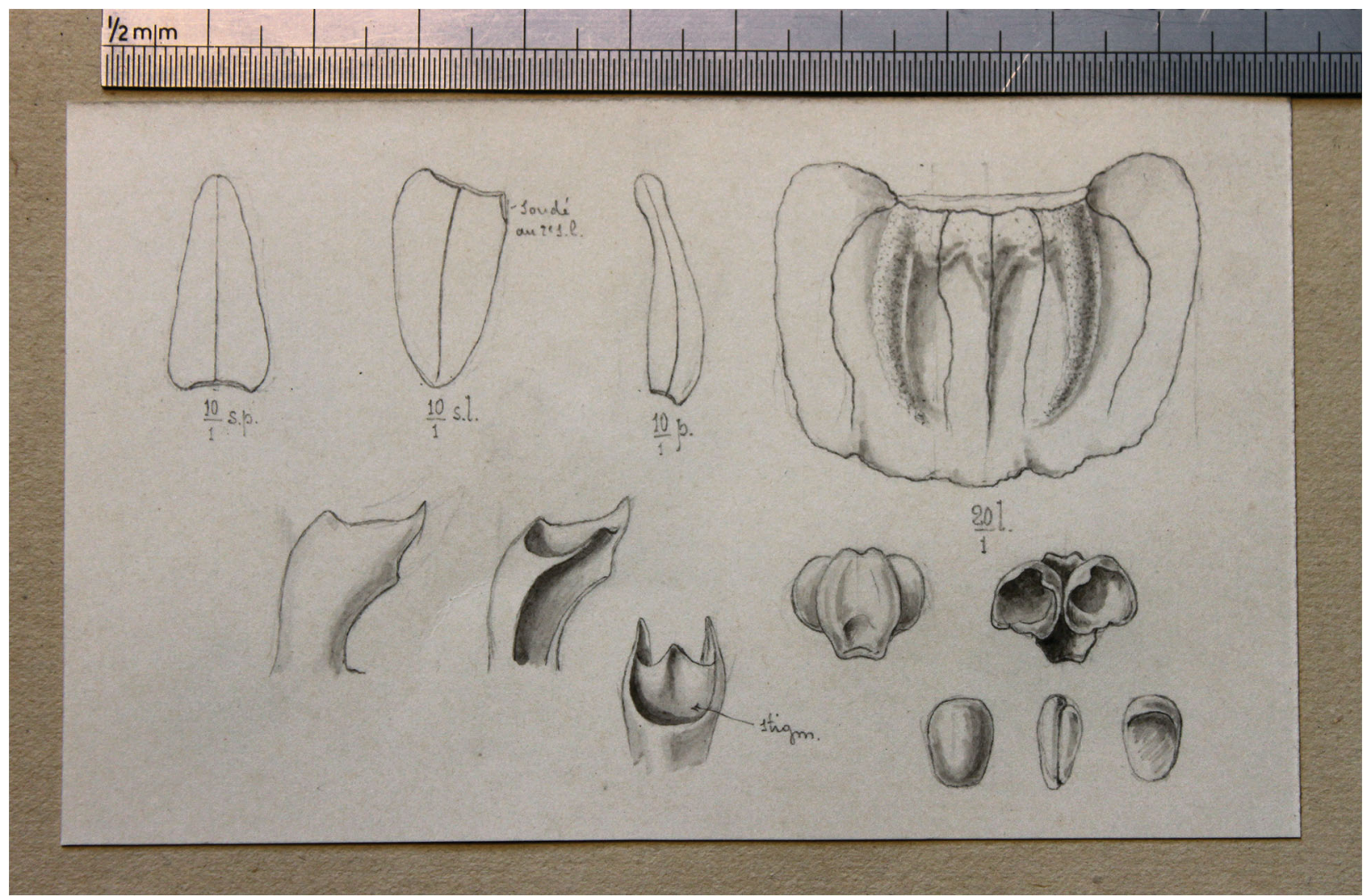

Fig. 74. Malaxis cardiophylla. Drawing by E.-A. Finet on Humblot 437 in P. Courtesy of the Muséum national d'Histoire naturelle, Paris.

shortly acute, c. $4 \times 0.35 \mathrm{~mm}$. Lip 3-lobed, the lobes obtuse, the lateral lobes auriculate the mid-lobe a little bigger, with the auricles at the base as long as the lobes and completely enveloping the column, midlobe with a rounded apex, c. $5 \times 4.5 \mathrm{~mm}$. Column short, wings small, obtuse.

RECOGNITION. Malaxis madagascariensis is a small plant with conical-cylindrical pseudobulbs, pleated undulate leaves, and a long inflorescence with up to 30 flowers. The flowers are small, non-resupinate, and have a distinctly three-lobed lip with the basal auricles surrounding the column.

It has some similarities with Malaxis physuroides but in M. madagascariensis the pseudobulbs are thicker and shorter, the lip is three-lobed (vs suborbicular). There are some vegetative similarities with $M$. seychellarum but again the three-lobed lip with entire margins vs oblong, distinctly dentate at the margin lip is very different. In many ways the species is more akin to some E Asian species, such as Crepidium punctatum (J.J.Wood) Szlach. (Szlachetko 1995: 131), a species that also has spotted leaves, a similar habit but a different flower structure with the dorsal sepal broader and the lip far less deeply three-lobed.

DISTRIBUTION. Madagascar: Hamelin seems to have collected mainly in the North and Eastern forests of
Madagascar in search of horticulturally desirable species like Eulophiella elisabethae Rolfe (1891: t.325). Map 54.

SPECIMEN EXAMINED. MADAGASCAR. S. loc., 1893, Hamelin s.n. (holotype LE $\dagger$ ).

HABITAT. Not known.

CONSERVATION STATUS. Data deficient, known from the type only with an imprecise locality.

ETYMOLOGY. Referring to the assumed country of origin.

NOTES. Klinge originally described it as Microstylis madagascariensis but Summerhayes (1954) transferred it to the genus Malaxis. Margonska (in Margonska et al. 2012: 303) placed the species under Crepidium koordersii (J.J.Sm.) Szlach. (Szlachetko 1995: 127) from Indonesia. Margonska does not substantiate this decision apart from stating that "they are without any doubt conspecific and that no species from Crepidium has ever been recorded from Madagascar and that the origin of the Microstylis madagascariensis plant cultivated at Hort. Petrop. was Madagascar and the subsequent mechanical transferring of taxa without careful checking have led to citation errors in contemporary publications relating to Madagascar". Although the plant habit and lip have some similarities there are significant differences between the two species: the leaves of Malaxis madagascariensis are considerably 

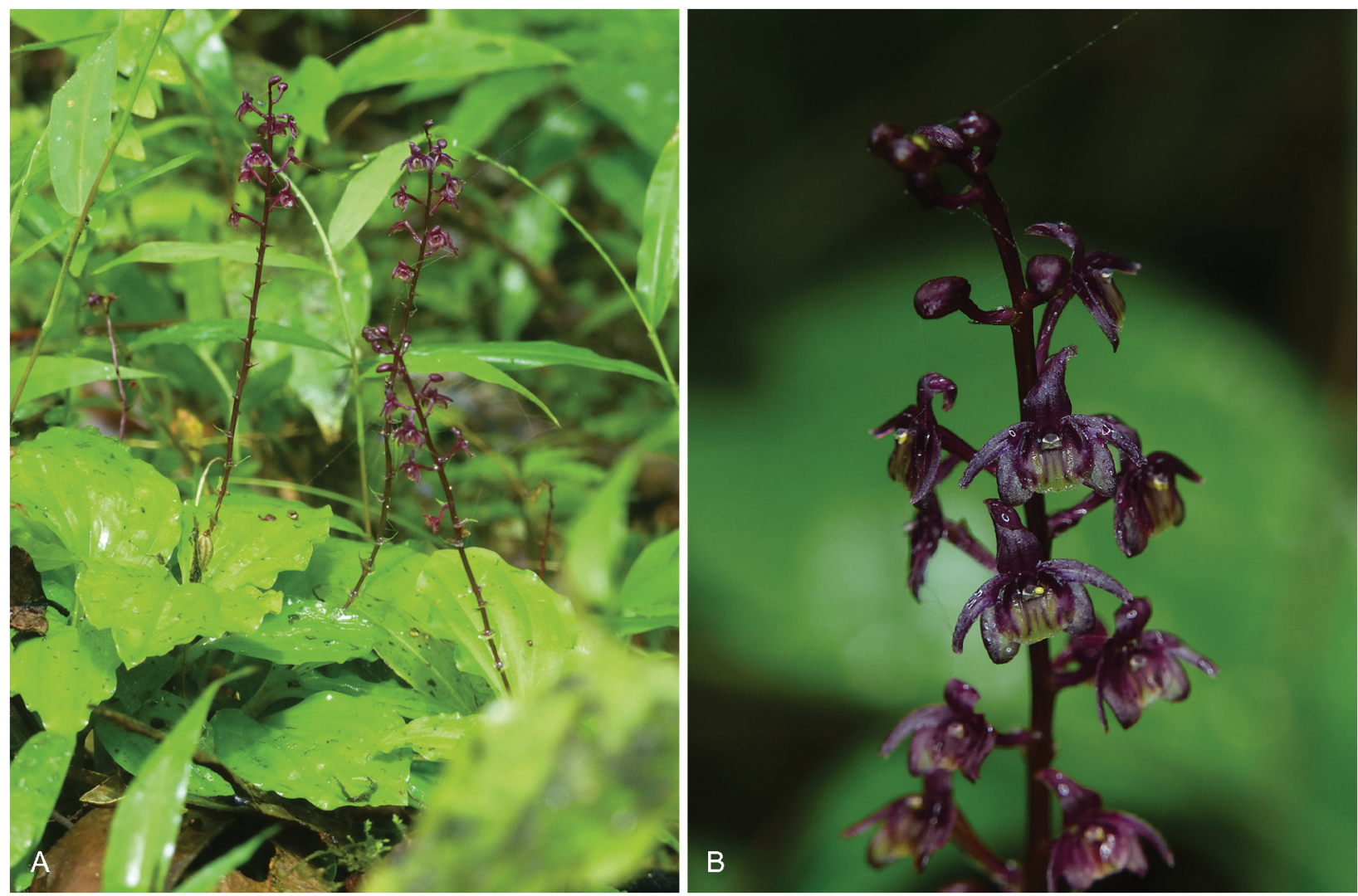

Fig. 75. Malaxis cardiophylla. A habit; B flowers. PHOtOS: ETIENNE VENNETIER.

smaller and said to be spotted by Klinge (vs green), the inflorescence is much shorter, the proportions of the lip are different with the mid-lobe narrower and the lateral lobes longer. In addition C. koordersii has completely green flowers whilst Klinge clearly indicates a purple colouration for both rachis and flowers. Although Klinge is clear about the origin of the plant being from a Humblot Madagascar collection, it is entirely possible that this may have been a mix-up, as suggested by Margonska but there is no evidence for this. It is not clear if the species actually belongs in Crepidium and there is no doubt that several closely related Malaxis are found on Madagascar. On this evidence there is no reason to remove this species from the Madagascar Flora until a more credible case is put forward. Margonska cited the original Klinge drawing at LE as the iconotype. In 2014 Margonska proposed to conserve the name Microstylis koordersii (Crepidium koordersii) from Java and Sulawesi against $M$. madagascariensis because the name of the latter would have priority and the new nomenclatural combination would be a potential source of confusion and imply occurrence in Madagascar.

Malaxis madagascariensis is therefore somewhat enigmatic being based on a single specimen collected at an unknown locality in 'Madagascar' by Hamelin who was a commercial collector there in the late $19^{\text {th }}$ century, supplying plants to the nurseries of Linden and Messrs F. Sander \& Co in Europe. He collected large quantities of Eulophiella elisabethae in Madagascar at the same time as the Malaxis specimen. Nothing is known about the exact localities where he collected or how the new plant reached Johannes Klinge in Leningrad. Klinge's description is based on a cultivated plant flowering in the hothouses of the Imperial Botanical Collections, Leningrad. His type specimen was kept at the Komarov Botanical Institute in Leningrad (LE) but according to Christenson (1995) much of the type material was lost or destroyed, including the type of Klinge's Microstylis madagascariensis. It has not been possible to verify this with LE. It was therefore necessary to select a new type with the illustration by Klinge the only option.

Klinge's description is not detailed and his more detailed drawing has no scale which makes most of the description speculative. It is entirely possible that there was a mix-up in the origin of the cultivated plant, especially as no further material has been recorded from Madagascar. The species may remain ambiguous.

ILLUSTRATION. Klinge (1898: t.2) (Fig. 76).

Malaxis physuroides (Schltr.) Summerh. (Summerhayes 1954: 578); Hermans et al. (2007: 225); Cribb \& Hermans (2009: 160). Type: Madagascar, Sambirano 
0

250

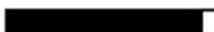

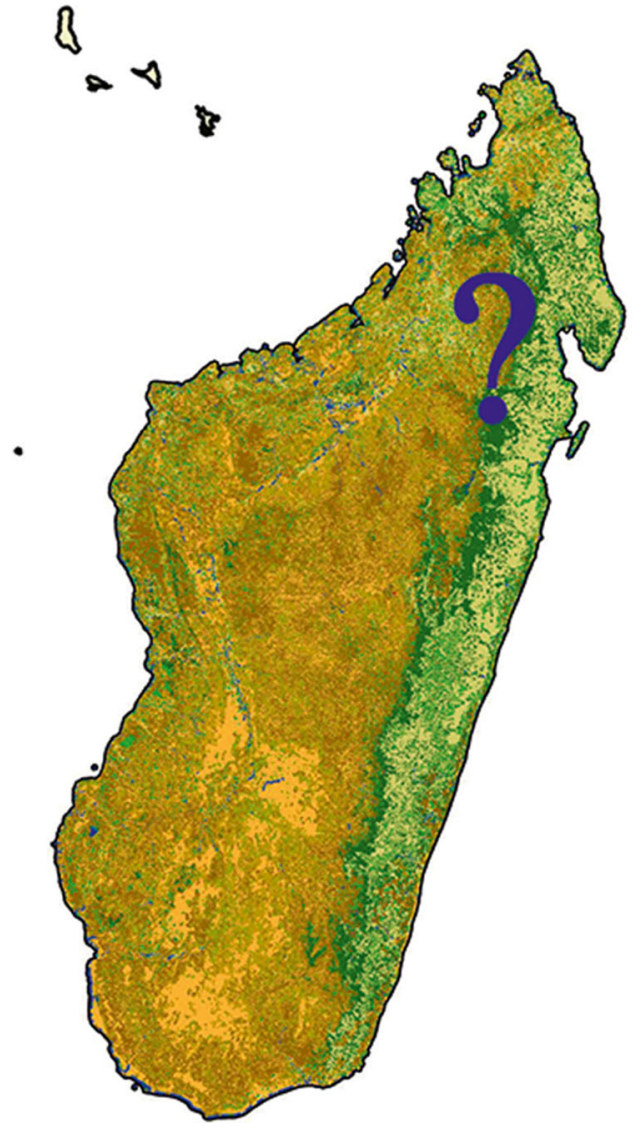

Map 54. Distribution of Malaxis madagascariensis.

Manongarivo massif, 400 m, April 1909, Perrier 8010 (89 of Schlechter) (holotype P).

Microstylis physuroides Schltr. (Schlechter 1913: 164; 1924: 133); Perrier (1936: 233; 1939: 258).

Lisowskia physuroides (Schltr.) Szlach. (Szlachetko 1995: 121).

Small scrambling terrestrial, epiphytic or lithophytic plant $9-11 \mathrm{~cm}$ high, on a short creeping rhizome with the new growth emerging from the base or node of the previous withered decumbent pseudobulb, cov-

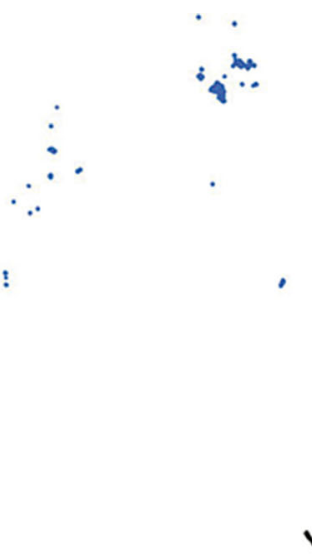

$$
\text { ; }
$$

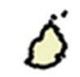

ered in brown scarious sheath remnants, roots filiform, flexuose, villous. Pseudobulbs caulescent, succulent, cylindrical, $5-7.5 \mathrm{~cm}$ long, $3-6 \mathrm{~mm}$ diam., covered with $3-4$ yellowish, papery overlapping sheaths attenuate at the tip, with $2-3$ (rarely 4) leaves at the apex. Leaves erectly spreading, broadly oval-acute, rounded to sub-cordate at the base and contracted into a $8-12 \mathrm{~mm}$ petiole, overall $3.3-7.2 \times$ $2.4-4.1 \mathrm{~mm}$. Inflorescence erect, thin, $7-14 \mathrm{~cm}$ long, with up to 40 flowers. Peduncle about as long as the raceme, somewhat angular, with several small bract- 

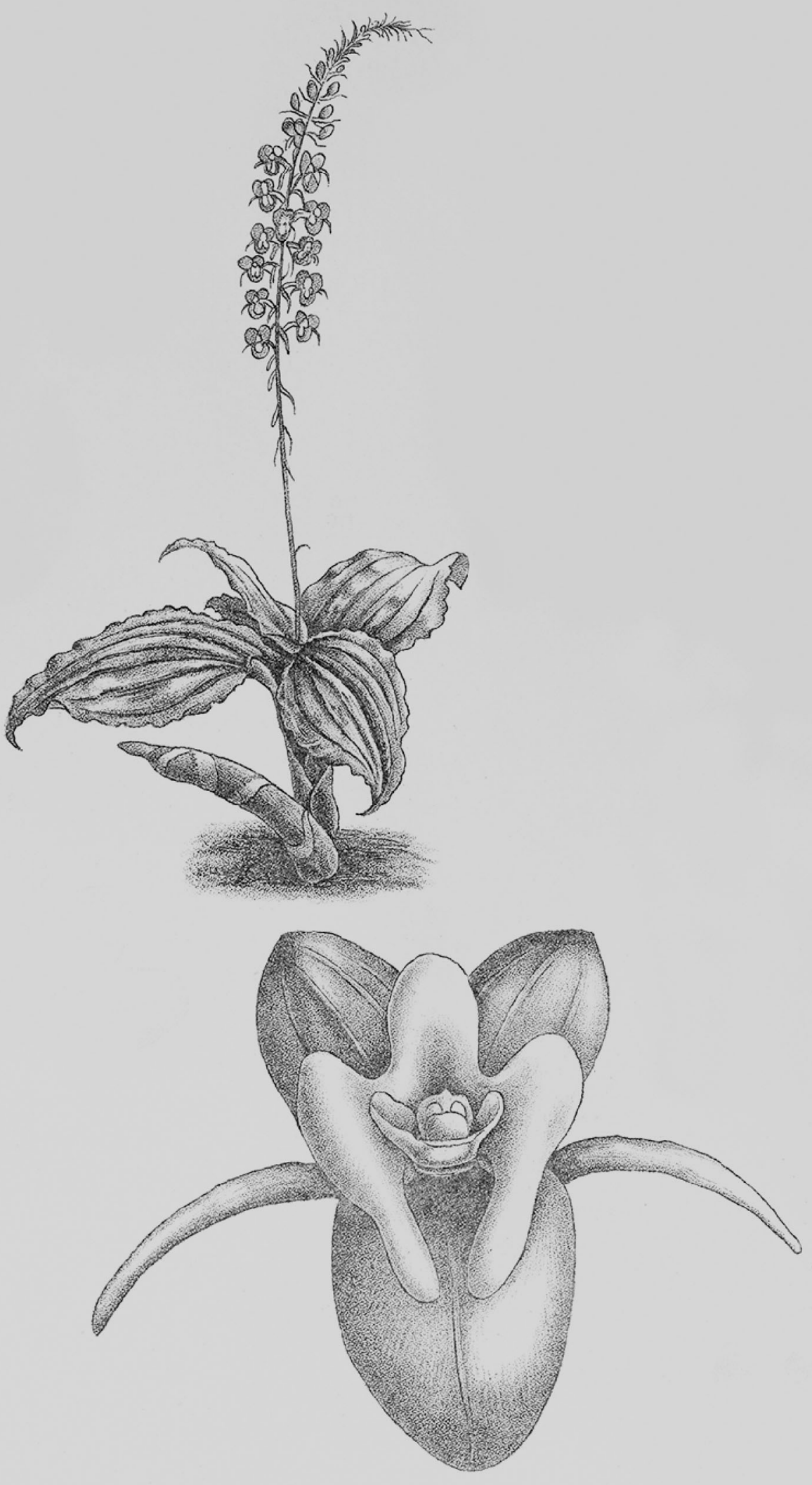

Fig. 76. Malaxis madagascariensis. Habit and flower, from Klinge 1898: t2. 
like sheaths, red. Rachis very densely racemose. Floral bracts erect, narrowly lanceolate, acute, up to $2.3 \times 0.5$ $\mathrm{mm}$. Flowers not resupinate, c. $3 \times 4 \mathrm{~mm}$, dark red. Pedicel and ovary glabrous $2-2.3 \times 0.2-0.4 \mathrm{~mm}$. Dorsal sepal oval-lanceolate obtuse, $1.7-2 \times 0.8-0.9 \mathrm{~mm}$. Lateral sepals oval-obtuse, $1.2-1.7 \times 0.7-0.8 \mathrm{~mm}$. Petals linear, $1-1.2 \times 0.2-0.3 \mathrm{~mm}$. Lip suborbicular, obtuse with distinct obtuse basal wings folded around the column, margins of the blade sinuate, anterior margin rounded-truncate to a little indented, disk with a subreniform callus (perhaps pubescent) just below the middle, $1.6-1.9 \times 1.5-1.7 \mathrm{~mm}$. Column short, straight, with indistinct wings, c. $0.5 \times 0.2 \mathrm{~mm}$. Anther ovate, truncate at the back, angular-obtuse at the front c. $0.33 \times 0.2 \mathrm{~mm}$. Pollinia ovoid c. $2 \mathrm{~mm}$.

RECOGNITION. A small plant with cylindrical succulent pseudobulbs, two to three broadly apical oval leaves. Inflorescence almost as long as the plant, very denselyflowered, flowers small, red, lip suborbicular with obtuse basal wings alongside the column, anterior margin rounded-truncate with a distinct rounded callus on the disc.

Schlechter, in his description, likened it to Microstylis stelidostachya Rchb.f. and Malaxis katochilus Schltr. from E Africa (now Malaxis prorepens (Kraenzl.) Summerh. (Summerhayes 1934: 208) but the rachis is much less dense and the flowers are different especially in the shape of the lip and the rounded callus. Malaxis physuroides differs significantly from all the other Malaxis from the Madagascar region by the very dense rachis of small flowers and the distinct rounded single callus on the lip.

DISTRIBUTION. Endemic to Madagascar: Antsiranana and Toamasina provinces (Map 55).

SPECIMENS EXAMINED. MADAGASCAR. Sambirano Manongarivo massif, $400 \mathrm{~m}$, April 1909, Perrier 8010 (89 of Schlechter) (P); confluence of the Onive and the Mangoro area, c. 700 m, Feb. 1924, Perrier 17188 (P); Mt d'Ambre, Nov. 2007, 1400 m, Nusbaumer et al. LN2374 (G).

HABITAT. Humid evergreen forest, shaded wet rocks. Altitude: 400 - $1400 \mathrm{~m}$.

CONSERVATION STATUS. Category EN: the extent of occurrence (EOO) of Malaxis physuroides is estimated to be $31,200 \mathrm{~km}^{2}$ (which falls within the limits for Endangered status under criterion B1) whereas its minimal area of occupancy (AOO) is estimated to be $20 \mathrm{~km}^{2}$ (which also falls within the limits for Endangered status under the criterion B2). Malaxis physuroides is only known from three subpopulations representing three locations (sensu IUCN), this species has thus been preliminarily assessed as EN using the green listing method. This species is threatened by selective logging, timber harvesting for small-scale subsistence and tavy (slash-and-burn farming), resulting in habitat reduction and habitat quality reduction.

FLOWERING TIME. November to April.
ETYMOLOGY. A reference to the orchid genus Physurus Rich. ex Lindl. (now Erythrodes Blume (1825: 410)) with which it shares the habit of some of the species. NOTES. In 1913 Schlechter described it as Microstylis physuroides, based on material collected by Perrier and also illustrated the plant and flower. Schlechter, in his early collaboration with Perrier, used a different numbering system for specimens than Perrier. It was placed into the genus Malaxis by Summerhayes (1954). Szlachetko (1995) transferred it to his new genus Lisowskia but none of the morphology or genetics support this. Margonska (in Margonska et al. 2012: 454) designated as lectotype P00094916, referring to Perrier's specimen in Paris 8010 (89 of Schlechter). She designated a hypothetical specimen in Berlin that was assumed lost as an isolectotype, but there is no reason to believe that such a specimen existed or was lost. As there is only one Perrier sheet (annotated by Schlechter) that is obviously original material used by the author, there is no need to assign lectotypes.

ILLUSTRATIONS: Schlechter (1913: pl.7; 1932: T.51).

Malaxis seychellarum (Kraenzl.) Summerh. (Summerhayes 1954: 578); Robertson (1989: 223).

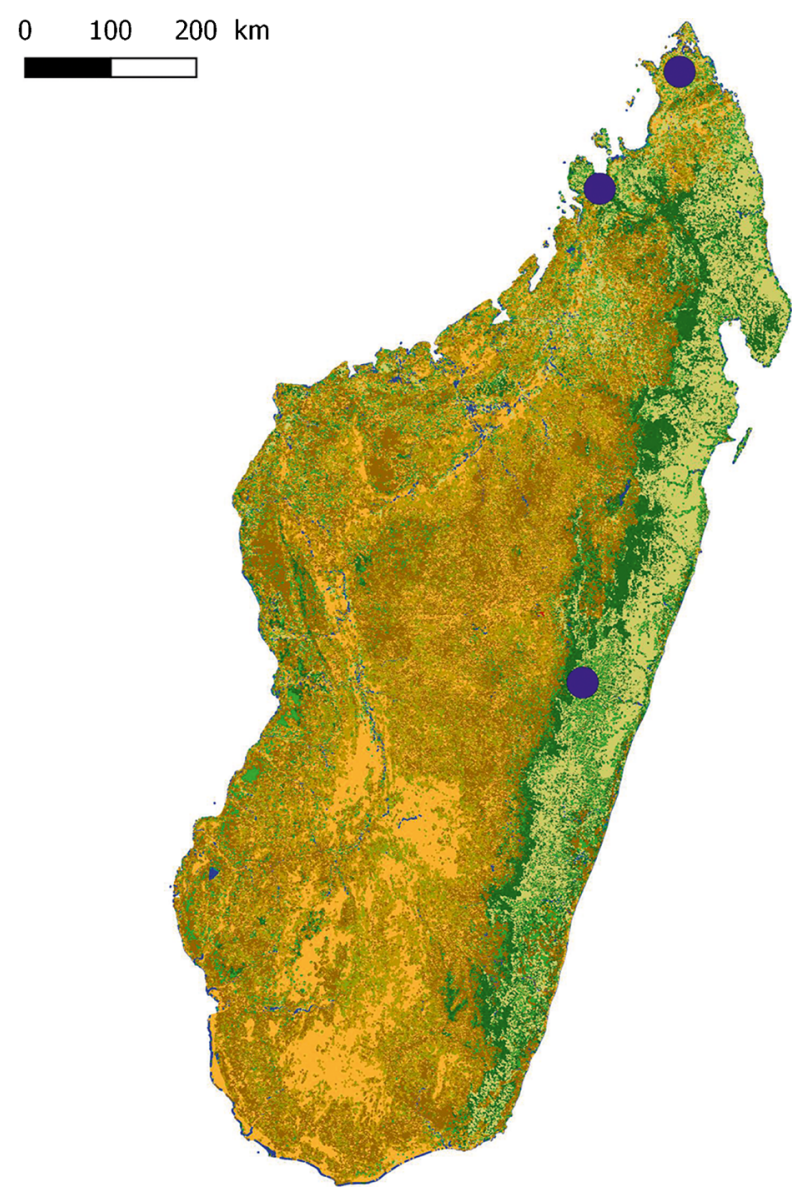

Map 55. Distribution of Malaxis physuroides. 
Type: Seychelles, Mahé, Mt Harrison, 1888, Schimper $104+\& 352 \uparrow$. Neotype designated here: Seychelles, above La Misère, c. 2000 ft, March 4, 1888, Lister s.n. (BM).

Liparis seychellarum Kraenzl. (Kraenzlin 1902: 60).

Microstylis seychellarum (Kraenzl.) Schltr. (Schlechter 1915a: 411); Diels (1922: 439).

Microstylis thomassetii Rolfe (1922: 24). Type: Seychelles, Mahé, Cascade Estate, Aug. 1902, Thomasset 99 (holotype K: K000242167, isotype K000242166)

Seidenfia seychellarum (Kraenzl.) Szlach. (Szlachetko 1995: 122); Margonska et al. (2012: 538).

Medium to large humicole plant, epiphyte or lithophyte $10-33 \mathrm{~cm}$ tall but generally between 15 and 25 $\mathrm{cm}$, rhizome very short, repent, roots filiform, flexuose more or less pilose. Pseudobulbs stem-like, narrowly cylindrical-ovoid to subcylindrical, thickened-bulbous at the base, $5-8 \mathrm{~cm}$ long, $1-2 \mathrm{~cm}$ in diam., covered by $2-3$ long and overlapping stem-sheaths, sometimes the older pseudobulb obliquely divergent and always leafless, with up to $2-5$ leaves but generally $3-4$, starting half-way up the stem and ending with $2-3$ larger ones towards the apex. Leaves erectly spreading, obliquely elliptic to ovate-elliptic, apiculate to obtuse, base rounded-cuneate and then attenuate into a 1.5 $3 \mathrm{~cm}$ petiole, overall $7-20 \times 2.5-7 \mathrm{~cm}$, plicate, margins a little undulate to crenulated, thin, purple becoming green or green. Inflorescence erect, up to 30 $\mathrm{cm}, 2-3 \mathrm{~mm}$ in diam., green to purple, densely racemose with up to 50 flowers. Peduncle costate, with 2 -3 bract-like peduncle sheaths, up to $4 \times 2 \mathrm{~mm}$. Rachis around $3 / 4$ of the inflorescence. Floral bracts arched, descending, linear-lanceolate-acuminate, $3-8 \times 1.5-$ $2 \mathrm{~mm}$, green to purple-brown. Flowers not resupinate, very small to small, opening in succession, overall c. 5 $\times 6 \mathrm{~mm}$, variable in colour from pale greenish-yellow, lemon-yellow, purplish green to purple, fading to yellow-orange, there seem to be distinct colour forms in different locations. Pedicel and ovary linear, slightly arched, $3.2-5 \times 0.3-0.8 \mathrm{~mm}$, green, often tinted purple. Dorsal sepal lanceolate, obtuse, $2.3-3.9 \times 0.4 \times$ $1.1 \mathrm{~mm}$. Lateral sepals linear-oblong, obtuse, subfalcate, $2.3-3.2 \times 0.9-1.6 \mathrm{~mm}$. Petals linear, obtuse, arched and crossing below the column, $2.9-3.8 \times 0.3-0.6$ mm. Lip transversally oblong to flabellate, shortly winged at the base, with a more or less distinct basal callus, distinctly irregularly dentate at the anterior margin, $1.8-2.1 \times 2.5-3.3 \mathrm{~mm}$. Column slightly incurved, wings small, distinctly rounded, apex triangular, $1.2-1.6 \times 0.3-0.8 \mathrm{~mm}$. Anther broadly ovoid, angular at the base, c. $0.3 \times 0.4 \mathrm{~mm}$. Seed capsule obovoid, shortly pedicellate, $8-10 \mathrm{~mm}$ long

RECOGNITION. This is a large plant, with nonresupinate flowers, arched descending floral bracts, subfalcate petals, an oblong to flabellate lip with a callus at the base and dentate margin, and an anther with rounded lobes at the apex.

Kraenzlin mentioned that in shape it was similar to Liparis flavescens but the obviously wider petals and the short wedge-shaped, very wide at the front, toothed lip were distinctive. It is indeed similar to several Liparis from Madagascar and the Mascarenes and vegetatively comparable with species like L. ochracea but the dense rachis of small non-resupinate flowers with a dentate lip margin make it very distinct. Rolfe, in describing Microstylis thomassetii, stated that it was related to the Asian Microstylis rheedii Lindl. (Lindley 1830a: 21) but differed by the narrower leaves and the shorter dentate lip. The latter shows, together with a number of other species from Asia, a number of similarities both in plant and flower but the flowers of Malaxis seychellarum are smaller and the teeth at the margin of the lip are generally fewer $(6-8$ vs $8-18)$ and not as deeply and acutely dentate. There is undoubtedly a genetic relationship between the species but the Seychelles taxon warrants specific recognition.

DISTRIBUTION. Endemic to the Seychelles: on the islands of Mahé and Silhouette (Map 56).

SPECIMENS EXAMINED. SEYCHELLES. Mahé, Mt Harrison, 1888, Schimper 104 and $352(\dagger)$; above La Misère, 4 March 1888, Lister s.n. (BM); Mahé, Mt Siebert 6 April 1888, Lister s.n. (neotype BM); Mahé, Cascade Estate, 1901, Thomasset s.n. (K000242166 \& K000242167 on mixed sheet K); s. loc., 24 June 1918, Hort. Kew (K); Silhouette, 1908, Gardiner 112 (K); Silhouette, 1908, Gardiner 105 (K); Silhouette, 1908, Gardiner s.n. (K); Mare aux Cochons, 2000ft, 1908, Gardiner s.n. (K); Silhouette, Gardiner s.n. (K); Mahé, Morne Pilot, 2400 ft, Sept. 1908, Gardiner s.n. (K); Mahé, Mare aux Cochons, 1908, Gardiner s.n. (K); Mahé, Mourne Seychellois, 18 July 1936, Osborne Day 76 (BM); Mahé, Trois Frères, Dec. 1961, Jeffrey Ẽ Zelia 552 (K); Mahé, Trois Frères, 500 m, Nov. 1961, Jeffrey Ẽ Zelia 456 (K, MAU); Mahé, Trois Frères, $500 \mathrm{~m}$, Nov. 1961, Jeffrey E Zelia 452 (K); Mahé, above Sans Souci, 400 m, Nov. 1961, Jeffrey Ẽ Zelia 401 (K); Mahé, Mahe, summit of Morne Blanc, June 1970, $660 \mathrm{~m}$, Proctor 4021 (K); Mahé, Morne Blanc, Oct. 1970, Schlieben 116774 (K); Mahé, Congo Rouge, April 1972, Jacquemin 1035 (P); Mahé, Congo Rouge, April 1972, Jacquemin 971 (P); Mahé, Congo rouge, Hort. Tana, Jan. 1973, Jacquemin 1033 (P); Mahé, Congo Rouge, Oct. 1973, Proctor 4512 (K); Mahé, Cascade Estate, Morne Blanc, 600 m, March. 1975, Lesouef 192 (G); Mahé, Mt Harrison, April 1978, Robertson 2634 (K); Mahé, Mt Simpson, Nov. 1980, Friedmann 3523 (P); Mahé, Congo Rouge, Nov. 1980, Friedmann 3487 (P); Mahé, Congo Rouge, Nov. 1980, Friedmann 3489(P); Mahé, 600 - 700 m, Oct. 1981, Renz 13031.1 \& 13031.2 (RENZ); Mahé, Congo Rouge, May 1982, Bosser 226655 (P); Mahé, Morne Blanc, May 1982, Bosser 22686 (P); Mahé, Congo Rouge, May 1982, 


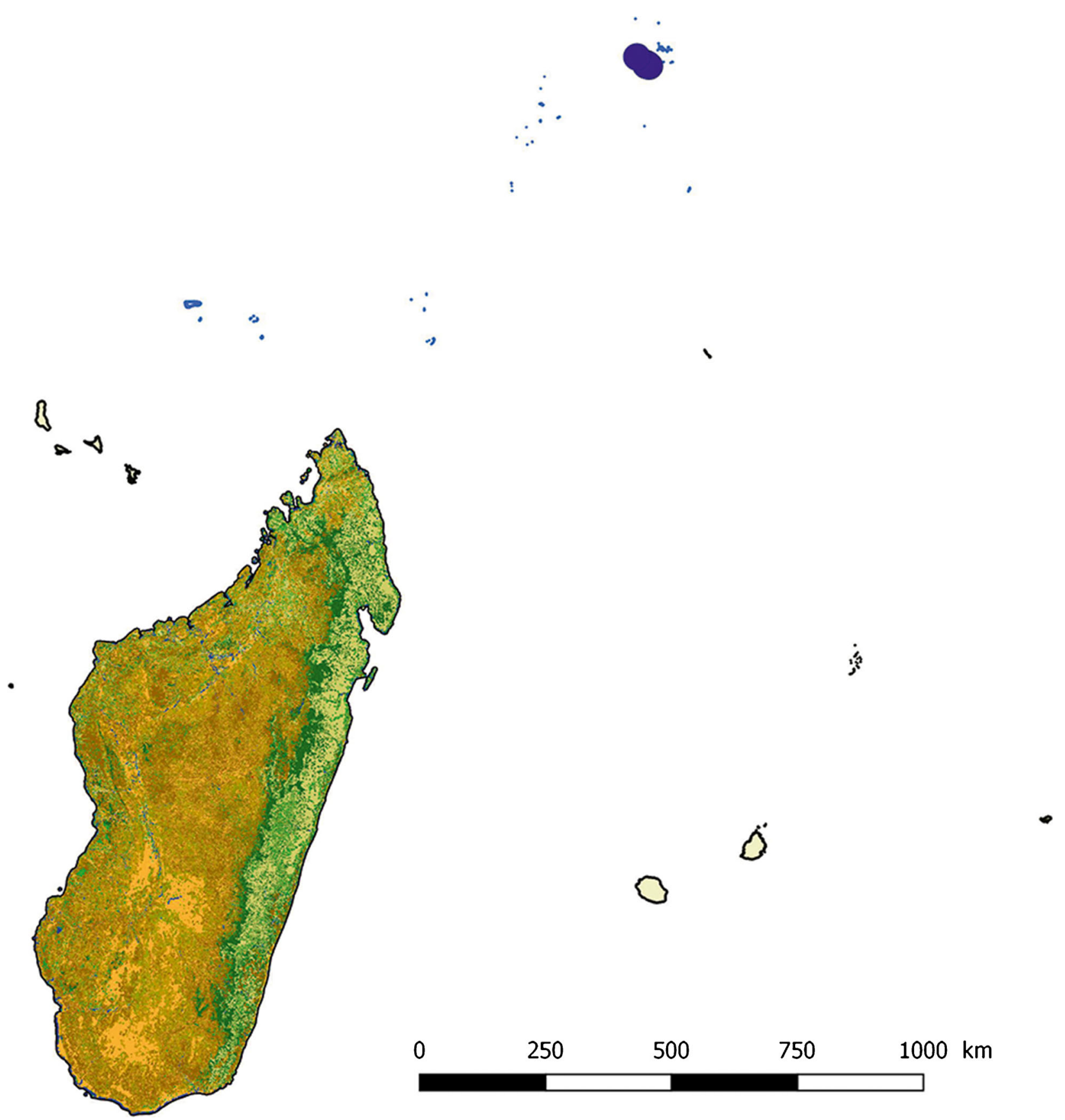

Map 56. Distribution of Malaxis seychellarum.

Bosser 22664 (P); Silhouette, Jardin Marron, June 1985, Friedmann 3487 (P); Morne Blanc, May 1985, Friedmann 5050 (P); Silhouette, Jardin Marron, June 1985, Friedmann 5284 (P); Mahé, Morne Blanc, March 2003, Rouhan E Vos 153 (P); s. loc., Horne s.n. (K).

HABITAT. Montane forest, growing in moss on rocks, on trees and tree ferns, in damp humus in shady undergrowth. Altitude: $400-750 \mathrm{~m}$.

CONSERVATION STATUS. Category EN: the extent of occurrence (EOO) of Malaxis seychellarum is estimated to be $65 \mathrm{~km}^{2}$ (which falls within the limits for Critically Endangered status under criterion B1) whereas its minimal area of occupancy (AOO) is estimated to be $24 \mathrm{~km}^{2}$ (which falls within the limits for Endangered status under the criterion B2). With only two known subpopulations representing three locations (sensu IUCN), this species has been preliminarily assessed as EN using the green listing method. This species is threatened by the presence of invasive species in the Seychelles, resulting in habitat quality reduction. 
FLOWERING TIME. The species seems to flower all year round with the main season from November to May. Flowering and seed-bearing plants co-exist.

ETYMOLOGY. In reference to the Seychelles archipelago where the species is endemic.

NOTES. Moore in Baker (1877: 343) commented on a flowerless specimen at $\mathrm{K}$ as follows: "gathered in the Seychelles by Mr Horne, which has the habit of Liparis flavescens, but with smaller bracts, shorter pedicels and smaller fruits. It is probably a new species belonging either to this genus or to its close ally Microstylis". Kraenzlin (1902) described L. seychellarum based on a collection by Andreas Schimper (1856 - 1901), a German botanist and geographer who, in 1898, took part in the SS Valdivia expedition which visited the Seychelles as part of its itinerary. It was transferred to the genus Microstylis by Schlechter (1915a). The report of the expedition did not appear until the 1920s where Microstylis seychellarum was included and illustrated (Diels 1922: 439). It is known that most of Kraenzlin's type material was lost and, as the Schimper type for L. seychellarum has not been found, it must be assumed lost. Most of Schimper's herbarium was kept as spirit in the Bonn (BON) herbarium but this was subsequently destroyed. Other material went to Basel (BAS) but there is no record of the plant there. The illustration in Diels (1922) could be based on Schimper's plant but there is no direct evidence for this, it also lacks detail to be able to assign it as an Iconotype. It was therefore necessary to create a new type for the species: a specimen collected by Joseph Lister (March 4 1888, Lister s.n. (BM)) was chosen. Lister (1857 - 1927) explored the Seychelles as naturalist on H.M.S. Egeria from February to May 1888. The specimen is in good condition, represents the species well and was collected on Mahé at La Misère not far from Schimper's collection locality on Mt Harrison. The neotype (Lesoeuf 192 in G) (indicated in error by the author as L. bernardi s.n., leg. Lesouef 192), chosen by Margonska et al. (2012: 538) is not representative.

In 1922 Microstylis thomassetii of Rolfe was published posthumously, based on a 1901 collection by Thomasset from the Cascade Estate on Mahé, the same area as Schimper's type locality. There is no doubt that it is the same species. It is in fact possible that this material was collected in the same place and had the same origin. Just before his death in 1901, Schimper sent some herbarium material from the Cascade Estate to Kew (Hemsley 1916: 3) but there is no evidence that the specimen used by Rolfe to describe his Microstylis thomassetii did not come directly from Thomasset. Summerhayes (1931) in his enumeration of the angiosperms of the Seychelles archipelago removed Rolfe's species to synonymy in Microstylis seychellarum and in 1954 he transferred it to the genus Malaxis. Szlachetko (1995) included the species in his new genus Seidenfia, together with several other Malaxis, but there is no evidence for this.

ILLUSTRATIONS. Fig. 77; Diels (1922: 440); Robertson (1989: 219); Margonska et al. (2012: 538).

Malaxis weberbaueriana (Kraenzl.) Summerh. (Summerhayes 1934: 208). Type: Cameroon, Cameroon Mts, 1906, Weberbauer 42 (holotype $\mathrm{B} \uparrow$, iconolectotype K K000106616, selected by Cribb (1984: 289)).

Liparis weberbaueriana Kraenzl. (Kraenzlin 1908: 128).

Lisowskia weberbaueriana (Kraenzl.) Szlach. (Szlachetko 1995: 121).

Malaxis francoisii (H.Perrier) Summerh. (Summerhayes 1954: 578); Hermans et al. (2007: 225); Cribb \& Hermans (2009: 160). Type: Madagascar, Mandraka, E Imerina, François in Perrier 17585 (holotype P) synon. nov.

Microstylis francoisii H.Perrier (1936: 234; 1939: 259).

Very small to small terrestrial or epiphytic plant up to $12 \mathrm{~cm}$, on a tufted to creeping rhizome roots wiry, villous. Pseudobulbs swollen at the base, then cauliform, thin, $4-8 \mathrm{~cm} \times 2-5 \mathrm{~mm}$, partly covered by $2-3$ thin sheaths with $3-4$ apical leaves, one often considerably smaller. Leaves ovate, attenuate at base and tip, narrowed into a short petiole, thin, with prominent veins, pale to dark green, $3-7.5 \times 2-4.5 \mathrm{~cm}$. Inflorescence erect, thin, c. $1-2 \mathrm{~mm}$ in diam., up to $13 \mathrm{~cm}$ long. Peduncle about $1 / 2$ the length of the inflorescence, with several sterile bracts towards the base. Rachis laxly several- to many-flowered, with up to 18 flowers. Floral bracts lanceolate, spreading, 2.9 - 5.3 $\times 1.1-2 \mathrm{~mm}$. Flowers very small, erectly spreading, 3.5 $-4 \times 3-4.1 \mathrm{~mm}$ including the ovary, yellowish-green to brownish-red, petals and sepals pale translucent, lip a tinted maroon-purple. Pedicel and ovary cylindrical, ridged, $2.6-3.1 \times 0.3-0.8 \mathrm{~mm}$. Dorsal sepal ovate, obtuse to attenuate, $2.1-3.8 \times 1.1-1.7 \mathrm{~mm}$. Lateral sepals ovate, oblique, $1.8-2.1 \times 1-1.3 \mathrm{~mm}$. Petals linear-lanceolate, $2.8-3 \times 0.3-0.6 \mathrm{~mm}$. Lip entire, oval to suborbicular with two elongate, somewhat pubescent swellings on each side, the base recurved and folding around the column, often surpassing the column, $1.9-2.6 \times 1.8-2.8$ $\mathrm{mm}$. Column straight, with minute rounded wings at the apex, $0.6-0.8 \times 0.30 .5 \mathrm{~mm}$. Anther below the apex of the column, broadly ovate with a small lobule at the anterior margin, c. $0.4 \times 0.5 \mathrm{~mm}$. Pollinia orbicular, c. $0.2 \times 0.2 \mathrm{~mm}$.

RECOGNITION. This small plant has long thin pseudobulbs, two to three (rarely four) ovate leaves with short petioles at the tip, a long, laxly flowered inflorescence, and very small flowers, with a lip with 

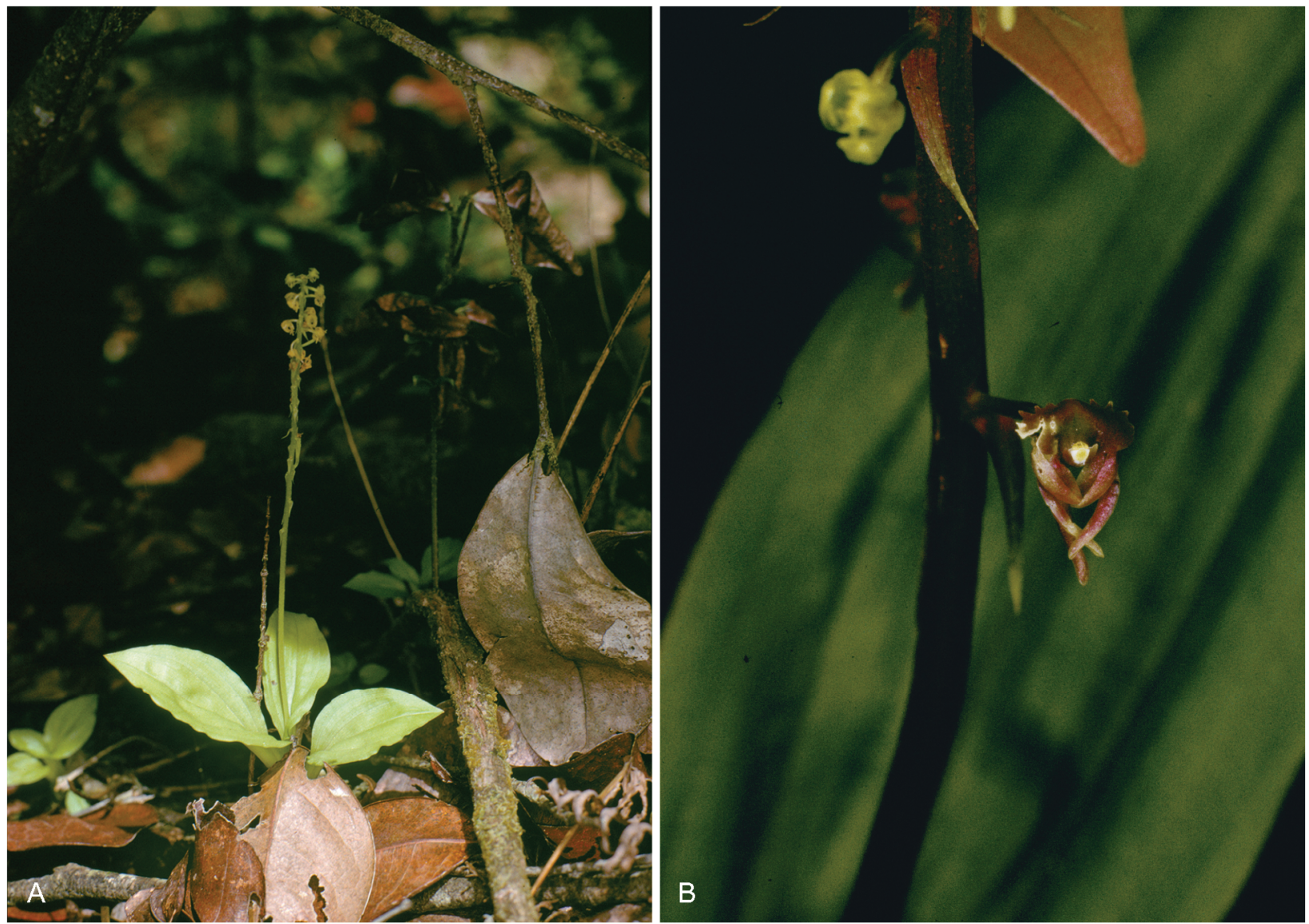

Fig. 77. Malaxis seychellarum. A habit; B flower. PHOtOS: JEAN-MICHEL HERVOUET.

pubescent swellings, a base folded around the column, and a column with rounded apical wings.

The oval lip is similar to that of Malaxis cardiophylla but plant and leaf are different with the base of M. cardiophylla being more cordate than in this species, the leaves of $M$. cardiophylla also have a distinct long petiole. The lip is broader in M. cardiophylla which also lacks the crescent-shaped swellings, M. weberbaueriana has much longer basal auricles that surround or surpass the column. The column has rounded apical wings (vs angular). It differs from $M$. welwitschii from Angola by the taller elongate plant with thin pseudobulbs, shorter pseudobulb sheaths, apical ovate leaves (vs caulescent, cordate), the entire ovate lip (vs three-lobed) with the basal wings folded around the column (vs below) and the rounded (vs angular wings) of the column.

DISTRIBUtION. Cameroon, Bioko, Fernando Po, Kenya, Malawi, Mozambique, Rwanda, Tanzania, Zaire, Zambia, Zimbabwe. Fairly widespread in Madagascar: Antananarivo, Antsiranana and Toamasina provinces (Map 57).

SPECIMENS EXAMINED. CAMEROON. Cameroon Mts, 1906, Weberbauer 42 (holotype $\mathrm{B} \dagger$, icono-lectotype K (K000106616)); Bamenda, Bali-Ngemba, June 1951,
Ujor 30424 (P); NW Region Boyo Laikom, Dec. 1998, $1860 \mathrm{~m}$, Etuge et al. 4606 (K). MADAGASCAR. Mandraka valley, E Imerina, Feb. 1926, François in Herb Perrier 17585 (holotype $\mathrm{P}$ ); Mts $\mathrm{N}$ of Mangindrano, near summit Ambohimirahavavy, 1200 m, Jan. - Feb. 1951, Humbert $25340 \mathrm{~K}, \mathrm{P}, \mathrm{REU}, \mathrm{TAN})$; NW of Tsiroanomandidy, 1997, Hermans 3567 (K); Ambihimirahavavy Mts, 1500 m, 1999, Hermans 2463 (K).

HABITAT. Terrestrial, evergreen forest on gneiss laterite, woodland floor. Altitude: 1200 - $1500 \mathrm{~m}$ in Madagascar, 1000 - $1800 \mathrm{~m}$ on Mainland Africa.

CONSERVATION STATUS. Category EN: the extent of occurrence (EOO) of Malaxis weberbaueriana is estimated to be $53,111 \mathrm{~km}^{2}$ (which exceeds the limits for Vulnerable status under criterion B1) whereas its minimal area of occupancy (AOO) is estimated to be $12 \mathrm{~km}^{2}$ (which falls within the limits for Endangered status under the criterion B2). Malaxis weberbaueriana is known from three subpopulations representing three locations (sensu IUCN), this species has thus been preliminarily assessed as EN using the green listing method. In Madagascar, this species is threatened by selective logging, timber harvesting for small-scale subsistence and tavy (slash-and-burn farming), 
$0 \quad 100 \quad 200 \mathrm{~km}$

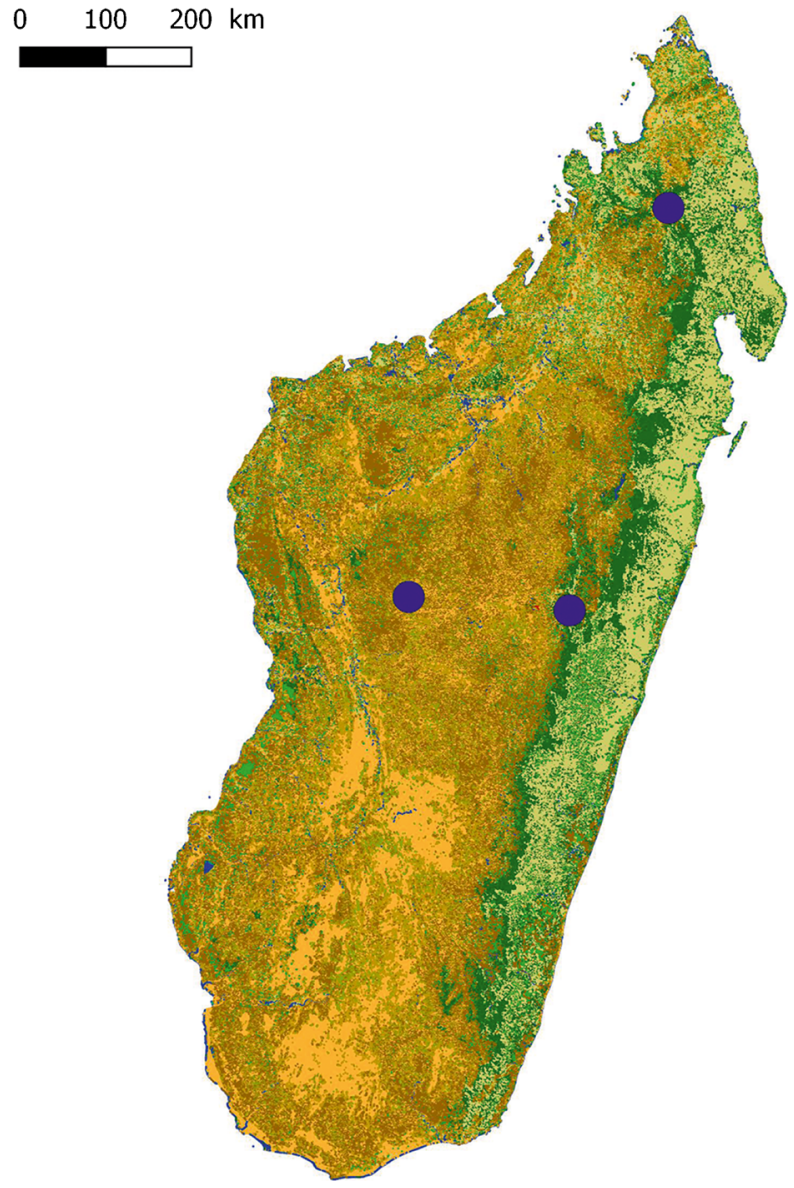

Map 57. Distribution of Malaxis weberbaueriana.

resulting in habitat reduction and habitat quality reduction.

FLOWERING TIME. January and February in Madagascar. December to June in mainland Africa.

ETYMOLOGY. Named by Kraenzlin for August Weberbauer $(1871$ - 1941) who first found the species in Cameroon and Microstylis francoisii H.Perrier for Edmond François (1887 - 1950).

NOTES. It was described as Liparis weberbaueriana by Kraenzlin (1908) from Mt Cameroon. In 1936 Perrier described Microstylis Françoisii, under the ICN code (Turland et al. 2018) this is corrected to Microstylis francoisii under Recommendation $60 \mathrm{~F}$ on the use of capitals in specific names and under Article 60.7 on the use of diacritical signs. It was based on a collection by François from central Madagascar. Both were transferred, together with other Microstylis, to the genus Malaxis by Summerhayes in 1934 and 1954 respectively. Szlachetko transferred the species to his new, divisive genus Lisowskia in 1995. Margonska put a number of species into synonymy in her Lisowskia welwitschii (Rchb.f.) Marg. (Margonska 2007: 50), it is also wrongly claimed that the lectotype was designated by Szlachetko (Szlachetlo \& Margonska 2001: 366). Margonska (2009: 90) considered Malaxis weberbaueriana the same as $M$. welwitschii from Angola (as Lisowskia welwitschii), in which she also included Malaxis atrorubra. Apart from stating that a thorough comparison was made, no other evidence or explanation was given. Looking at the types of Liparis welwitschii and taking into account geographical separation and variability, there are considerable differences as outlined above and the species is distinct from Malaxis weberbaueriana. Malaxis francoisii shows all the characteristics of $M$. weberbaueriana in plant habit, lip shape and column of $M$. weberbaueriana, the latter is the older name.

The transfer to Malaxis of Liparis welwitschii Rchb.f. (Reichenbach 1865: 184) was never made and is hereby validated:

Malaxis welwitschii (Rchb.f.) Hermans comb. nov.

http://www.ipni.org/urn:lsid:ipni.org:names:60479376-2

Liparis welwitschii Rchb.f., Flora 48: 184 (Reichenbach 1865). Type: Angola, Golungo, 1855, Welwitsch 660a (holotype W (R39776); isotypes $\mathrm{G}, \mathrm{K}, \mathrm{P})$.

Leptorkis welwitschii (Rchb.f.) Kuntze (1891: 671).

Lisowskia welwitschii (Rchb.f.) Marg. (Margonska 2007: $50)$.

ILlUStRAtIONS. Fig. 78. Williamson (1977: 111); Geerinck (1984: 271); Szlachetko \& Olszewski (2001: 369); Fischer et al. (2010: 278).

\section{Oberonia}

Oberonia Lindl. (Lindley 1830a: pl. 15). nom. cons. Type species: Oberonia ensiformis (Sm.) Lindl. (Lindley 1859: 4).

Iridorkis Thouars (1809: 319).

Iridorchis Thouars (1822: t.92), orth. var. of Iridorkis.

Titania Endl. (Endlicher 1833: 31).

Epiphytic herbs. Growths usually clustered, rarely borne on an elongated rhizome. Leaves generally iridiform and unifacial, often fleshy, articulate or not at base, distichous, often imbricate at base. Inflorescence unbranched, pubescent or glabrous. Floral bracts persistent, often erose. Flowers often in whorls, spiral to scattered, always omnidirectional on rachis, cupped, flat, reflexed, recurved. Sepals and petals free, spreading, sometimes erose. Lip sessile, entire or lobed, usually spreading, usually concave at base, lacking a callus or spur but sometimes with a thickened lip pad. Column lacking a foot and generally without wings; anther terminal, firmly attached to column apex, bilocular, pollinia waxy, four, cohering in two unequally sized pairs, viscidium absent or abbreviated; 


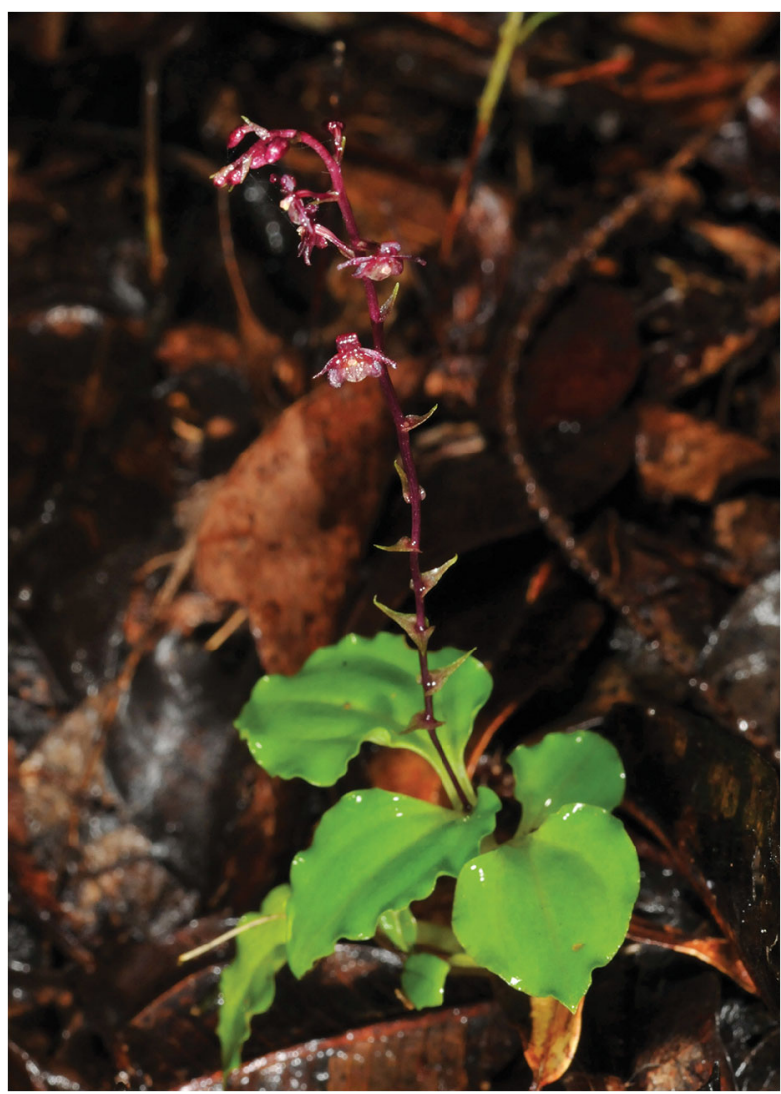

Fig. 78. Malaxis weberbaueriana. Habit. PHOTO: FRANÇOIS BRIGODE.

stigma transversely reniform to ovate; rostellum protruding. Ovary glabrous to papillate (adapted from Cribb in Pridgeon et al. 2005: 475)

DISTRIBUTION. A genus of some 150 - 200 species centred in tropical S and SE Asia and the Malay Archipelago but extending to tropical Africa, Madagascar, the Mascarene Islands, the Philippines, New Guinea, NE Australia and the SW Pacific Islands across to Tahiti. A single species in the Madagascar region; found on Madagascar, Réunion, Mauritius, Rodriguez and also E \& $\mathrm{S}$ Africa.

ETYMOLOGY. Named after Oberon, the fairy king who lived in hiding, in allusion to the hidden flowers of some species.

NOTES. The genus was first recognised by du PetitThouars in 1809, who referred to Lamarck's 'Angraecum distichum' (= Epidendrum distichum Lam.) as the only species. Thouars (1822: t.92) depicted this species under the names Iridorkis (as Iridorchis) equitiris and Cymbidium equitans. Oberonia Lindl. (Lindley 1830a) is conserved over Iridorkis Thouars.

\section{Taxonomy of Oberonia}

Oberonia disticha (Lam.) Schltr. (Schlechter 1924:
132); Perrier (1939: 253); Hermans et al. (2007: 236); Cribb \& Hermans (2009: 160); Bernet (2010a: 106); Bosser \& Lecoufle (2011: 426); Lebrun \& Stork (2017: 154); Hervouet (2018: 433). Types: Île de France [Mauritius] Commerson s.n. (P02088335) (lectotype P, designated here; lectoparatypes Commerson s.n. (P03756311) \& Commerson s.n., Jussieu 3871+A (P006730096) P-JUS)).

Epidendrum distichum Lam. (Lamarck 1783: 189).

Pleurothallis disticha (Lam.) A.Rich. (Richard 1828: 49). Cymbidium equitans Thouars (1822: t.92). Type?: s. loc. Thouars 15? (P005440569).

Iridorkis equitans (Thouars) Kuntze (Kuntze 1891: 669). Oberonia equitans (Thouars) Frapp. ex Cordem. (Frappier in Cordemoy 1895: 178) non Oberonia equitans (G.Forst.) Mutel 1837.

Oberonia equitans (Thouars) Schltr. (Schlechter 1915a: 411) non Oberonia equitans (G.Forst.) Mutel 1837.

Oberonia brevifolia Lindl. (Lindley 1830a: 16); Moore in Baker (1877: 343). Type: Mauritius, Bouton s.n. (K00718159) (holotype K-LINDL).

Malaxis brevifolia (Lindl.) Rchb.f. (Reichenbach f. 1864: 215).

Small to medium size epiphytic plant $3-17 \mathrm{~cm}$ high, with a single growth or clustered-tufted on a short rhizome, roots whitish, wiry c. $1 \mathrm{~mm}$ diam. Pseudobulbs elongate, covered with $2-9$ caulinary iridiform pairs of leaves. Leaves usually imbricate, bilaterally flattened, triangular-ensiform, acute or acuminate, decreasing towards the apex, more or less fleshy, yellowish green to pale green, $2-8.5 \times 0.5-2.5 \mathrm{~cm}$. Inflorescence sessile or shortly pedunculated, erect, reclining or pendant, 4 - $12 \mathrm{~cm}$ long. Peduncle short, about $1 / 4$ of the inflorescence. Rachis densely racemose, cylindrical, tapering, verrucose to hirsute, with 10 to more than 100 flowers. Floral bracts lanceolate-acuminate, verrucose to distinctly villose, $1.1-2 \times 0.8-1.1 \mathrm{~mm}$. Flowers very small, not resupinate, c. $2 \mathrm{~mm}$ in diam., yellowish green to pale orange, the anther and column paler. Pedicel and ovary cylindrical to fusiform, glabrous to verrucose, $1.3-2.3 \times 0.4-1.5 \mathrm{~mm}$. Dorsal sepal broadly oval to subtriangular, acute, $0.7-1.2 \times 0.4-0.8 \mathrm{~mm}$. Lateral sepals broadly oval $0.6-1.2 \times 0.4-0.7 \mathrm{~mm}$. Petals ovate to linear, apical margin more or less serrate, $0.6-0.8 \times 0.2-0.3 \mathrm{~mm}$. Lip auriculate at the base then flabellate-cordate with the anterior margin bilobed or sinuate to denticulate, deflexed, $0.9-1.5 \times$ $0.9-1.3 \mathrm{~mm}$. Column short, oblong, roundly bilobed at the apex, $0.4-0.5 \times 0.2-0.3 \mathrm{~mm}$. Anther oval with a small lobule at the anterior margin, c. $0.2 \times 0.2 \mathrm{~mm}$. Pollinia ovate c. $1 \mathrm{~mm}$ diam. Seed capsule ovoid to globular with distinct rounded ridges, c. $2.5 \times 2.5 \mathrm{~mm}$.

RECOGNITION. This is a distinctive small to mediumsized plant with distichous leaves, a long dense inflorescence with numerous very small flowers. Lip 
auriculate at the base, then flabellate-cordate with the margin bilobed to denticulate.

Oberonia disticha is very variable in plant size and shape, inflorescence and flower shape. Lip morphology, and especially the anterior margin, can vary from deeply dentate to almost entire. If the flowers were much larger it is possible that the various forms would have been classified as distinct species. Oberonia disticha is similar to a number of other Oberonia from Australasia and especially O. equitans (G.Forst.) Mutel (1837: 84) which is very variable itself. The plants are very similar, although $O$. disticha generally has a narrower basal sheath of the leaf. The rachis of $O$. equitans is denser, the flowers are about the same size although those of $O$. equitans are generally smaller. One of the main differences is that the pedicellate ovary of $O$. equitans is pilose to villose, that of $O$. disticha glabrous to verrucose (this may not appear so as the villose floral bract often embraces the ovary). The lip of $O$. equitans is subentire to subquadrate (vs auriculate at the base then flabellate-cordate in $O$. disticha), the anterior margin of the lip of $O$. disticha is more deeply and irregularly dentate.

DISTRIBUTION. One of the few widespread species: the Comoros, throughout Madagascar but mainly in Antananarivo and Toamasina provinces, Mauritius (including Rodrigues) and Réunion (Map 58). Also in Eastern and Southern Africa.

SPECIMENS EXAMINED. S. loc. Thouars s.n. P005440569 (P); s. loc. Herb. Richard 509 (W). COMOROS. Anjouan, $1000-1400$ m, June \& Aug. 1875, Hildebrandt 1709 (W); Grande Comore, June 1899, Pobeguin s.n. P00101337 (P); 1885, Humblot s.n. R37830 (W); Comoros, Moheli, $600 \mathrm{~m}$, June 1945, Legrand s.n. P00101311 (P); Grande Comore, Mioumbadjou, on Karthala, Aug. 1958, Duran 1196 (TAN); Nioumbadou, Aug. 1958, Benson 86 (P); Grande Comore, la Grille forest, May 1963, Bosser 17967 (P); Anjouan, Dzindi, 1964, Lavanchie 34 (P); Anjouan, 1964, Lavanchie s.n. P101339 (P); Mirongoné, St. Antoine, c. 700 m, Nov. 1968, Schlieben 11233 (K, M); Karthala, 1300 m, March 1975, Floret 1294 (P); Anjouan, between Koki and Chandra, Aug. 1987, D'Arcy 17578 (MO); Anjouan, Ntingui Mts, 1595 m, Dec. 1990, Hunter 104 (MO); Grande Comore, Mdjoiezi, 340 m, Nov. 1999, Labat E Y Yahaya 3120 (CNDRS, K, MO, P); Grande Comore, Bahani, $600 \mathrm{~m}$, July 2000, Brionnaud et al. 20 (CNDRS, K, MO, P); Grande Comore, Singani, Mdjoiezi, $410 \mathrm{~m}$, July 2000, Brionnaud et al. 34 (CNDRS, MO, P); Karthala, Oct. 2008, 575 m, Rouhan et al. 894 (P); Miringoni, Nov. 2008, 890 m, Rouhan et al. 813 (P); N'dzwani, 800 m, Nov. 2009, Pignal E Loup 3690 (P); Grande Comore, Coulon 9. MADAGASCAR. Herbier de Lamarck s.n. P00382691 (P); s. loc. Commerson s.n. P00094922 (P); s. loc. Commerson s.n.
Jussieu 3871+A P006730095 (P-JUS); s. loc. Commerson s.n. (G); Ambanivola 1855, Goudot s.n. (G); Ankafana, 1880, Deans Cowan s.n. P00101302 (P); coast to capital, May 1880, Kitching s.n. (K); S Betsileo, 1881, Hildebrandt 4209 (W); Imerina, 1881, Deans Cowan s.n. BM00088456 (BM); Central, Jan. 1882, Baron 1091 (K, P); Ankeramadinika, Nov. 1886, Fox 59 (K ex LDS); Central, Baron 2188 (K, P); s. loc. 1887, Le Myre de Vilers s.n. P00101303-4 (P); Ambohimitombo forest, 1350 1440 m, Dec. 1894, Forsyth Major 287 (K); Ambohimitombo forest, 1350 - 1440 m, Jan. 1895, Forsyth Major s.n. (G); Ambodilasa, Nov. 1899, Warpur s.n. (K); Maroa, Antongil Bar, Mocquerys s.n. (G); Ankaratra, Perrier 1860bis P101333 (P); Humblot 379 P00101313-5 (K, P, W); between Tamatave \& Antananarivo, July - Aug. 1862, Meller s.n. (K); Analamazaotra, Aug. 1862, Baron (K); Baron 379 (K); Mandraka forest, Oct. 1905, d'Alleizette 481M (P); 1905, Mandraka forest, Alleizette s.n. P02222760 (P); Manongarivo massif, c. 1900 m, April 1909, Perrier 1923 (P); Analamazaotra forest, c. 800 m, Feb. 1912, Perrier 1860 (P); Analamazaotra forest, $800 \mathrm{~m}$, Perrier 11877 (P); Ambre forest, July 1917, Poisson 135 (P); Antanambe, Feb. 1920, Decary 36 (P); Andringitra massif, 1800 m, Feb. 1922, Perrier 14584 (P); Befotaka, Farafangana, Aug. 1926, Decary 5183 (P); Farafangana, Vondrozo forest, Sept. 1926, Decary 5323 (P); Farafangana, high Rienana valley, Oct. 1926, Decary 5525 (P, TAN); Itomampy basin, Mt Papanga near Befotaka, Dec. 1928, Humbert 6928 (P); Kalambatitra massif, 1400 - 1750 m, Nov. 1933, Humbert 11885 (P); Analamazaotra, Oct. 1936, Herb. Jard. Bot. Tan. 2162 (TAN); Analamazaotra, Oct. 1937, Herb. Jard. Bot. Tan. 3062 (P); Antamalaza, Oct. 1938, Herb. Jard. Bot. Tan. 4058 (TAN); between Vohemar and Ambilobe, July 1939, Decary 14722 (P); Zahamena reserve, March 1941, Decary 16806 (P); Zahamena reserve, March 1941, Decary 16731 (P); Fanovana, Eastern forest, July 1942, Decary 18065 (P); Antsiranana, Joffreville to Mt d'Ambre, Oct. 1944, Homolle 9 (P); Ankaratra, 850 m, Dec. 1944, Cours 2047 (K, P); Rahopevava, 960 m, March 1951, Cours 4277 (K, P, TAN); Sendrisoa, Ambalavao, Feb. 1953, Rakoto 5551RN (P, TAN); Andranomiadiloha, Vohimary, Mahazony, Ambalavao, Nov. 1954, Rakotovao 639 (P); Farafangana, Lahoney, Oct. 1955, Rakotovao 7663RN (P); Ambatoloana, Mangatiandriana distr., Sept. 1956, Benson 86 (TAN); 1959, Rauh 1959 (HEID); Ambalavao, Aug. 1960, Rakotoniaina 11203RN (P); Manaka East, Ambatondrazaka, Jan. 1961, Rakotovao 11775RN (P); s. loc. Mason 1963, 29222 (K-spirit); Périnet, 1966, Herb. Jard. Bot. Tan. 1340 (P); Sahamataga, Oct. 1966, Rakatozafy 721 (TAN); Ivohibe towards Ihosy, May 1971, Cremers 1524 (TAN); 


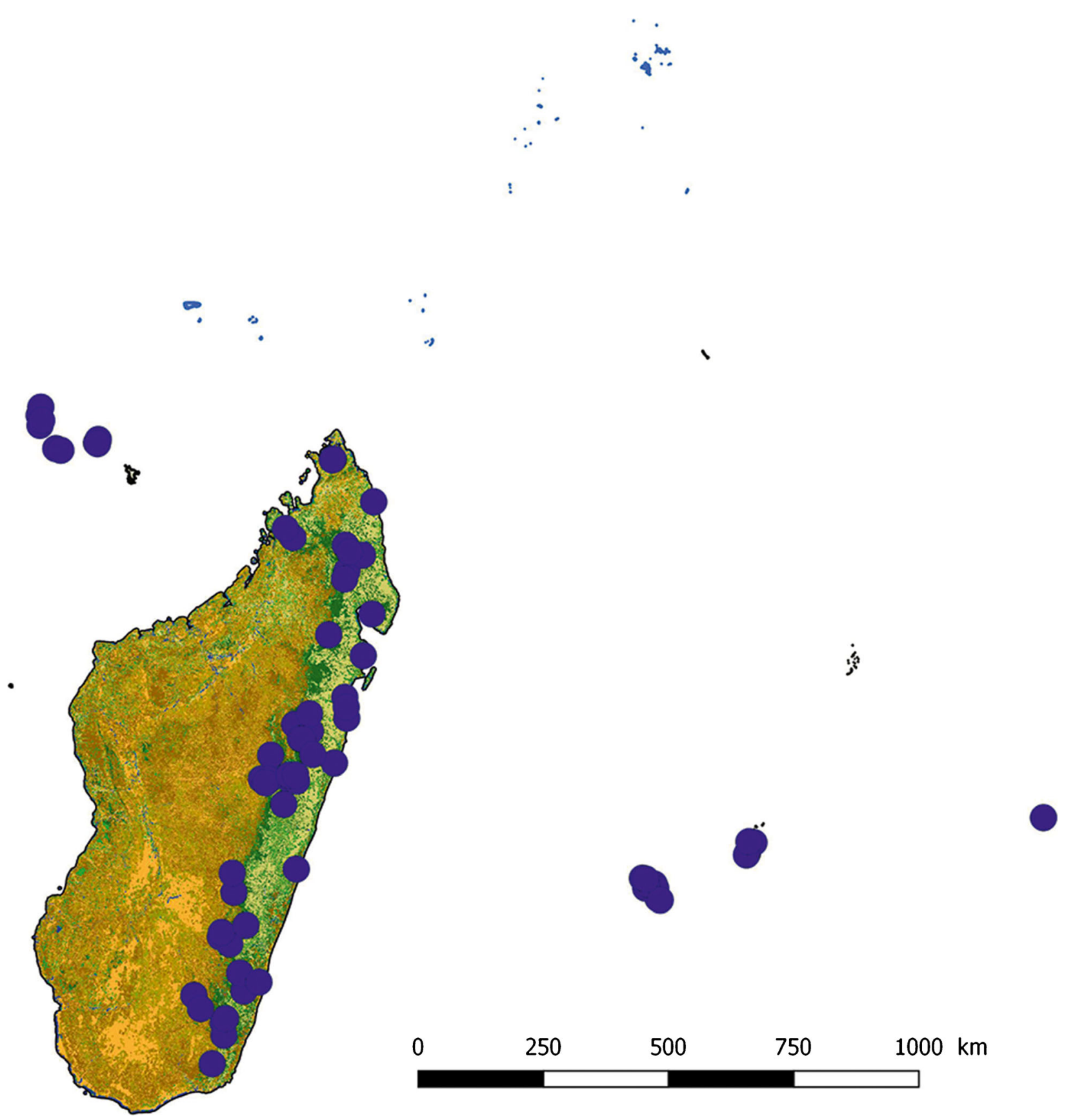

Map 58. Distribution of Oberonia disticha.

Ampasimpotsy, 800 m, Feb. 1972, Bosser 21140 (P); Mandritsara, Antsiasiaka, April 1974, Morat 4518 (P, TAN); S of Fénérive, Feb. 1975, Croat 32585 (K, MO, P, TAN); Marojejy, Nov. 1983, Deroin 108 (P); Andasibe Périnet area, Nov. 1984, Dorr E Barnett 3233 (K, MO, P); Toamasina, Alaotra-Mangoro, $1000 \mathrm{~m}$, May 1984, Dorr 3096 (MO); W of Foulpointe, 0 - 50 m, Dec. 1984, Barnett E Dorr 227 (M); Tampolo forest, Oct. 1986, Pettersson $\mathcal{E}^{\circ}$ Nilsson 25 (K); Antananarivo, Anjozorobe forest, $1400 \mathrm{~m}$, Sept. 1991, Rakotozafy et al. 2694 (K, MO, P, TAN); Sambirano, Mt Antsatrotro, $1500 \mathrm{~m}$,
Oct. 1991, Andrianatoandro 008 (P); Toliara, Andohahela, 500 - 1000 m, Feb. 1993, Malcomber et al. 2139 (BR, K, MO, P, TAN); Masoala Peninsula, Ambanizana river, Nov. 1993, Lance 86 (K); Anjozorobe, 1250 - 1400 m, Jan. 1993, Schatz 3478 (MO); Mt d'Ambre, 1994, Daniel duPuy 1 (P); Antsiranana, near Andranotsarabe, 1050 m, Nov. 1994, Hermans 3217 (K); Toamasina, Ambatondrazaka, SE of Lake Alaoatra, 1120 m, Jan. 1995, David DuPuy et al. M796 (K, P); Antananarivo, around Lake Mantasoa, Jan. 1996, Hermans 3568 (K); 1996, Muller 16295 
(RENZ); Angavokely, Feb. 1996, Ceplitis E $\mathcal{E}$ Brostrom 1012 (R, TAN); Antsiranana, 1800 m, May 2000, Gautier E $\mathcal{E}$ Rakotomanonjy 3719 (P); Fianarantsoa, Mahabo-Mananivo, 24 m, Aug. 2003, Razakamala 745 (MO, TEF); Fianarantsoa, Fivondronana: Nosy Varika, 13 m, June 2004, Ranaivojaona et al. 829 (MO, P, TEF); Fianarantsoa, Andringitra, 1770 m, Jan. 2005, Fischer \& Andriantiana 1770 (WU); Toamasina, Moramanga, 1032 m, Feb. 2005, Antilahimena et al. 3389 (MO, P, TAN); Analamay, Ambatovy, Ampitabe, $1109 \mathrm{~m}$, Feb. 2005, Razafindraibe $\mathcal{E}$ Antilahimena 56 (MO, P); Fianarantsoa, Iakora, Begogo, Bekora, $1392 \mathrm{~m}$, Feb. 2005, Andrianjafy et al. 855 (MO, P, TAN); Toamasina, Andasibe, Menalamba. Ambatovy, 1020 m, March 2005, Antilahimena et al. 3673 (MO, P, TAN); Antananarivo, Fivondronana: Anjozorobe, $1436 \mathrm{~m}$, March 2005, Rabehevitra et al. 1364 (MO, TAN); Toamasina, Ampitambe, Ambatovy, 1173 m, March 2005, Andriantiana 126 (MO, TAN); Toliara, Betroka, Ivahona, Befarafara, 1102 m, May 2005, Andrianjafy et al. 1102 (MO, P, TAN); Fianarantsoa, Befotaka, 1239 m, Sept. 2005, Rakotovao et al. 2075 (TAN); Fianarantsoa, Antakohandra, Manombo, $18 \mathrm{~m}$, Sept. 2005, Razakamalala et al. 2244 (MO, P, TAN); Toamasina, Brickaville, Maroseranana, $341 \mathrm{~m}$, Nov. 2005, Andriamihajarivo et al. 728 (MO, P, TAN); Toliara, Betroka, Ivahona, $1424 \mathrm{~m}$, Nov. 2005, Andrianjafy et al. 492 (MO, P, TAN); Sava, Ambodivohitra. Anjialavabe, $1156 \mathrm{~m}$, March 2006, Rakotovao et al. 2842 (P, TAN); Antsiranana, Sava, Doany, Andranomololo, 738 m, May 2006, Rakotovao et al. 3194 (MO, TAN); Toamasina, Didy, Amboarabe, Est d'Antsevabe, forêt de Ambolotsangana, 1200 m, June 2006, Andriamihajarivo et al. 1002 (MO, TAN); Antsiranana, Doany, Andranomilolo, forêt d'Andrakengy, 942 m, Nov. 2006, Razakamalala et al. 2855 (MO, P, TAN); Antsiranana, Diego, Sava, Vohemar, Andrafainkona, 1427, Nov. 2007, Razakamalala 3687 (MO, P, TAN); Vohemar, Nov. 2007, 1327 m, Razakamalala et al. 3687 (P); Antsiranana, Mt d'Ambre, Nov. 2007, Nusbaumer et al. 2447 (G, P); Mahajanga, Fokotany Tsaravilona, $950 \mathrm{~m}$, Feb. 2008, Ravelonarivo et al. 3031 (MO, P, TAN); Mt d'Ambre, 1000 m, April 2008, Trigui et al. 207 (G, P, TEF); Fivondronana, Ambatovy, 1125 m, May 2008, Antilahimena et al. 6126 (MO, P, TAN); Moramanga, Ambohibary, Ambatovy, 1098 m, Sept. 2008, Miandrimanana 366 (TAN); Toamasina, Sahafasenina, 1190 m, Dec. 2008, Fischer $\mathcal{E}$ Andriantiana 1190 (WU); Toamasina, Didy, $1108 \mathrm{~m}$, Jan. 2010 , Andrianaivoravelona 230 (K, MO, TAN); Fianarantsoa, Ambalavao, Andringitra, 1600 m, Nov. 2010, Rakotonasolo 1671 (K, TAN); Antananarivo, Manjakandriana, Nandihizana-Carion, $1686 \mathrm{~m}$,
March 2011, Rabarimanarivo et al. 308 (MO, P, TAN); Toamasina, Analamay, 1019 m, July 2011, Andriamiarinoro 221 (MO, TAN); Toamasina, Andasibe, Bekalakody, Mantadia, 943 m, April 2012, Razafindrahaja \& Antilahimena 230 (MO, P, TAN); Mantadia, 970 m, Dec. 2013, Antilahimena et al. 8719 (MO, TAN); Andasibe, Fokontany Falierana, 990 m, Dec. 2013, Antilahimena et al. 8770 (MO, TAN); Andasibe, Analamazaotra, 976 m, Dec. 2013, Razafindraibe et al. 511 (TAN); Andasibe, Analamazaotra, 966 m, Dec. 2013, Razafindraibe et al. 558 (TAN); Analamazaotra, 927 m, Dec. 2013, Razafindraibe et al. 625 (TAN); E of Ambalavao, Haine 235 (K); Central plateau, Hodgkin E Stansfield (K); Blackburn s.n. (K); 1400 - 1750 m, Homolle 1167 (P); Desvaux s.n. P00101301 (P); Leman s.n. Herb. Maire P00101340 (P); Angavokely, Bosser 14874 (P); Bosser 15381, 19280 (TAN); Périnet, Sept., Herb. Bot. 2162 (TAN); Dorr 1196 (TAN); Rakoto 11 (TAN); s. loc. Fischer E Andriantiana WU084706 (WU). MAURITIUS. s. loc. Commerson s.n. P02088335 lectotype (P); s. loc. Commerson s.n. P03756311 and s. loc. Commerson s.n. Jussieu 3871+A P006730096 lectoparatypes (P-JUS); s. loc. Commerson s.n. (G); s. loc. 1816, Thouars s.n. BM0088459 (BM); s. loc. 1819, Macgregor s.n. BM00088458 (BM); s. loc. Sept. 1849, Boivin s.n. P002088325 (P); s. loc. Bouton s.n. K00718159 (KLindl.); s. loc. 1864, Bouton Herb Hooker (K); Bois Fandaman, 1928, Vaughan 509 (K); Bassin Anglais, Oct. 1941?, Vaughan 3025 (P); Pouce Mt, April 1963, Guého 10671 (BM); Bassin Blanc, April 1974, Bosser 21850 (P); Gaulettes Serrées, March 1980, Bosser 19604 (MAU, P); Grand Bassin, March 1980, Bosser 21164 (P); Grand Bassin, March 1980, Bosser 22578(P); Petrin, Jan. 2004, Pynee 23789 (P); s. loc. Wallich s.n. BM00088458 (BM); s. loc. forest interior, Bojer Herb Hooker (K); s. loc. Herb Hooker (K); s. loc. Bouton s.n. P02088334 (P); s. loc. Bojer I 132 (W); s. loc., 1833, Bojer s.n. (G); Rodriguez, Balfour 1223, Venus Expedition BM00088457 (BM, K). RÉUNION. s. loc. 1846, Armange 162 P02088321 (P); s. loc. 1847, Boivin 1033 (P); s. loc. 1867, Cordemoy s.n. (MARS); s. loc. 1837, Richard 396 (P); Helle Bausy St. Martin, 1875, del'Isle 228 (K, P); Haut de Meniol, May 1957, Bosser 12203 (P); St. Philippe, Nov. 1968, Schlieben 10965 (P); Plaine des Palmistes, 700 m, 1969, T. Cadet s.n. (P); Hauts de Bras Panon, Oct. 1972, Bosser 21202 (P); Basse Vallée, April 1974, Bosser 21806 (P); Montée de la Plaine des Affouches, March 1974, Bosser 21735 (P); Morne des Patates à Durand, March 1974, Bosser 21652 (P); Montée de la plaine des Affouches, March 1974, Bosser 21736 (P); Les Trois Bras. May 1974, Bosser 22082 (P); Route de Cilaos, 600 m, Feb. 1978, Bosser 20725 (P); Les Marais du Bassin blanc, 1978, Bosser 18892 (P); 
Bassin Blanc, March 1978, Bosser 22409 (P); Sentier Bras Rouge, Cilaos, April 1978, Bosser 22491 (P); April 1987, J. Renz 15152 (RENZ); s. loc. Potier s.n. (P); s. loc. Delteil s.n. P02088318 (P); without data, R0068788 (W); s. loc. Bory s.n. R15323 (W).

HABITAT. Evergreen forest, wet dense forest, cloud forest, littoral forest, coffee plantations. Altitude: $300-$ $1600 \mathrm{~m}$ in the Comoros, 0 - $1900 \mathrm{~m}$ in Madagascar, c. $500 \mathrm{~m}$ in Mauritius, $300-1200 \mathrm{~m}$ in Réunion.

CONSERVATION STATUS. Category LC: the extent of occurrence (EOO) of Oberonia disticha is estimated to be $1,566,838 \mathrm{~km}^{2}$ (far exceeding the limits for Vulnerable status under criterion B1) whereas its minimal area of occupancy (AOO) is estimated to be $344 \mathrm{~km}^{2}$ (which falls within the limits for Endangered status under the criterion B2). With 59 known subpopulations representing 69 locations (sensu IUCN), this widespread species has been preliminarily assessed as LC using the green listing method. This species is threatened by mining activities, selective logging, timber harvesting for small-scale subsistence, tavy (slash-and-burn farming), grazing and anthropogenic fires, resulting in habitat reduction and habitat quality reduction.

Previously assessed and published in the IUCN Red data listing for Réunion as LC (Picot 2013: 17).

FLOWERING TIME. October to August, but mainly June to November in the Comoros; throughout the year but mainly November to March in Madagascar; January to September, but mainly March to April, in Mauritius; March to November, but mainly March to May, in Réunion.

ETYMOLOGY. Refers to the distichous leaves, Lindley's Oberonia brevifolia refers to the short leaves.

VERNACULAR NAMES. 'Fontsilahinjanahary' (Baron 1901: 714; Dandouau 1909), 'Ahipisabato' (Réserves naturelles Madagascar, Rakotovao 11775RN (P)).

NOTES. The nomenclature and typification of the species is confusing and complex. The main complication has been the mix-up with Epidendrum equitans described by Johann Georg Forster (1786: 60) for a plant from Polynesia (Oberonia equitans (G.Forst.) Mutel 1837), the two species were often confused which is not surprising as Forster's description was very rudimentary. Meanwhile Thouars illustrated his Cymbidium equitans Thouars (1822: t.92), the name having been used by Swartz (1799: 72); it is unknown if the original name refers to the Forster plant from the Pacific.

Richard (1828: 49) used the name 'Pleurothallis disticha Nob.' and listed both Cymbidium equitans Swartz and Du Petit-Thouars and Epidendrum equitans Forst. below, he also illustrated the species. At first sight it appears that Richard was creating a new species with a new name but studying the context and Richard's methodology it seems that he had his own particular concept of precedence in nomenclature. When Richard wrote 'Nob.' he seems to be indicating that he changed either the genus, species name or both, in some instances he also used it in the traditional sense of him creating an entirely new entity. For example, in Platylepis goodyeroides Nob (Richard 1828: 34) he had Thouars' Goodyera occulta as a 'synonym', a similar pattern is repeated for several other species. With his Pleurothallis disticha he simply created a new name for Swartz's \& Thouars Cymbidium and Forster's Epidendrum, he listed them as 'synonyms' and cited Thouars type material amongst others. In his introduction he mentioned the link between Asian and African species and he probably started the confusion with Forster's Epidendrum.

Lindley (1830a: 16) employed the name Oberonia brevifolia, giving Epidendrum equitans Forst. (Pacific entity), Cymbidium equitans (Forst.) Sw. (Pacific entity) and Pleurothallis disticha Rich. (African entity) as synonyms. Lindley's name was based on Bouton s.n. (K-Lindl. 00718159), a mixed sheet collected by Louis Sulpice Bouton on Mauritius; specimens of the same origin are also in Hooker's herbarium at $\mathrm{K}$ and at $\mathrm{P}$. Frappier in Cordemoy (1895) included as synonyms in his Oberonia equitans (Thouars) Frapp. ex Cordem. (African entity) the following: Oberonia brevifolia Lindl. (African \& Pacific entity), Epidendrum equitans Forst. (Pacific entity), Cymbidium equitans (Forst.) Sw. (Pacific entity), Pleurothallis disticha Rich. (African entity) and Malaxis brevifolia (Lindl.) Rchb.f. (African \& Pacific entity). Other authors (e.g. Durand \& Schinz 1895: 7) more or less mixed the nomenclature of the African and the Polynesian / Asian species. Finet annotated several specimens in $\mathrm{P}$ as Oberonia equitans Mutel var. brevifolia (Commerson s.n., Thouars s.n. etc).

The typification of Epidendrum distichum is equally complex: Lamarck's description (1783: 189) mentioned plants seen by Commerson on Île de France [Mauritius] as: "observée dans l'Île de France par M. Commersom v.s.”, he also confirmed seeing herbarium material (vidi siccam). A specimen in Lamarck's herbarium (P00382691) has 'Madagascar Com.' on the label and may belong to the type. In addition to various collections from Madagascar, three specimens in the Paris herbarium are labelled as coming from Île de France [Mauritius], collected by Commerson: Commerson s.n. (P006730096), as Epidendrum ? pusillum and annotated in error by Finet as 'Oberonia equitans Mantel, var. brevifolia'. Another Commerson s.n. (P02088335) has a printed label and is identified in the same way by Finet. The third is a Commerson collection in the de Jussieu herbarium with two plants: Jussieu $3871+\mathrm{B}$ on the left (P00673095) has Cymbidium equitans and coming from Madagascar, the one on the right Jussieu 3871+A (P006730096) is labelled in error 
'Epidendrum pusillum ? Île de France, Commerson'. Of the three, Commerson s.n. (P02088335) corresponds best with Lamarck's description and is designated here as lectotype. Commerson s.n. (P03756311) and Commerson s.n. in Herb. Jussieu 3871+A (P006730096) are lectoparatypes. There is a similar Commerson collection in G, also labelled Cymbidium equitans.

The Du Petit-Thouars collection P005440569 in $\mathrm{P}$ refers to his Cymbidium distichum but the status of this type is doubtful however: 'Cymbidium equitans' is not given on the sheet and it is not known if it was based on the Forster (Swartz) plant from the Pacific.

ILlUStRATIONS. Fig. 79; Du Petit-Thouars (Thouars 1822: t.25); Richard (1828: t.8); Cowan (1880: 16); Perrier (1939: 255); Cadet (1989: t.56); LaCroix \& Cribb (1995: 287); Du Puy et al. (1999 pl.31); Hermans et al. (2007: pl.48); Cribb \& Hermans (2009: 163); Bernet (2010a: 104); Bosser \& Lecoufle (2011: 426); Pailler et al. (2013: 57); Szelengowicz \& Tamon (2013: 377); Hervouet (2018: 433).

\section{Stichorkis}

Stichorkis Thouars (1809: 318), lectotype: Stichorkis disticha (Lam.) Pfitzer (1897: 103) designated by Rasmussen (1979: 132), Typ. Cons.

Stichorchis Thouars (1822: Tab. 1 \& t.90).

Distichis Thouars ex Lindl. (Lindley 1847: 181).

Liparis Rich. Sect. Distichae Ridl. (Ridley 1886b: 244). Disticholiparis Marg. \& Szlach. (Margonska \& Szlachetko 2004: 175).

Epiphytic or rarely terrestrial or lithophytic plants. Rhizome creeping, covered by tubular scales. Stem pseudobulbous, erect, one-noded, clustered or not, covered when young by $2-5$ sterile sheaths, oneleafed at apex. Leaf erect, linear or oblanceolate, conduplicate. Inflorescence erect, racemose, rachis laterally flattened, shorter than peduncle; floral bracts distichous, imbricate. Flowers non-resupinate, opening in succession, usually yellow, green, or orange, often translucent. Sepals recurved, dorsal sepal free, lateral
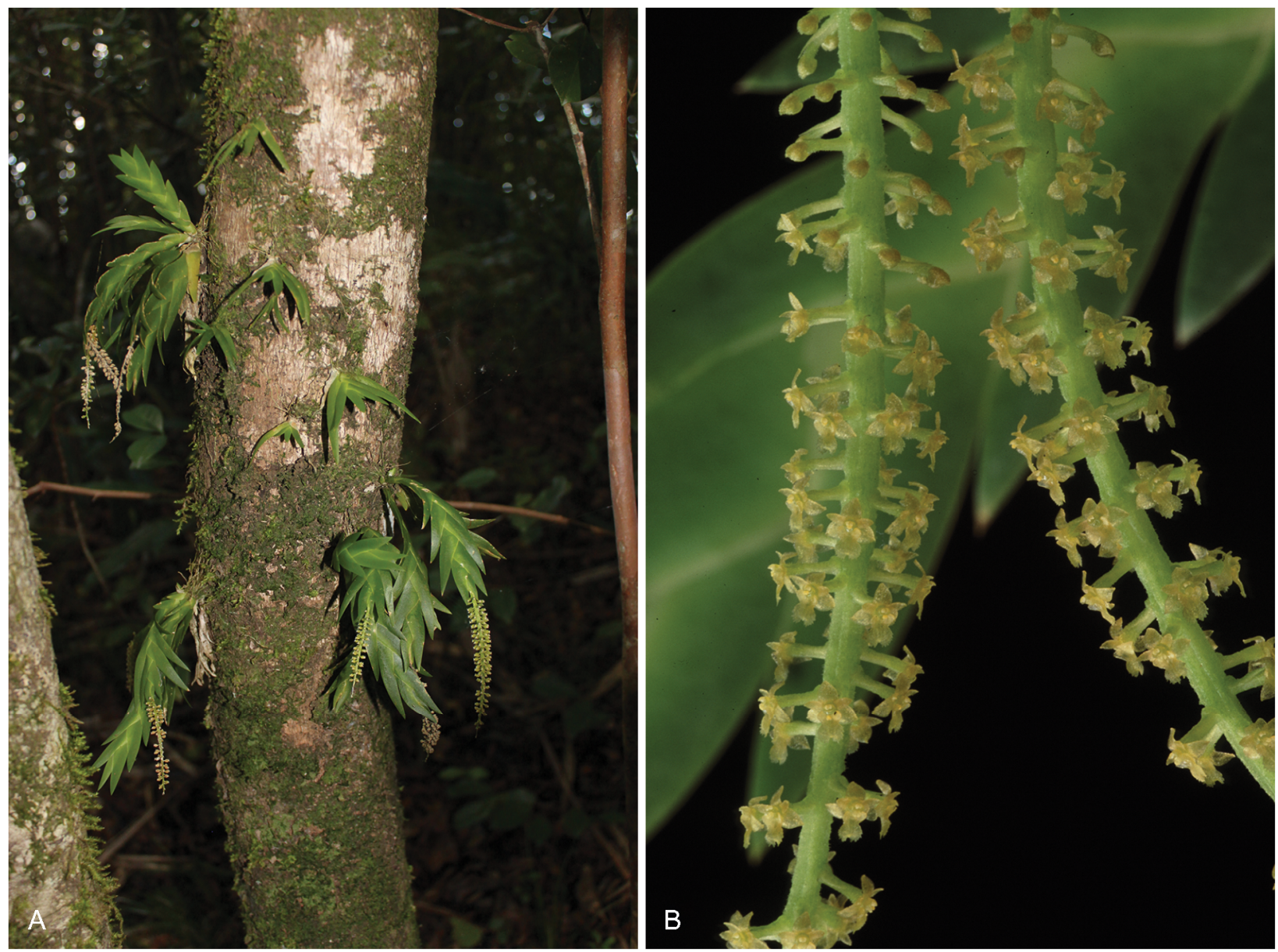

Fig. 79. Oberonia disticha. A plants in habitat; B inflorescence. PHOTOS: JOHAN HERMANS. 
sepals sometimes fused for part or all of length. Petals free, often linear and unlike sepals, erect. Lip often reflexed, entire or lobed, usually with a pad-like callus, concave at the base, lacking a spur. Column incurvedarcuate, laterally winged near apex; anther attached by a slender filament, biloculate, pollina waxy, ovoid bilaterally flattened, four in two parts, each with a small viscidium; stigma concave; rostellum thin-textured, blunt (adapted from Cribb in Pridgeon et al. 2005: 483).

DISTRIBUtION. A genus of some 38 species from the Mascarenes, Comoros, the Malay Archipelago, the Philippines, New Guinea, Australia and the SW Pacific Islands. Pridgeon et al. (2005: 485) reports the genus from Madagascar in error.

ETYMOLOGY. From the Greek Stichos, row or rank, and Orchis, orchid, in reference to the two distichous rows of bracts that characterise this genus.

NOTES. Du Petit-Thouars described Stichorkis and Leptorkis (Thouars 1809: 317 - 318). Stichorkis has most often been included in Liparis Rich. (Richard 1817: 21) (conserved over Leptorkis Thouars), but it is now recognised as distinct. Thouars (1822) considered Stichorkis to comprise two species, one of which was already described by Lamarck as Angraecum cespitosum (= Epidendrum cespitosum Lam.). He described the other species as $S$. distichis Thouars, with Malaxis disticha as alternative name, and depicted it with $S$. cestichis Thouars (alternatively Malaxis cespitosa (Lam.) Thouars).

The Thouarsian new-style epithets 'Distichus' and 'Cestichis' which appeared at the lower left corner of the illustrations of Thouars (1822) were mistaken for generic names by Lindley. Pfitzer (1888) accepted Stichorkis as a distinct genus but used Lindley's erroneous name 'Cestichis'. Pfitzer (1897: 103) corrected this mistake and made four combinations in Stichorchis. Ames (1905, 1908), apparently unaware of Pfitzer's work, used Cestichis Lindl. ex Pfitz. for some Asiatic species. Schlechter (1911a) used 'Cestichis' as a name for a subgenus.

Rasmussen (1979) reviewed some of the nomenclatural problems caused by the confusion over the two sets of names used by Thouars and suggested conservation of Liparis against Stichorkis, but he recognised that this concept represents a well-defined group of species and lectotypified Stichorkis with Malaxis disticha Thouars. Based on the same species, Ridley (1886b) recognised Liparis sect. Distichae with an epiphytic habit, single-leaved pseudobulbs, a linear to oblanceolate leaf, a flattened rachis with distichous, imbricate bracts and flowers opening in succession.

Margonska \& Szlachetko (2004: 175) superfluously established the genus Disticholiparis, based upon the morphological characters listed above, for this group of distinctive species. They were unaware of Rasmussen's lectotypification of Stichorkis.
The DNA analysis of Cameron (2005) indicated that Liparis is polyphyletic, the species of Liparis sect. Distichae forming a clade sister to both Oberonia and another group of epiphytic Liparis with linear leaves. On the basis of his results, Stichorkis has now been accepted.

Thouars did not indicate a type in his rudimentary description of 1809, but erroneously included Lamarck's Angraecum caespitosum. Rasmussen (1979) therefore selected Stichorkis disticha as the type for the genus based on Thouars 1822 work. Szlachetko et al. (2008) rejected this interpretation but have not been followed by other botanists.

\section{Taxonomy of Stichorkis}

Stichorkis disticha (Thouars) Pfitzer (1897: 103); Bernet (2010a: 88). Type: Réunion - Mauritius, s. loc., Thouars 17 (holotype P, P00112462).

Liparis disticha (Thouars) Lindl. (Lindley 1824: sub t.882); Frappier in Cordemoy (1895: 180).

Malaxis disticha Thouars (1822: t.89).

Cestichis disticha Pfitzer (1888: 131).

Liparis disticha (Thouars) A.Rich. (Richard 1828: 54);

Hermans et al. (2007: 218).

Leptorkis disticha Kuntze (1891: 671).

Disticholiparis disticha (Thouars) Marg. \& Szlach.

(Margonska \& Szlachetko 2004: 178).

Liparis gregaria Lindl. (Lindley 1830a: 33); Moore in Baker (1877: 343).

Disticholiparis gregaria Marg. \& Szlach. (Margonska \& Szlachetko 2004: 178).

Stelis micrantha Sieb. ms. in Herb. Maur. 168 (G, P).

Medium-sized, erect epiphytic or lithophytic plant up to $20 \mathrm{~cm}$ high, on a short, branching rhizome, roots thin, wiry. Pseudobulbs ovoid to pyriform, more or less angular, 8 - $15 \times 5-12 \mathrm{~mm}$, covered with 3-5 lanceolate-acute sheaths, the upper ones longer (up to $25 \mathrm{~mm}$ ), disintegrating with age, a single leaf at the apex. Leaf linear, bilobulate-acute at the apex, longly attenuate at the base, $12-20 \times 0.9-1.5 \mathrm{~cm}$. Inflorescence terminal, more or less arching, $8-18 \mathrm{~cm}$ long with up to 20 flowers. Peduncle thin, about $2 / 3$ of the inflorescence, with $1-3$ amplectant sheaths. Rachis flattened, covered with prominent floral bracts, $1-5 \mathrm{~cm}$ long. Floral bracts distichous, initially partly overlapping becoming distant with age, some without flower, greenish-yellow, persistent, oval acute, $3-6.5 \times 1.5$ $-1.8 \mathrm{~mm}$. Flowers medium in size, overall av. $12 \times 6 \mathrm{~mm}, 2$ to 10 , opening in succession, sepal and petals greenish yellow to orange, lip darker yellow to dark orange. Pedicel and ovary cylindrical, recurved at the base, $6-9 \times 0.8-2$ mm. Dorsal sepal reclined and almost parallel with the ovary, narrowly oval, acute, $4.5-7 \times 2-2.5 \mathrm{~mm}$. Lateral sepals descending, the margins recurved obliquely ovalacute, $5-7 \times 2.1-3.2 \mathrm{~mm}$. Petals erect, margins recurved, linear obtuse, $3.8-7 \times 1.1 \times 1.5 \mathrm{~mm}$, sometimes a little 
wider at the tip. Lip pandurate, recurved at the base, the margins forming two rounded lobes, at the angular basal part carrying 2 small calli, the middle inflexed, the terminal part triangular-acute, recurved, $3.6-5.5 \times 2-$ $4.1 \mathrm{~mm}$. Column triangular with the base very broad, wings triangular-acute towards the apex, $2.1-3 \times 1.1-2 \mathrm{~mm}$. Anther oval, with a small lobule at the anterior margin, c. $0.4 \times 0.5 \mathrm{~mm}$. Pollinia ovate, in two parts, c. $0.3 \times 0.2 \mathrm{~mm}$. Seed capsule ovoid, triangular, $8-10 \times 4-5 \mathrm{~mm}$.

RECOGNITION. Stichorkis disticha is a medium-sized pseudobulbous epiphyte with a single linear leaf, flattened rachis, with large distichous floral bracts, medium-sized, and orange-yellow flowers, with a pandurate lip with two calli at the base, column that is broad at the base, and has triangular wings.

It is vegetatively similar to some of the Asian species in the genus, especially Stichorkis gibbosa (Finet) Cootes (syn. Liparis gibbosa (Finet) J.J.Wood (in Wood et al. 2011: 531)) from tropical Asia and the SW Pacific but the lip and calli are a different shape with the lip pandurate - two-lobed vs four-lobed, with two distinct calli vs ecallose and the floral bracts are about a third shorter in Stichorkis disticha.

DISTRIBUTION. Comoros (Grande Comore, Anjouan), Mauritius and Réunion (Map 59).

SPECIMENS EXAMINED. S. loc., Thouars 17 (holotype P, P00112462); s. loc. Herb. Blackburn s.n. (K); s. loc., Bélanger 1828 - 1829 (G); s. loc., ex Herb. Paris 1821, Herb. de Candolle s.n. (G). CoMoros. Grande Comore, June 1899, Pobéguin s.n. (P); Grande Comore, March 1989, Monnerat 23 (P); Grande Comore, Maoueni, la Grille forest, $780 \mathrm{~m}$, Nov. 1999, Labat et al. 3091 (P); Anjouan, 1999, Hermans 5100 (K); Grande Comore, Maoueni, La Grille forest, $830 \mathrm{~m}$, July 2000, Brionnaud et al. 10 (CNDRS, K, MO, P); Karthala, 890 m, Oct. 2008, Rouhan et al. 810 (P); Anjouan, Bosser Jard. Bot. Tan. 492 (P). MAURITIUS. s. loc. 1828, Sieber s.n. in Herb de Candolle (G); s. loc. Sieber s.n. in Herb Moricand (G); s. loc. leg. Sieber s.n. (G); Grand Bassin, Bouton s.n. 1830 (K, P); s. loc. Bouton s.n. (G); s. loc., Blackburn in herb. Henslow (CGE); s. loc. 1835, Herb. Shuttleworth s.n. BM00090080 (BM); s. loc., 1838 herb. Sieber 108 \& 168

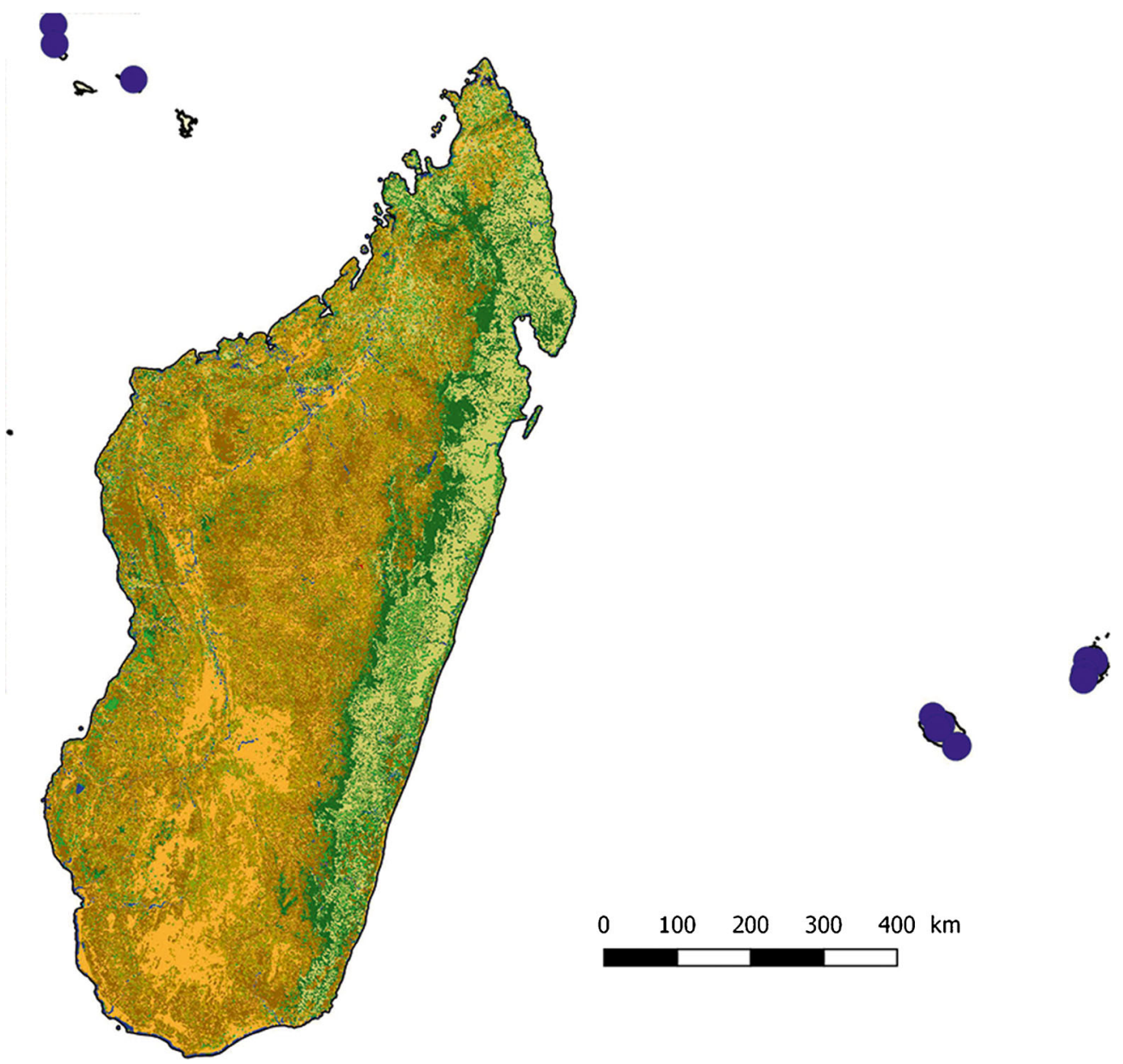

Map 59. Distribution of Stichorkis disticha. 

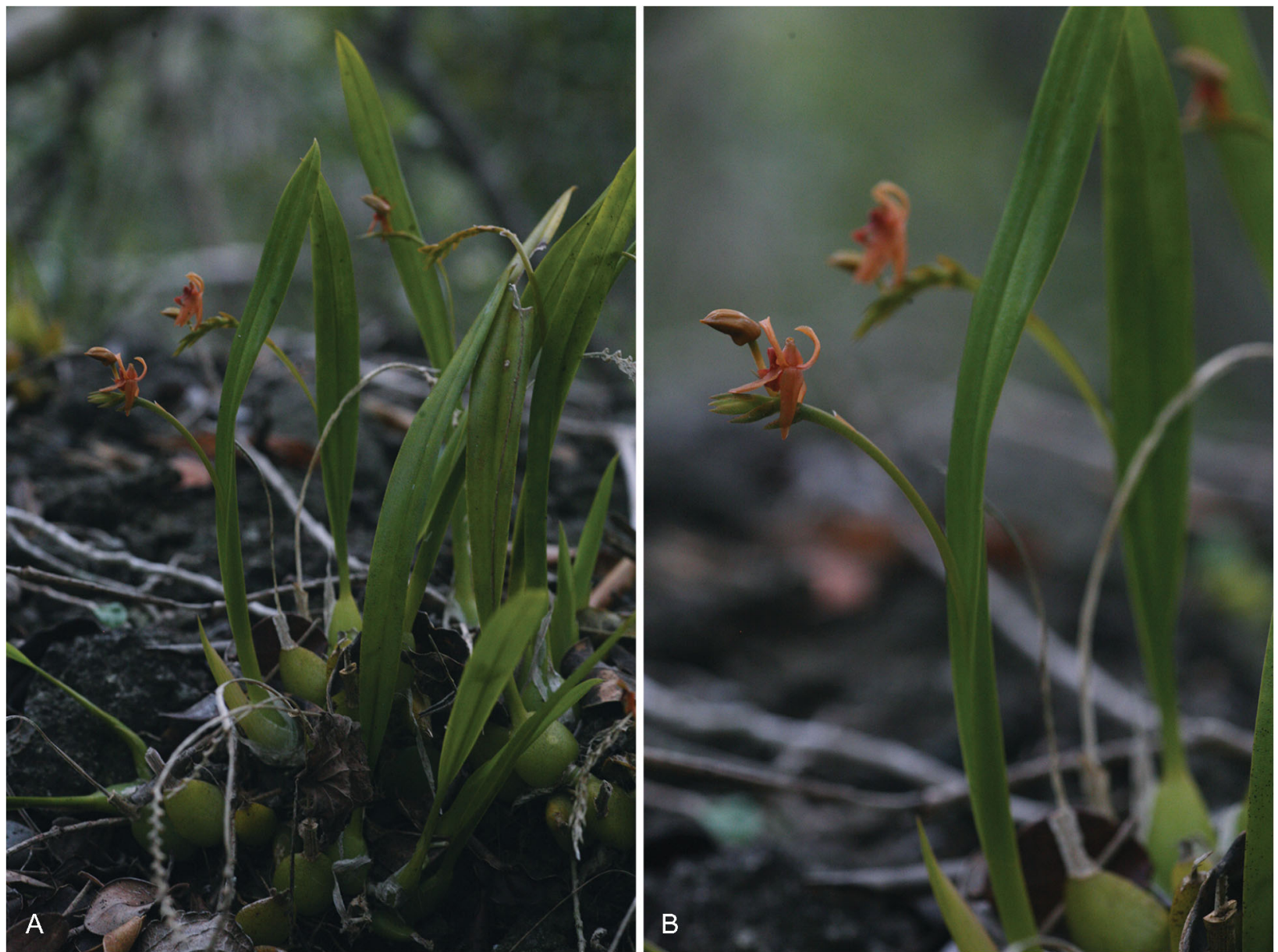

Fig. 80. Stichorkis disticha. A habit; B inflorescence. PHOTOS: JOHAN HERMANS.

(P); s. loc. Ayres s.n. rec. Feb. 1864 (K, P); s. loc. Commerson s.n. (P); Cascade des Galets, Sept. 1941, Vaughan 3020 (MAU, P); Plaine Paul, March 1963, Guého 10672 (MAU, P); Aug. 1975, Guého 17502 (MAU, P); Gaulettes Serrées, March 1980, Bosser 22581 (P); Gaullettes Serrees, May 1997, Page 24179-80 (MAU); Gaulettes Serrées, near Camp Thorel, June 1997, Florens et al. 22808 (MAU, P); Gaulettes Serrées, 420 m, Dec. 1998, Florens et al. 22977 (MAU, P); Pouce, c. 800 m, May 2000, Florens et al. 23335 (P). RÉUNION. s. loc., 1829, Goudot s.n. (G); s. loc., 1829, Herb Moricand (G); s. loc., 1847 - 1852, Boivin 1037 (P); s. loc. Richard 400 (P); Salazii, Cordemoy 8bis (P); s. loc., Richard s.n. (G, K-Lindl.); s. loc., Boivin s.n. (K); s. loc., 1876, DeLisle s.n. (P); Saint Philippe (Mare Longue), 300 m, May 1957, Bosser 11880 (P); Cilaos, Nov. 1967, Staub 13009 (P); Route de Cilaos, 500 - 600 m, Feb. 1971, Bosser 20721 (P); Îlet à Guillaume, Dec. 1971, Bosser 21032 (P); Hell-bourg-Bélome, Dec. 1972, Bosser 21593 (P); Illet à Guillaume path, 700 m, Jan. 1972, Friedmann 1546 (P); Bassin Blanc, April 1974, Bosser 21852 (P); Grand Matarum, March 1974, Bosser 21699 (P); Grande Chaloupe, 400 m, Jan. 1975, Bernardi 14997 (G); forest of Brûlé de Baril, 300 m, 18 May 1977,
T. Cadet s.n. (P); Cilaos, 1400 m, 5 Feb. 1969, J. Cadet 1985 (P); Saint-Denis, Bois de Nefles, 1050 m, April 2006, Ferard É Pausé 1969 (CBNM); Le Tampon, Grand Bassin, sentiuer Piton, 1250 m, Jan. 2006, Grondin E Lavergne 1832 (CBNM); s. loc., Rauh 10243 (HEID); Van Heurck s.n. (P); Delteil s.n., Herb. Drake (P); Desvaux 270 (P); Cosson s.n. (P).

HABITAT. Dense humid forest, evergreen forest, locally forming small populations on tree trunks, main branches or rock in undergrowth. Altitude: $300-1400 \mathrm{~m}$.

CONSERVATION STATUS. Category LC: the extent of occurrence (EOO) of Stichorkis disticha is estimated to be $3,899,035 \mathrm{~km}^{2}$ (far exceeding the limits for Vulnerable status under criterion B1) whereas its minimal area of occupancy (AOO) is estimated to be $64 \mathrm{~km}^{2}$ (which falls within the limits for Endangered status under the criterion B2). With 11 known subpopulations representing 13 locations (sensu IUCN), this species has been preliminarily assessed as LC using the green listing method. This species is threatened by selective logging, timber harvesting for small-scale subsistence, slash-and-burn farming, grazing and anthropogenic fires, resulting in habitat reduction and habitat quality reduction. 
FLOWERING TIME. Throughout the year but mainly from December to March.

ETYMOLOGY. Refers to the distichous habit of the rachis and floral bracts.

NOTES. The species was first described and illustrated by Thouars in 1822 as Malaxis disticha. He was not specific on the origin of the type specimen but in the accompanying table he recorded it both from Mauritius and Réunion. Due to confusion over Thouars' complex nomenclature, Lindley both transferred it to Liparis in 1824 and created L. gregaria in 1830, now considered conspecific with it. Pfitzer finally transferred the species to Stichorkis in 1897. Several Sieber specimens of this species in P and G are labelled 'Stelis micrantha' in error. Stichorkis is morphologically distinct and is also supported as separate from Liparis in genetic evidence.

ILlUStRAtions. Fig. 80; Du Petit-Thouars (Thouars 1822: t.89); Cadet (1989: 54); Bernet (2010a: 88), Pailler et al. (2013: 61); Szelengowicz \& Tamon (2013: 374).

\section{Acknowledgements}

We are most grateful to the directors and staff at BM, BR, BRLU, CBDM, DUB, G, HEID, K, M, MAU, MO, P, REU, SZU, TAN, TEF, W, WU, M, SZL, ZSS and their relevant libraries. Marc Pignal at $\mathrm{P}$ for many years of hospitality. The botanical artists and especially Juliet Beentje, Judi Stone and Oliver Whalley. Clare Hermans for processing huge amounts of data. Simon Verlynde \& Tariq Stévart for making the Ambatovy herbarium available. Patrice Bernet for providing material from Réunion. Justin Moat for general advice on mapping. Michael Kiehn for his advice and help. Daniel Geiger for reviewing Oberonia. Brian Fisher of the California Academy of Sciences for help in ant identification. We are also most grateful to the brave anonymous reviewers. In the context of the description of Liparis laurentii, Louis Nusbaumer thanks Laurent Gautier for the specimens and for initiating and leading the botanical researches in Loky-Manambato, Rodolphe Spichiger and PierreAndré Loizeau for supporting the project, Nicolas Spitznagel for the treatment of the field picture, the institutions which funded the researches in Loky-Manambato: CJBG, Université de Genève, Conservation International (CBC fund), Malagasy NGO Fanamby, Fondation Jean-Marcel Aubert, and Vontobel Stiftung as well as the Direction Générale des Eaux et Forêts de Madagascar and the Département de Biologie et Ecologie Végétale de l'Université d'Antananarivo for supporting our project. The first author is particularly grateful to Nirina Ranaivoson for his great help and support during our travels in Madagascar.
Open Access This article is licensed under a Creative Commons Attribution 4.0 International License, which permits use, sharing, adaptation, distribution and reproduction in any medium or format, as long as you give appropriate credit to the original author(s) and the source, provide a link to the Creative Commons licence, and indicate if changes were made. The images or other third party material in this article are included in the article's Creative Commons licence, unless indicated otherwise in a credit line to the material. If material is not included in the article's Creative Commons licence and your intended use is not permitted by statutory regulation or exceeds the permitted use, you will need to obtain permission directly from the copyright holder. To view a copy of this licence, visit http://creativecommons.org/ licenses/by/4.0/.

\section{References}

Ames, O. (1905). Orchidaceae 1. Houghton Mifflin \& Co, Boston.

(1908). Orchidaceae 2 - 3. Houghton Mifflin \& Co, Boston.

(1920). Orchidaceae 6. Houghton Mifflin \& Co, Boston.

Averyanov, L. V. (1991). The system of orchids of the Vietnamese flora. Bot. Zhurn. (Kiev) 76: 120 - 128.

Baker, J. G. (1877). Flora of Mauritius and the Seychelles. L. Reeve, London.

Baron, R. (1901). Compendium des plantes Malagaches. Rev. Madagascar 3: 714 - 725.

Bentham, G. (1881). Notes on Orchideae, J. Linn. Soc., Bot. 18.

\& Hooker, J. D. (1883). Genera Plantarum 3. London.

Bernet, P. (2010a). Orchidées de la Réunion. Naturae Amici éditions.

(2010b). Orchidées nouvelles pour l'île de la Réunion et Madagascar. L'Orchidée. 38: 69 - 74.

Bluff, M. J. \& Fingerhuth, C. A. (1838). Compendium Florae Germaniae 2. J. L, Schrag, Nürnberg.

Blume, K. L. (1825). Bijdragen tot de flora van Nederlandsch Indï. Lands Drukkerij, Batavia.

Bosser, J. (2011). A propos de la citation du nom d'auteur de certaines orchidées établies dans la Flore de l'île de la Réunion de E. Jacob de Cordemoy (1895). Orchidophile (Asnières) 42: 117 119.

\& Lecoufle, M. (2011). Les Orchidées de Madagascar. Biotope, Mèze.

Cadet, J. (1989). Joyaux de nos Forêts: Les Orchidées de la Réunion. Réunion.

Cameron, K. M. (2005). Leave it to the leaves: a molecular phylogenetic study of Malaxideae (Epidendroideae, Orchidaceae). Amer J. Bot. 92: 1025 - 1032. 
Chase, M., Whitten, M., Kores, P. J., Jarrell, D. C., Albert, V. A., Yukawa, T., Hills, H. G. \& Goldman, D. H. (1999). A phylogenetic analysis of the Orchidaceae: evidence from $r b c L$ nucleotide sequences. Amer. J. Bot. 86(2): 208 - 224.

Candolle, A. de (1855). Géographie botanique raisonnée. Masson, Paris.

Christenson, E. (1995). Type specimens of Orchidaceae conserved at the Komarov Institute, St. Petersburg, Russia (LE). Brittonia 47: 31 - 43.

Claessens, J. \& Kleynen, J. (2017). The Pollination of European Orchids. J. Hardy Orchid Soc. 14: 130.

\& Seifert, B. (2018). Ant pollination of Dactylorhiza viridis. Orchid Digest 82: 154 - 158.

Cowan, W. D. (1880). Drawings of Madagascar Orchids. Natural History Museum, London.

Cribb, P. (1984). In: R. M. Polhill (ed.), Flora of Tropical East Africa, Orchidaceae (Part 2). Amsterdam, Balkema.

\& Hermans, J. (2009). Field Guide to the Orchids of Madagascar. Kew Publishing, Royal Botanic Gardens, Kew.

Dandouau, A. (1909). Catalogue Alphabétique des noms Malgaches de Végétaux. Imprimerie Officielle, Antananarivo.

Dauby, G., Stévart, T., Droissart, V., Cosiaux, A., Deblauwe, V., Simo-Droissart, M., Sosef, M. S. M., Lowry II, P. P., Schatz, G. E., Gereau, R. E. \& Couvreur, T. L. P. (2017). ConR: An R package to assist large-scale multispecies preliminary conservation assessments using distribution data. Ecology and Evolution 7(24): 11292 - 11303. https://doi.org/ 10.1002/ece3.3704.

Diels, L. (1922). Beitrage zur Kenntnis der Vegetation und Flora der Seychellen. Auftrage des Reichsamtes des Innern hrsg. von Carl Chun. 2: 407 - 466 .

Dorr, L. J. (1997). Plant Collectors in Madagascar and the Comoro Islands. Royal Botanic Gardens, Kew.

Dressler, R. L. (1993). Phylogeny and classification in the orchid family. Timber Press, Portland.

Dumortier, B. C. (1827). Florula Belgica. J. Casterman, Tournay.

Du Puy, D., Cribb, P., Bosser, J., Hermans, J. \& Hermans, C. (1999). The Orchids of Madagascar. Kew Publishing, Royal Botanic Gardens, Kew.

Durand, T. A. \& Schinz, H. (1895). Conspectus florae Africae 5. Charles vander Weghe, Bruxelles.

Eaton, A. (1822). A manual of botany 3. Websters \& Skinners, Albany.

Endlicher, S. (1833). Prodromus florae Norfolkicae. Friedrich Beck, Vindobonae.

Feldmann, P. \& Barré, N. (2004). Atlas des Orchidées sauvages de la Guadeloupe. Patrimoines Naturels 48. MNHN, Paris.
Felix, L. P. \& Guerra, M. (2010). Variation in chromosome number and the basic number of subfamily Epidendroideae (Orchidaceae). J. Linn. Soc., Bot. 163: $234-278$.

Finet, A. (1909). Orchidées nouvelles ou peu connues. Bull. Soc. Bot. France 56: 97 - 104.

Fischer, E., Killmann, D., Delespierre, G. \& Lebel, J.-P. (2010). The Orchids of Rwanda. Koblenz geographica colloquia series biogeographical monographs, 2. University of Koblenz-Landau, Koblenz.

Forel, A. (1891). Histoire Naturelle des Hyménoptères, Les Formicides. In: A. Grandidier, Histoire Physique, Naturelle et Politique de Madagascar. Impremerie Nationale, Paris.

Forster, G. (1786). Florulae insularum Australium prodromus. Joann, Christian Dieterich, Gottingae.

Frappier, C. de Monbenoist (1880). Orchidées de l'île de la Réunion, Catalogue des Espèces Indigènes Découvertes Jusqu'à ce Jour. Réunion.

(1895). Orchidées. In: J. E. de Cordemoy (1895). Flore d'île de la Réunion: 165 - 262. Klincksieck, Paris.

Freudenstein, J. V. \& Rasmussen, F. N. (1999). What does morphology tell us about orchid relationships? A cladistics analysis. Amer. J. Bot. 86: $225-$ 248.

Friis, I. \& Rasmussen, F. N. (1975). The two alternative systems of nomenclature proposed and used for orchids by du Petit-Thouars, with special regard to Corymborkis Thouars. Taxon 24: 307 - 318.

Gagnepain, F. (1929). Quelques Liparis nouveaux d'Indo-chine. Bull. Soc. Bot. France 76: $514-515$.

Garay, L. \& Romero-Gonzales, G. (1999). Schedulae orchidum II. Harvard Pap. Bot. 4: 475 - 478.

Gautier, L., Ranarison, P., Nusbaumer L. \& Wohlhauser, S. (2006). Aperçu des massifs forestiers de la région Loky-Manambato. In: S. M. Goodman \& L. Wilmé (eds), Inventaires de la faune et de la flore du Nord de Madagascar dans la région LokyManambato, Analamerana et Andavakoera: 81 - 99. CIDST, Ministère de l'Education Nationale et de la recherche Scientifique, Antananarivo.

Geerinck, D. (1984). Flore d'Afrique Centrale, Orchidaceae. Jardin botanique national de Belgique, Meise.

Govaerts, R. (2017). World Checklist of Selected Plant Families. Facilitated by the Royal Botanic Gardens, Kew. Published on the Internet: http:// apps.kew.org/wcsp/.

Gray, S. F. (1821). A natural arrangement of British plants 2. Baldwin, Cradock \& Co, London.

Guérin, J.-C. \& Hervouet, J.-M. (2011). Neuvième voyage à Madagascar: Ambondrombe, la montagne des morts. Orchidophile (Asnières) 42: 87 - 101.

\& _ (2013). Dixième voyage a Madagascar: Ambondrombe, le pic Boby, le pic Ivohibe et le 
corridor de Vondrozo. Orchidophile (Asnières) 44: 319 -334 .

Harvey, W. H. (1863). Conspectus Tabularum. Thesaurus Capensis 2: $1-64$.

Hemsley, W. B. (1916). Flora of Seychelles and Aldabra. J. Bot. 54(Suppl. 2): 1 - 24.

Hermans, C., Hermans, J., Hervouet, C. \& Hervouet, J.-M. (2018). Retour a Madagascar: voyage vers le nord. Orchidophile (Asnières) 49: 11 - 22.

Hermans, J. (2013). Henry Ridley: His life and work \& the Orchids of Madagascar. In: J. Elliott (ed.), Proceedings 20th WOC Singapore Conference pp. 388 398. National Parks Board \& Orchid Society of South East Asia, Singapore.

(2015). Nouvelles espèces et nouvele nomenclature pour les orchidées malgaches. Orchidophile (Asnières) 46: 245 - 252.

(2016). Nuove Orchidee e nuovi nomi di alcune Orchidee del Madagascar. Caesiana 44: $1-7$.

\& Cribb, P. (2014). New species and new names in Malagasy orchids (Orchidaceae). Kew Bull. 69(9517): $1-16$.

, Hermans, C., Du Puy, D., Cribb, P. \& Bosser, J. (2007). Orchids of Madagascar $2^{\text {nd }}$ edition. Kew Publishing, Royal Botanic Gardens, Kew.

Hervouet, J.-M. (2018). A la recherche des Orchidées de Madagascar. Biotope, Mèze.

\& Barthelat, F. (2014). Liste commentée des orchidées de Mayotte. Orchidophile (Asnières) 45: 257 -270 .

Hoffmannsegg, J. C. (1842a). Verzeichniss der Orchideen. Dresden.

(1842b). Preis-Verzeichniss der Orchideeen. Linnaea 16(Litt): 227 - 287.

Hooker, J. D. (1888). Liparis Richard. Flora of British India 5: 691 - 708 L. Reeve, London. (1889). Hooker's Icones Plantarum 19: t.1886.

Hooker W. J. (1827). Liparis foliosa. Bot. Mag. t.2709. (1830). The Late Mr Barclay. Bot. Misc. 122 - 128. \& Arnott, G. W. (1832). Bot. Beechey Voyage. London.

Humblot, L. (1882 - 1885). Humblot's Notebooks. Mss. MNHN, Paris.

IUCN (2012). IUCN Red List Categories and Criteria: Version 3.1. 2nd edition. Gland and Cambridge. (2017). Guidelines for Using the IUCN Red List Categories and Criteria. Version 13. http:// www.i u c n red list.org / d ocuments / redlist_guidelines_v1223290226.pdf.

Jacquin, N. (1760). Enumeratio systematica plantarum. Theodorum Haak, Lugduni Batavorum.

Jourde, G., Rasamoelison, D., Raveloson, S. A. \& Razanakolona, J. (1974). Carte Géologique W33, X33 Milanoa-Vohémar. Madagasikara 1:100'000. Service Géologique, Antananarivo.

Kaiser, R. (1993). Vom Duft der Orchideen. Editiones Roche, Basel.
Klinge, J. (1898). Diagnoses orchidearum novarum. Acta Horti Petropolitani 17: 134 - 144 t.2.

Kowalkowska, A. \& Margonska, H. B. (2008). Diversity of labellar micromorphological structures in selected species of Malaxidinae (Orchidales). Acta Soc. Bot. Poloniae 78: 141 150.

Kraenzlin, F. (1902). Beiträge zur Flora von Afrika XXIV. Orchidaceae Africanae VII. Bot. Jahrb. Syst. 33: $53-75$.

(1908). Neue und Kritische Arten. Orchis 2: 127 129.

Kuntze, O. (1891). Revisio Genera Plantarum 2. Arthur Felix, Leipzig.

La Croix, I. \& Cribb, P. J. (1995). Orchidaceae. In: G. V. Pope (ed.), Flora Zambesiaca. Flora Zambesiaca Management Committee, London.

Lamarck, J.-B. (1783). Encyclopédie méthodique, Botanique 1. Panckoucke, Paris, Liège.

(1804). Encyclopédie méthodique, Botanique 6. Panckoucke, Paris, Liège.

Lebrun, J.-P. \& Stork, A. L. (2017). Tropical African Flowering Plants, Ecology and Distribution. 10 Orchidaceae Part Two (Genera $H-Z$ ). Conservatoire et Jardin botaniques de la Ville de Genève.

Lindley, J. (1821). Collectanea Botanica. Rare and Curious Exotic Plants. App. London.

(1824). Isochilus prolifer. Bot. Reg. sub t. 825.

(1825). Liparis foliosa. Bot. Reg. sub t. 882.

(1830a). The genera and species of orchidaceous plants. Ridgways, London.

(1830b). Reports upon New or Rare Plants.

Trans. Hort. Soc. London. 7: $46-75$.

(1840). Characters of Four New Cape

Orchidaceae. Ann. Nat. Hist. 4: $314-315$.

(1847). Vegetable Kingdom, ed. 2. Bradbury \& Evans, London.

(1859). Folio orchidacea 8. Asher \& Co., Amsterdam.

Link, H. F. (1822). Enumeratio plantarum horti regni berolinensis altera 2. G. Reimer, Berolini.

Linné, C. von (1753). Species Plantarum ed. 1. Impensis Laurentii Salvii, Holmiae.

Liu, Z. J., Chen, S. C. \& Chen, L. J. (2008). Ypsilorchis and Ypsilorchidinae, a new genus and a new subtribe of Orchidaceae. J. Syst. Evol. 46: 622 - 627.

Loddiges, C. (1825). Liparis foliosa. Bot. Cab. t.1097.

Margonska, H. B. (2006). Platystyliparis Margonska un genre nouveau de la sous-tribu Malaxidinae. Richardiana 7: 33 - 41 .

(2007). Nouvelle combinaison, nouveau synonyme et lectotype dans le genre Lisowskia Szlachetko (Orchidaceae, Malaxidinae). Richardiana 7: 50 - 53 .

(2009). Nomenclatural changes in Malgasian representatives of Malaxidinae. Richardiana 9: 90 99. 
Kowalkowska, A. K., Gorniak, M. \& Rutkowski, P. (2012). Taxonomic Redefinition of the Subtribe Malaxidinae (Orchidales, Malaxideae). Koeltz, Koenigstein.

, (2014). Proposal to conserve the name Microstylis koordersii (Crepidium koordersii) against $M$. madagascariensis (Orchidaceae). Taxon 63: 192-193.

\& Lipinska, M. in Pratt, D. (2018). Liparis stricklandiana (Orchidaceae, Liparidinae) - study of flower structures in the context of the pollination processes. $18^{\text {th }}$ European Orchid Council Conference and Exhibition, Programme.

\& Szlachetko, D. L. (2004). Disticholiparis, a new genus of subtribe Malaxidinae. Orchidee (Hamburg) 55: $175-179$.

$\&$ (2006). Taxonomic revision of the African genus Orestias Ridl. (Malaxidinae, Orchidaceae). Ann. Naturhist. Mus. Wien, B 107B: $209-220$.

\& __ (2010). Orchidaceae of Tahiti, French Polynesia. Gdansk University Press, Gdansk.

\& Szelengowicz, M. (2011). A new taxon of Malagasian Liparis salassia (Orchidaceae, Malaxidinae) from Le Réunion. Biodivers. Res. Conservation 24: 13 - 18.

McNeill, J., Barrie, F. R., Buck, W. R., Demoulin, V., Greuter, W., Hawksworth, D. L., Herendeen, P. S., Knapp, S., Marhold, K., Prado, J., Prud'homme Van Reine, W. F., F. G Smith, Wiersema, J. H. \& Turland, N. J. (2012). International Code of Nomenclature for algae, fungi and plants (Melbourne Code) adopted by the Eighteenth International Botanical Congress Melbourne, Australia, July 2011. Regnum Veg. 154. Koeltz, Koenigstein.

(2014). Holotype specimens and type citations: General issues. Taxon 63: 1112 - 1113.

Mercks, V. (2013). La Liste rouge des espèces menacées en France. Flore vasculaire de Mayotte, IUCN, France.

Miquel, F. (1855). Tribes Malaxeae. In: Flora van Nederlansch Indie 3. C. G. van der Post, Amsterdam.

Mutel, M. A. (1837). Mémoire surs Plusieurs Espèces Nouvelles ou Peu Connues de la Famille des Orchidées. Mém. Soc. Roy. Centr. Agric. Sci. Arts Dépt. Nord. 77 - 92.

Nusbaumer, L. (2011). Species distribution patterns in steep environmental gradients: downscaling of a biogeographical framework (Loky-Manambato Region, NE Madagascar). PhD. thesis, University of Geneva.

Pailler, T., Tournebize, R. \& Henze, F. (2013). Guide des Orchidées de la Réunion. Université de La Réunion.

Paxton, J. \& Harrison, J. (1831). Choice of Beautiful Plants. Hort. Reg. Eं Gen. Mag. 1: 189 - 190.

Percival, W. S. (1965). Floral Biology. Pergamon Press, London.

Perrier de la Bâthie, H. (1936). Les Liparidinées de Madagascar. Notul. Syst. (Paris) 5: 231 - 260.
(1939). In: H. Humbert, Flore de Madagascar. $49 e$. Famille. - Orchidées. Imprimerie Officielle, Tananarive.

Persoon, C. H. (1807). Synopsis Plantarum 2. G. Cottam, Parisiis Lutetiorum.

Pfitzer, E. H. (1887). Entwurf einer natürlichen Anordnung der Orchideen. Carl Winter's Univeritätsbuchhandlung, Heidelberg.

(1888). In: A. Engler \& K. Prantl, Die Natürlichen Pflanzenfamilien 2. W. Engelmann, Leipzig.

(1897). In: A. Engler \& K. Prantl, Die Natürlichen Pflanzenfamilien. Nachträge 1. W. Engelmann, Leipzig.

Picot, F. (ed.) (2013). In: UICN France, CBNM, FCBN \& MNHN. La Liste rouge des espèces menacées en France. Flore vasculaire de la Réunion.

Pridgeon, A. M., Cribb, P. J., Chase, M. W. \& Rasmussen F. N. (2005). Genera Orchidacearum, Epidendroideae (Part one) 4. Oxford University Press.

Rafinesque, C. S. (1819). Remarques critiques et synonymiques sur les ouvrages de MM. Pursh, Nuttall, Elliott, Jorrey, Eaton, Bigelow, Barton, Muhlenberg etc. Sur les plantes des Etats-Unis. J. Phys. Chim. Hist. Nat. 89: $256-262$.

(1825). Neogenyton, or Indication of sixty-six new genera of plants of North America. Lexington.

(1833). Herbarium Rafinesquianum 73. Philadelphia.

(1838). Flora Telluriana 4. Philadelphia.

Rasmussen, F. N. (1979). Nomenclatural notes on Thouars work on Orchids. Bot. Not. 132: 385 392.

Ravenna, P. (2011). Pycnantha, a new genus of a new family of monocotyledons, including a new species from Argentina. Onira 12: 29 - 32.

Reichenbach, H. G. (1826). Iconographia botanica seu plantae criticae 4. Fridericum Hofmeister, Leipzig.

(1828). Conspectus regni vegetabilis. Carolum Cnobloch, Lipsiae.

(1864). XXVIII Orchides. Ann. Bot. Syst. 6: 167 933.

(1865). Dr. Welwitsch's Orchideen aus Angola. Flora 48: 177 - 191.

(1872). Neue Orchideen, endeckt und gesammelt von Herrn Gustav Mann. Flora 55: 273 - 278.

(1877). Orchidiographische Beiträge. Linnaea 41: $17-98$.

(1881). VIII Novitae africanae. Otia Bot. Hamburg. 1: $95-119$.

(1885). Comoren-Orchideen Herrn Leon Humblot's. Flora 68: 535 - 544.

Richard, A. (1828). Monographie des Orchidées des Îles de France et Bourbon. Mém. Soc. Hist. Nat. Paris 4: $1-70$.

Richard, L. C. (1817). De Orchideis europaeis annotationes. Typographia A Belin, Paris.

Ridley, H. N. (1885). The Orchids of Madagascar. J. Linn. Soc., Bot. 21: 456 - 523.

(1886a). On Dr. Fox's collection of Orchids from Madagascar, along with some obtained by the Rev. R. 
Baron from the same Island. J. Linn. Soc., Bot. 22: 116 127.

(1886b). A monograph of the genus Liparis. J. Linn. Soc., Bot. 22: $244-297$.

(1887). On a new Genus of Orchideae from the Island of St. Thomas, West Africa. J. Linn. Soc., Bot. 24: 197 - 199.

(1888). A revision of the genera Microstylis and Malaxis. J. Linn. Soc., Bot. 24: 308 - 351.

(1896). Apostasiaceae of the Malay Peninsula. J. Linn. Soc., Bot. 32: 219 - 416.

Riquier, J. (1968). Carte pédologique de Madagascar. Feuille Nord. Antananarivo, ORSTOM, Direction de la Récherche Scientifique.

Robert, C-H. (2019). Découverte d'un nouveau Liparis à La Réunion. Orchidophile (Asnières). 50: 349 - 352.

Robertson, S. A. (1989). Flowering Plants of Seychelles. Royal Botanic Gardens, Kew.

Rodrigues, J. B. (1877). Genera et. species Orchidarum novarum 1. Sebastianopolis.

Rolfe, R. A. (1891). In: J. Linden, L. Linden \& E. Rodigas (eds), Lindenia Iconographie des Orchidees 7: t.325. Gent

(1903). F. B. Forbes \& W. B. Hemsley, Enumeration of all the Plants known from China proper, Formosa, Hainan, the Corea, the Luchu Archipleago and the Island of Hongkong. J. Linn. Soc., Bot. 36: 5 - 67.

(1908). XI New Orchids, Decade 31. Bull. Misc. Inform., Kew 1: 68 - 73.

(1922). New Orchids: Decas XLIX. Bull. Misc. Inform., Kew 23 - 24.

Schlechtendal, D. F. L. (1842). Preis-Verzeichniss der Orchideen in Graff Hoffmannseggischen Garten zu Dresden. Linnaea 16 (Litteratur-Bericht): 227 - 237.

Schlechter, R. (1905a). In K. M. Schumann \& C. A. G. Lauterbach, Die flora der deutschen Schutzgebiete in der Südsee, Nachtr. Gebrüder Borntraeger, Leipzig.

(1905b). Orchidaceae africanae. Bot. Jahrb. Syst. 38: $1-60$.

(1911a). Beitrage zur Kenntnis der Orchidaceen-

Flora von Sumatra. Beibl. Bot. Jahrb. Syst. 45: 1 - 83 . (1911b). Die Orchidaceen von Deutsch Neu-

Guinea. Repert. Spec. Nov. Regni Veg. Beih. 1.

(1913). Orchidacées de Madagascar. Orchidaceae

Perrieranae Madagascarienses. Ann. Mus. Colon.

Marseille, sér. 3, 1: 148 - 202.

(1915a). Kritische Aufzählung der bisher von

Madagaskar, den Maskarenen, Komoren und Seychellen bekantgewordenen Orchidaceen. Beih. Bot. Centralbl. 33: 390 - 440.

(1915b). Orchidaceae Stolziana. Bot. Jahrb. Syst. 53: $478-605$.

(1916). Orchidaceae Perrierianae (Collectio secunda). Beih. Bot. Centralbl. 34: 1 - 341.
(1924). Orchidaceae Perrieranae. Repert. Spec. Nov. Regni Veg. Beih. 33: 1 - 240.

(1932). In: R. Mansfeld, Blutenanalysen neuer Orchideen, Orchideen III. Afrikanische und Madagassische Orchideen. Repert. Spec. Nov. Regni Veg. Beih. 68: t.1 - 68.

Scopoli, J. A. (1777). Introductio ad historiam naturalem. Apud Wolfgangum Gerle, Prague.

Seidenfaden, G. (1978). Malaxis Sol. ex Sw. Dansk Bot. Ark. 33: 42 - 85.

\& Wood, J. (1992). The Orchids of Peninsular Malaysia and Singapore. Olsen \& Olsen, Fredensborg.

Senghas, K. H. (2002). 42. Subtribus: Liparidinae Lindl. ex Miq. In: Rudolf Schlechter, Die Orchideen, $3^{\text {rd }}$ ed., Suppl. 1C. Paul Parey, Berlin.

Smith, J. J. (1909). Neue Orchideen des Malaischen Archipels 3. Bull. Dép. Agric. Indes Néerl. 22: 1 - 51.

(1913). Die Orchideen von Niderlandisch New Guinea 3. Nova Guinea 12: 1 - 108.

Stafleu, F. A. \& Cowan, R. S. (1976). Taxonomic Literature I: Bohn, Scheltema \& Holkema, Utrecht.

Steudel, E. G. (1821). Nomenclator Botanicus, ed 1. J. G, Cottae, Stuttgart \& Tubingen.

(1841). Nomenclator Botanicus, ed 2. J. G, Cottae, Stuttgart \& Tubingen.

Summerhayes, V. S. (1931). Enumeration of the angiosperms of the Seychelles archipelago, Trans. Linn. Soc. (Zool). ser. 2, 19: 291 - 292.

(1934). African Orchids VI. Bull. Misc. Inform., Kew 5: $205-214$.

(1937). African Orchids IX. Bull. Misc. Inform., Kew 8: 457 - 476.

(1953). African Orchids XXI. Kew Bull. 8: 131 162.

(1954). African Orchids XXII. Kew Bull. 8: 576 579.

Swartz, O. (1788). Nova genera E species plantarum seu Prodrumus. Uppsala \& Abo.

(1799). Dianome Epidendri Generis Linn. Nova Acta Regiae Soc. Sci. Upsal. 6: 61 - 88.

(1800). Dianome Epidendri Generis Linn. J. Bot. (Schrader) 2 (1899): 201 - 244.

Szelengowicz, M., Bègue, J.-F., Lacoste, M., Tamon, J.-M. \& Pausé, J.-M. (2011). Liparis microcharis Schltr., espèce endémique de Madagascar, découverte sur l'île de La Réunion (Orchidales: Orchidaceae). Cahiers scientifiques de l'Océan Indien occidental. 2: 7 - 12.

\& Tamon, J.-M. (2013). Les Orchidées des Mascareignes. Printec, Mahé, Seychelles.

Szlachetko, D. (1995). Systema Orchidalium. Fragm. Florist. Geobot. Suppl. 3: 1 - 137.

\& Margonska, H. B. (2002). Gymnostemia orchidalium II. Acta Bot. Fenn. 173: 1 - 275. 
\& Kułak, M. (2008). Nomenclatural Changes in Liparis-Complex (Malaxidinae, Epidendroideae). Acta Soc. Bot. Poloniae 77: 35 40.

\& Olszewski, T. (2001). Flore du Cameroun, Orchidaceae 2. Minrest, Cameroun.

Thouars, A. d. P. (1809). Extrait de trois Mémoires lus à la première classe de l'Institut, sur l'histoire des plantes Orchidées des îles australes d'Afrique. Nouv. Bull. Sci. Soc. Philom. Paris 1: 314 - 319.

(1822). Histoire particulière des Plantes Orchidées recueillies sur les trois Îles Australes d'Afrique. Bertrand, Treuttel \& Wurtz, Paris.

Turland, N. J., Wiersema, J. H., Barrie, F. R., Greuter, W., Hawksworth, D. L., Herendeen, P. S., Knapp, S., Kusber, W.-H., Li, D.-Z., Marhold, K., May, T. W., McNeill, J., Monro, A. M., Prado, J., Price, M. J. \& Smith, G. F. (eds) (2018). International Code of
Nomenclature for algae, fungi, and plants (Shenzhen Code) adopted by the Nineteenth International Botanical Congress Shenzhen, China, July 2017. Regnum Veg. 159. Glashütten: Koeltz. https://doi.org/10.12705/Code.2018.

Voeltzkow, A. (1917). Flora und Fauna der Comoren. Berlin.

Williamson, G. (1977). Orchids of South Central Africa. J. M. Dent, London.

Wood, J. J., Beaman, T. E., Lamb, A., Chan, C. L. \& Beaman, J. H. (2011). The Orchids of Mount Kinabalu 2. Natural History Publications (Borneo).

\section{Publisher's Note}

Springer Nature remains neutral with regard to jurisdictional claims in published maps and institutional affiliations. 